\title{
Hydrographs of Water Levels in Observation Wells in Idaho, 1944-93
}

By Annette M. Tungate

\section{U.S. GEOLOGICAL SURVEY}

Open-File Report 95-458

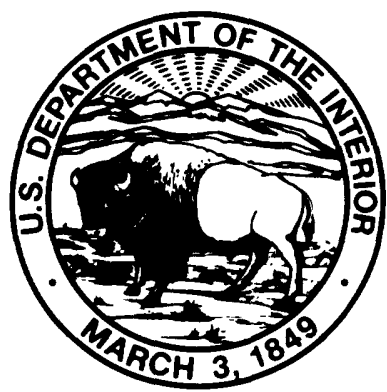




\section{U.S. DEPARTMENT OF THE INTERIOR \\ BRUCE BABBITT, Secretary \\ U.S. GEOLOGICAL SURVEY \\ Gordon P. Eaton, Director}

For additional information write to:

District Chief

U.S. Geological Survey

230 Collins Road

Boise, ID 83702
Copies of this report can be purchased from:

U.S. Geological Survey

Earth Science Information Center

Open-File Reports Section

Box 25286, MS 517

Denver Federal Center

Denver, CO 80225 


\section{CONTENTS}

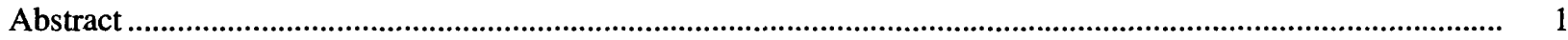

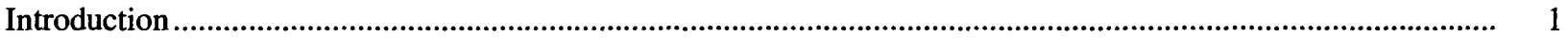

\section{FIGURES}

Figures 1-7. Locations of observation wells in:

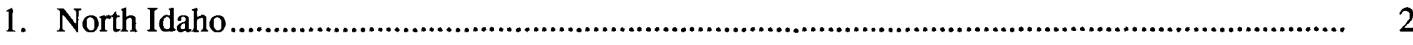

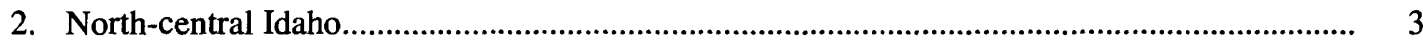

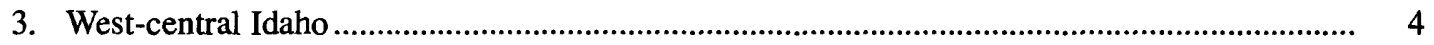

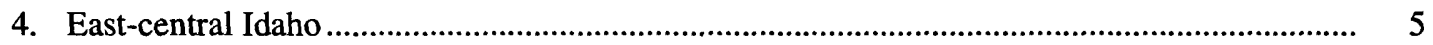

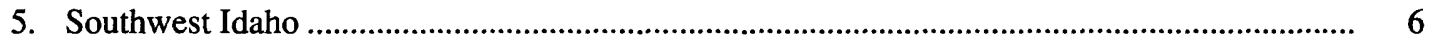

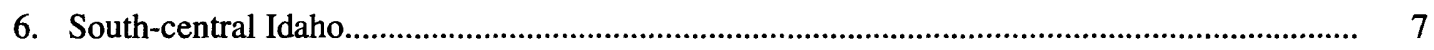

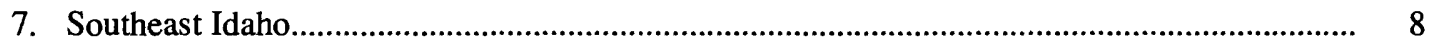

\section{HYDROGRAPHS, BY COUNTY}

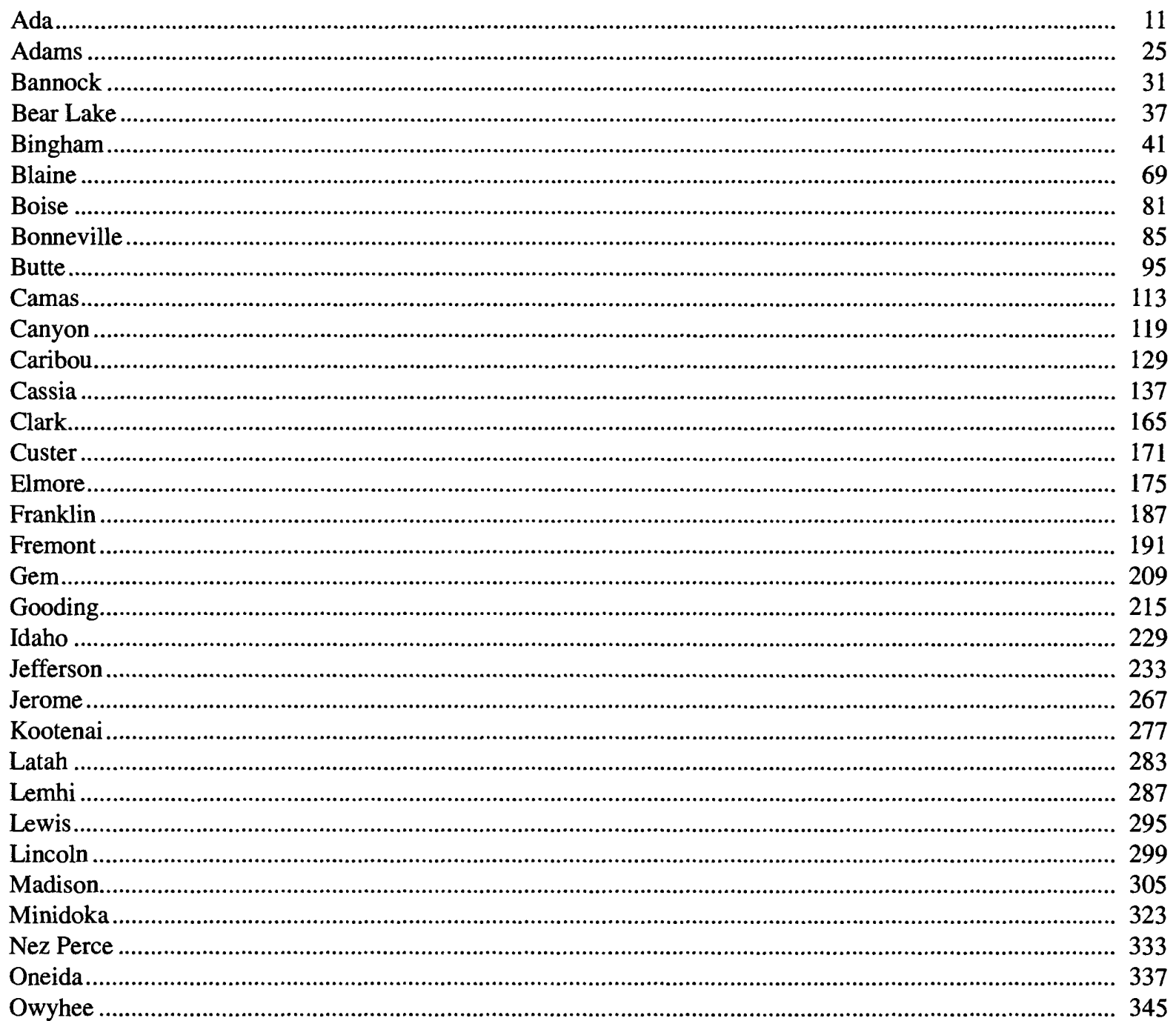




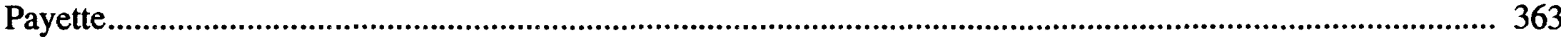

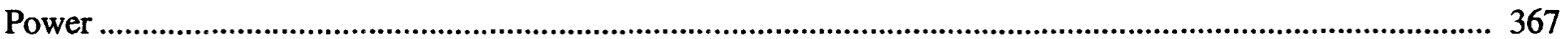

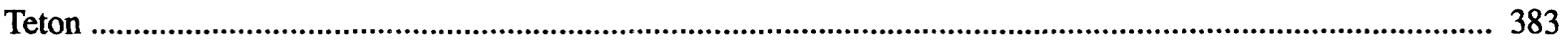

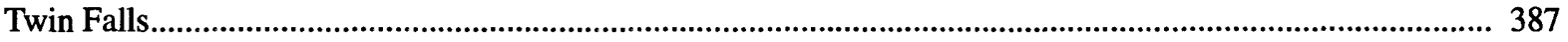

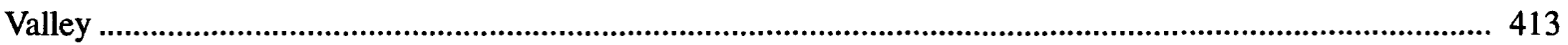

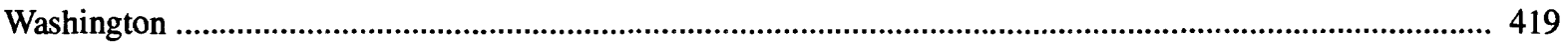

\section{WELL-NUMBERING SYSTEM}

The U.S. Geological Survey in Idaho numbers well locations within the official rectangular subdivision of the public lands, with reference to the Boise base line and Meridian. For example, the first segment ( $3 \mathrm{~N}$ ) of well number 3N-2E-21BCC1 designates the township north (or south); the second (2E), the range east (or west); and the third (21), the section in which the well is located. Letters (BCC) following the section number indicate the well's location within the section and are assigned in counterclockwise order beginning with the northeast quarter. The first letter $(B)$ denotes the $1 / 4$ section (160-acre tract), the second (C) denotes the 1/4-1/4 section (40-acre tract), and the third (C) denotes the 1/4-1/4-1/4 section (10-acre tract). The last number (1) is a serial number assigned when the well was inventoried.

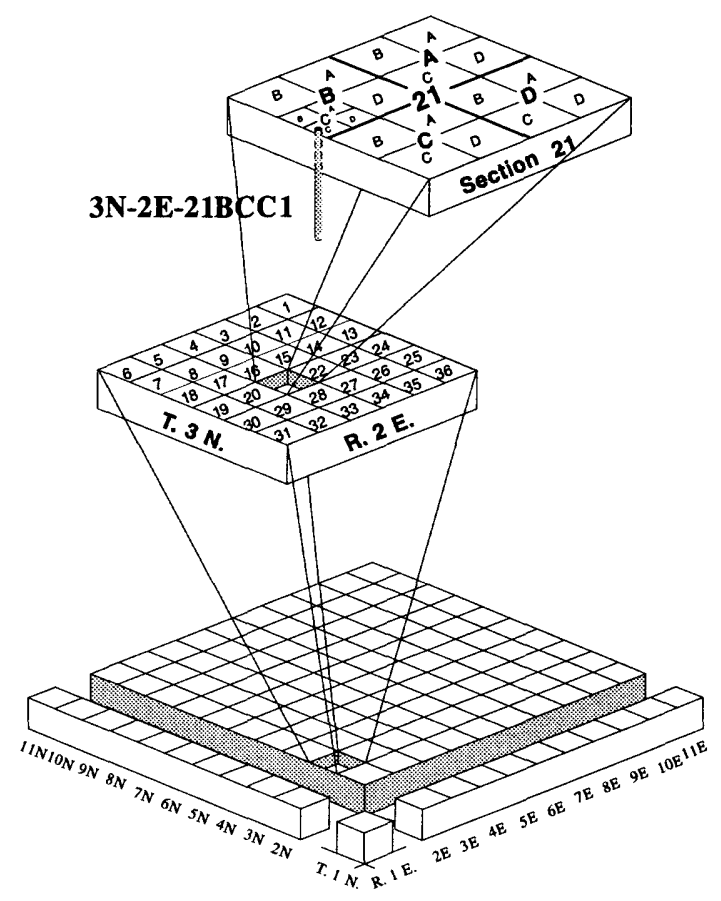




\title{
Hydrographs of Water Levels in Observation Wells in Idaho, 1944-93
}

\author{
By Annette M. Tungate
}

\section{Abstract}

This report presents hydrographs of water levels in 578 observation wells in the statewide monitoring network during 1944-93. The monitoring network is operated by the U.S. Geological Survey in cooperation with the Idaho Department of Water Resources, Bureau of Reclamation, and other Federal and State agencies.

\section{INTRODUCTION}

This report presents continuous recorder or periodic water-level measurements made in 578 observation wells in the statewide monitoring network during 1944-93. Periodic measurements were made monthly, bimonthly, quarterly, semiannually, or annually. The monitoring network is operated by the U.S. Geological Survey in cooperation with the Idaho Department of Water Resources, Bureau of Reclamation, and other Federal and State agencies. Locations of wells are shown in figures 1-7.

A solid line on the hydrographs is drawn between measured points; a break in the line indicates an interval of more than 1 year between measurements. An open triangle on a measurement point indicates the well was recently pumped; an open circle indicates the well was being pumped at the time of measurement. Hydrographs are based on calendar years ending December 31, 1993. Roman numerals on the X-axis indicate quarters of a calendar year. To facilitate graphical presentation, the hydrographs are separated into four groups: 10 years or less (1984-93), 20 years or less (1974-93), 30 years or less (1964-93), and 50 years or less (1944-93). 


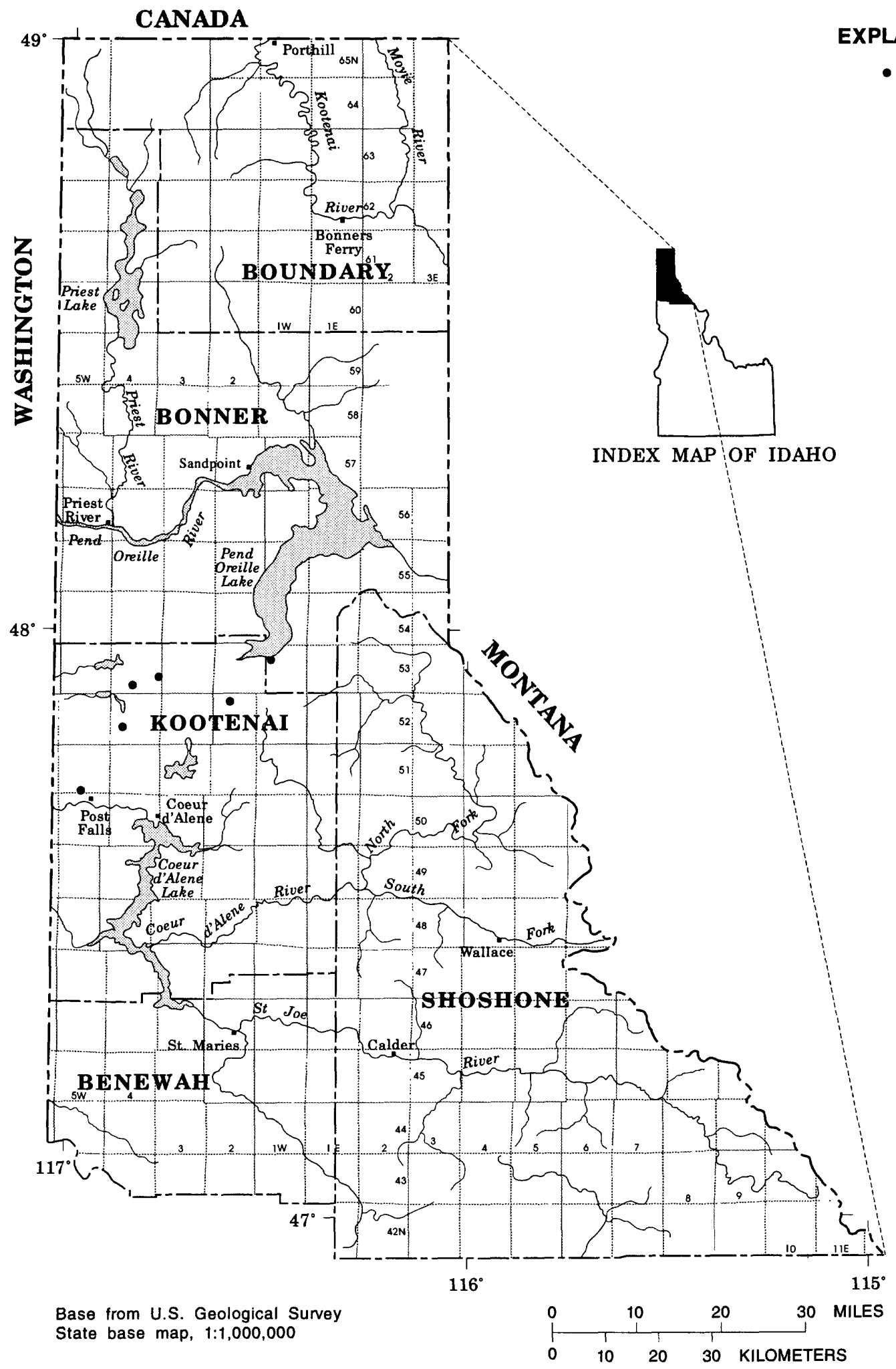

Figure 1. Locations of observation wells in north Idaho. 


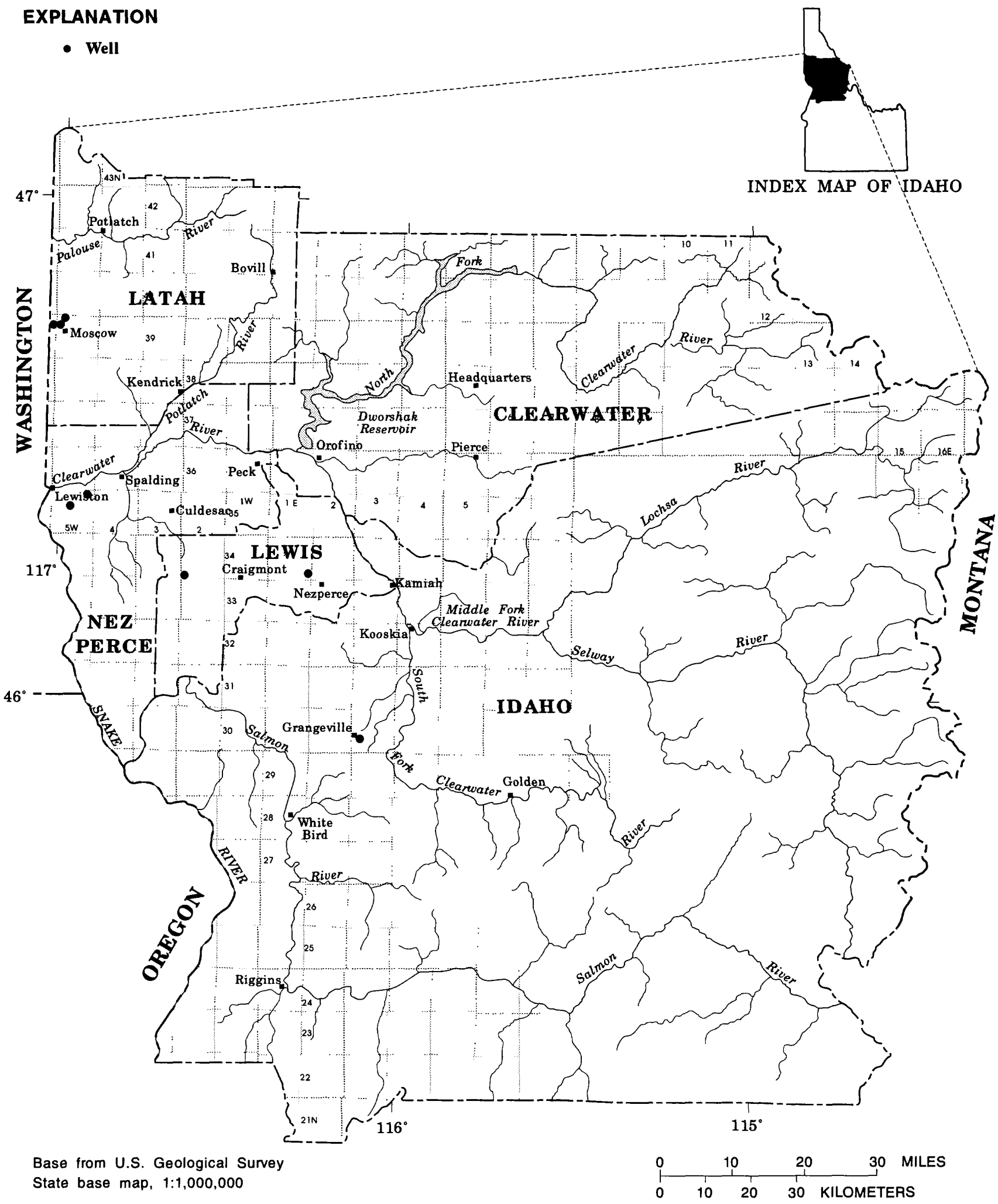

Figure 2. Locations of observation wells in north-central Idaho. 


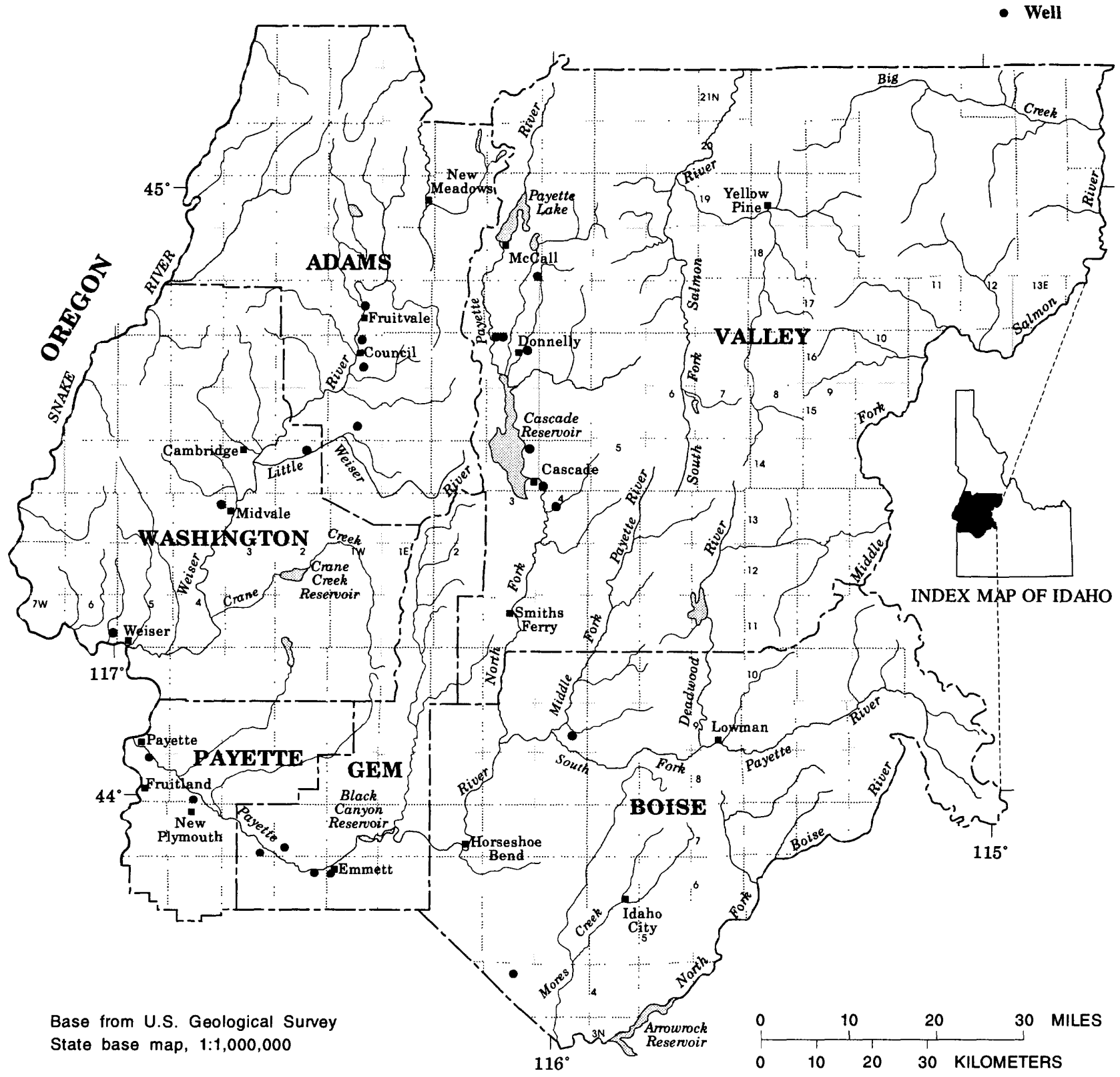

Figure 3. Locations of observation wells in west-central Idaho. 


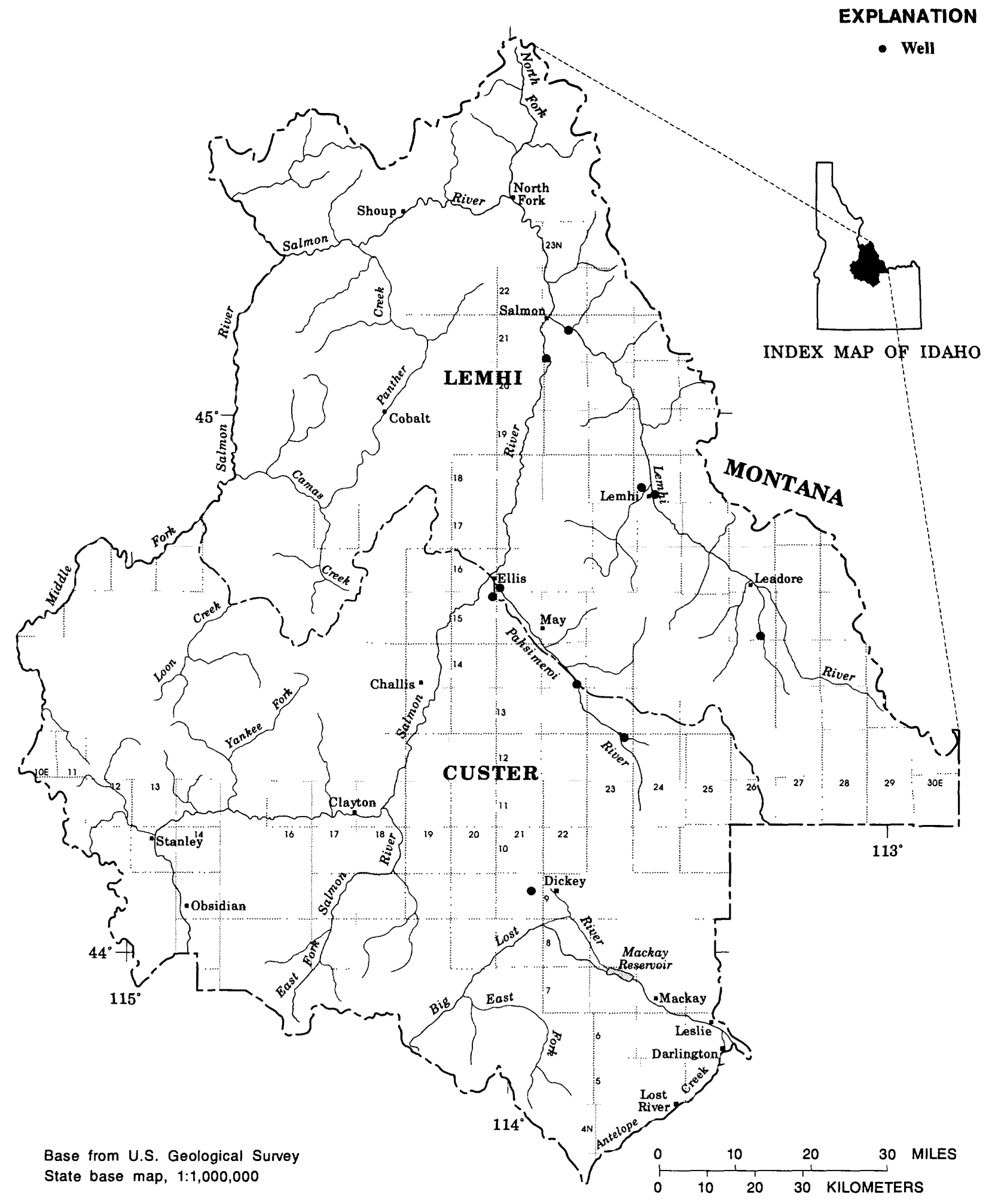

Figure 4. Locations of observation wells in east-central Idaho. 


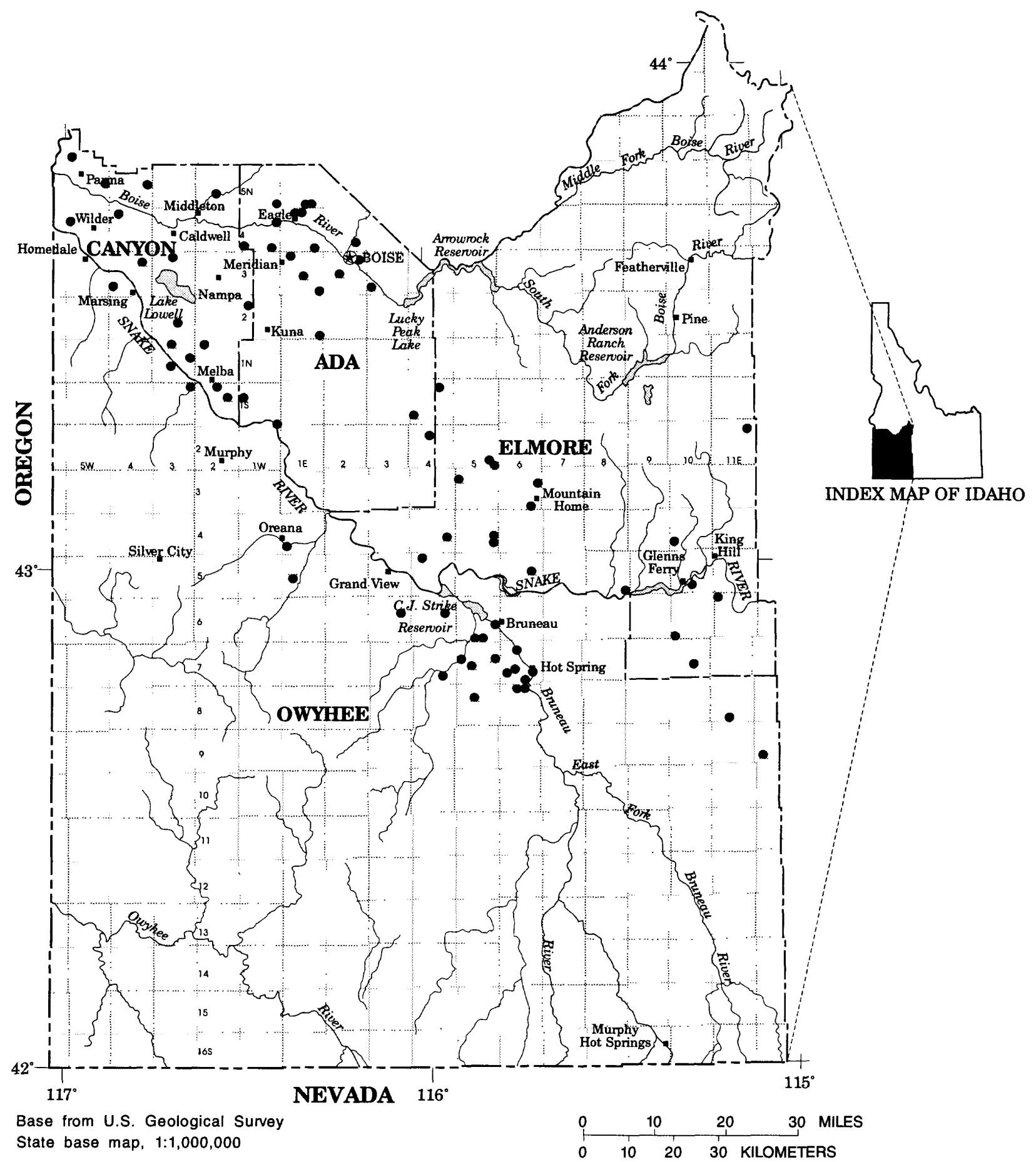

Figure 5. Locations of observation wells in southwest Idaho. 


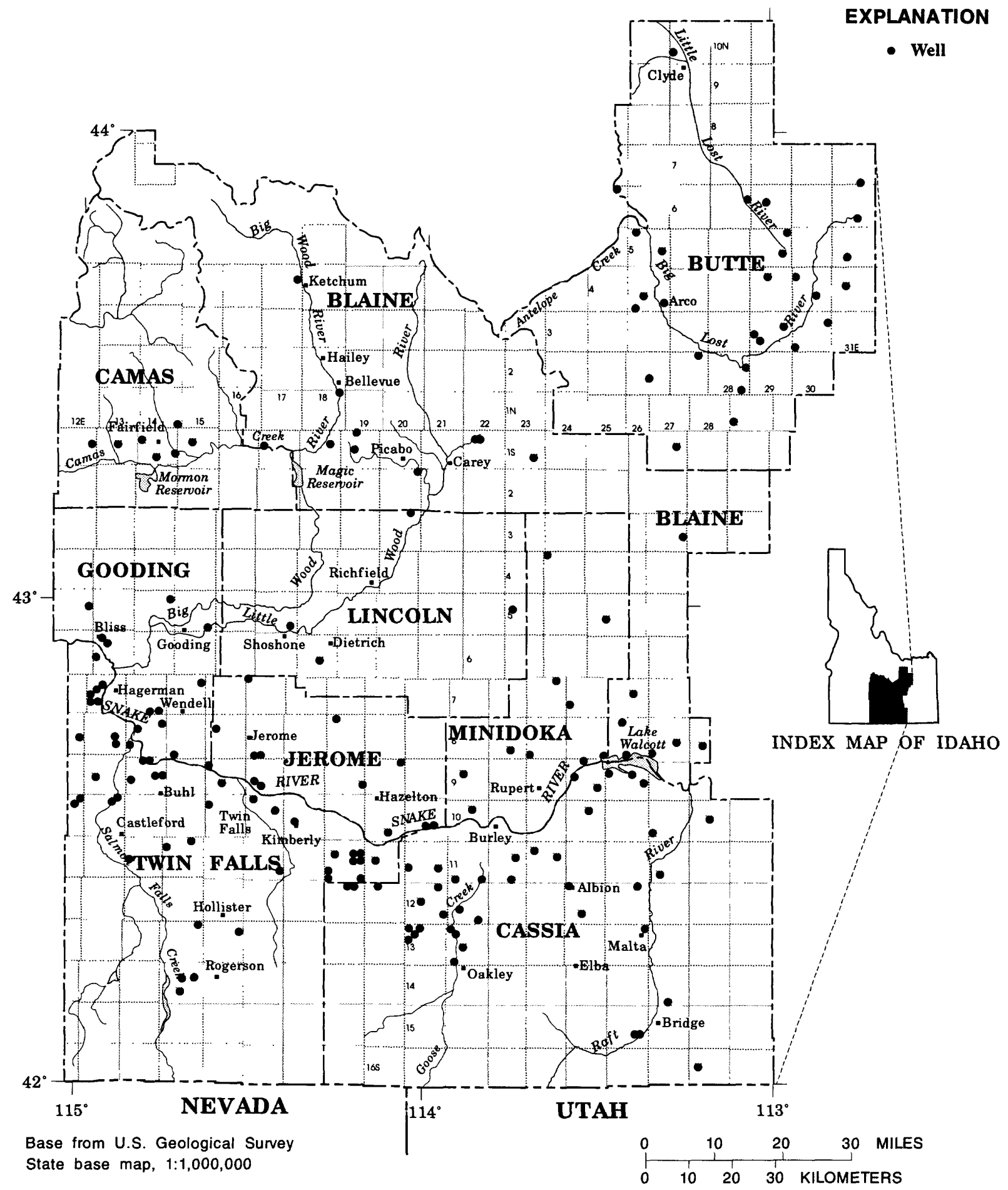

Figure 6. Locations of observation wells in south-central Idaho. 


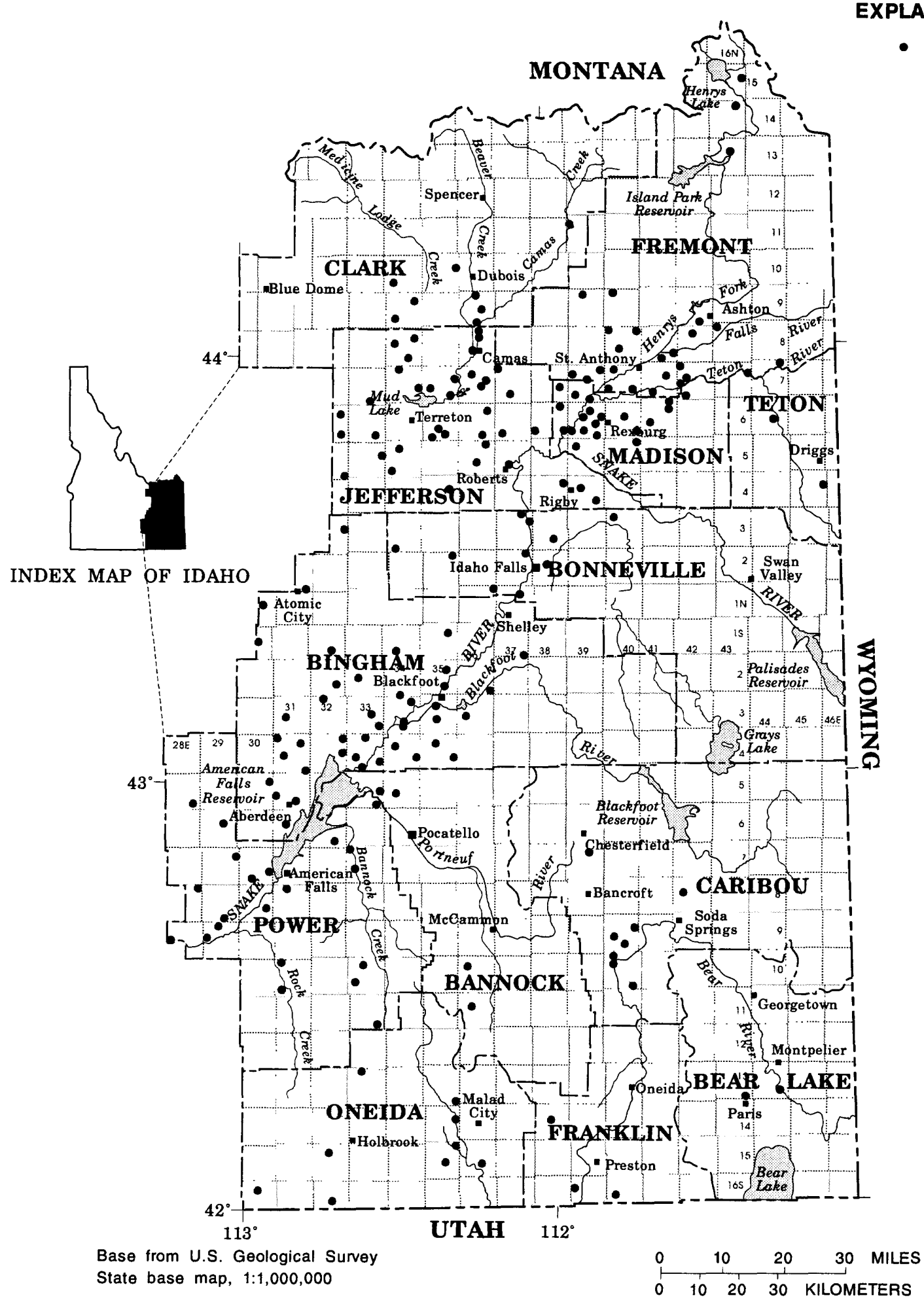

Figure 7. Locations of observation wells in southeast Idaho. 
HYDROGRAPHS, BY COUNTY 
Ada 

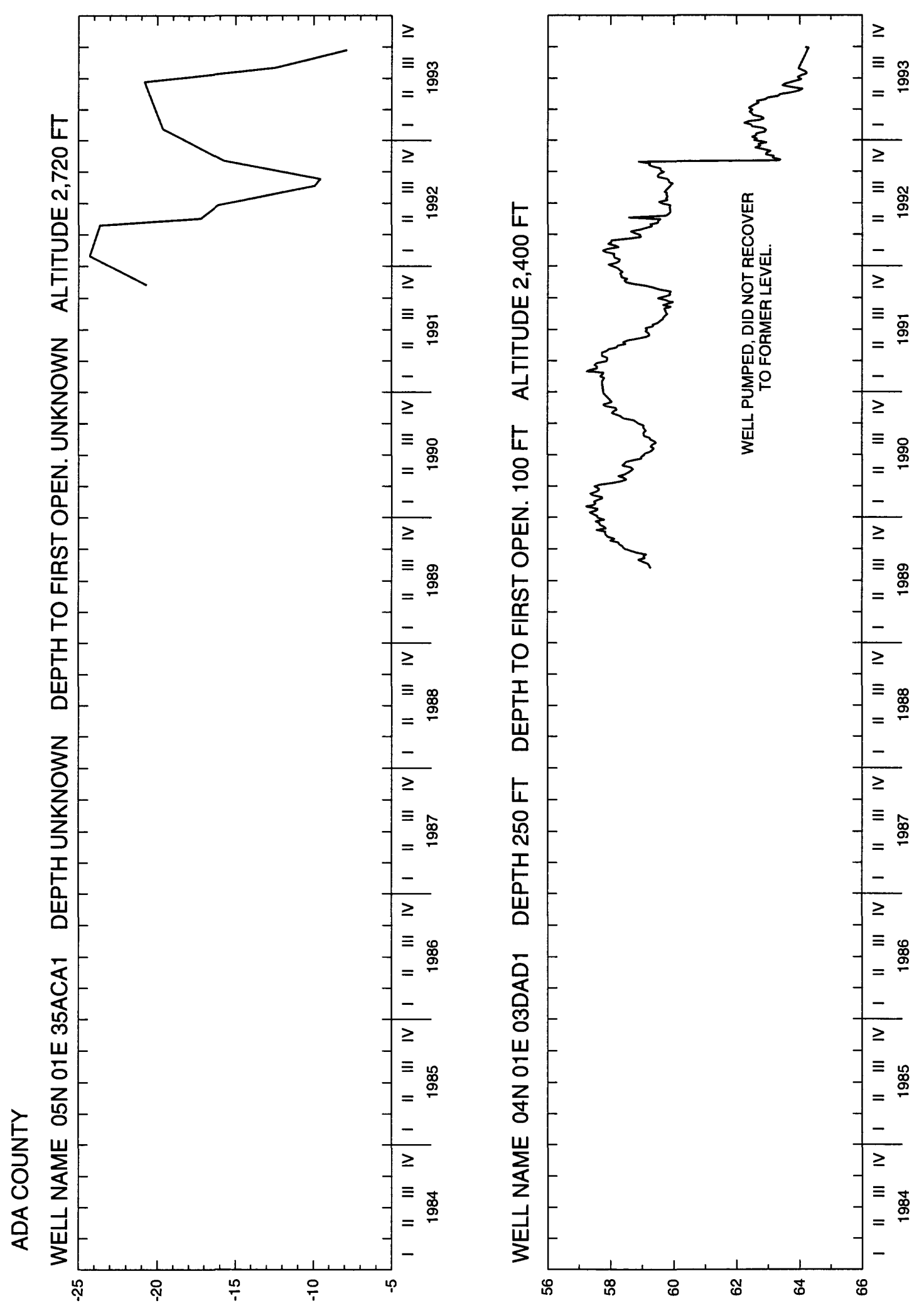

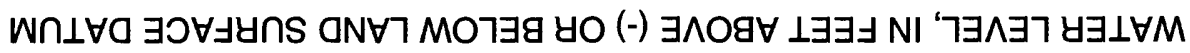



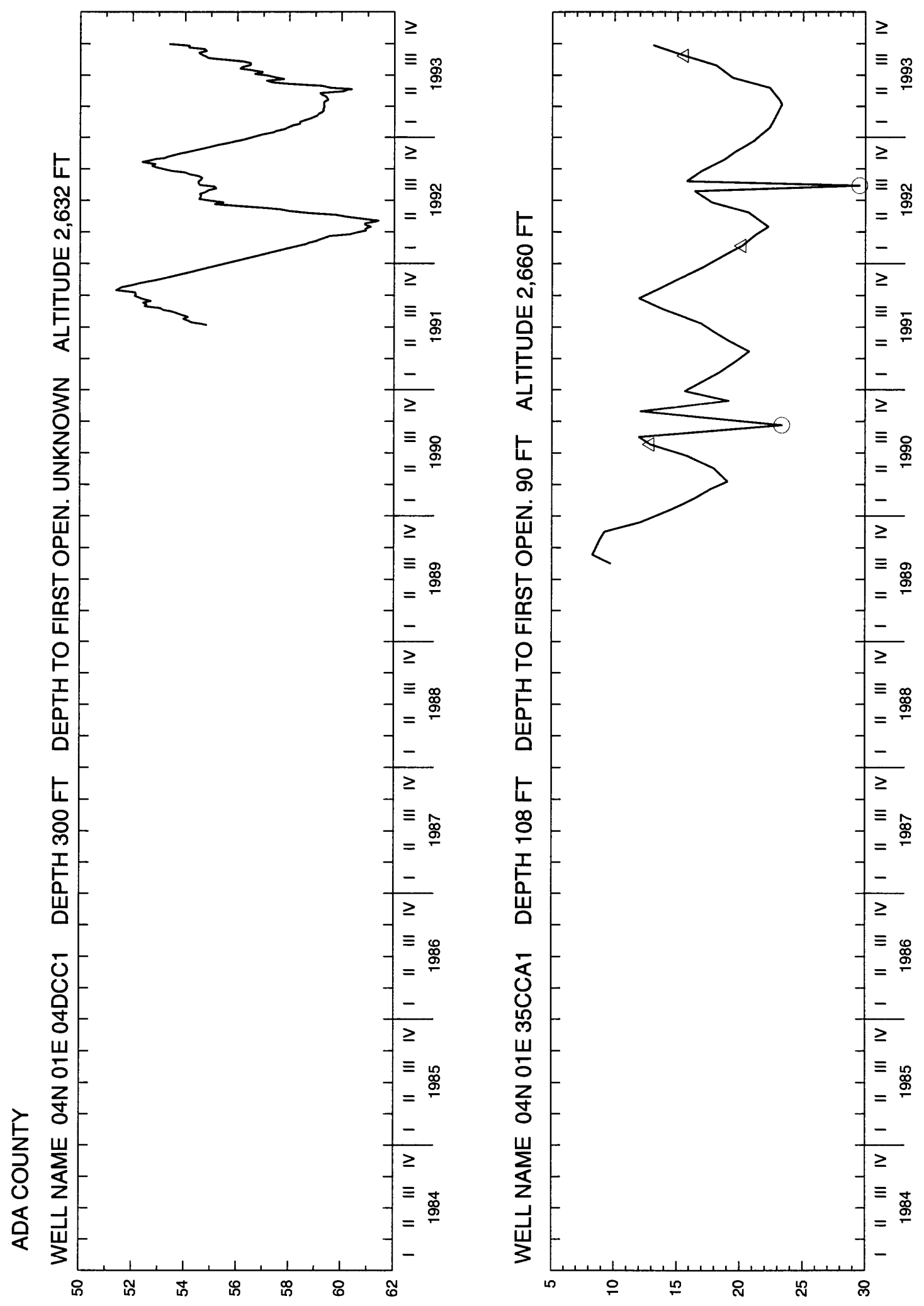

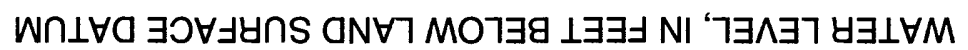



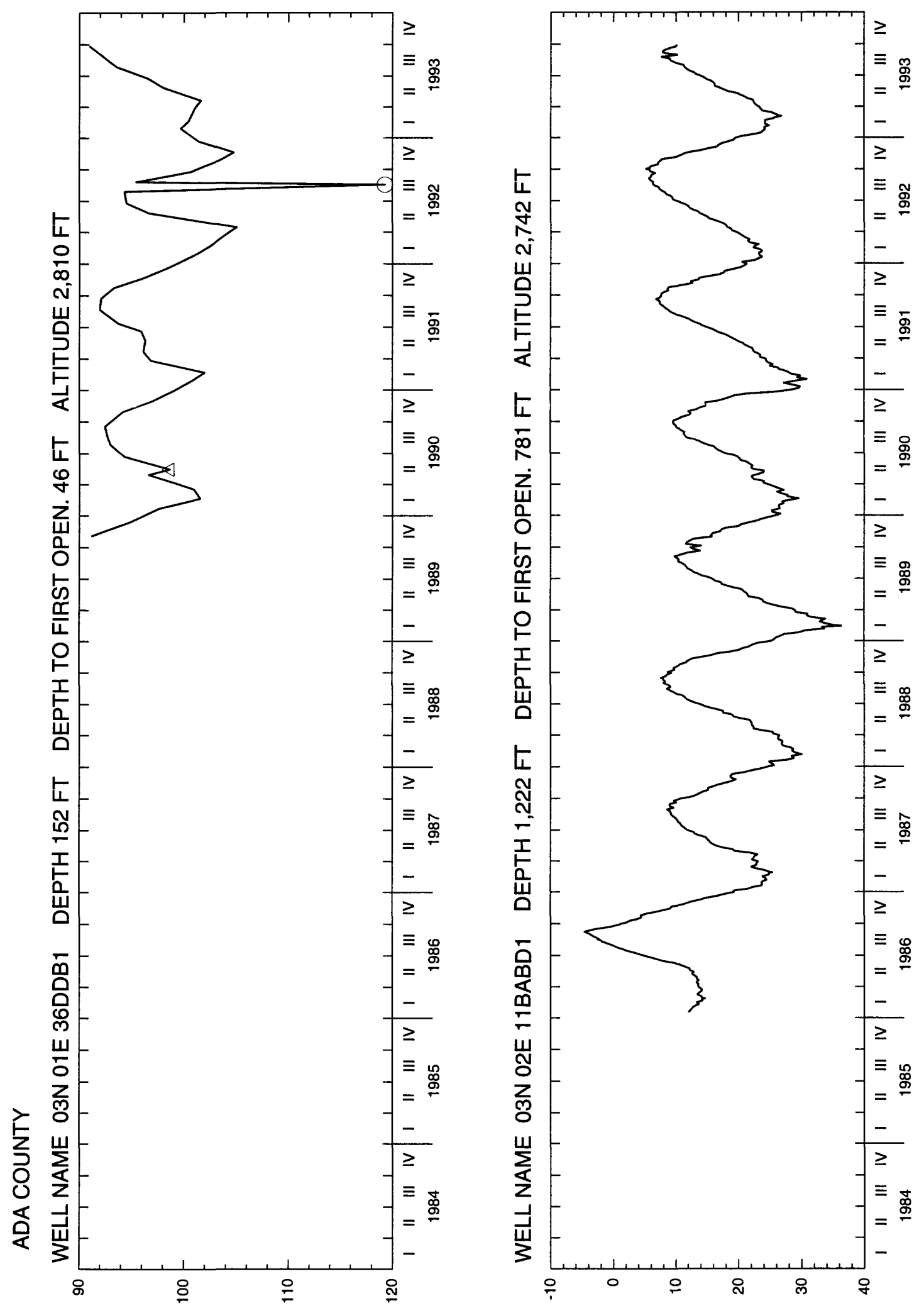

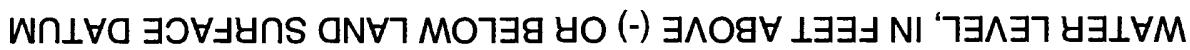



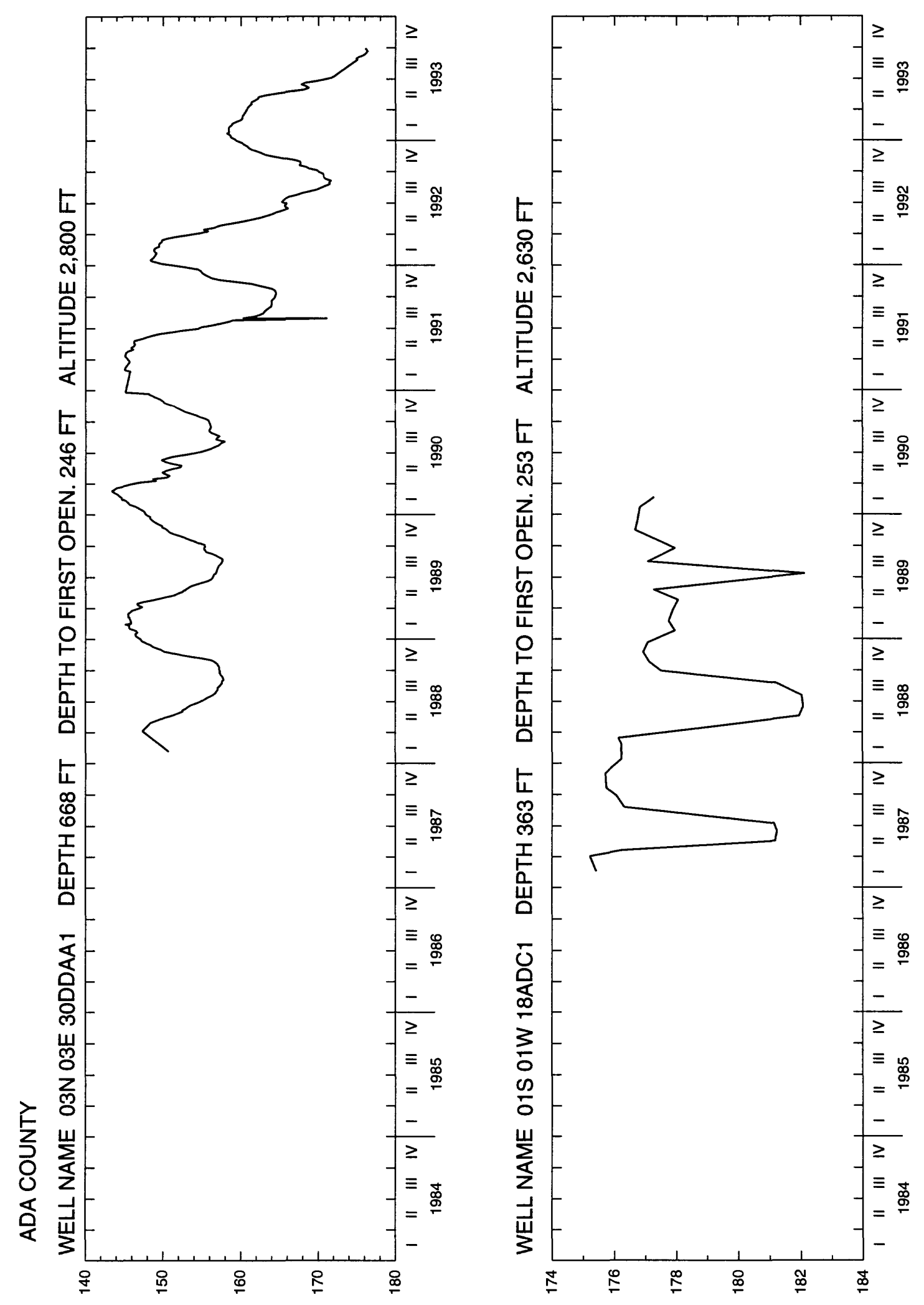

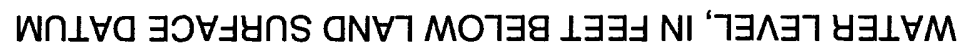




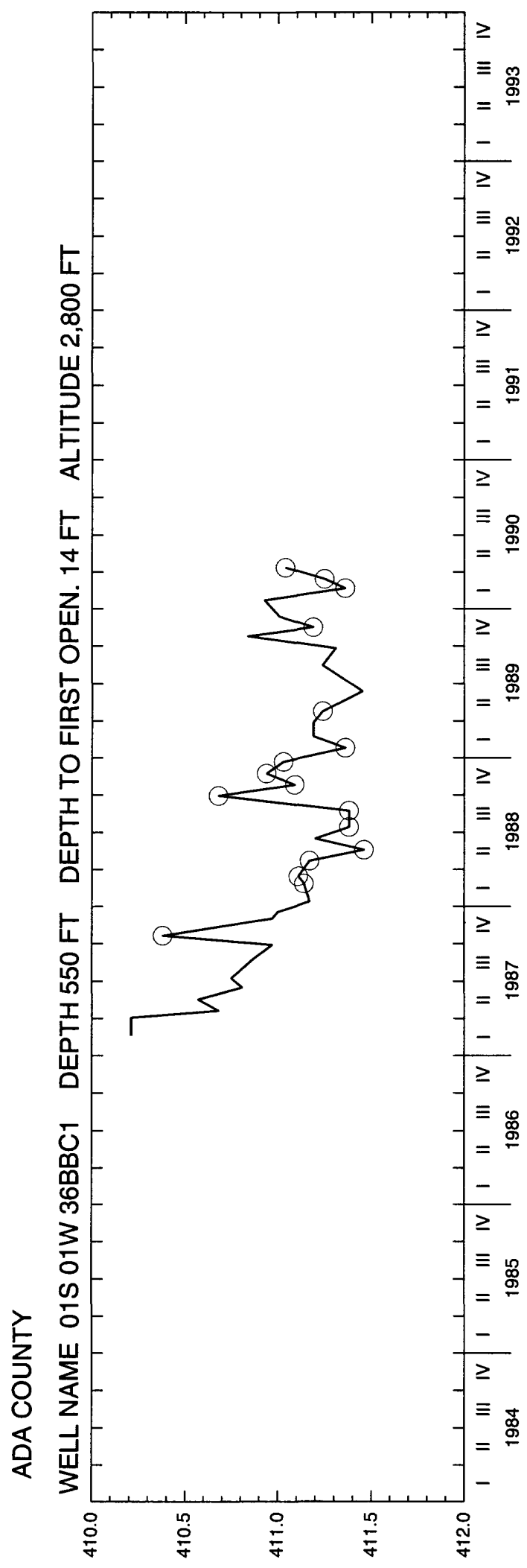

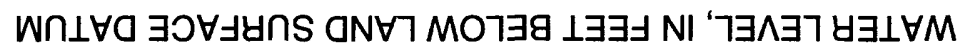




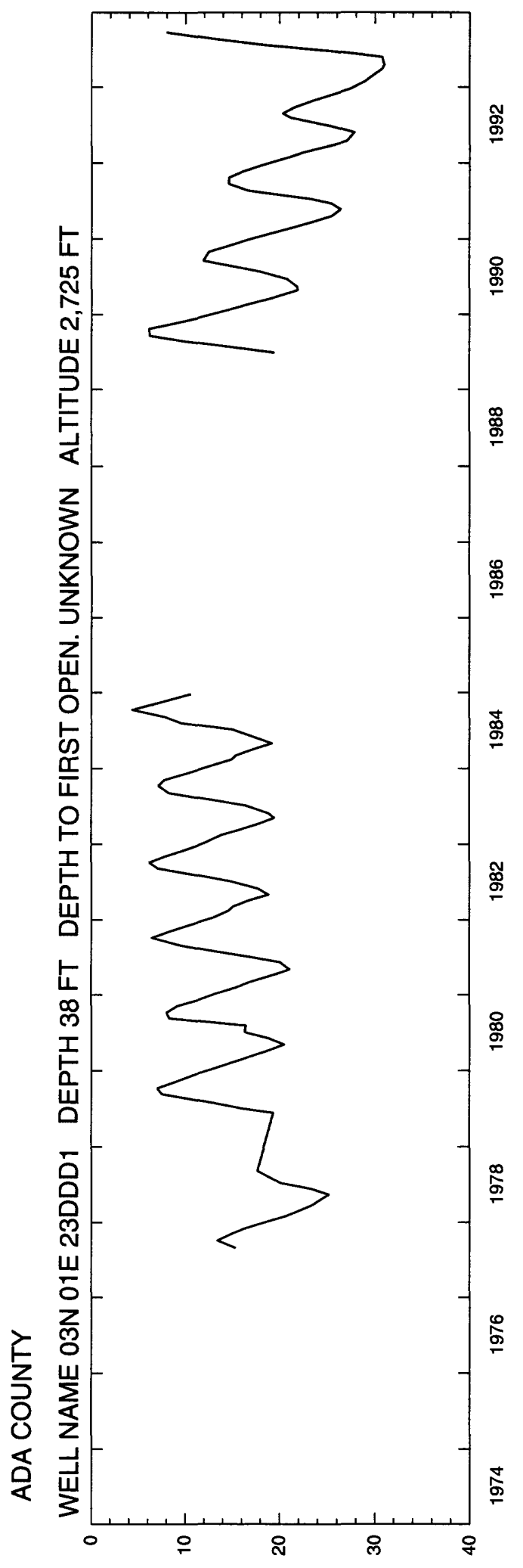

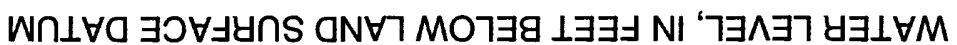




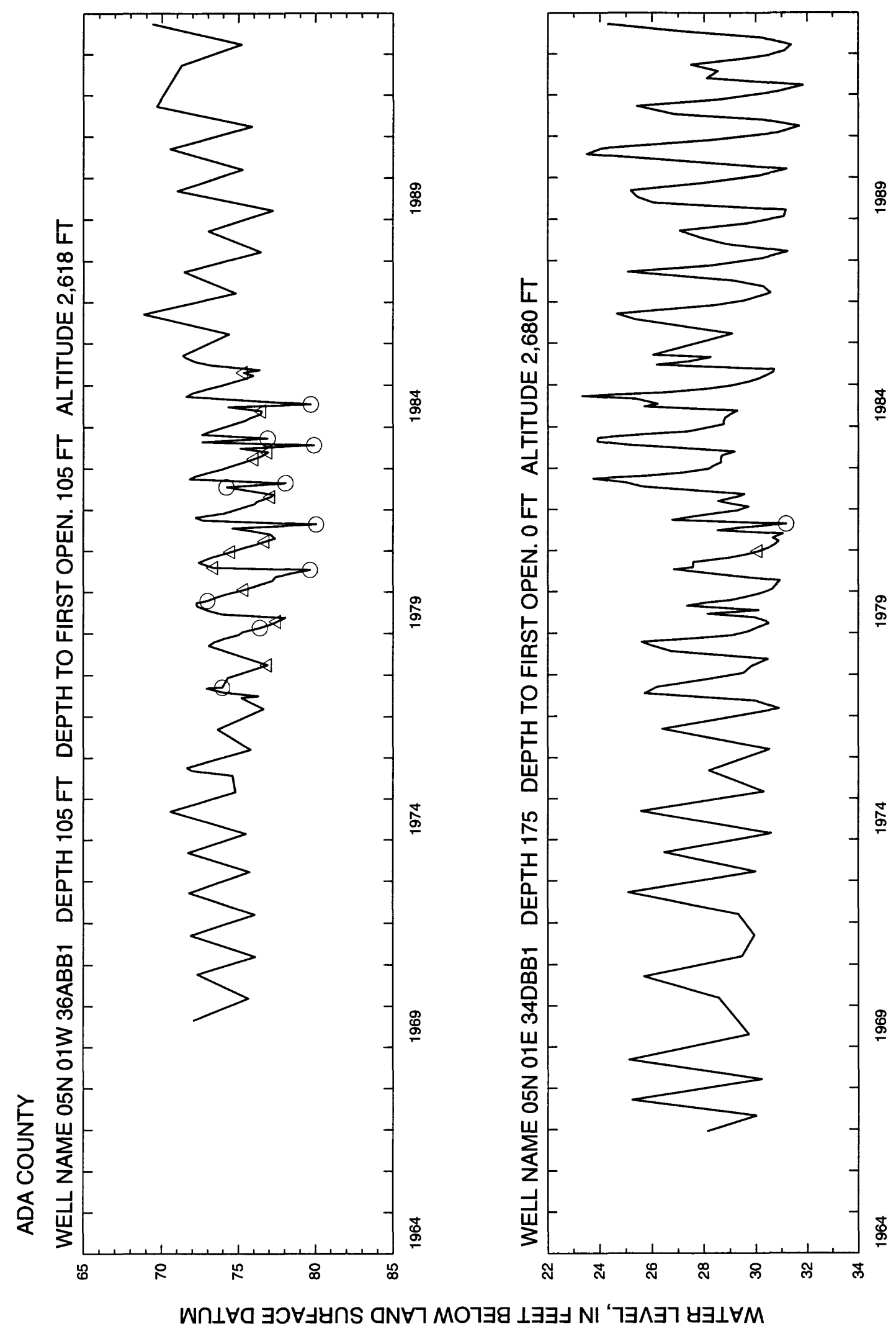




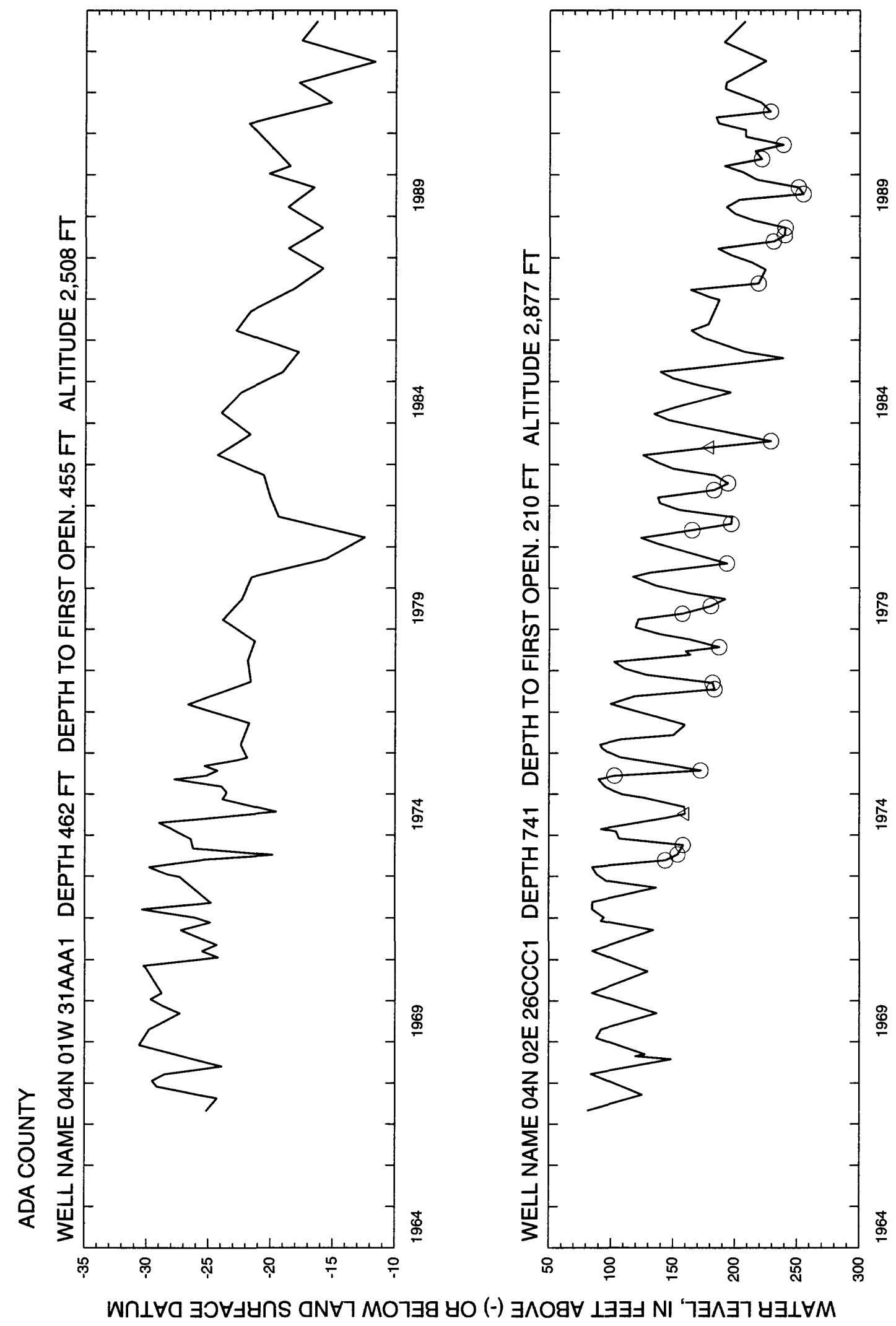



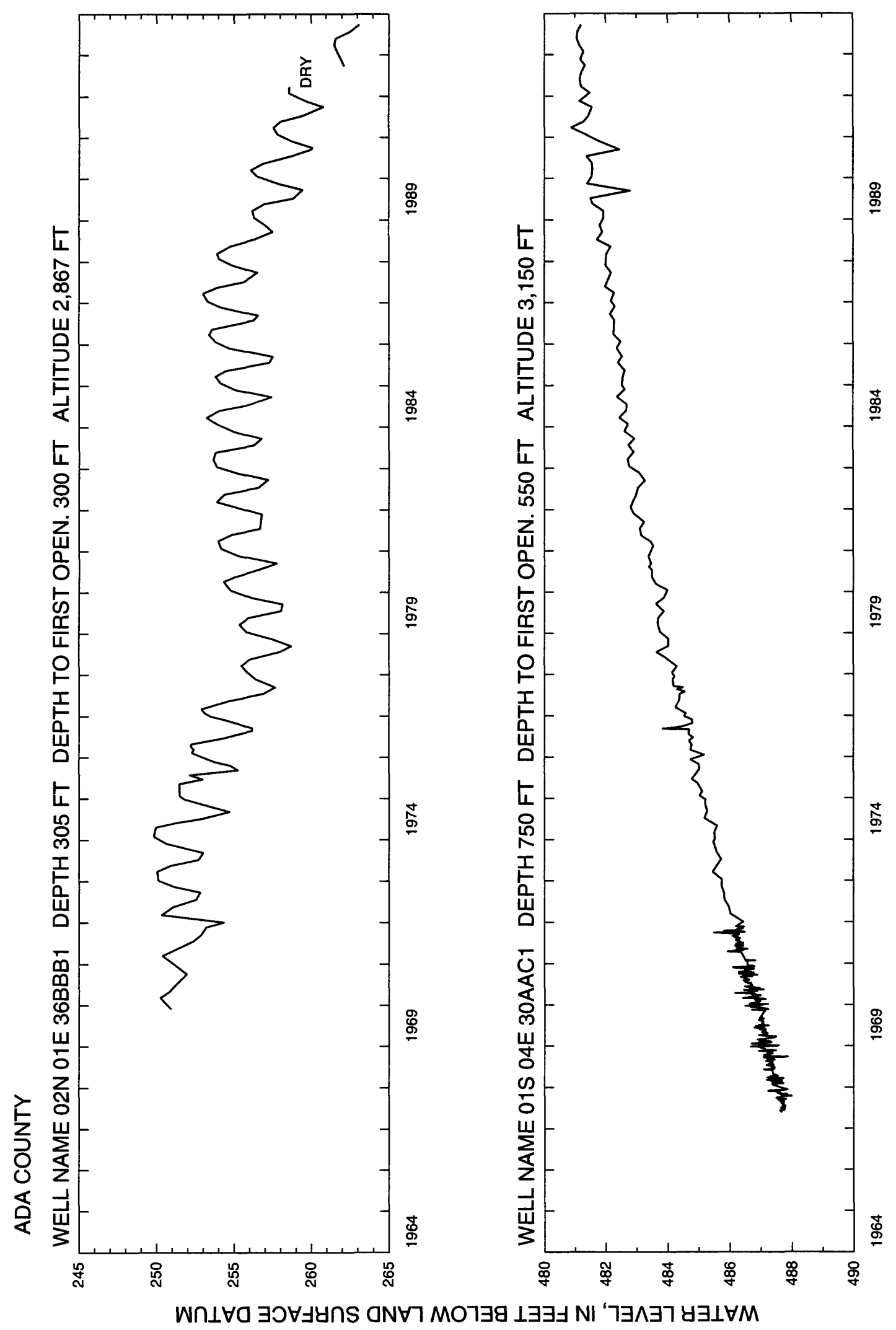


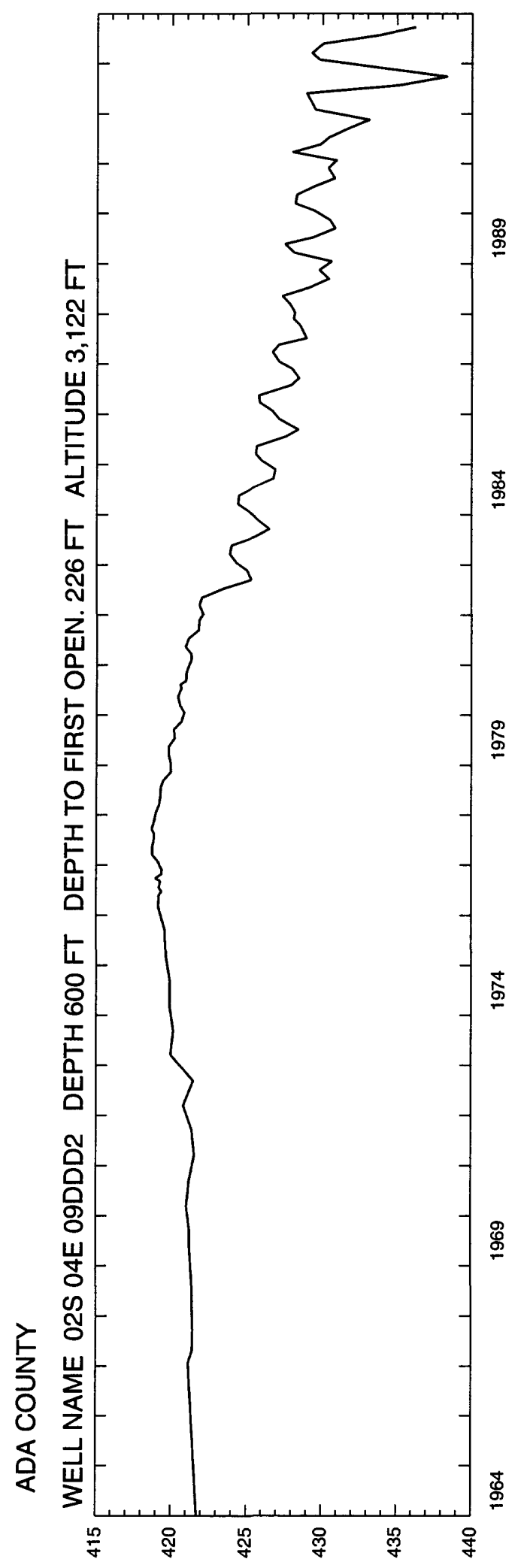

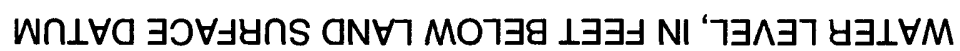




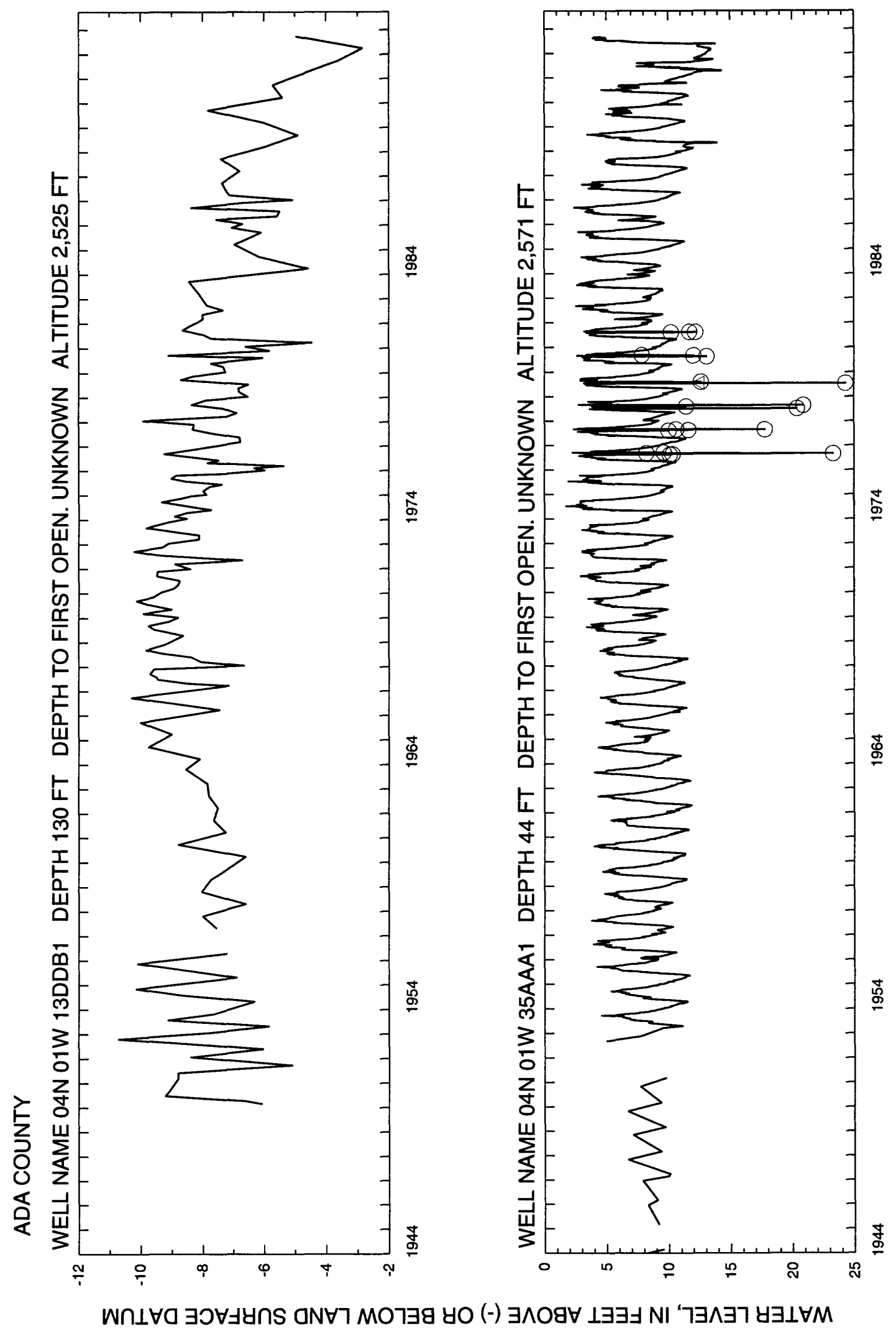



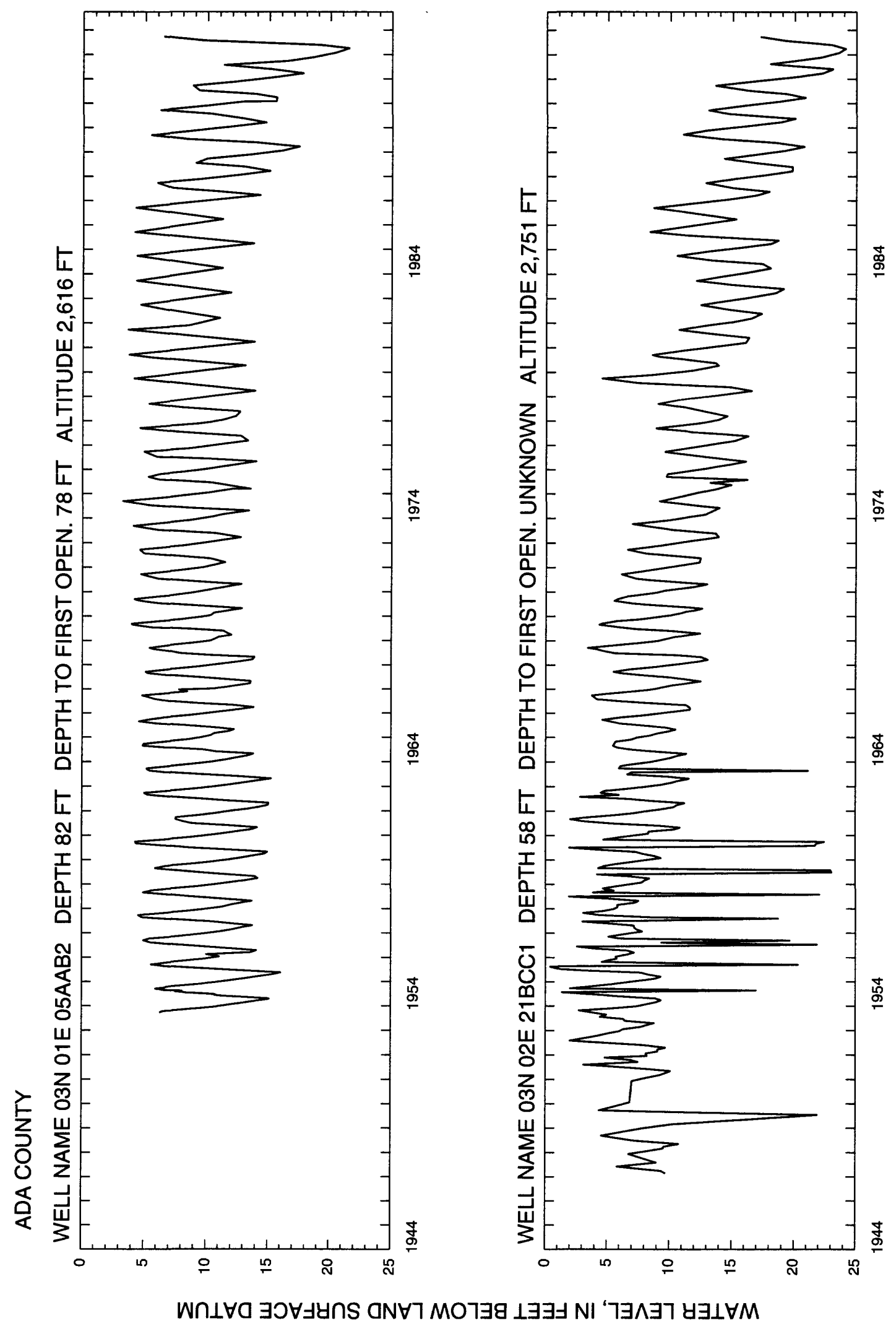
Adams 


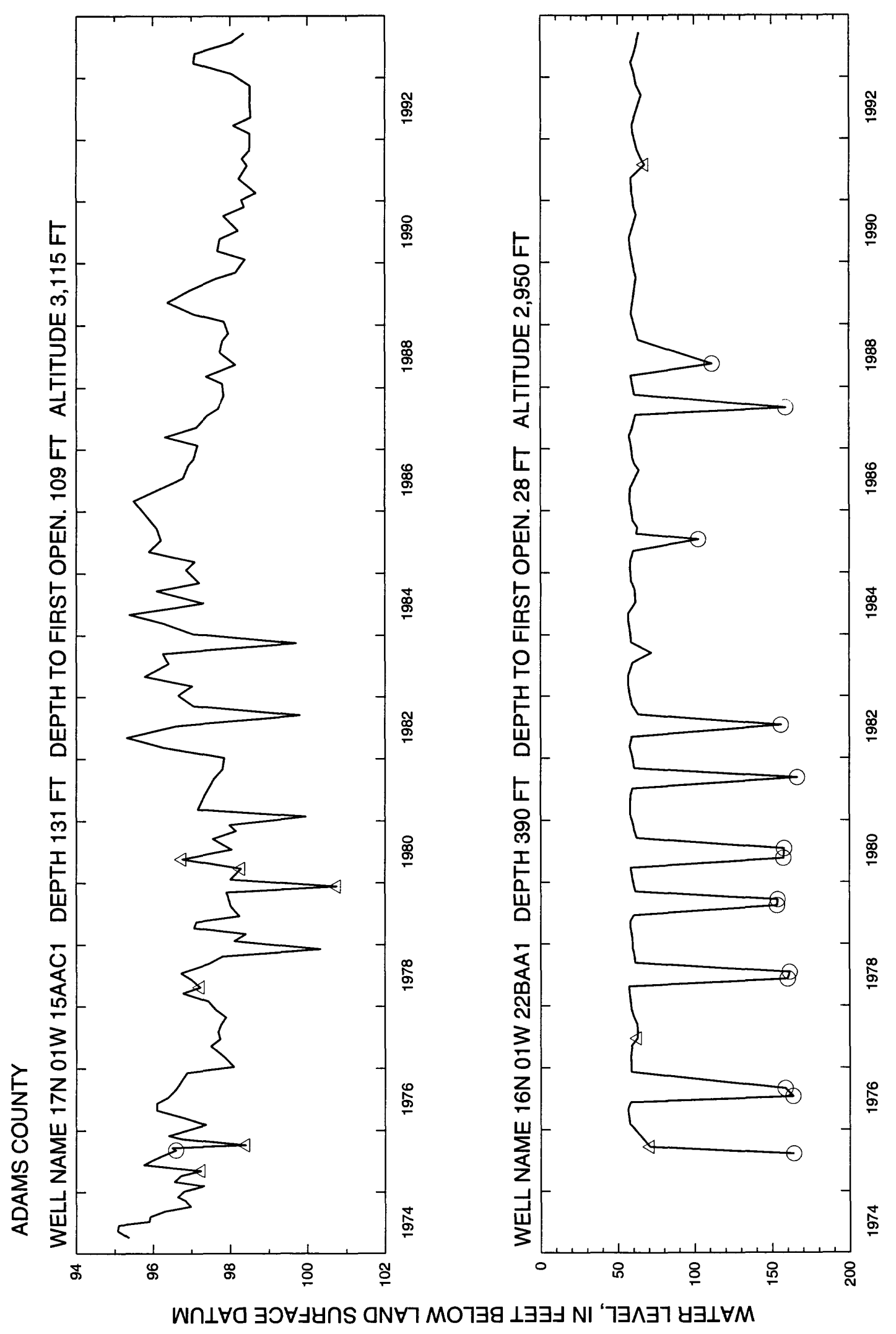




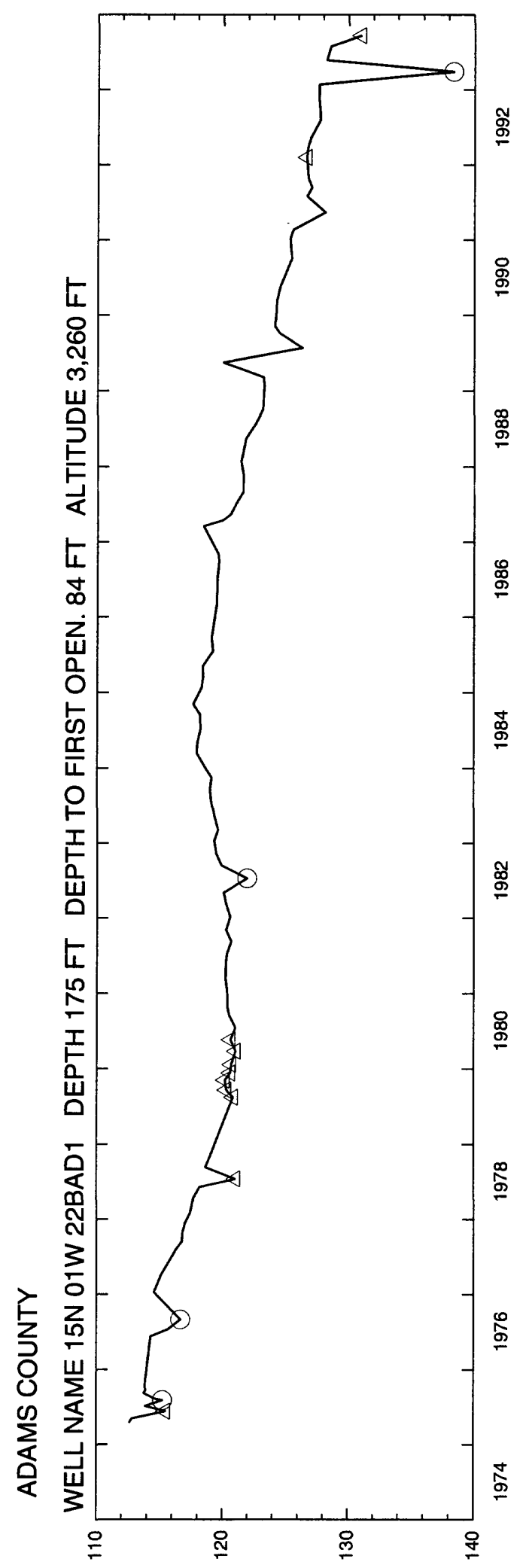

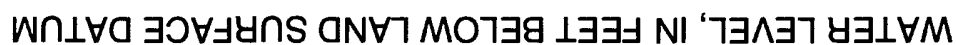




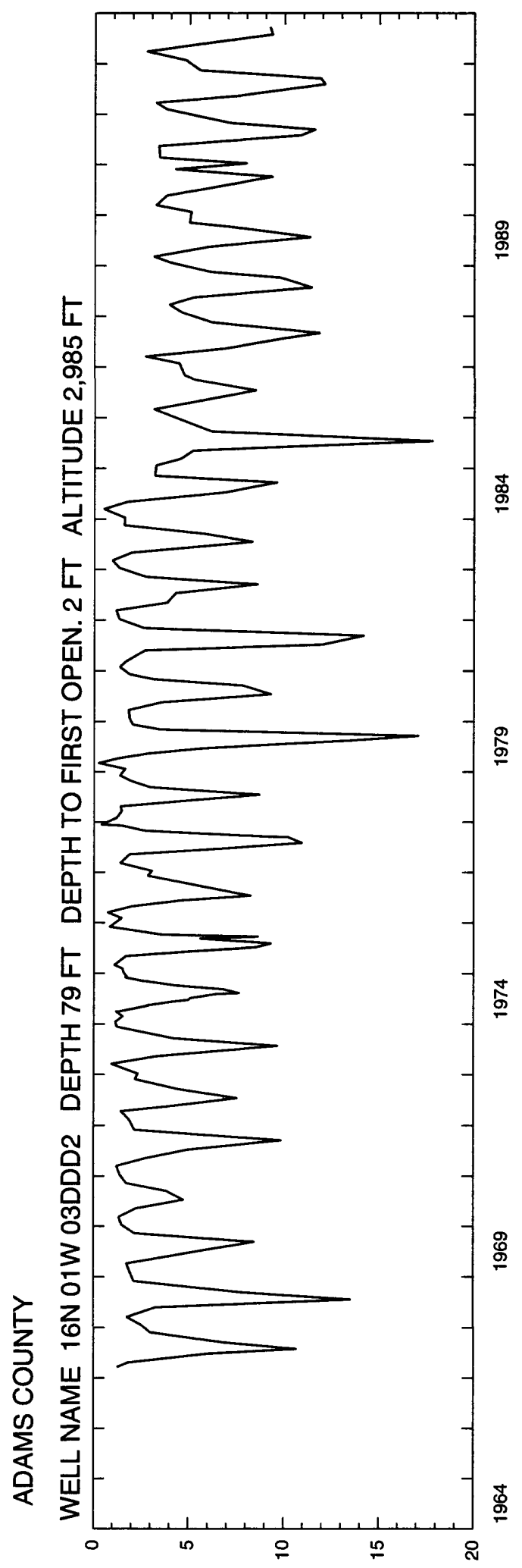

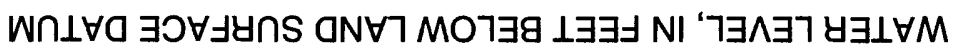

29 (paqe 31 Lollows) 


\section{Bannock}



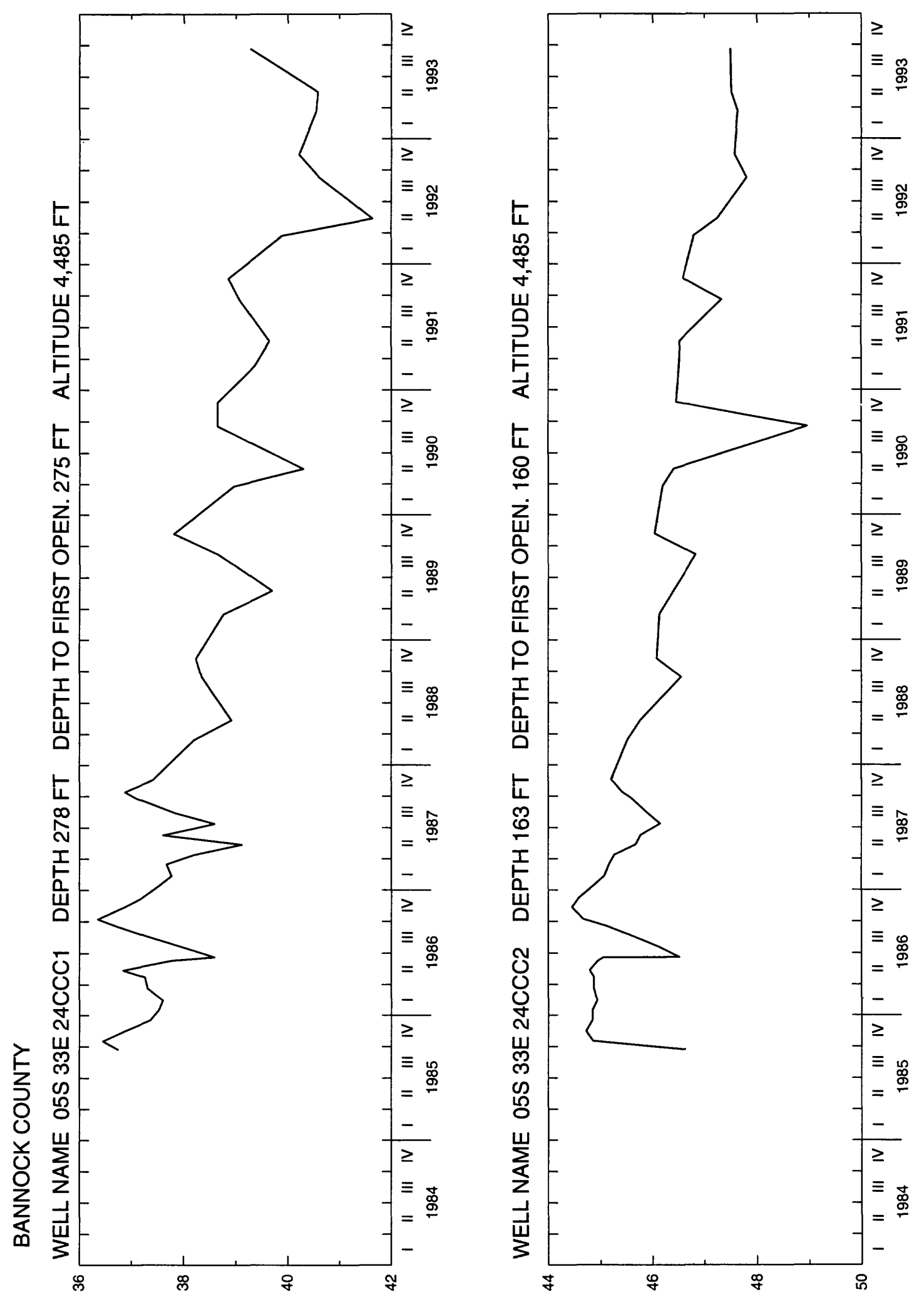

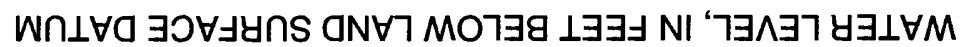




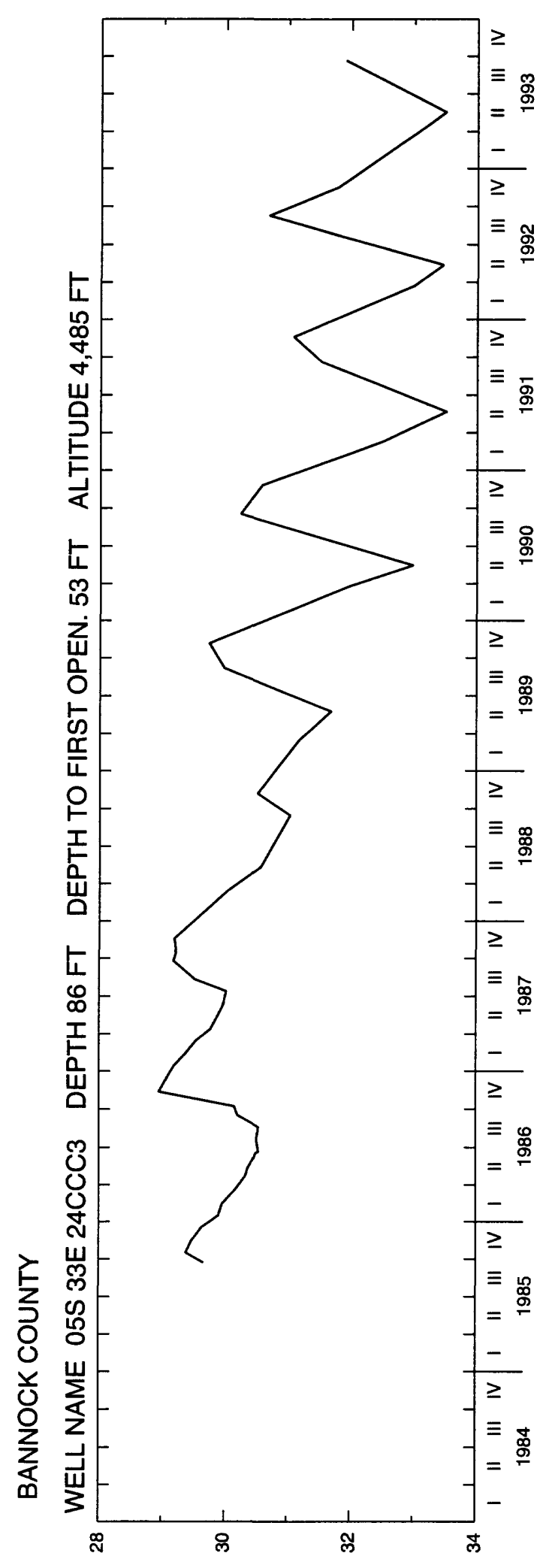

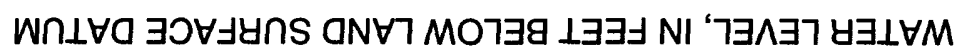




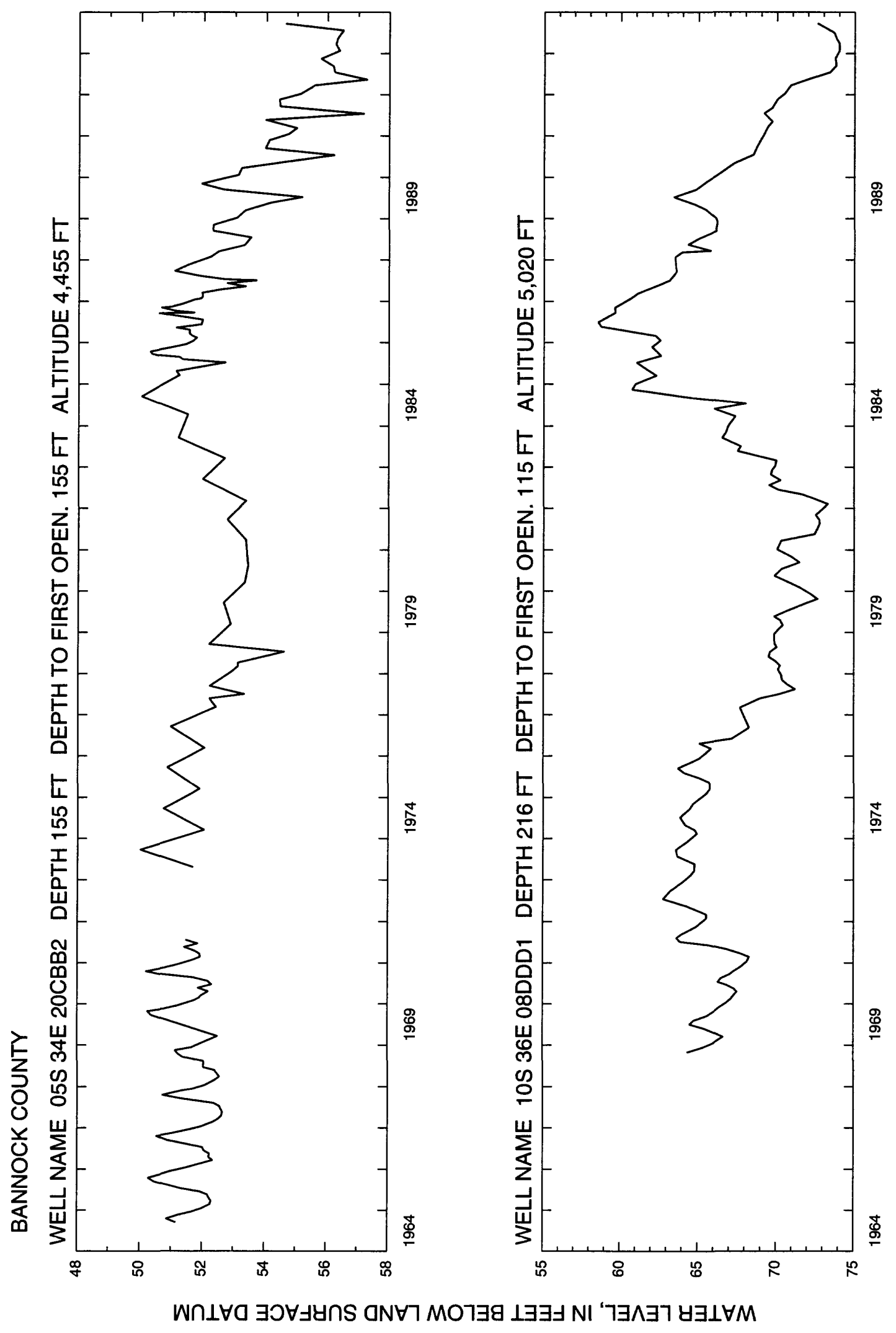




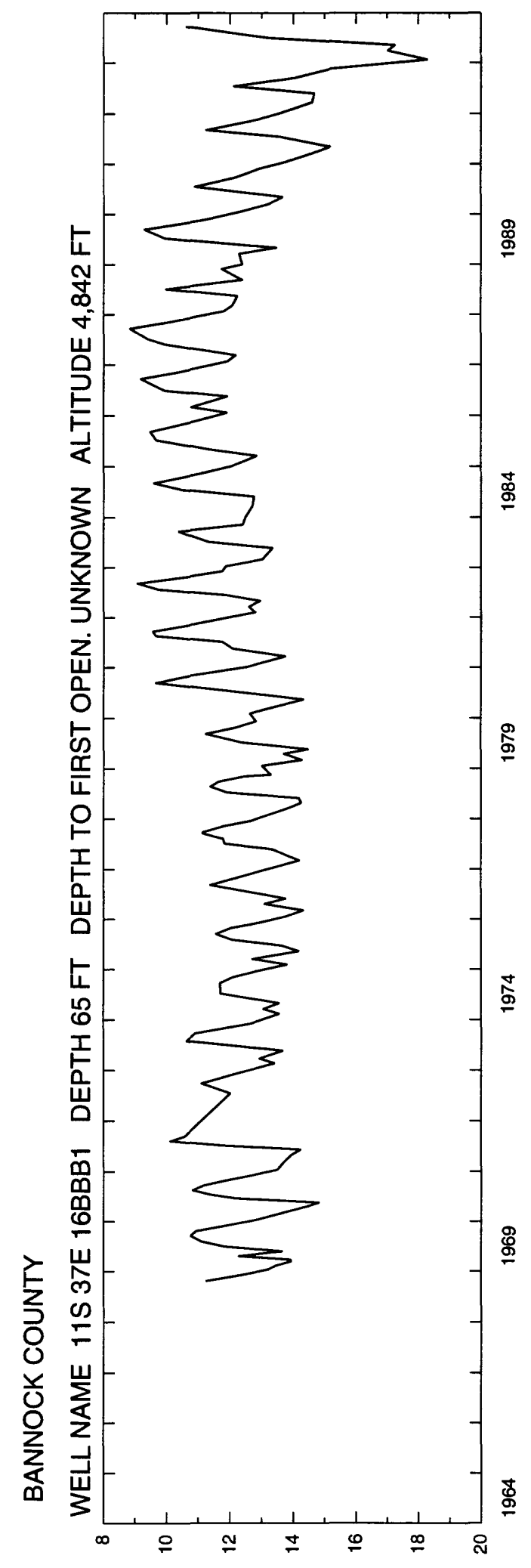

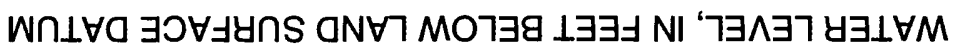




\section{Bear Lake}




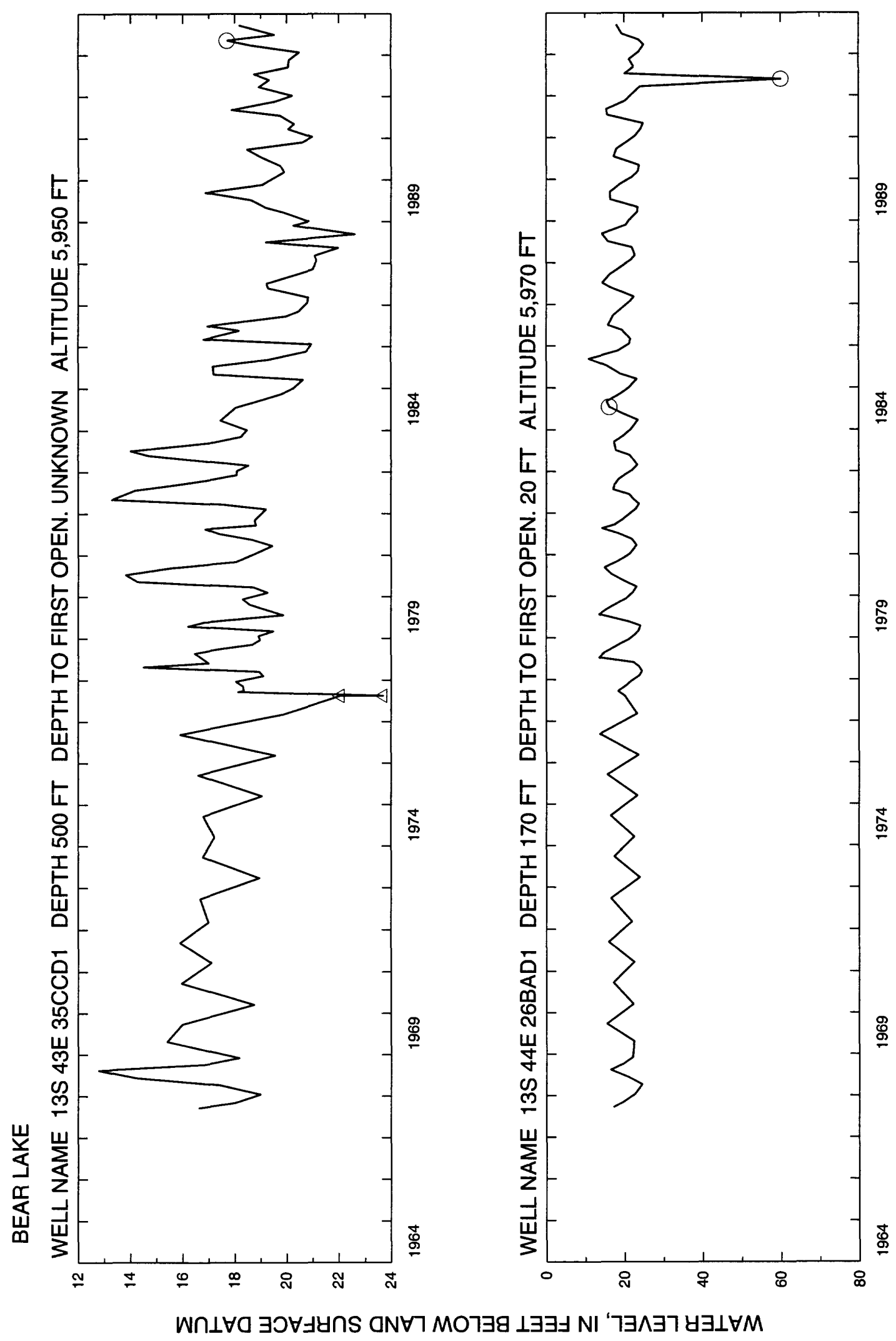

$\stackrel{\circ}{\circ}$

$\stackrel{\mathrm{g}}{\circ}$

$\stackrel{9}{\circ}$

$\stackrel{5}{\circ}$

\&

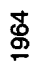




\section{Bingham}

${ }^{41}$ (page 43 follows) 


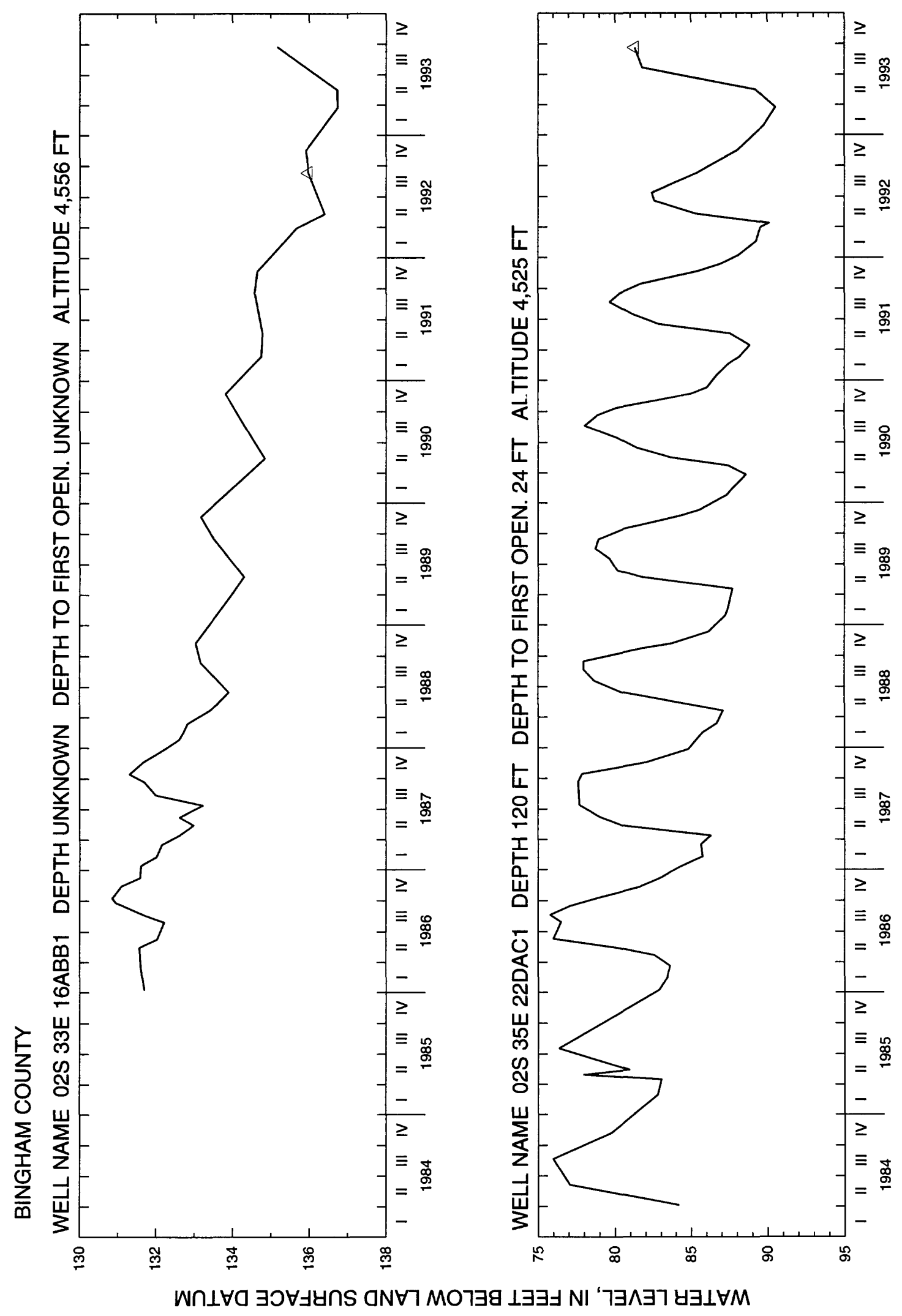




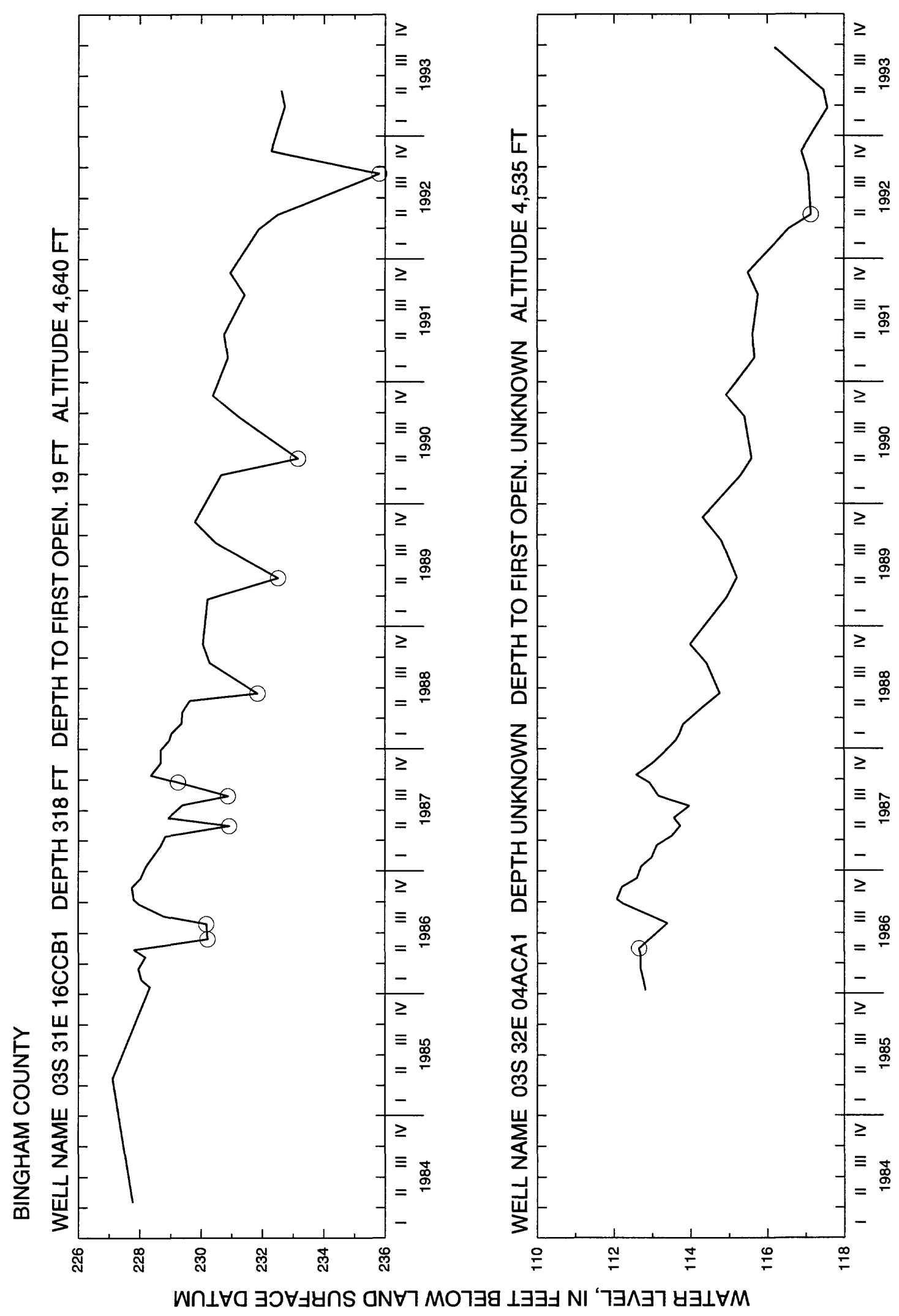




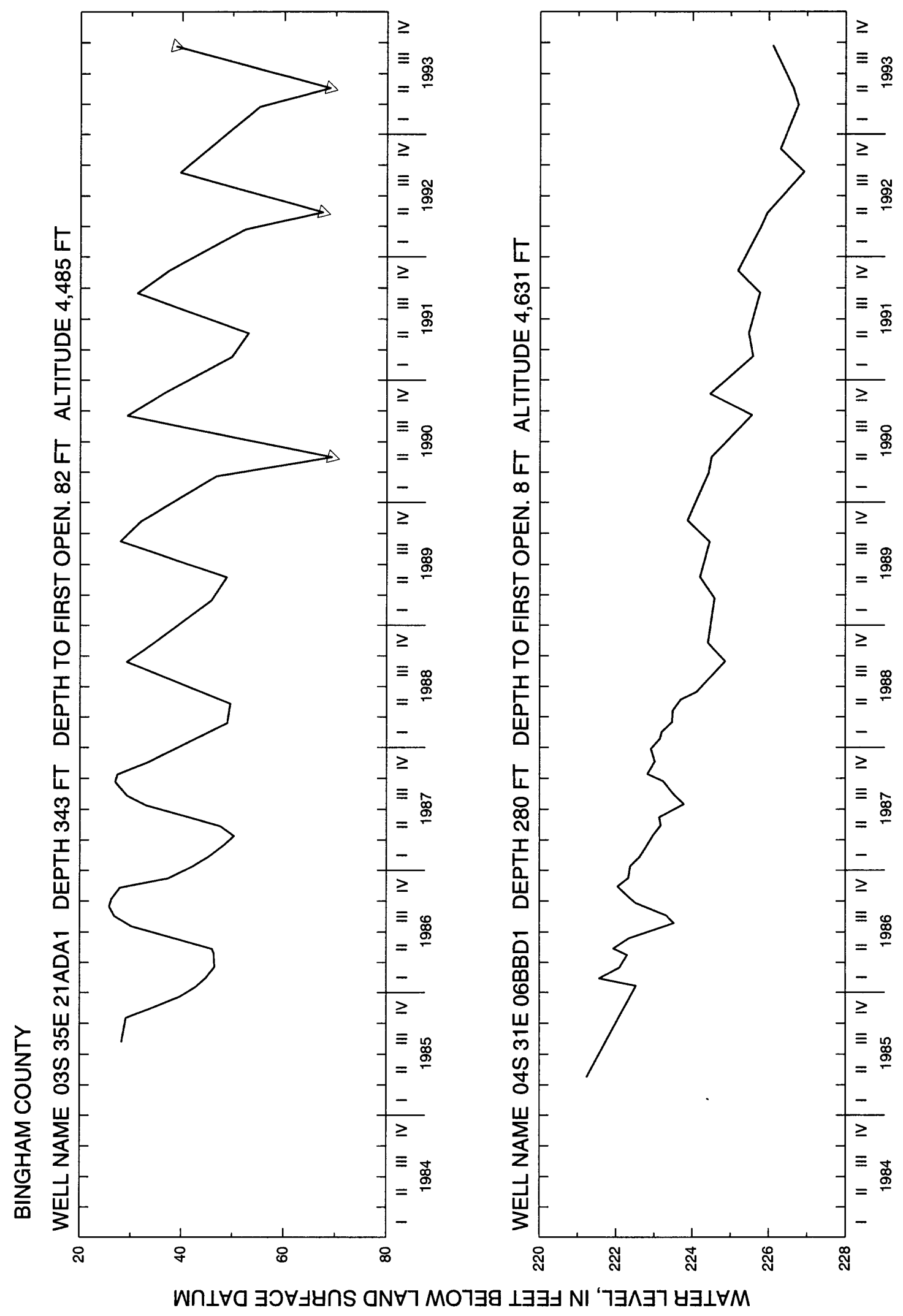



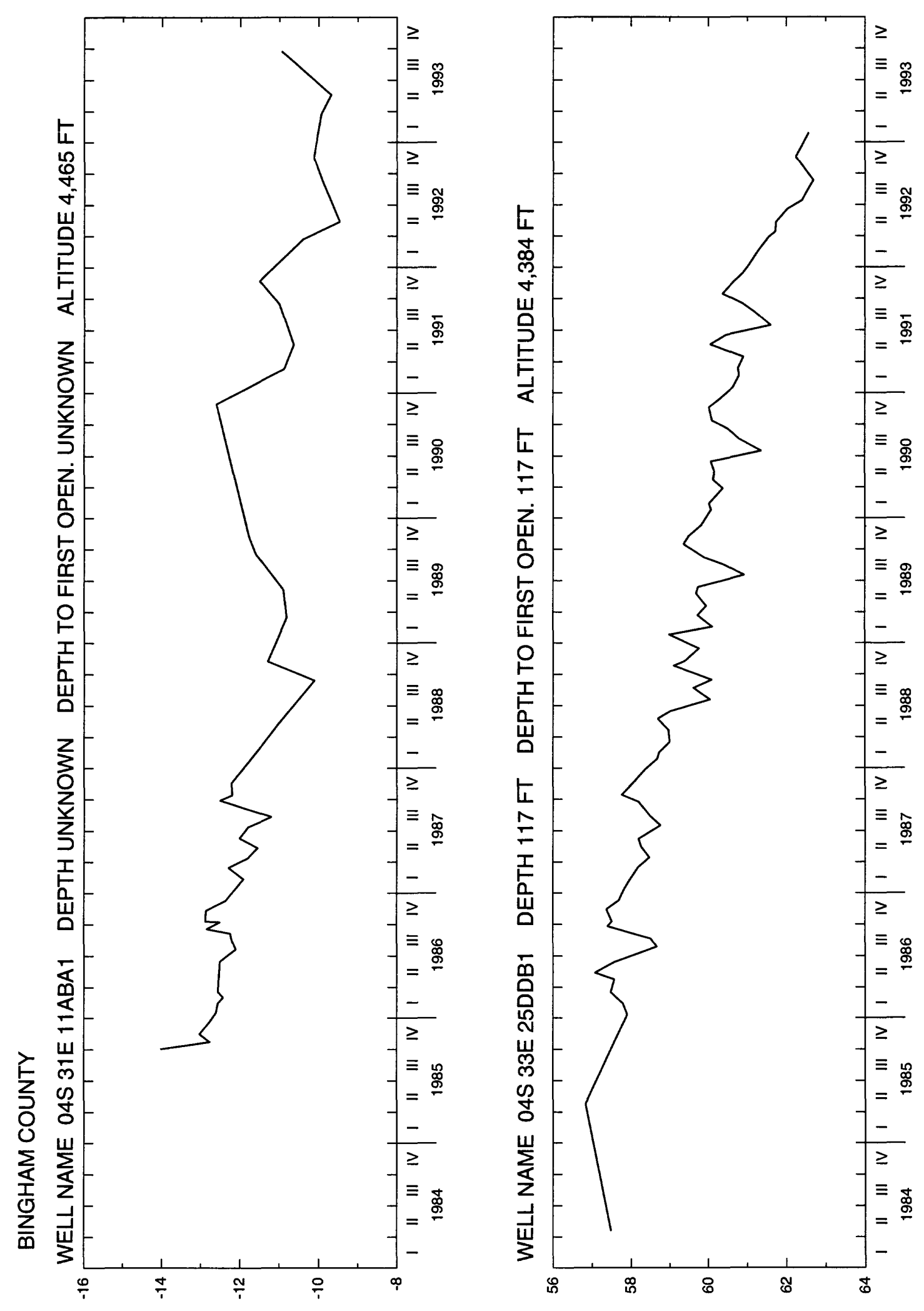

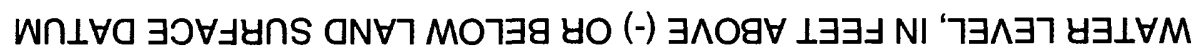




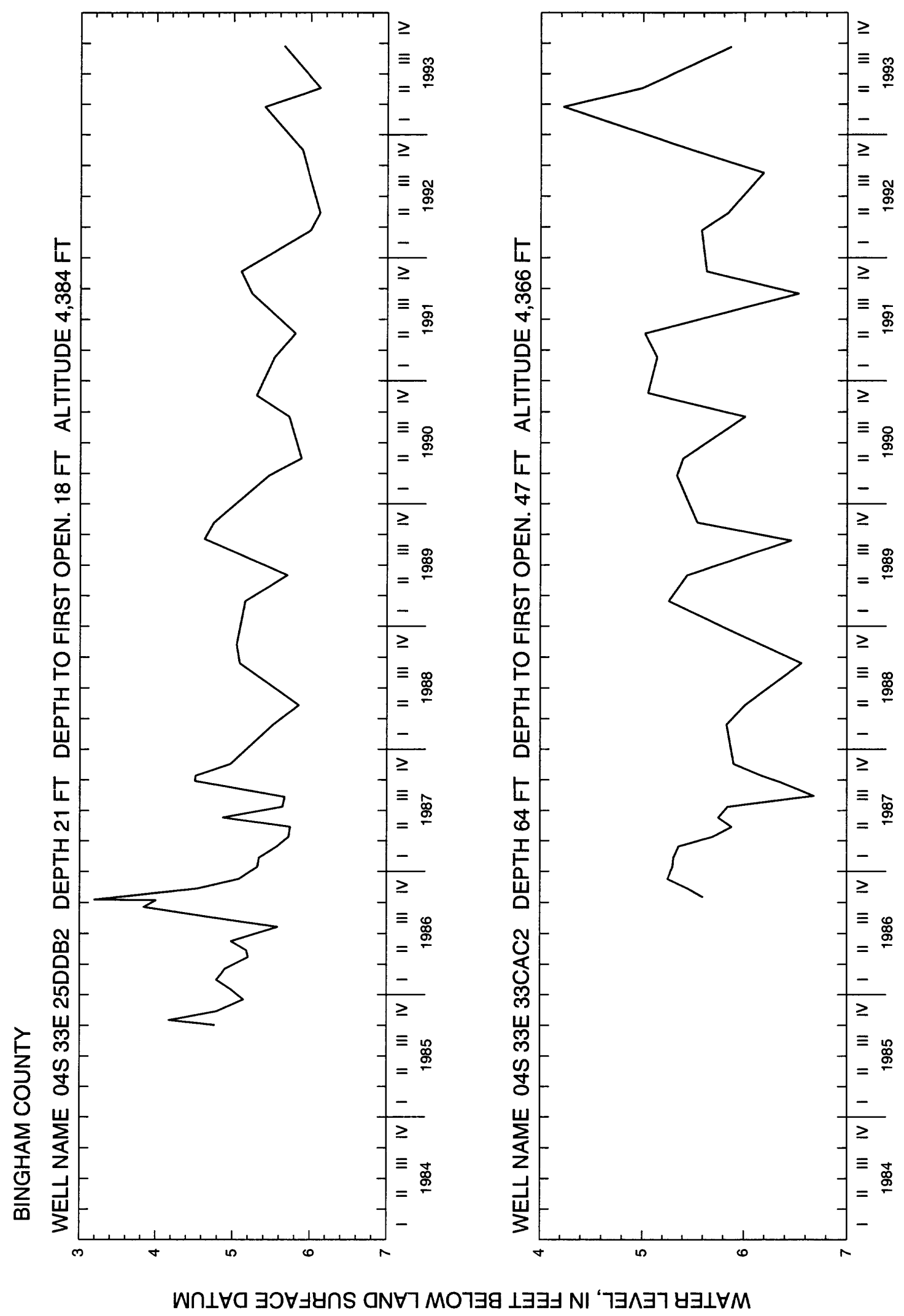




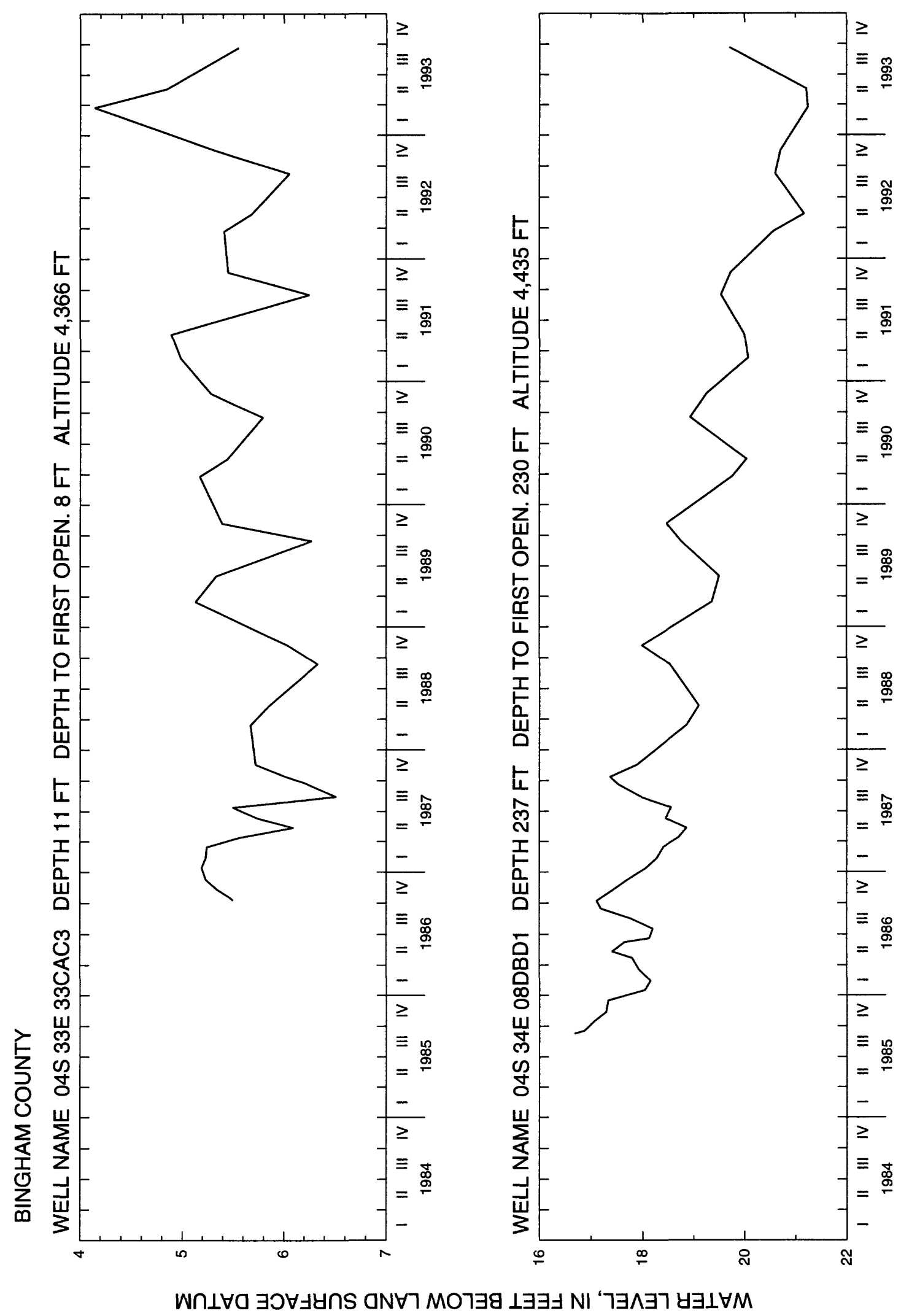




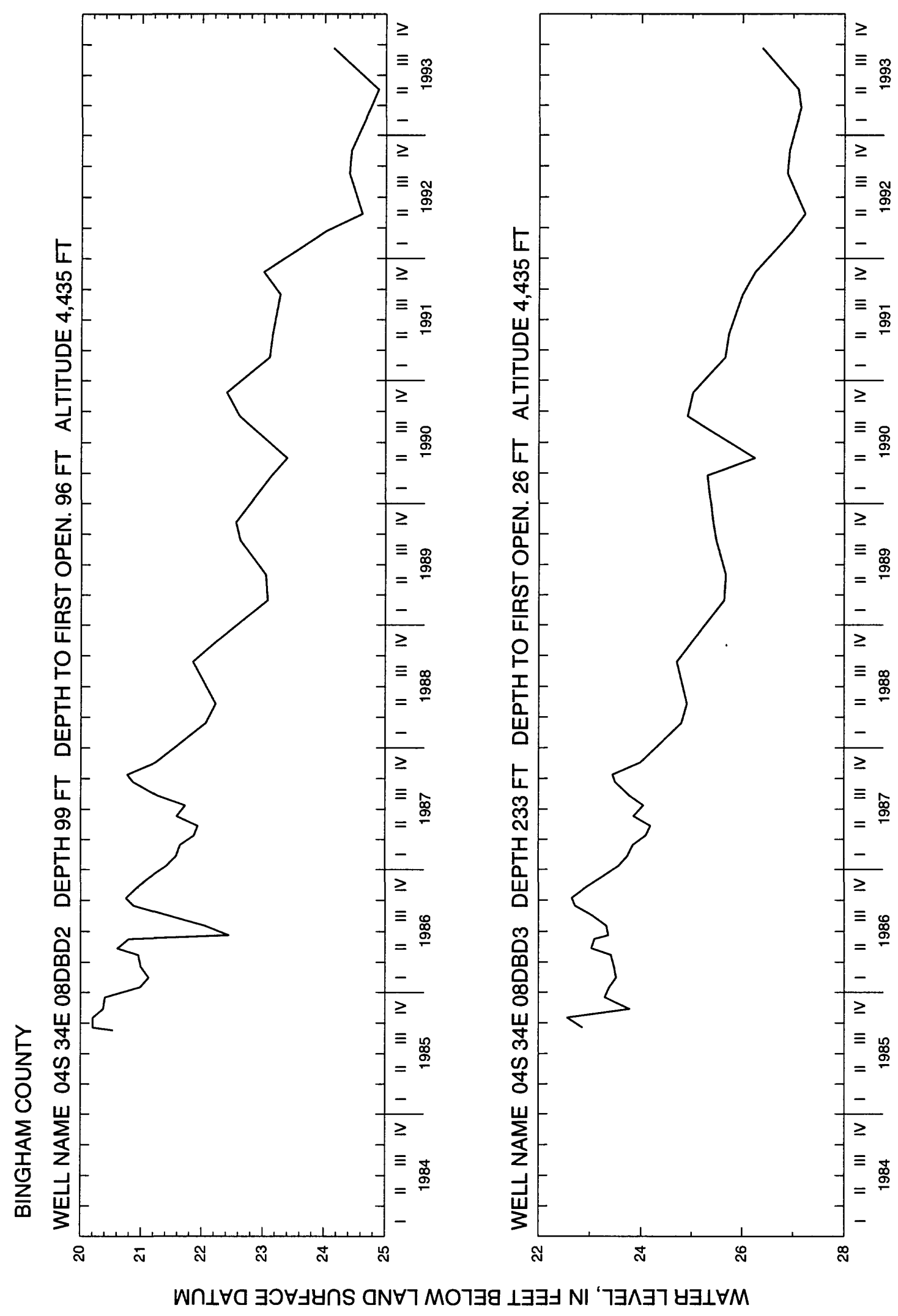




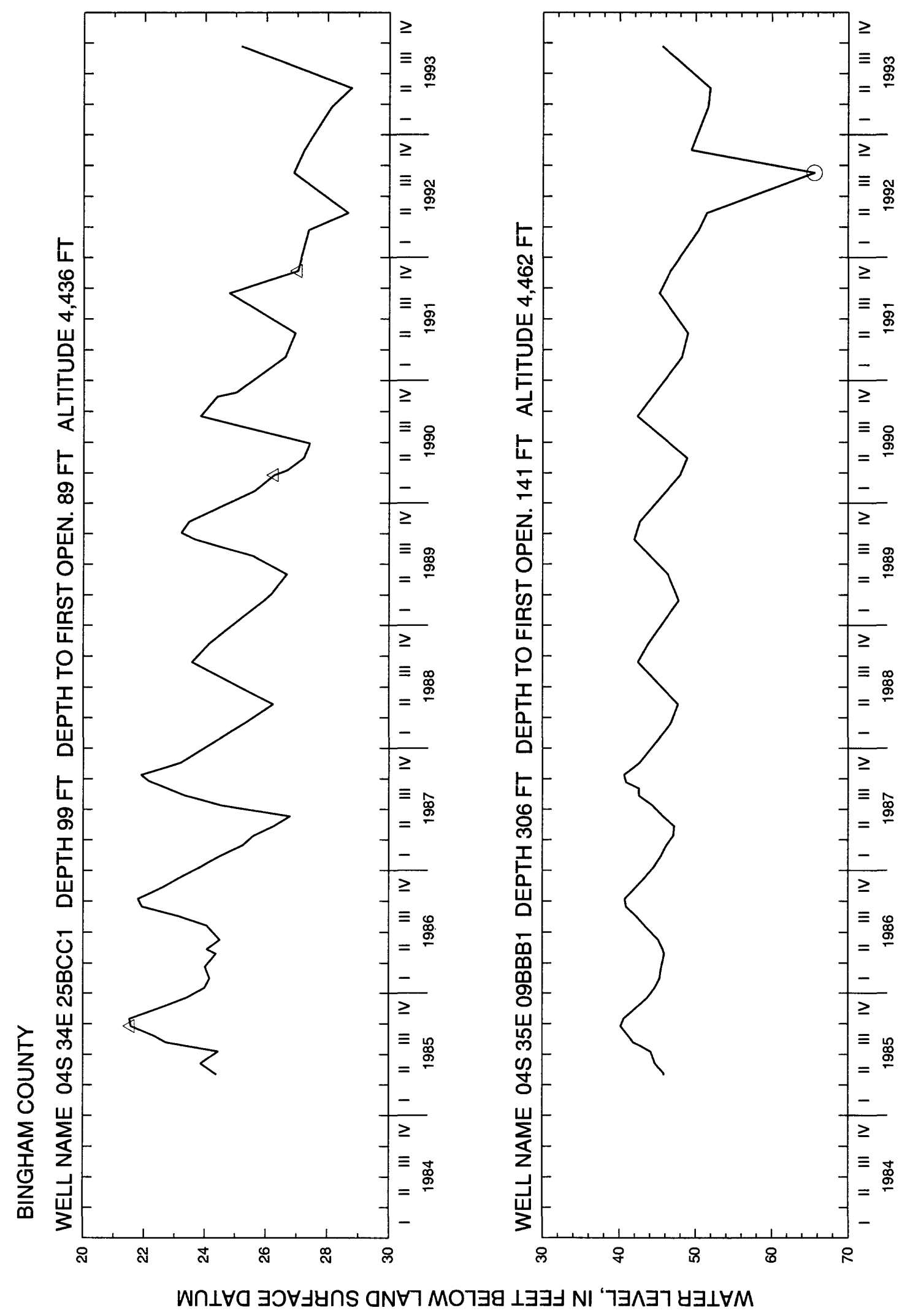




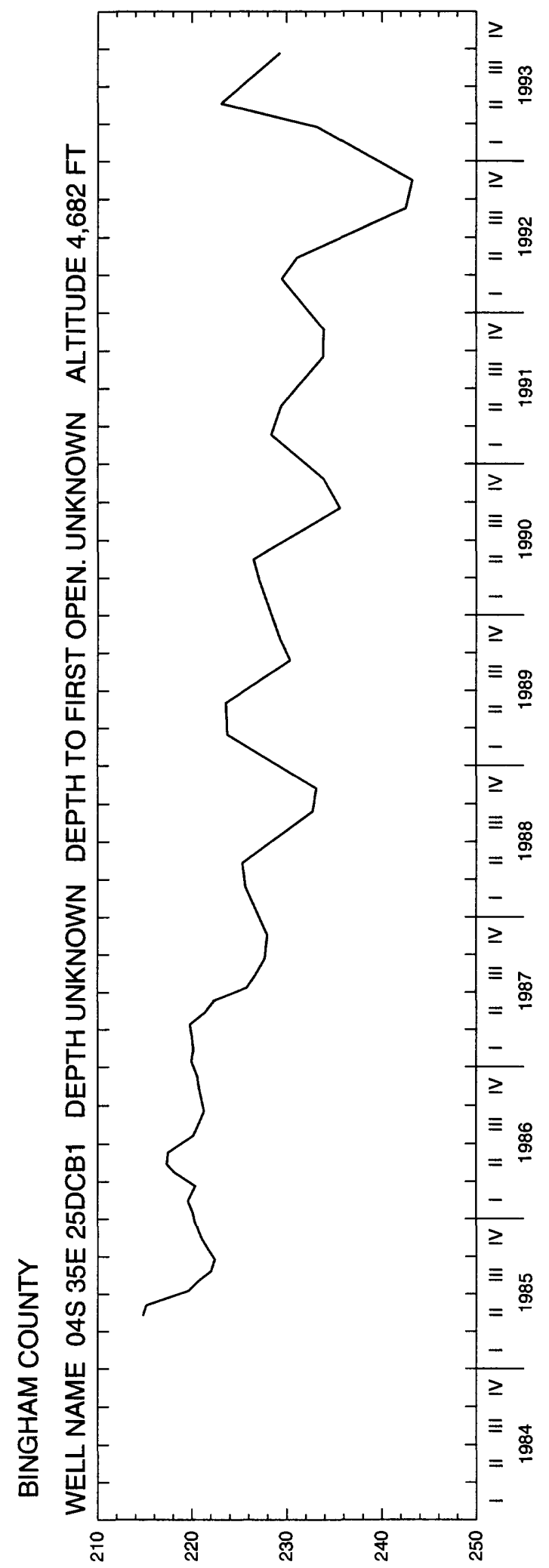

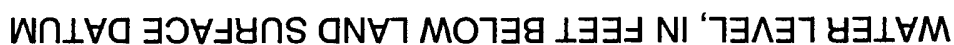




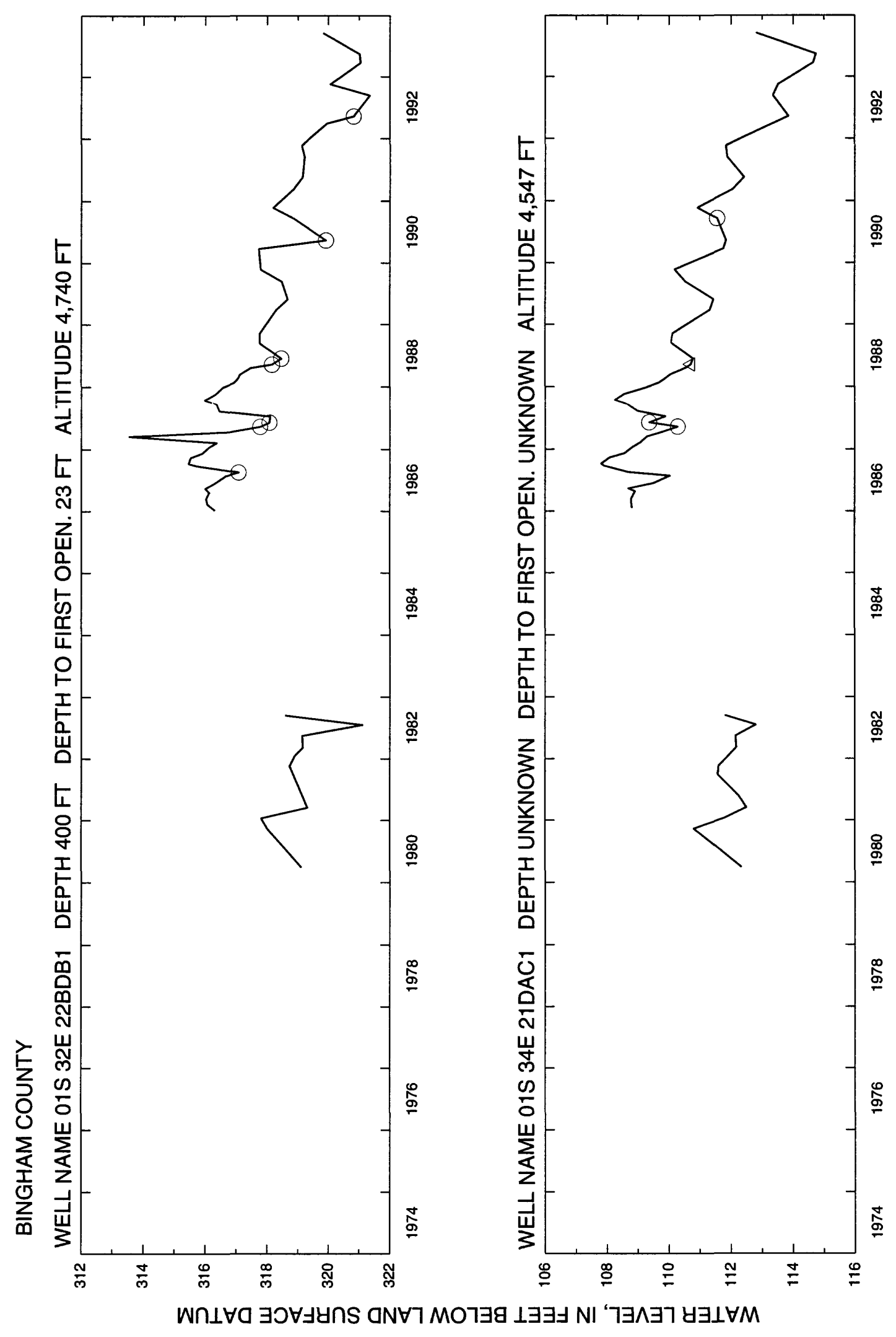




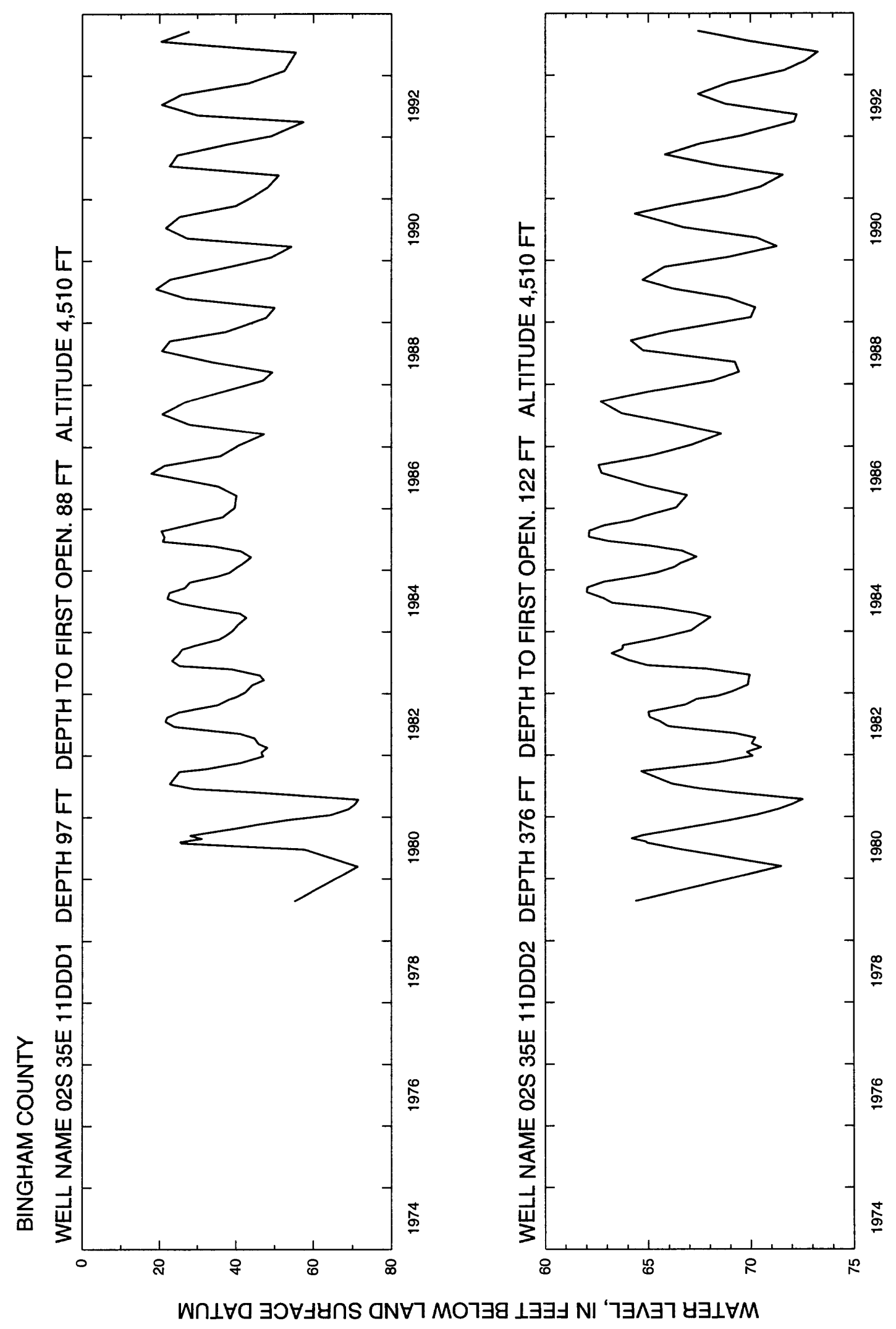




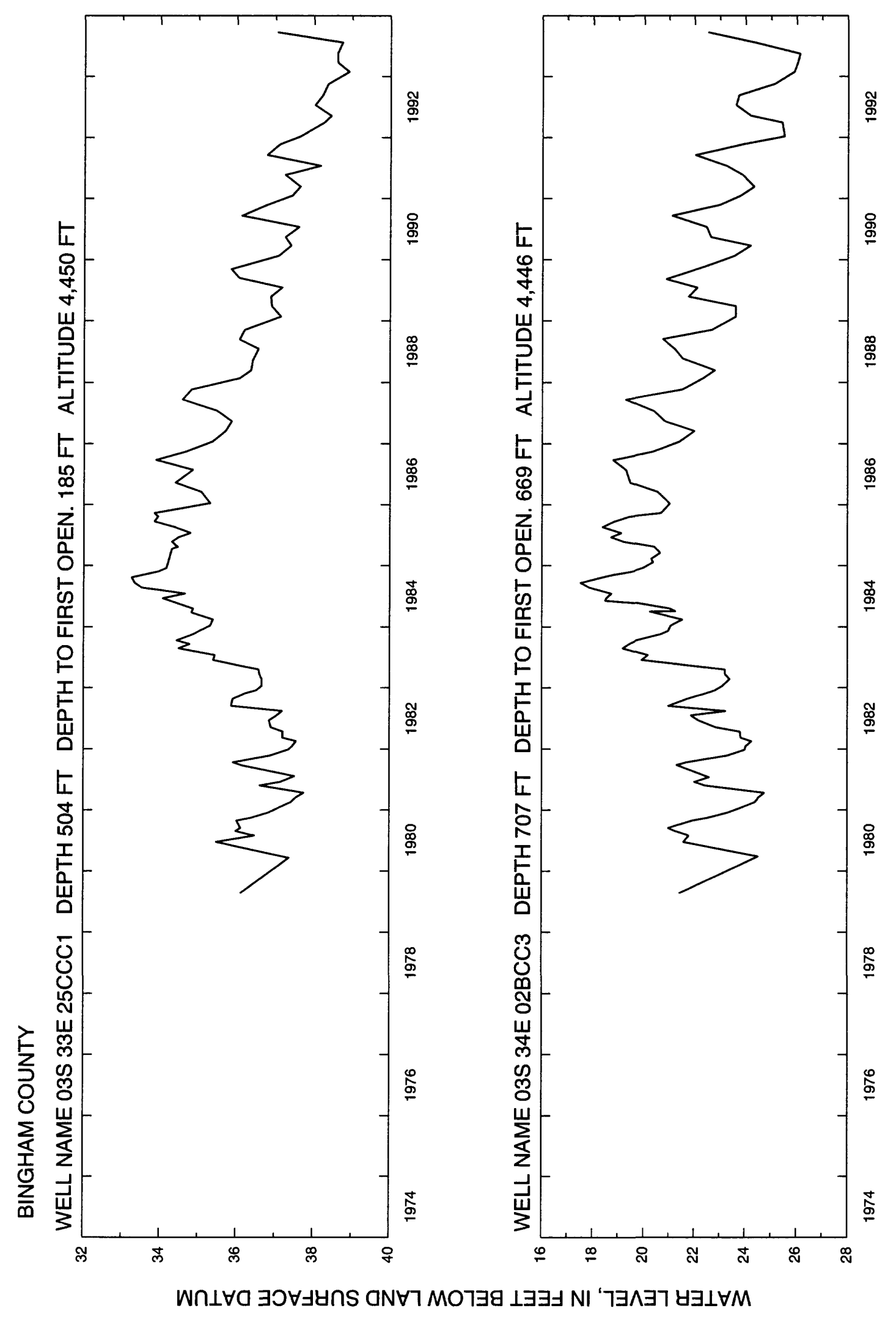




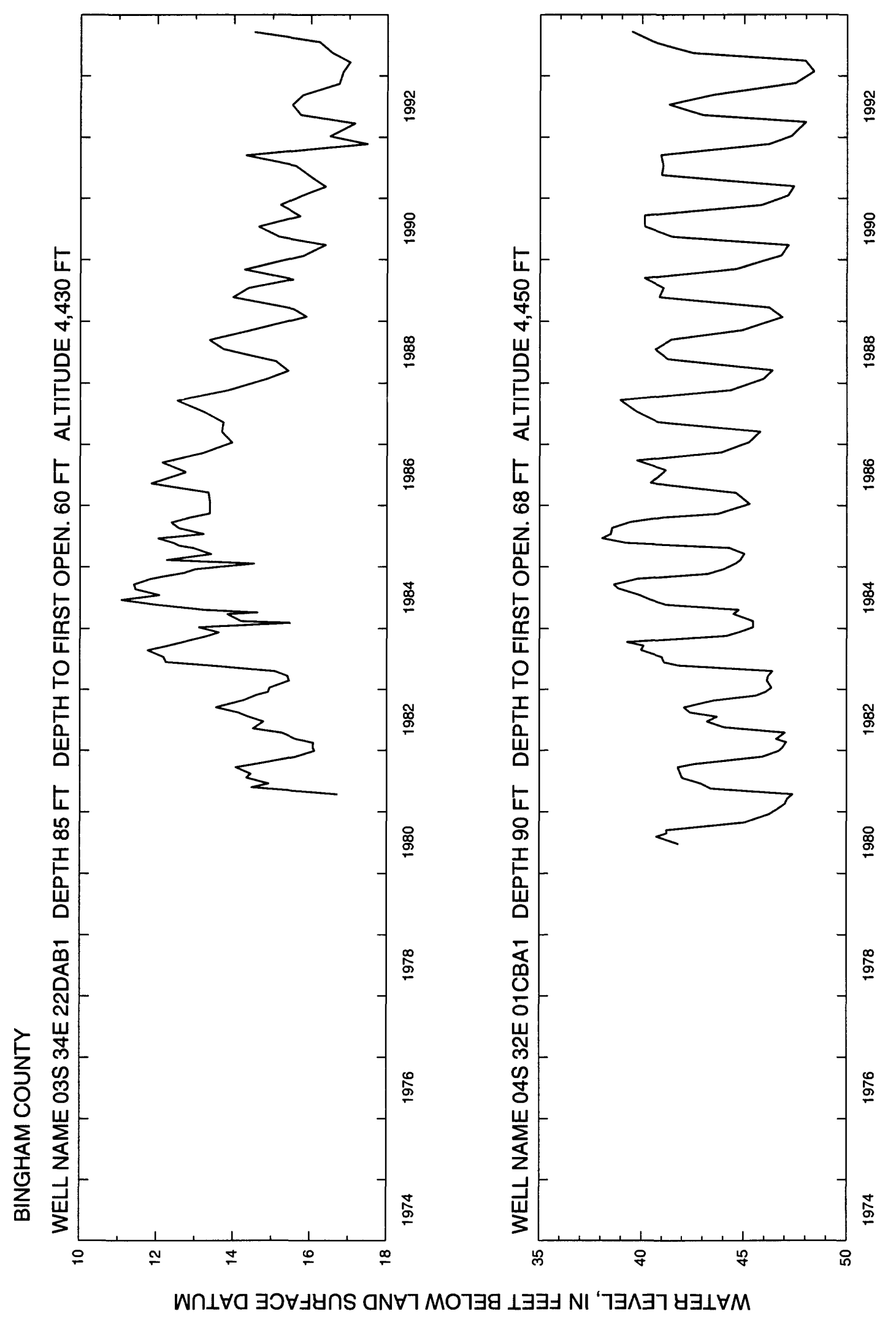




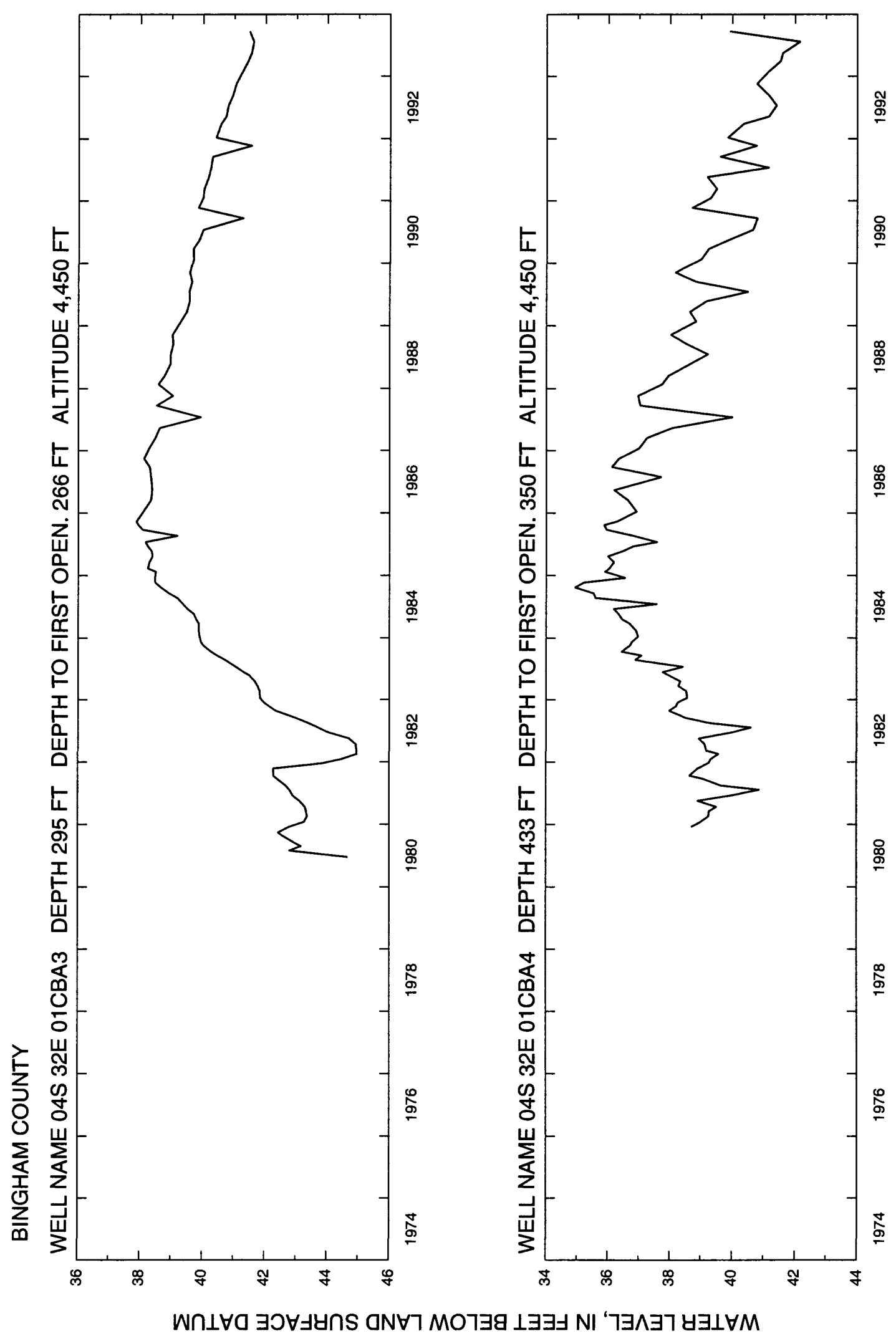




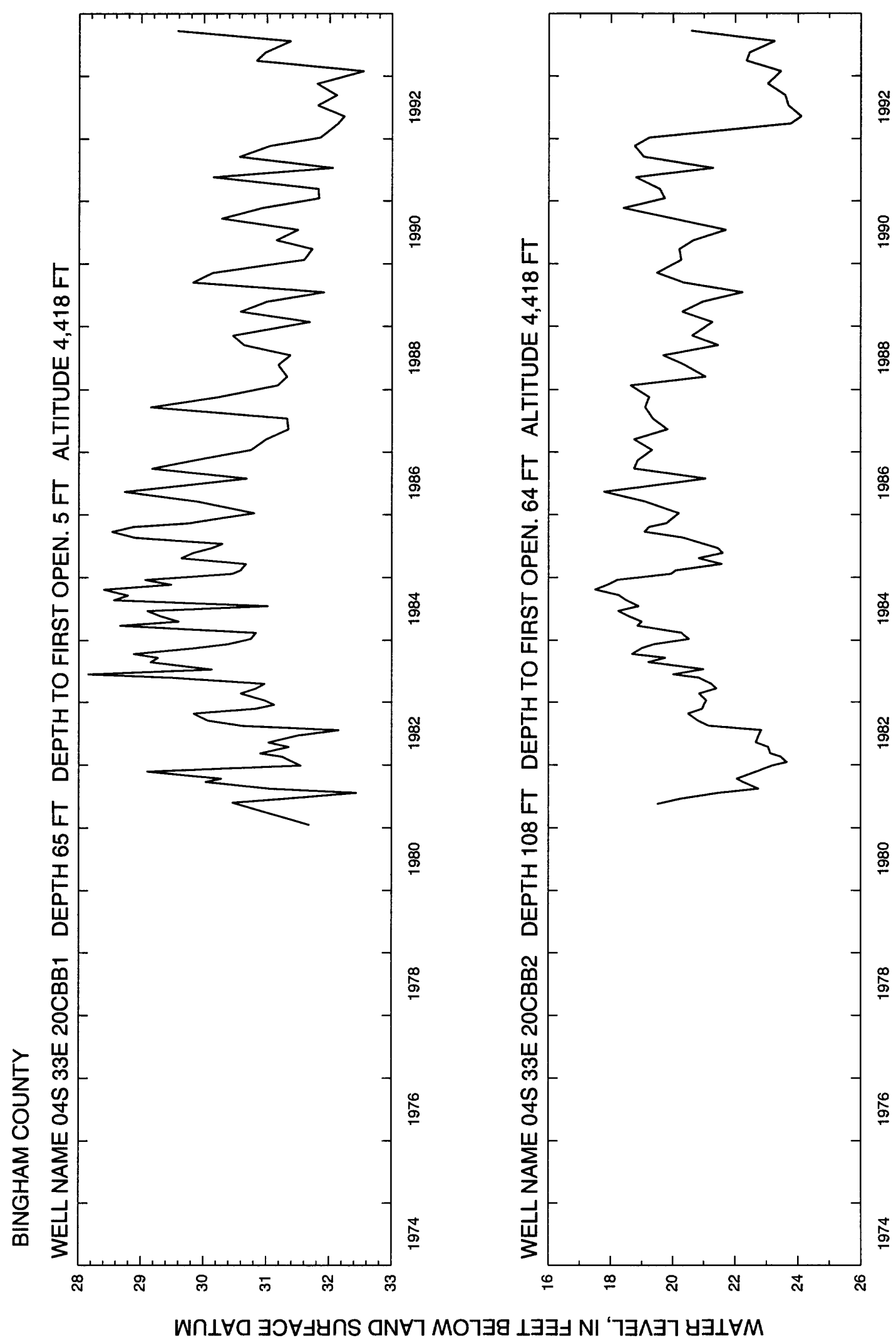




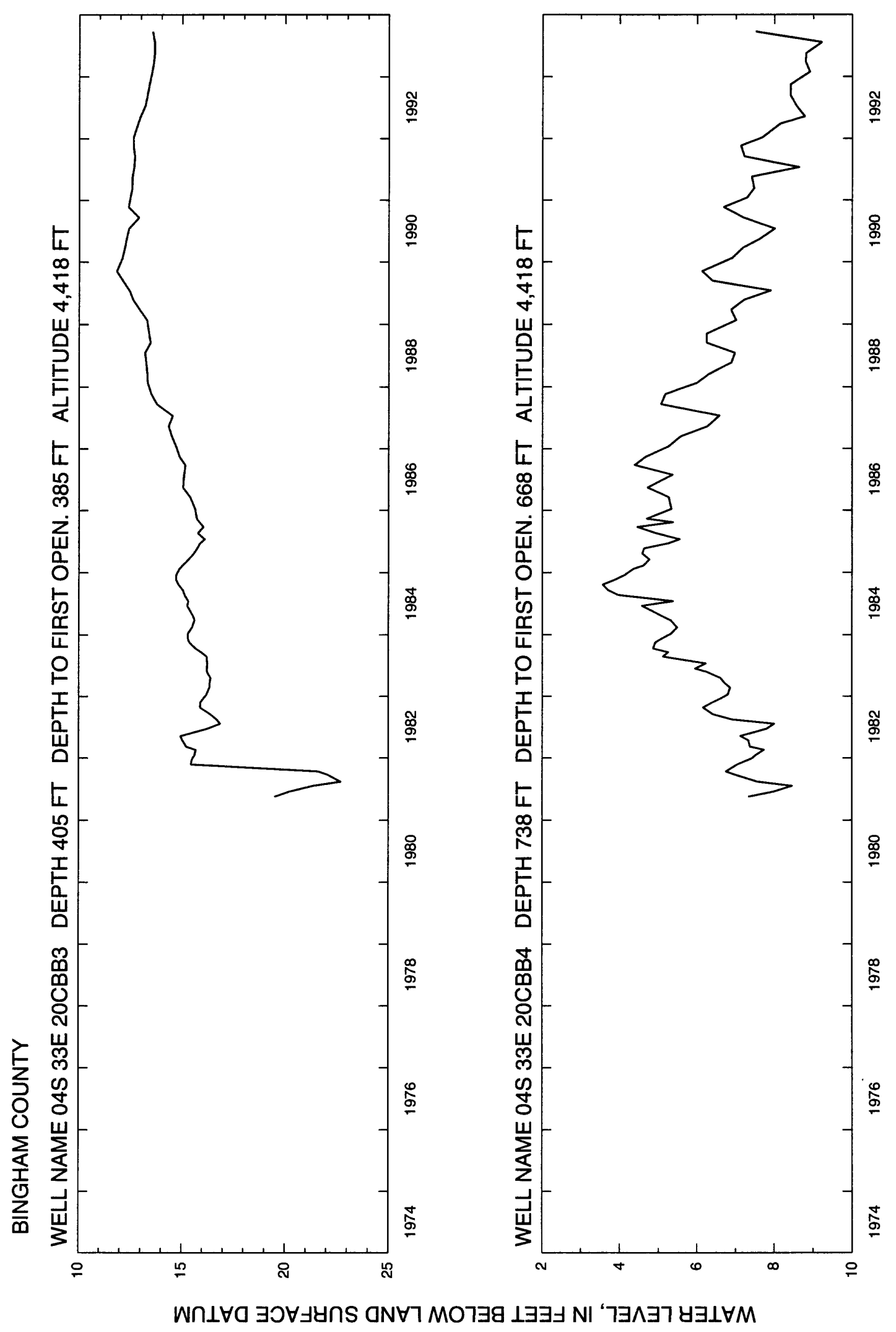




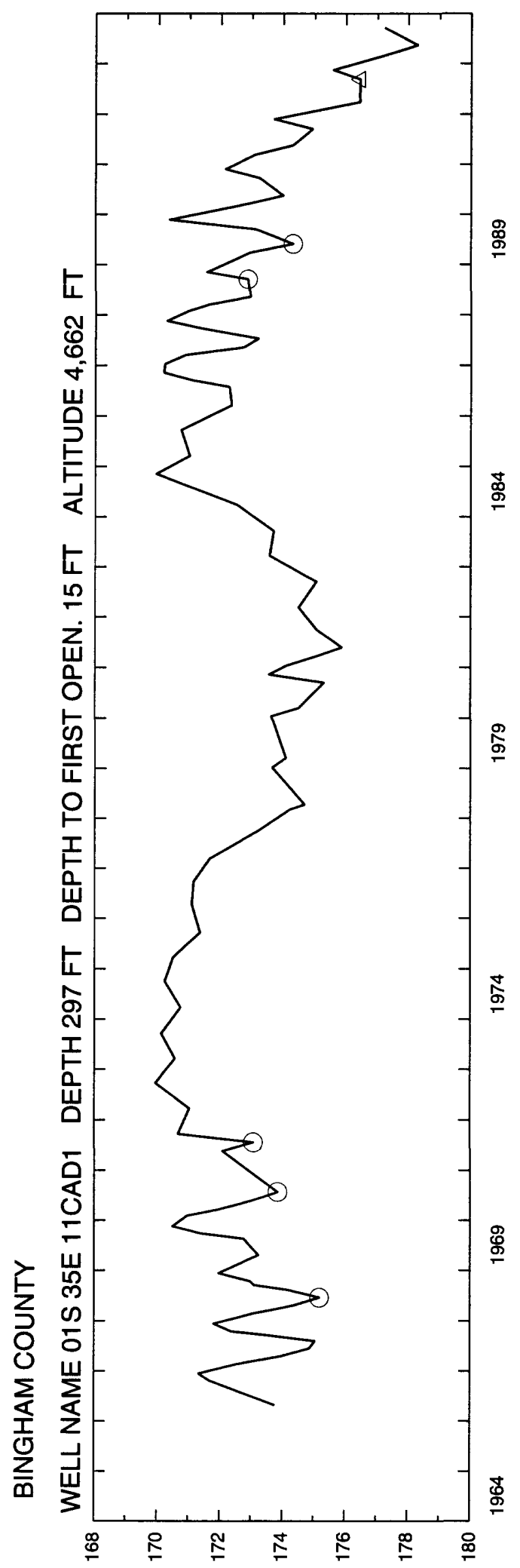

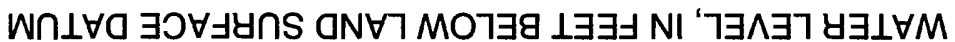




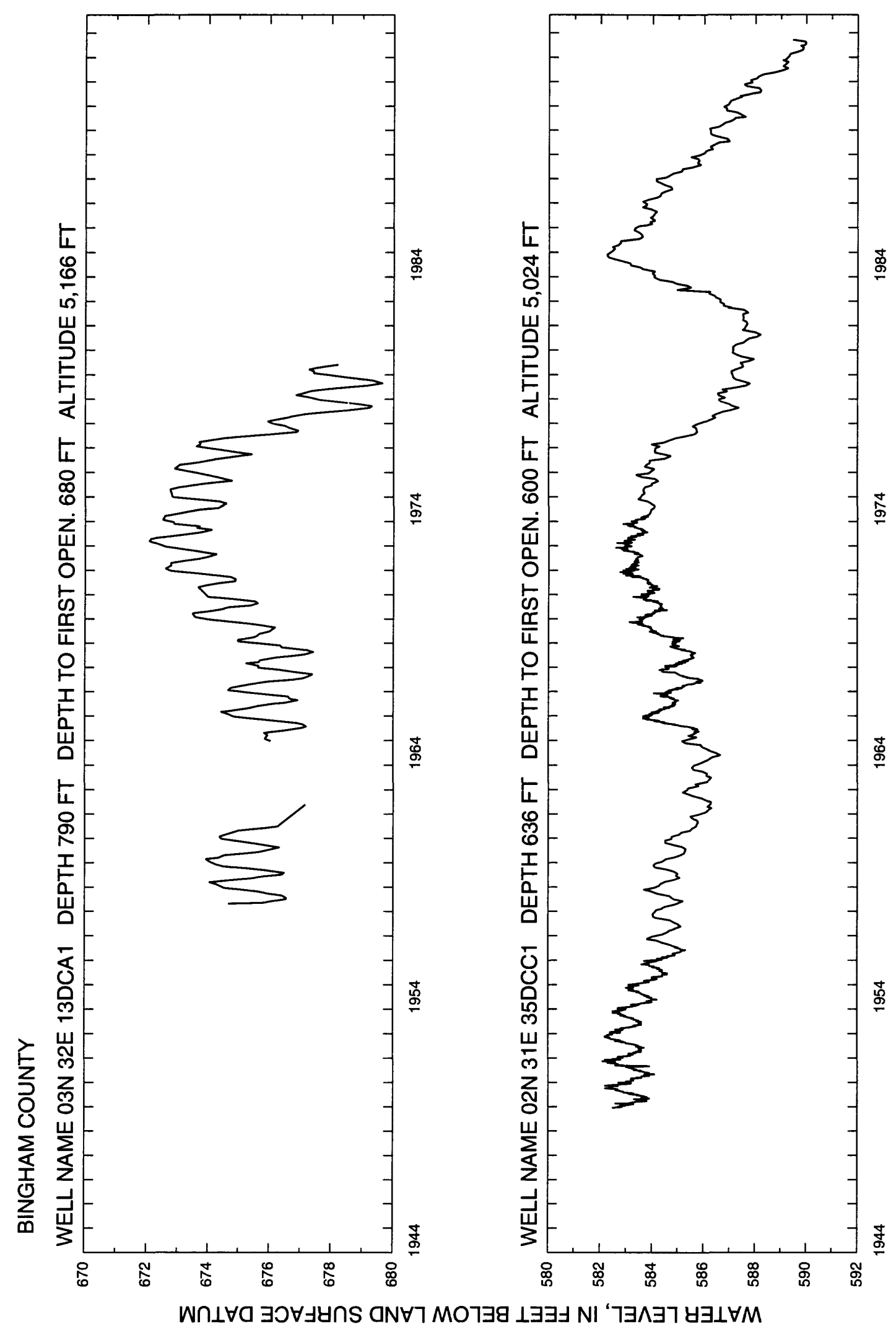




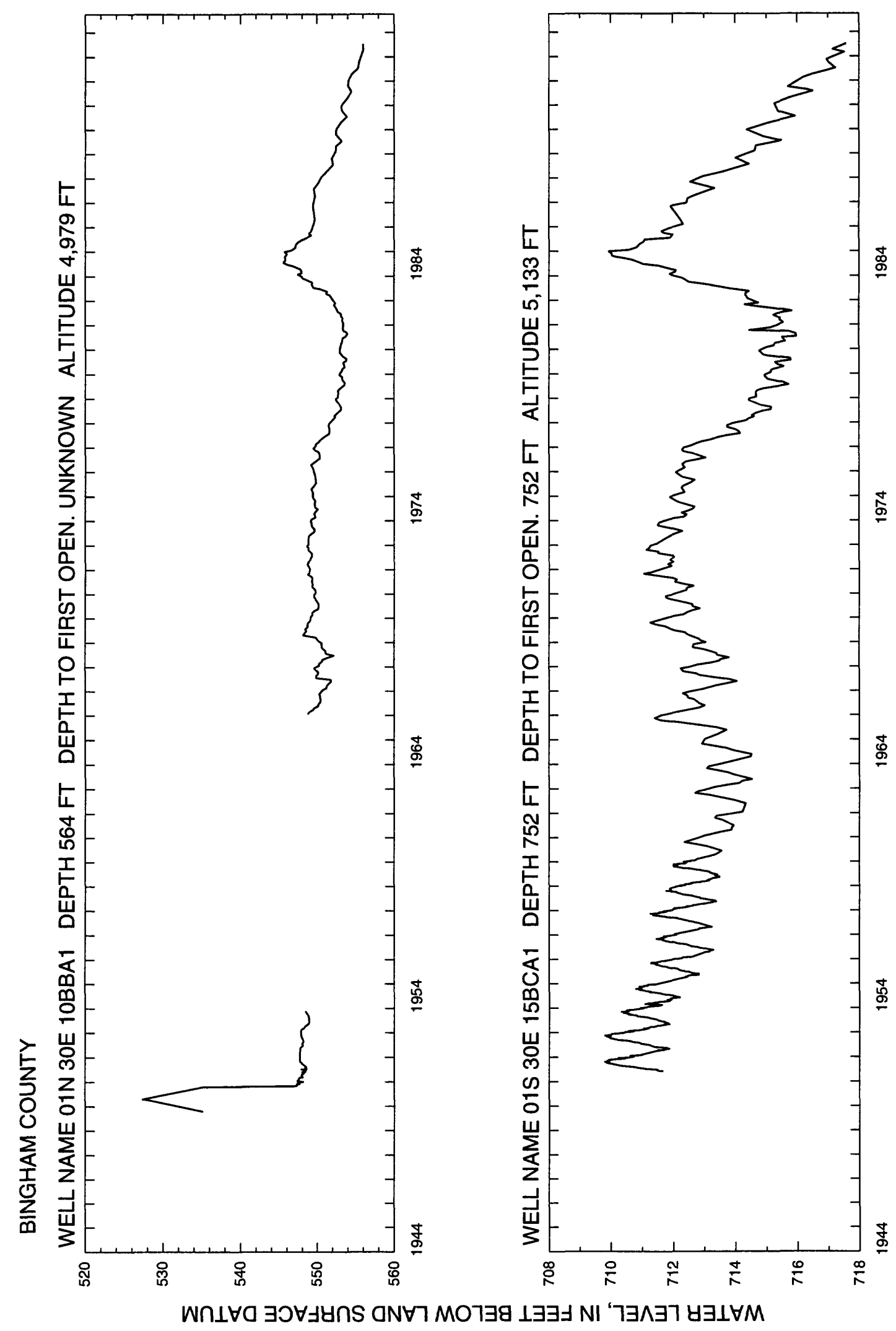




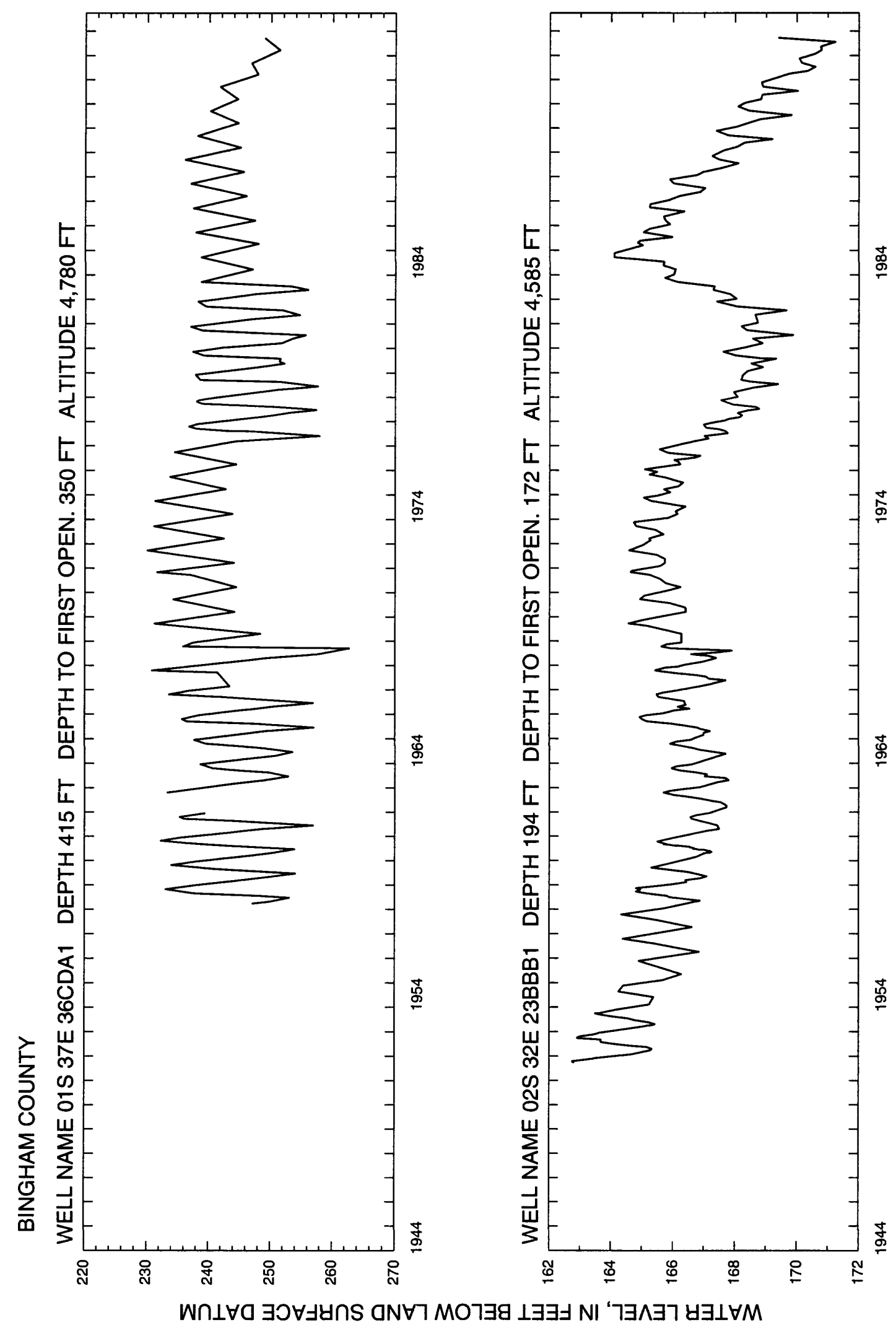

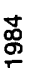

喜

$\stackrel{\rightleftarrows}{\leftrightarrows}$

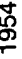




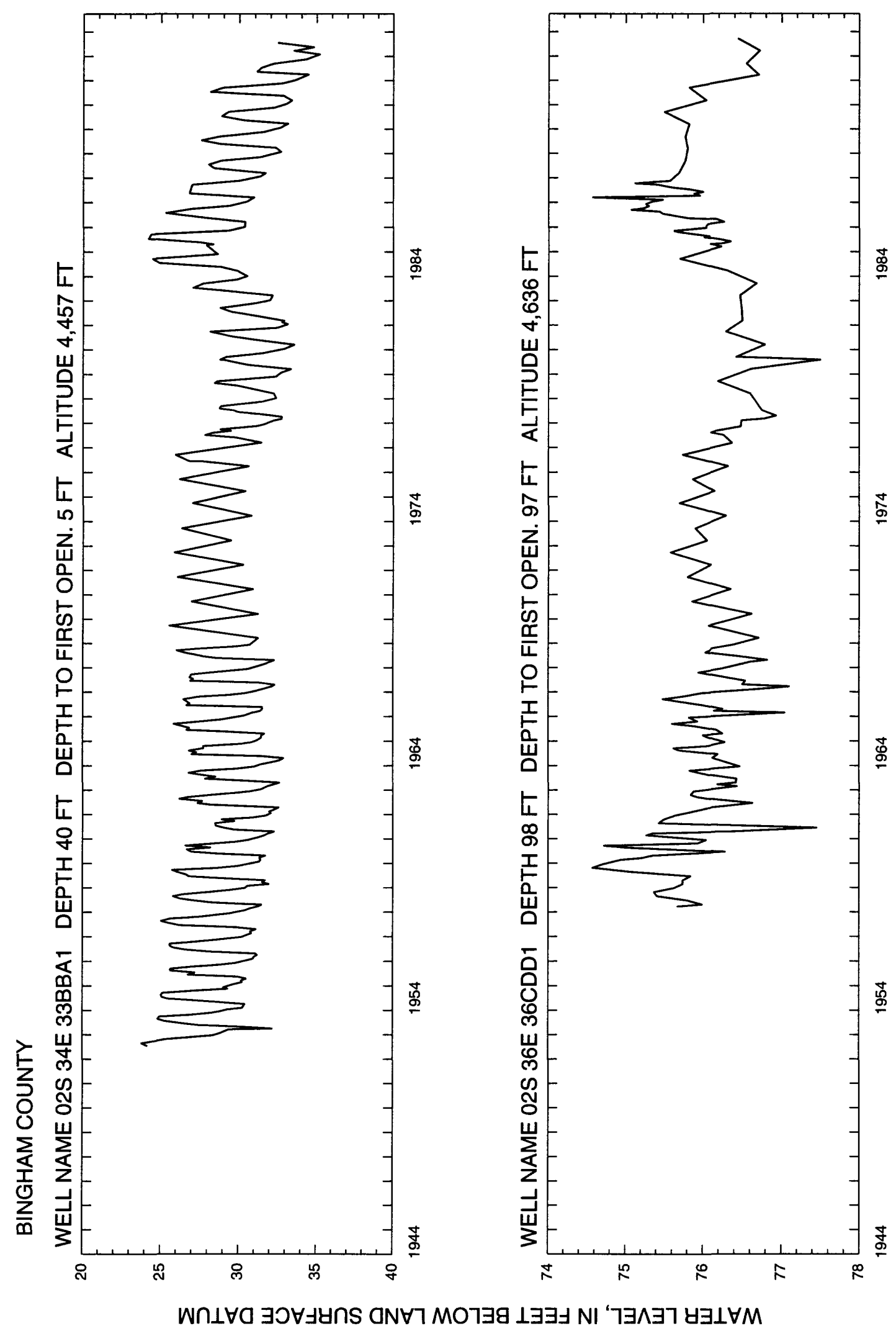

志

志

$\stackrel{\Xi}{\circ}$

落

志 


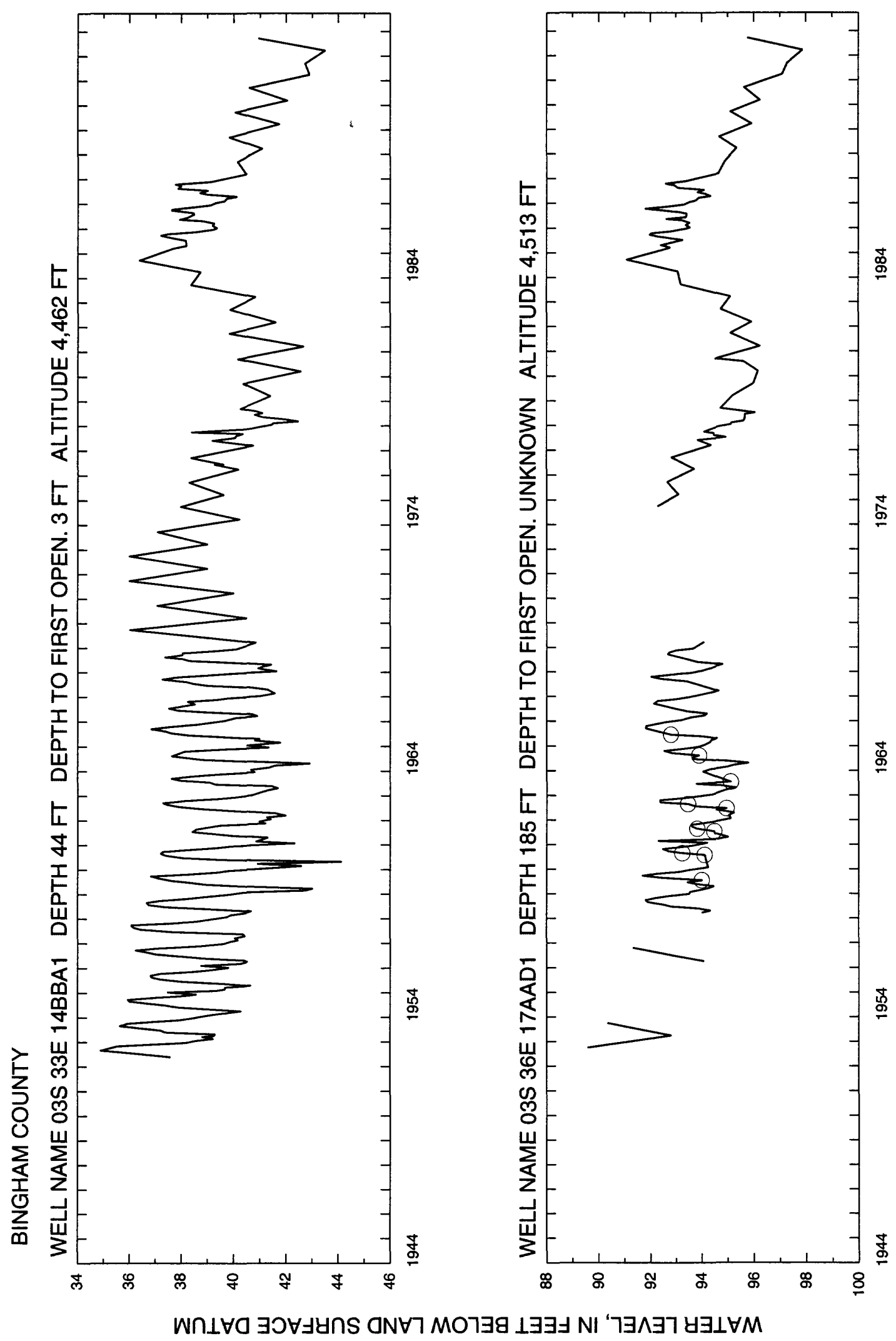




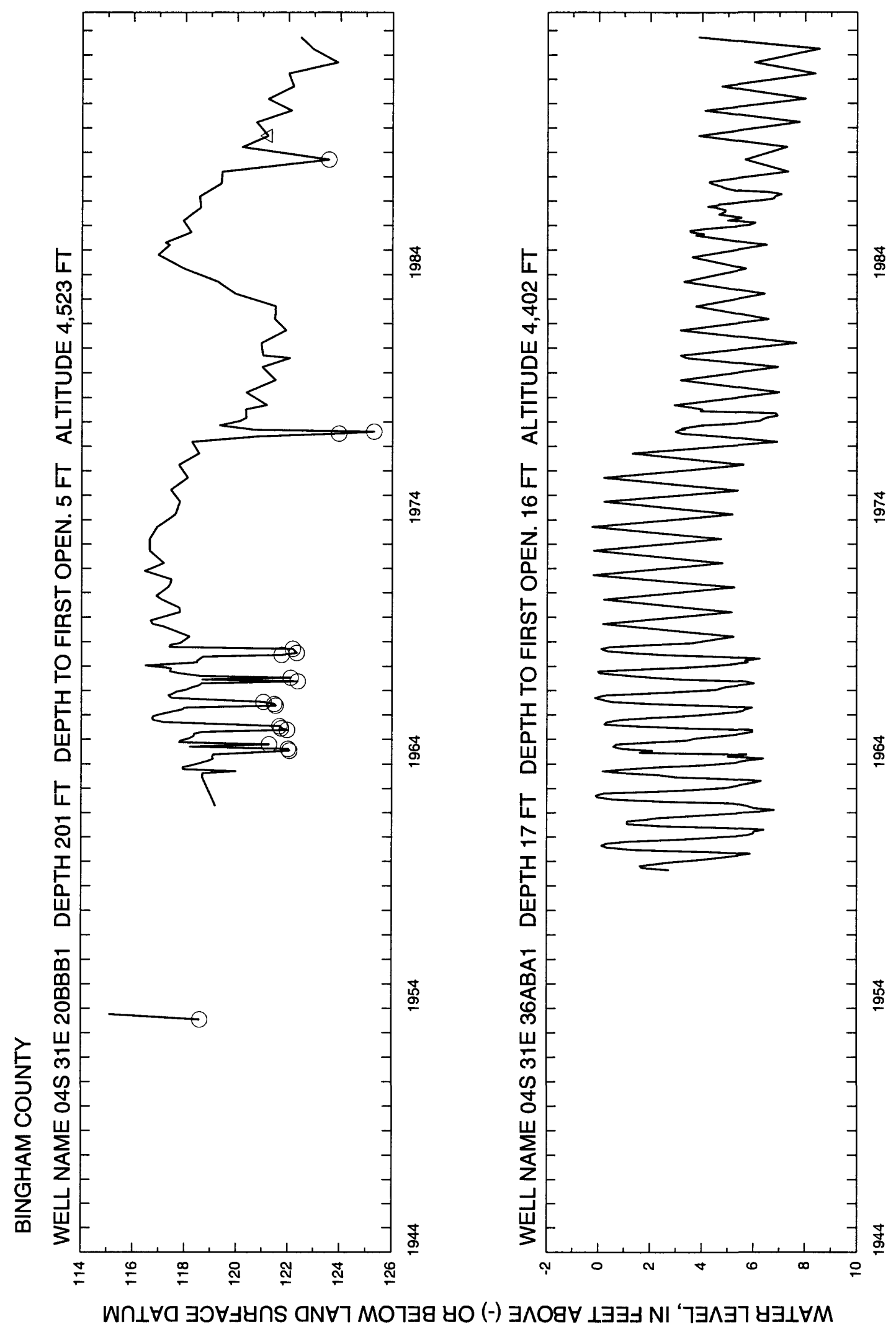




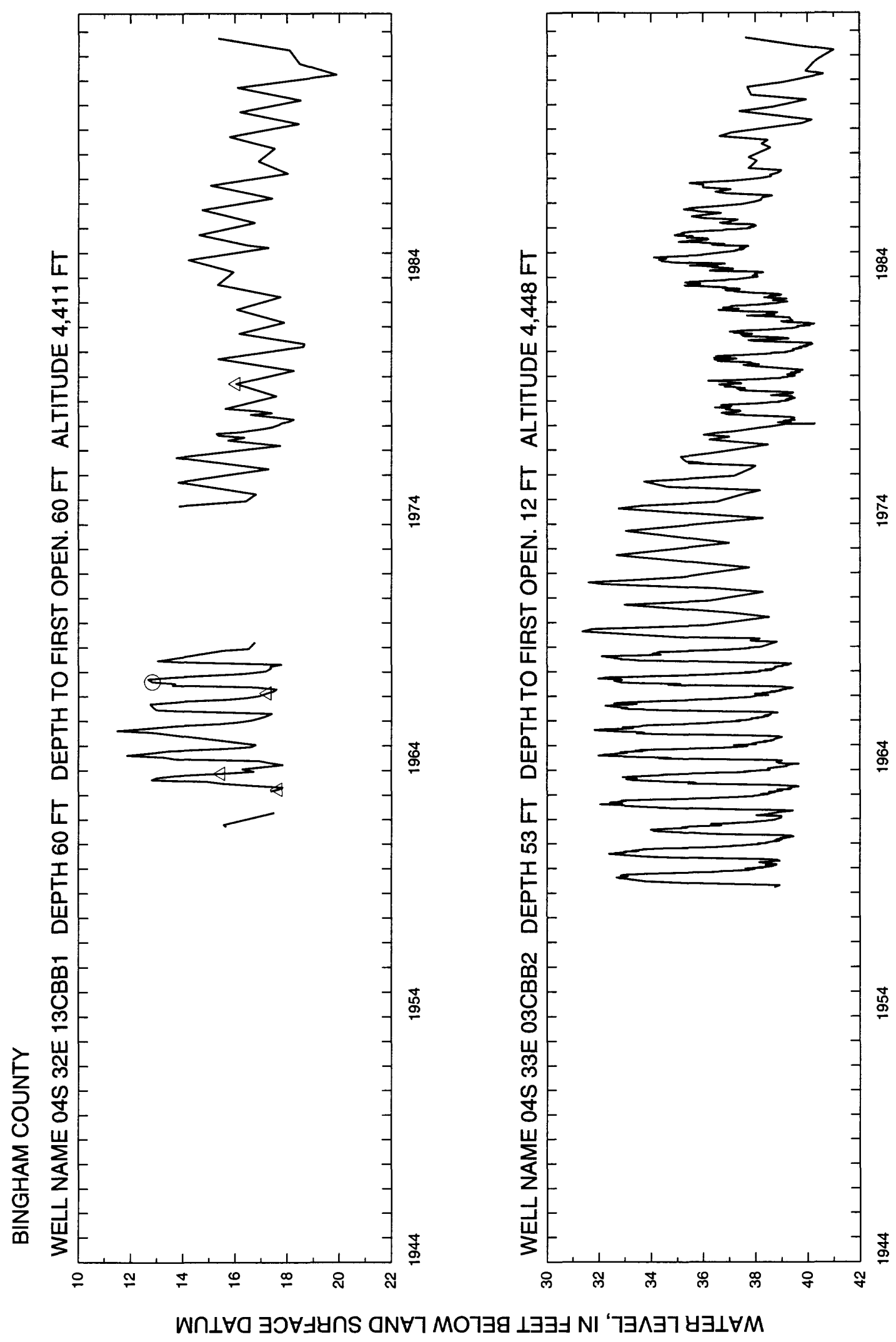




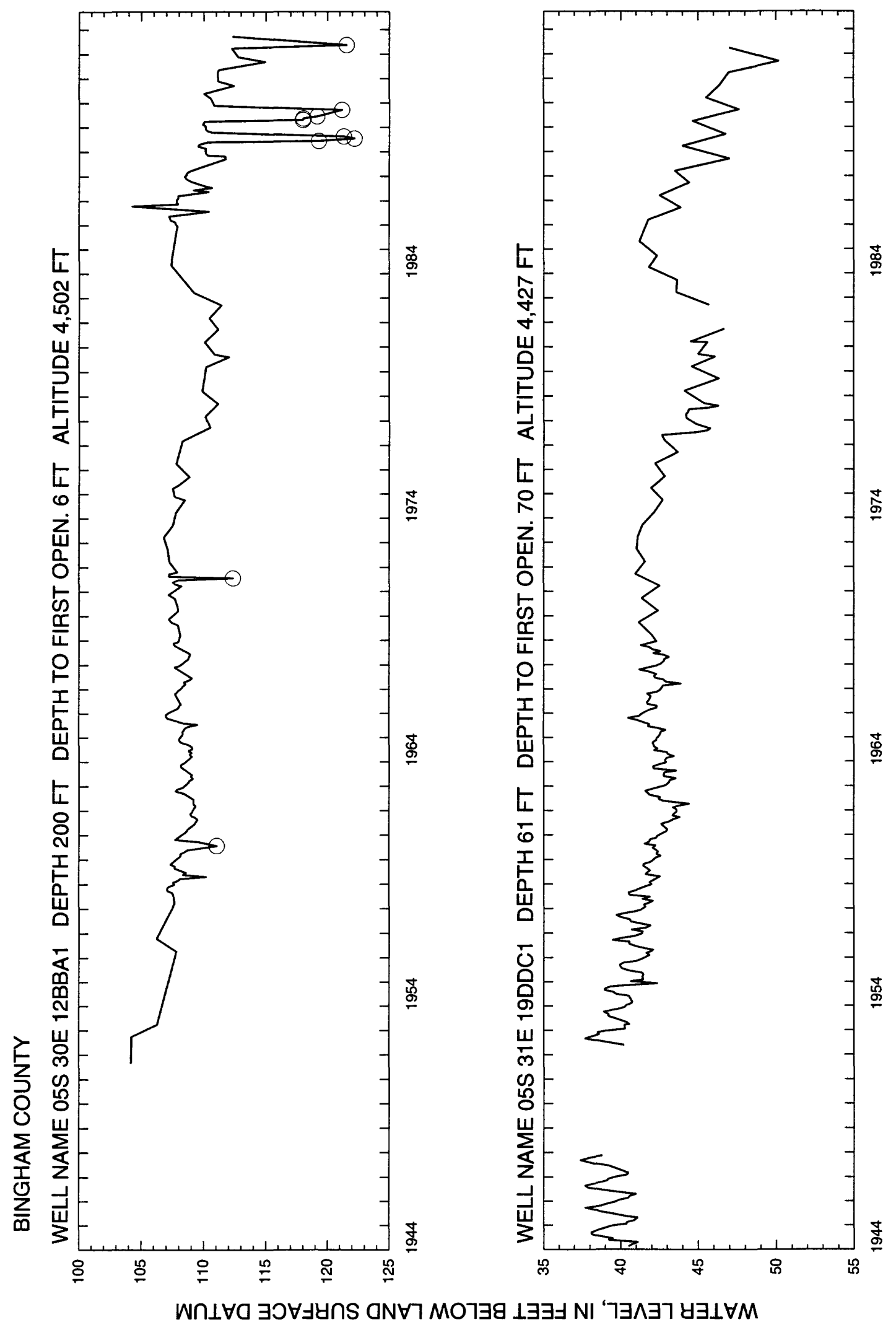




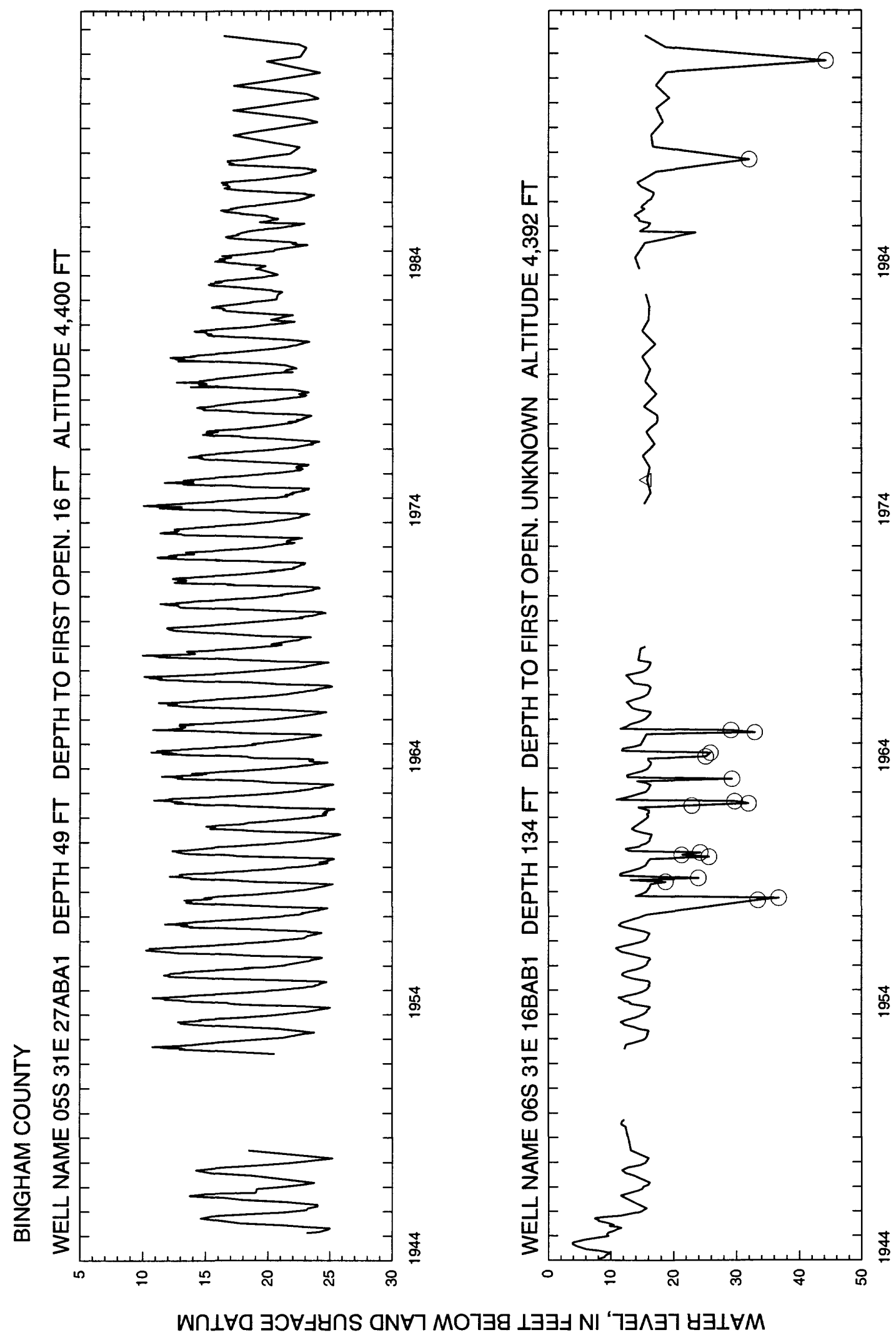

$\stackrel{\Xi}{\circ}$

芯 
Blaine 


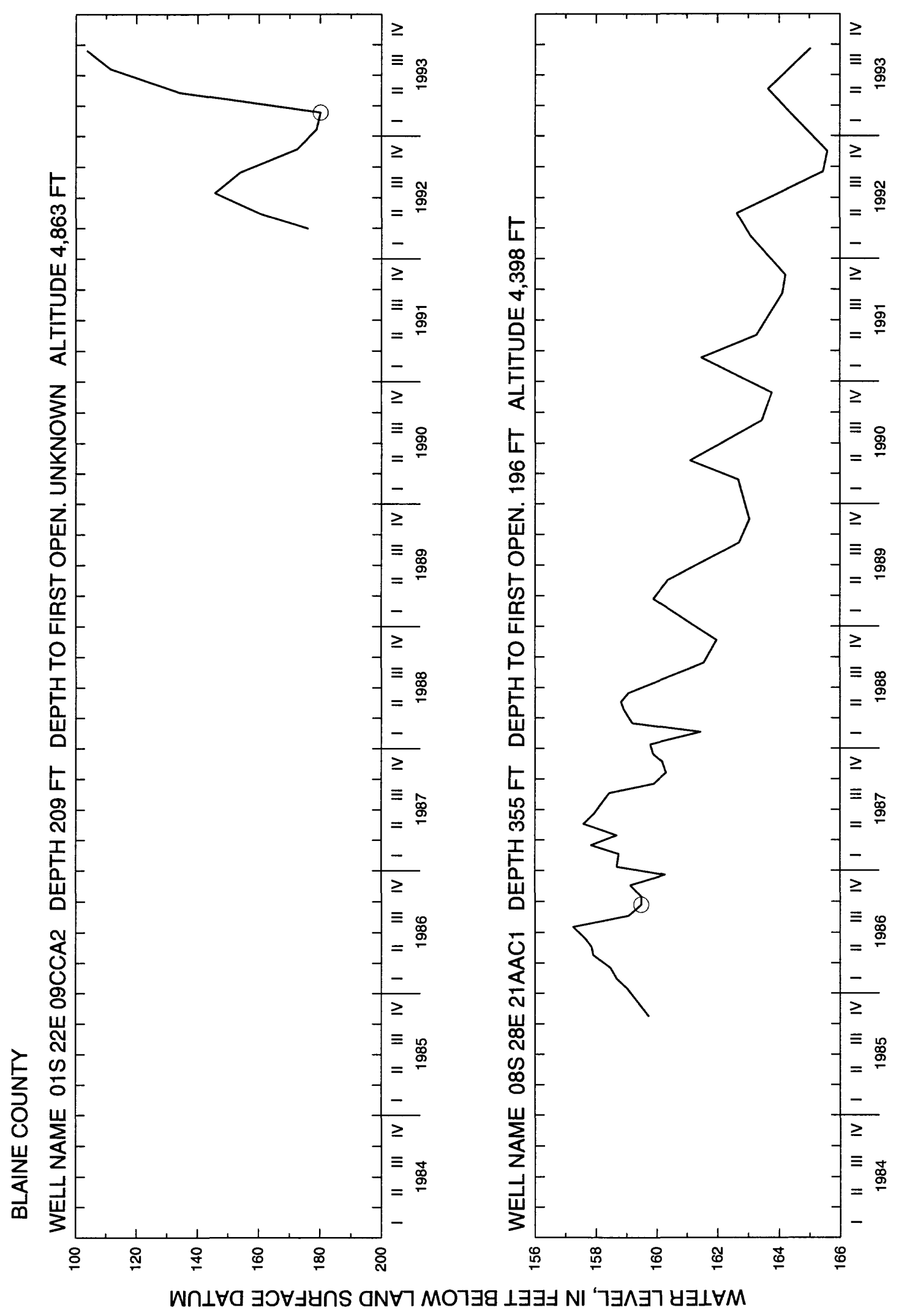




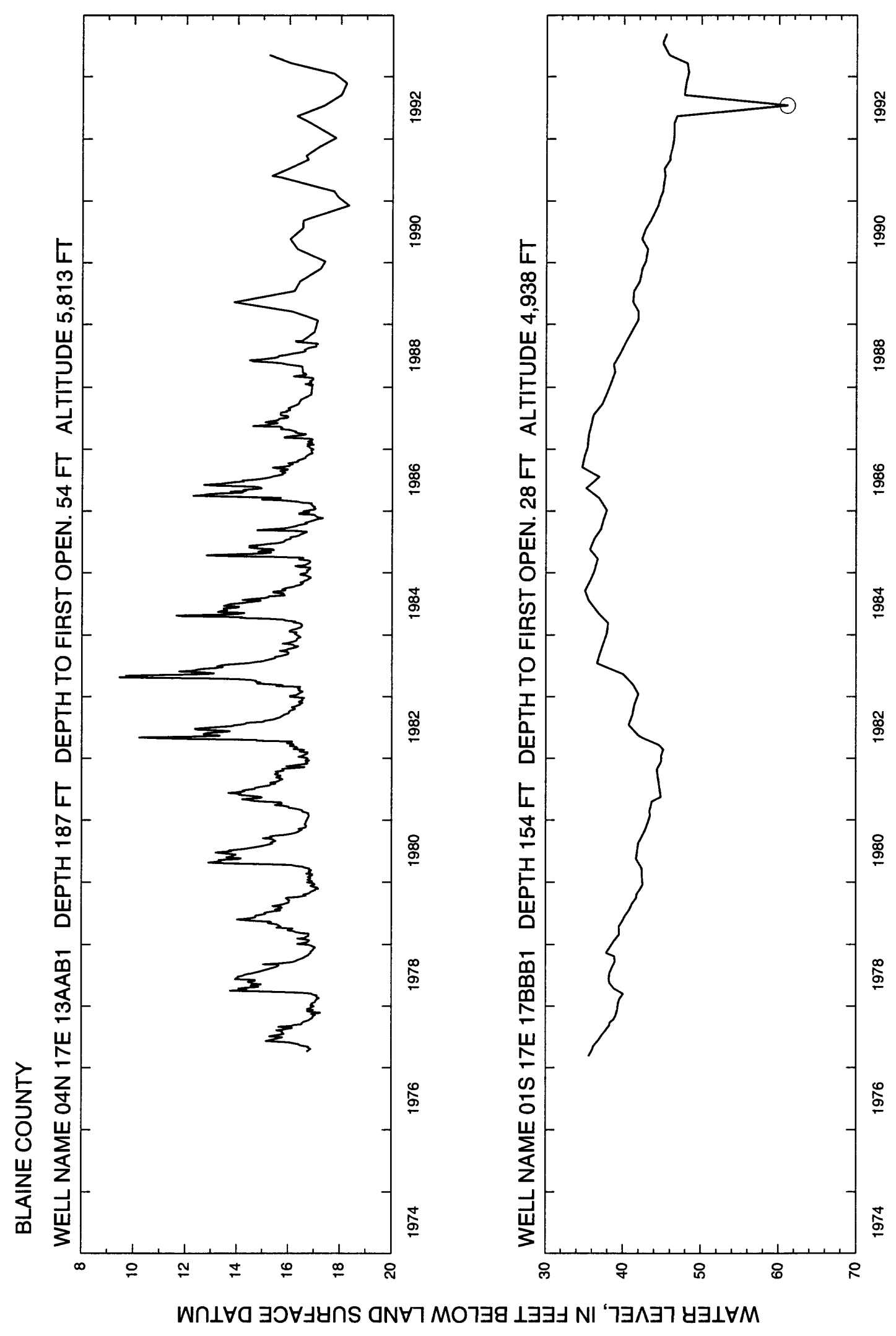




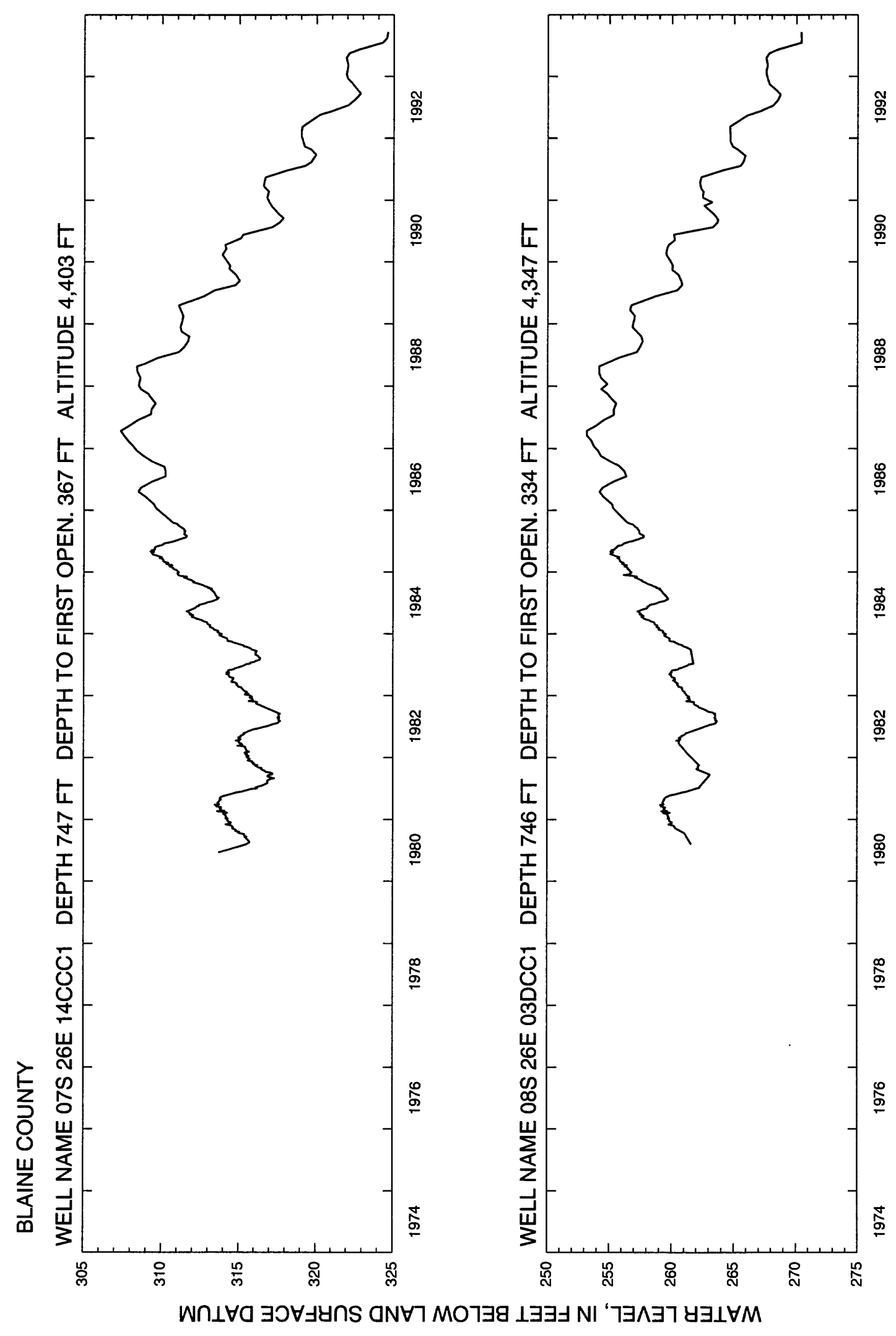




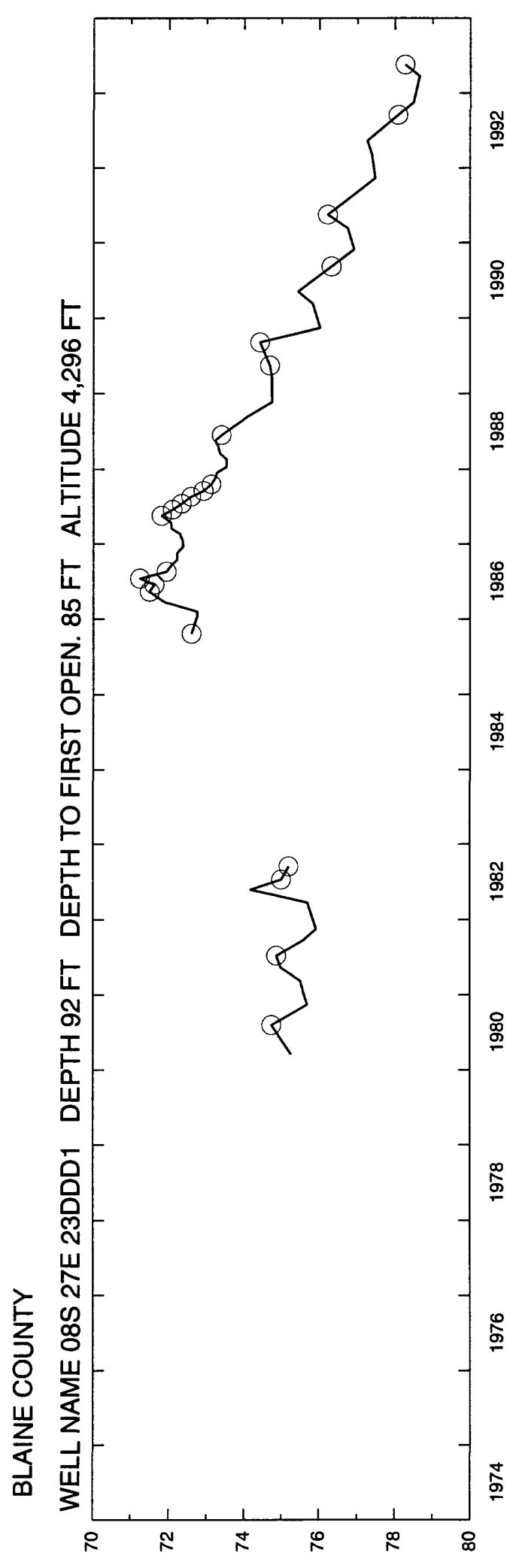

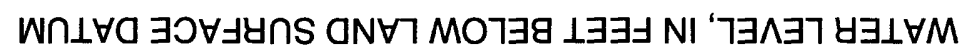




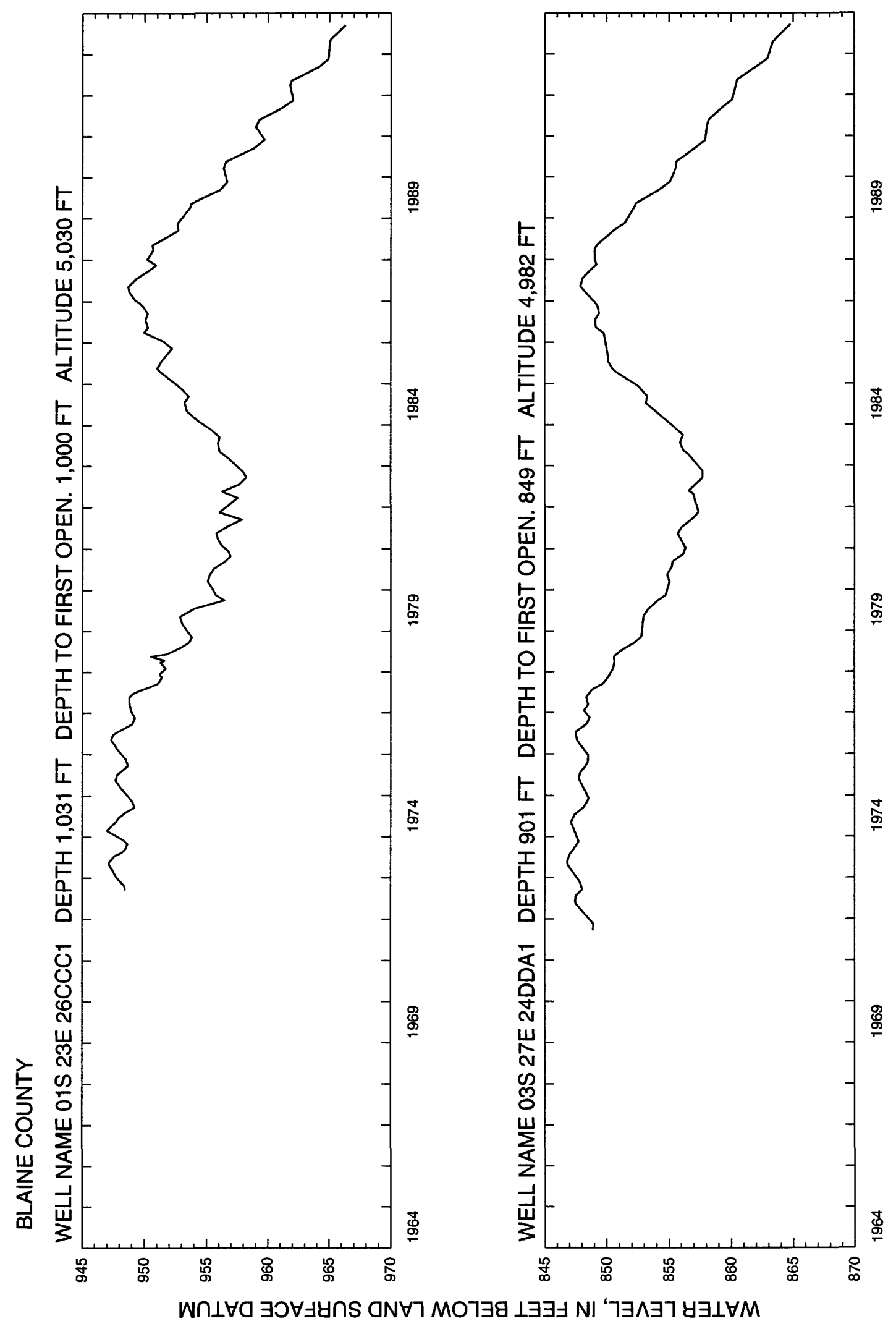




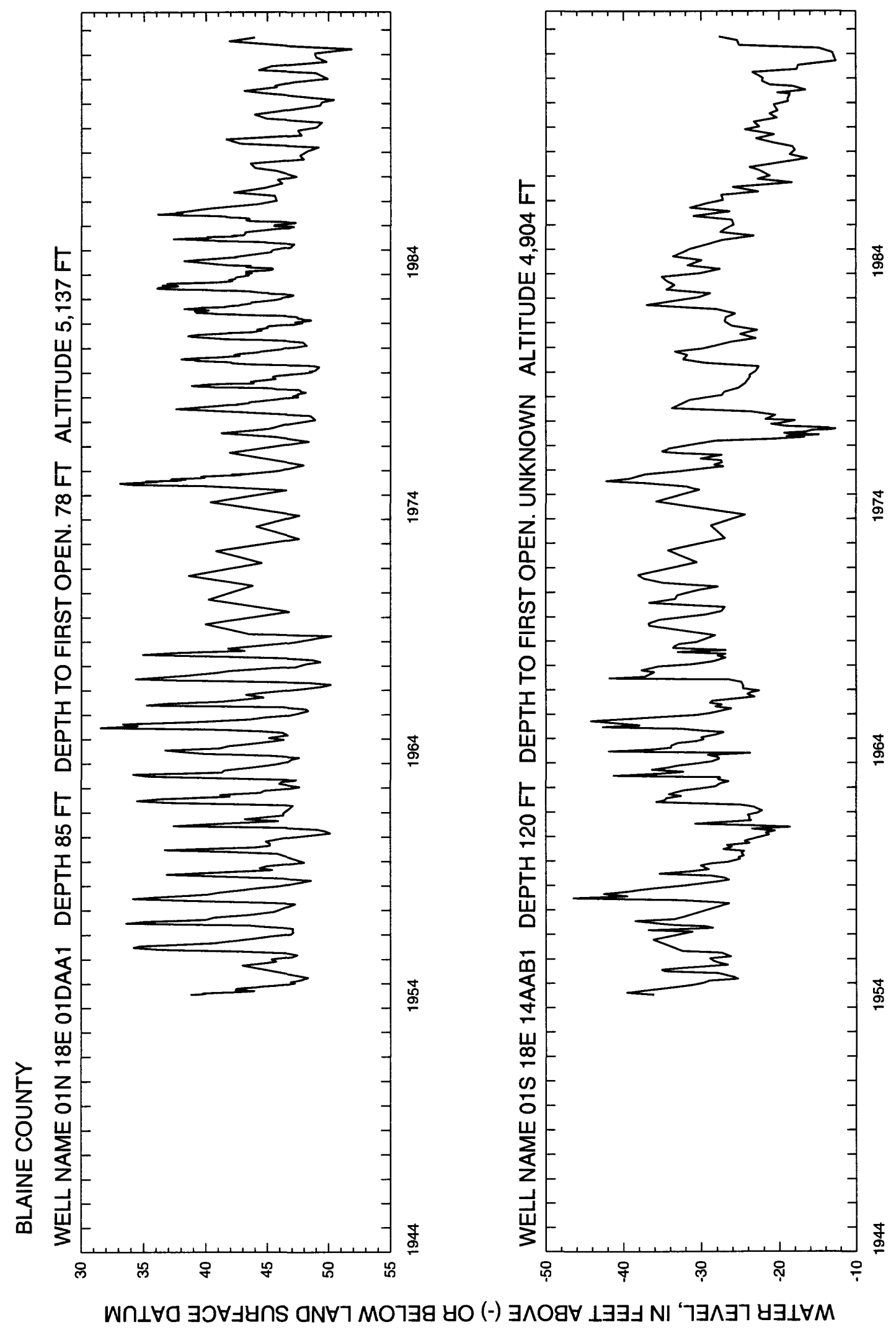




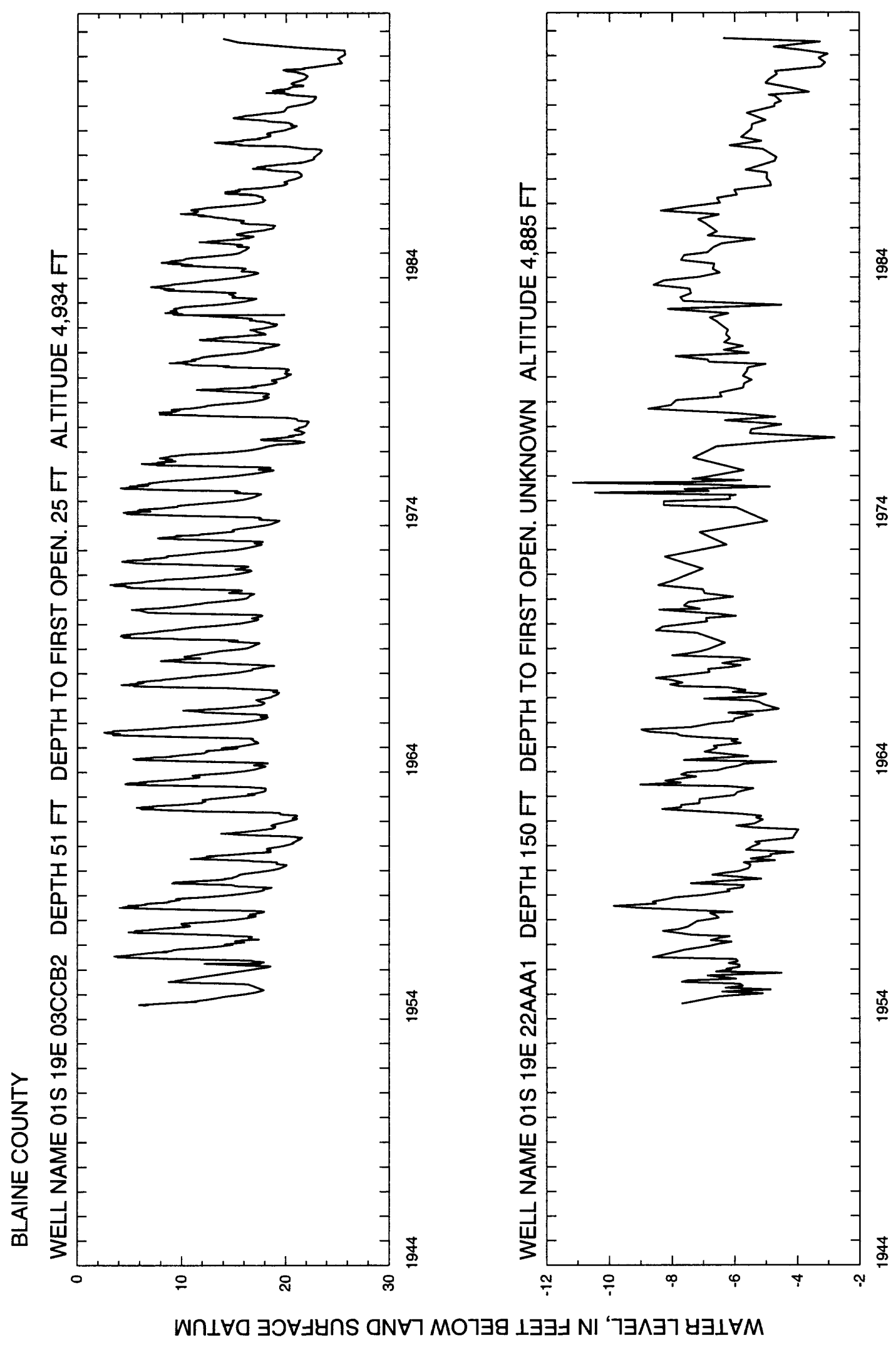




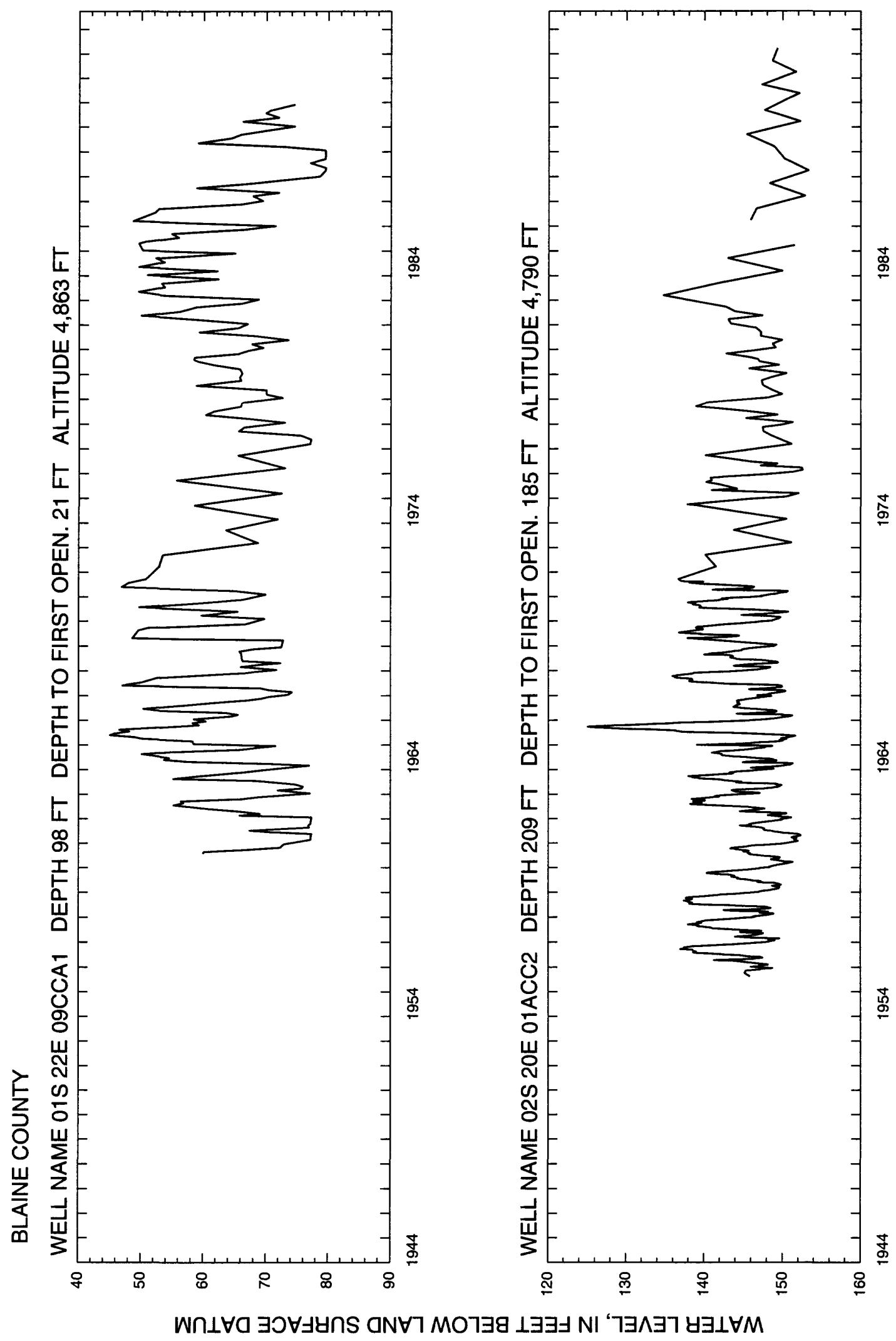




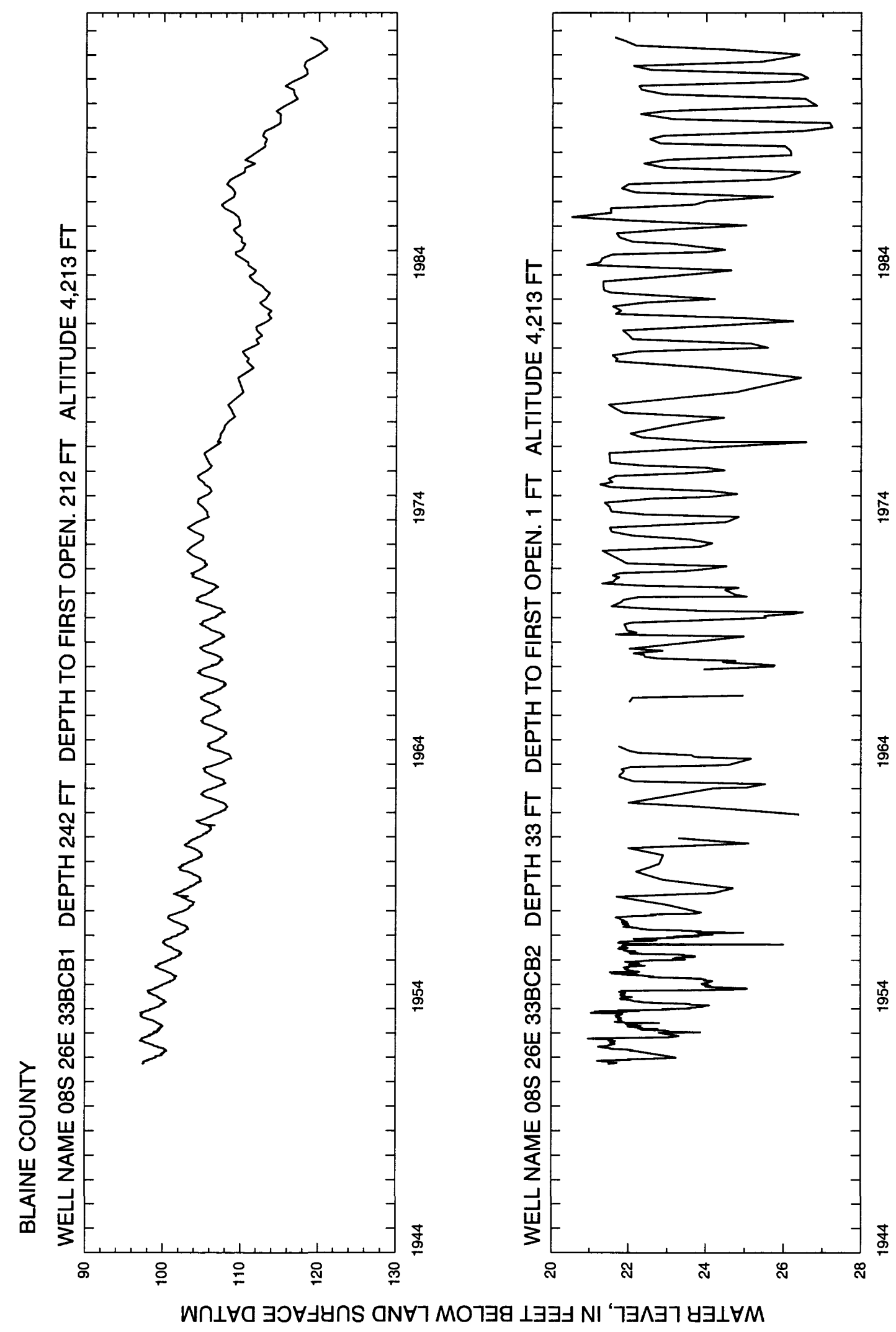

$\stackrel{\Xi}{\circ}$

志

$\stackrel{\circ}{\circ}$

范

絭

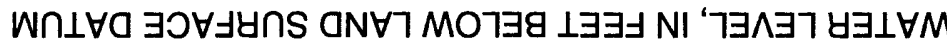




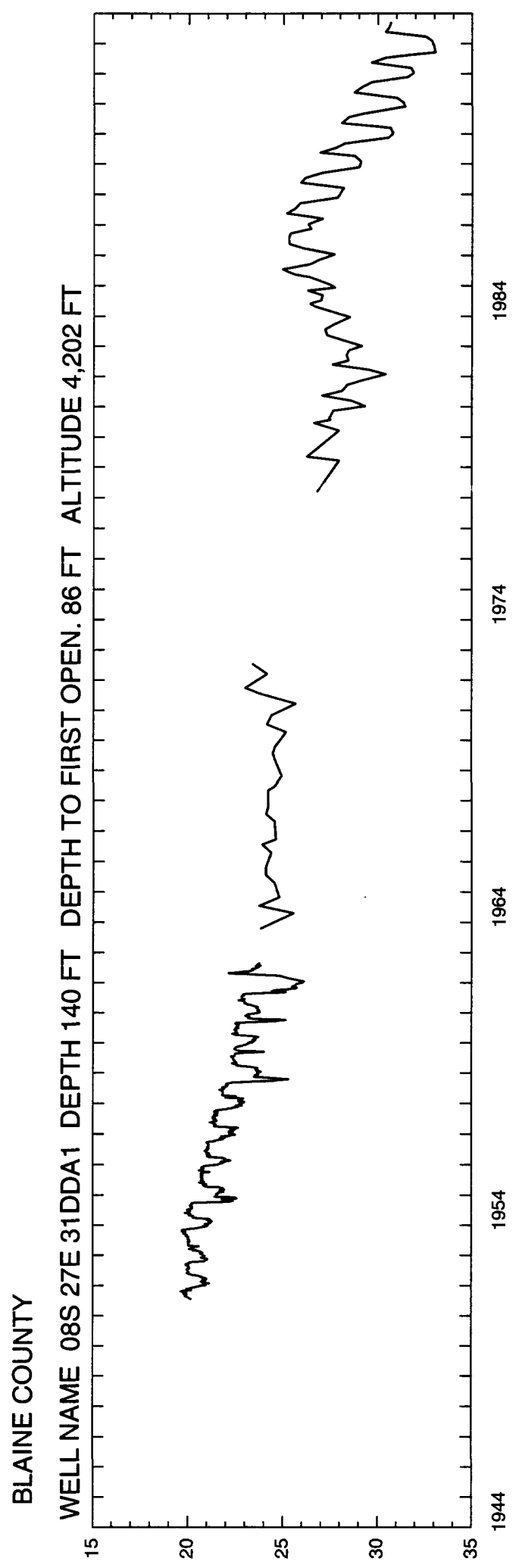

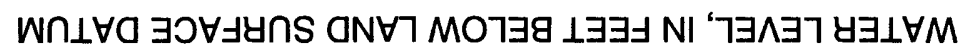


Boise

81 (page 83 Lollows) 


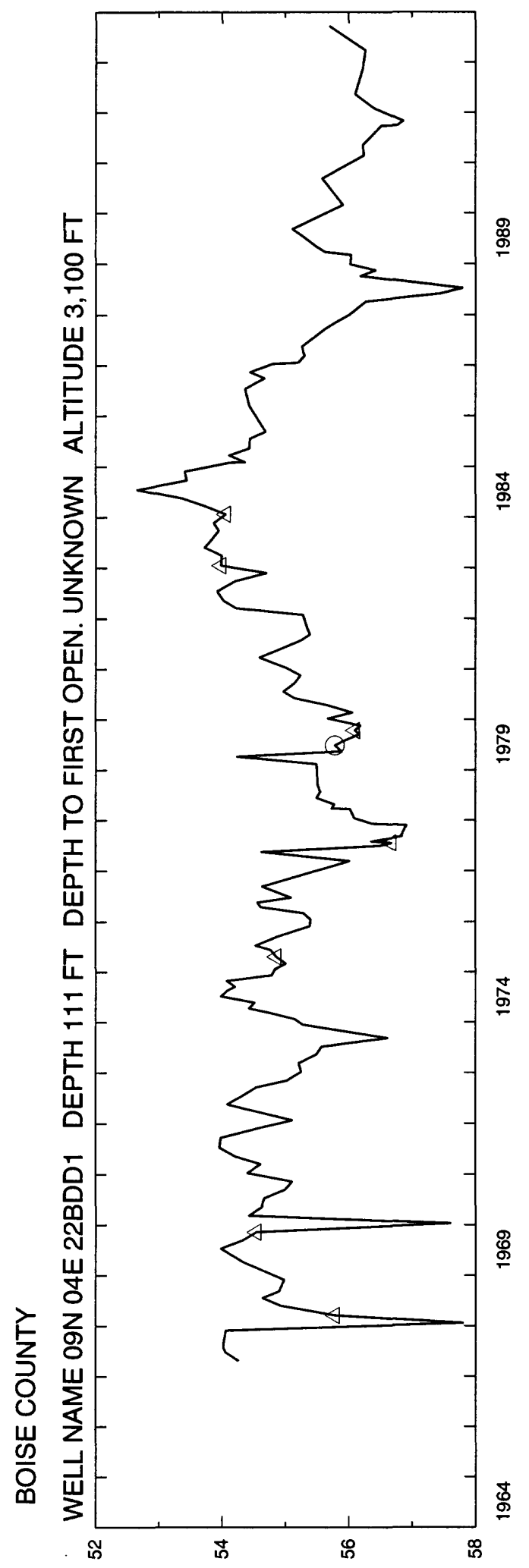

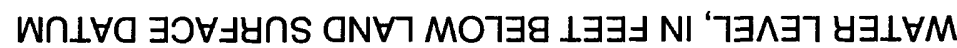

83 Caage 85 tollow 
Bonneville 


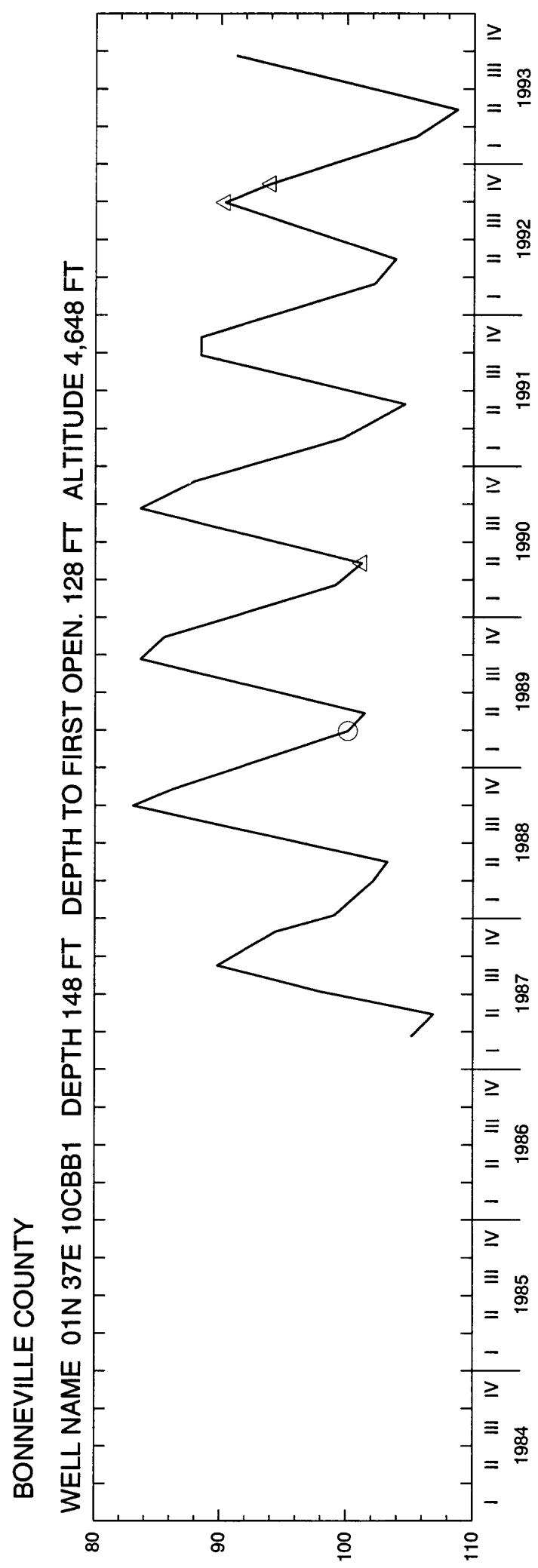

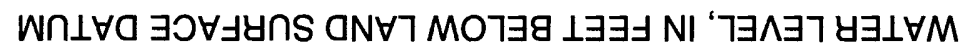



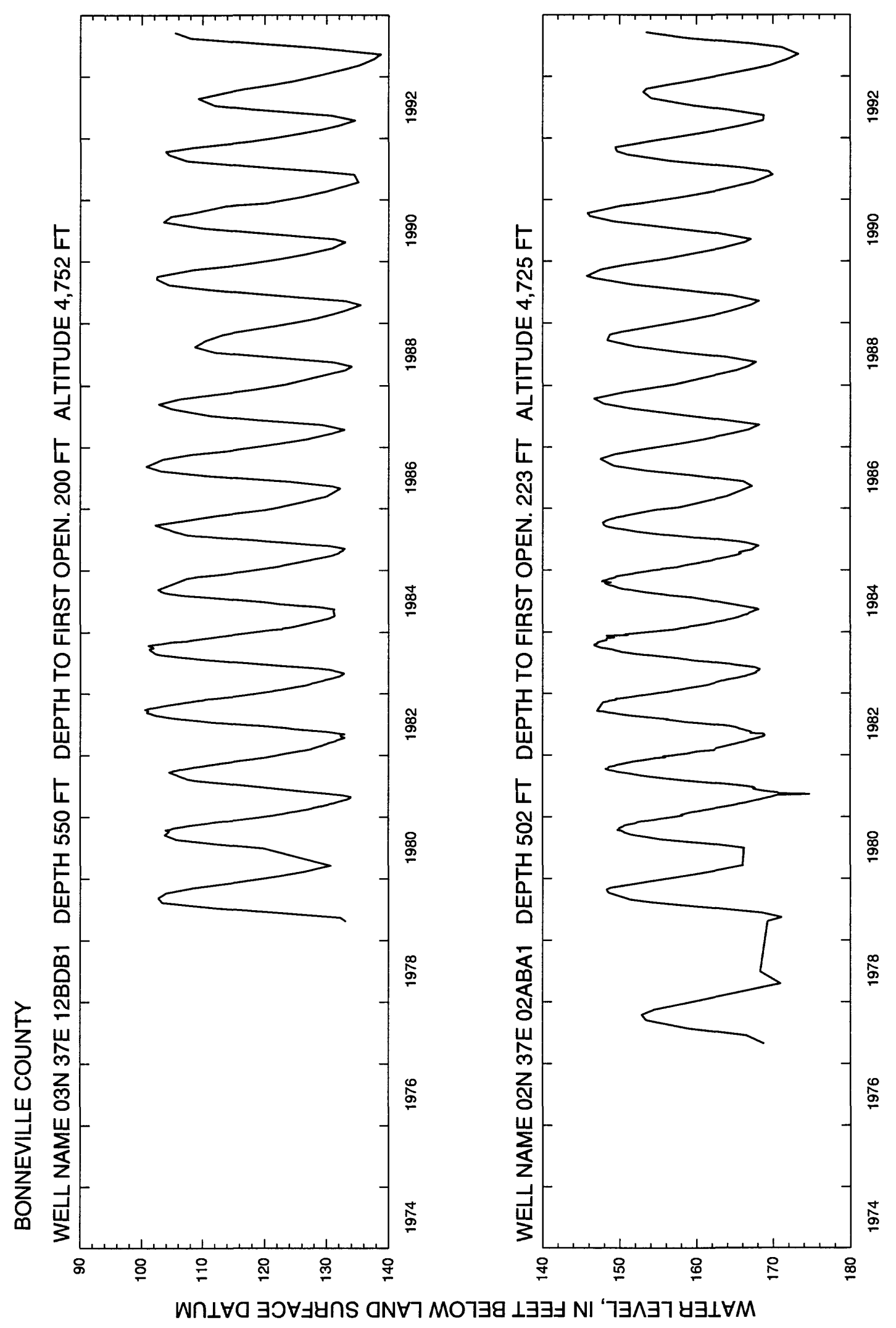


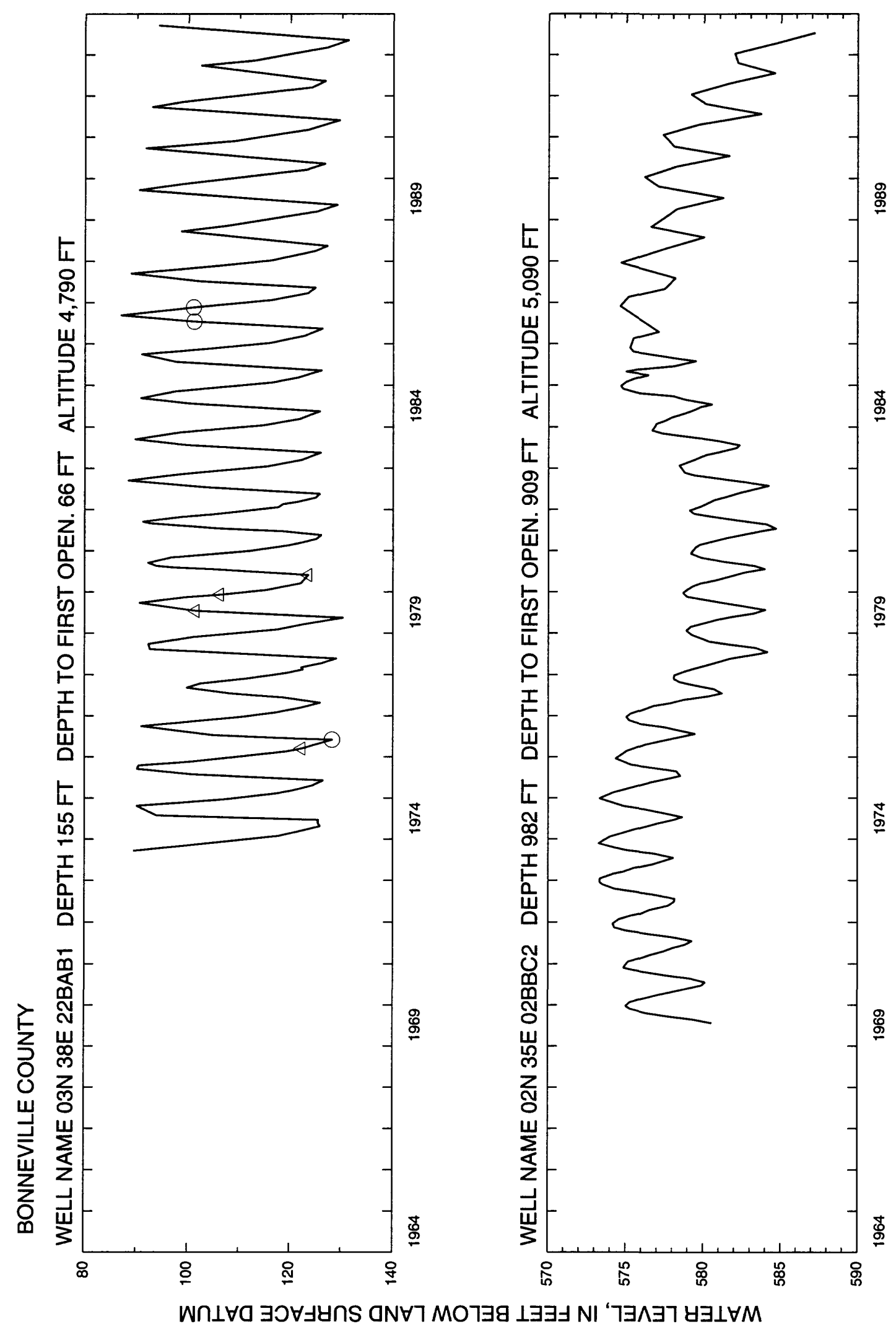




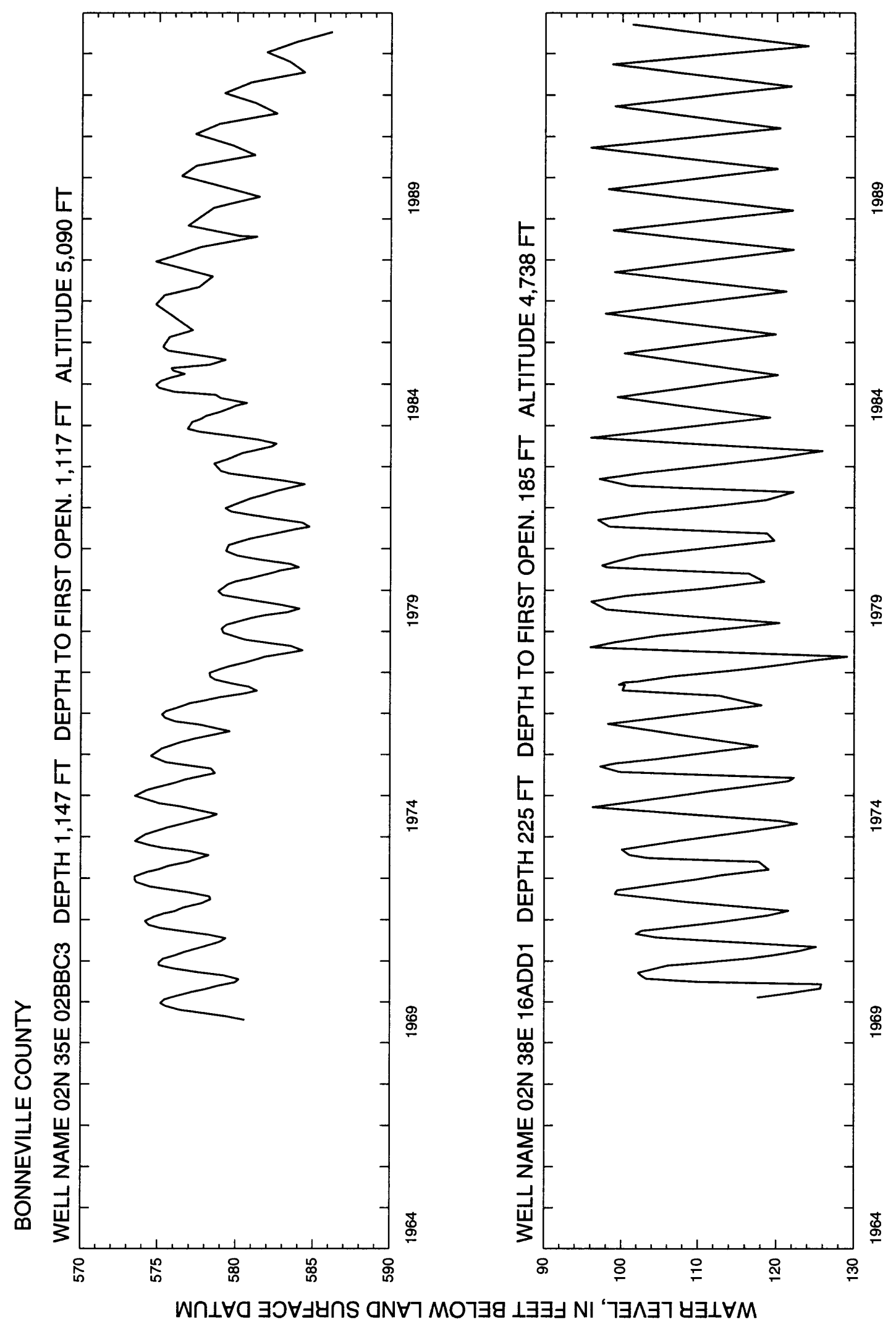




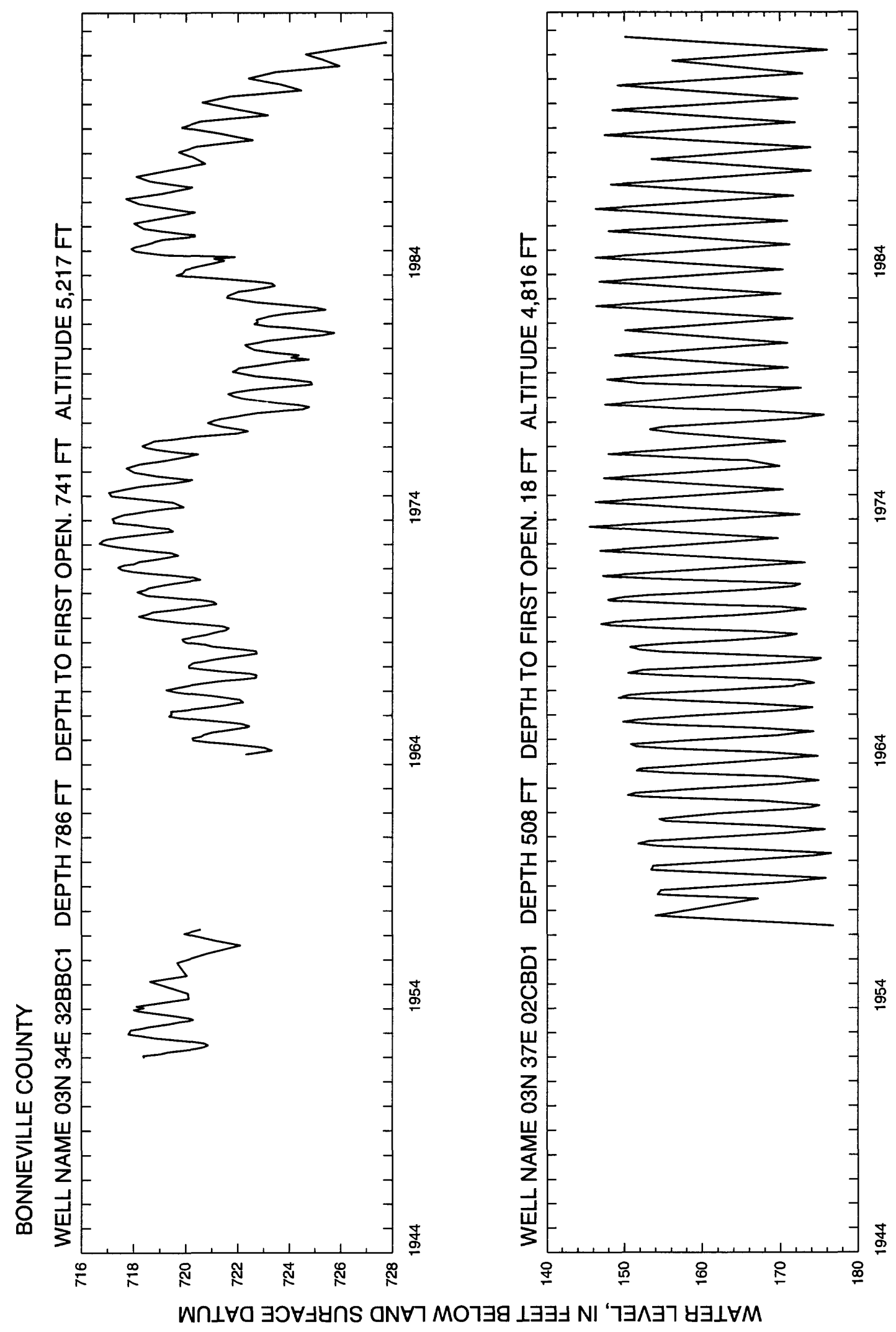

$\stackrel{\$}{\circ}$

㕝

\&

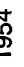

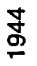

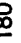




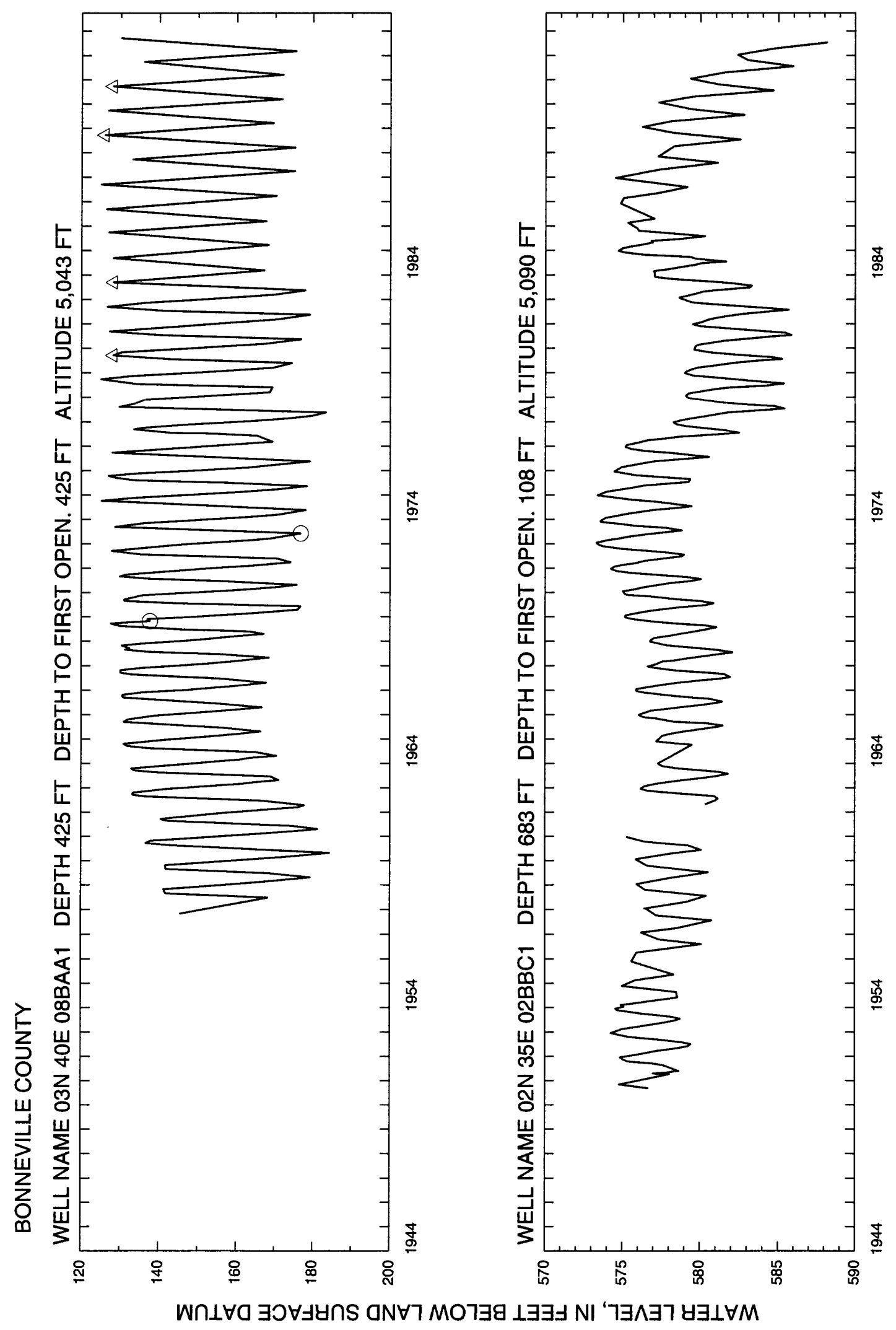




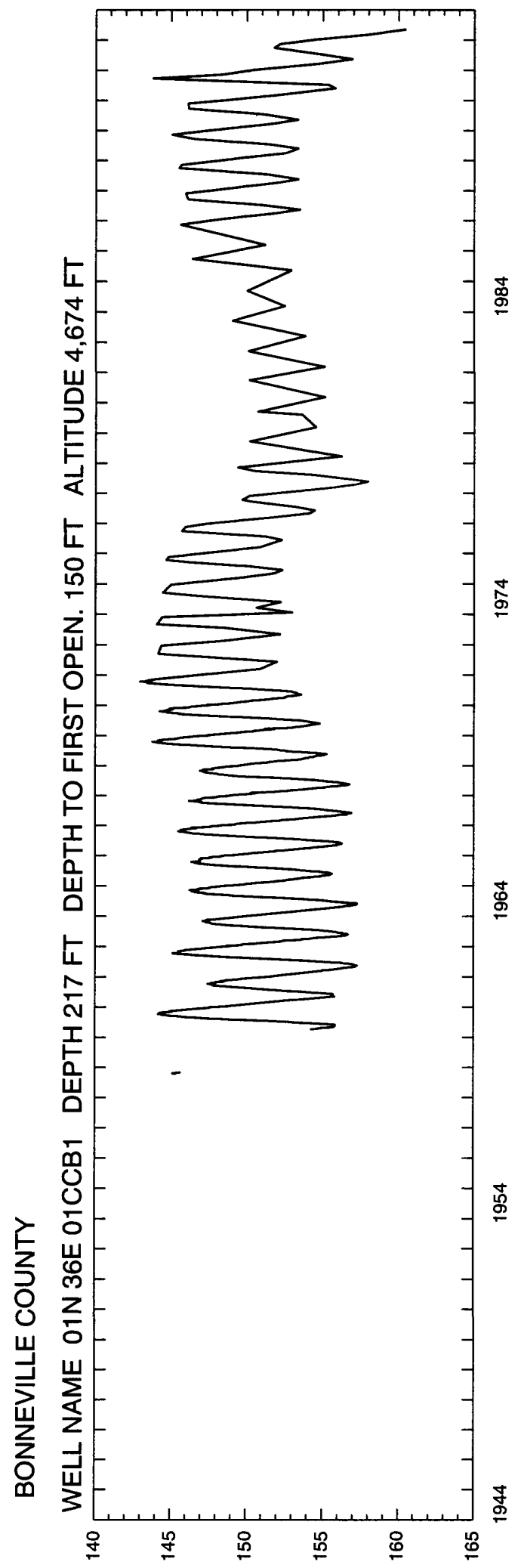

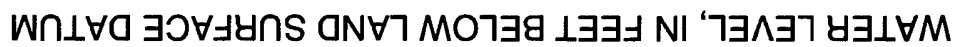

$\approx$ (pme 95 sollows) 
Butte

(page 97 follows) 


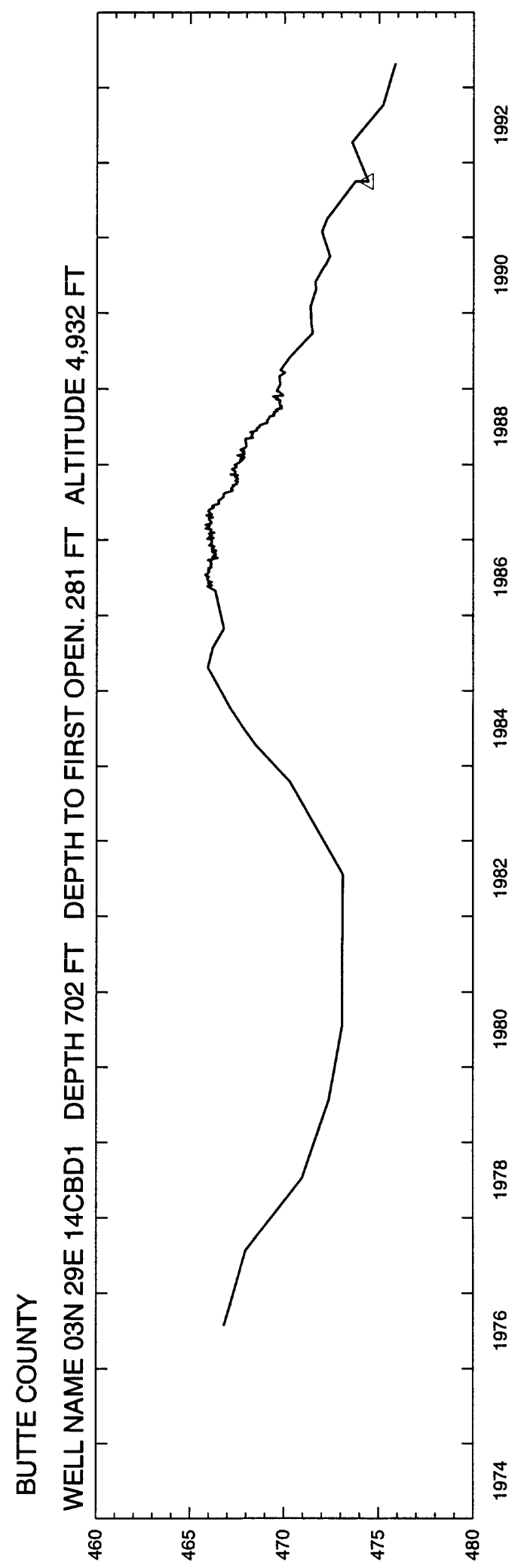

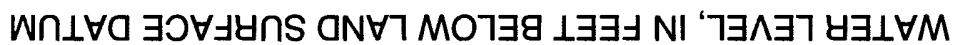




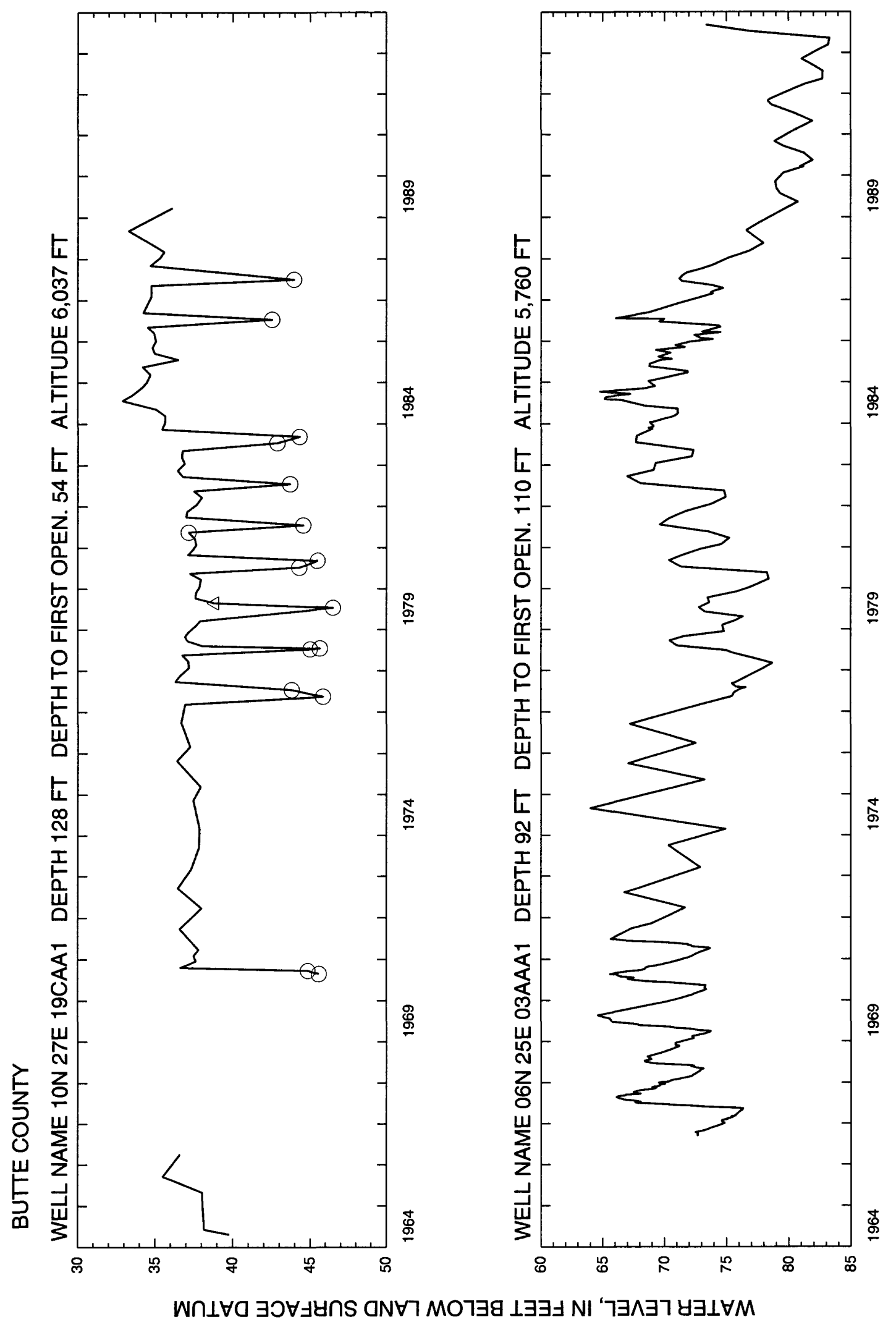




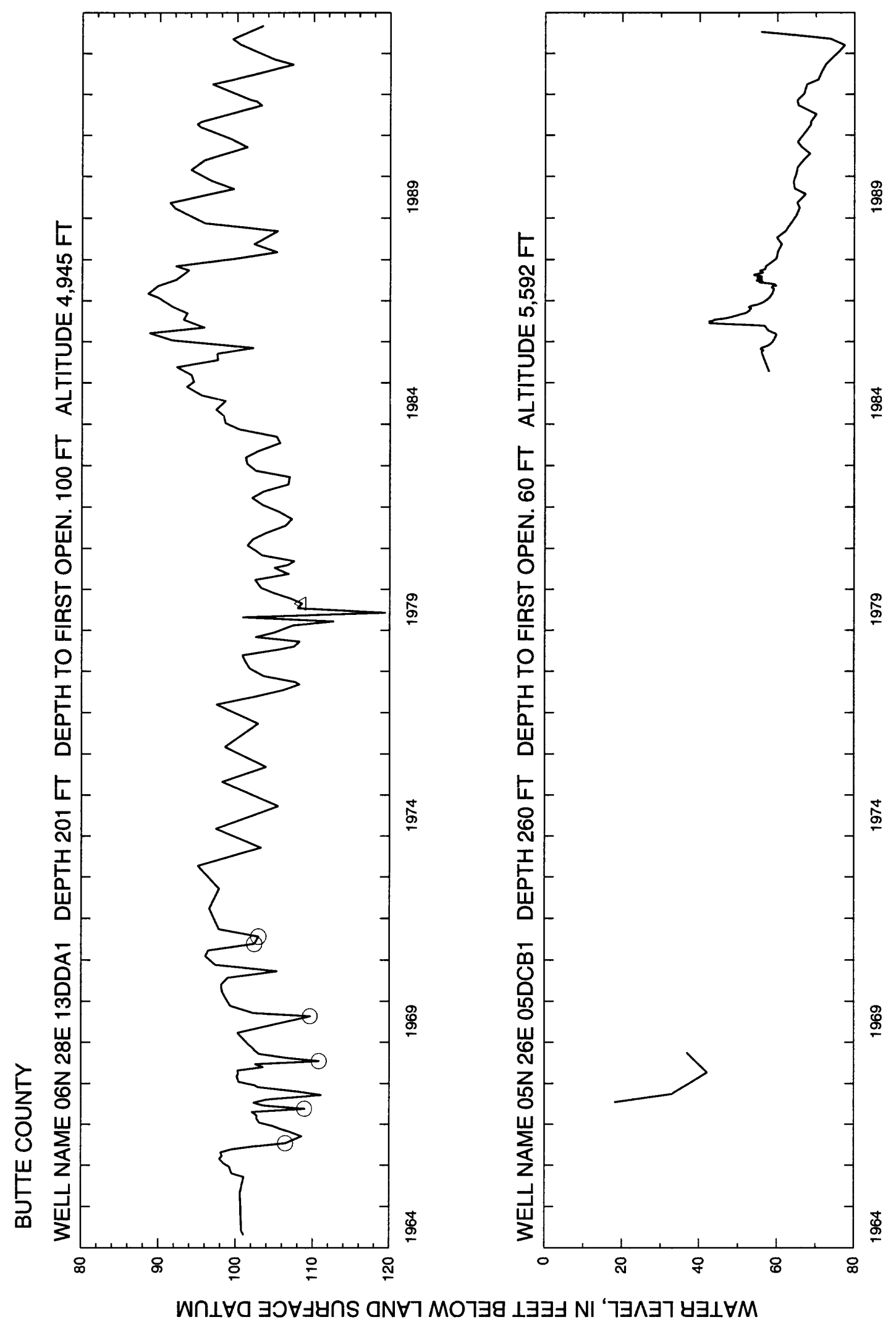




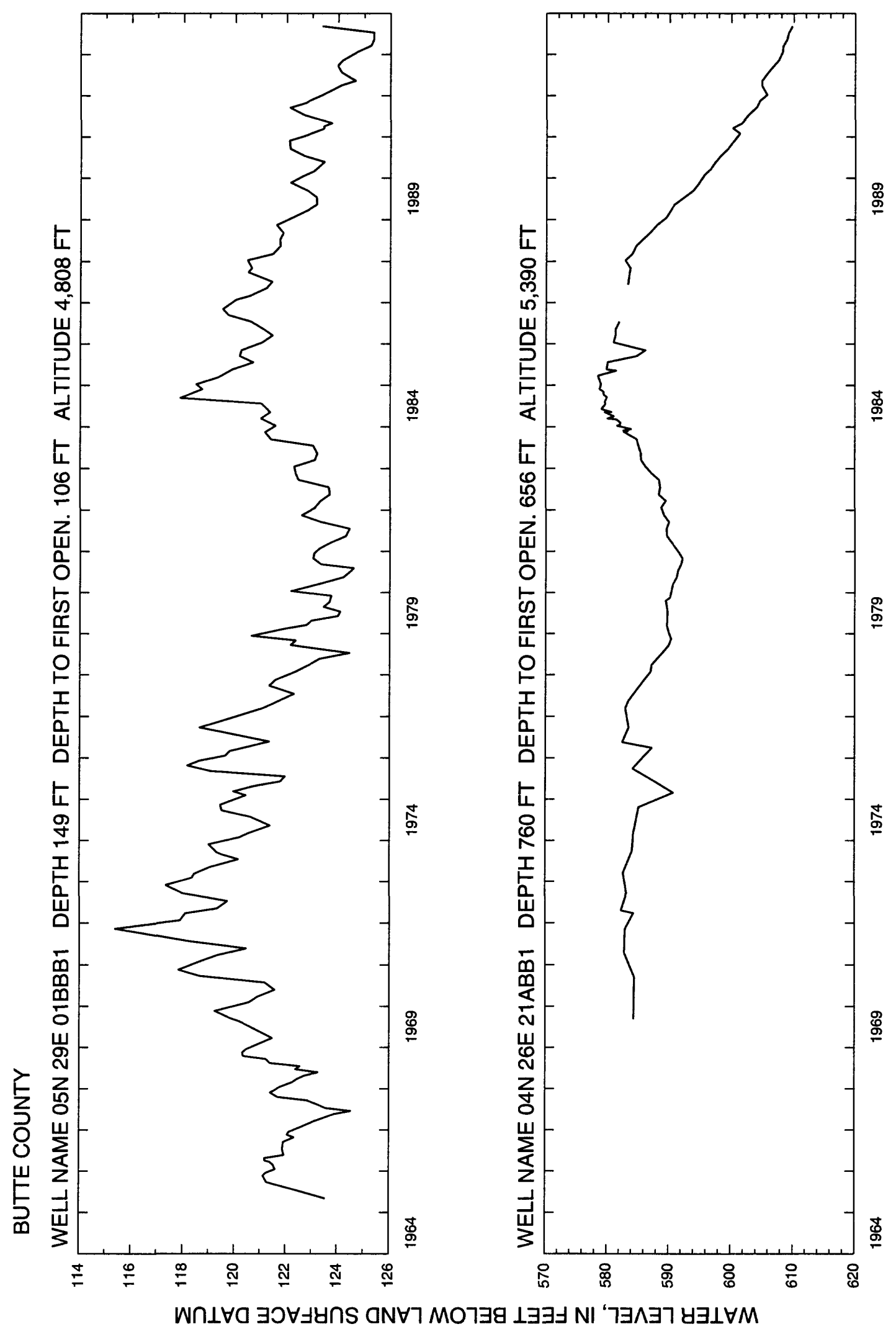




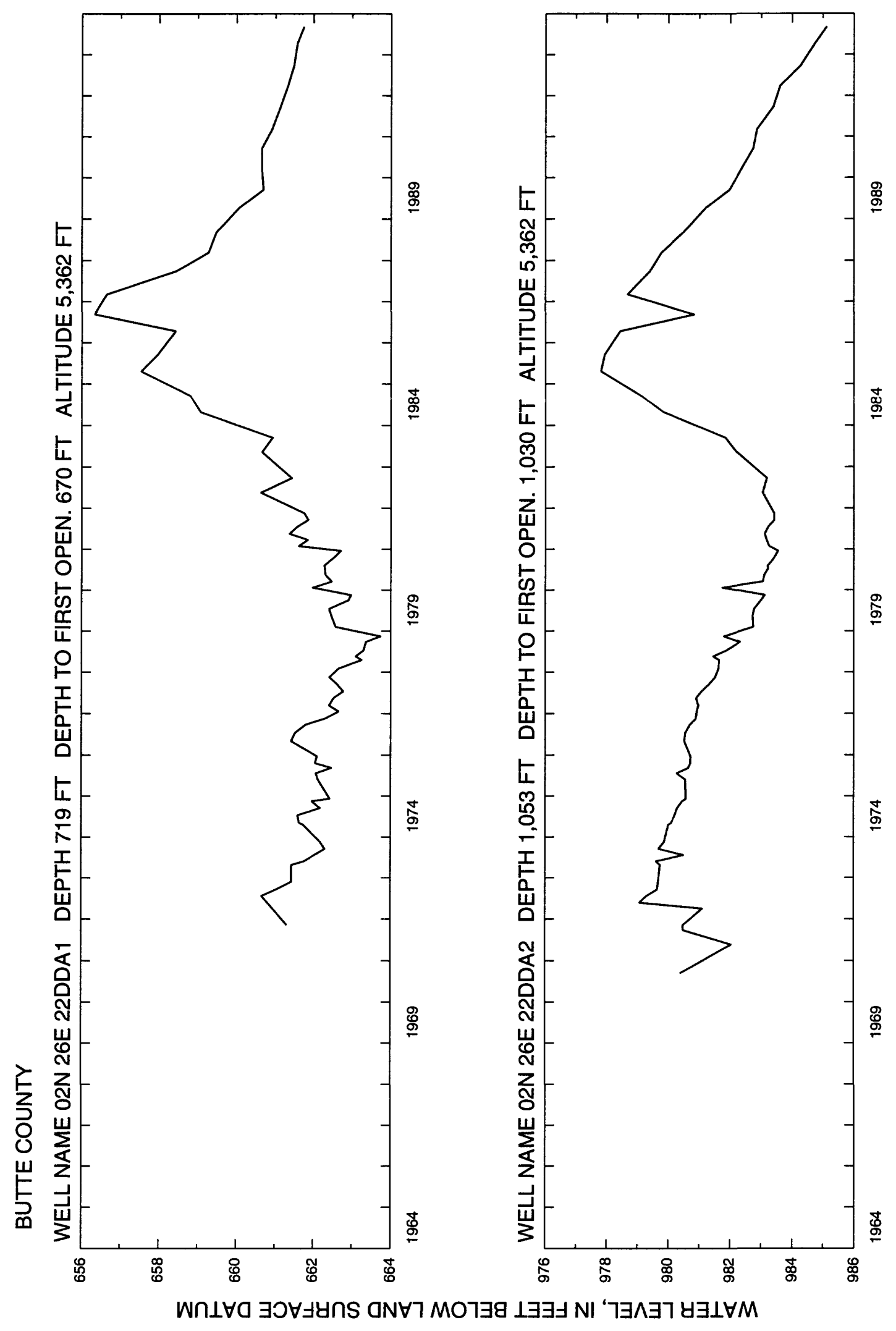




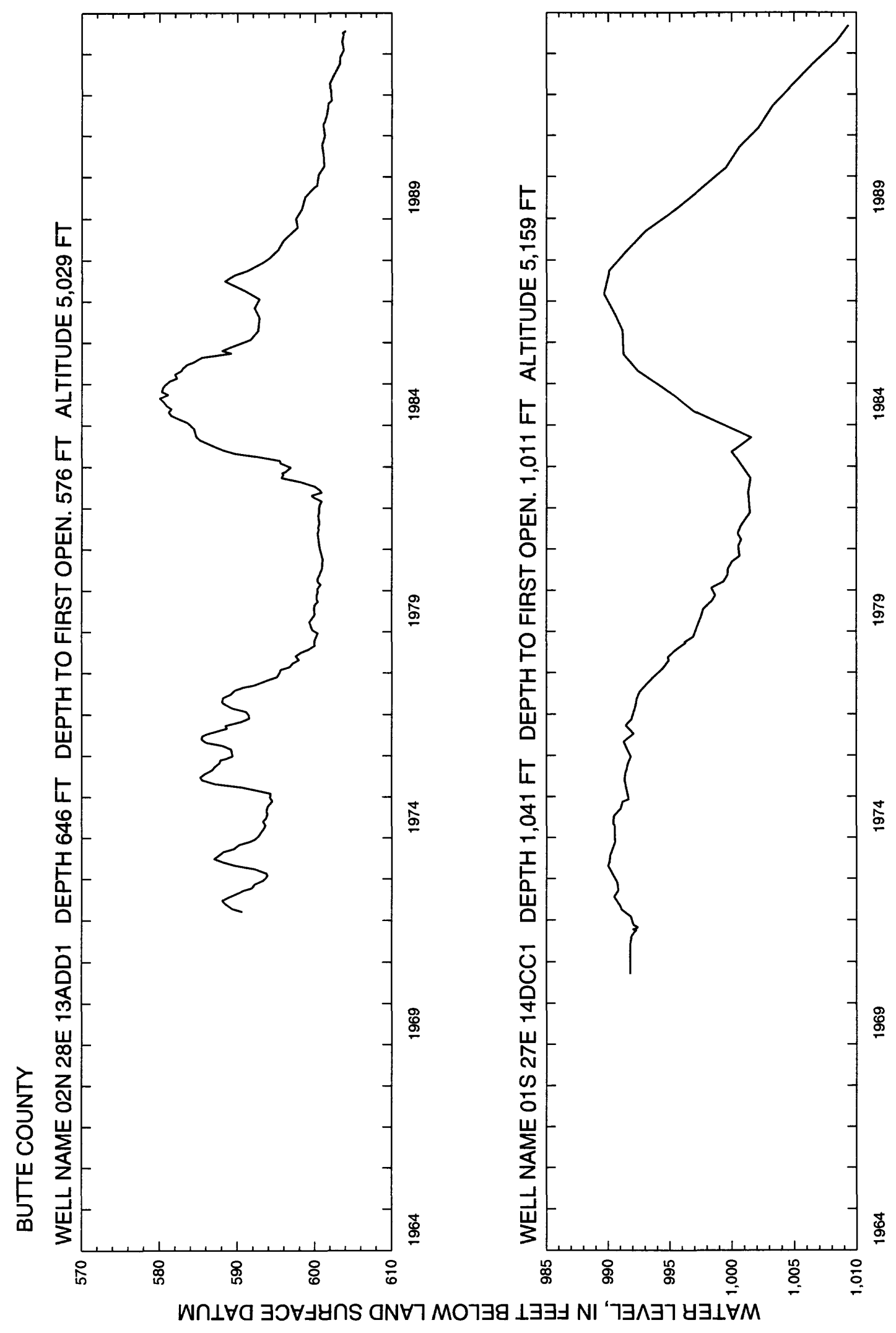



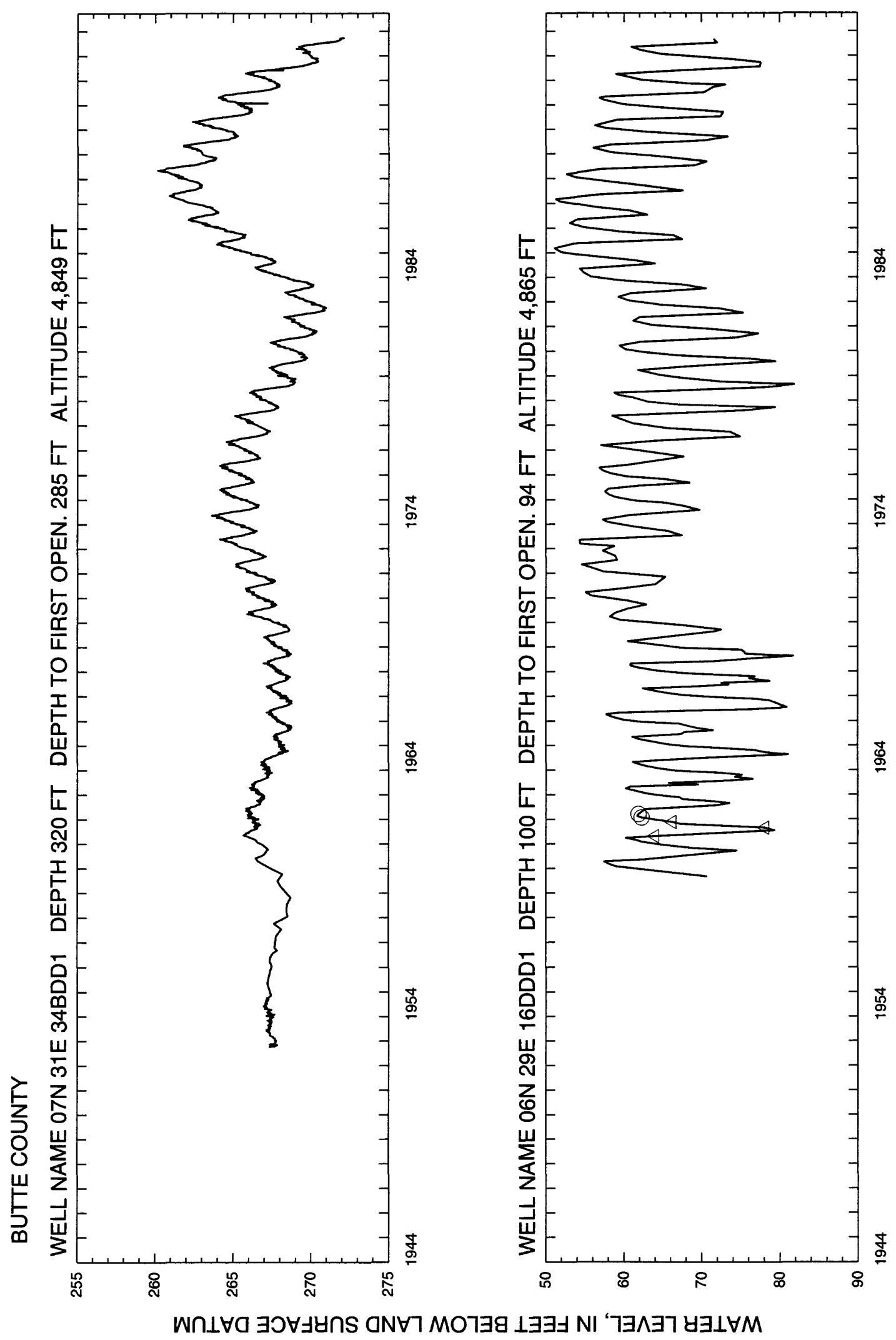


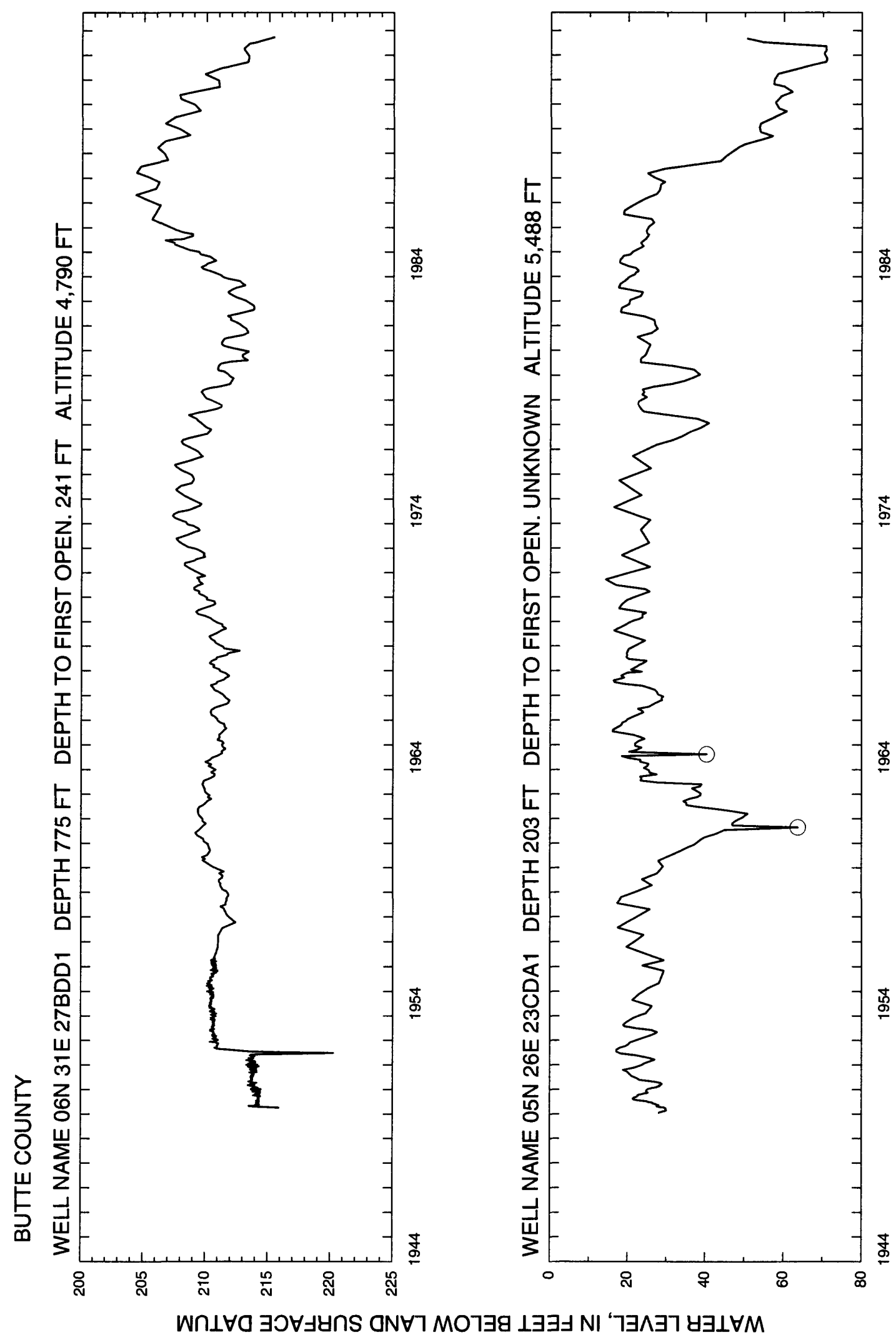




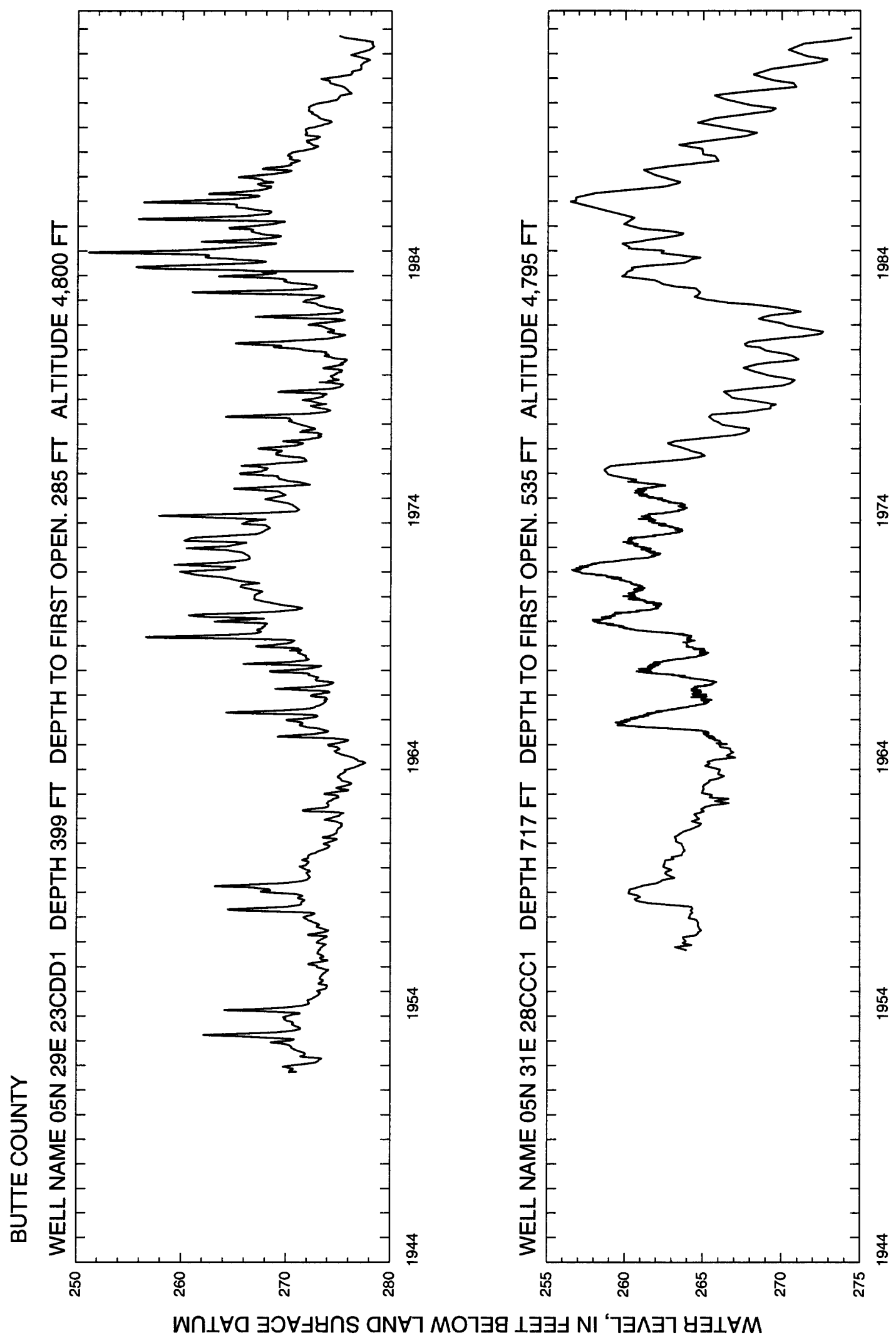




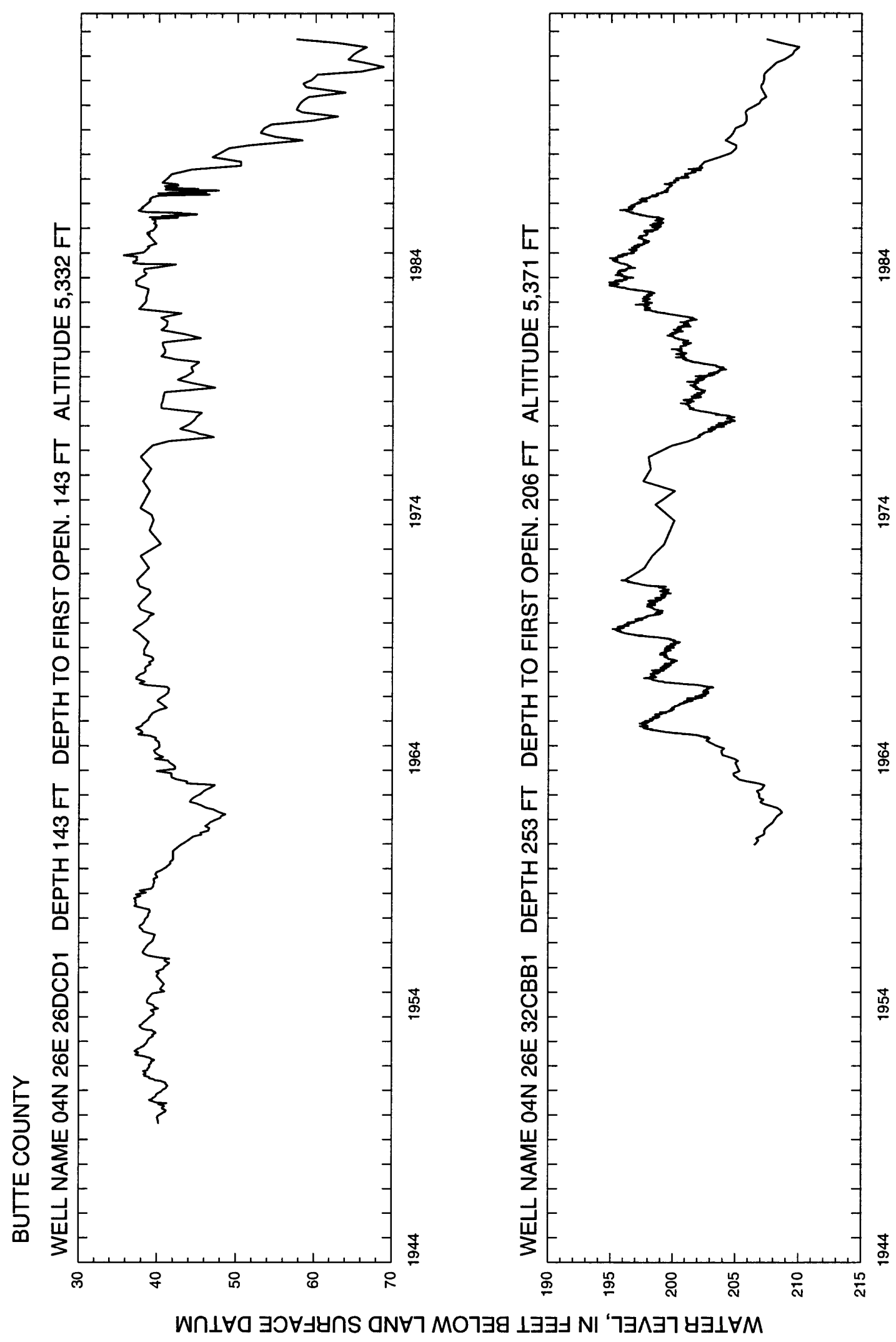

$\stackrel{\$}{\stackrel{\circ}{\circ}}$

$\stackrel{\square}{\circ}$

$\stackrel{+}{\circ}$ 


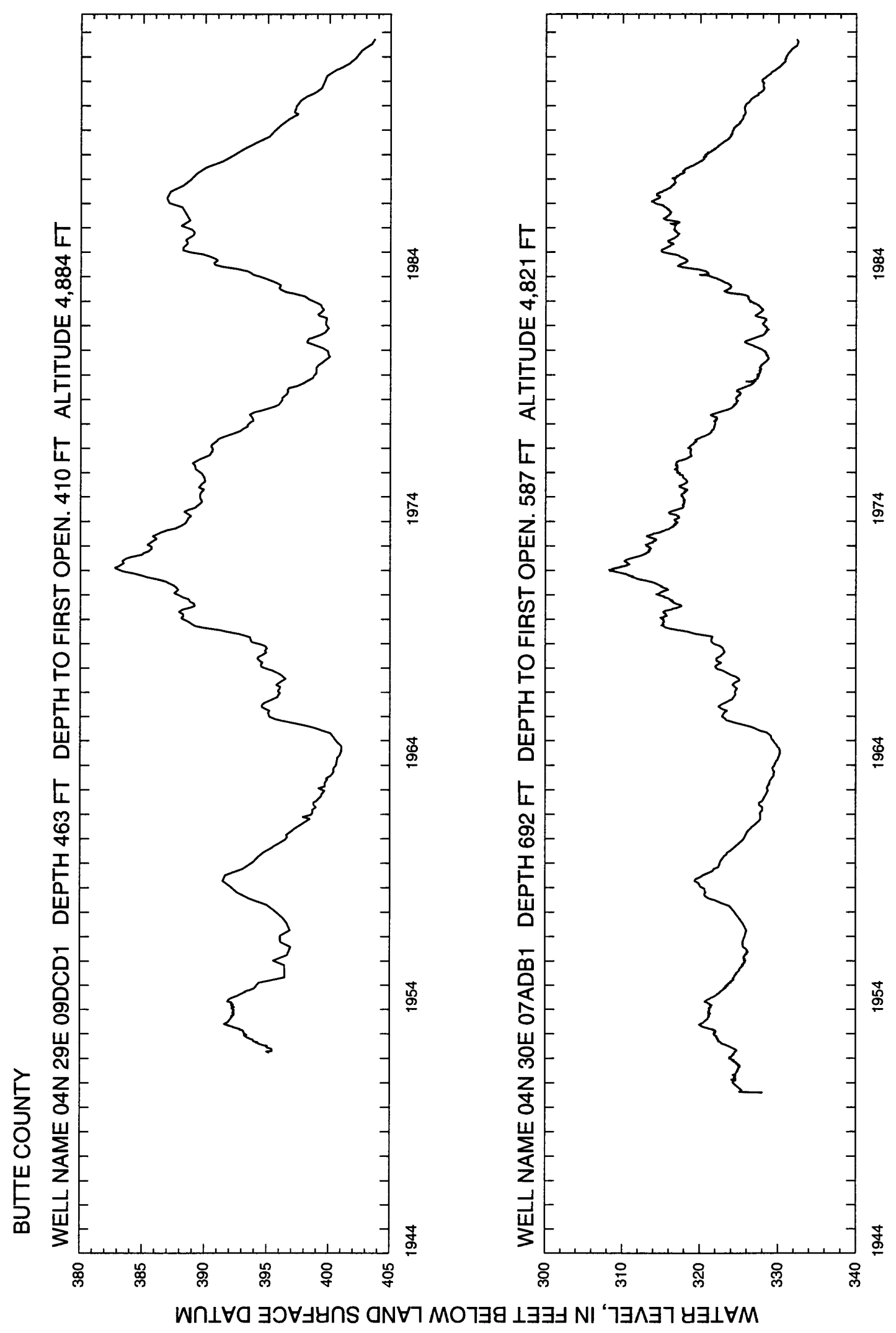




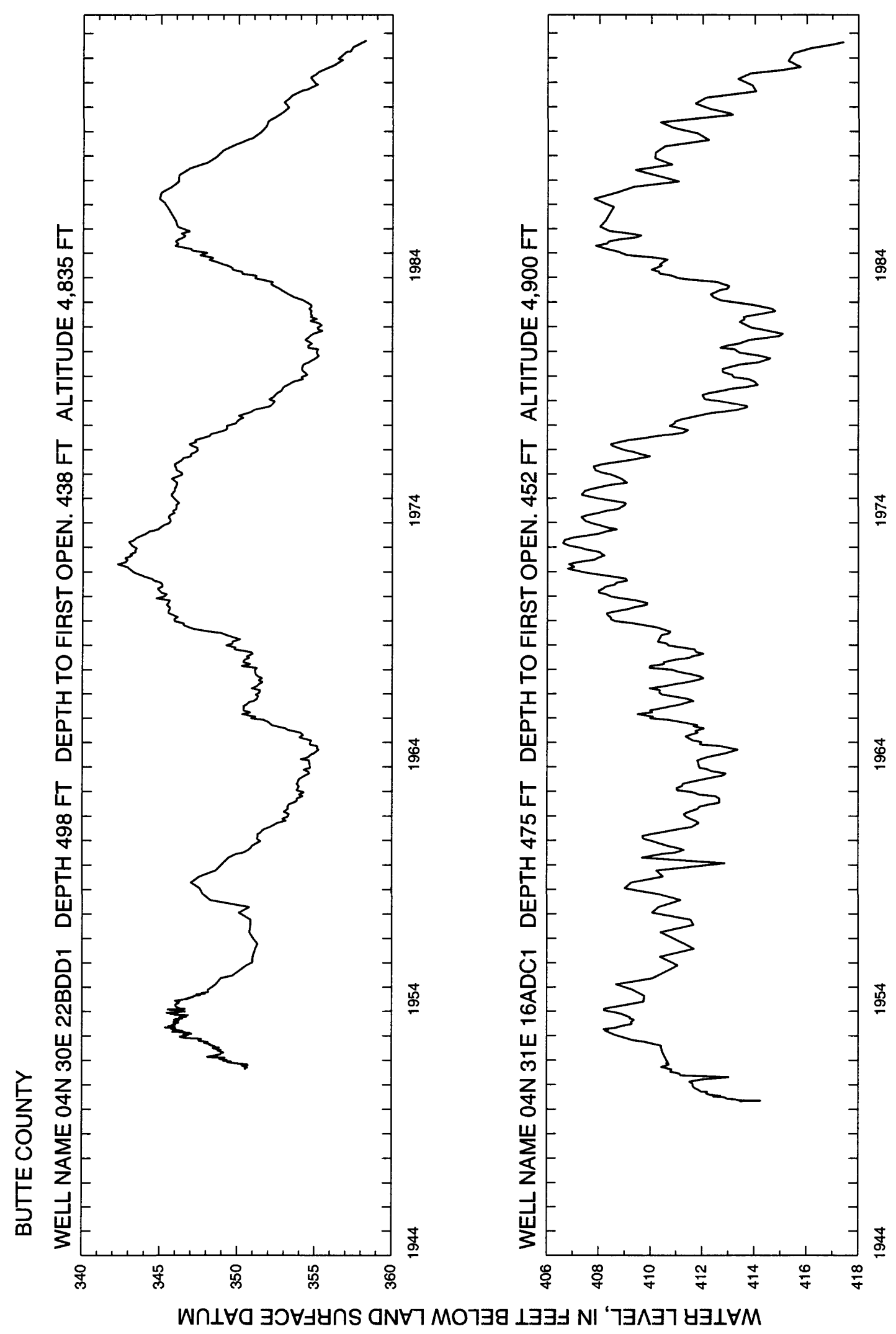




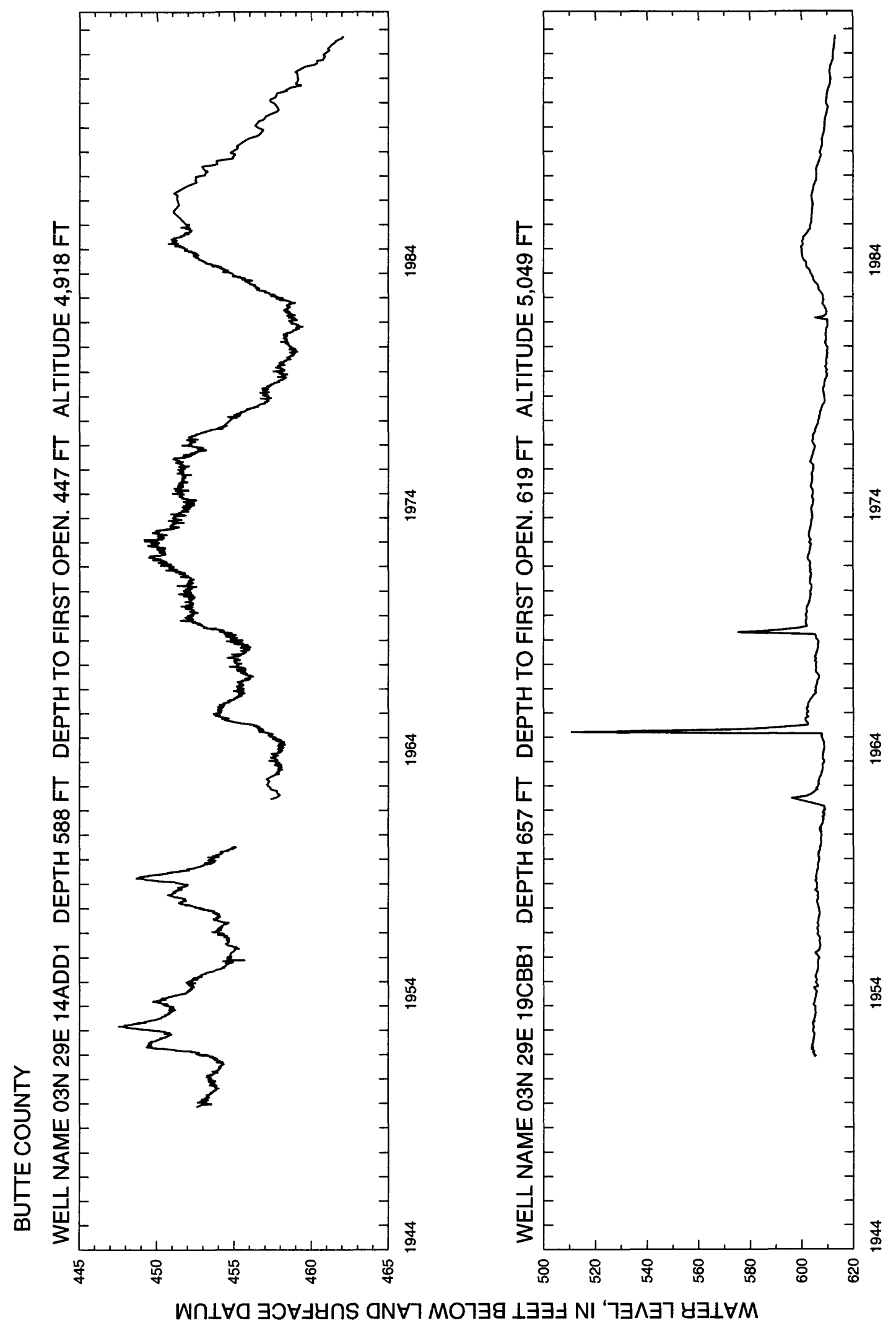




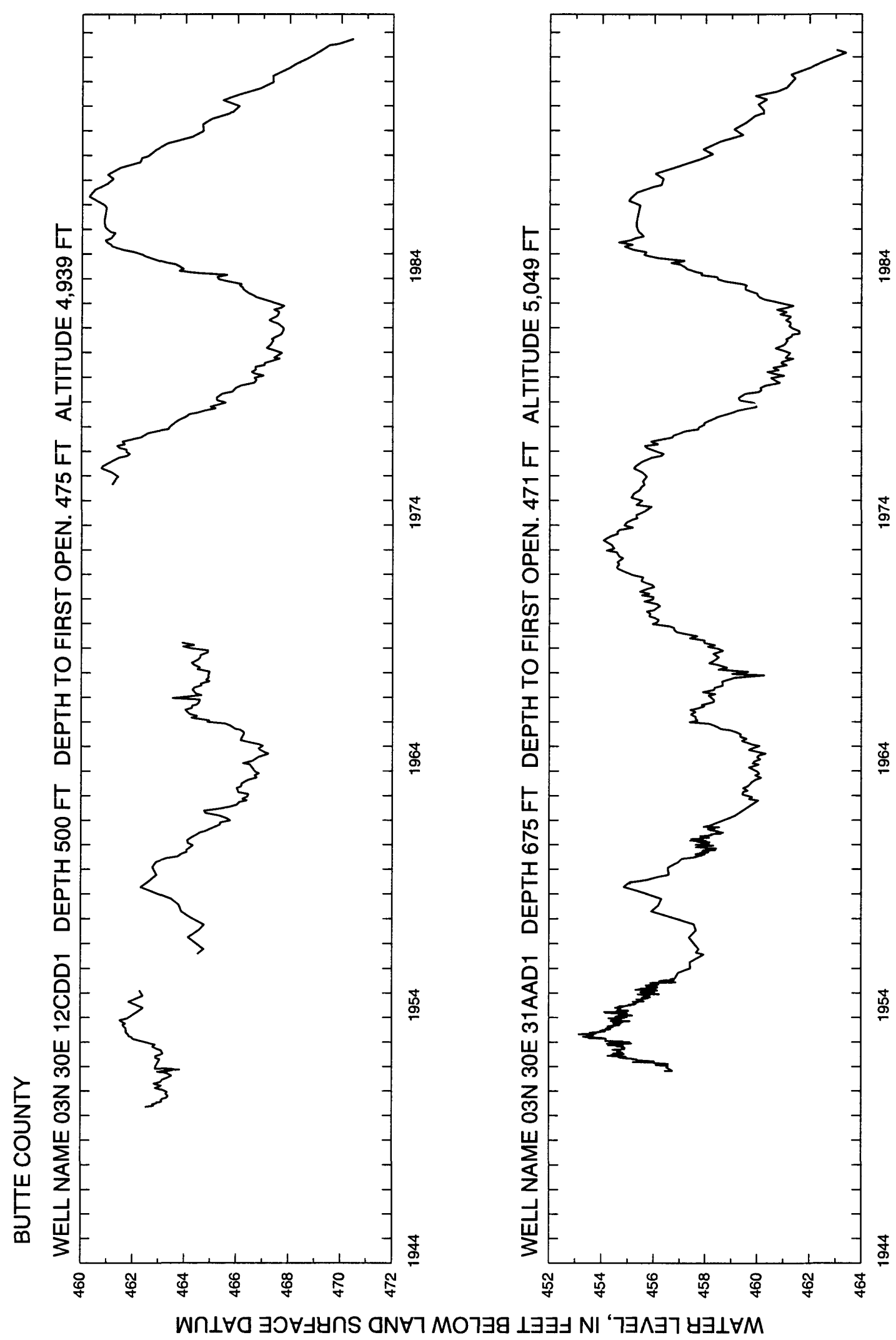




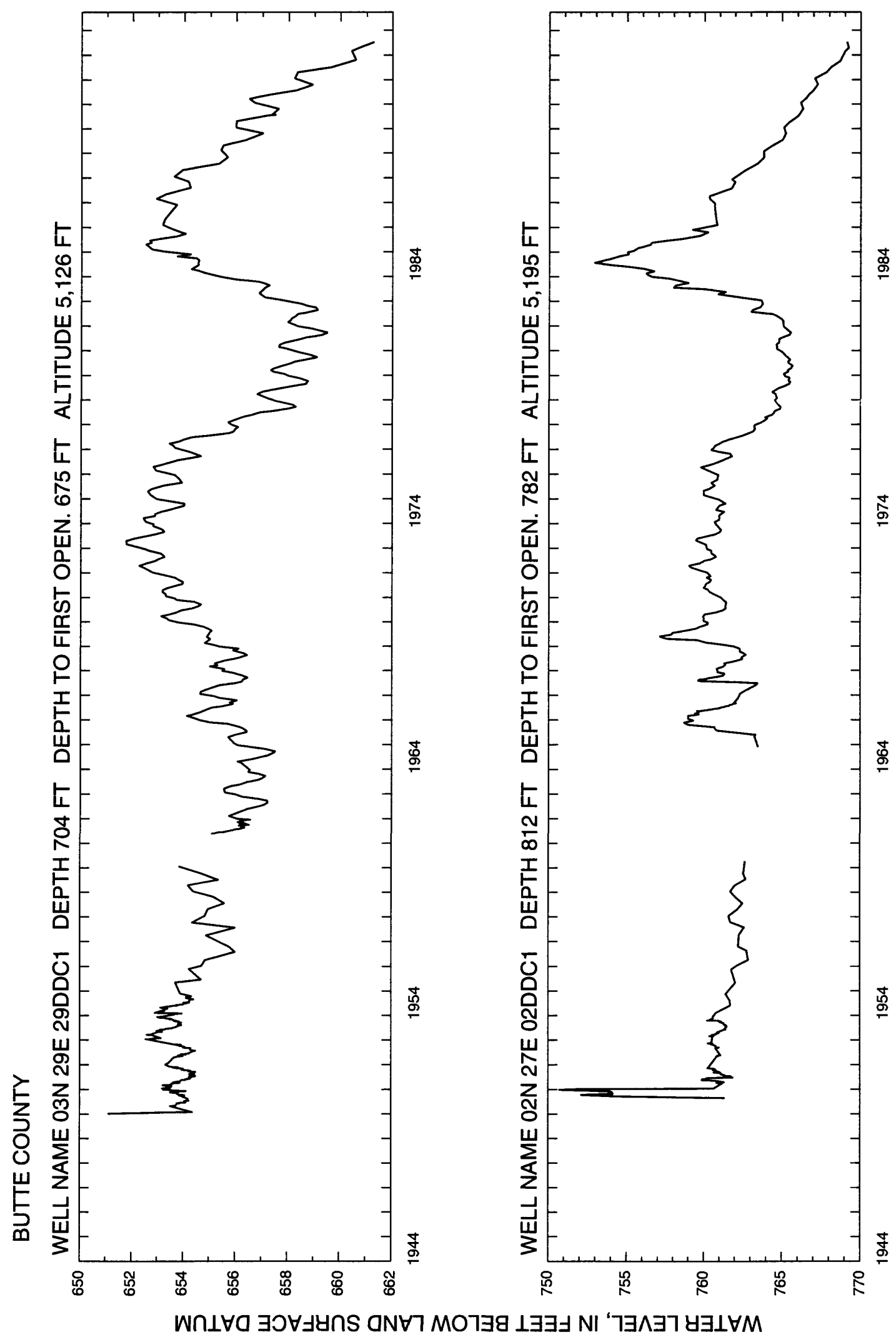




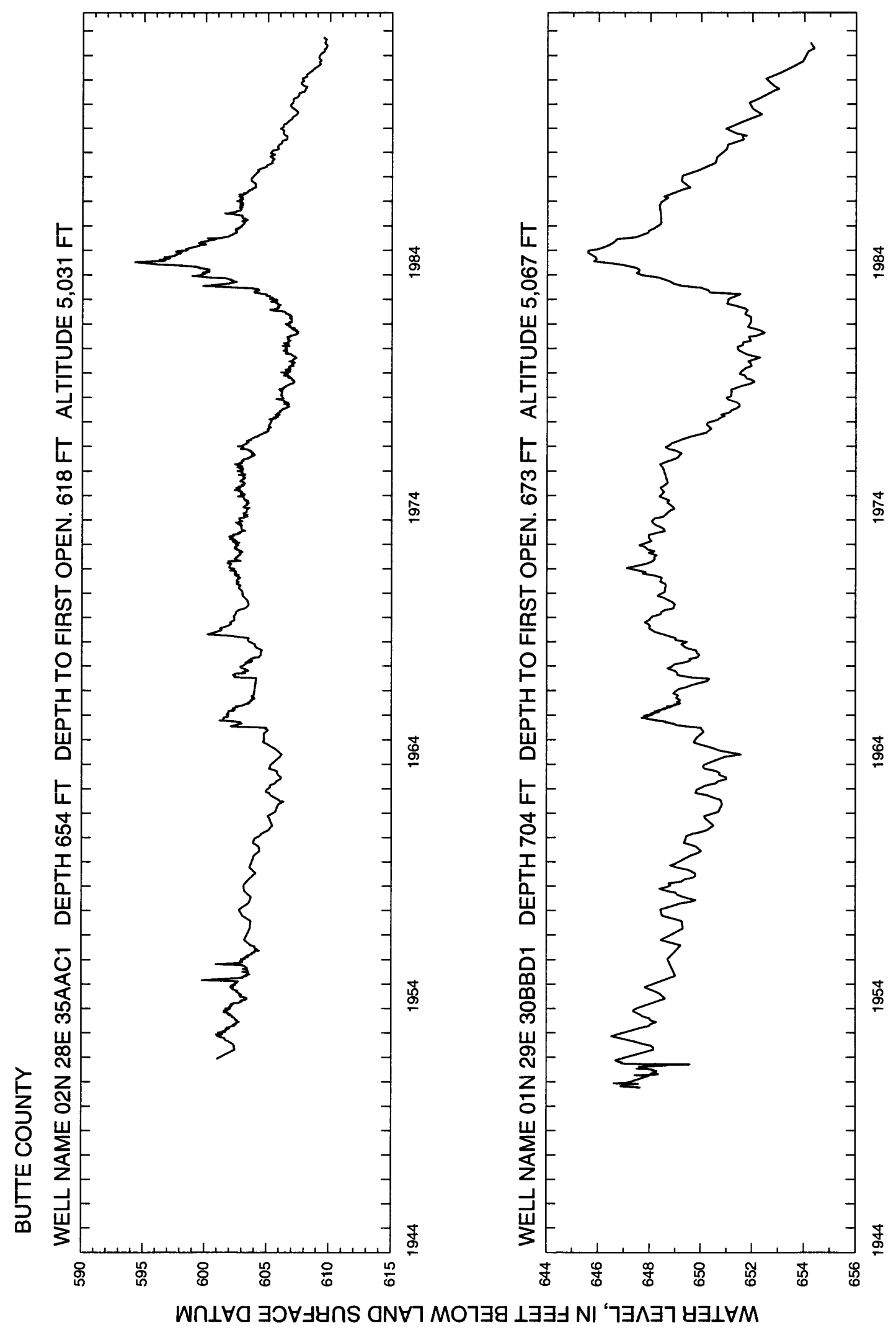




\section{Camas}




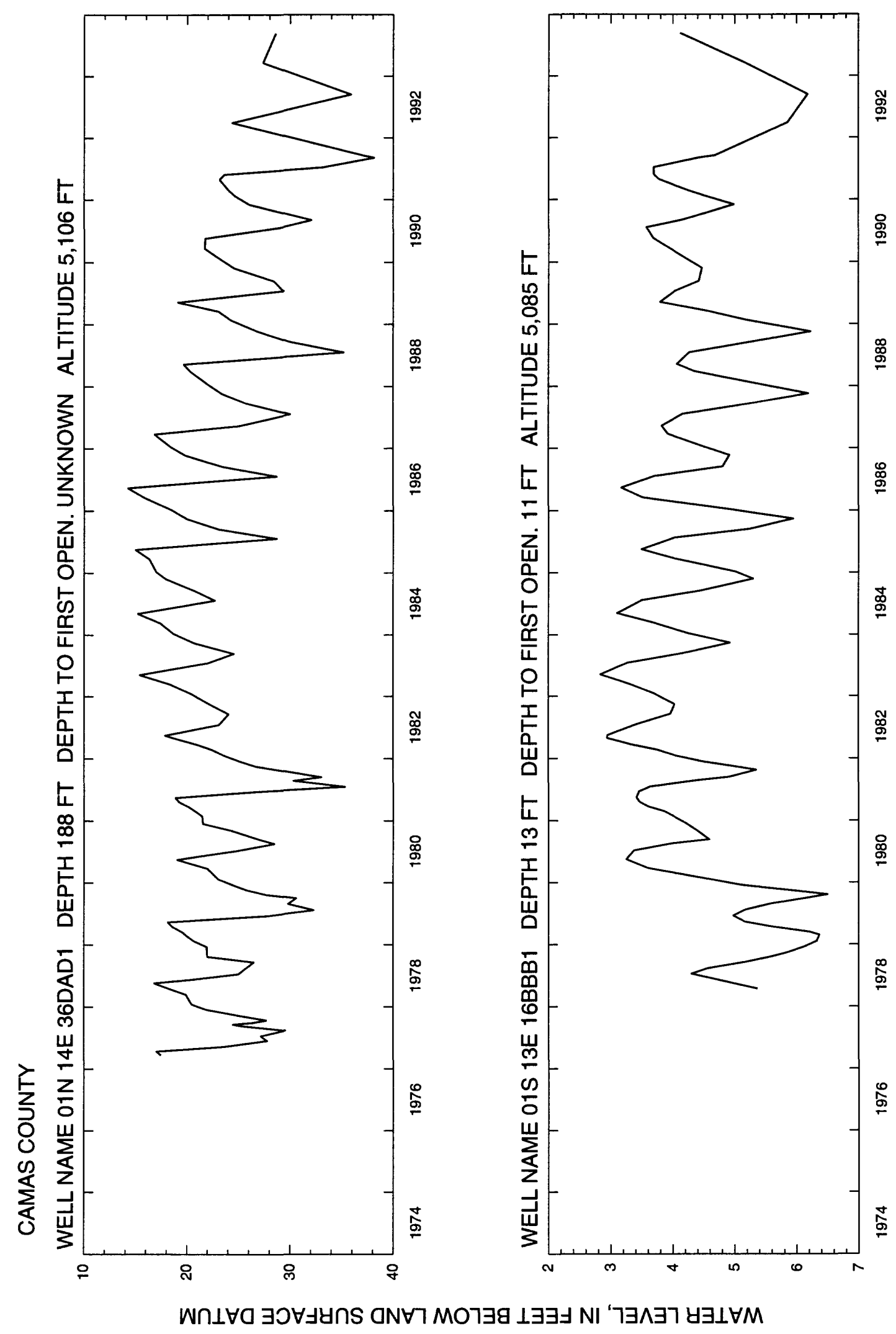




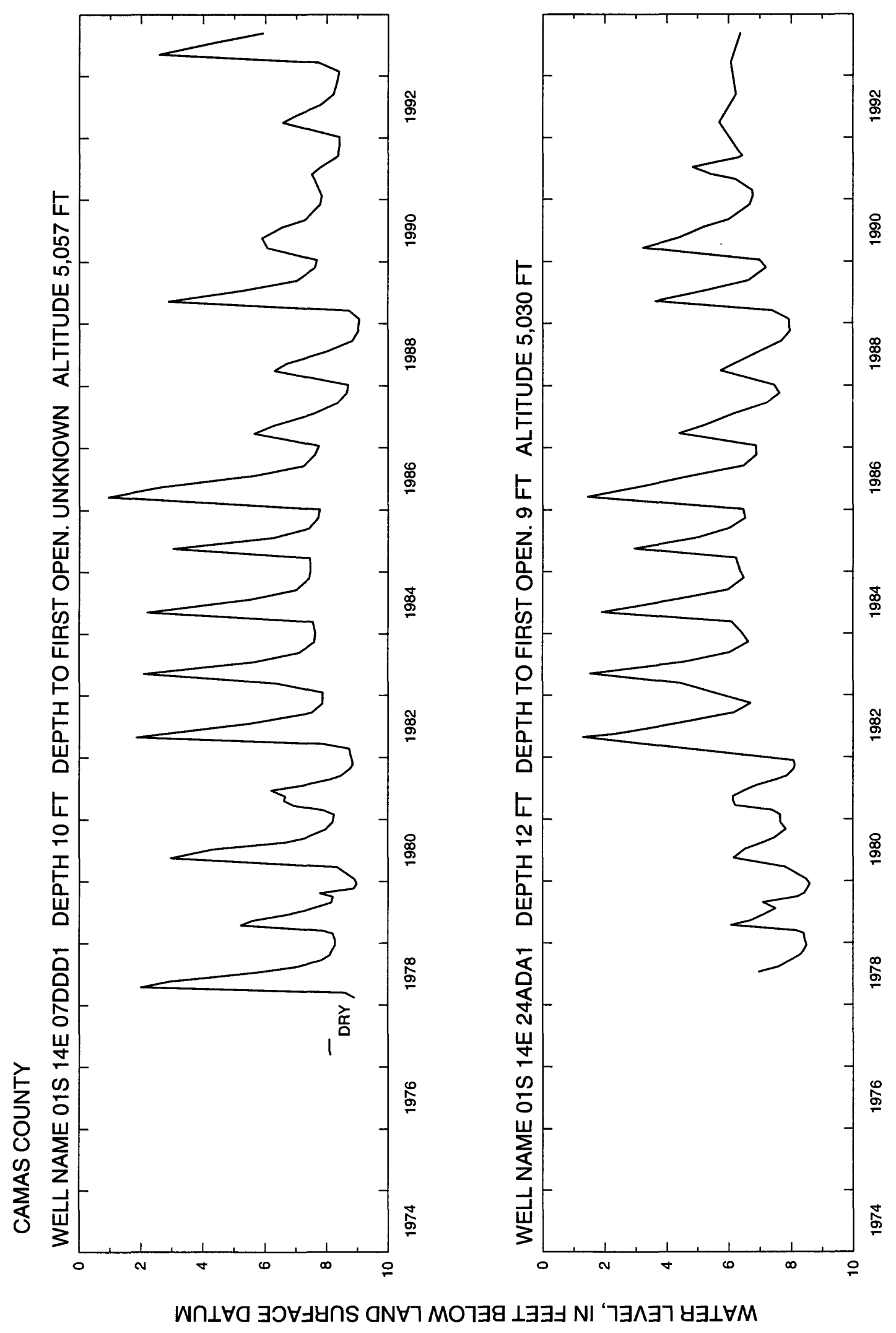




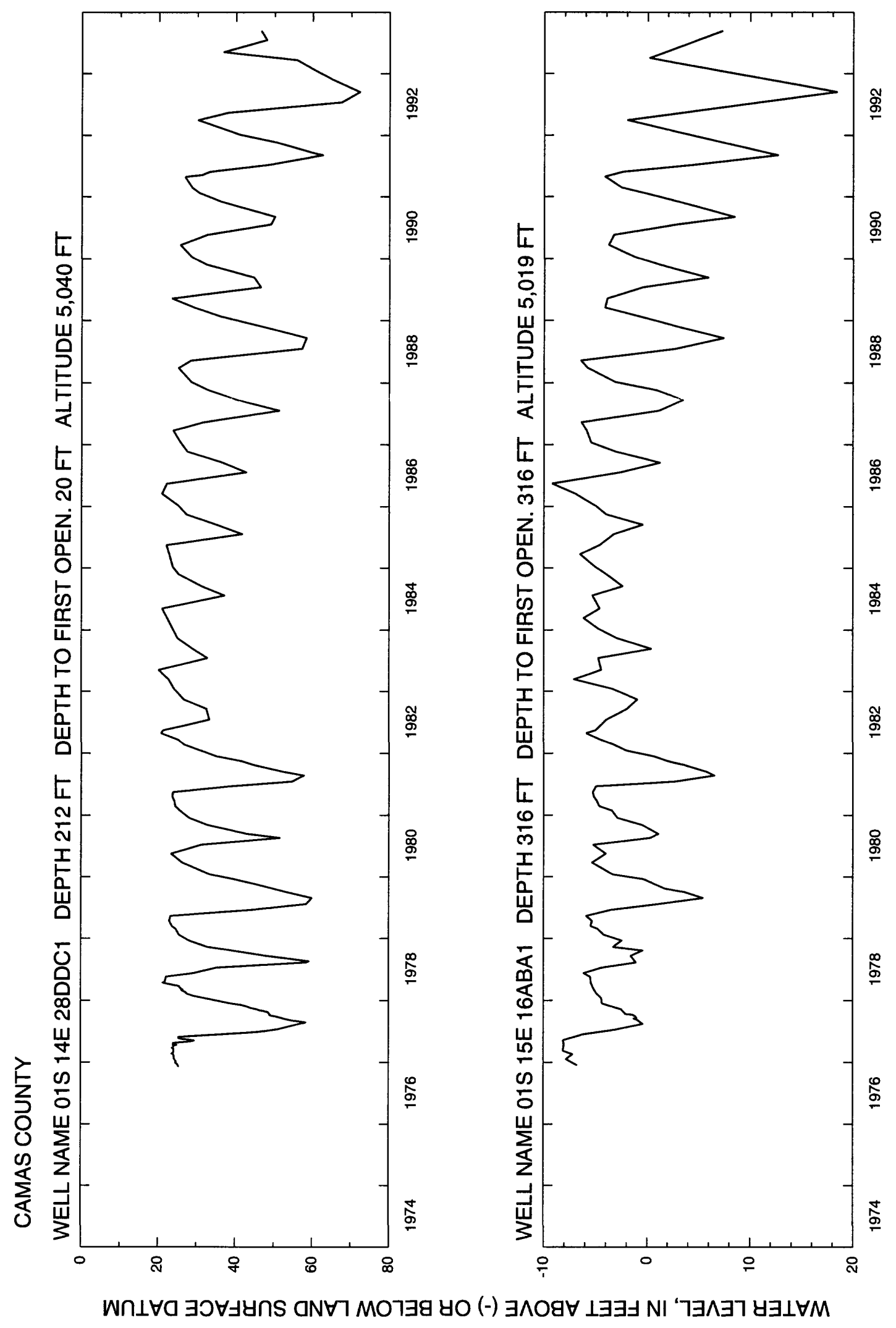




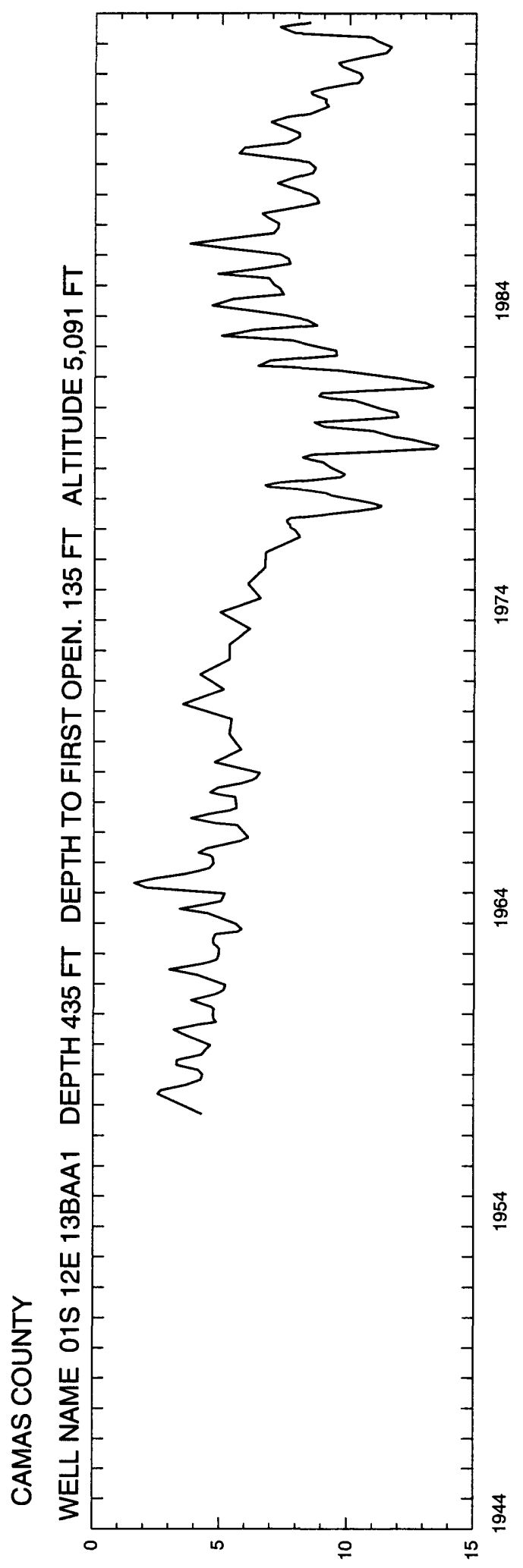

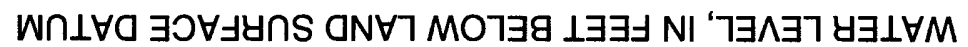


Canyon 


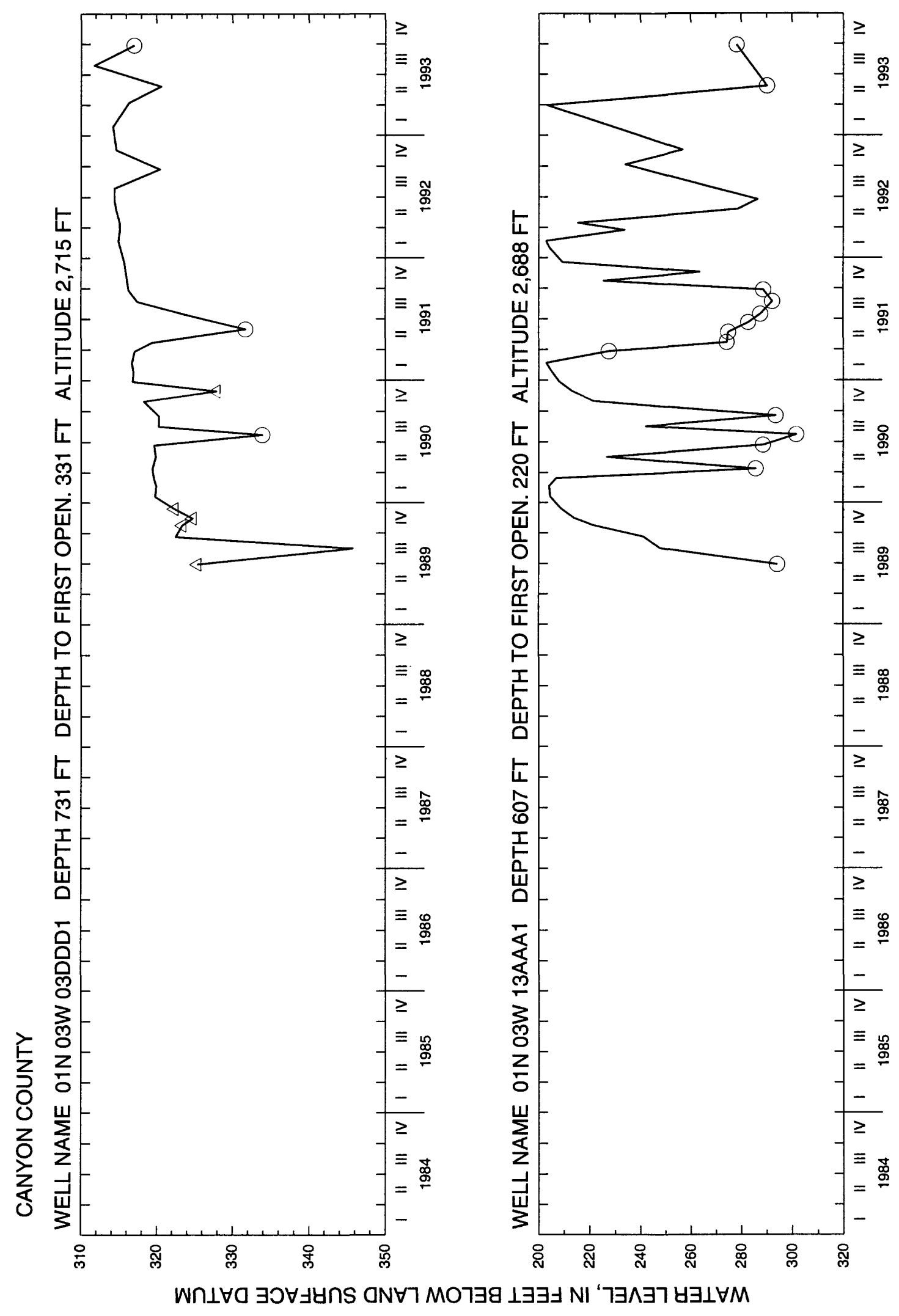




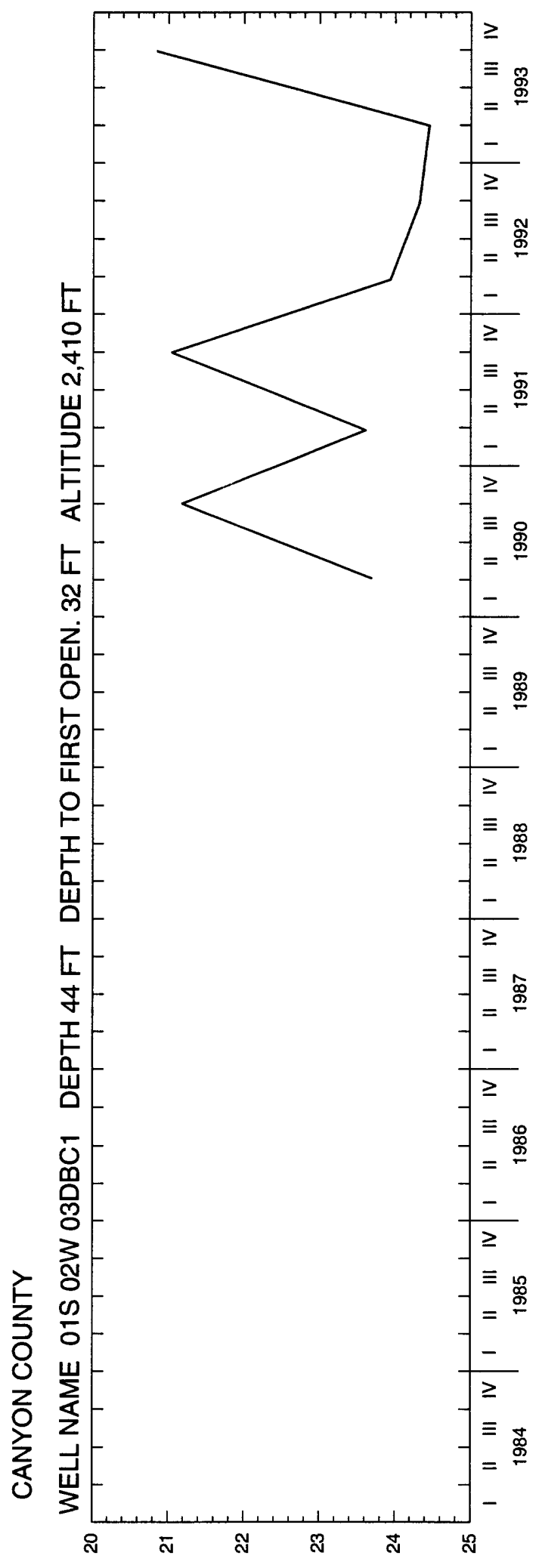

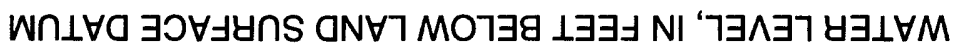




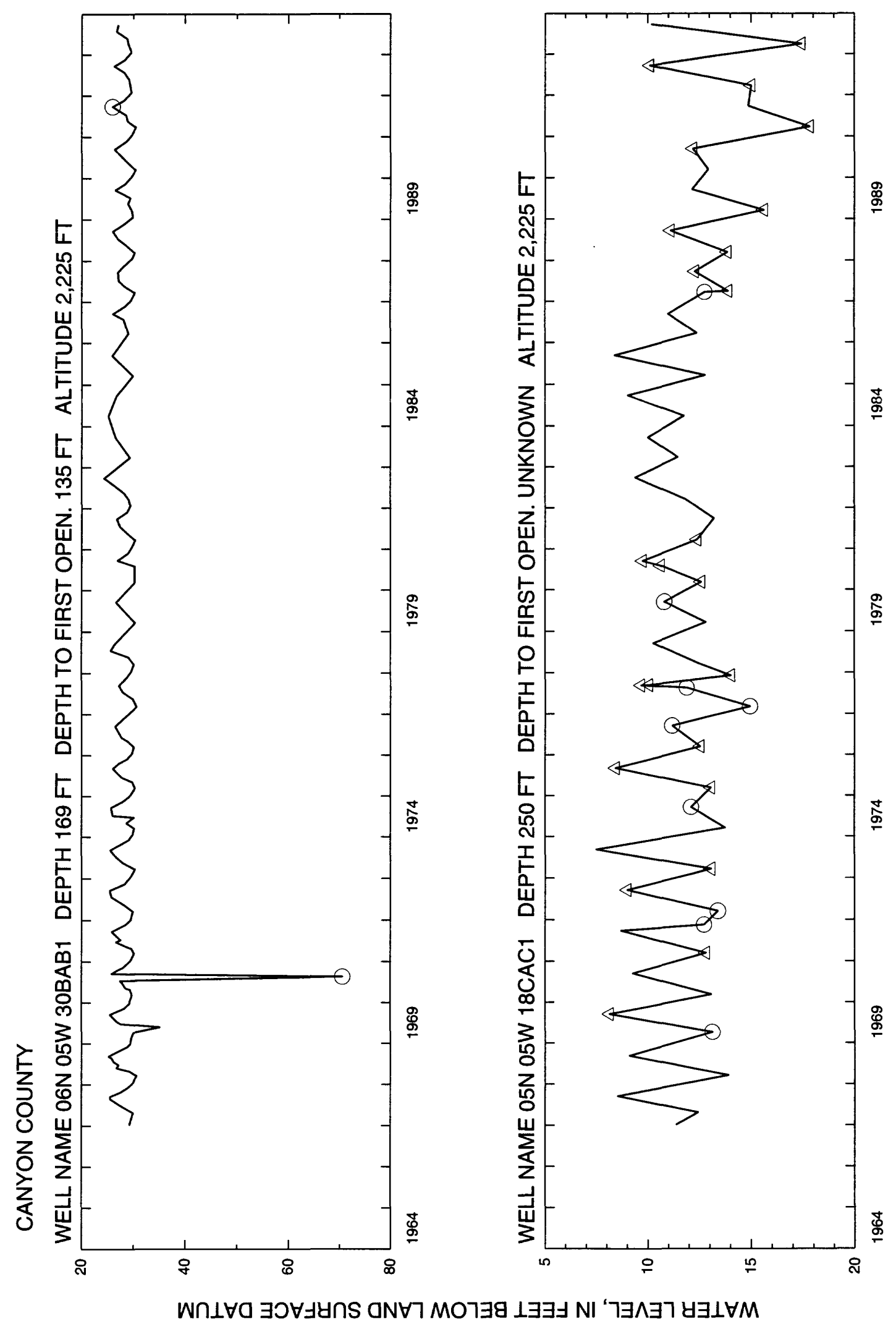




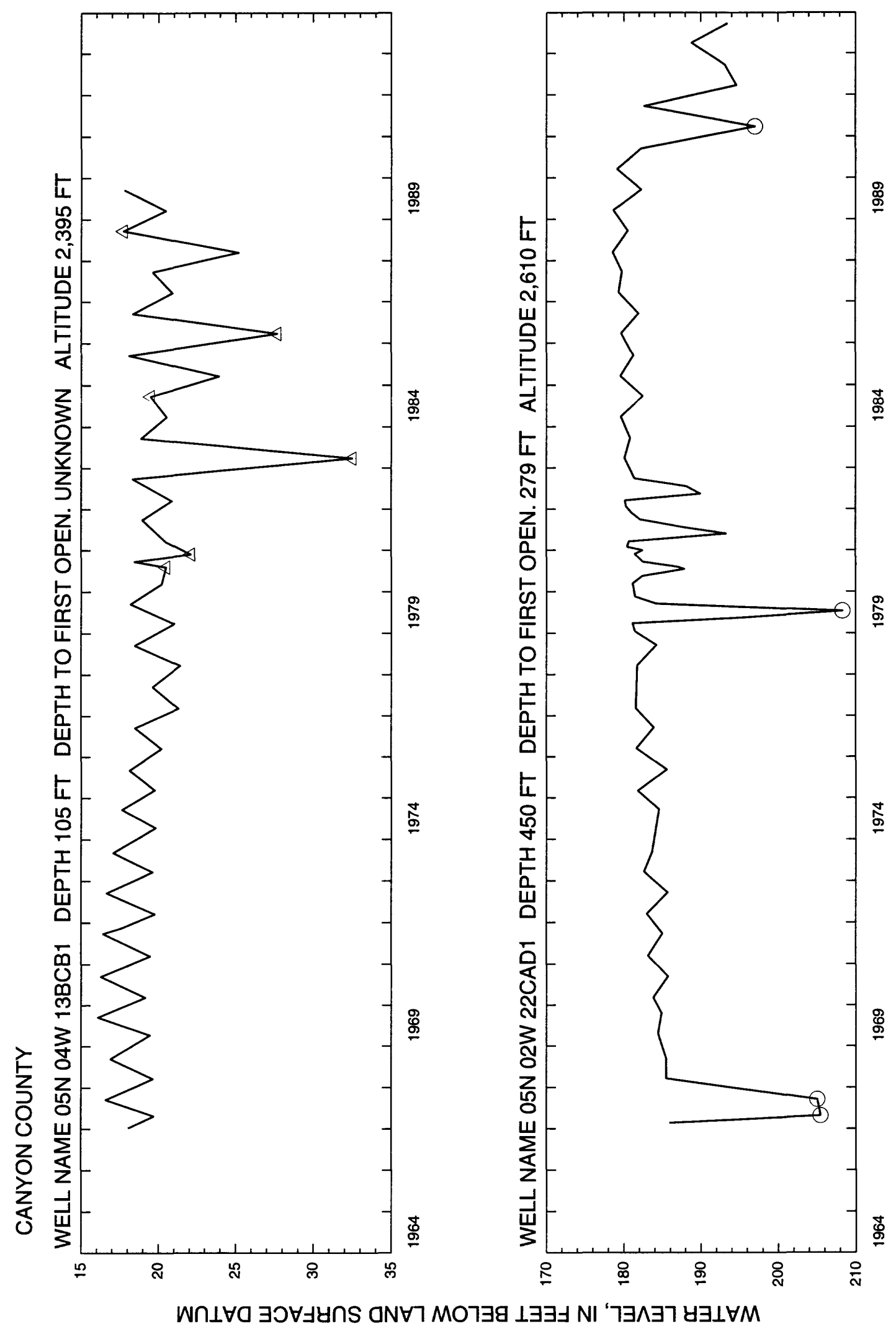




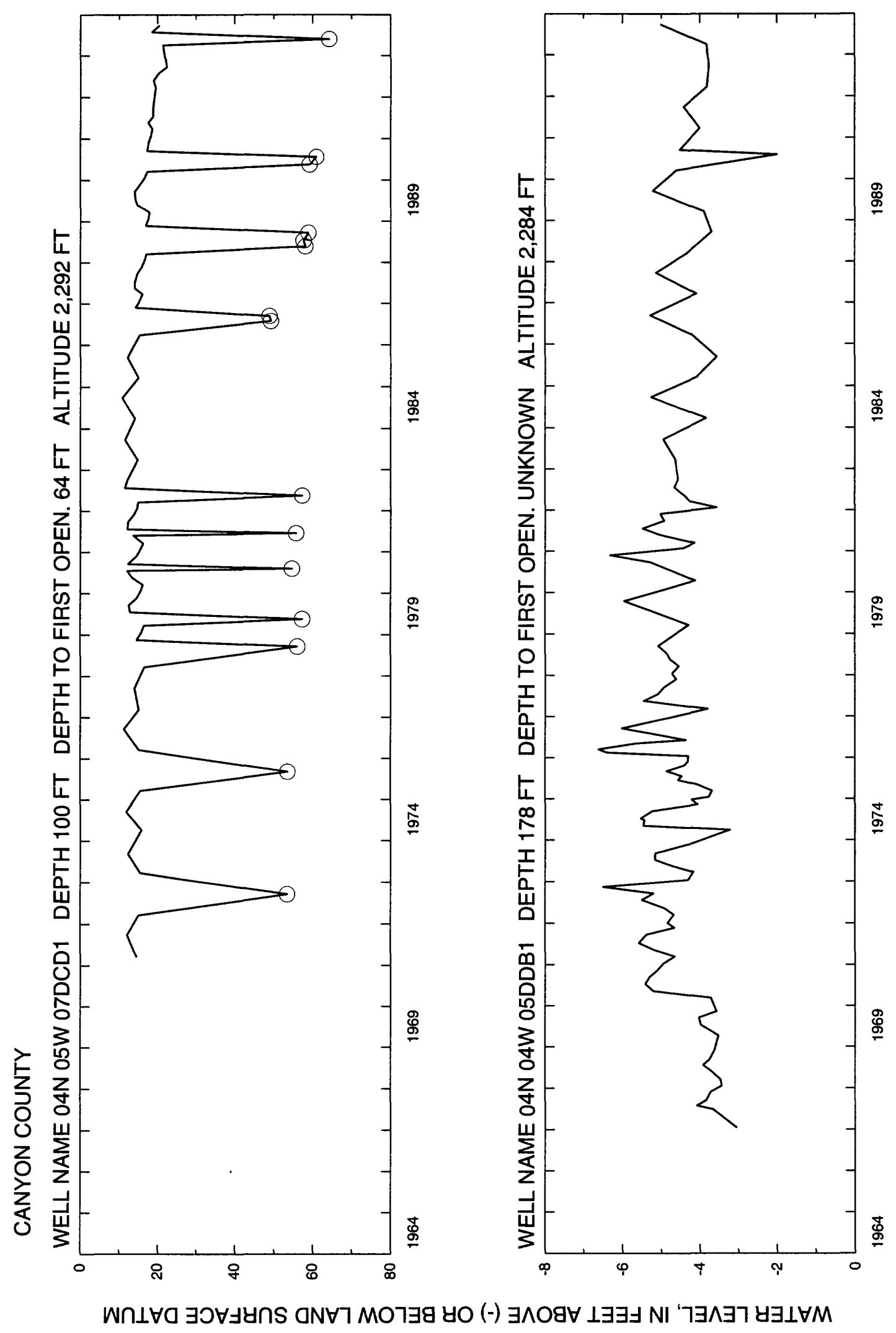




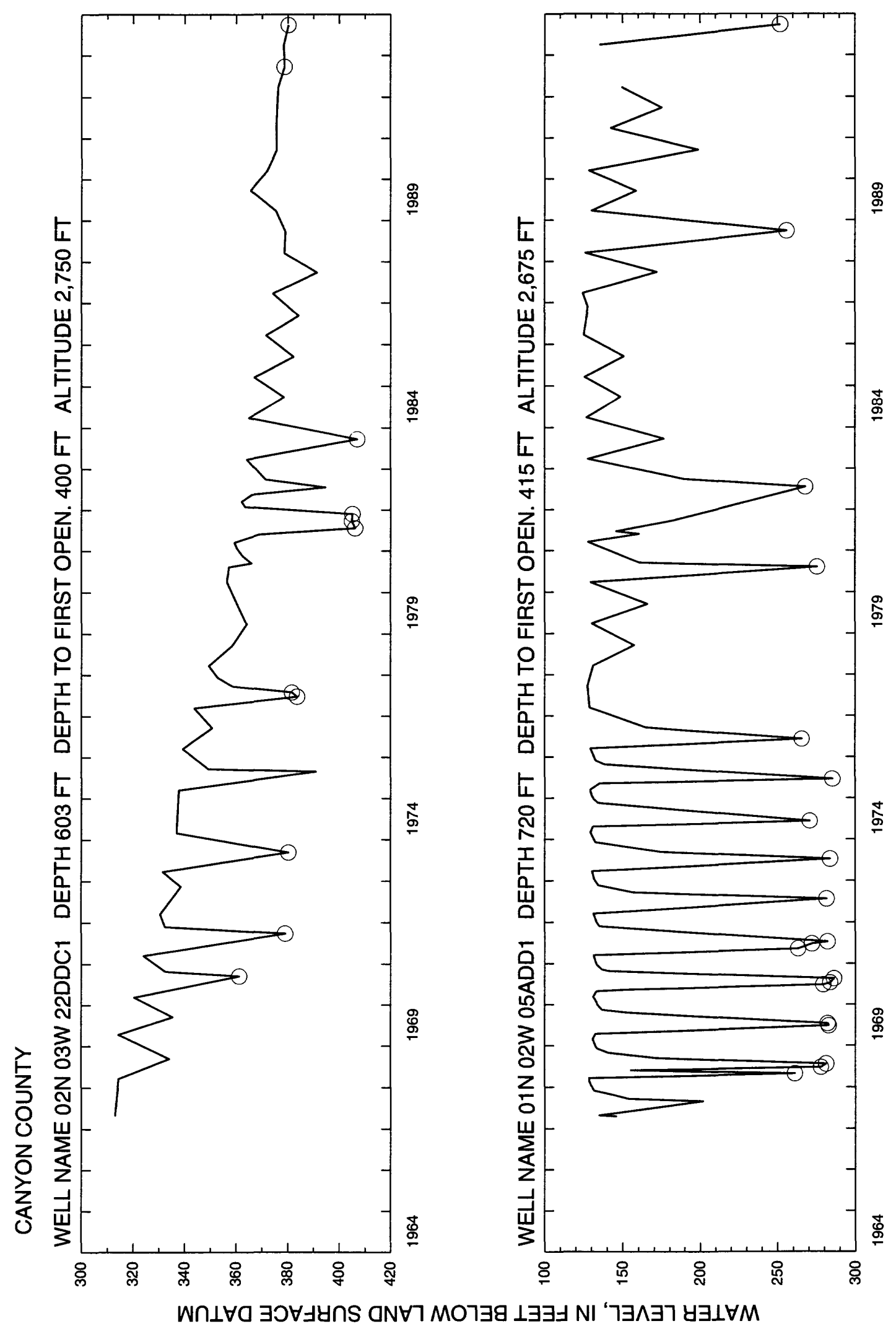




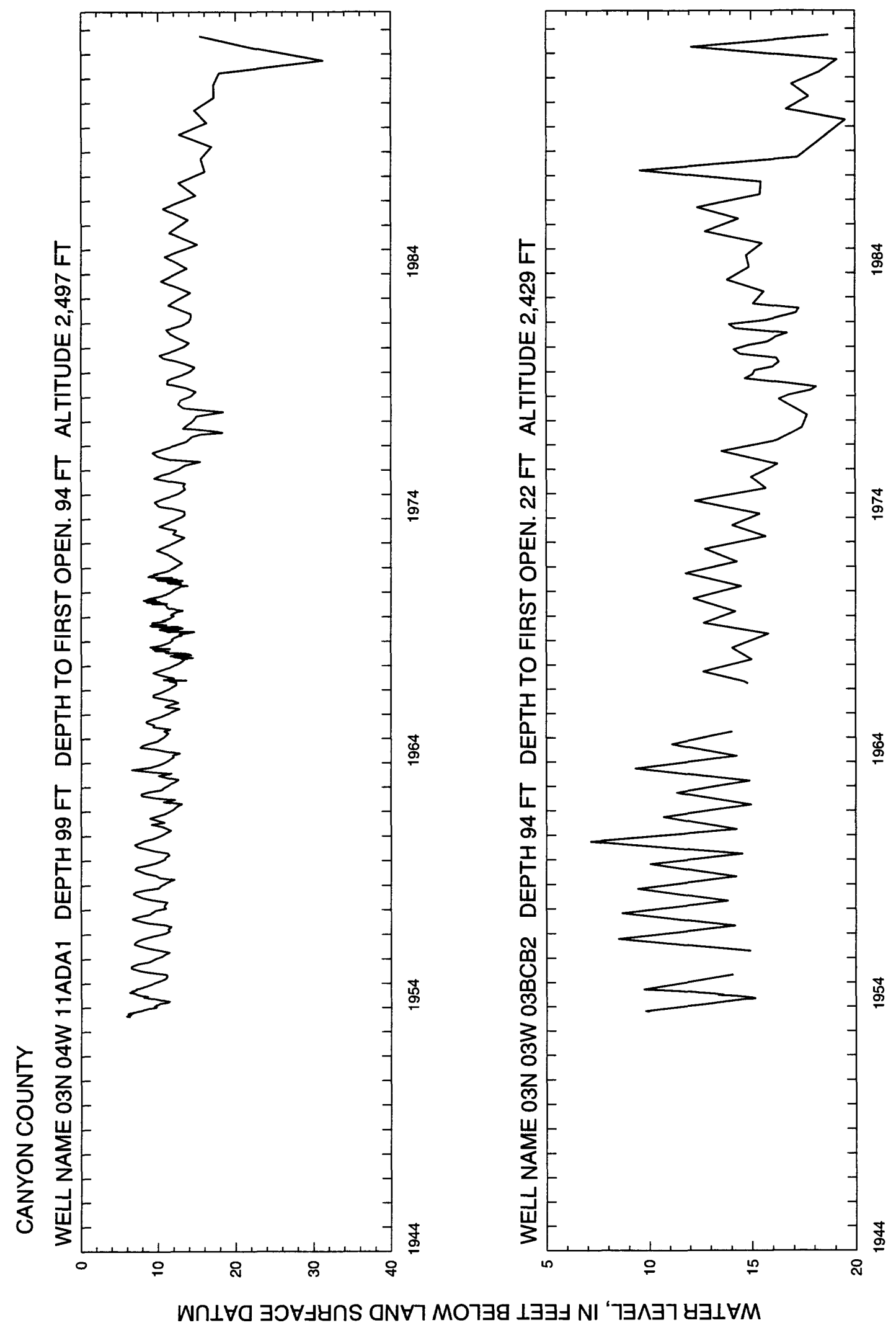




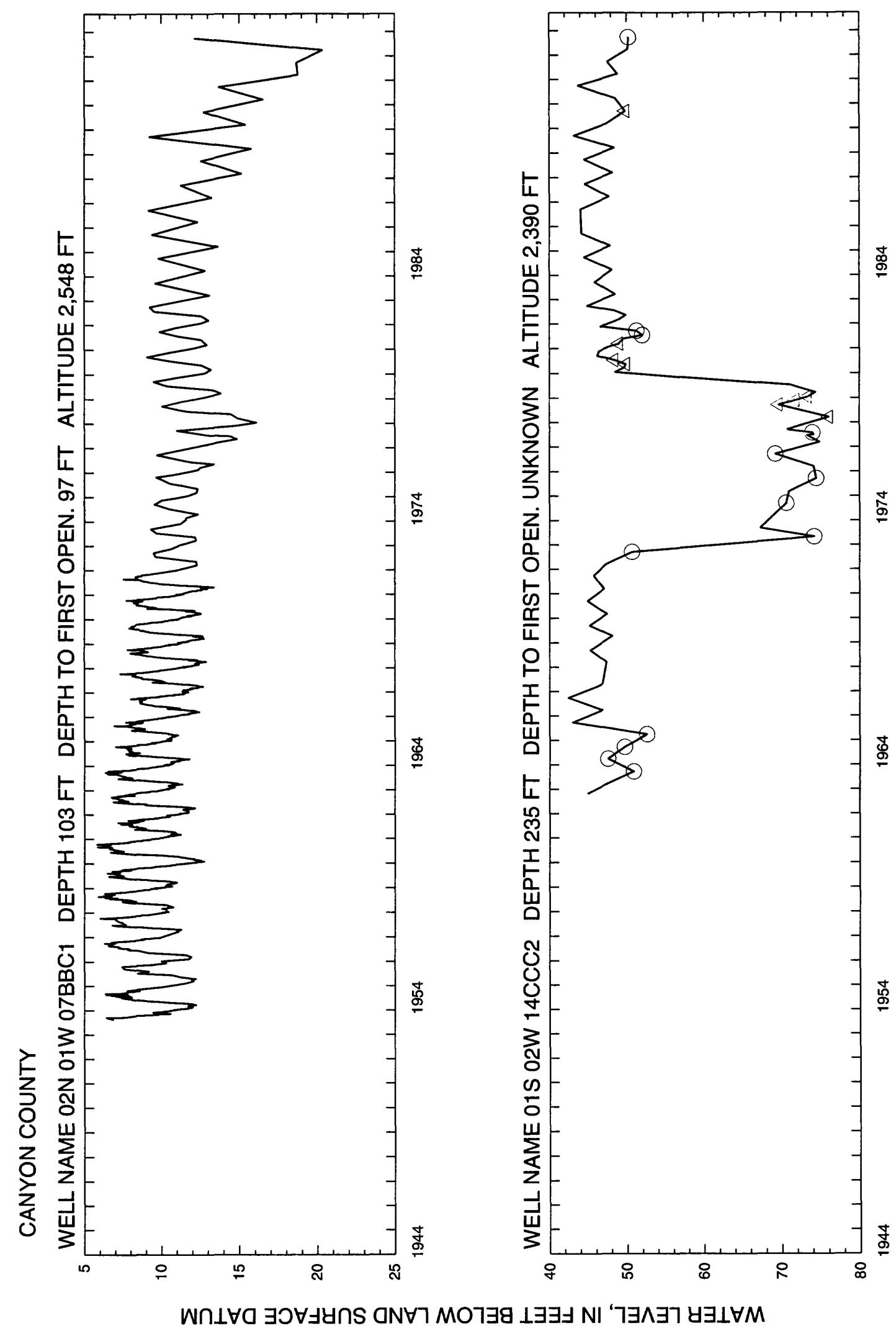

总

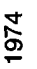

\$

ั으

素

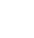

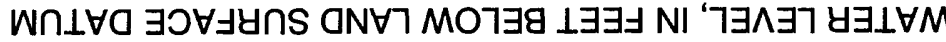




\section{Caribou}




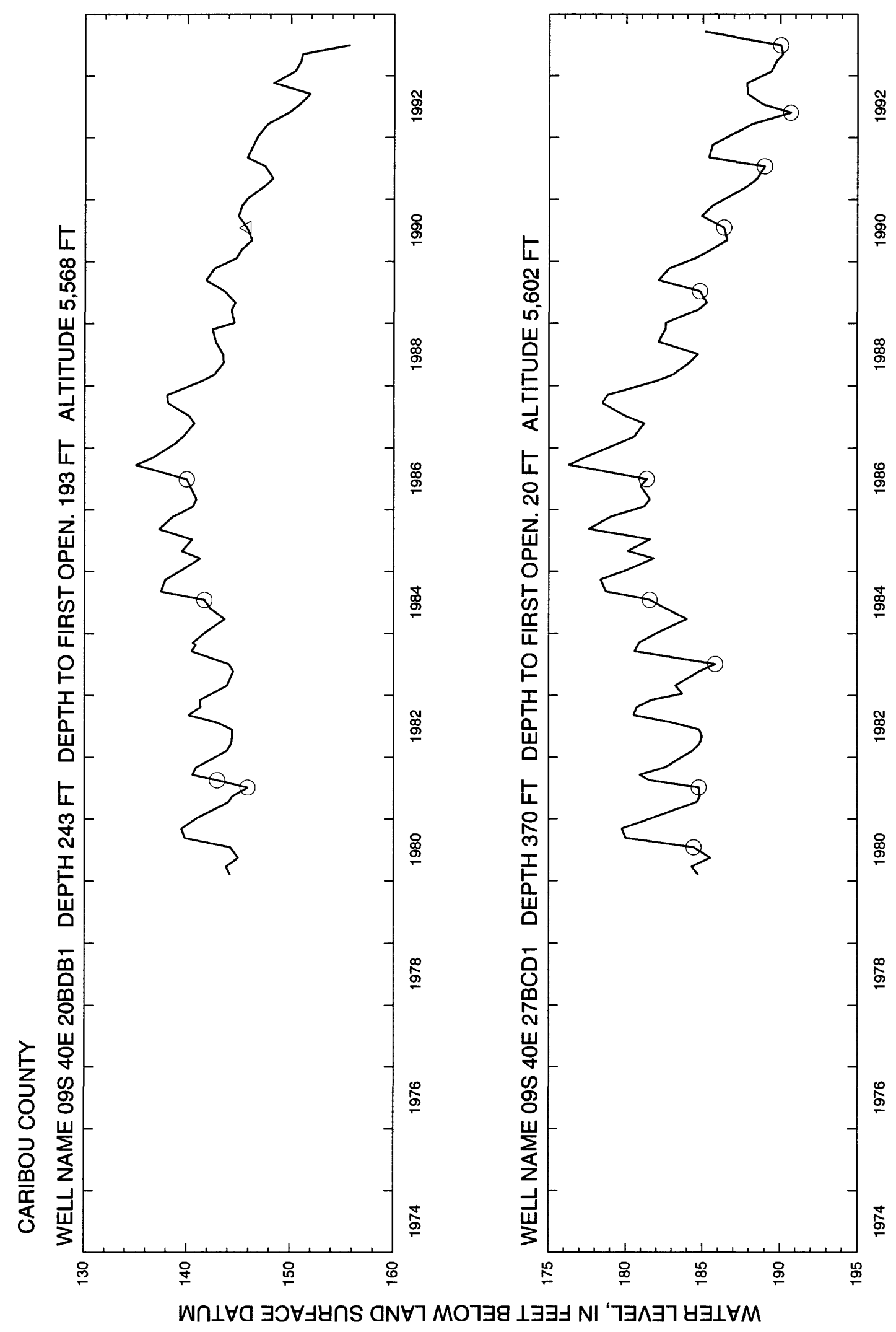




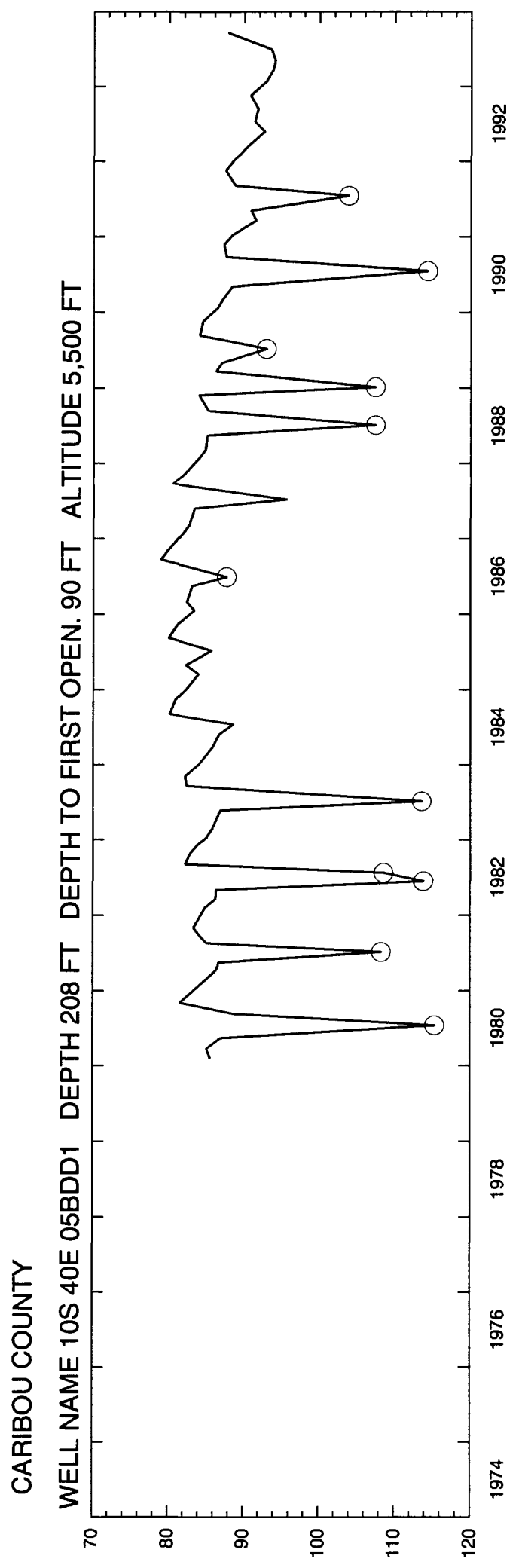

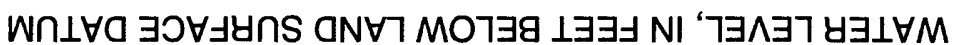




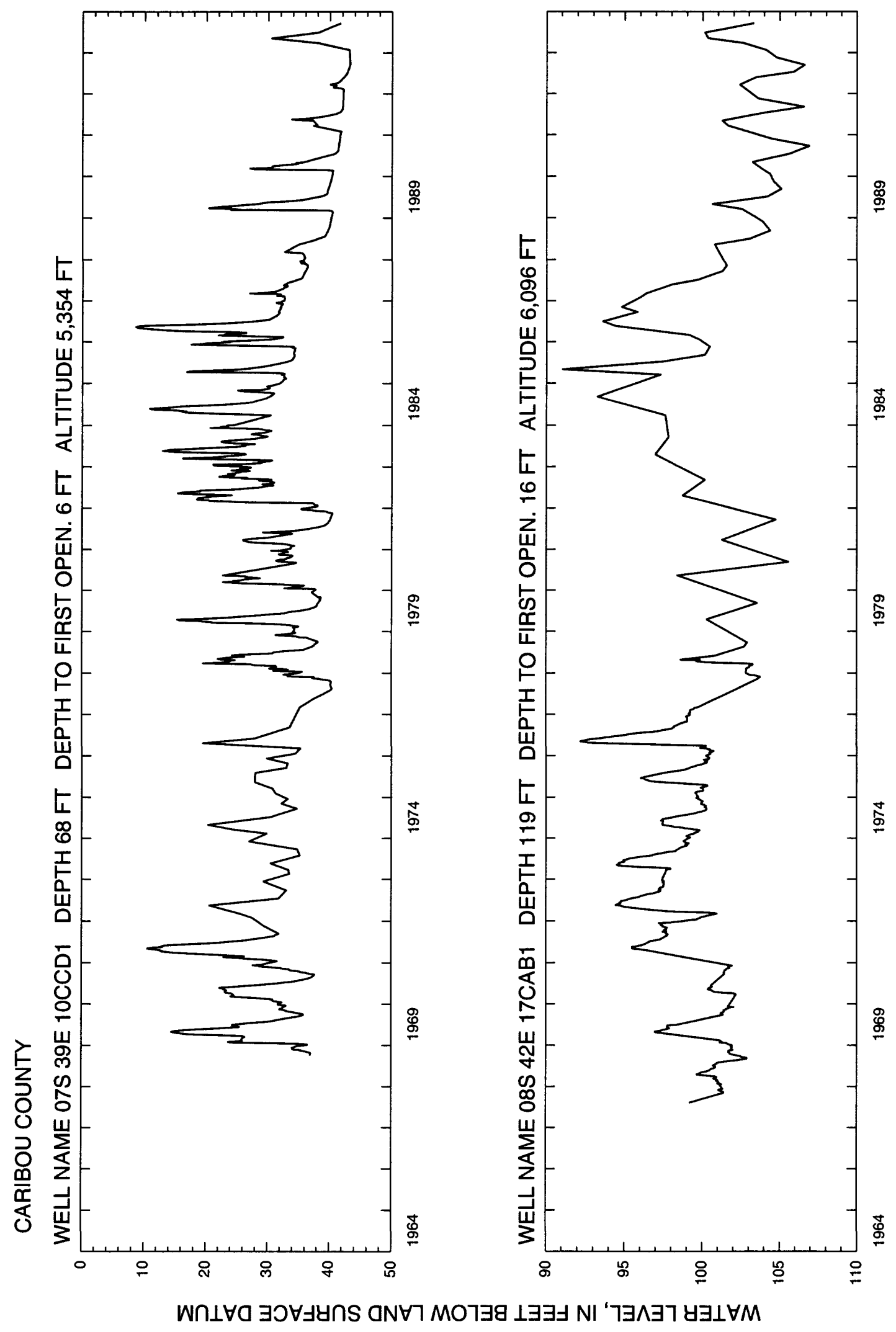




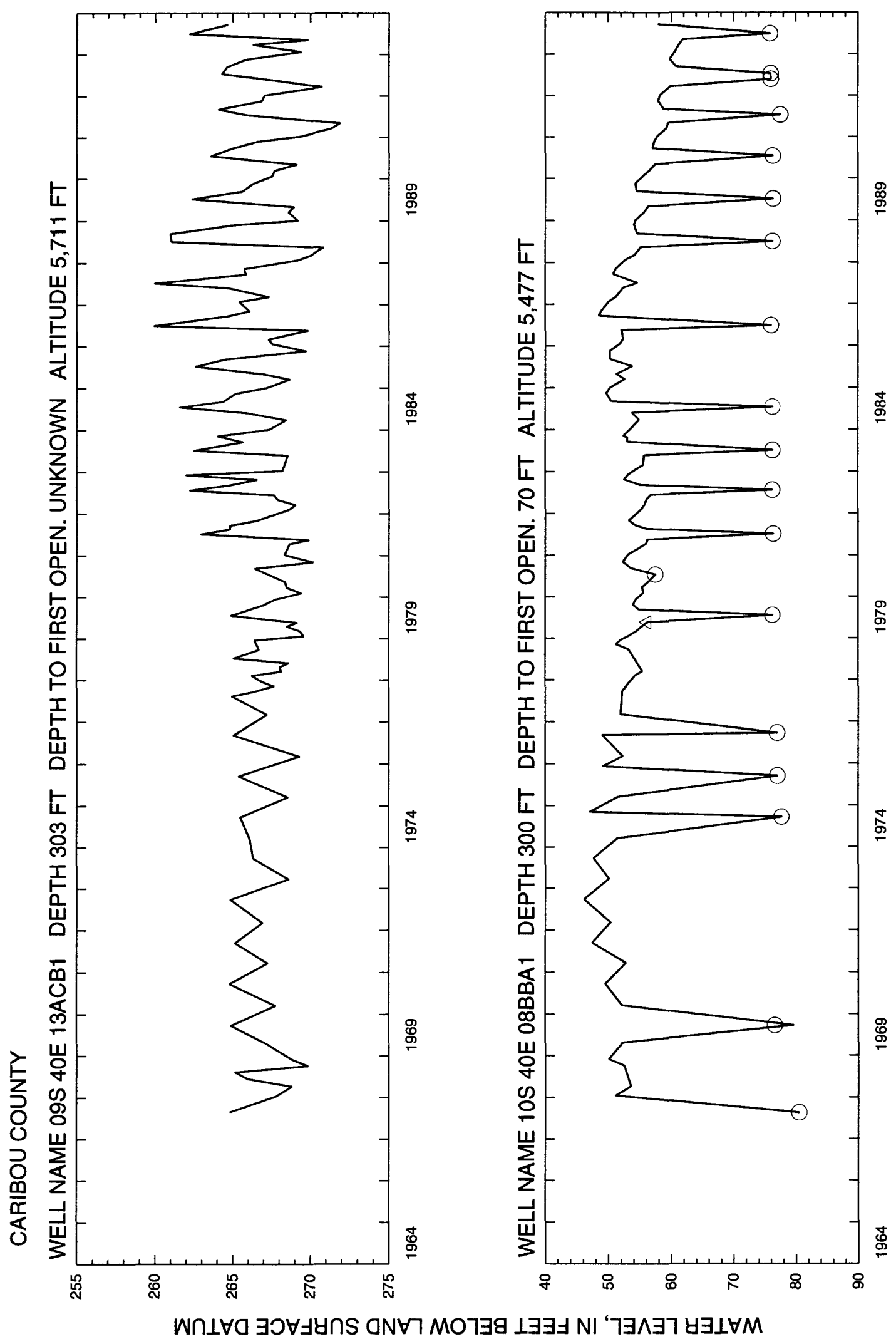

$\stackrel{9}{\circ}$

$\stackrel{\$}{\circ}$

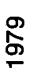

京

ळ

ષ 


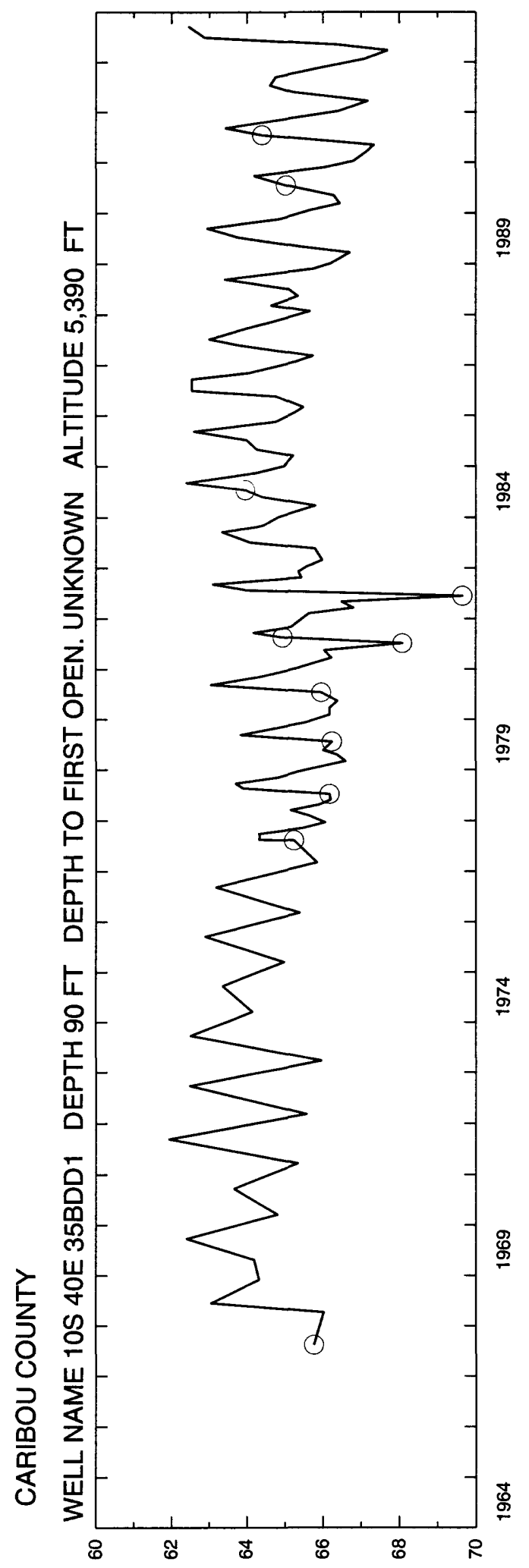

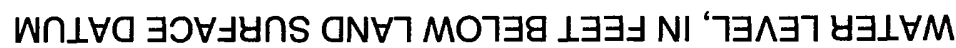


Cassia 


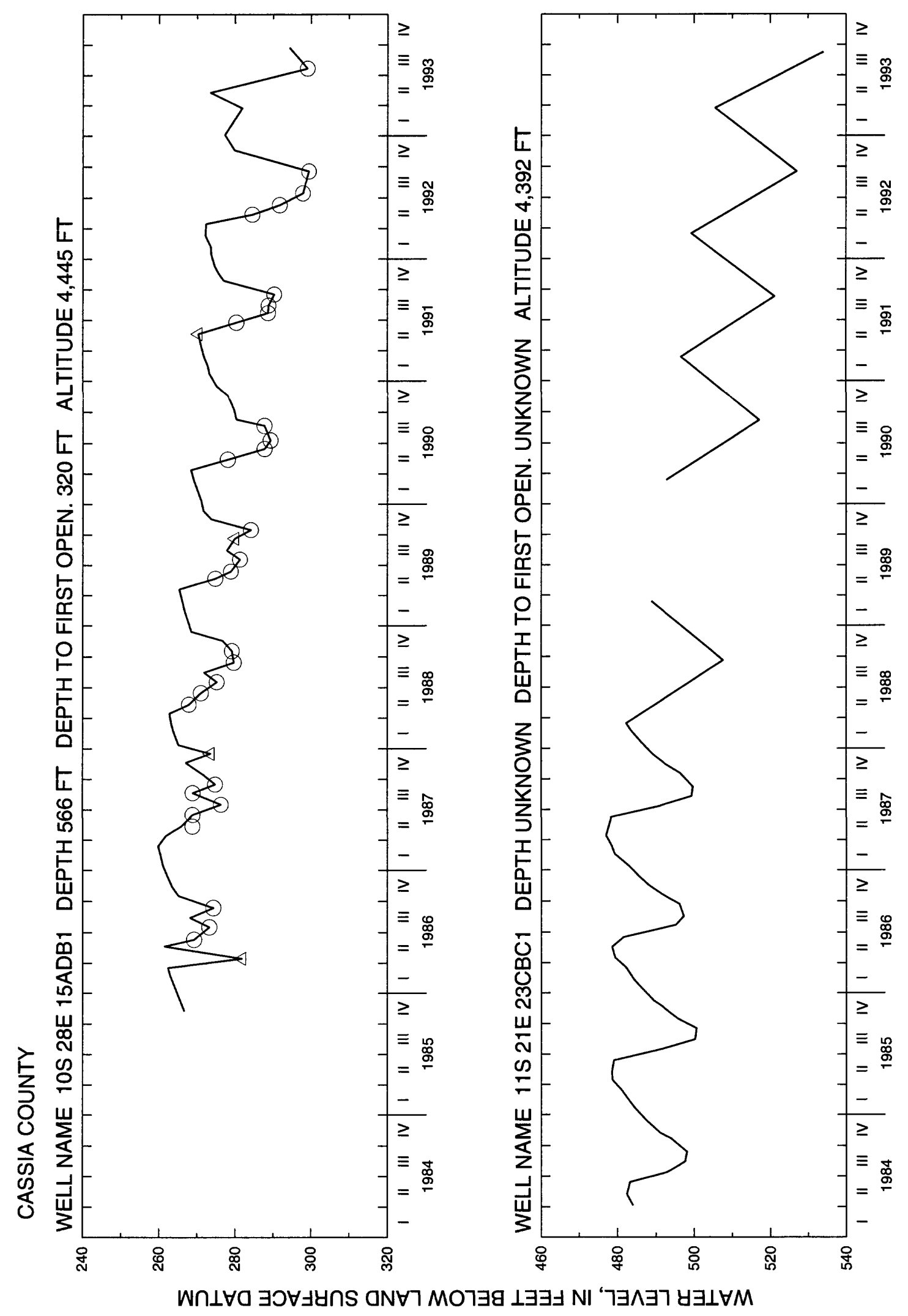




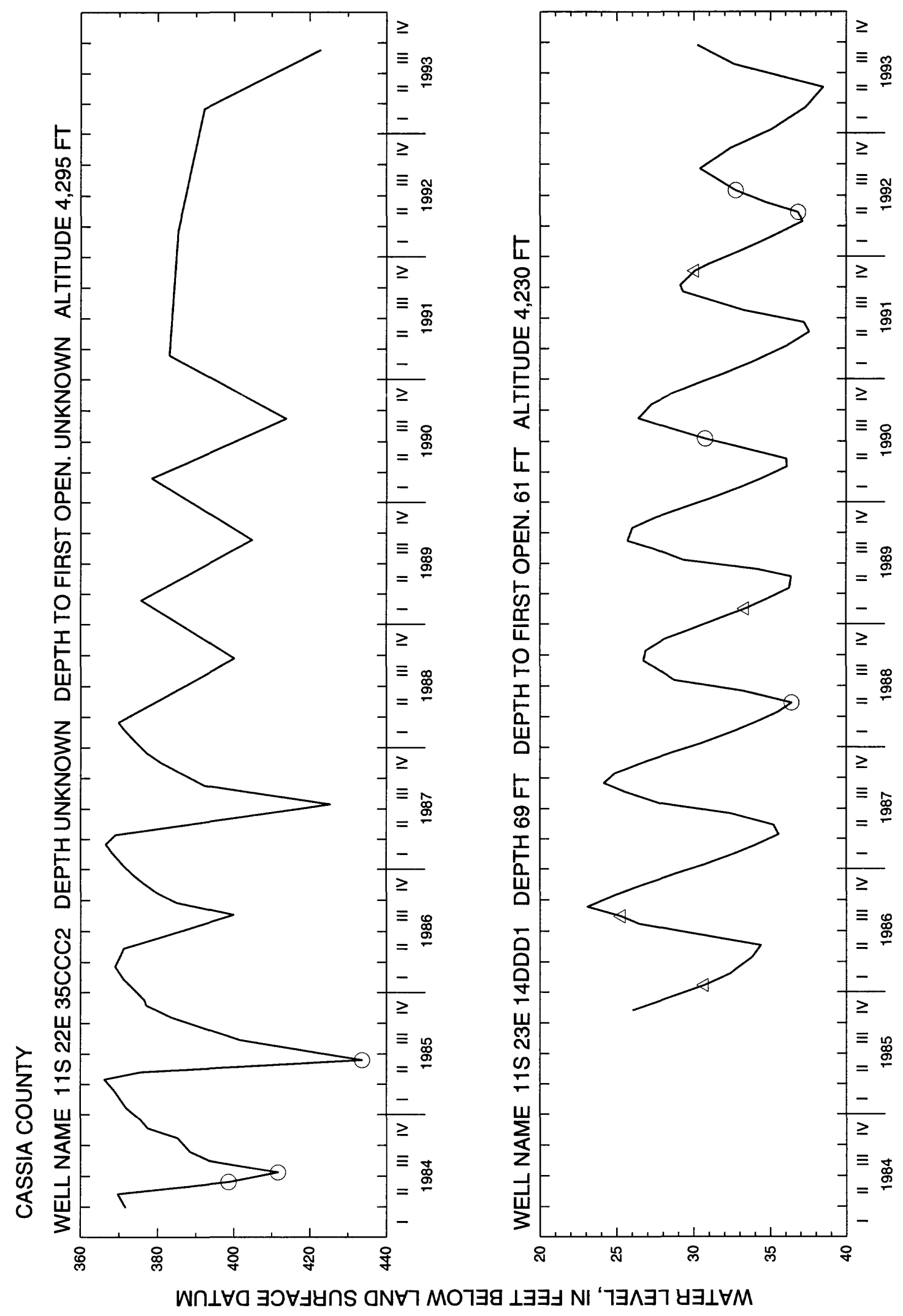




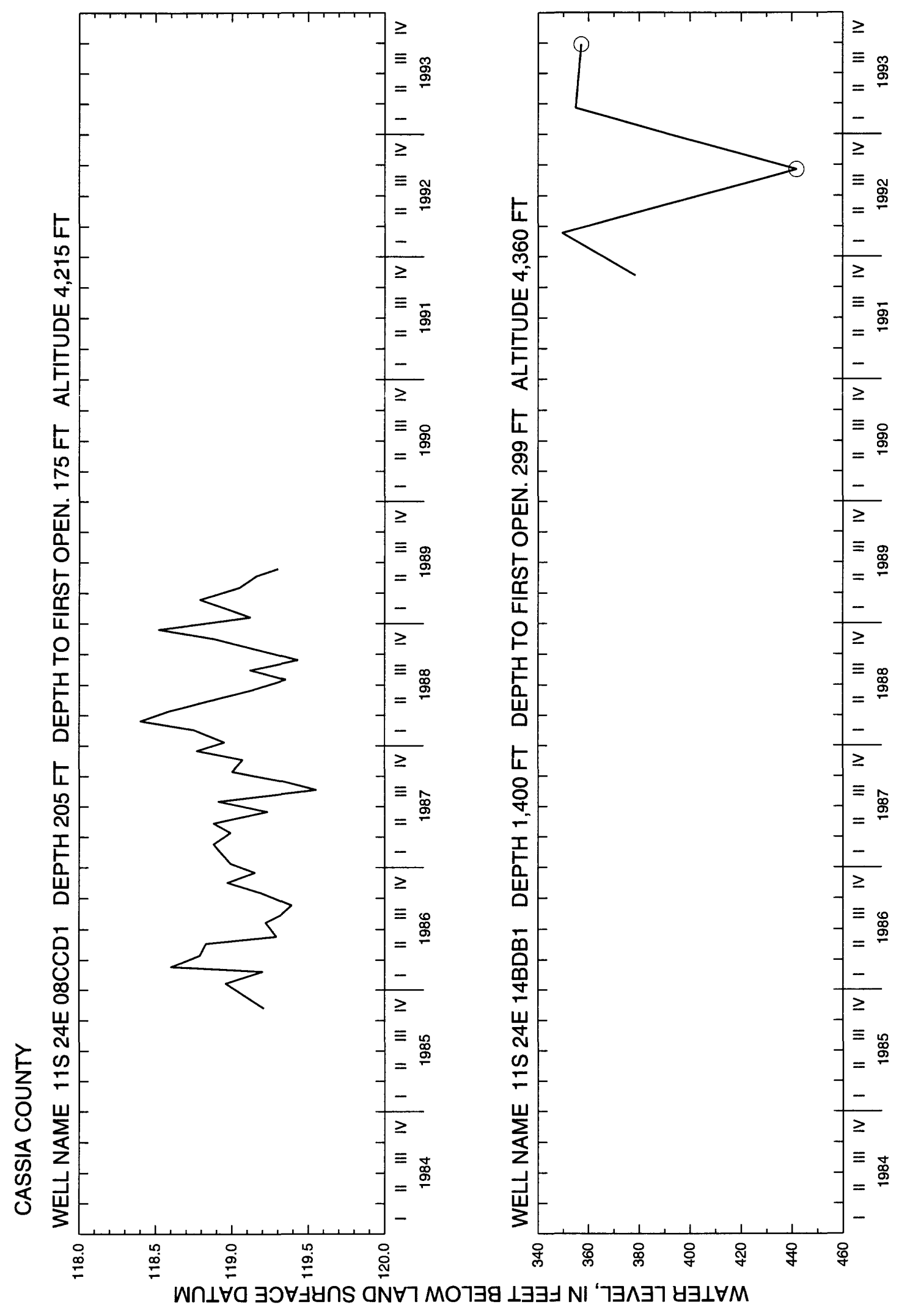




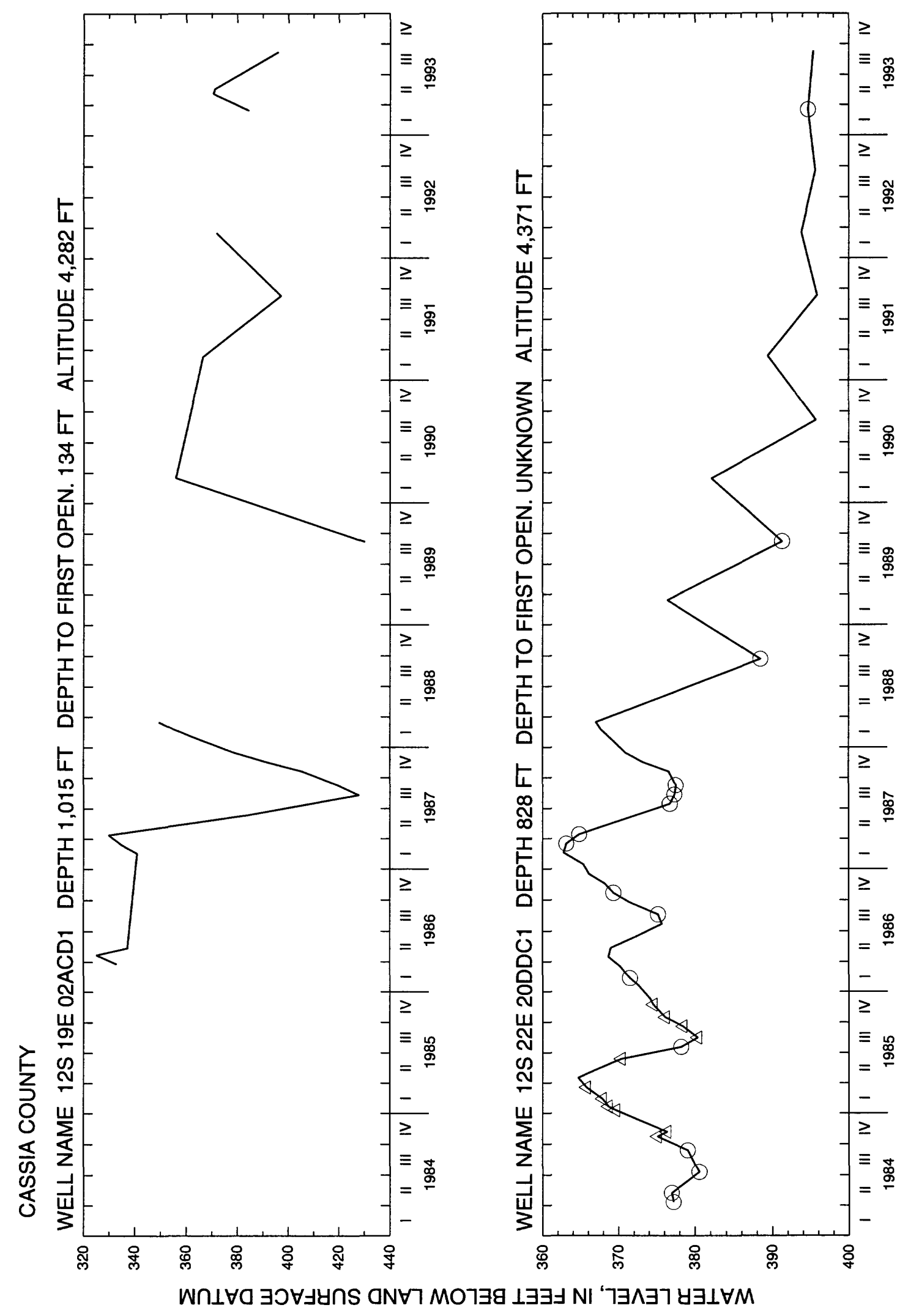




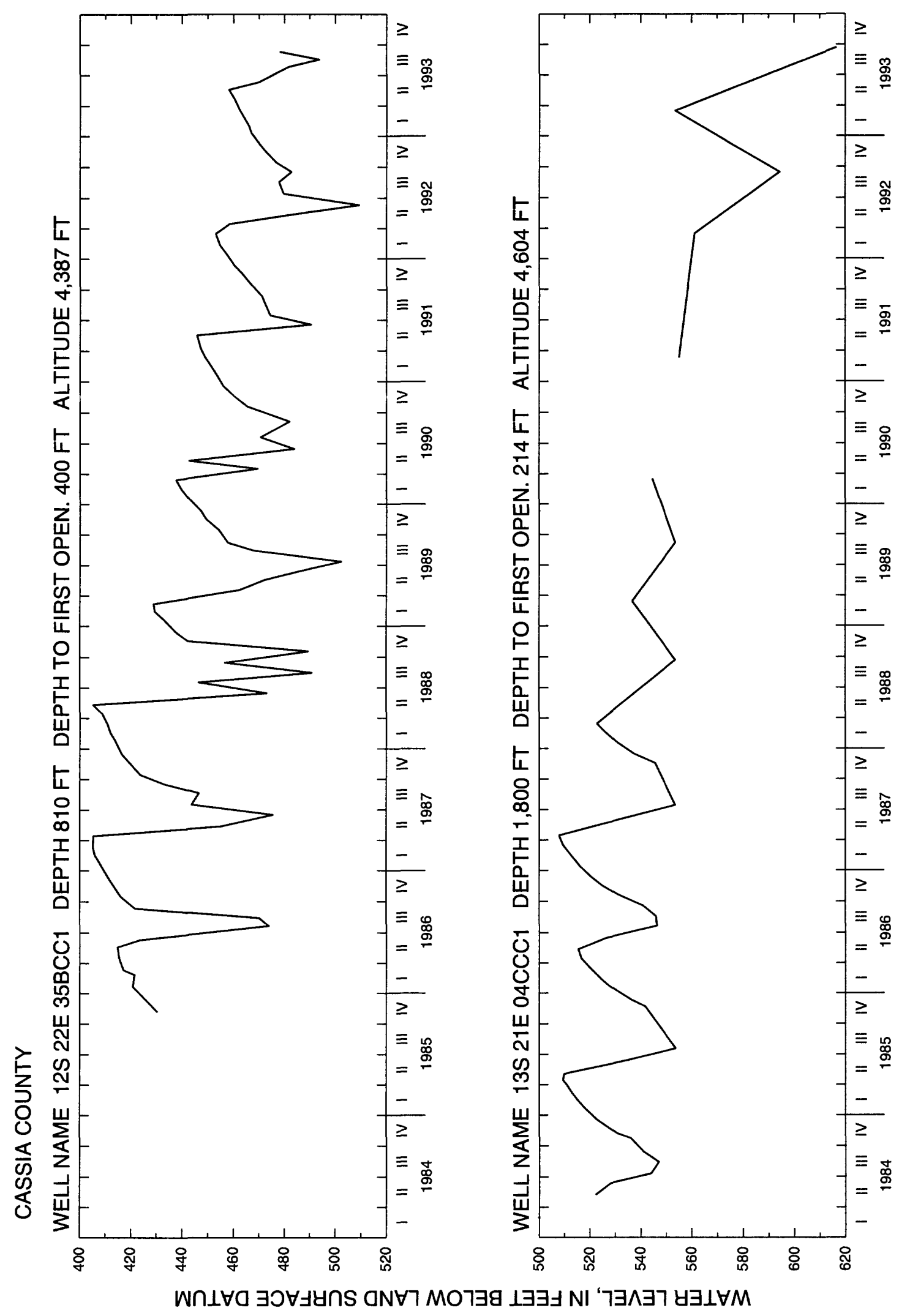




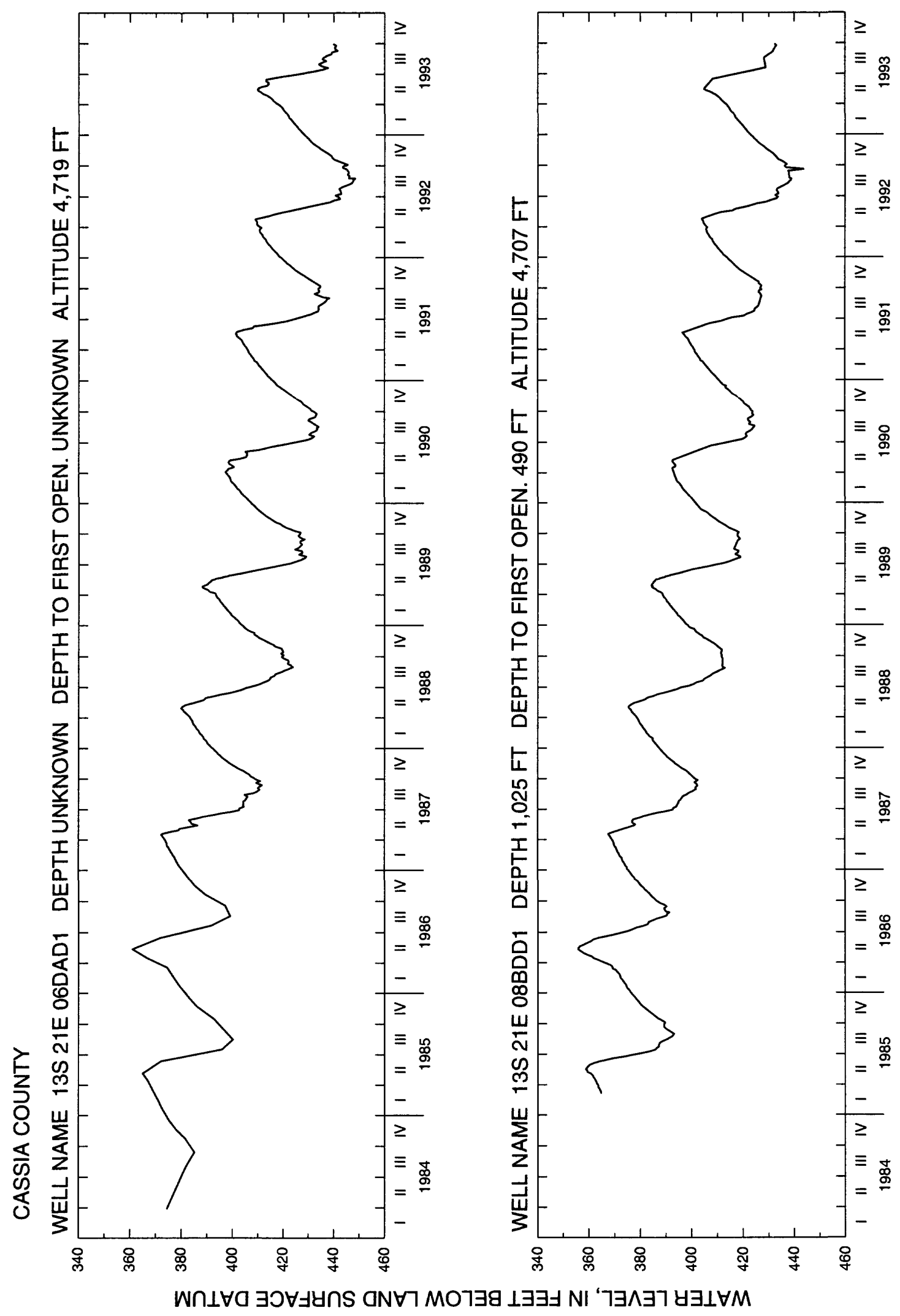




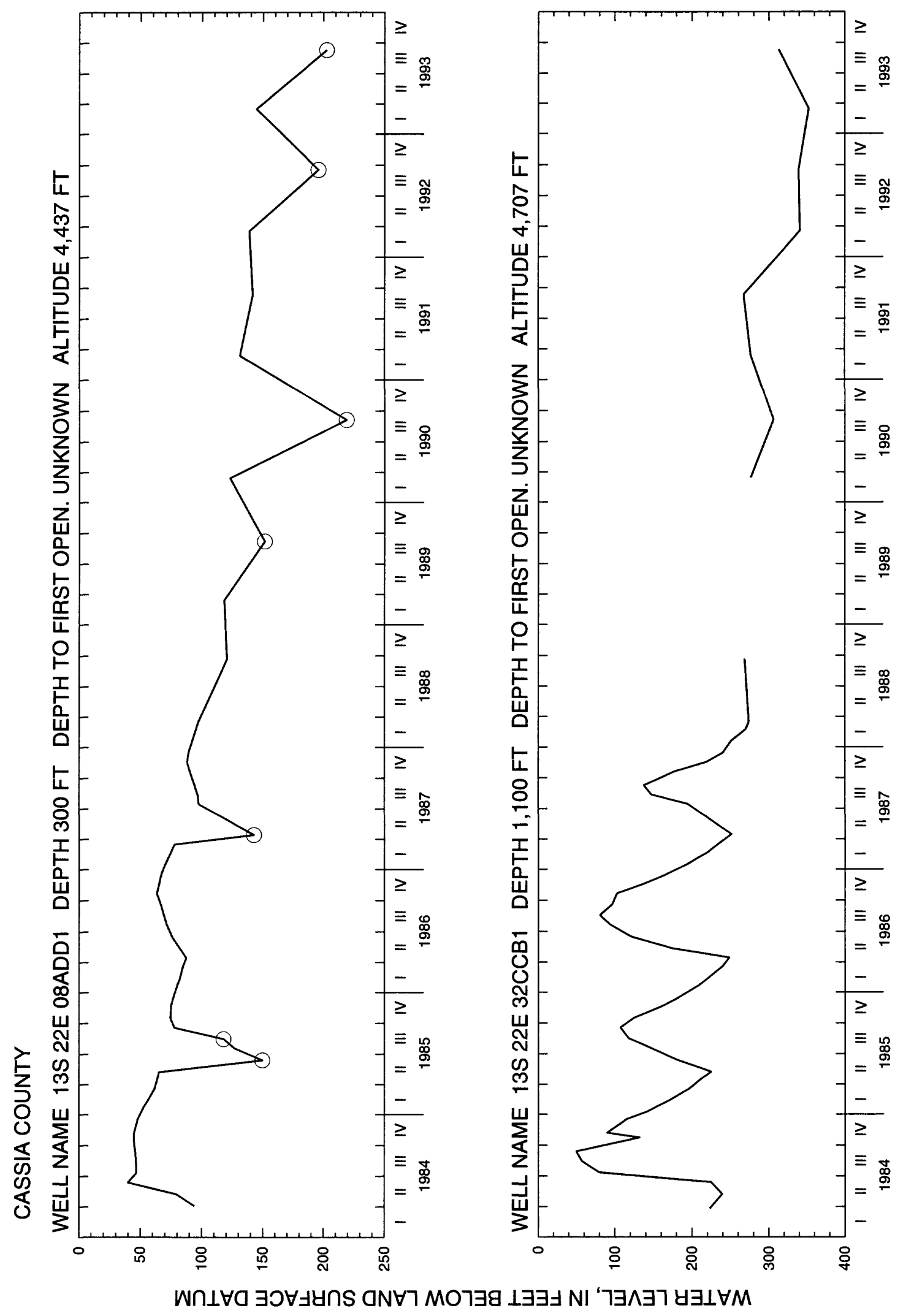




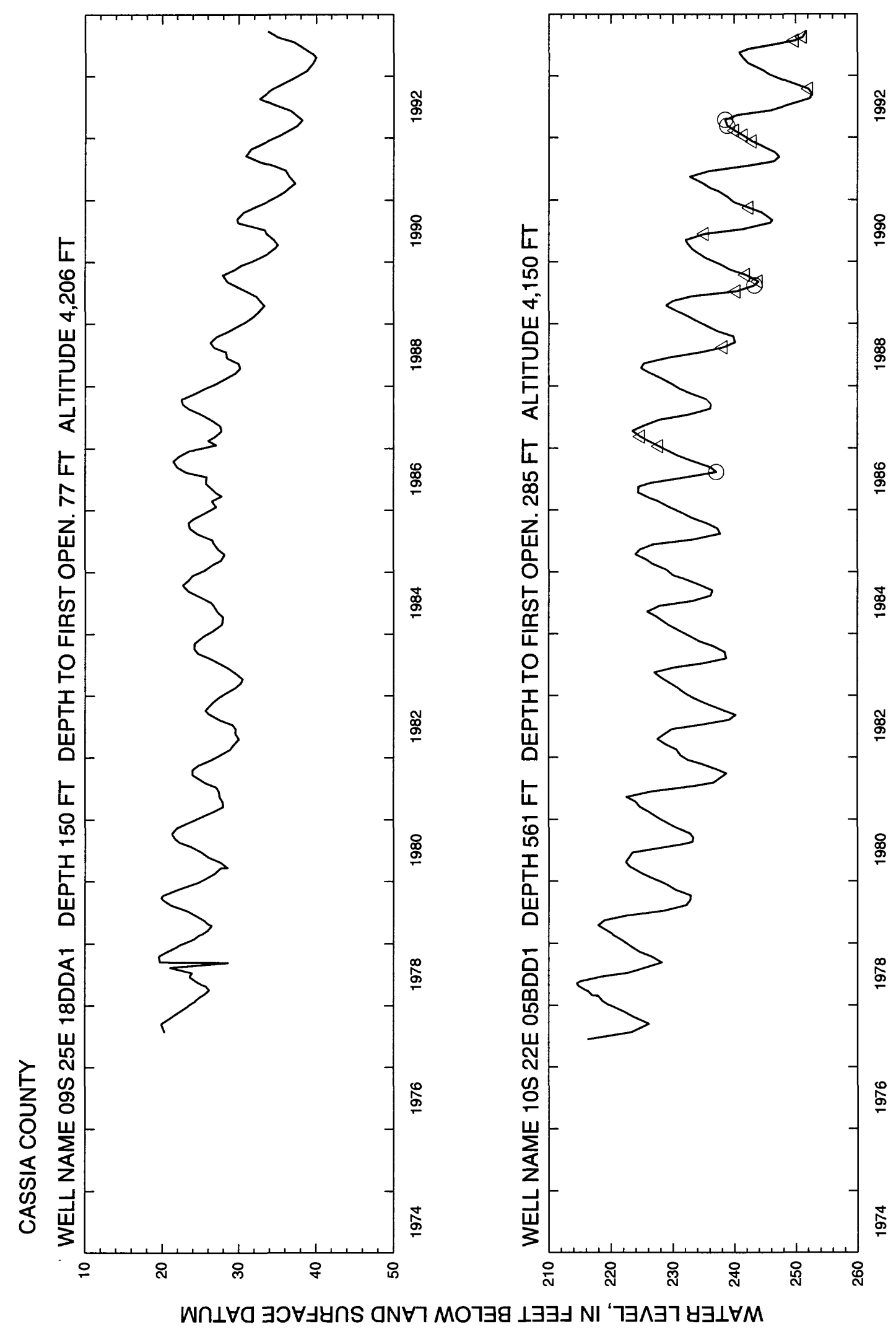




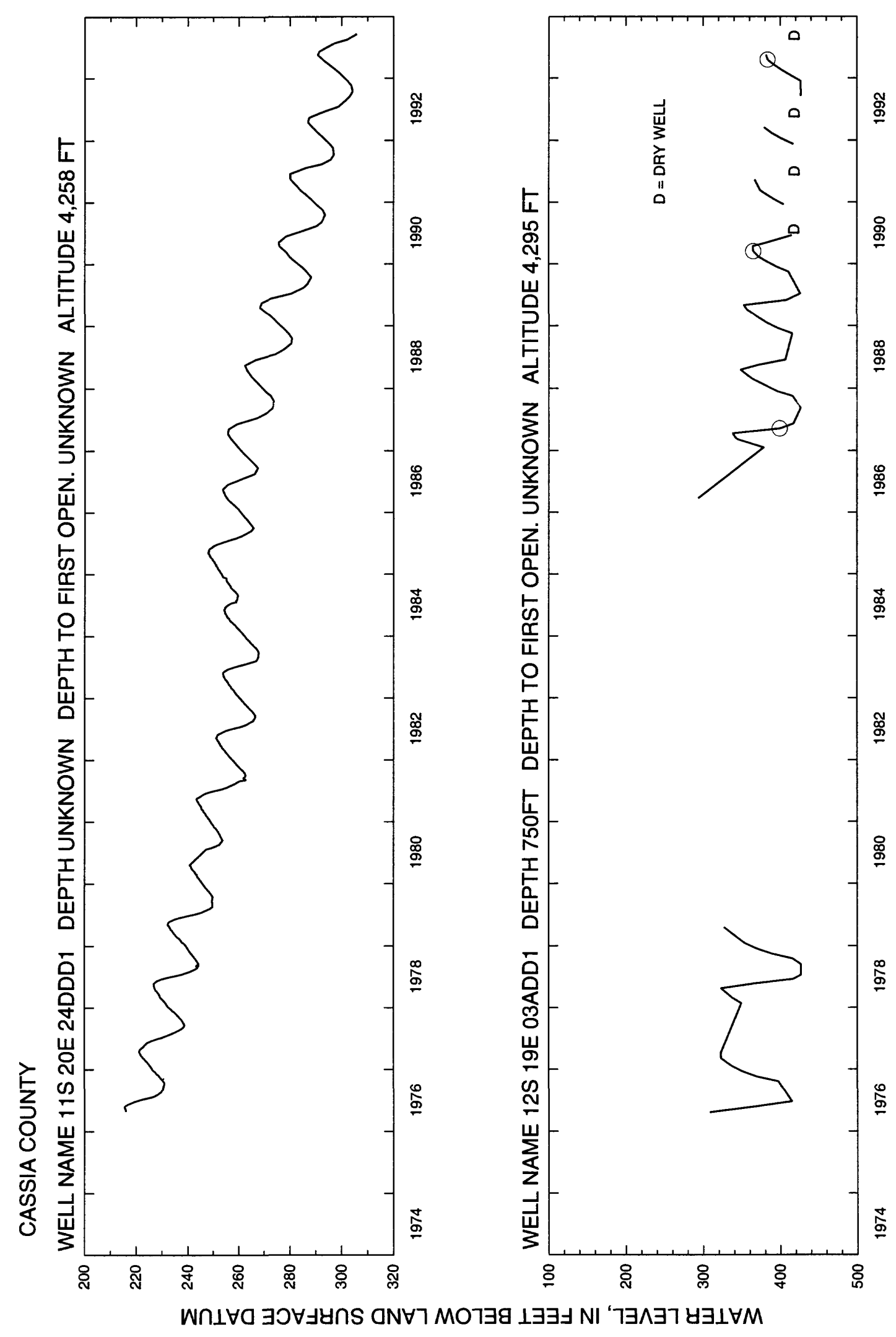




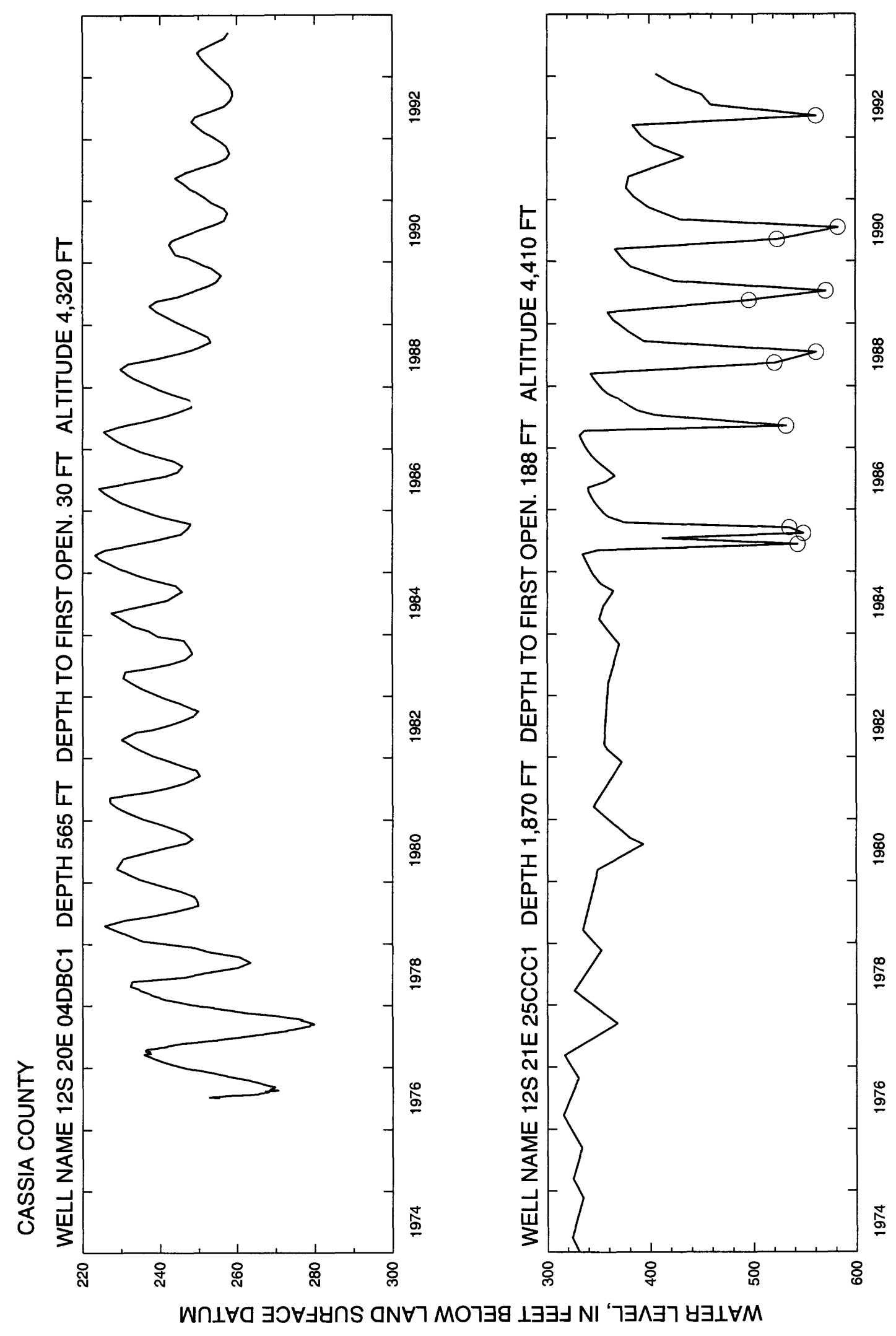




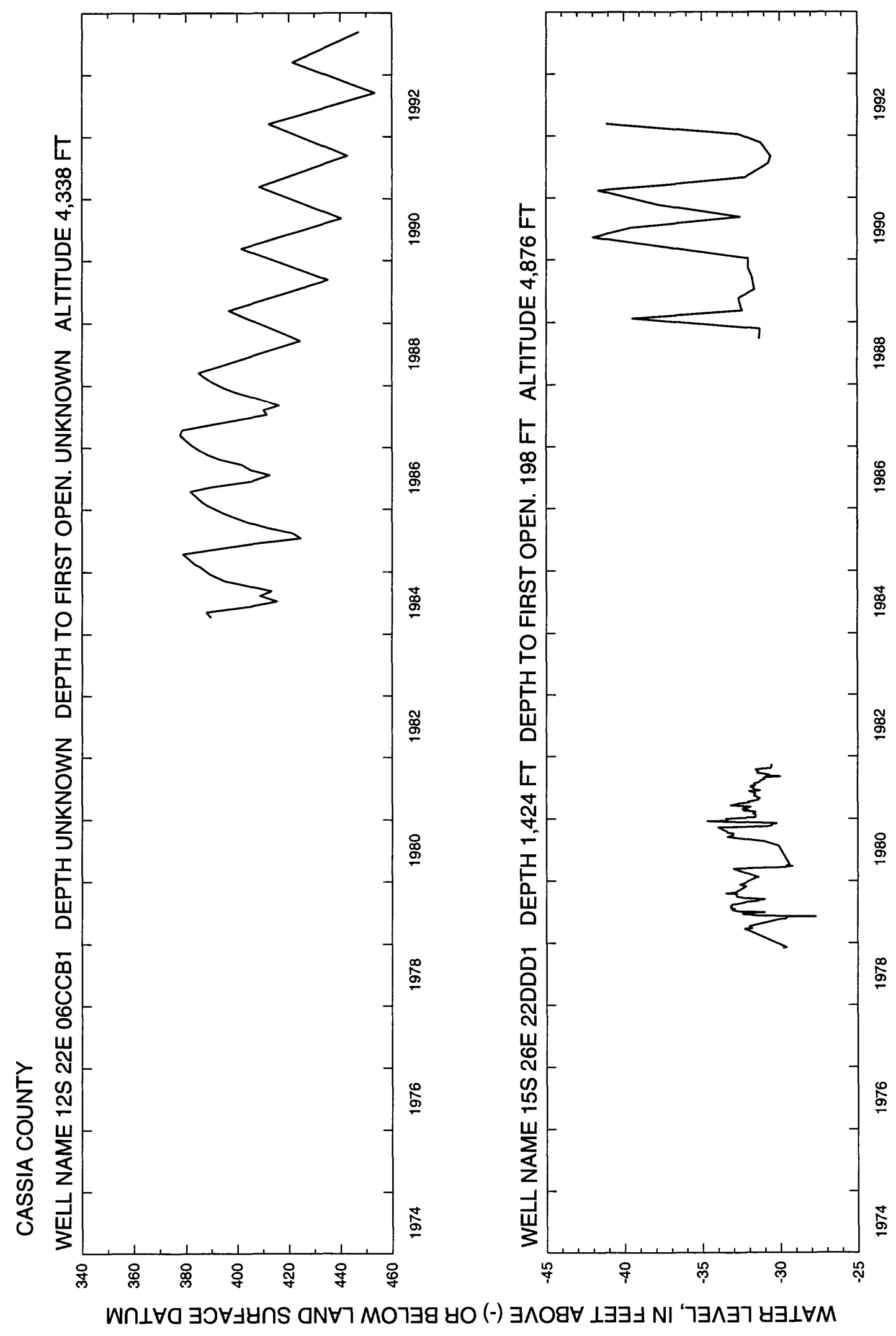




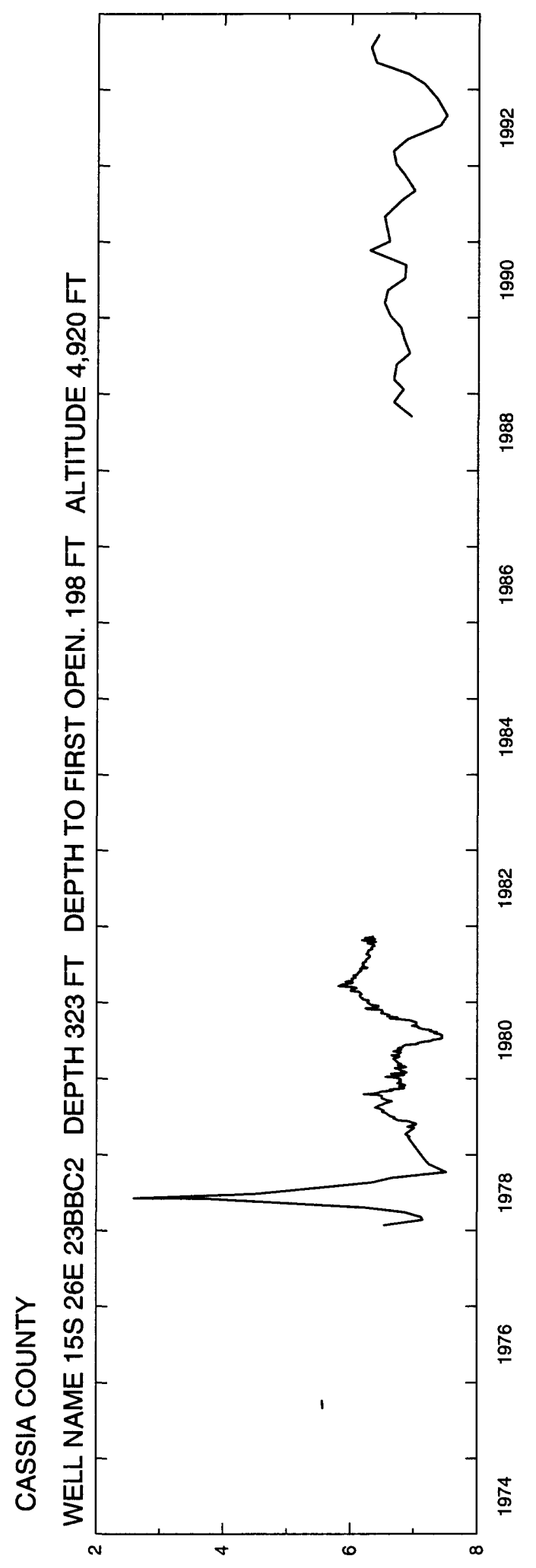

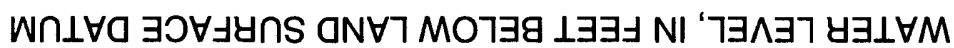




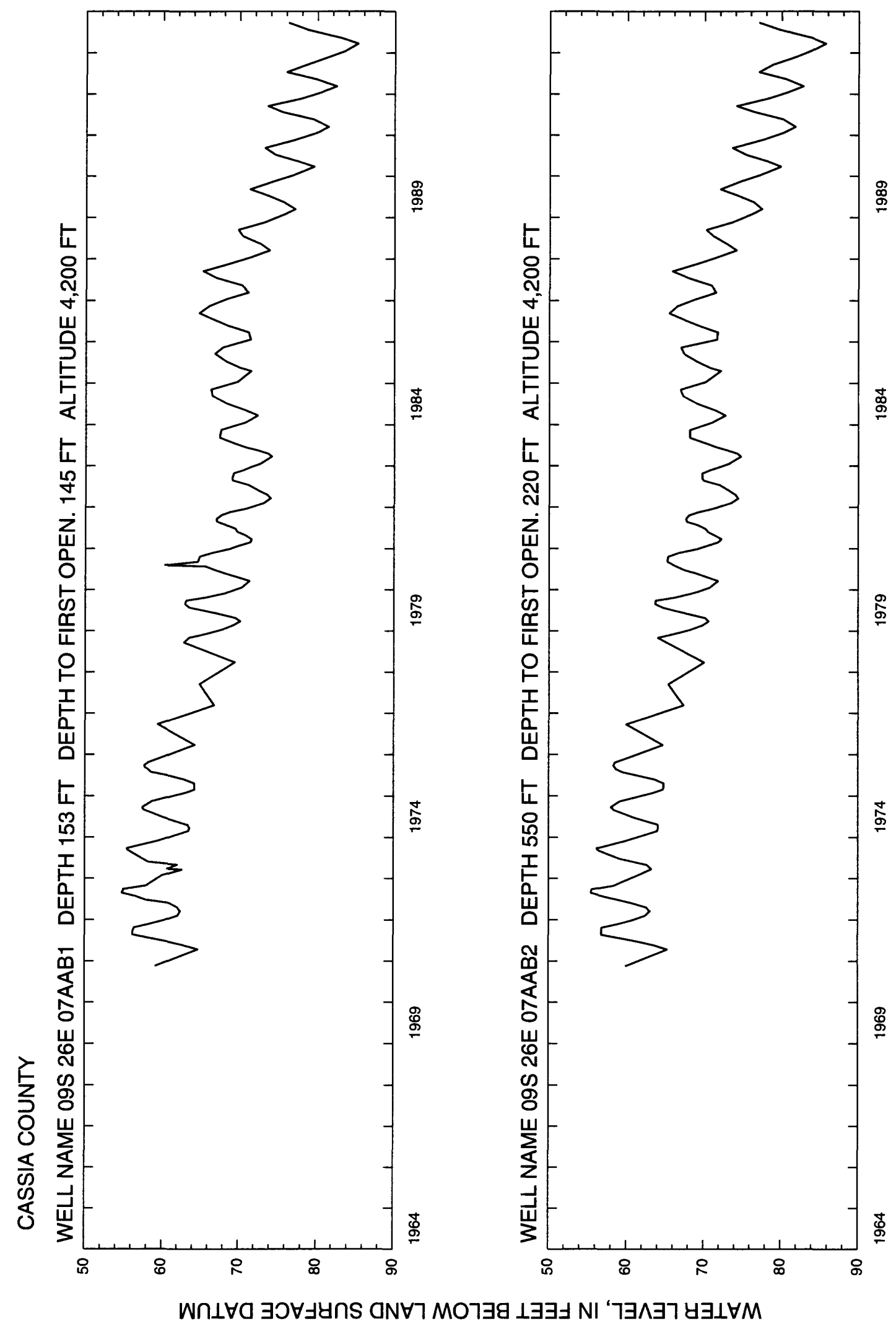




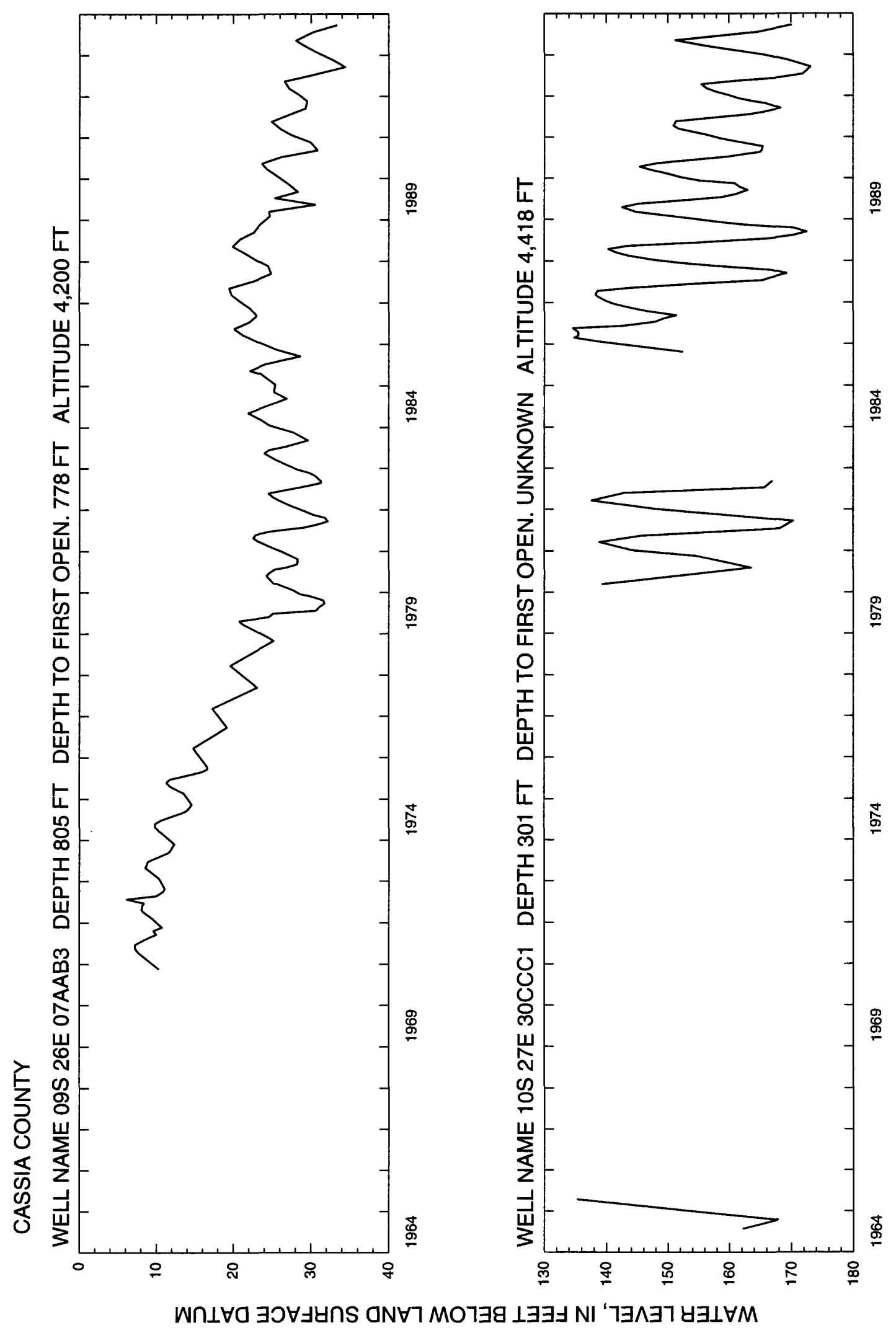




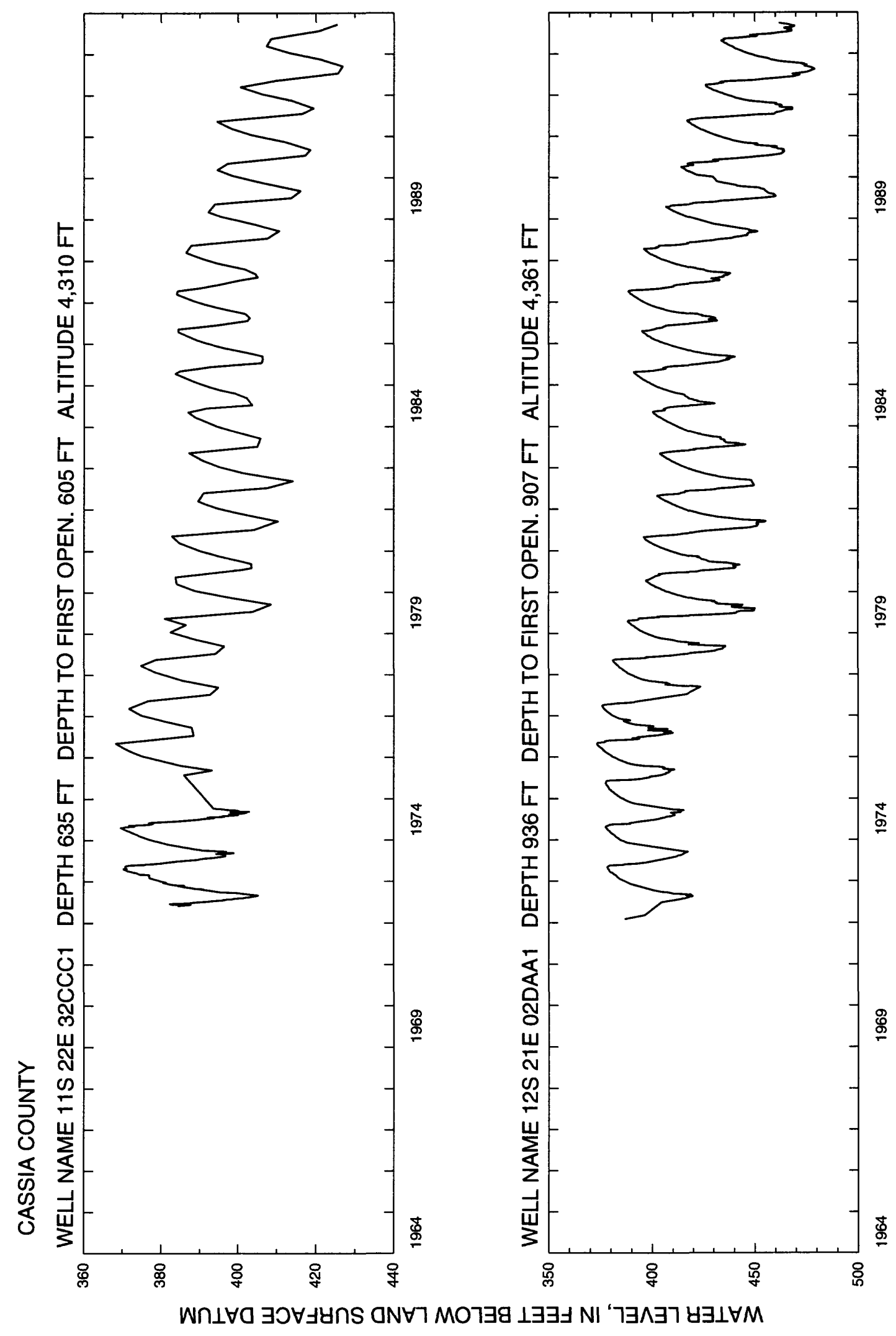




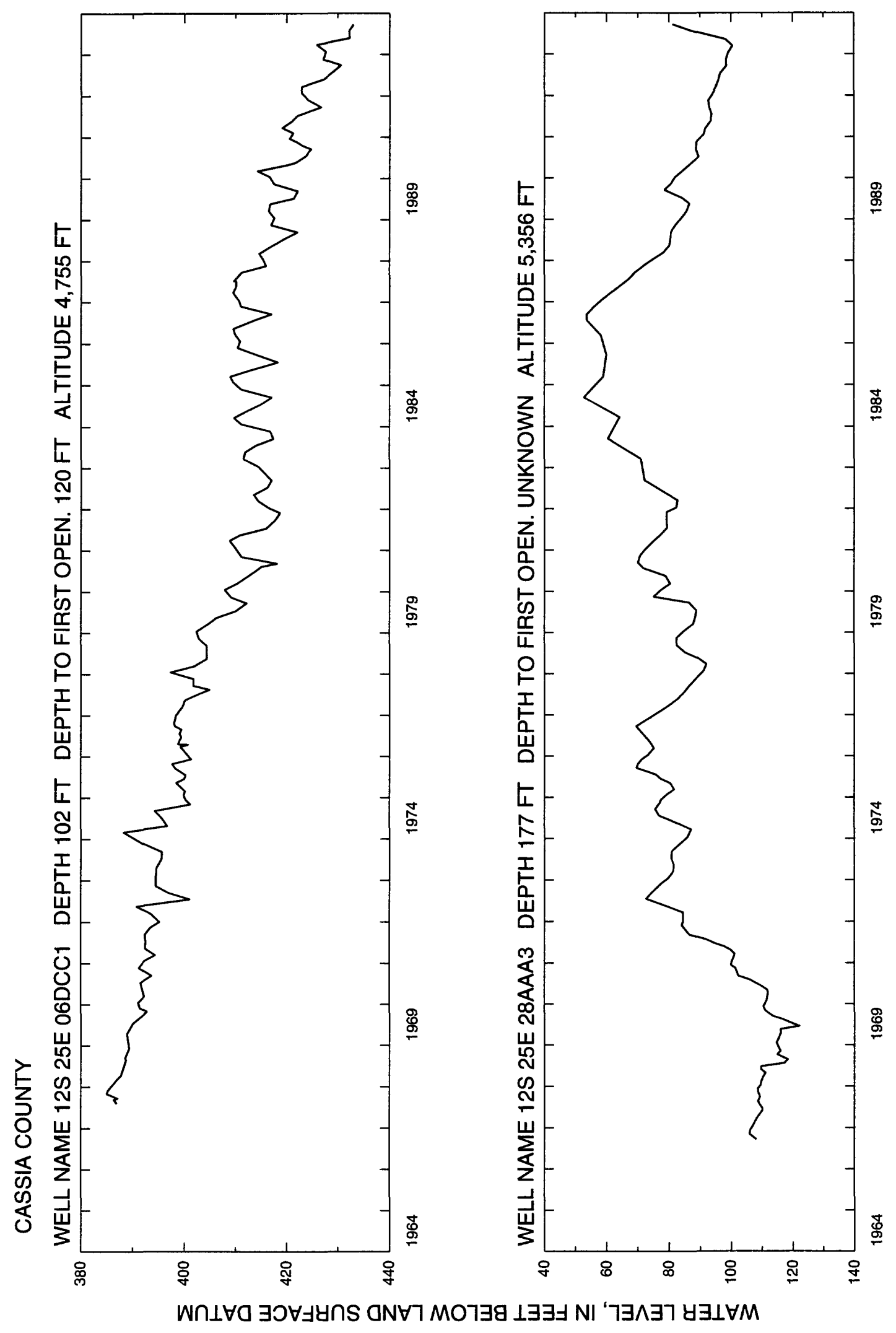




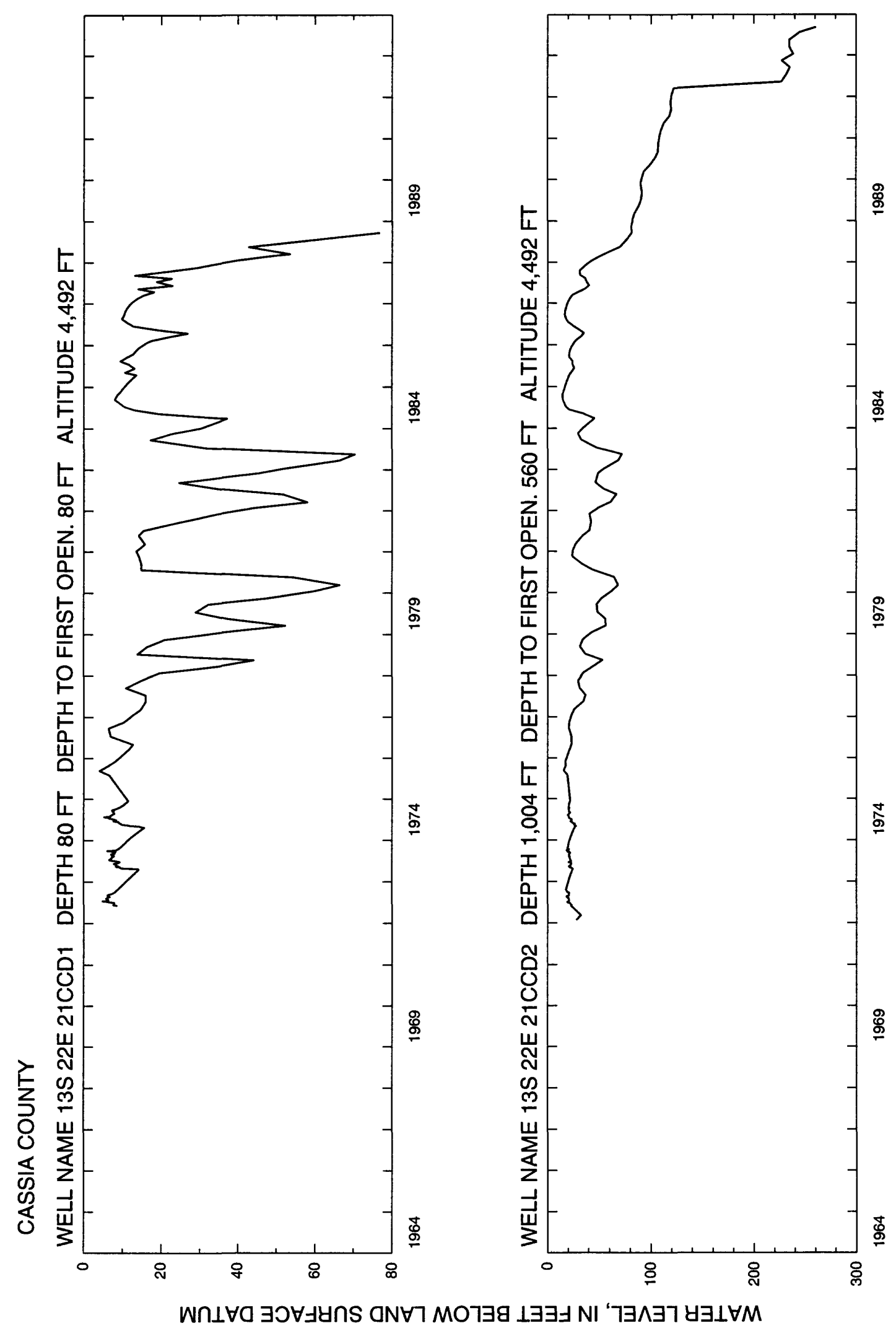




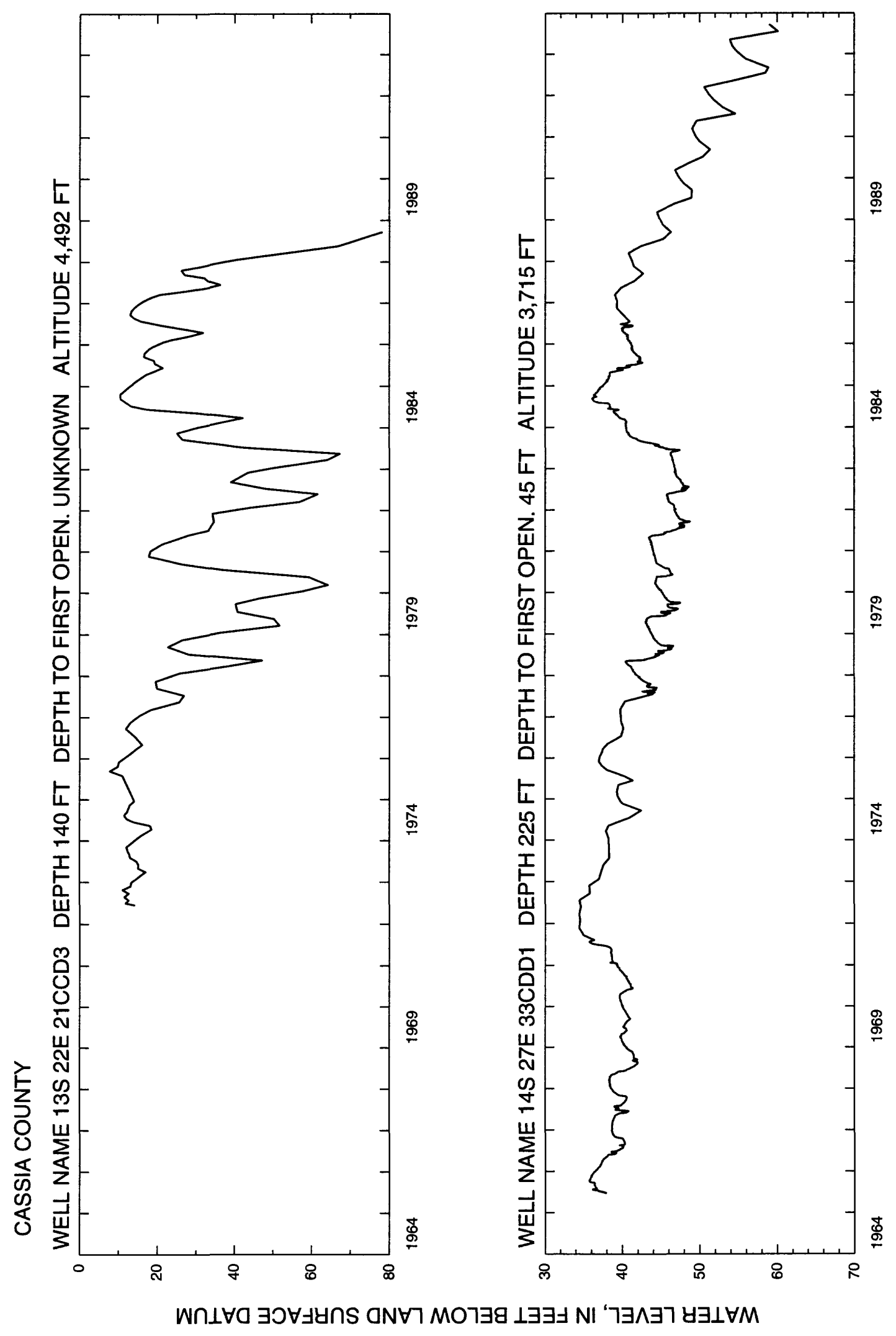




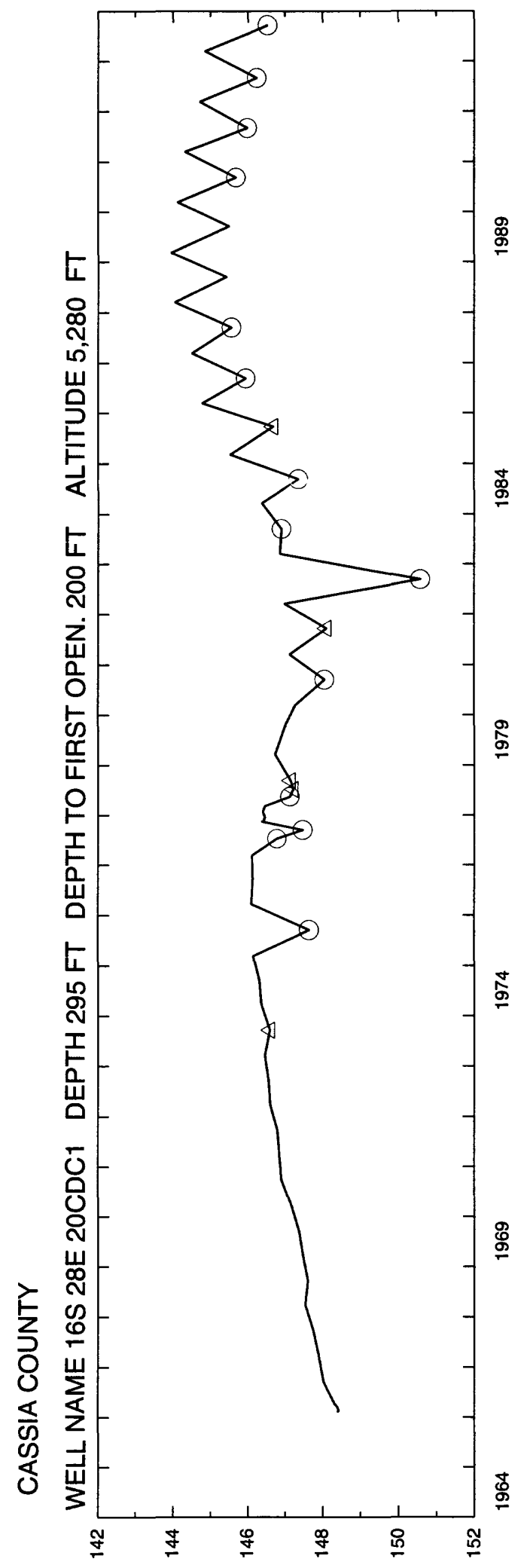

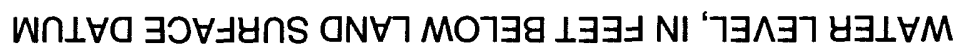




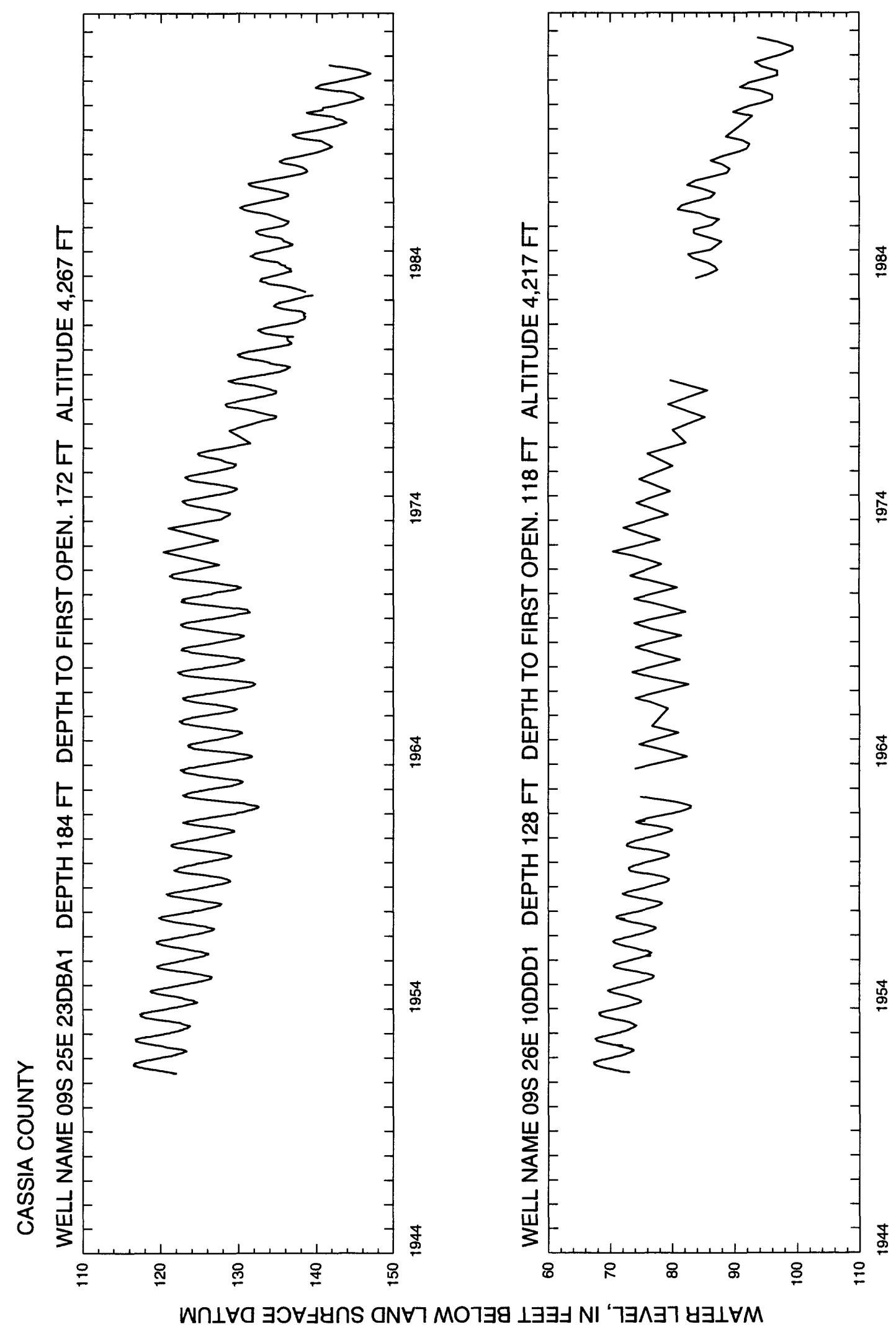




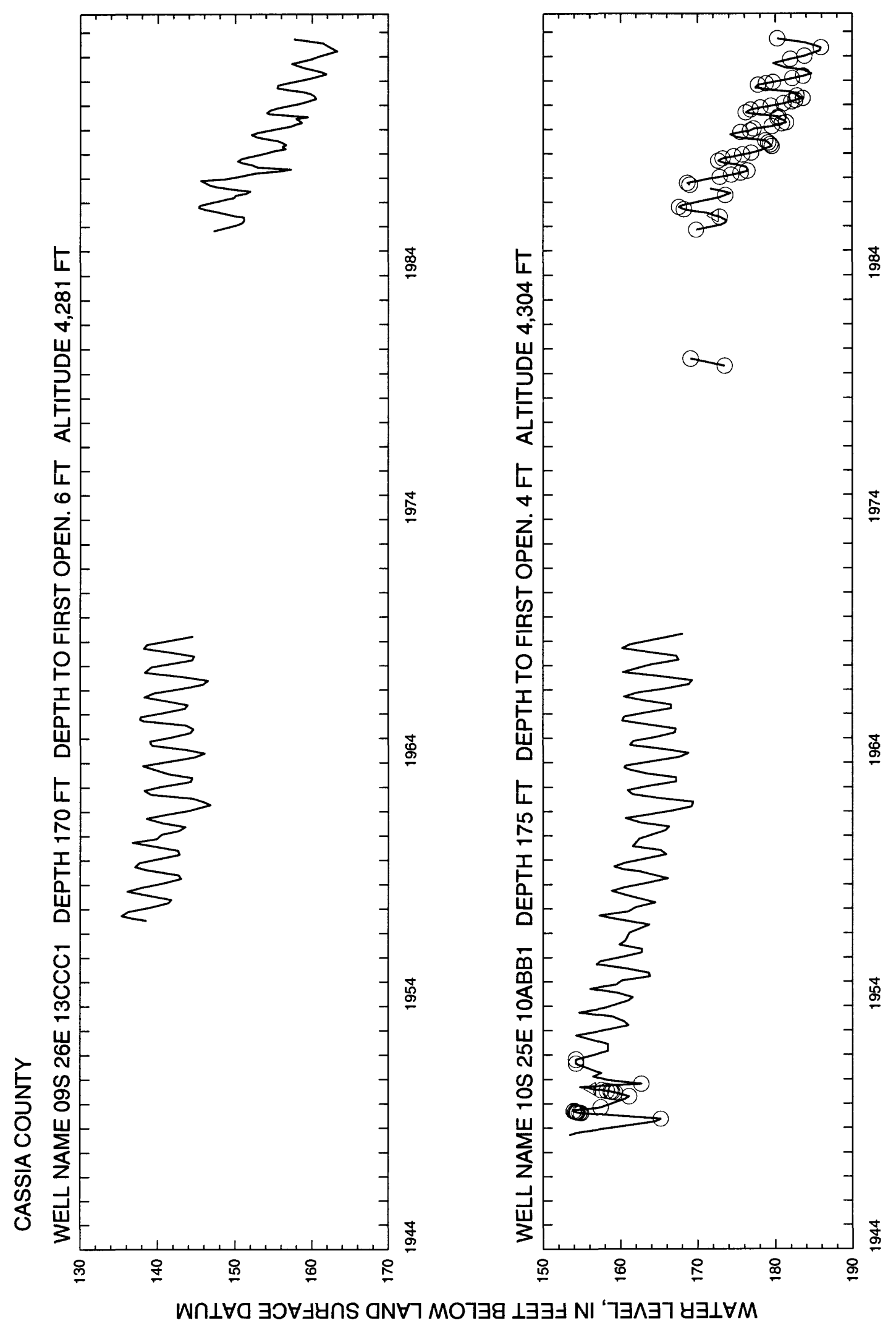




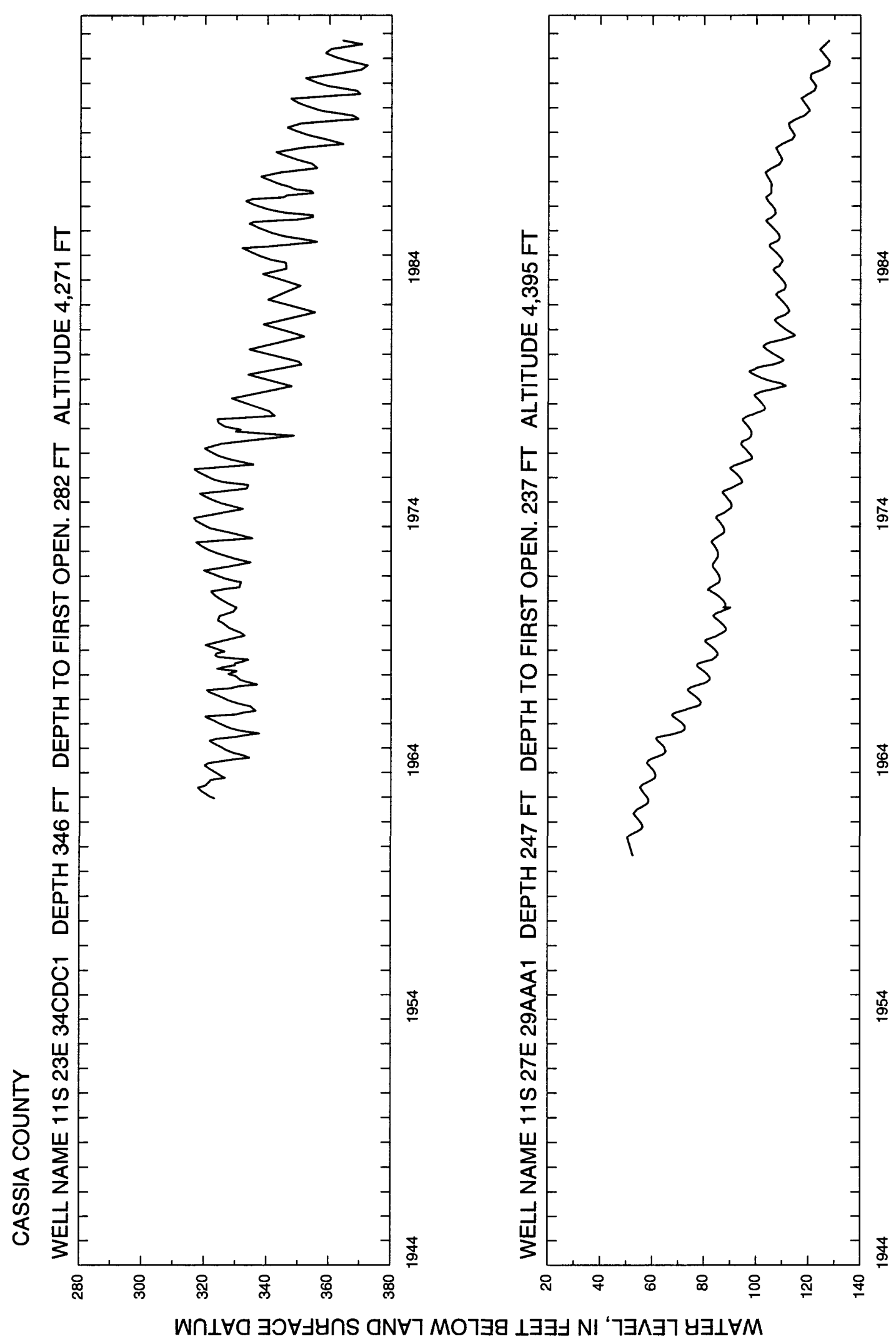




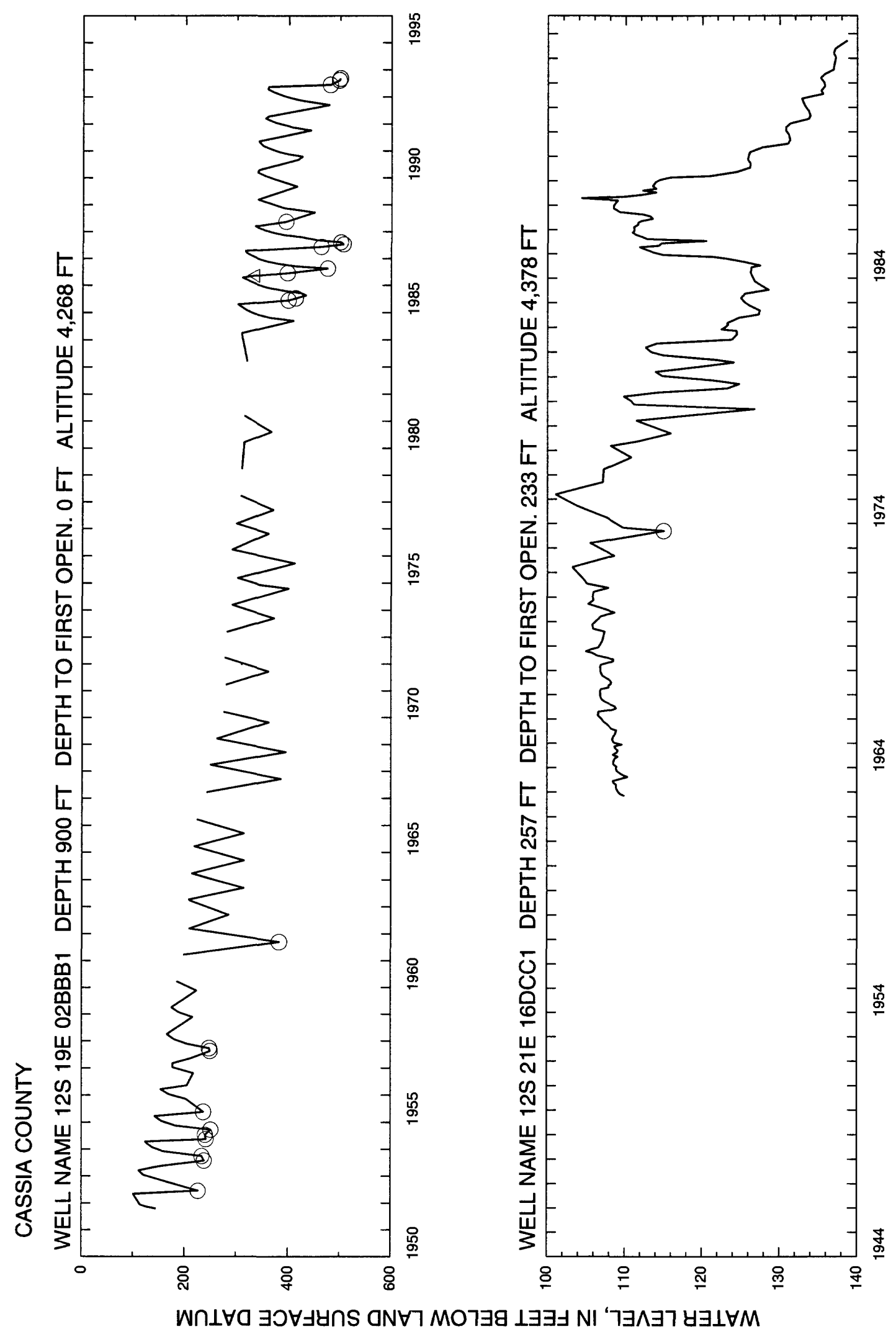




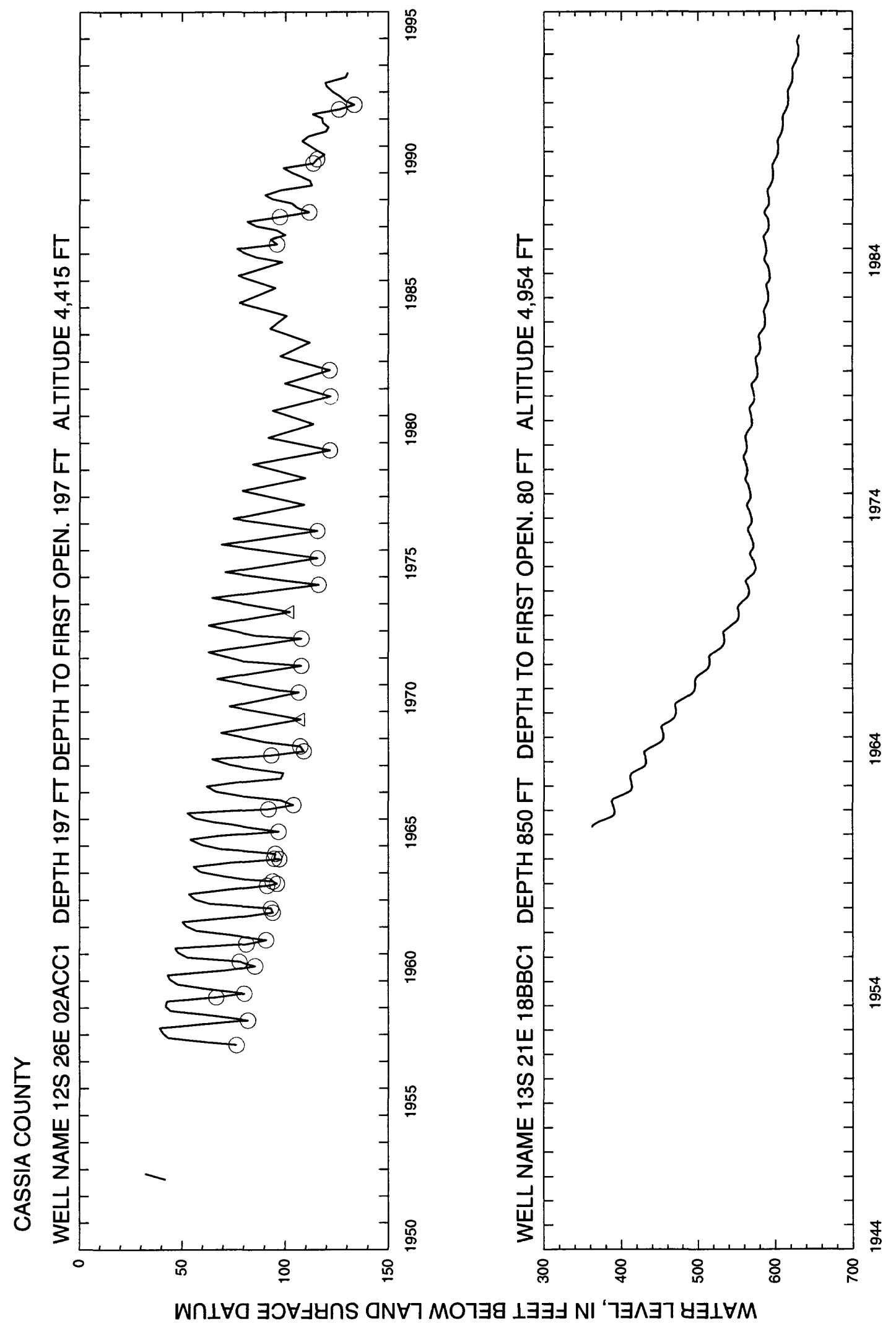




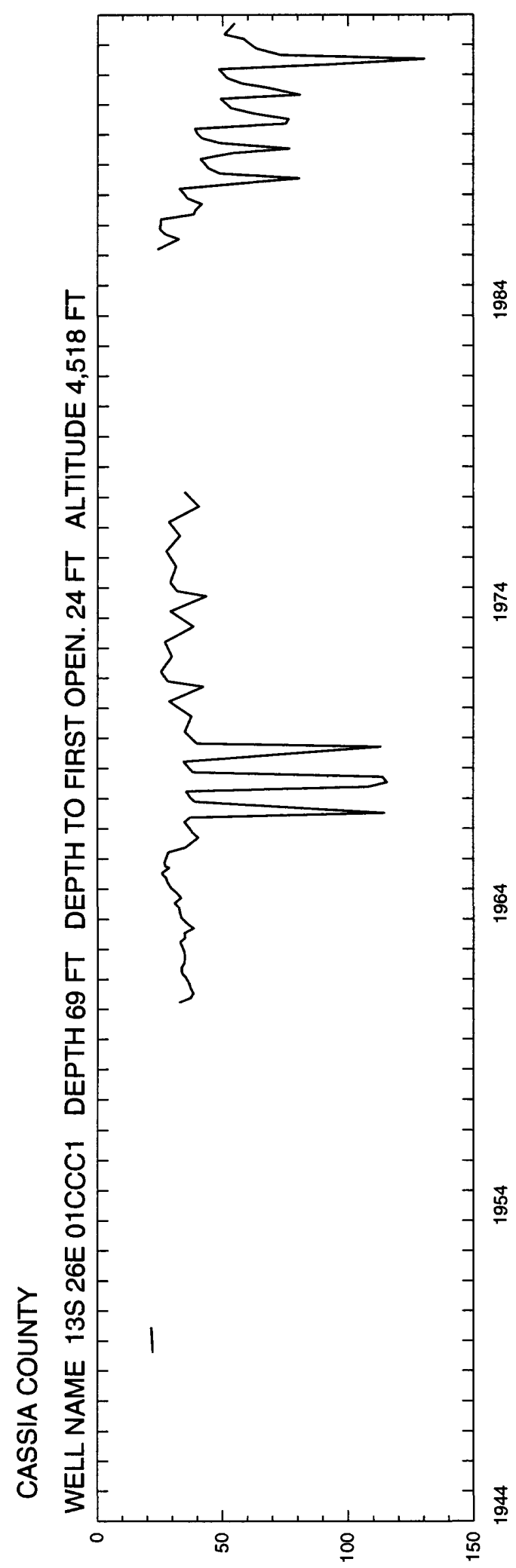

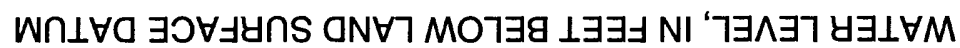


Clark 


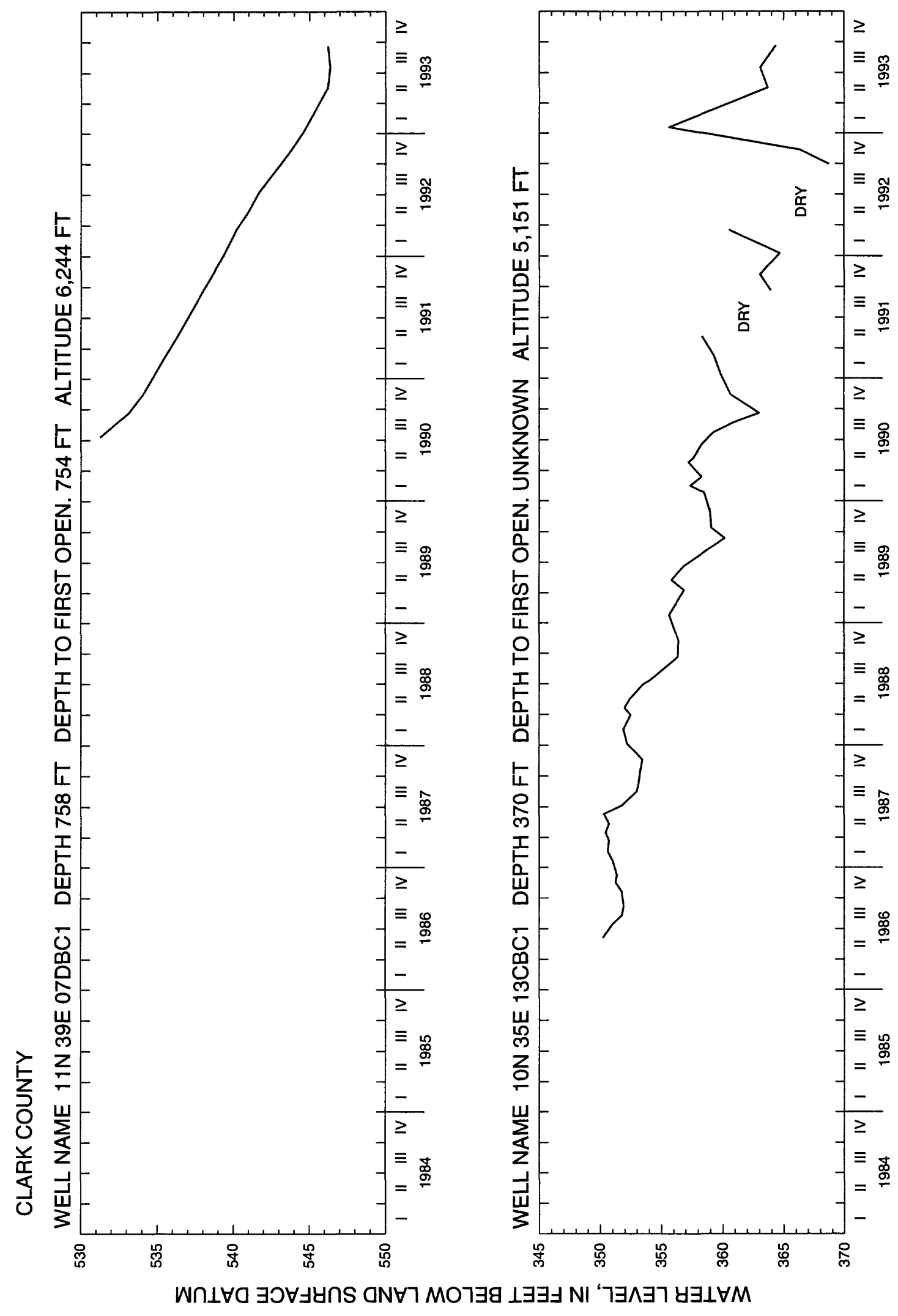




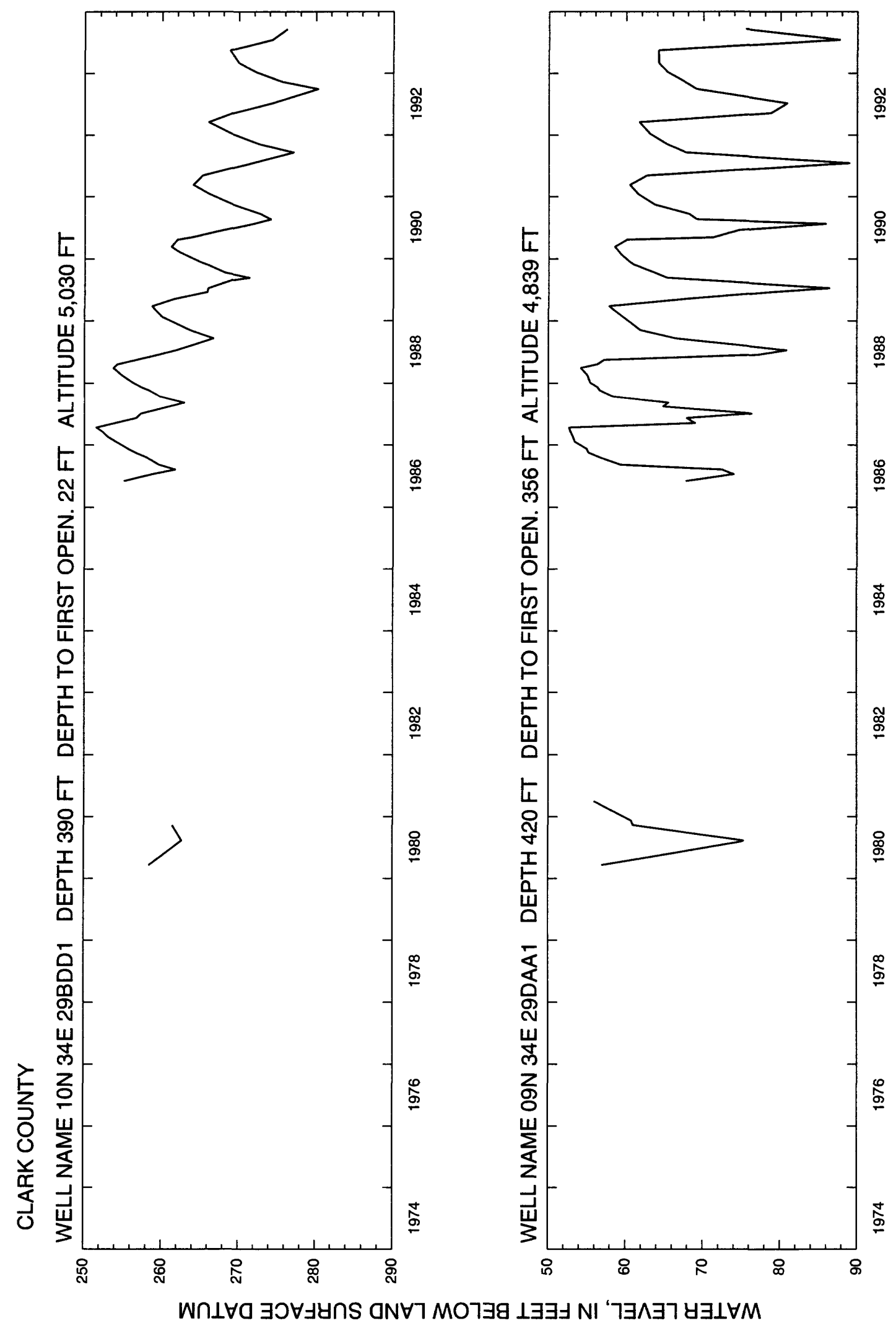




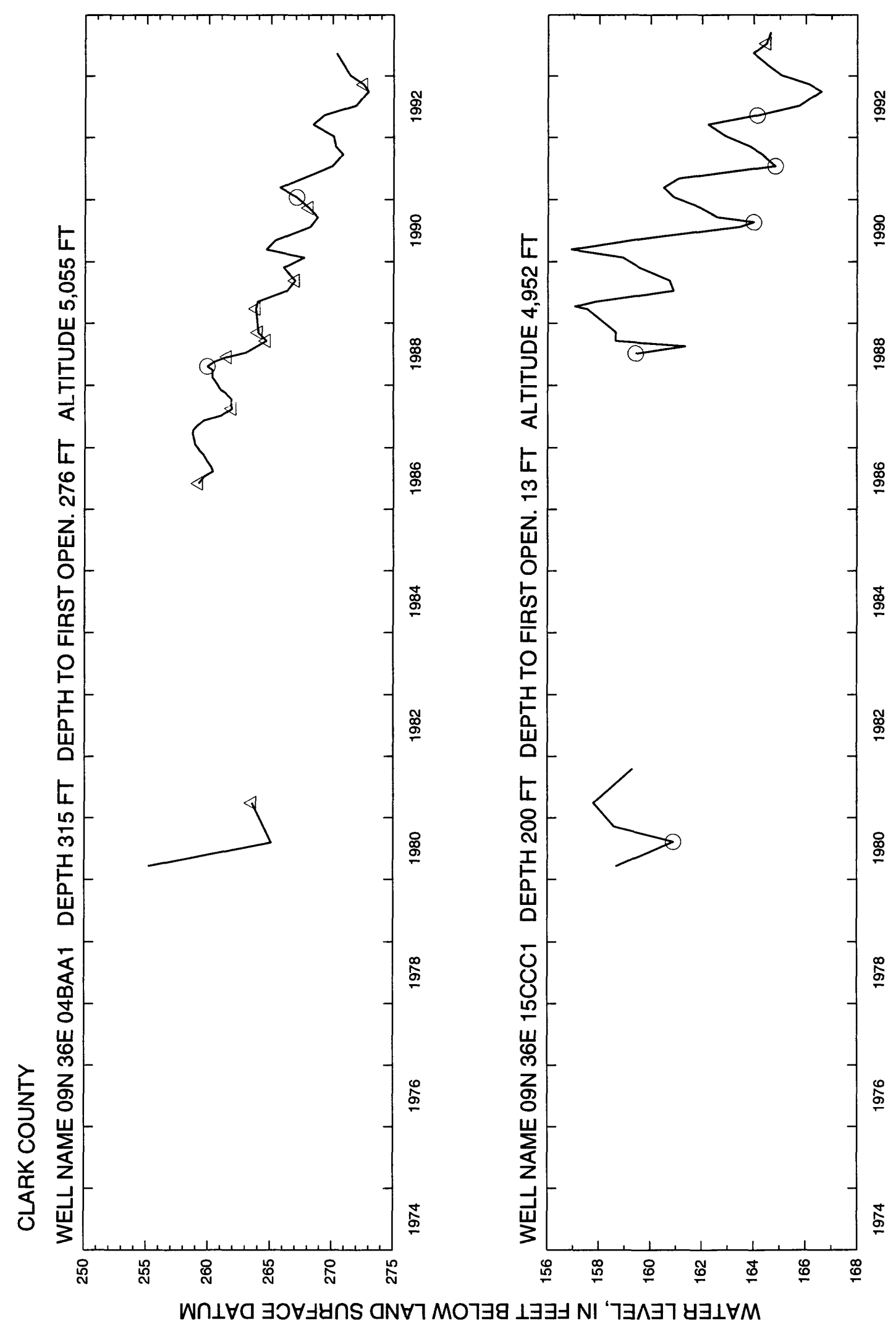




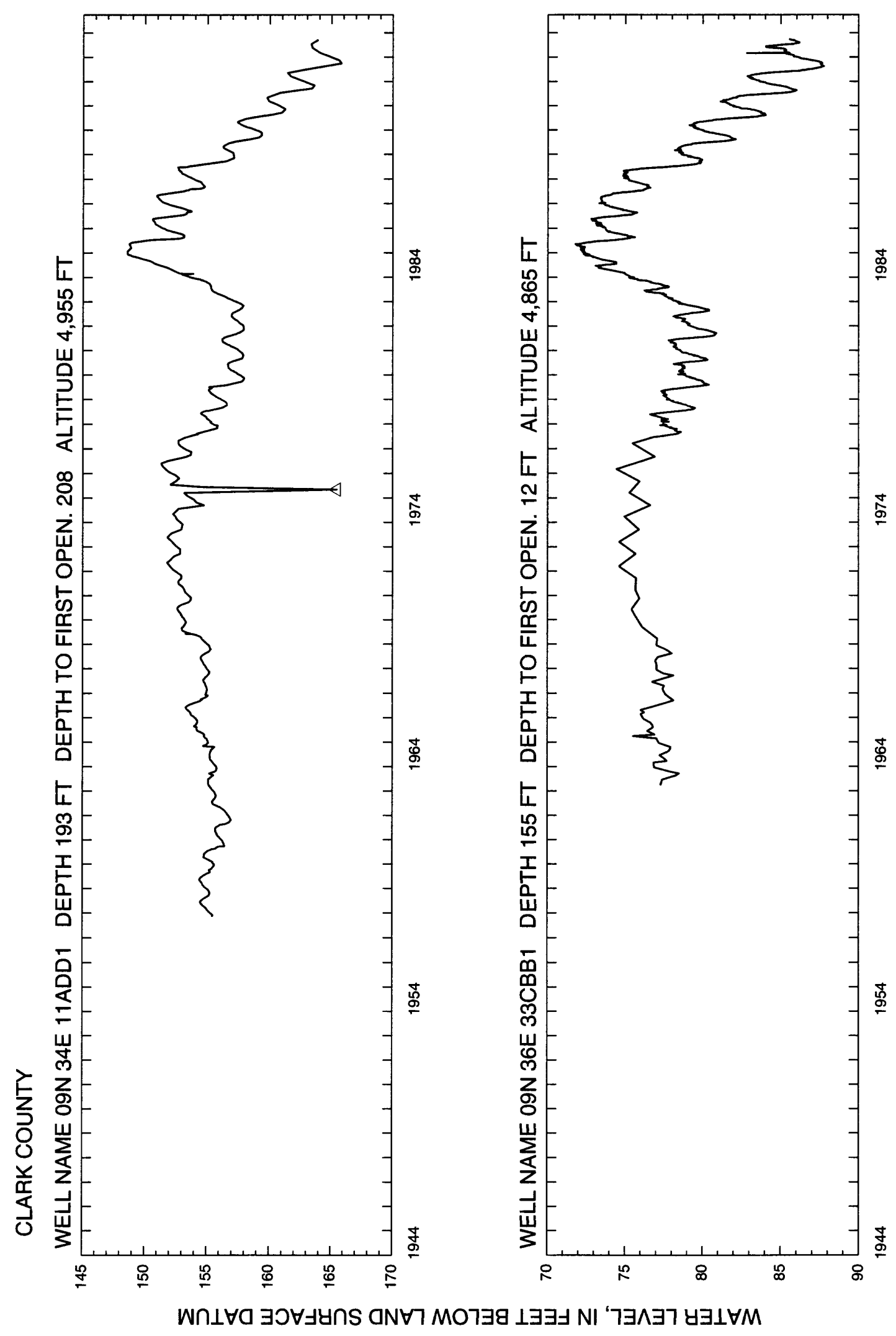




\section{Custer}




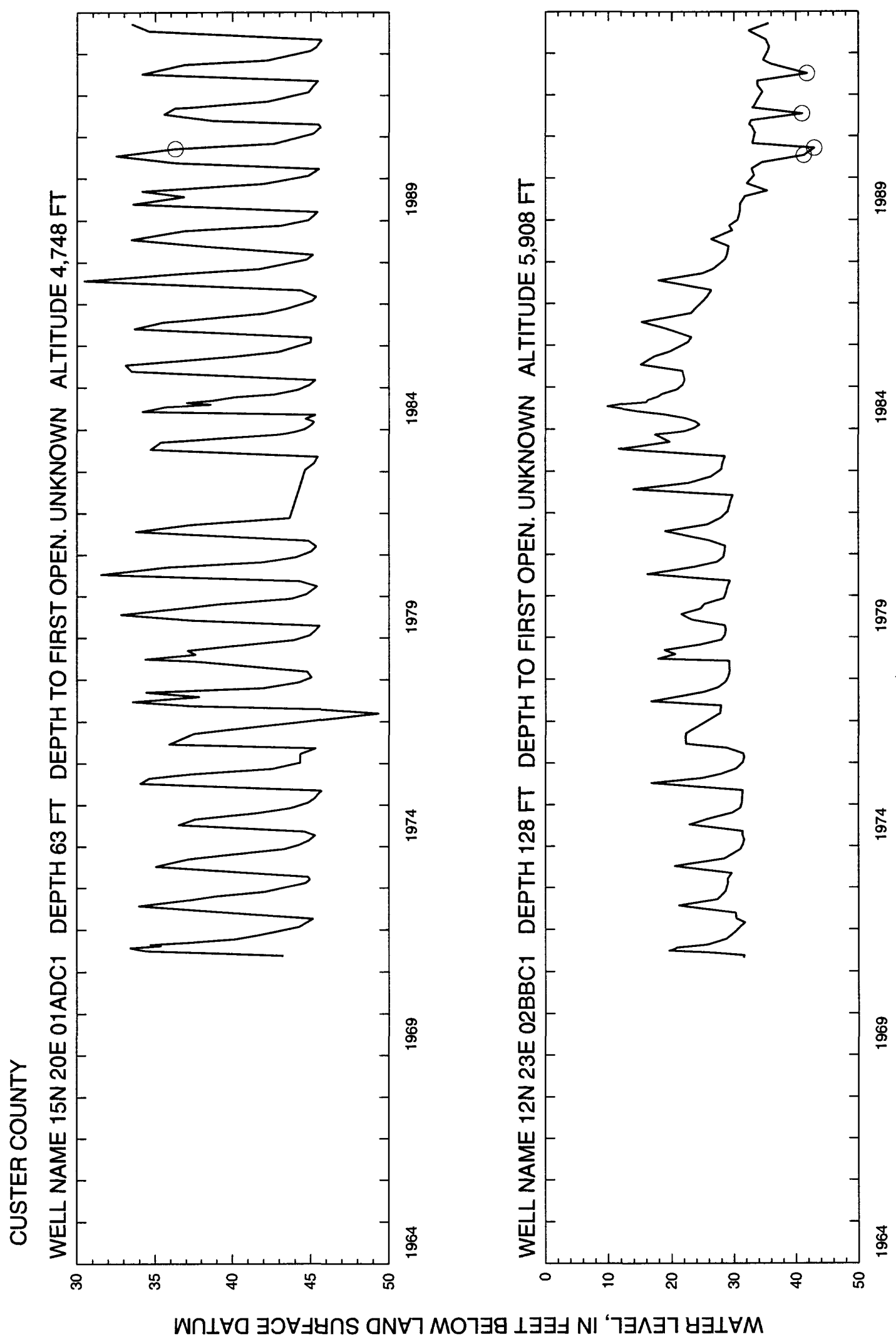




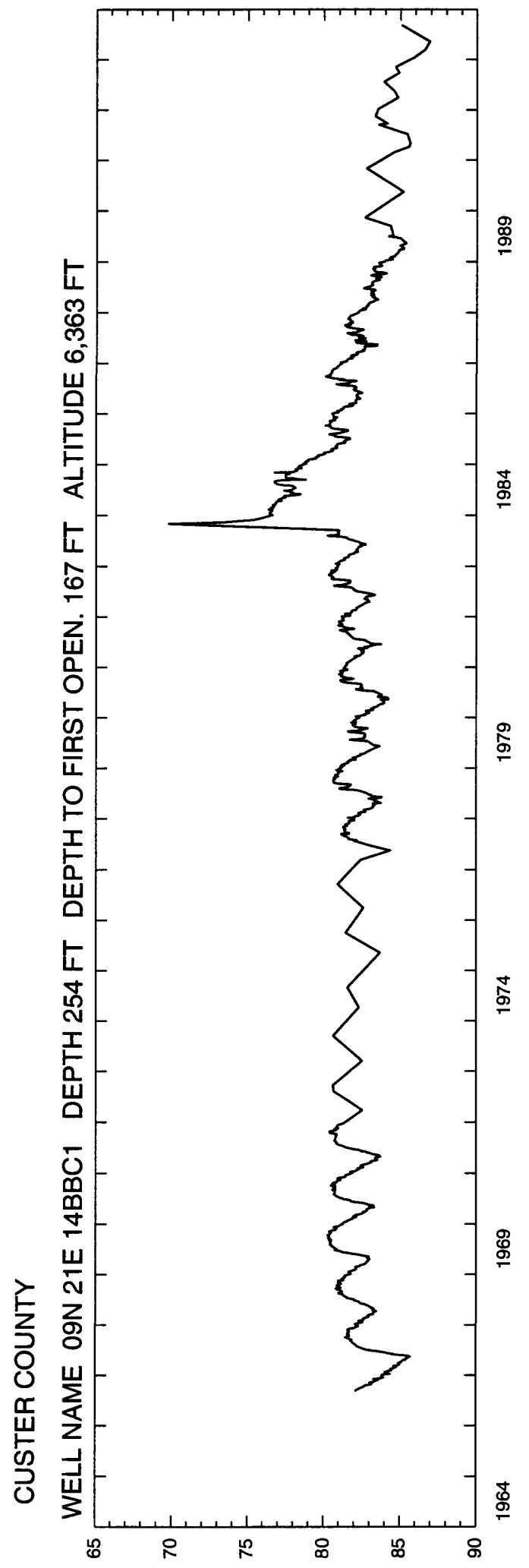

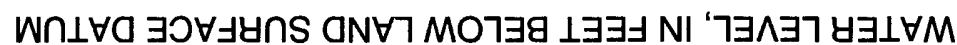


Elmore

175 (paye 177 Lollows) 


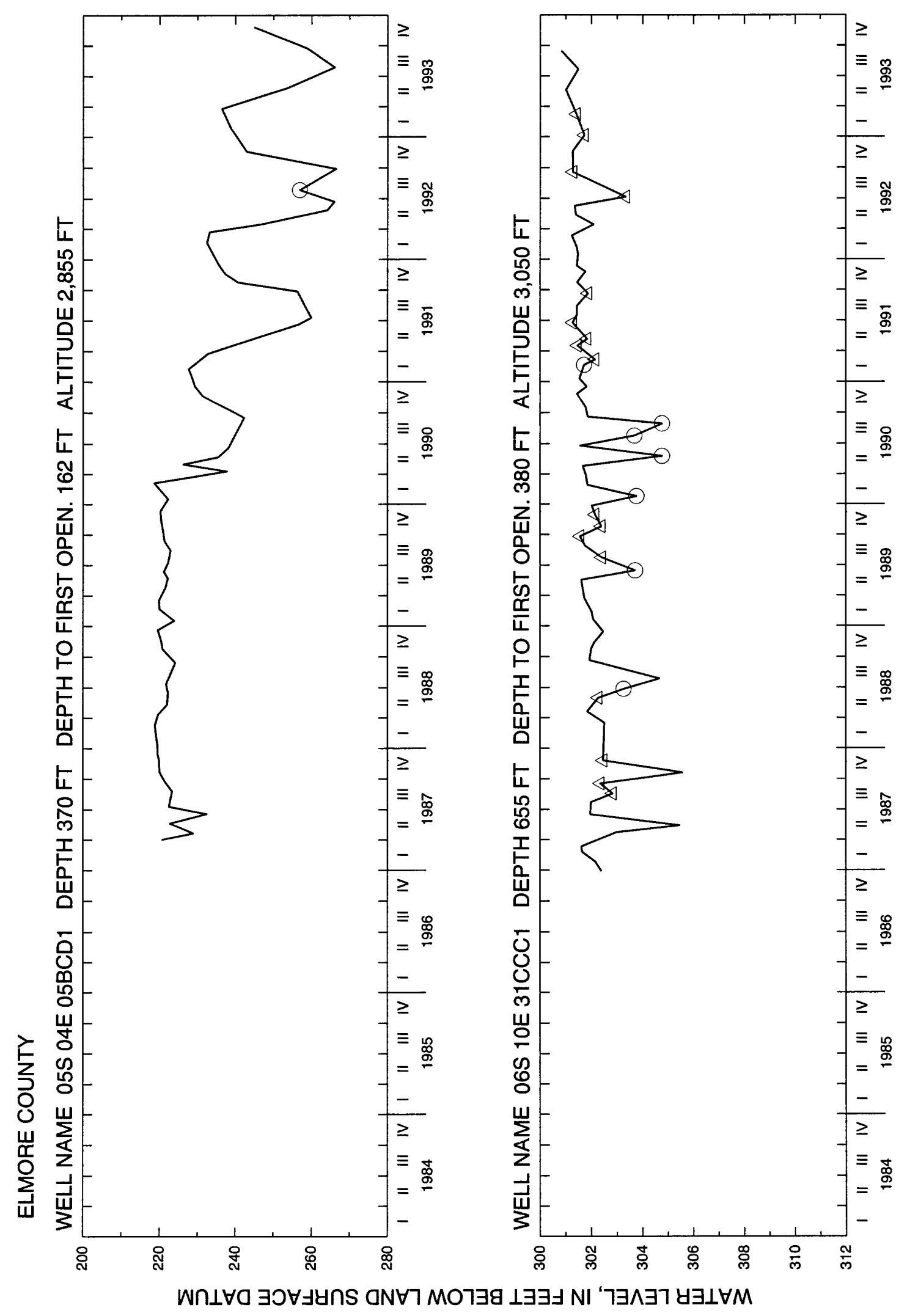




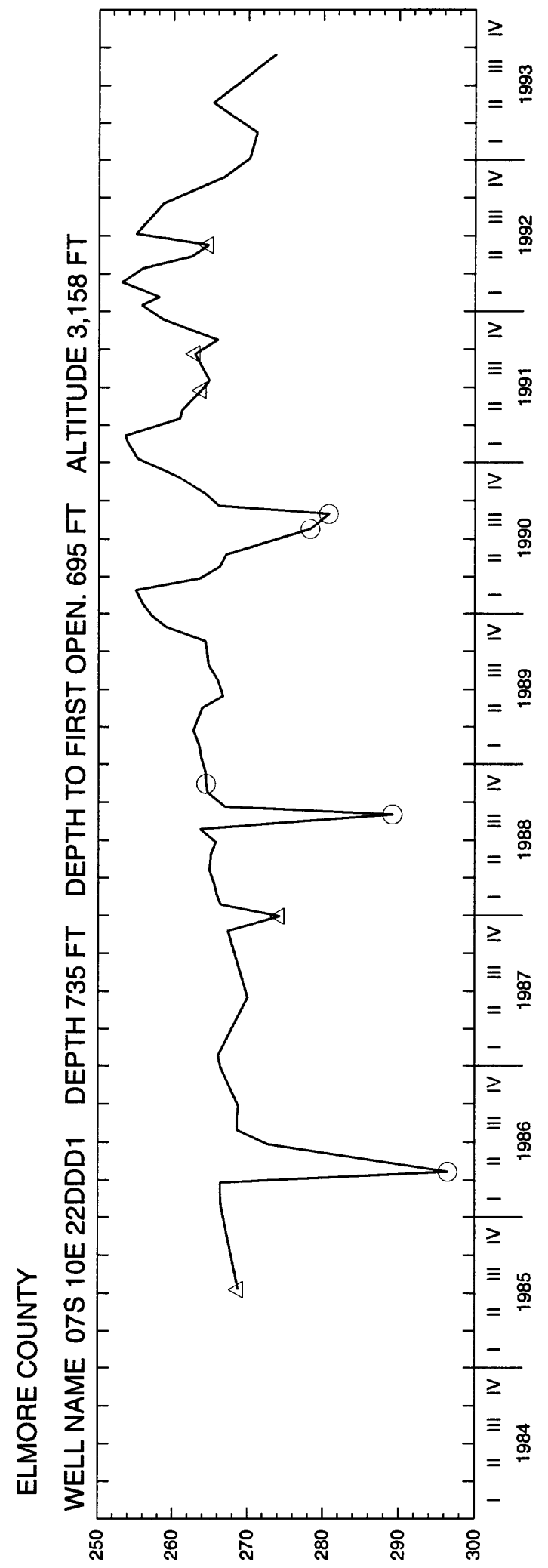

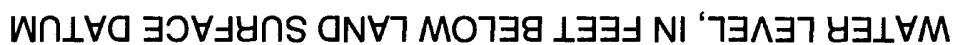




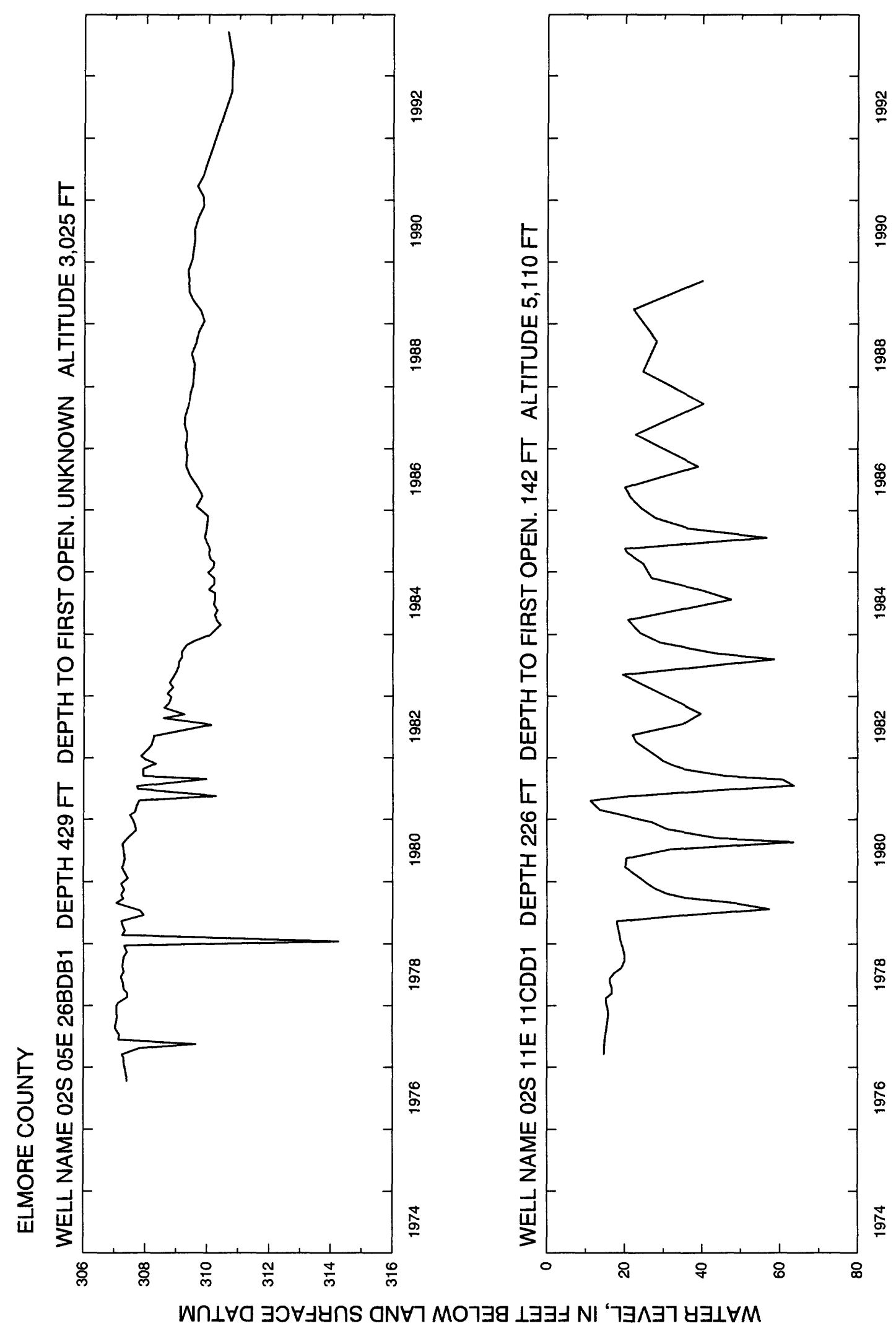




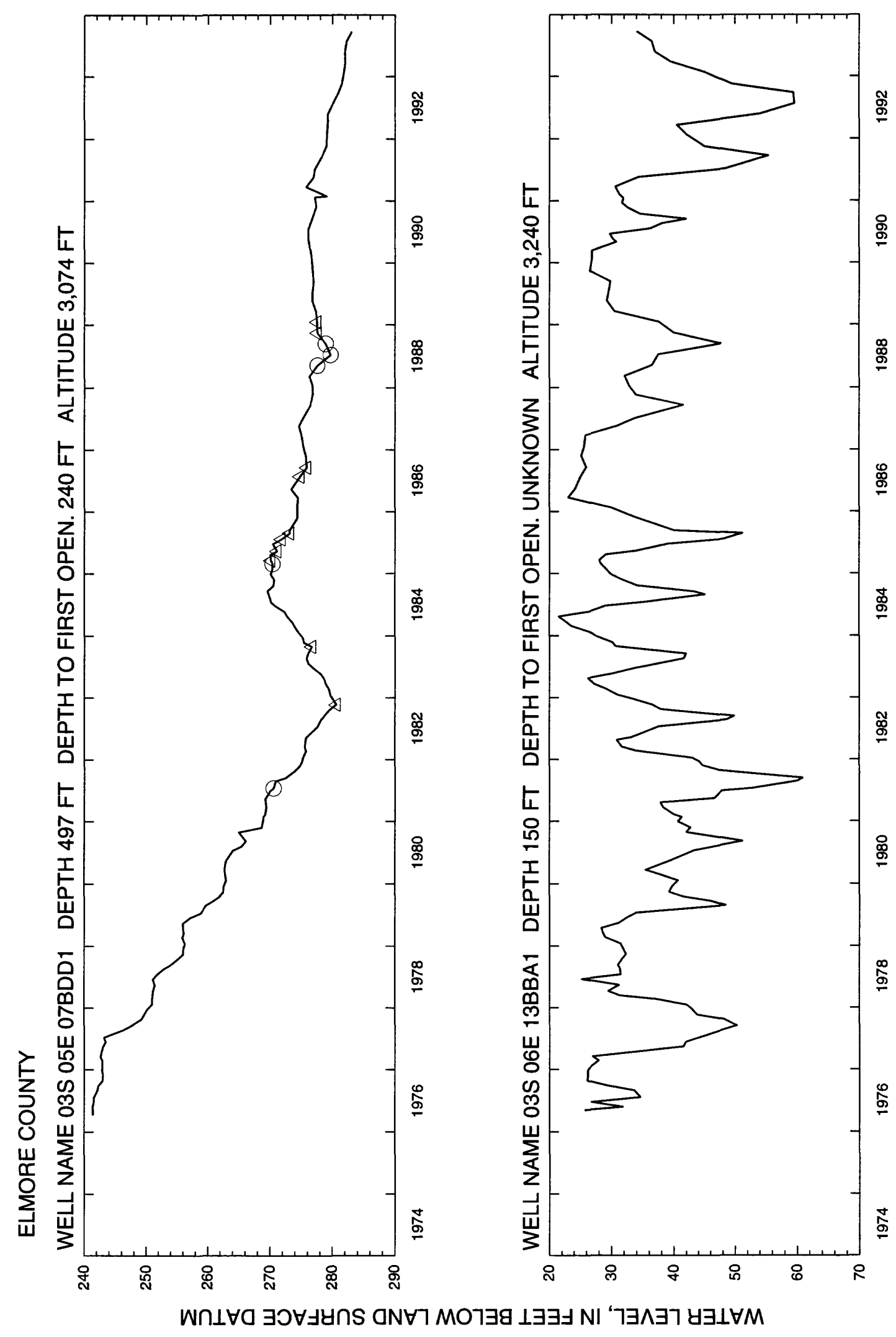




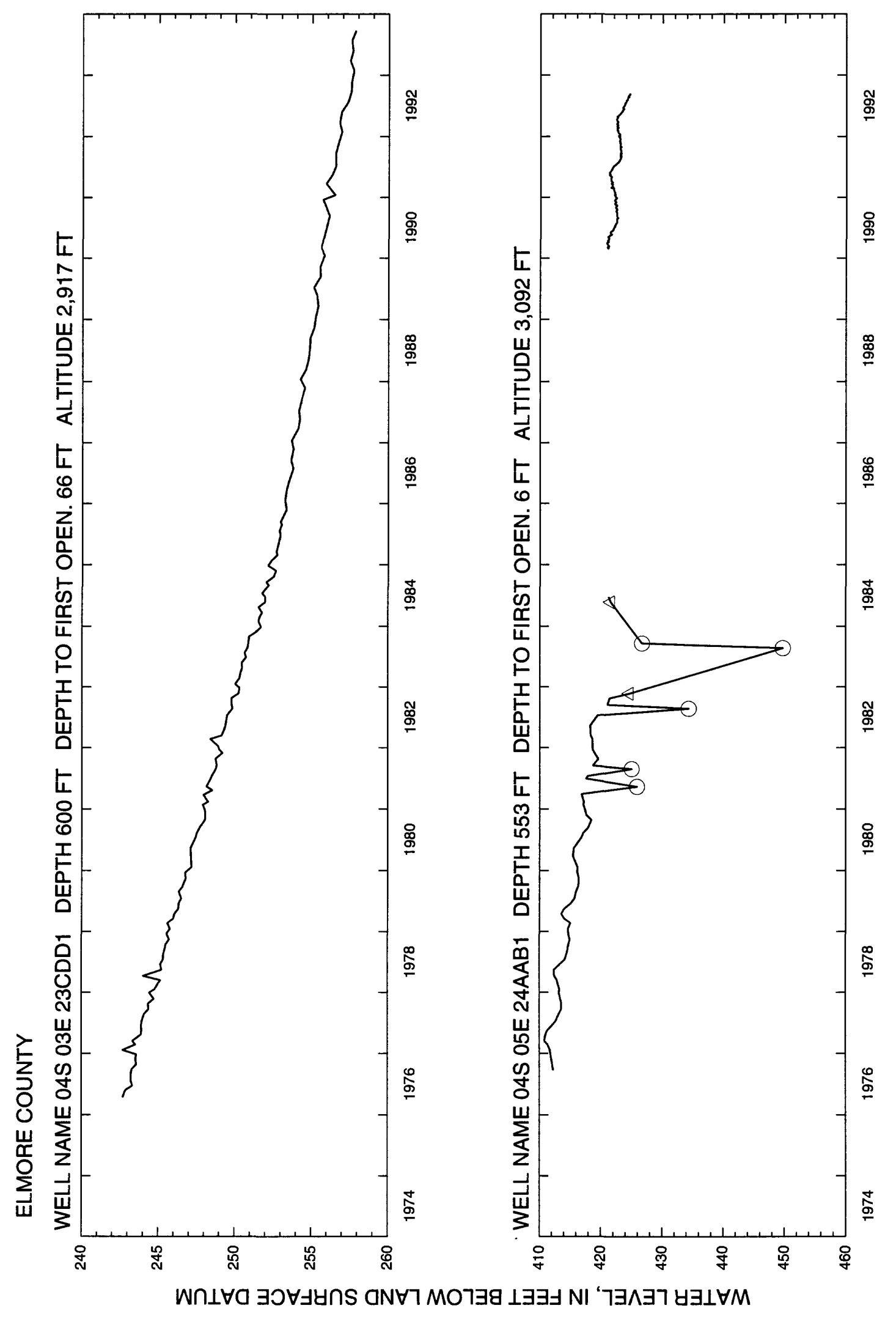




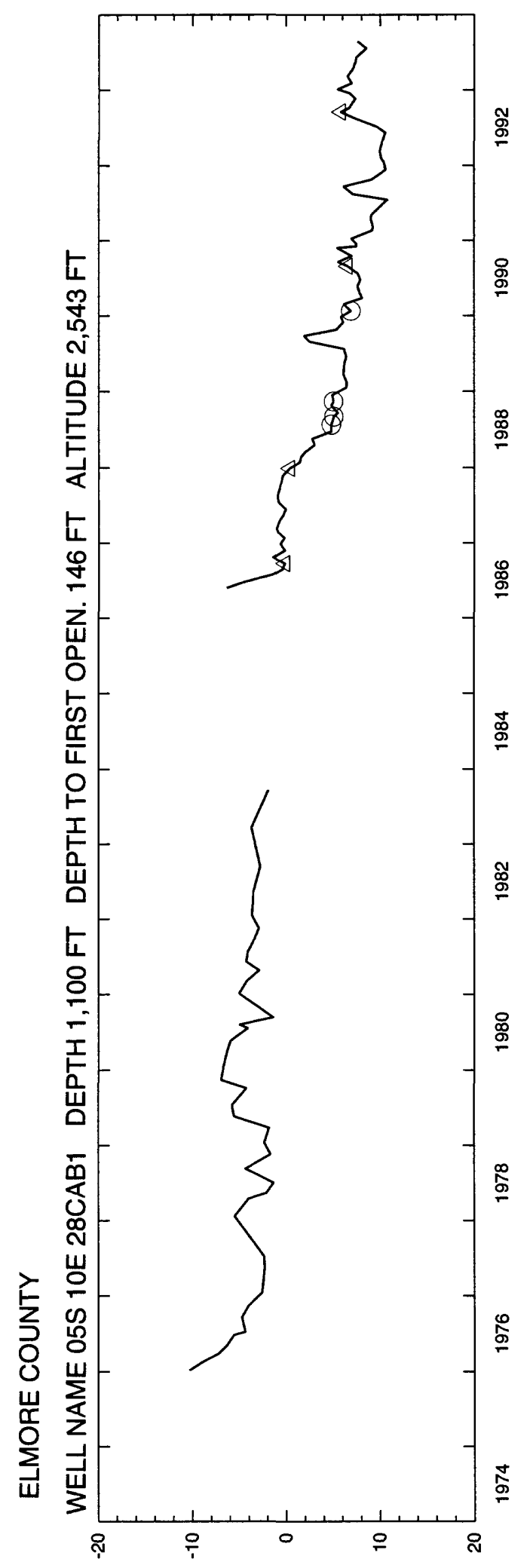

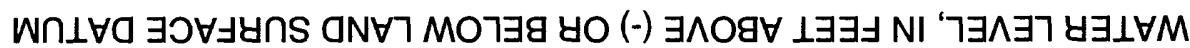




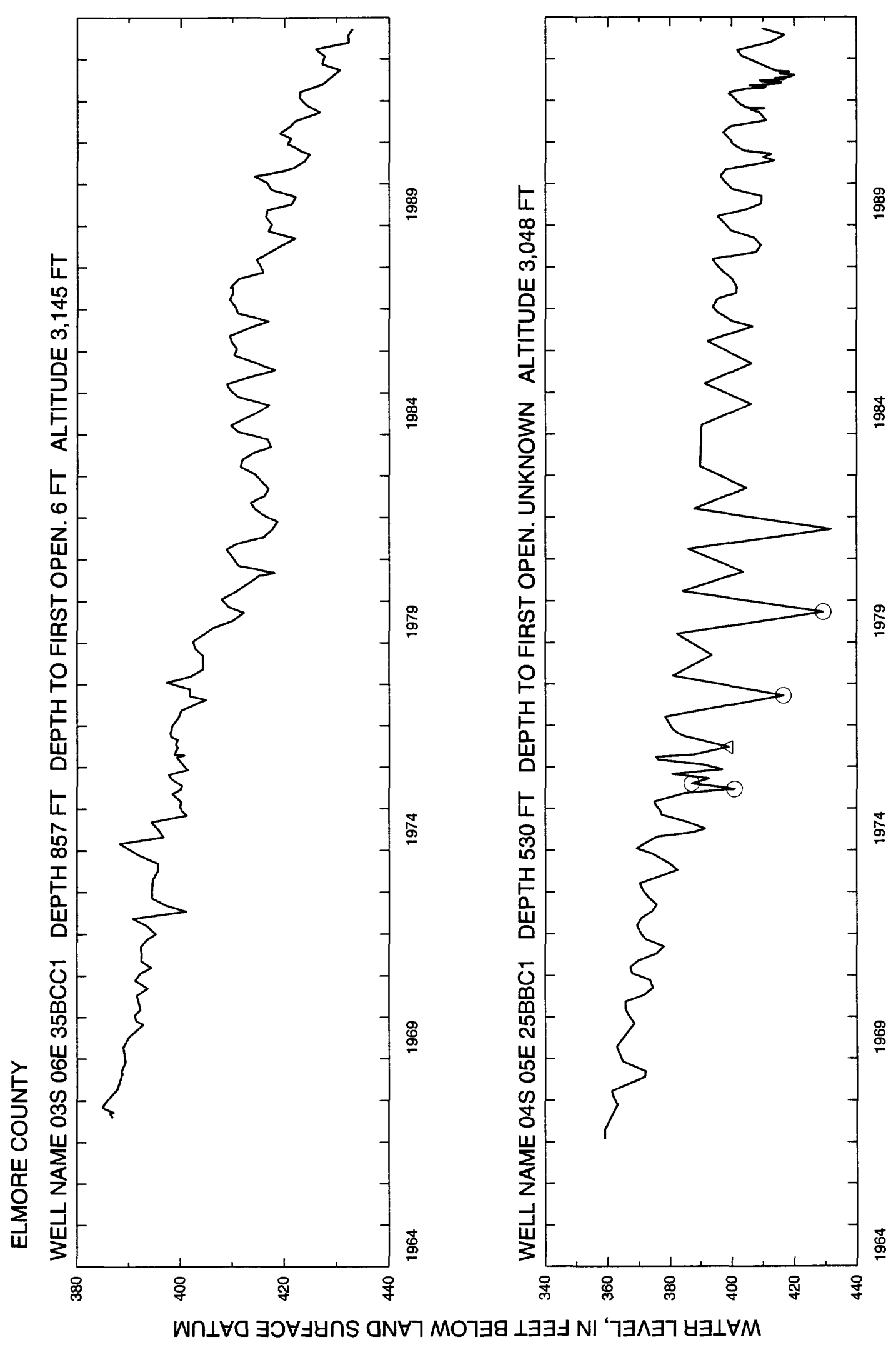




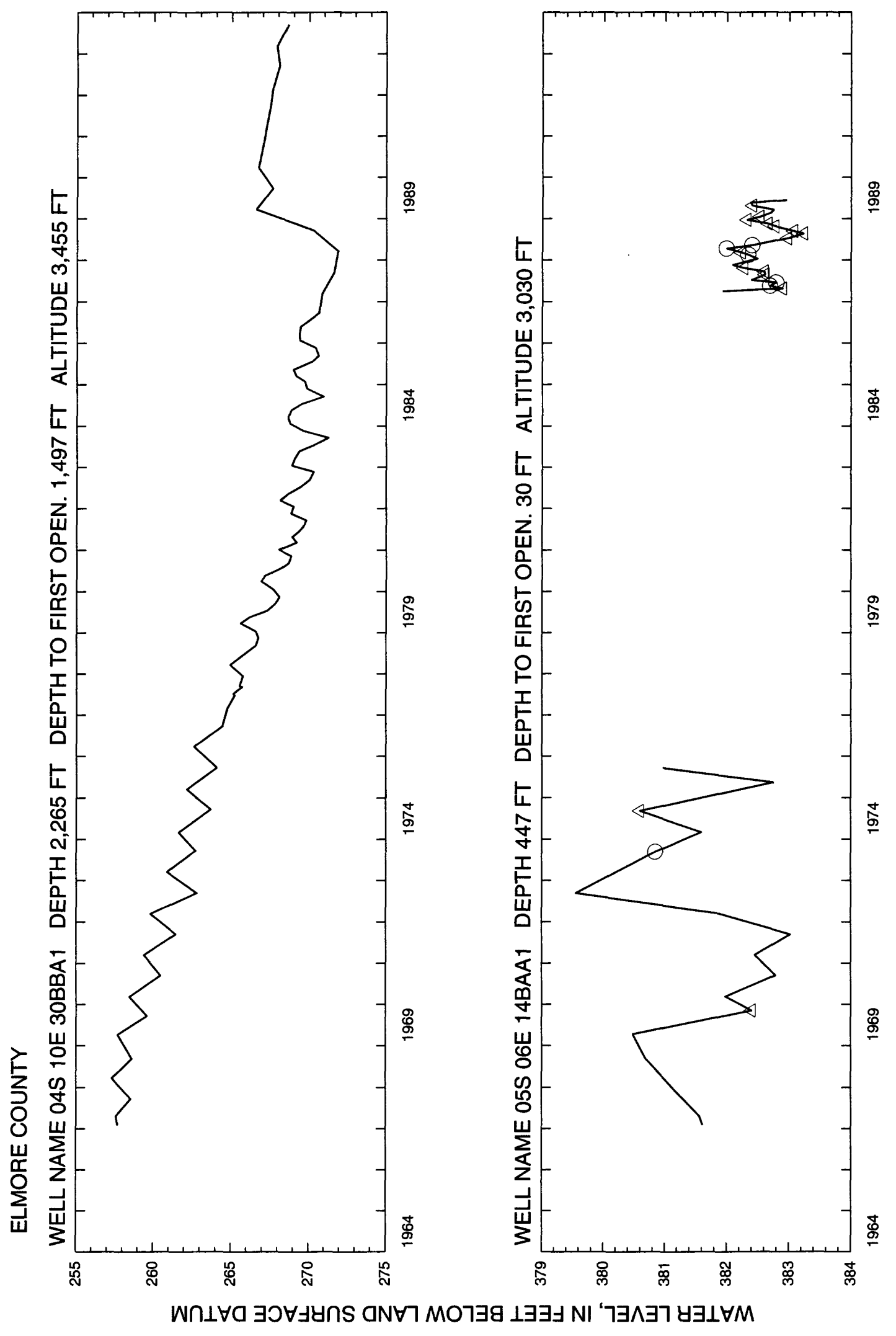




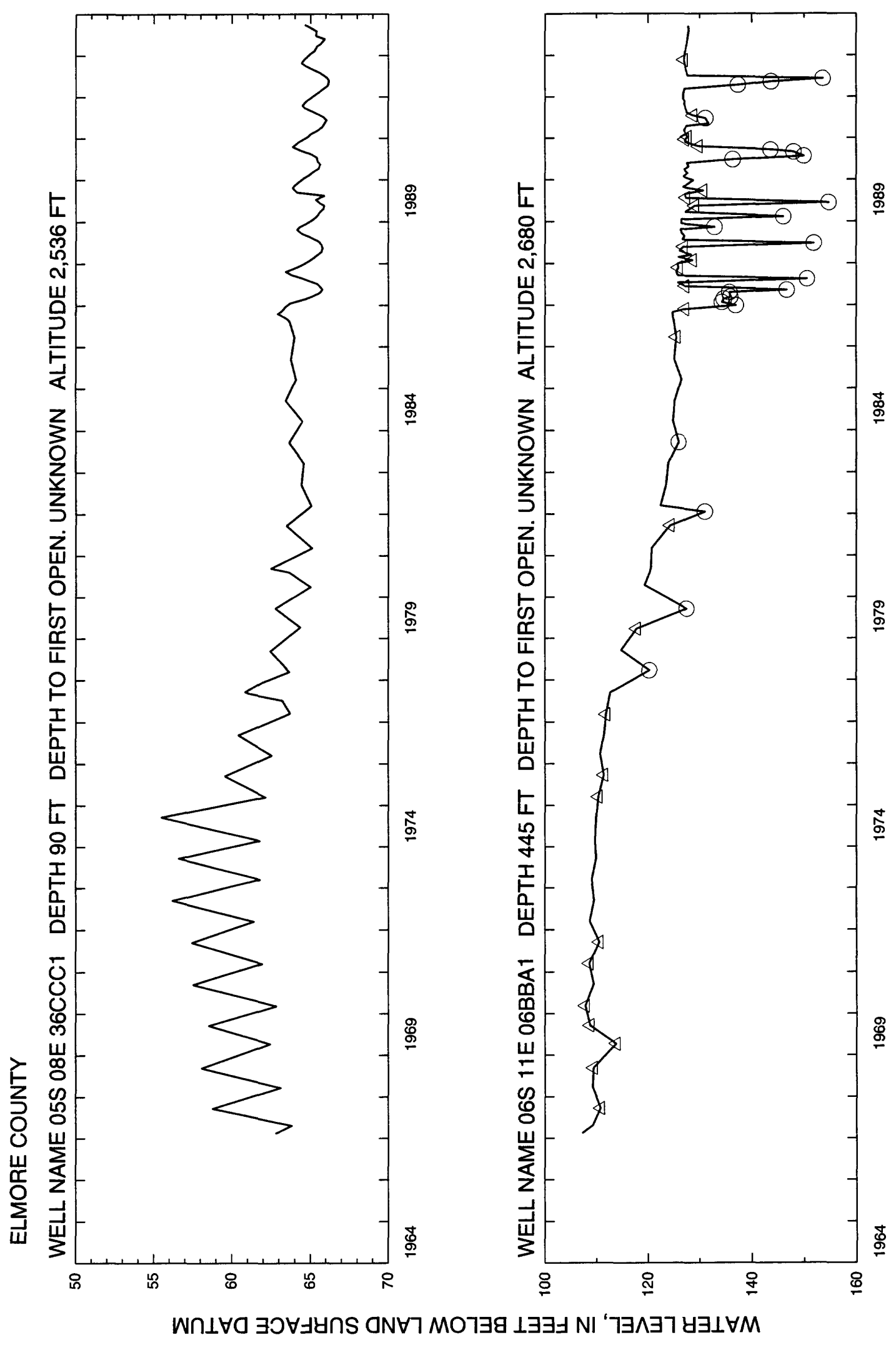




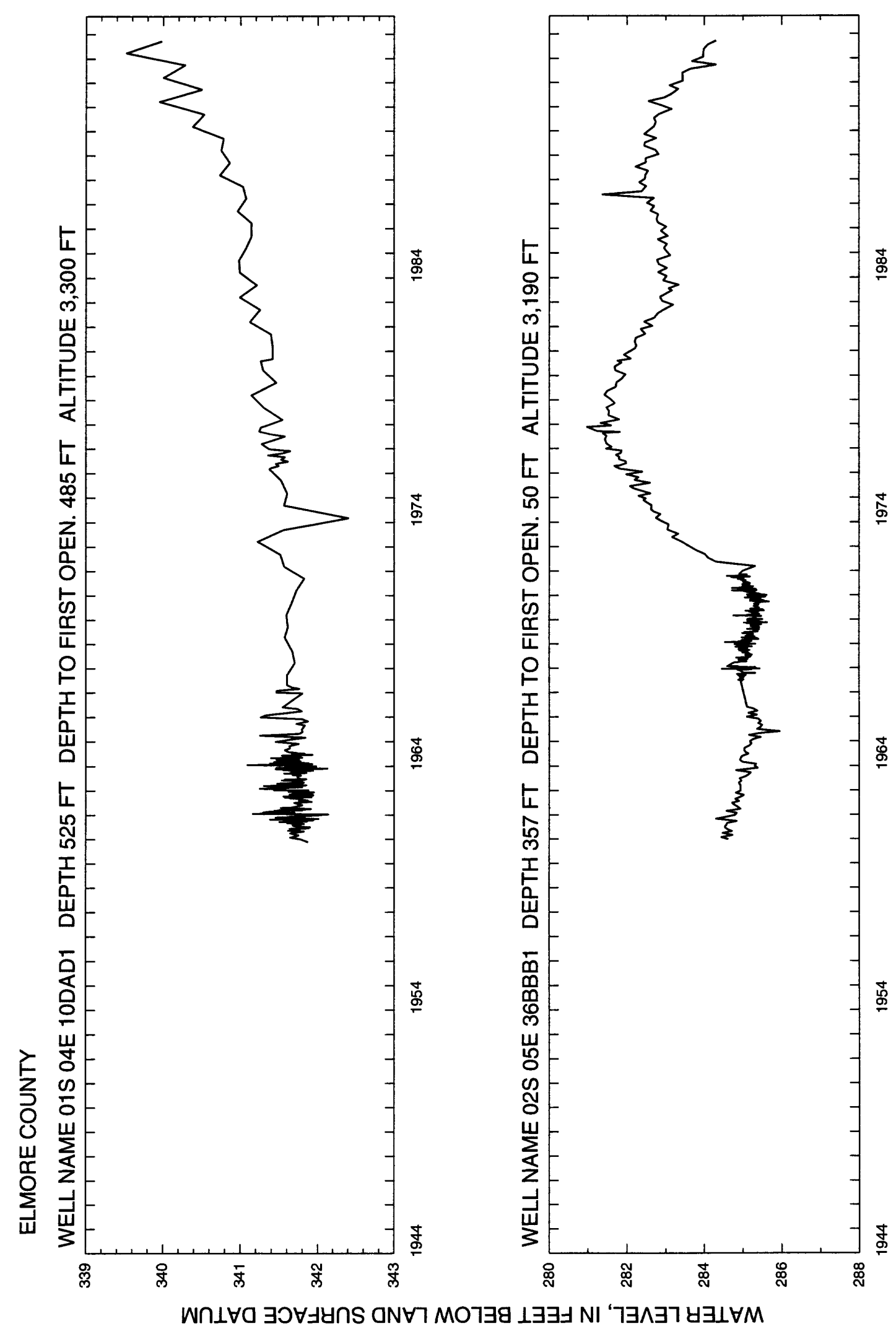


Franklin 


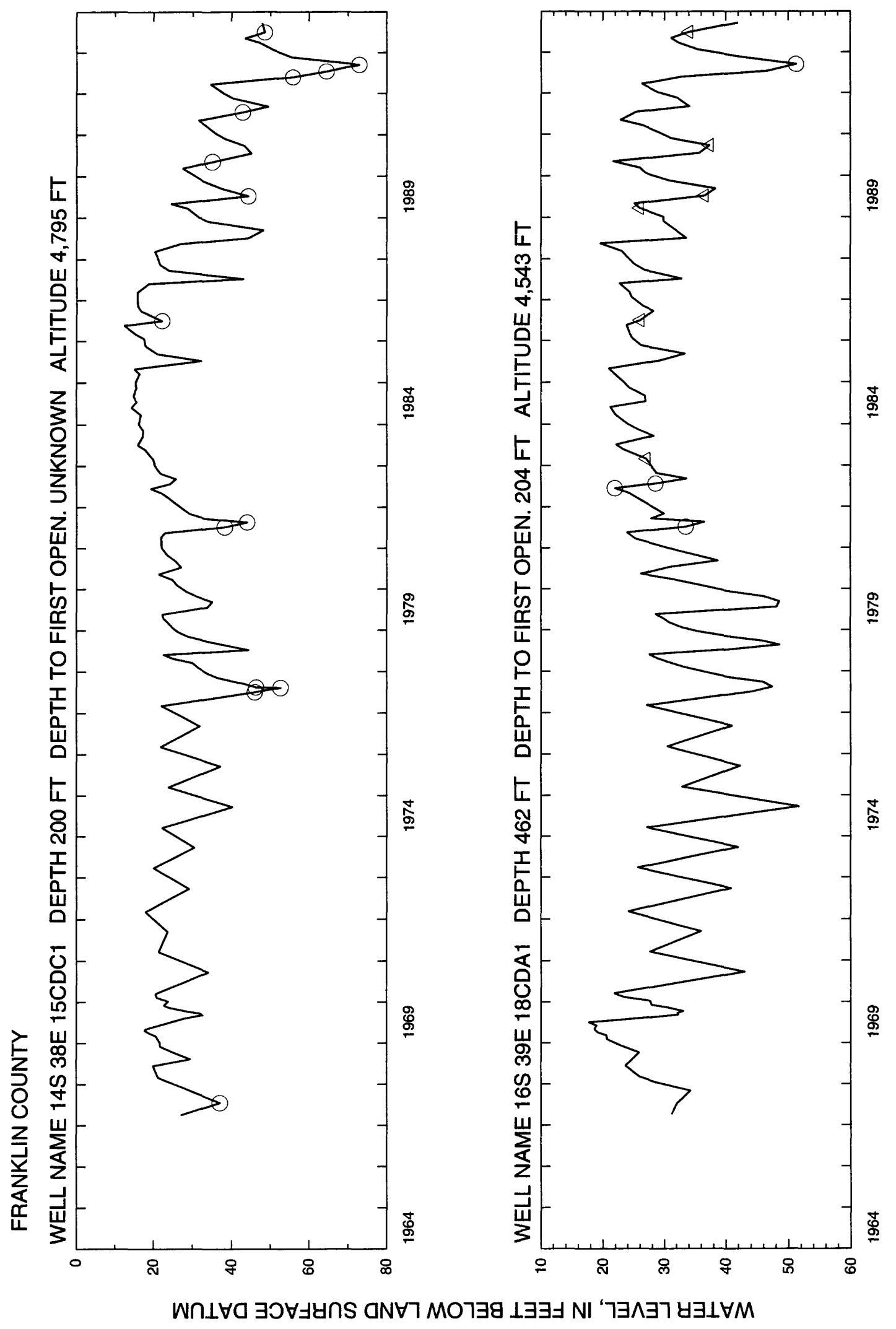




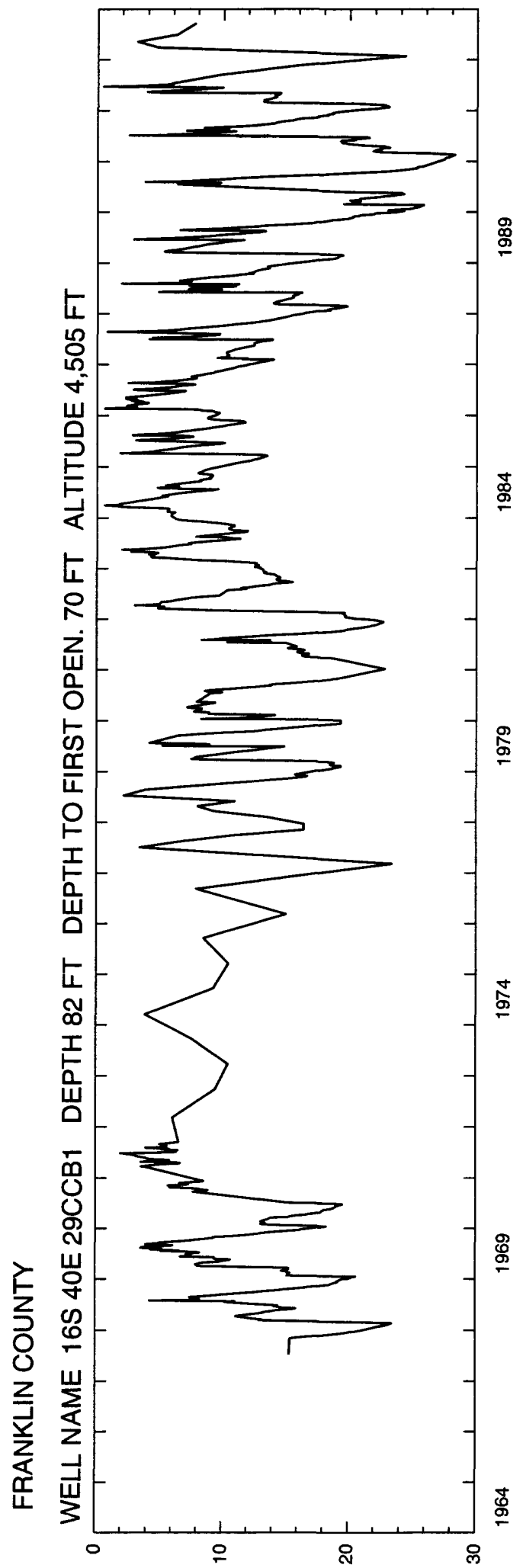

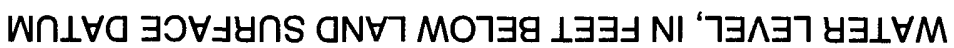


Fremont

191 (poye 193 follows) 


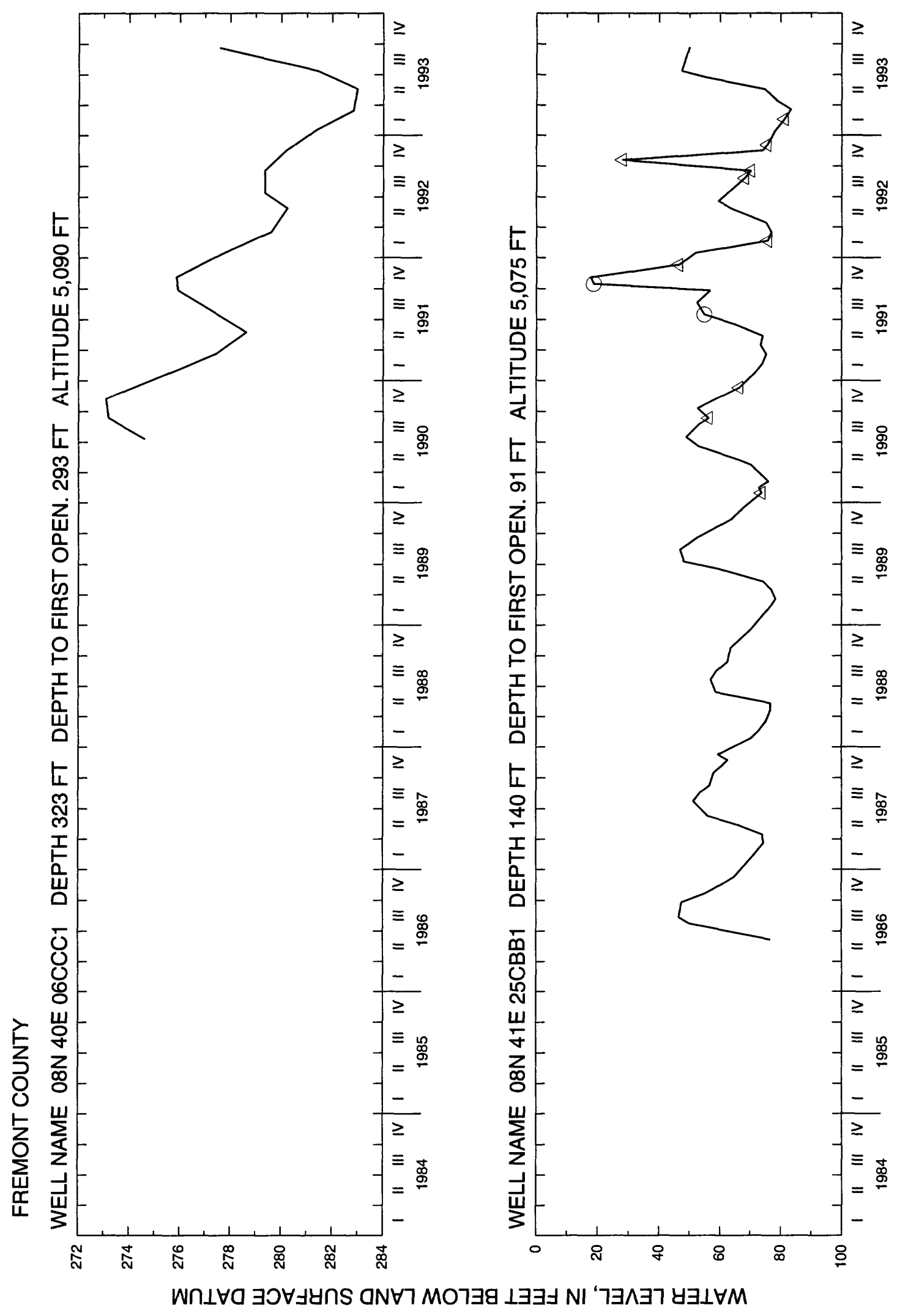




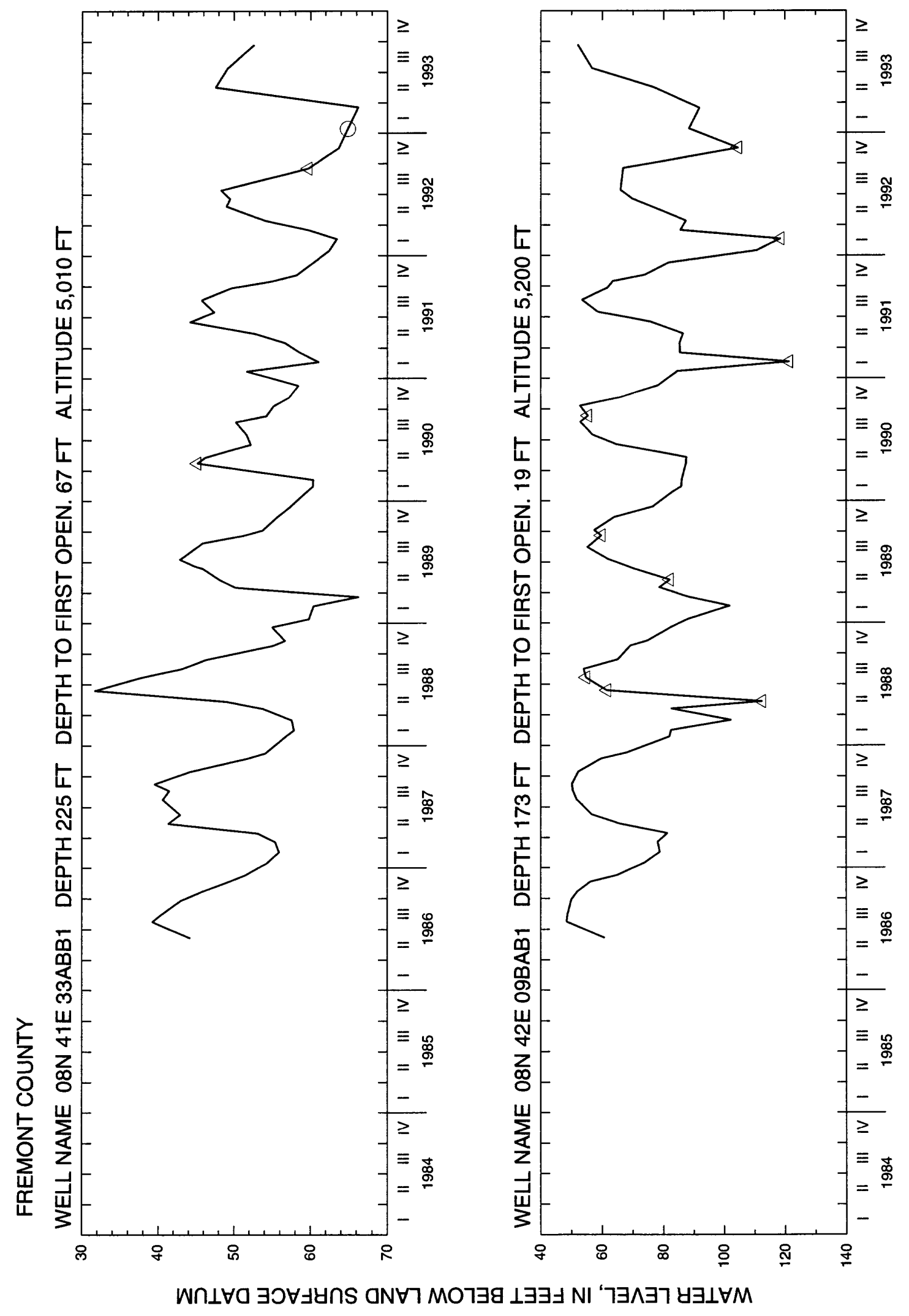




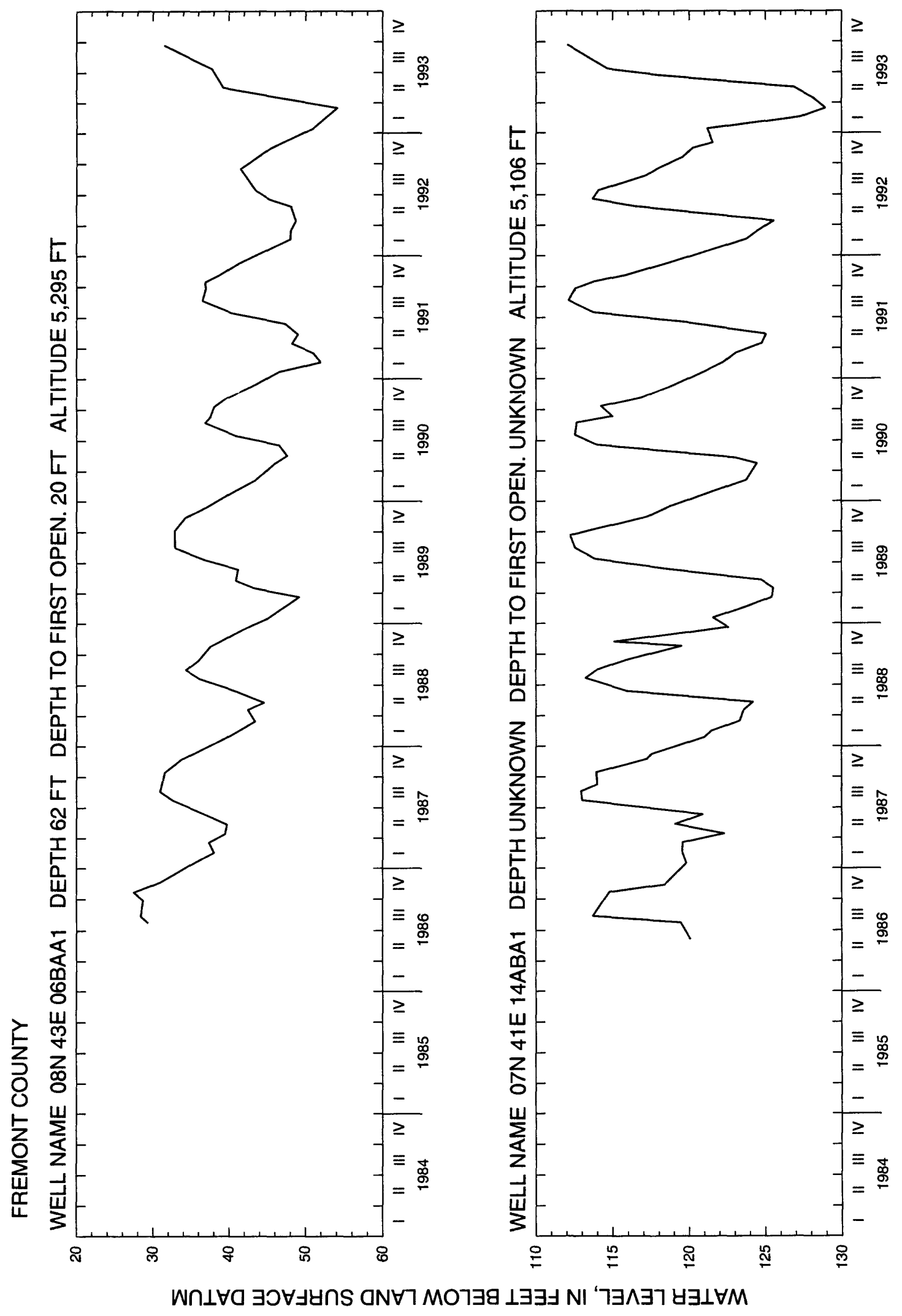




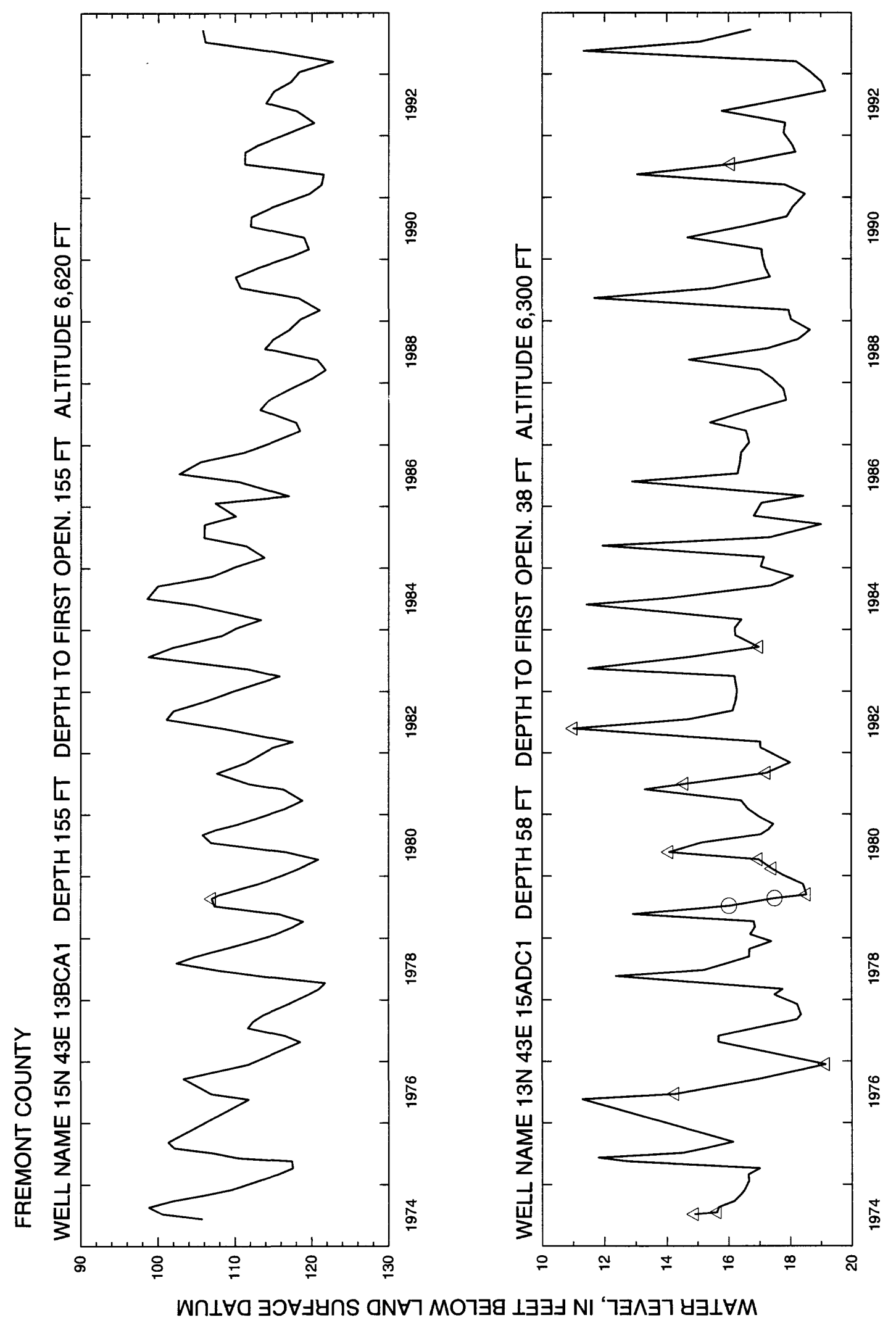




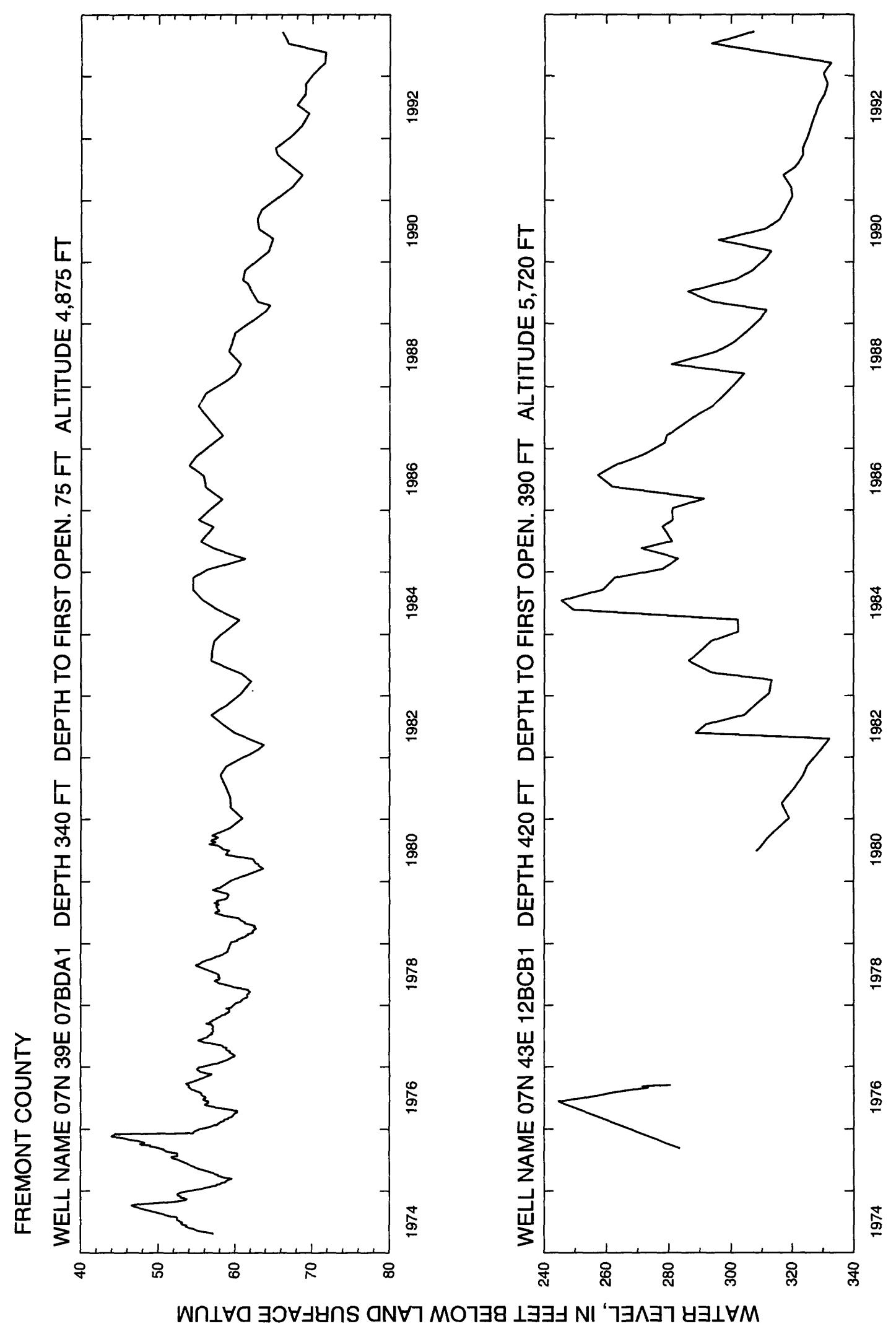




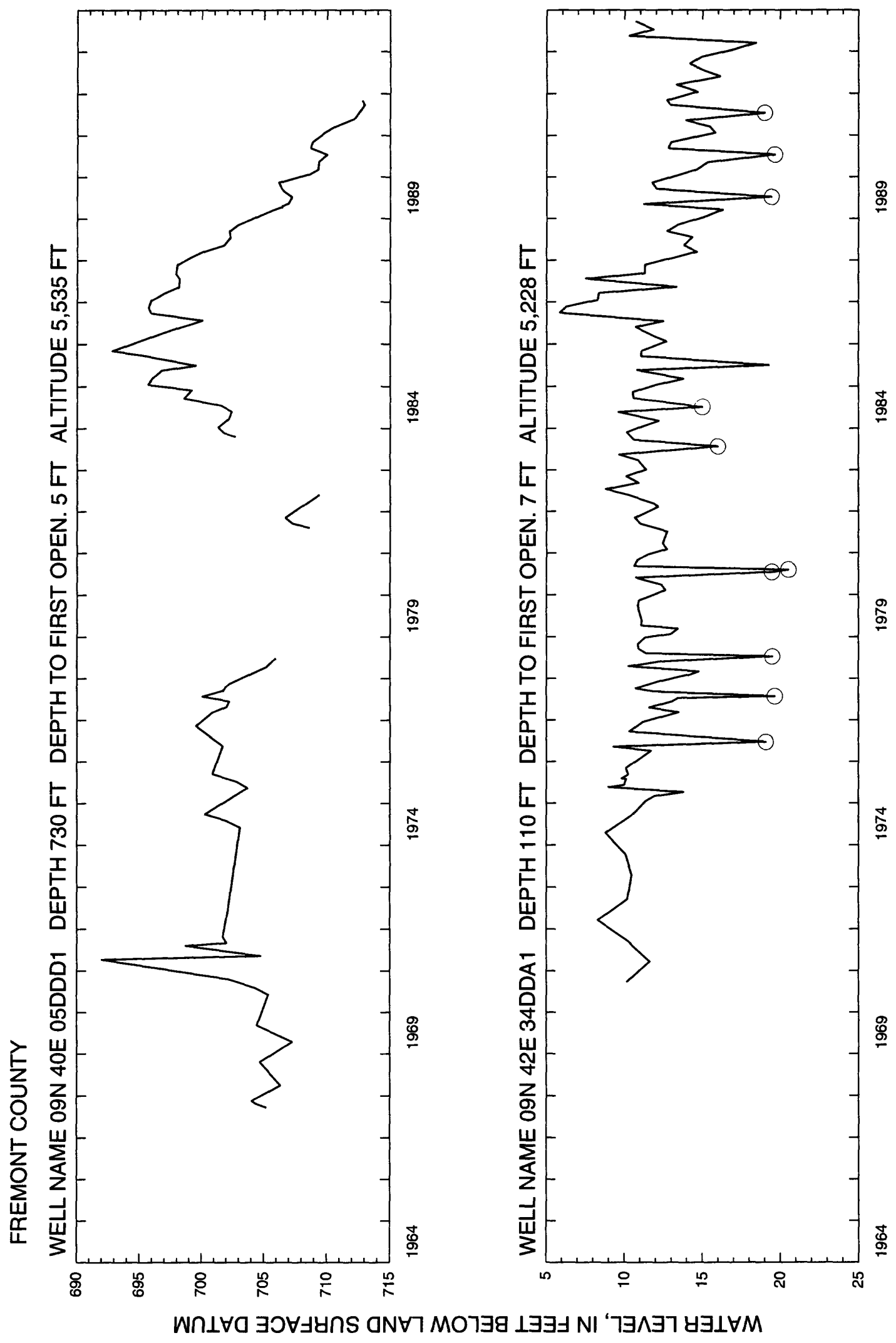




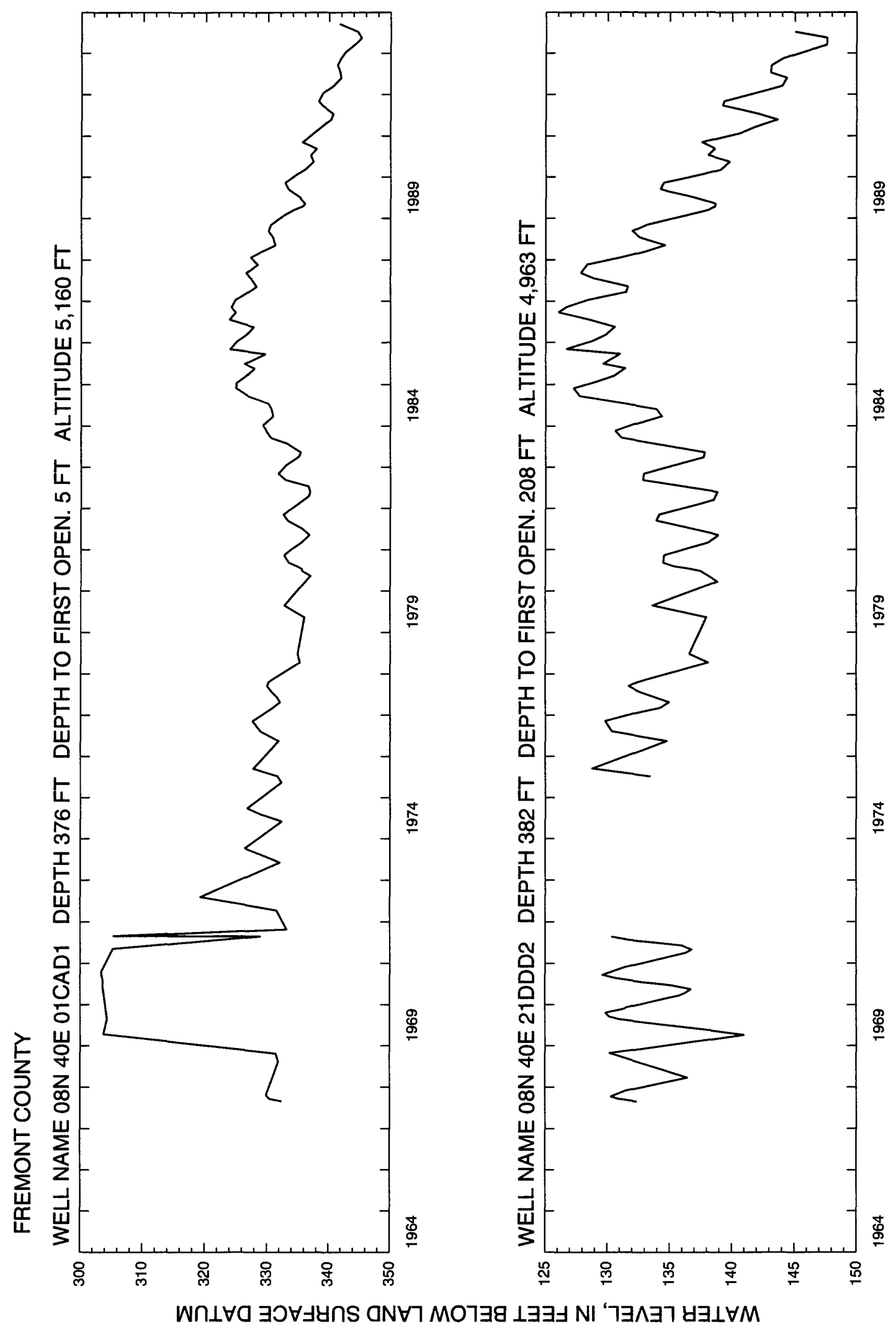




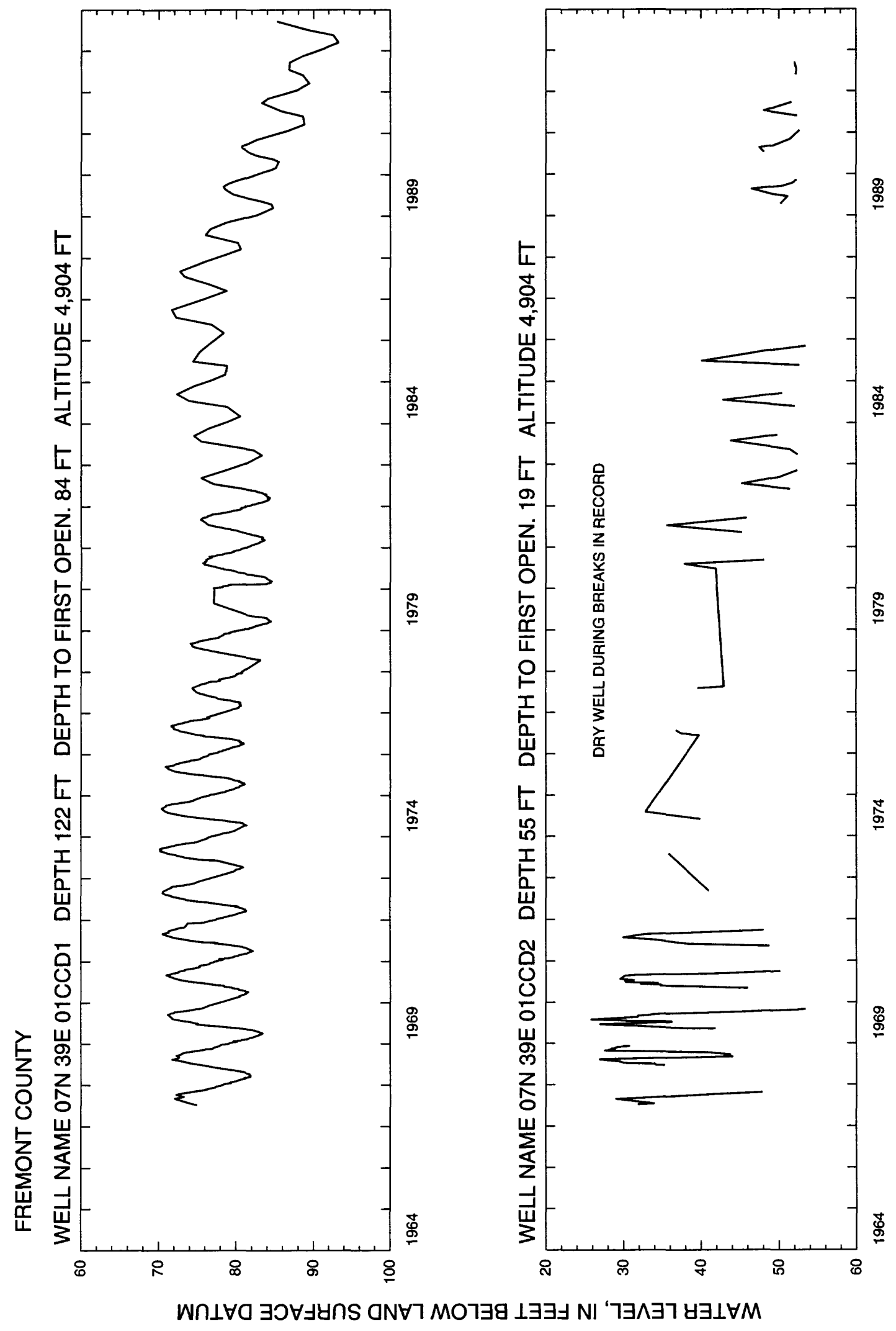




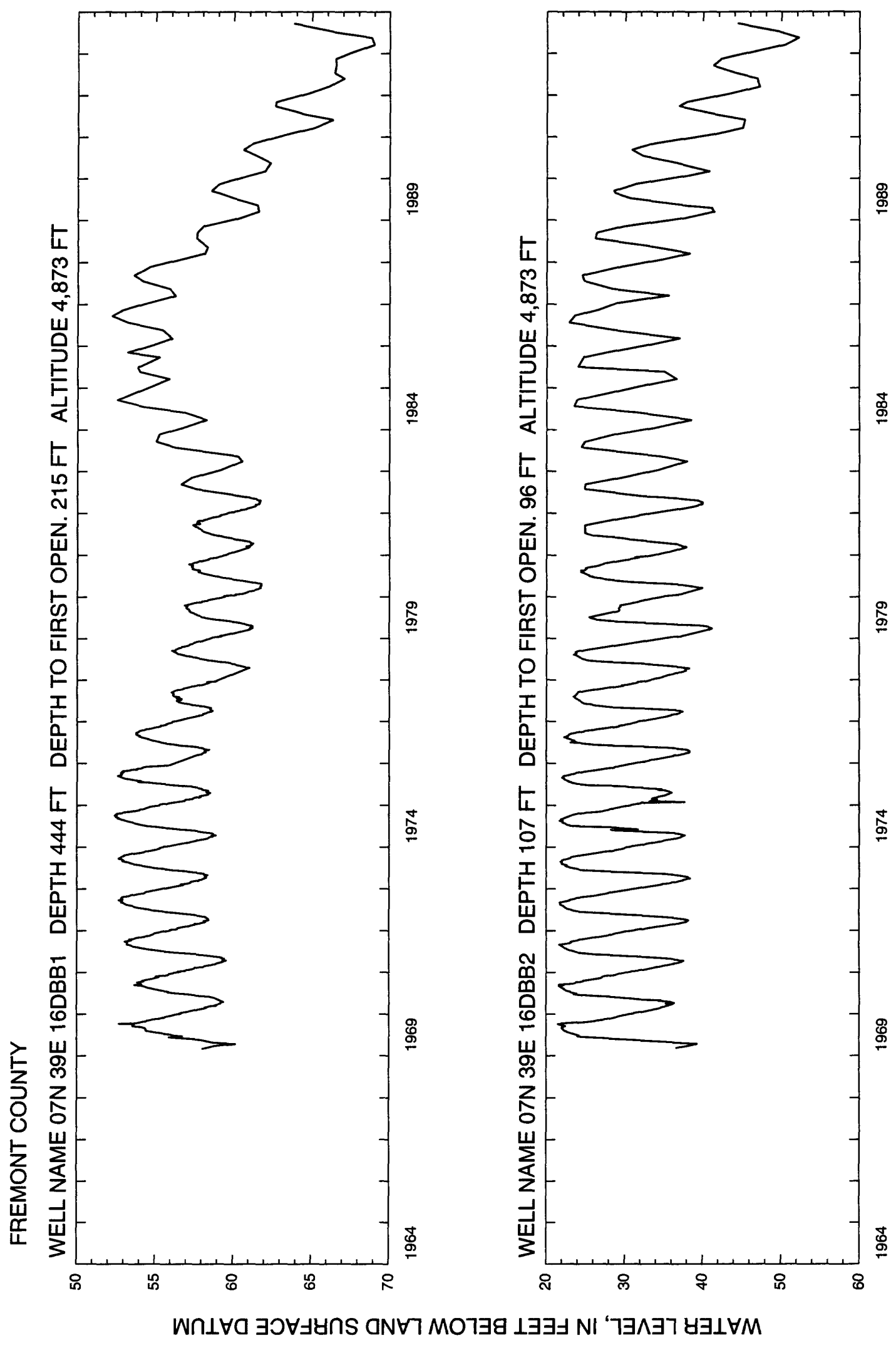

$\stackrel{8}{\circ}$

\%

$\frac{9}{9}$

$\frac{5}{5}$

8

๕

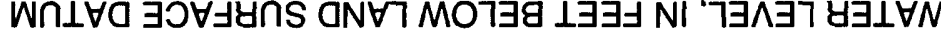




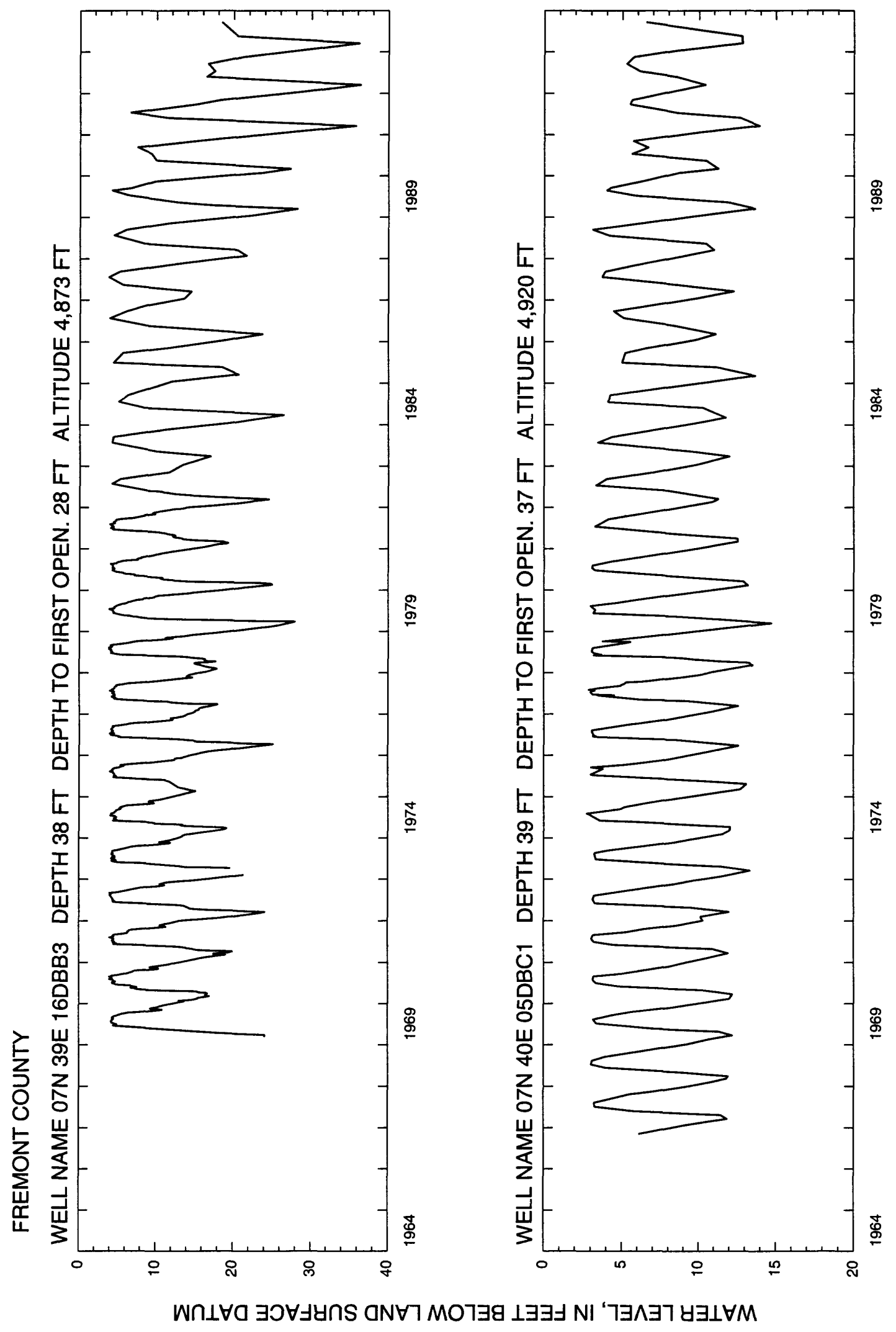




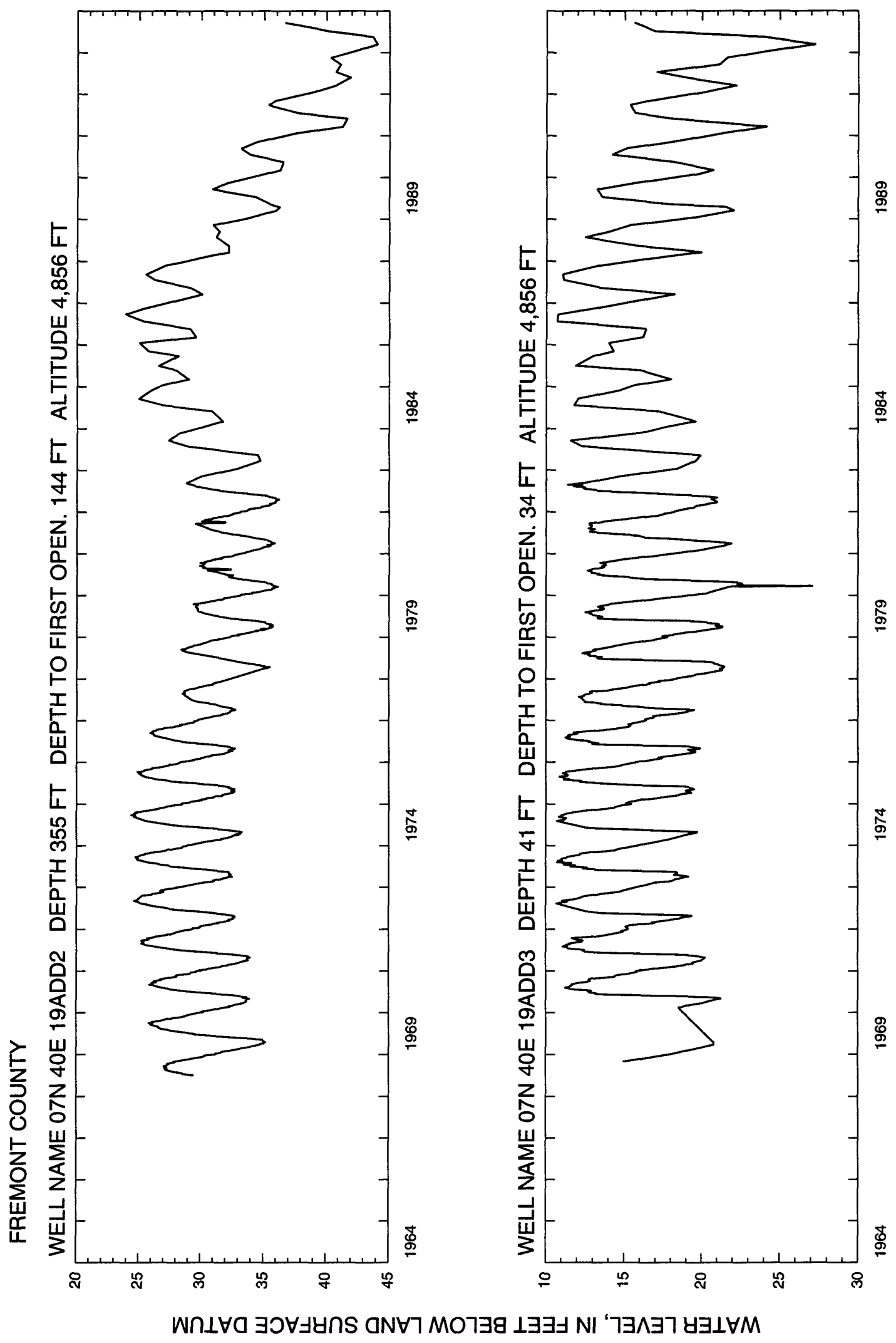

$\stackrel{\circ}{\circ}$

$\stackrel{\$}{\circ}$

$\frac{9}{\circ}$

志

욤

$\stackrel{\square}{\circ}$ 


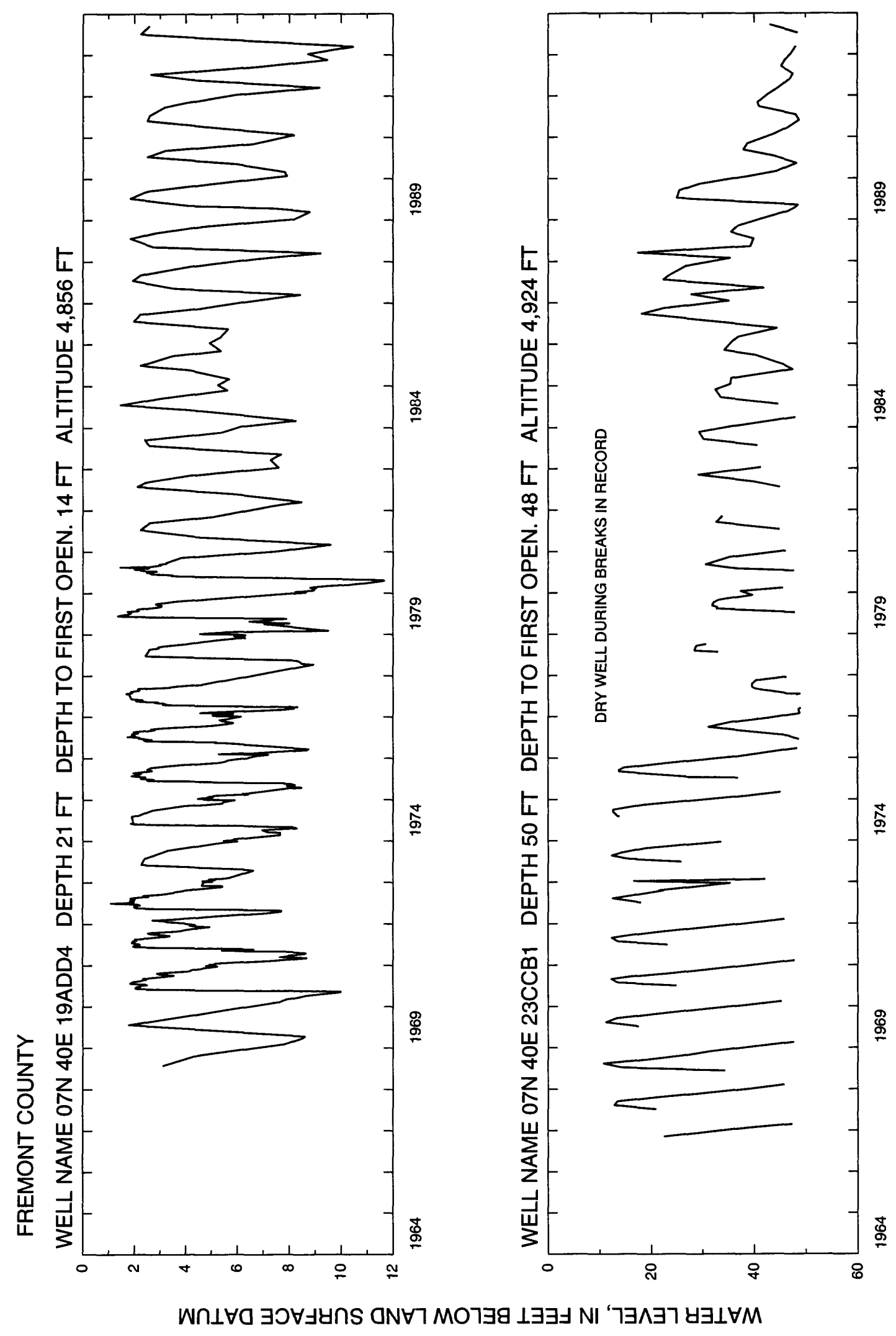




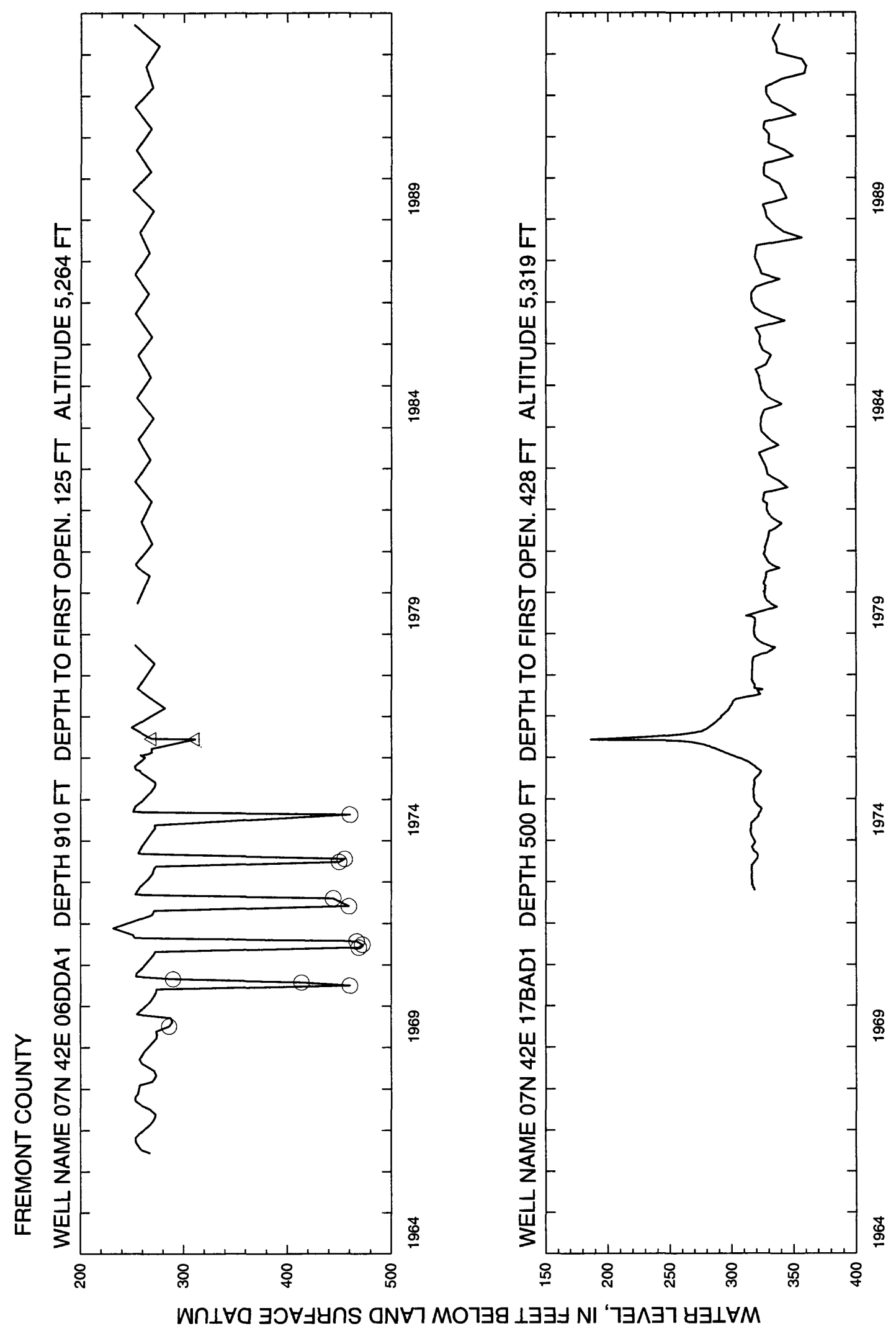




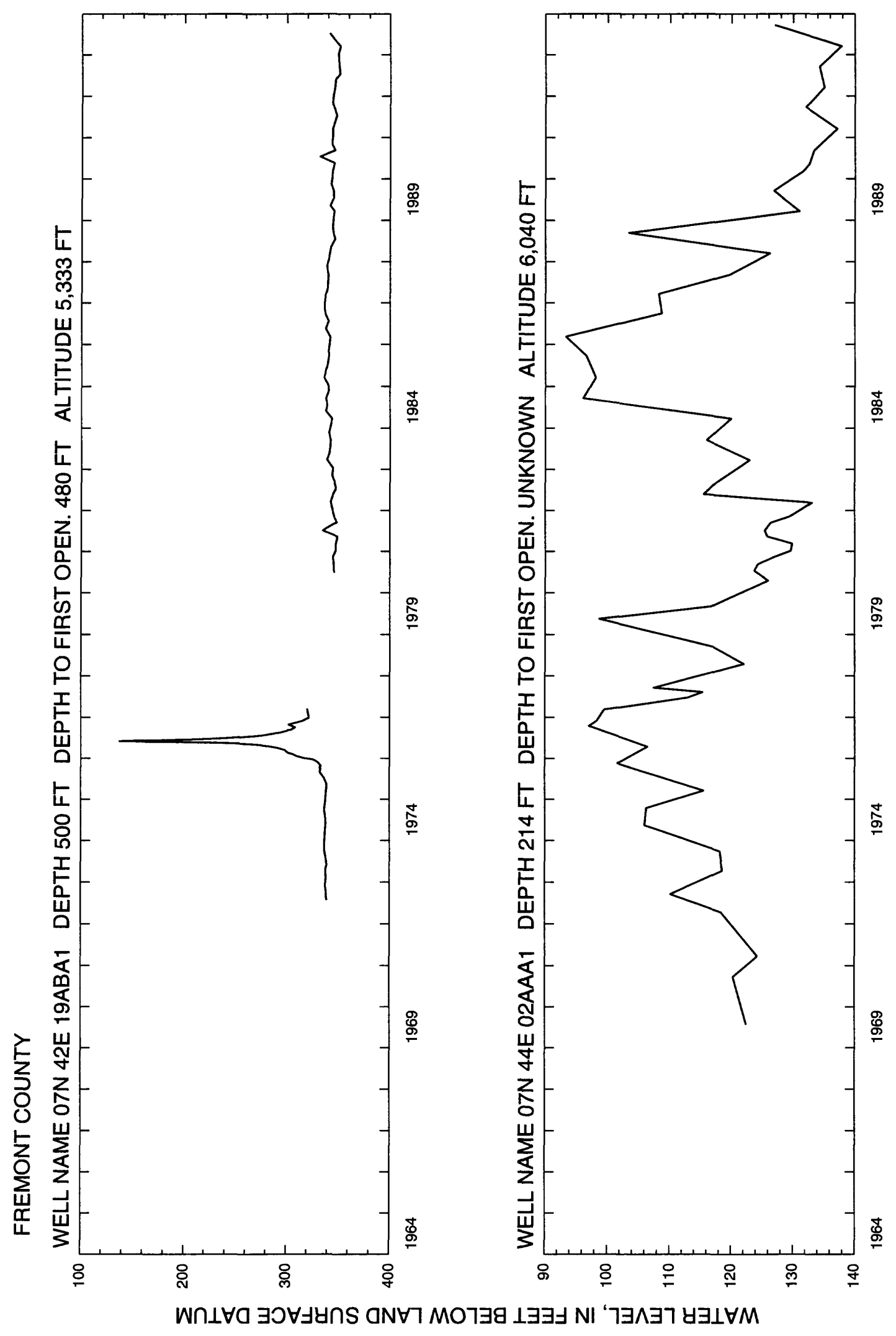


Gem 

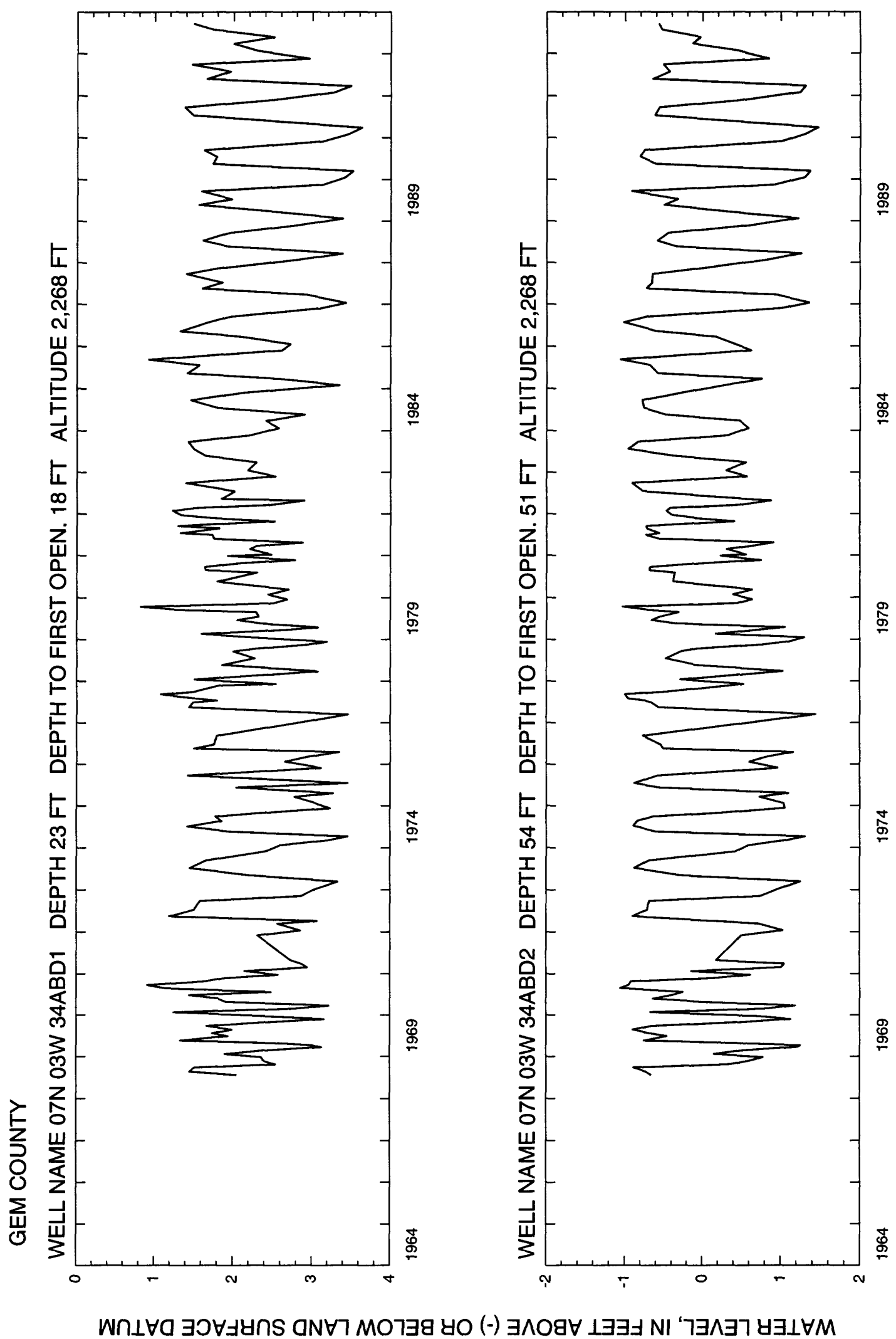

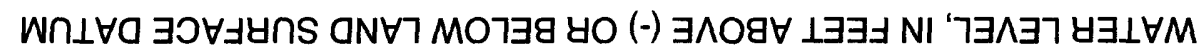



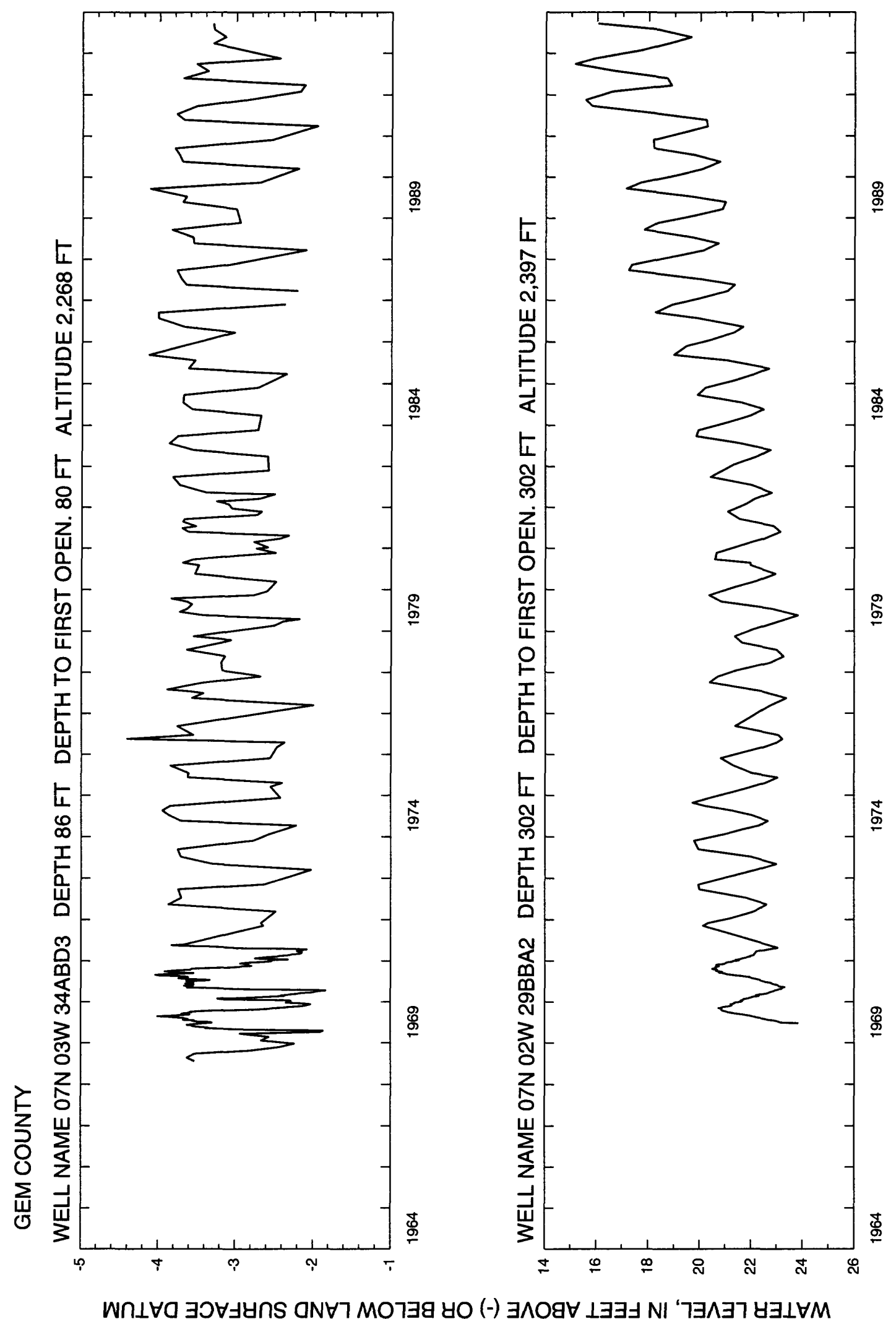

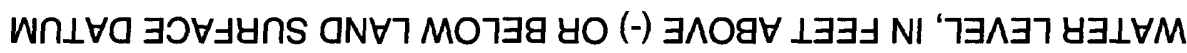



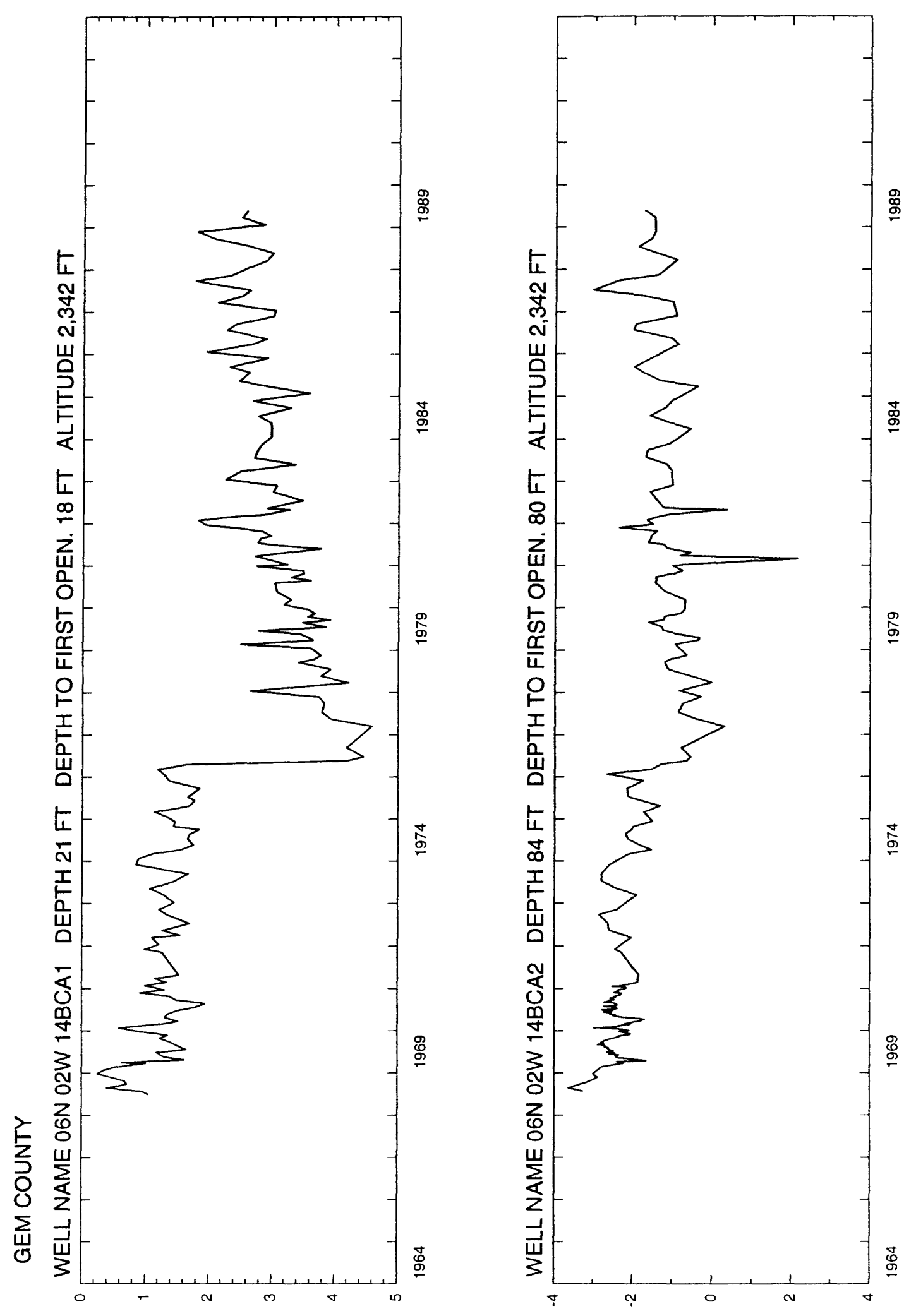

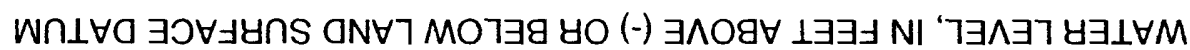




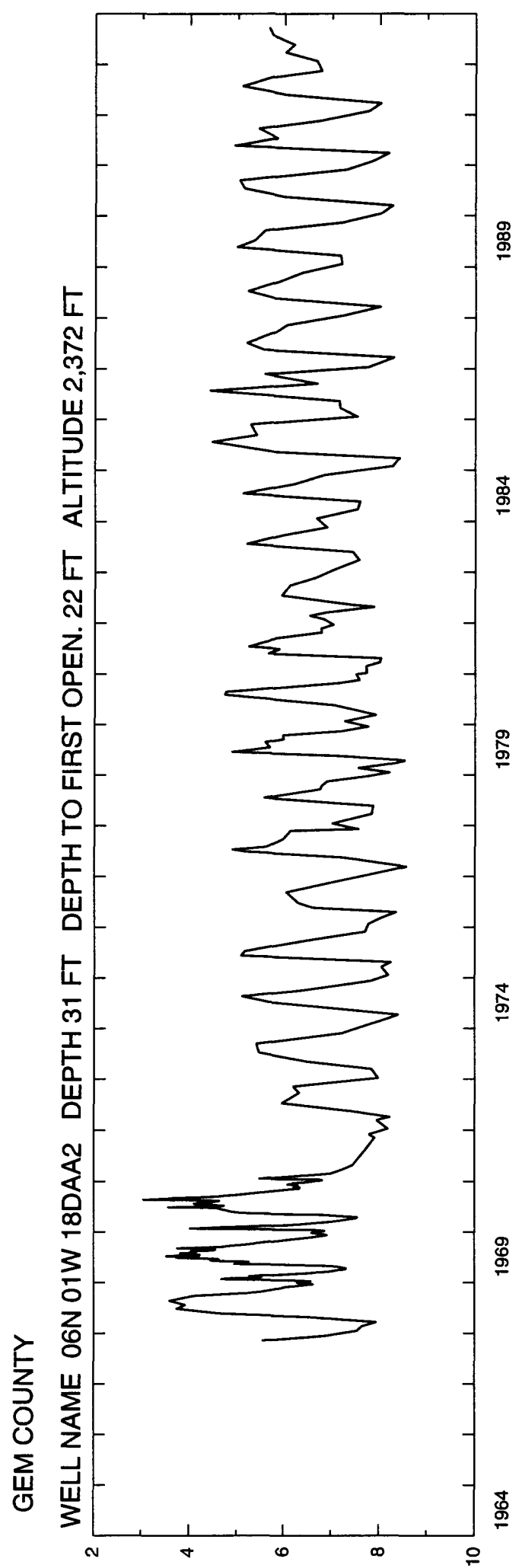

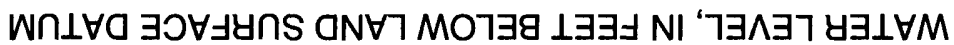


Gooding

215 (aye 2117 Dollows) 


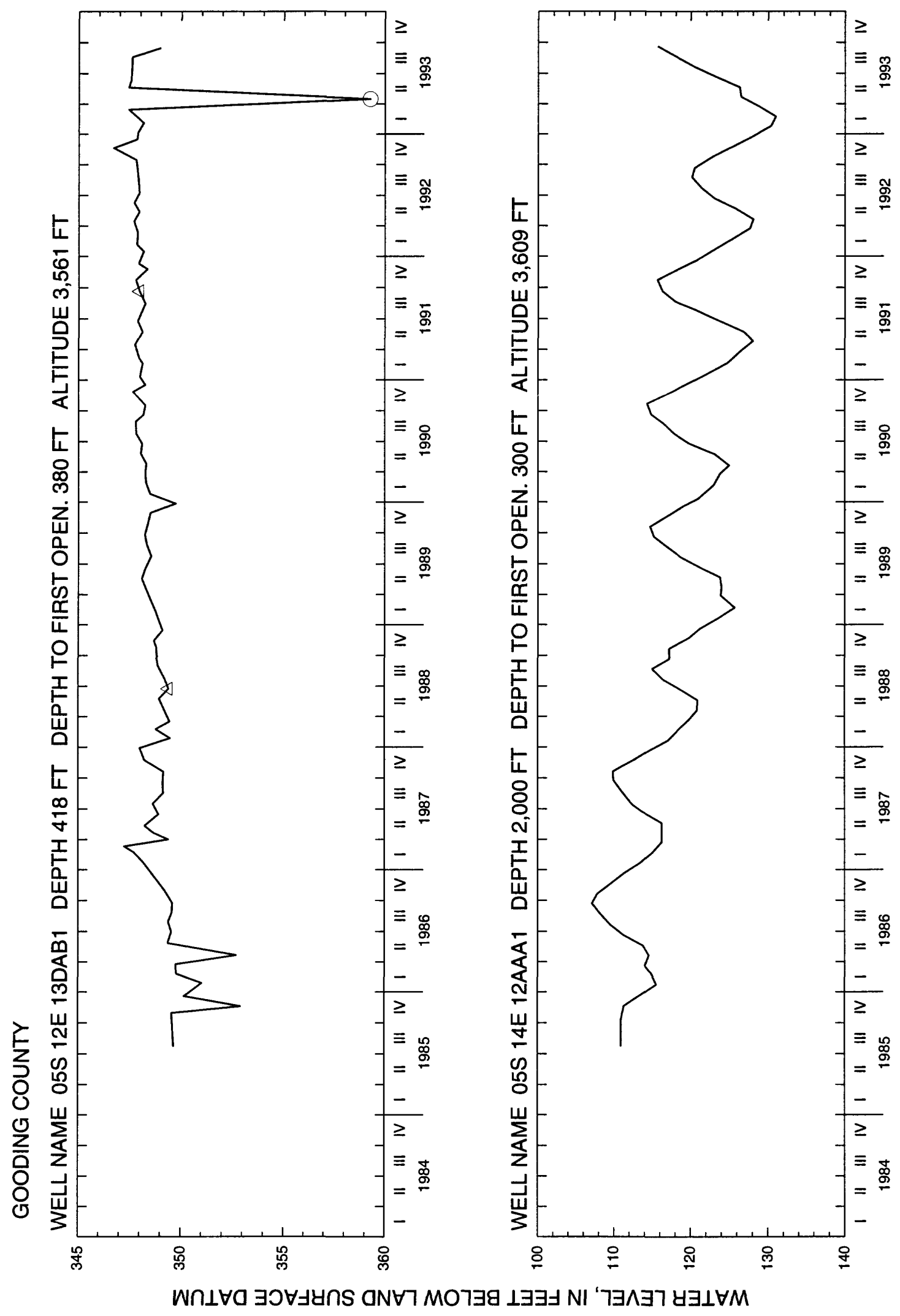




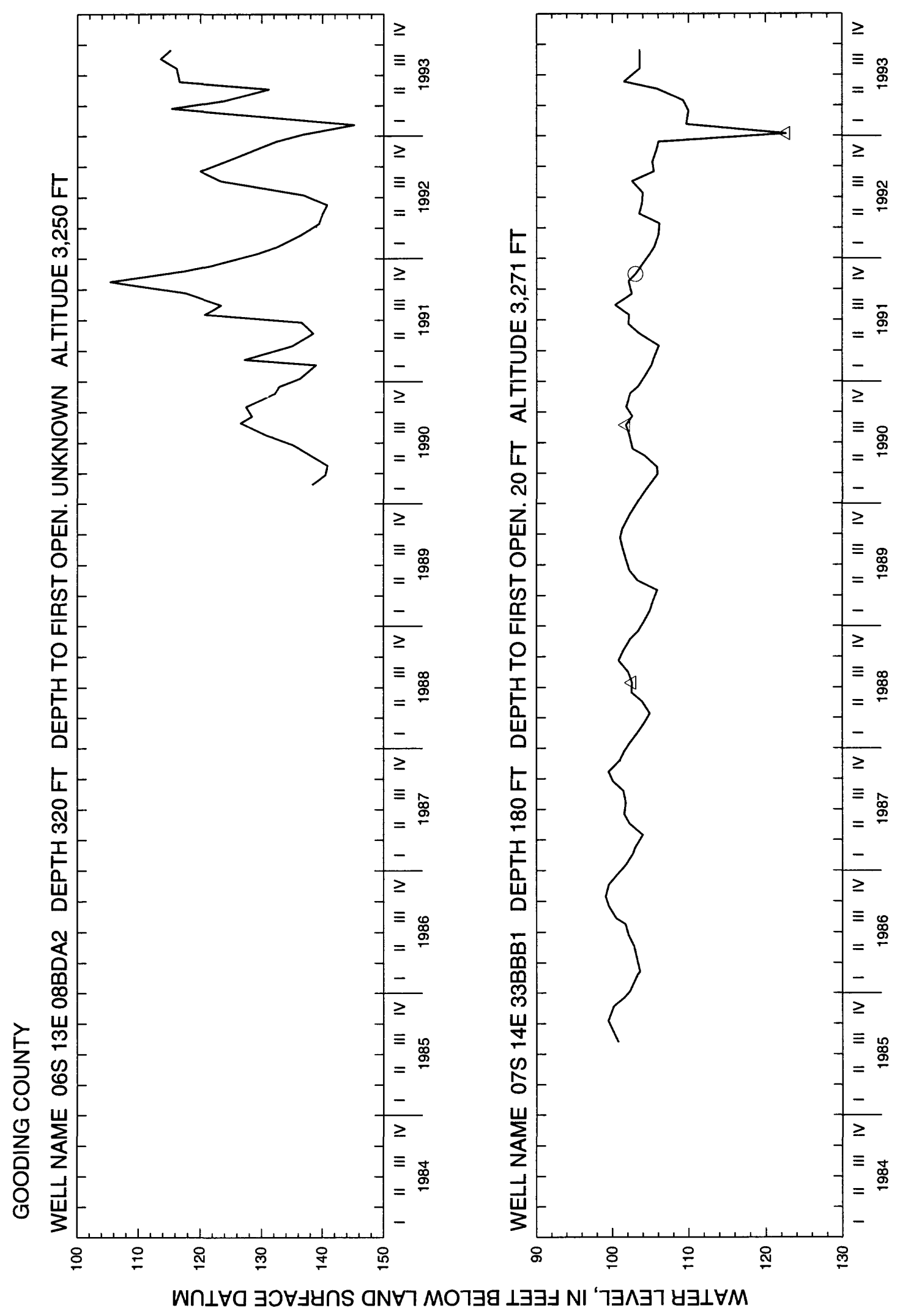




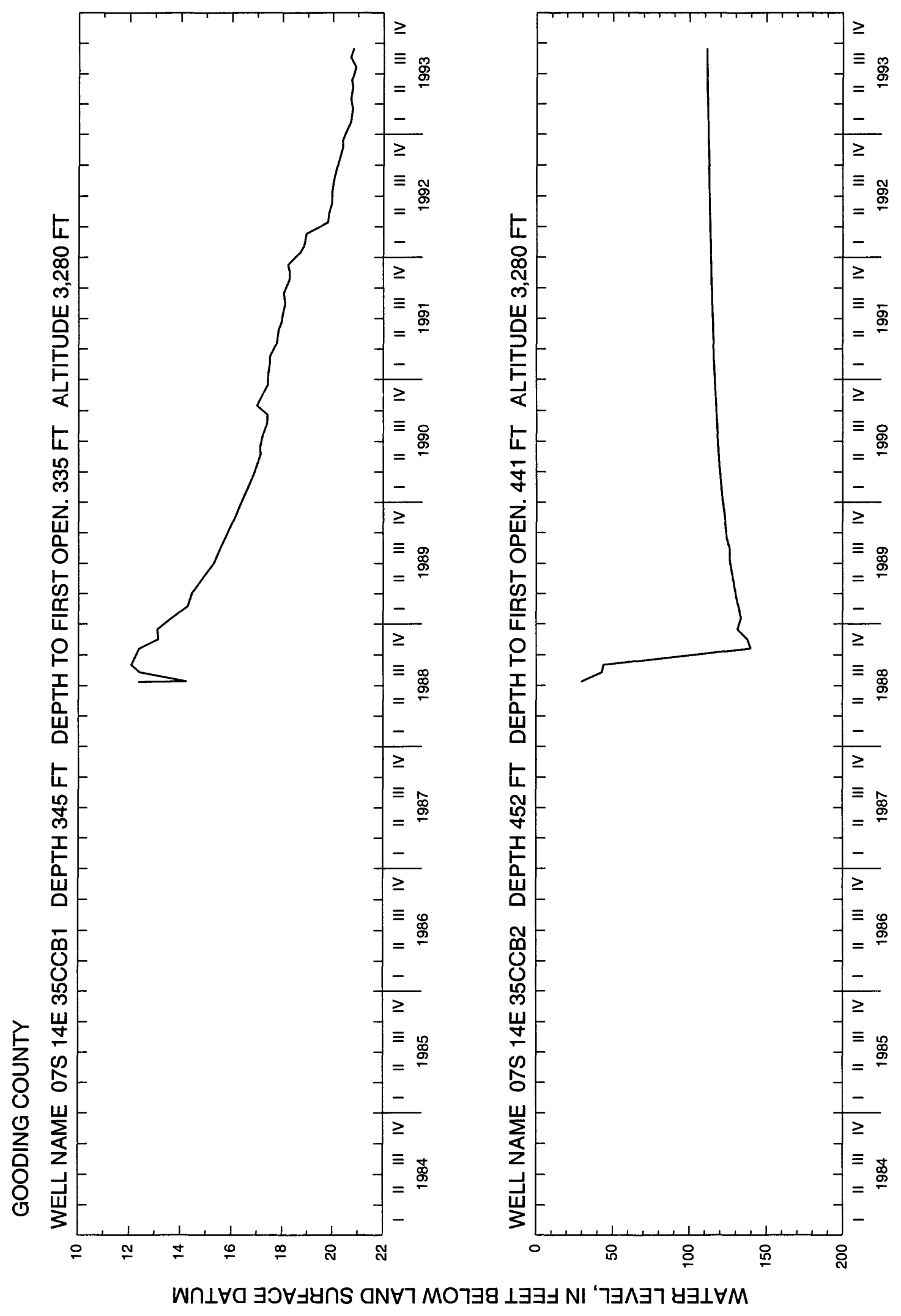




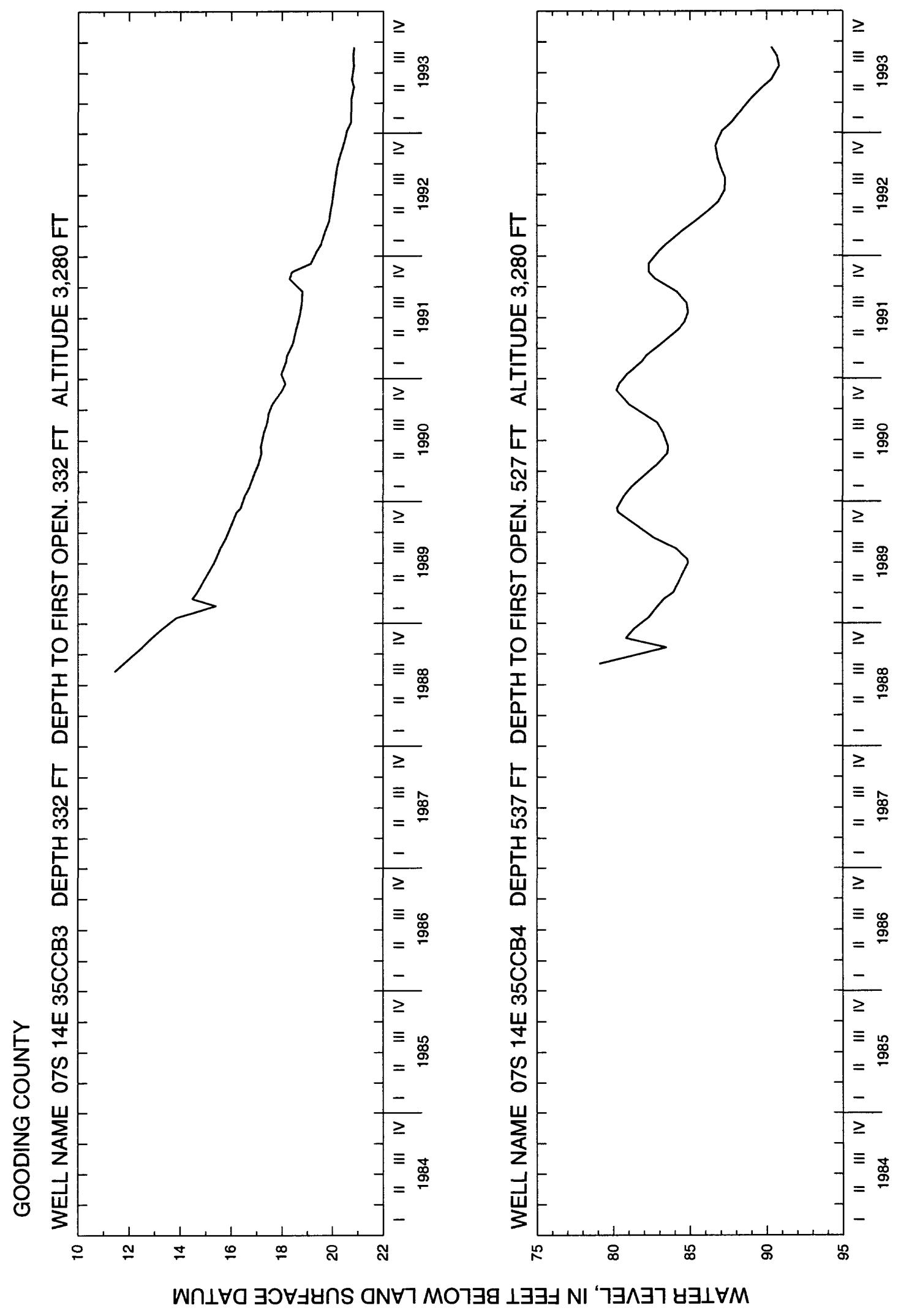




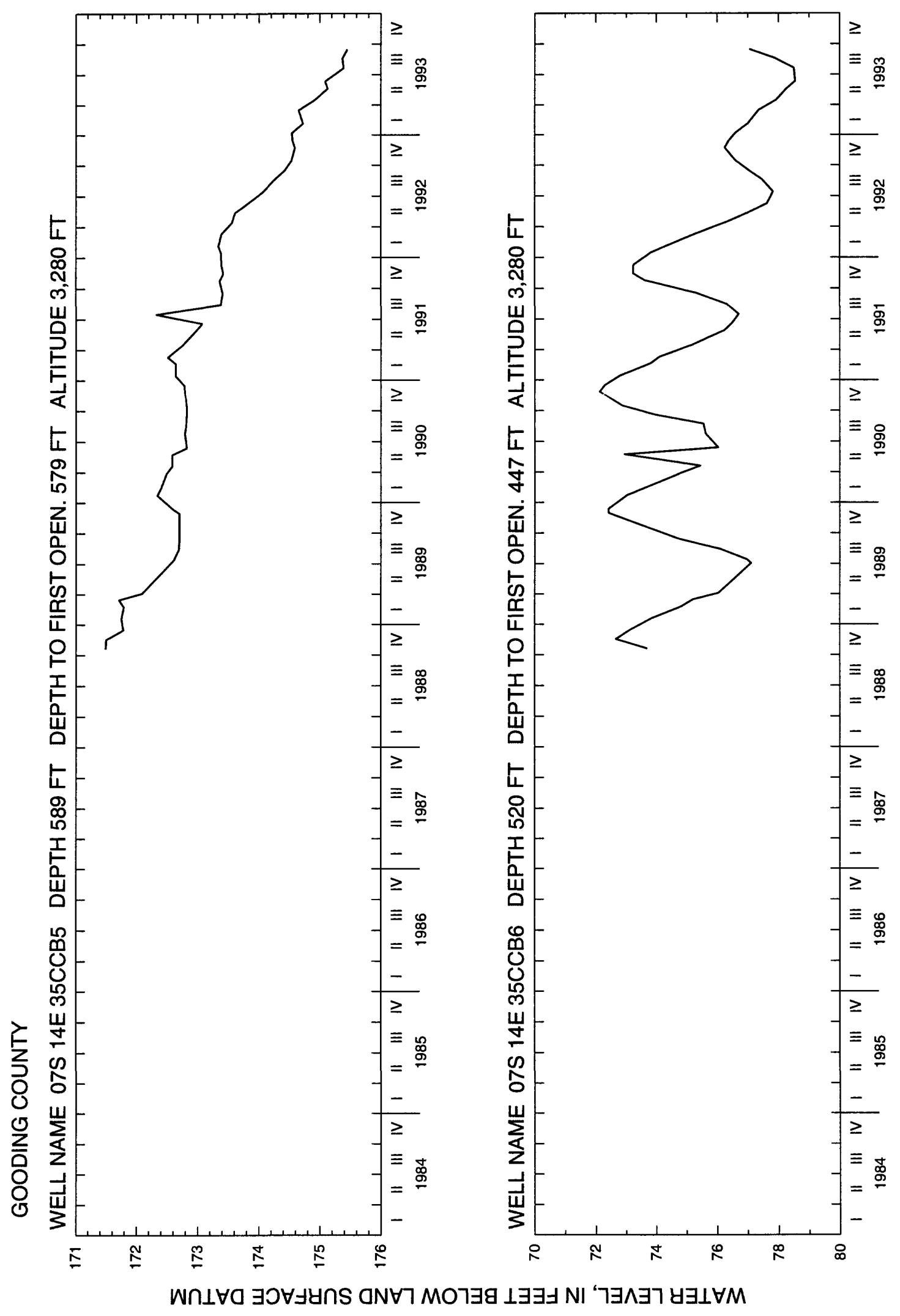




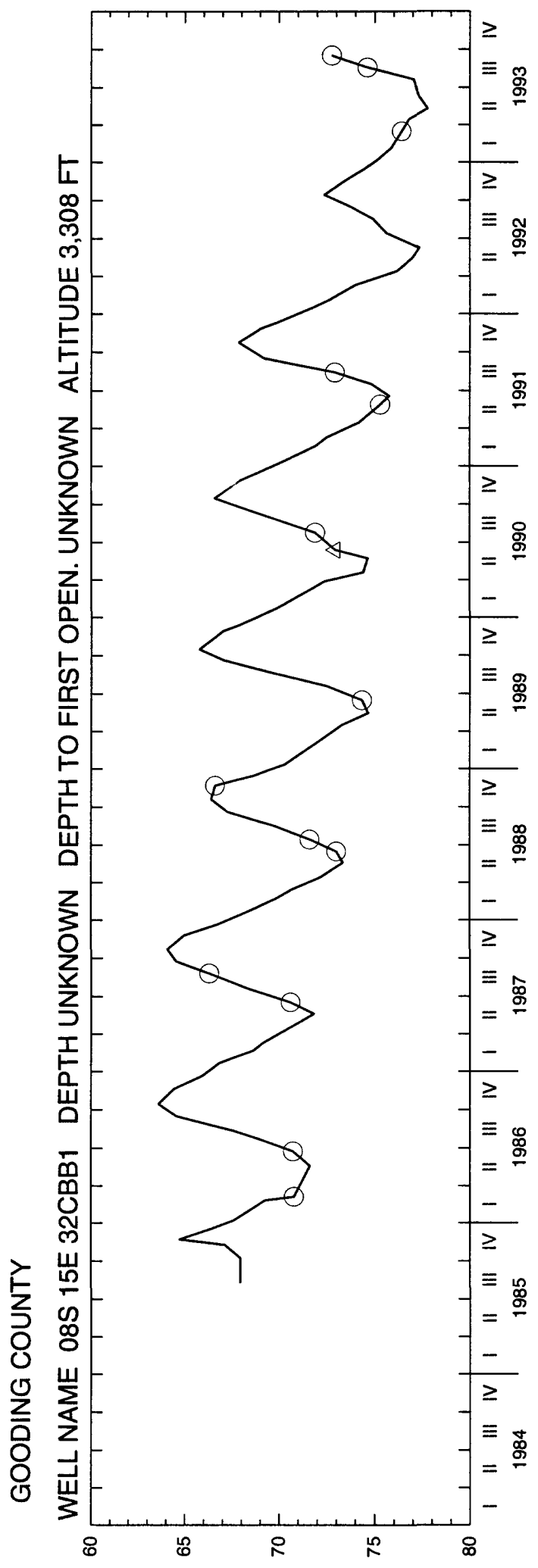

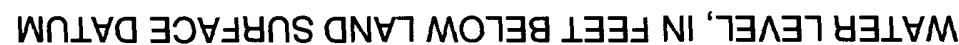




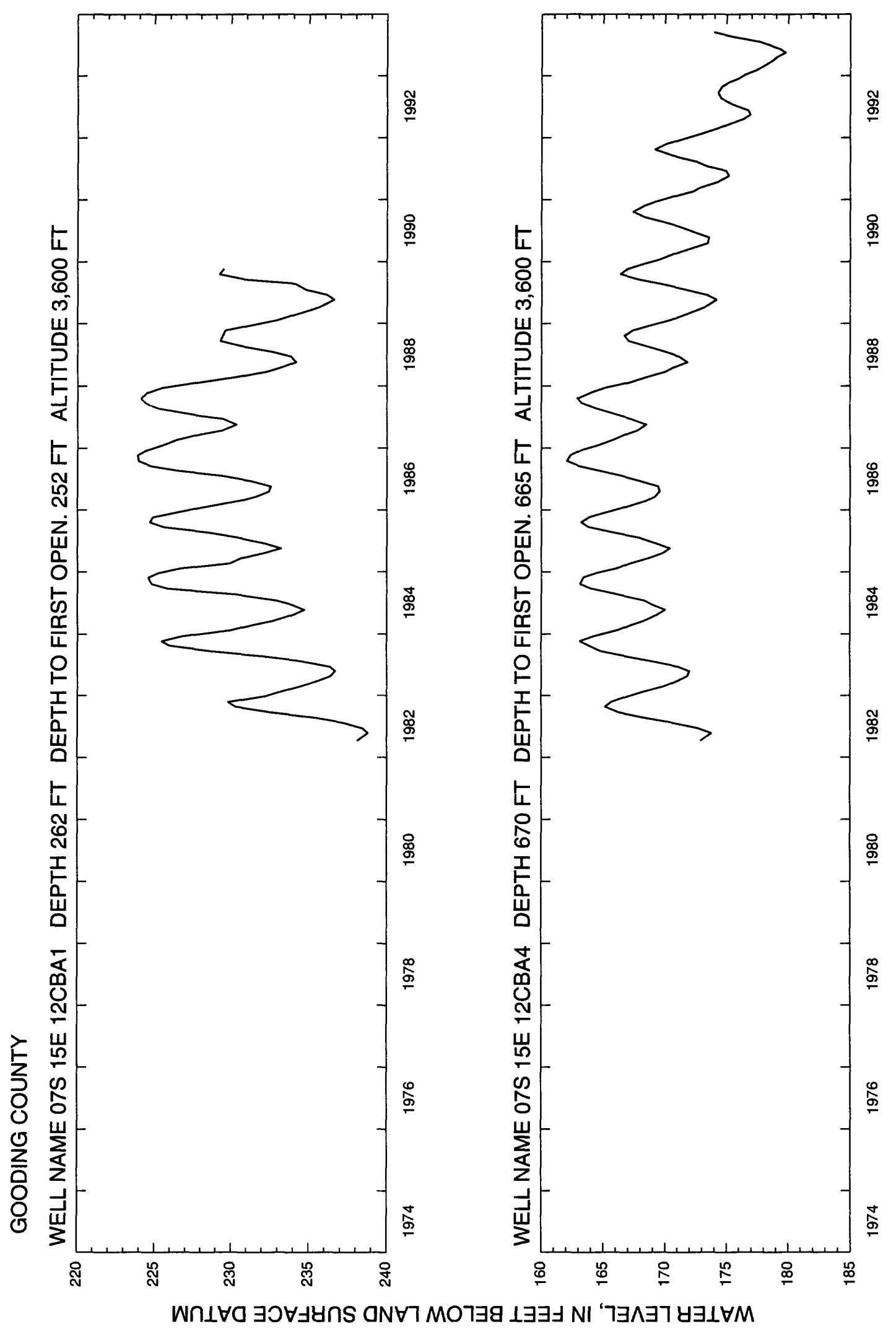




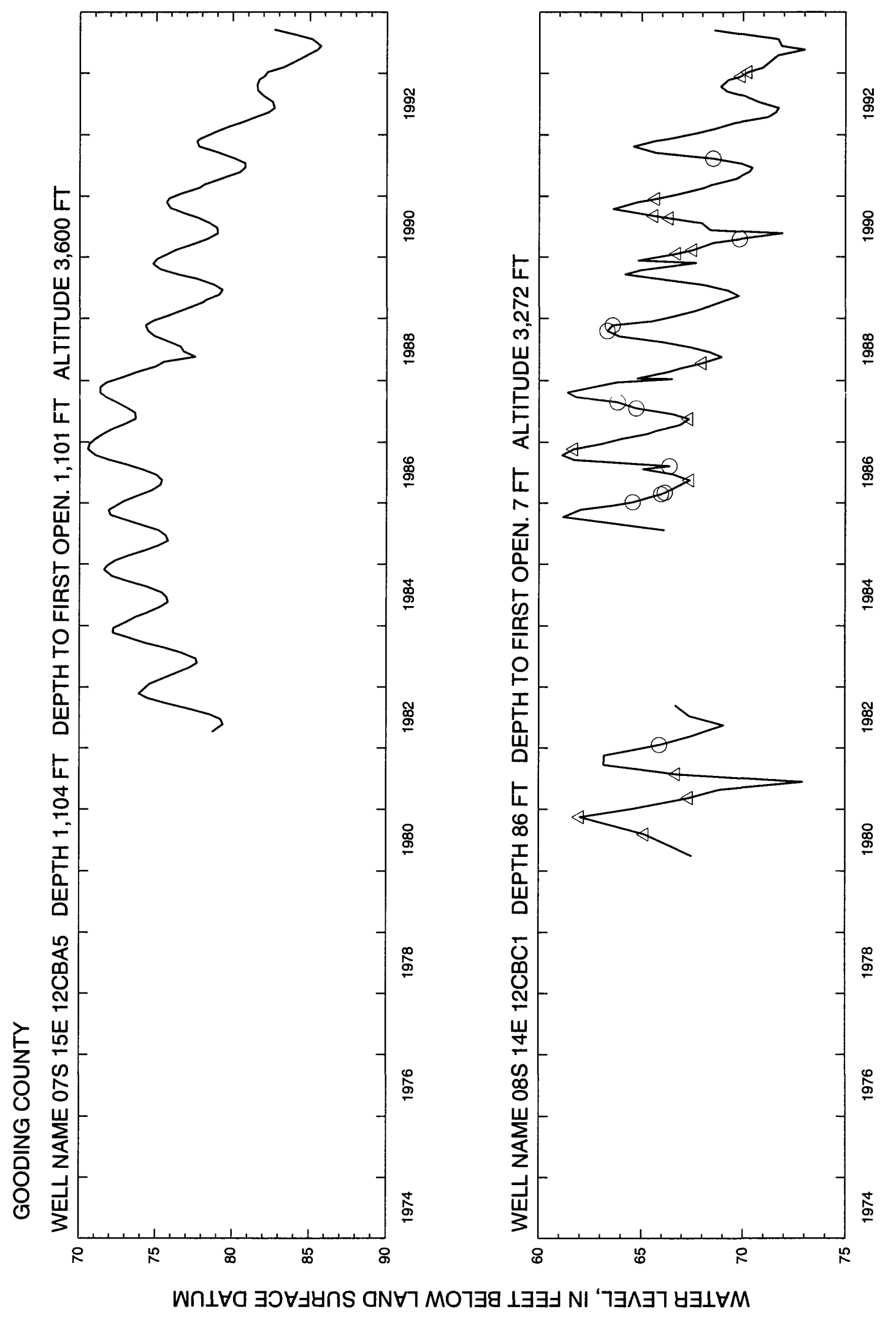




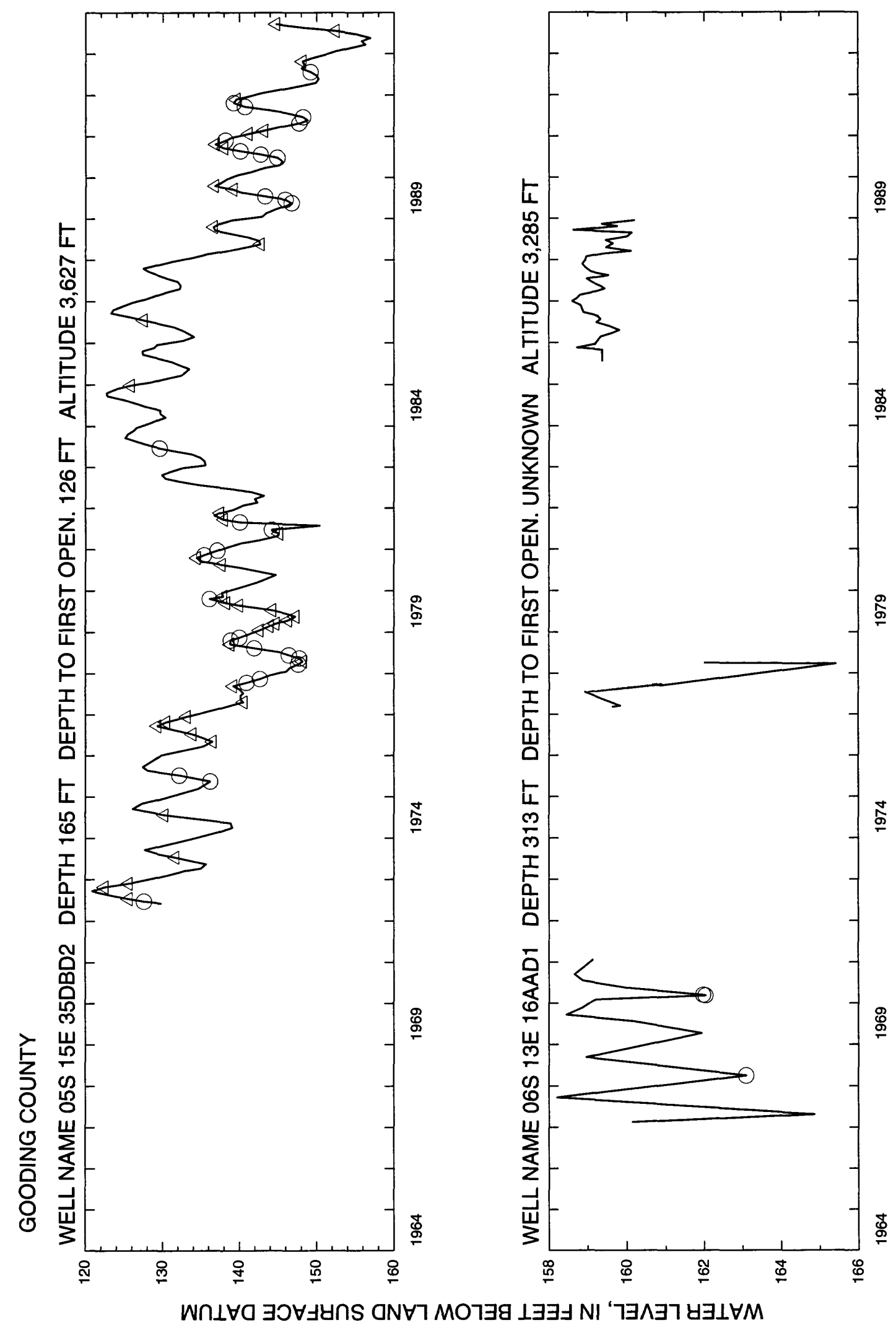




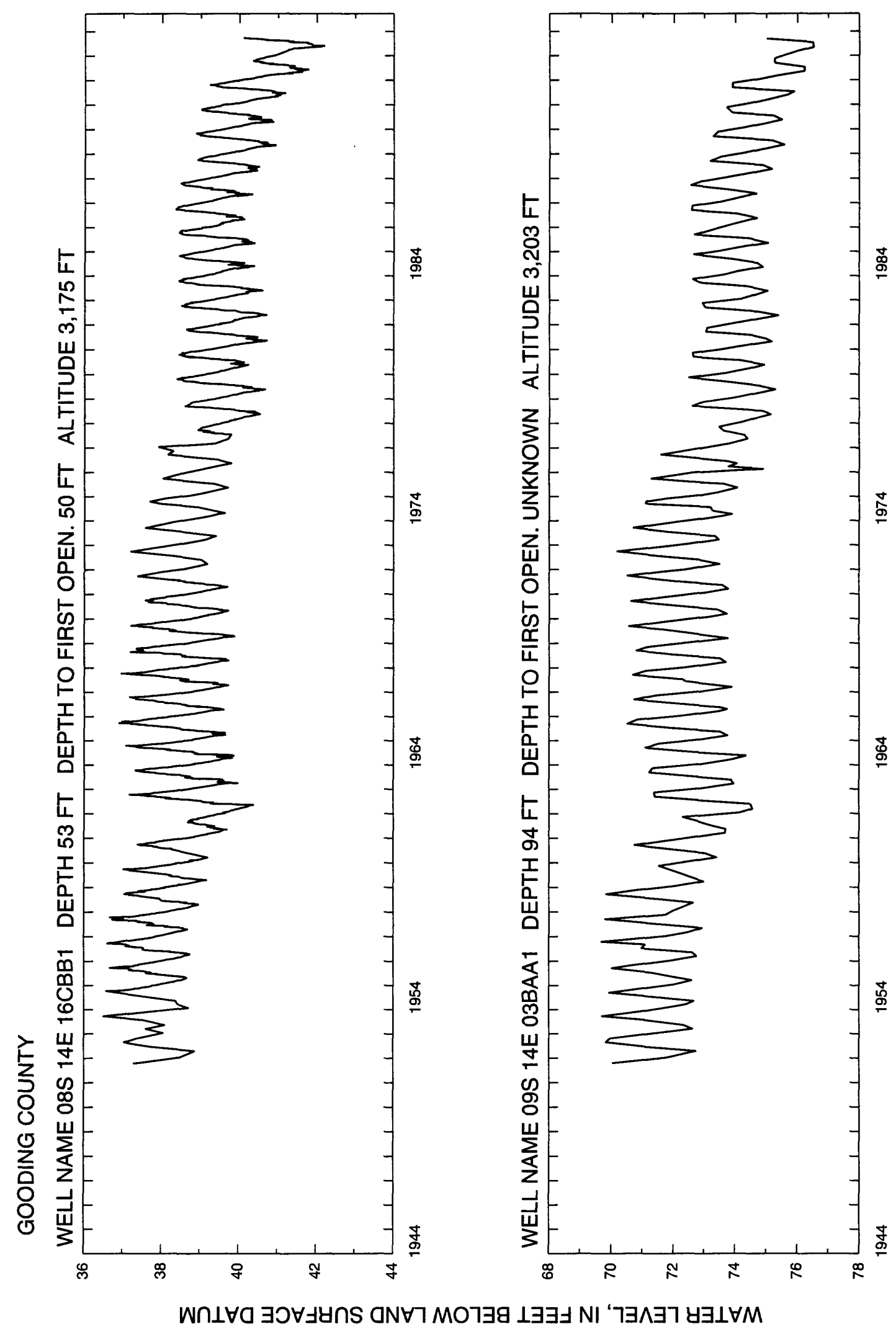

$\stackrel{+}{\mathrm{\Phi}}$

莽

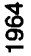

芩

声 


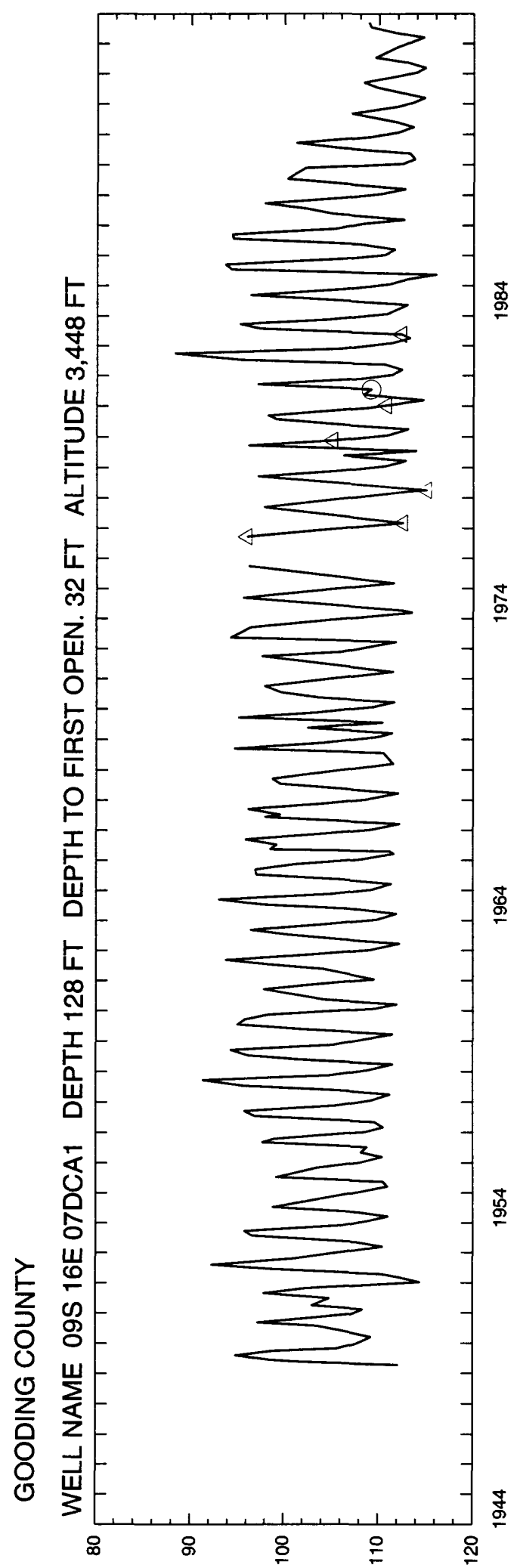

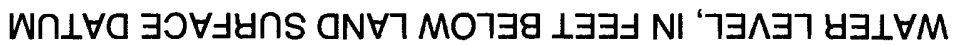


Idaho

229 (paye 231 follows) 


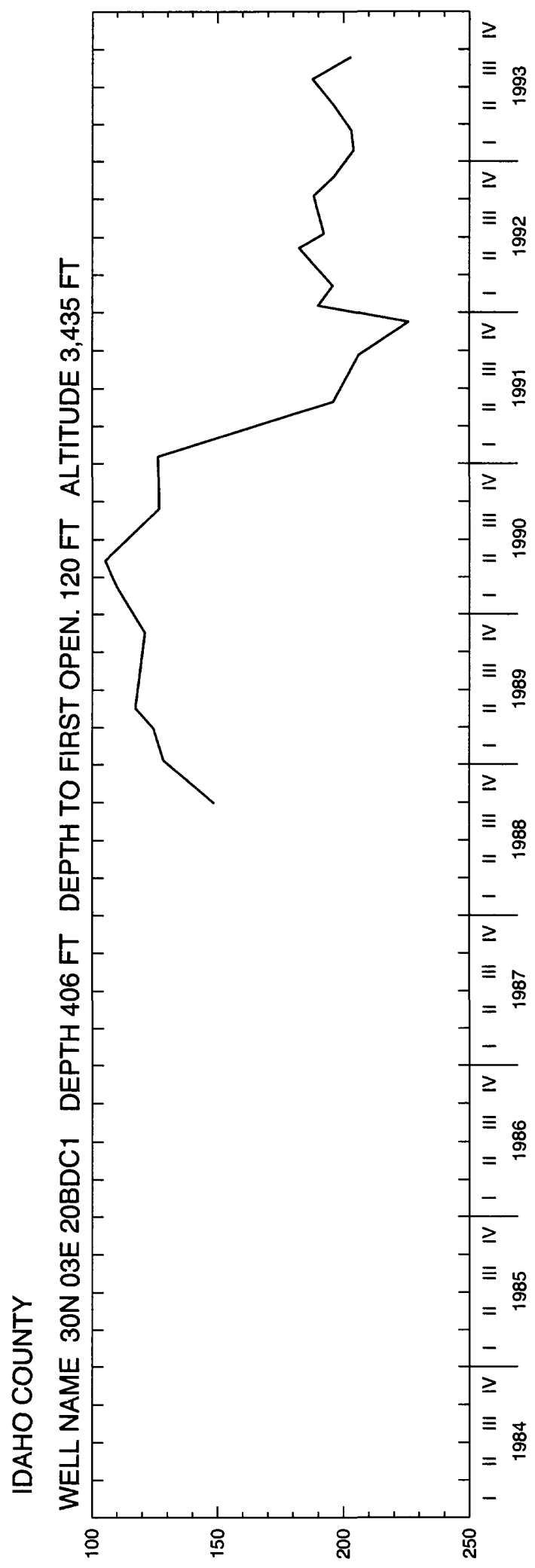

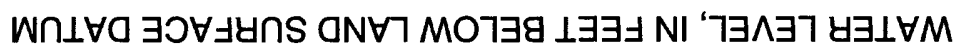

231 (page 233 dollows) 
Jefferson

233 (oage 235 dollows) 


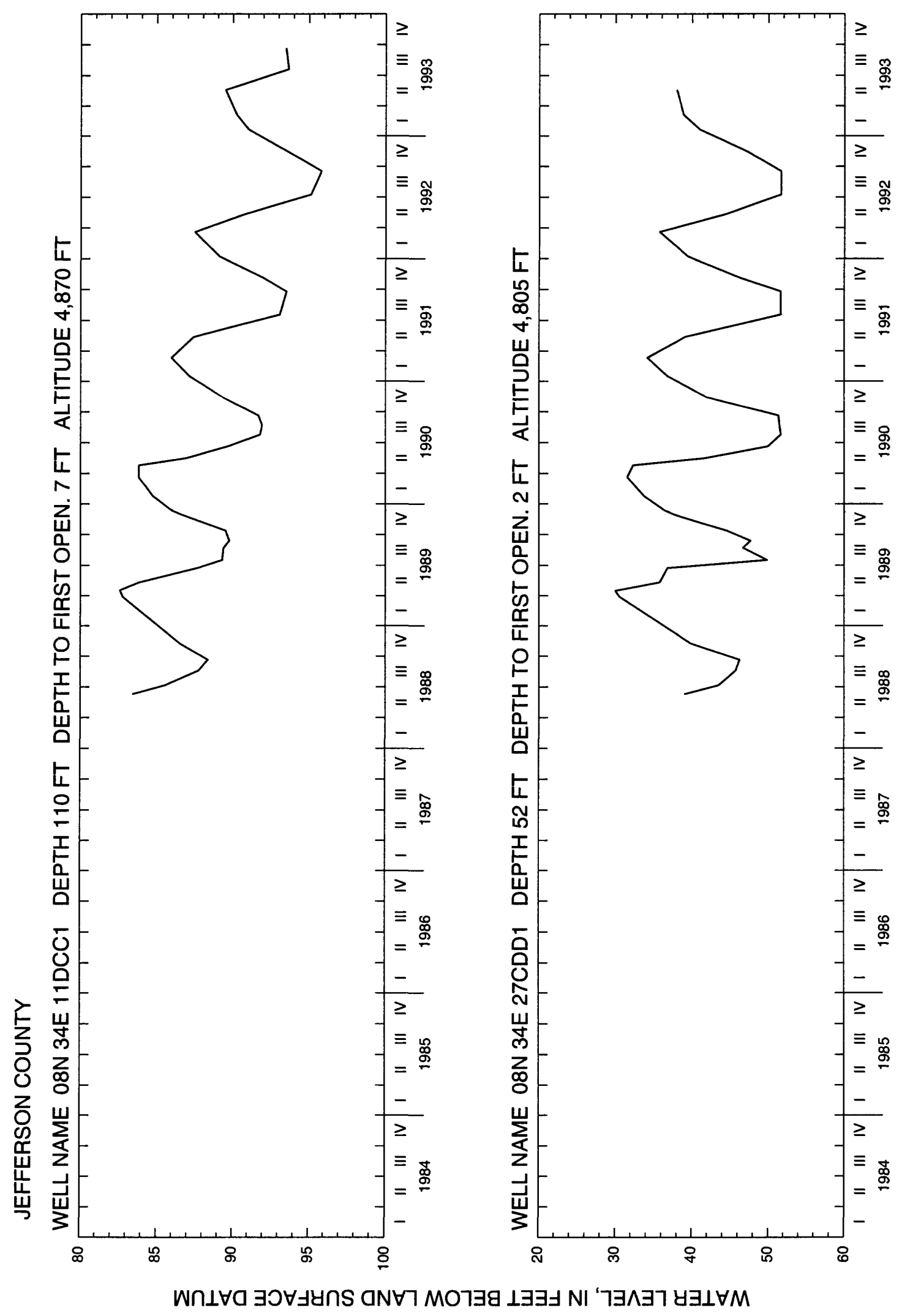




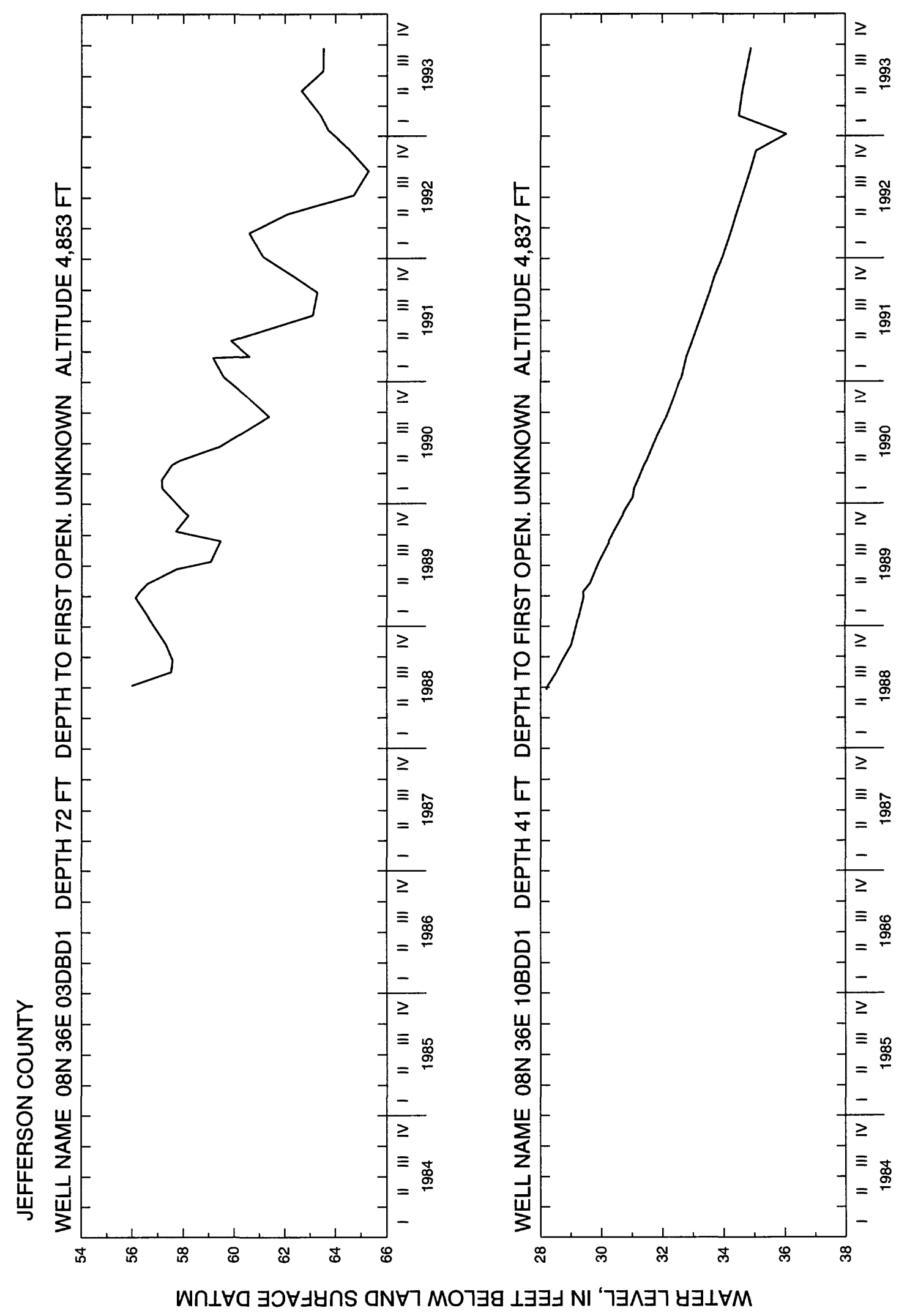




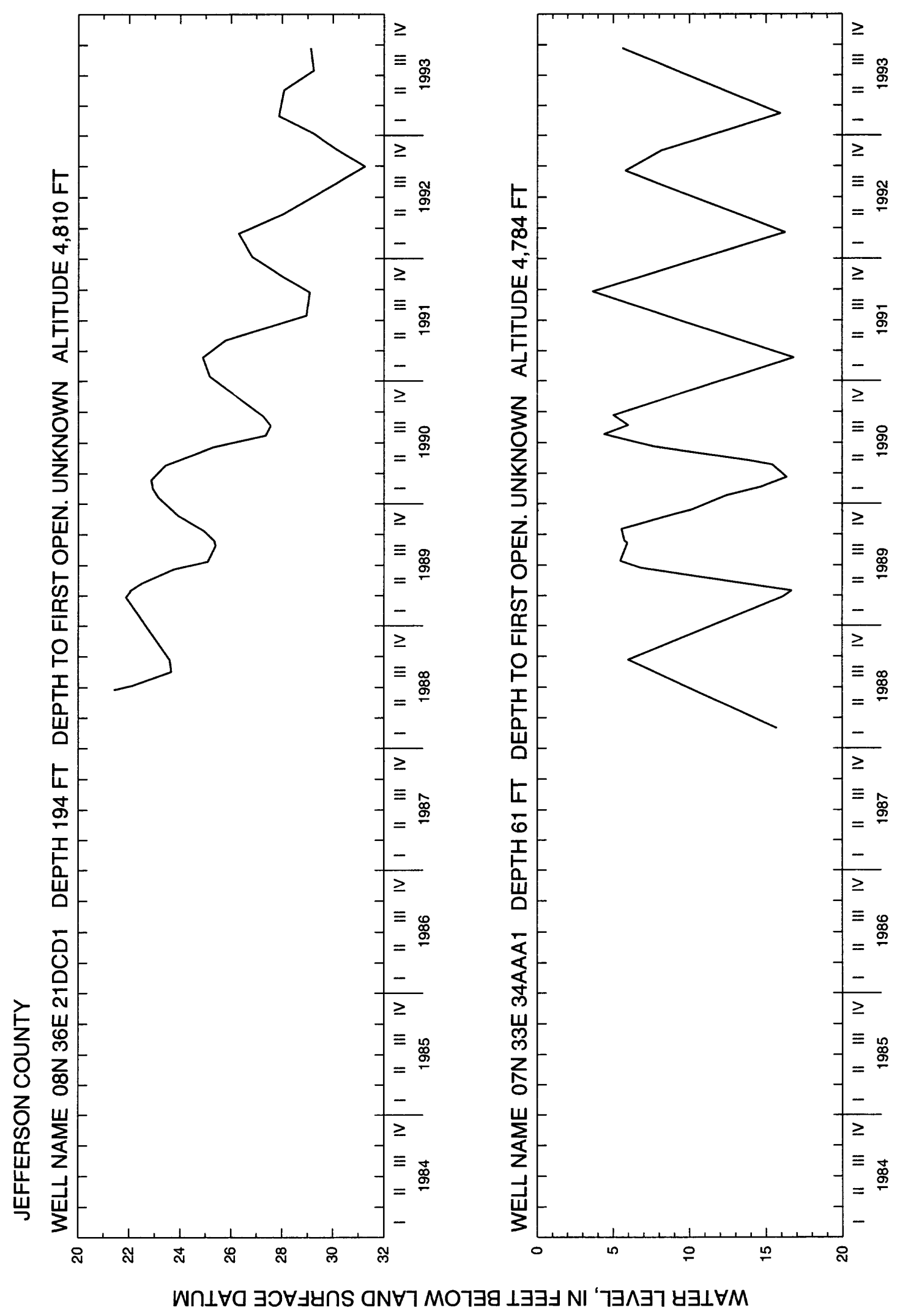




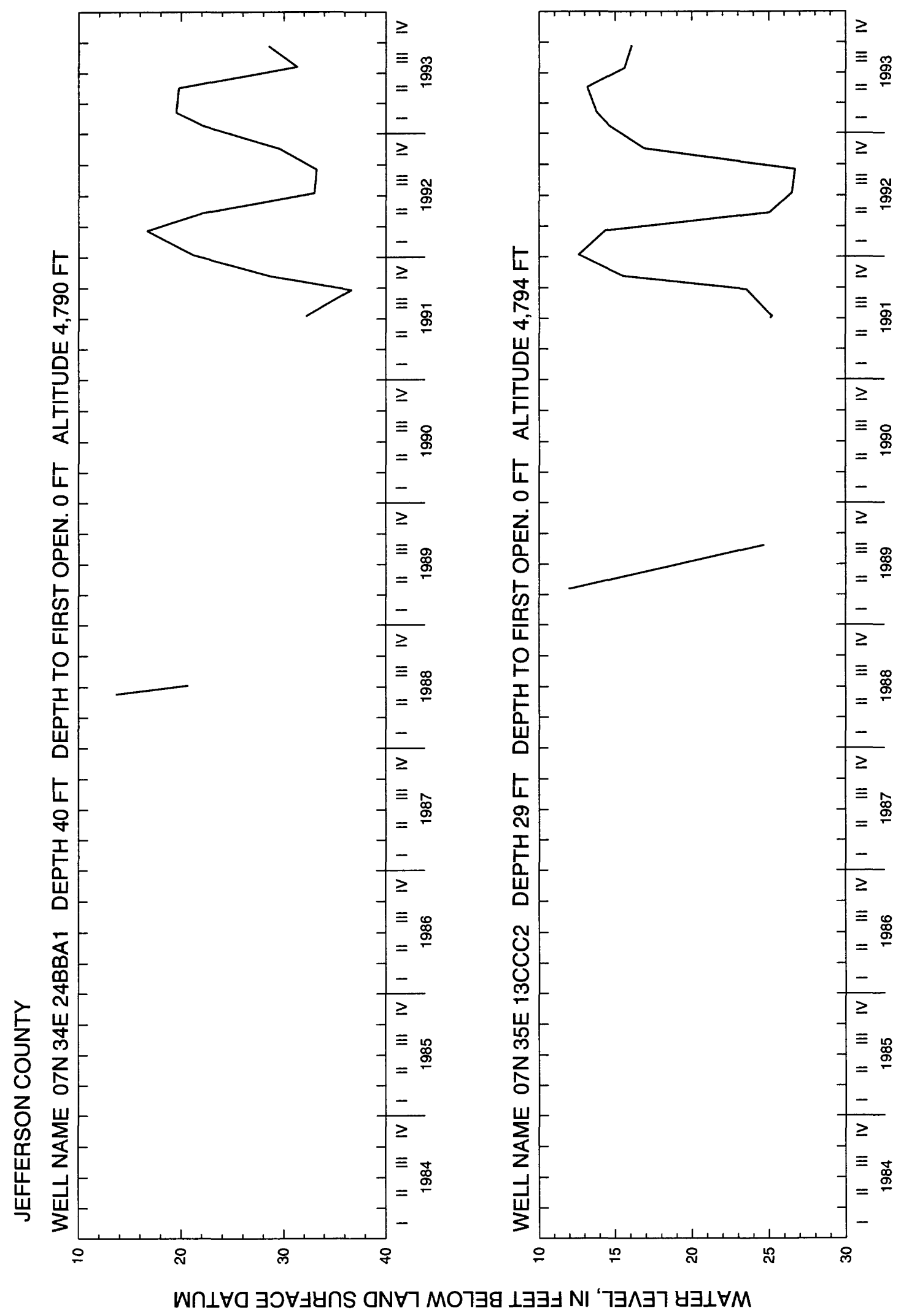




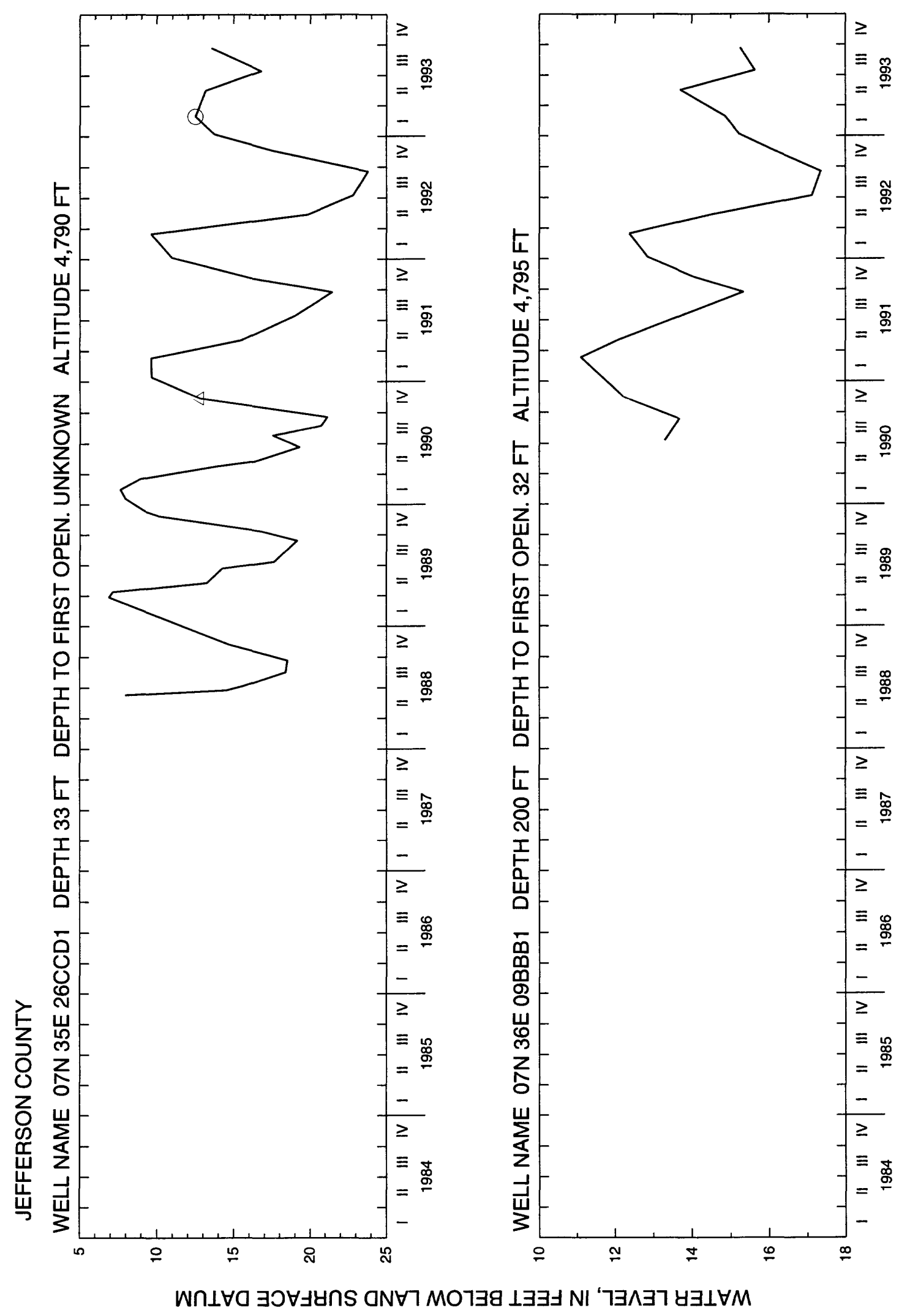




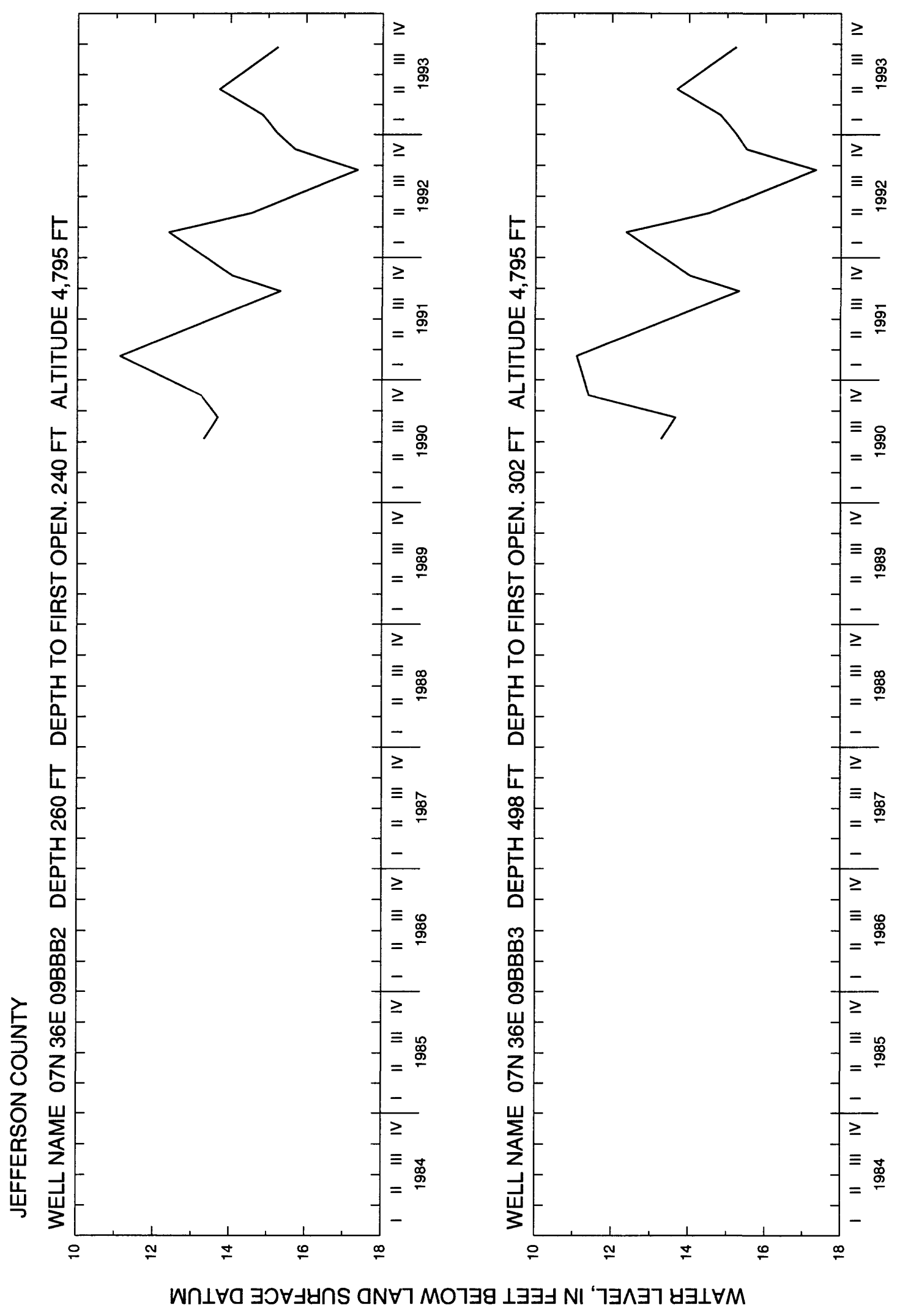




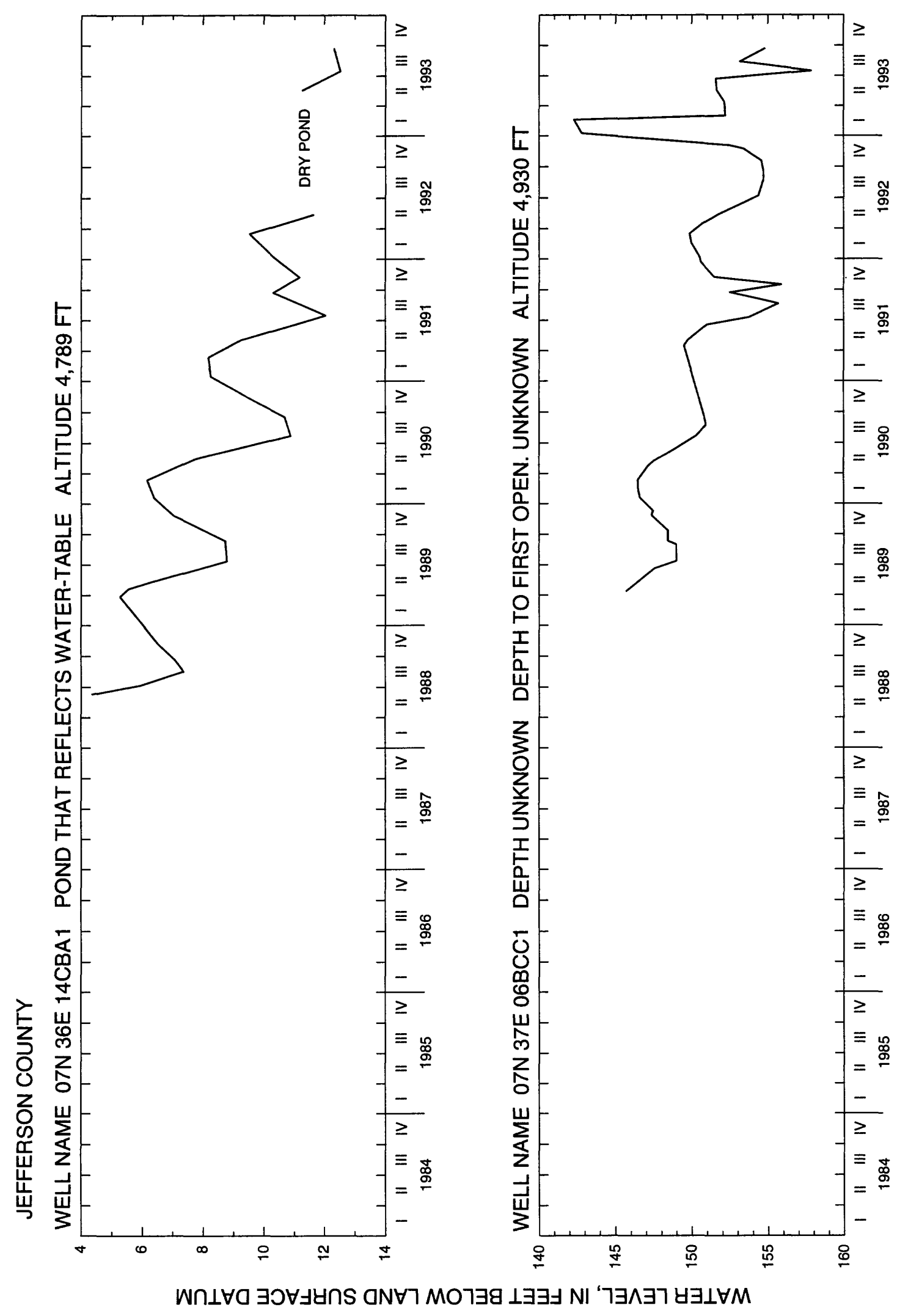




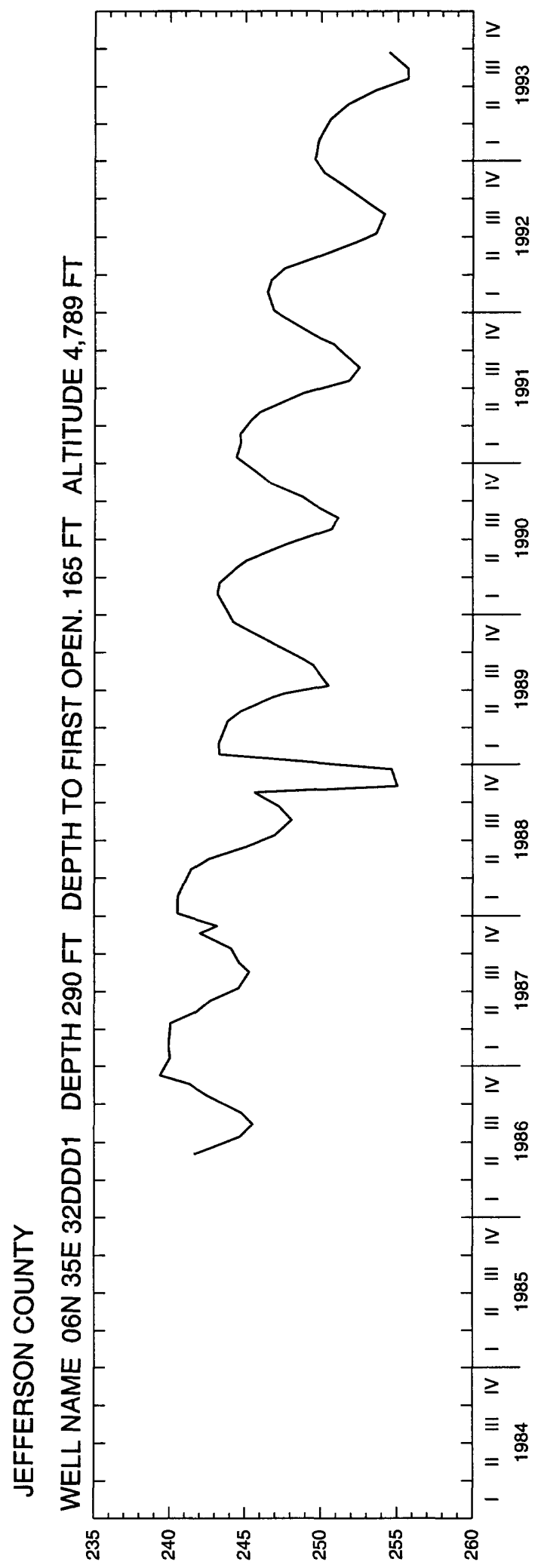

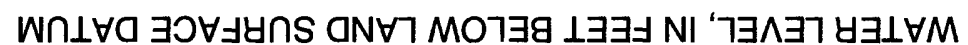




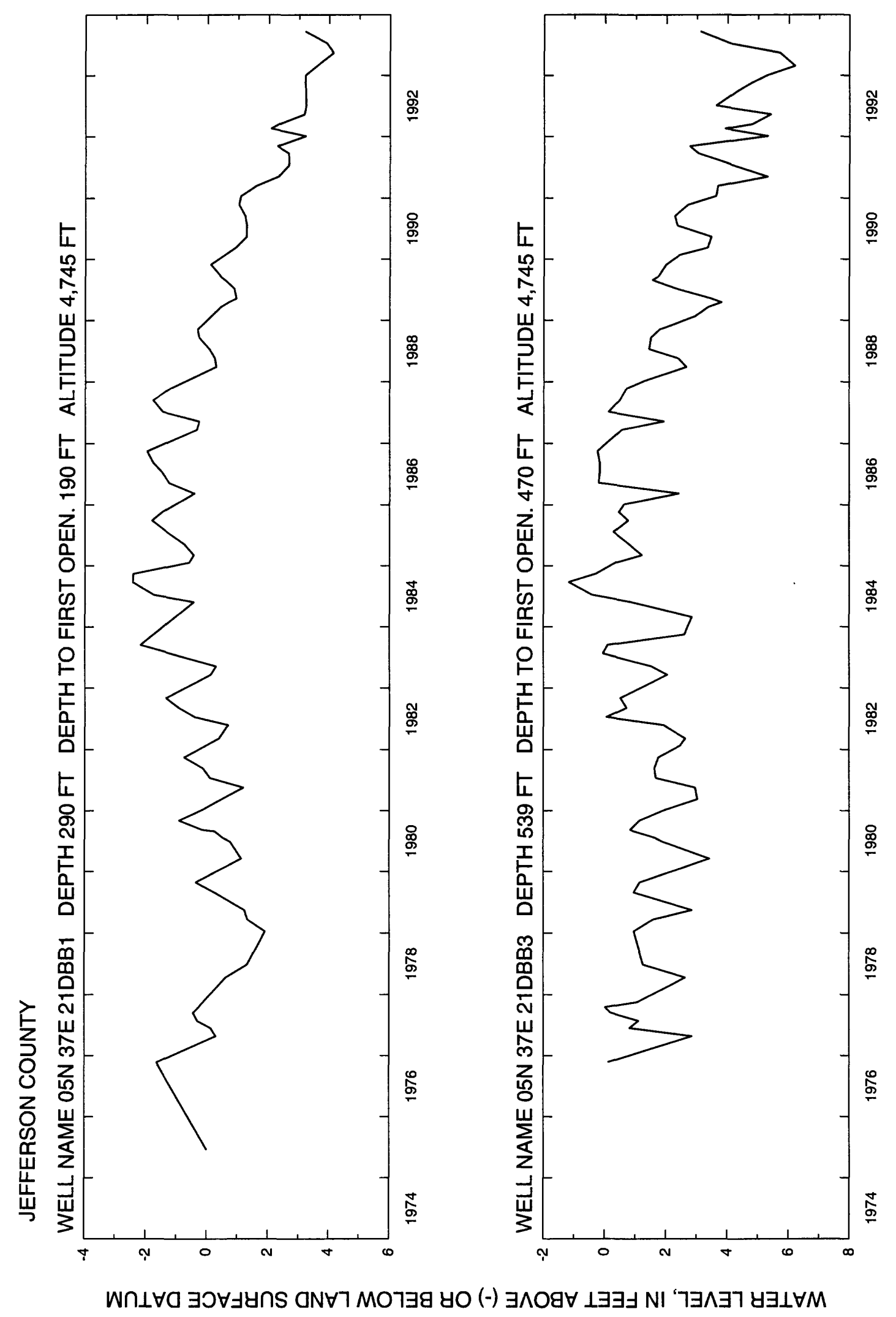




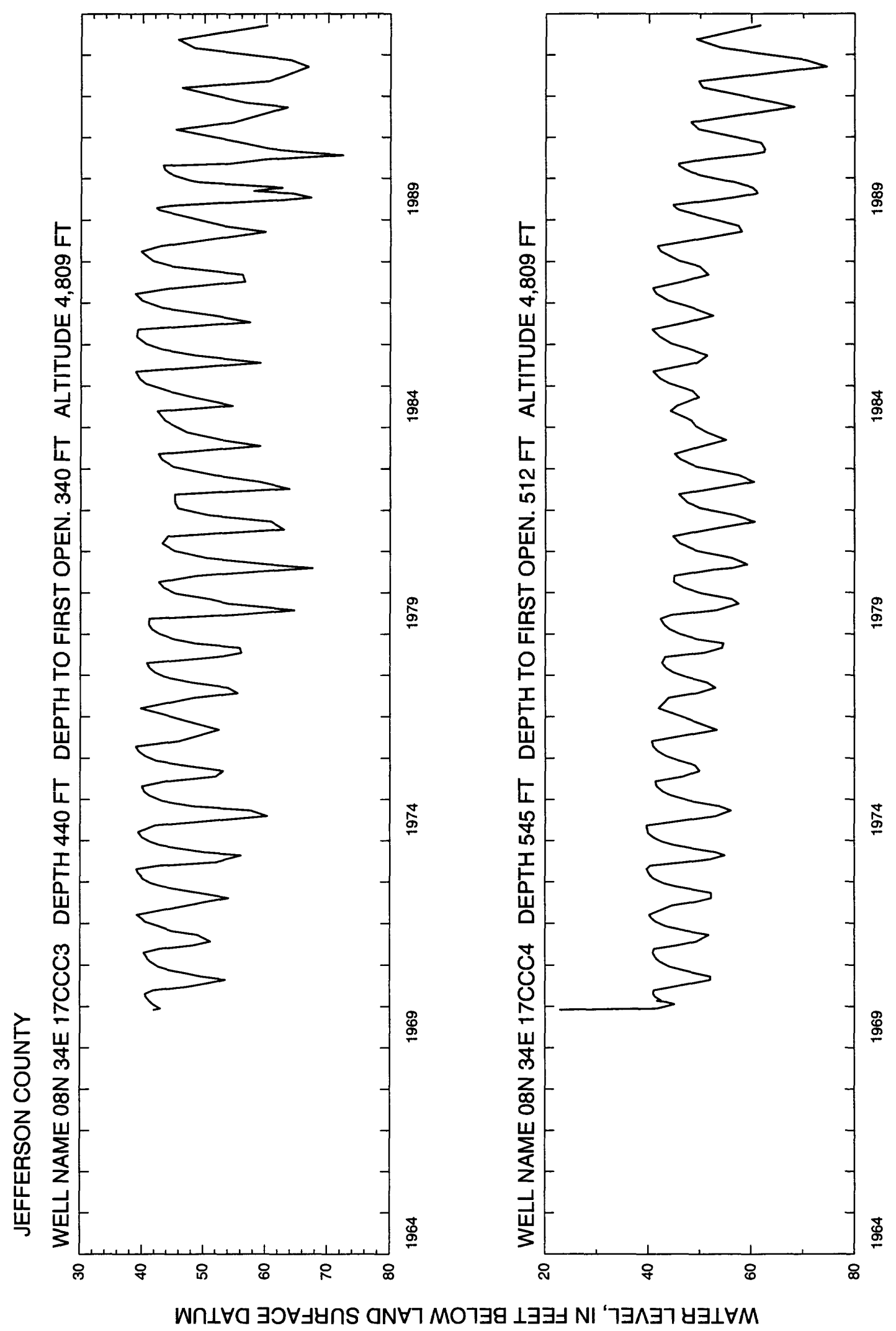




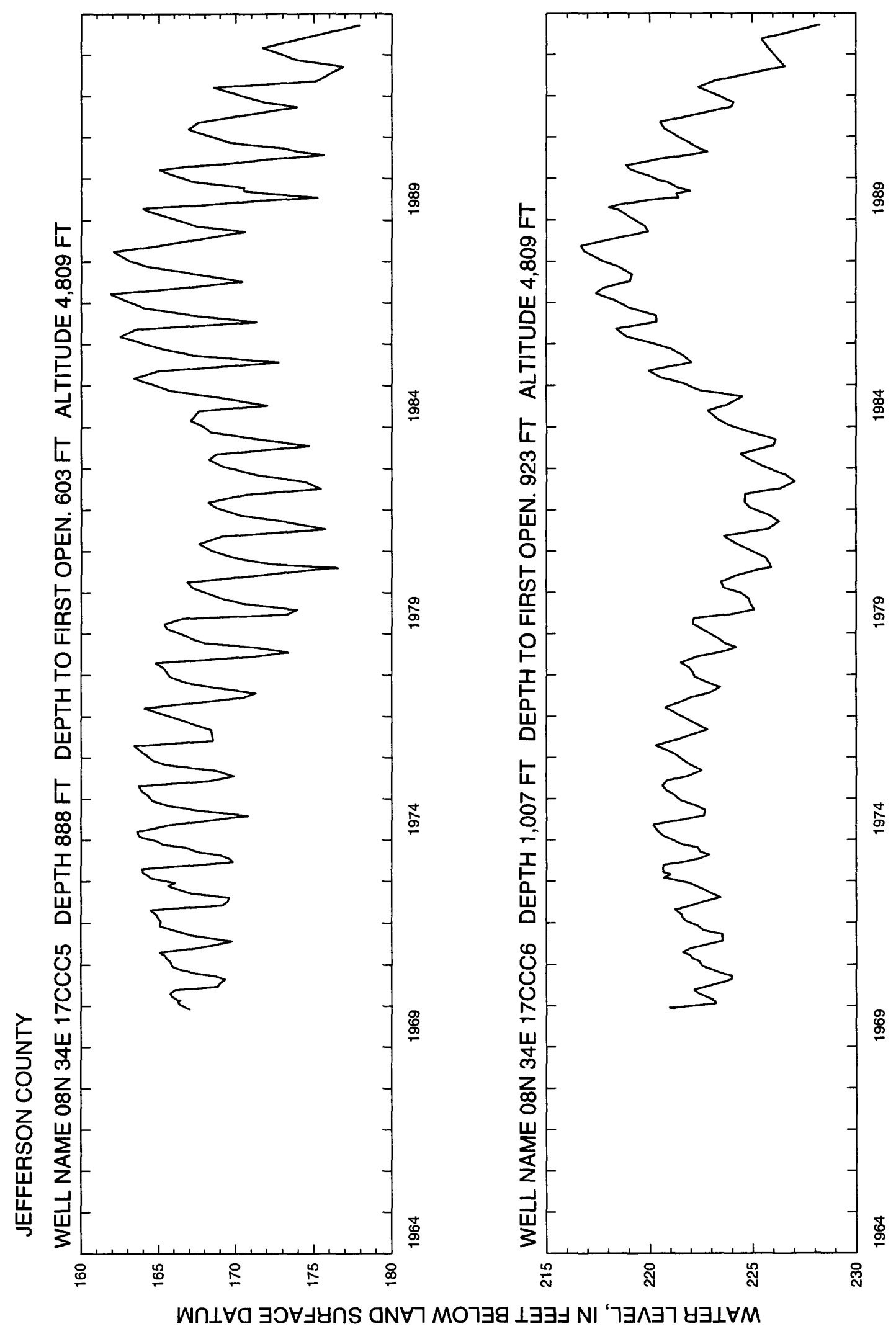




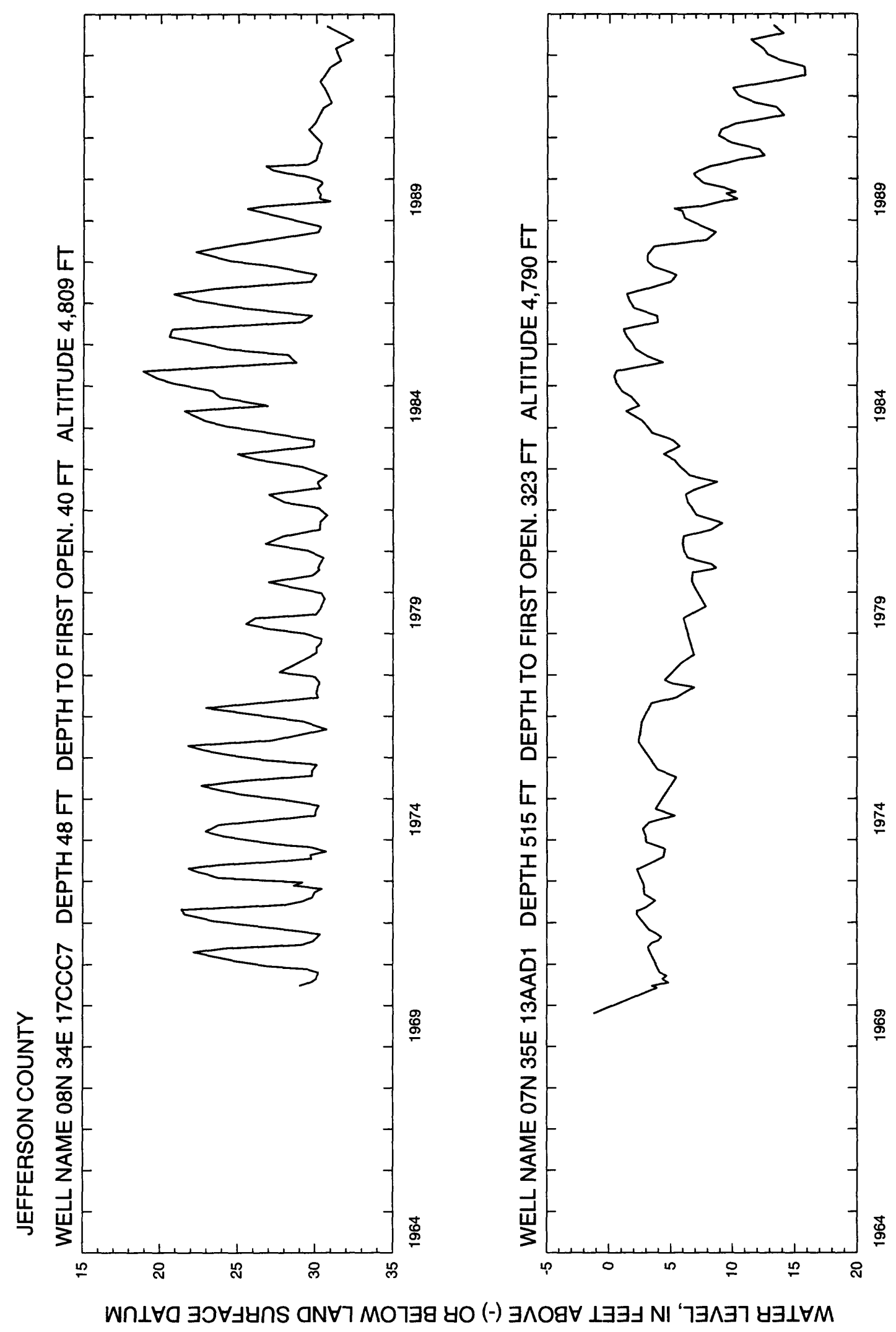

$\stackrel{\$}{8}$

$\stackrel{+}{ \pm}$

옹

京

吕

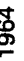

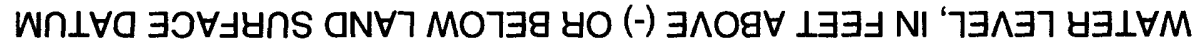



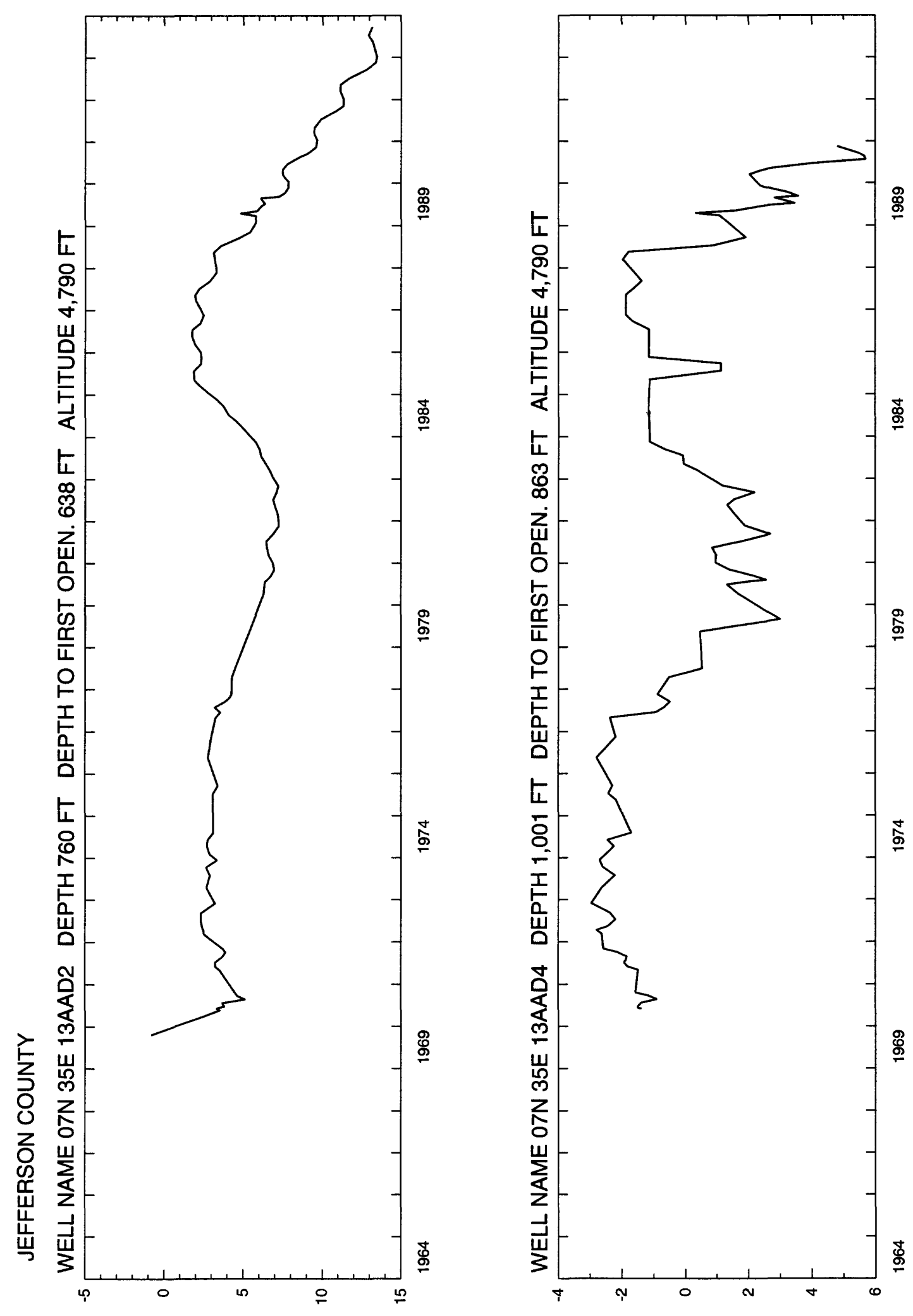

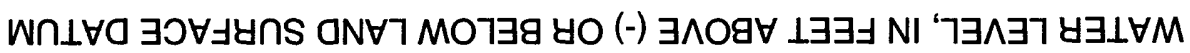




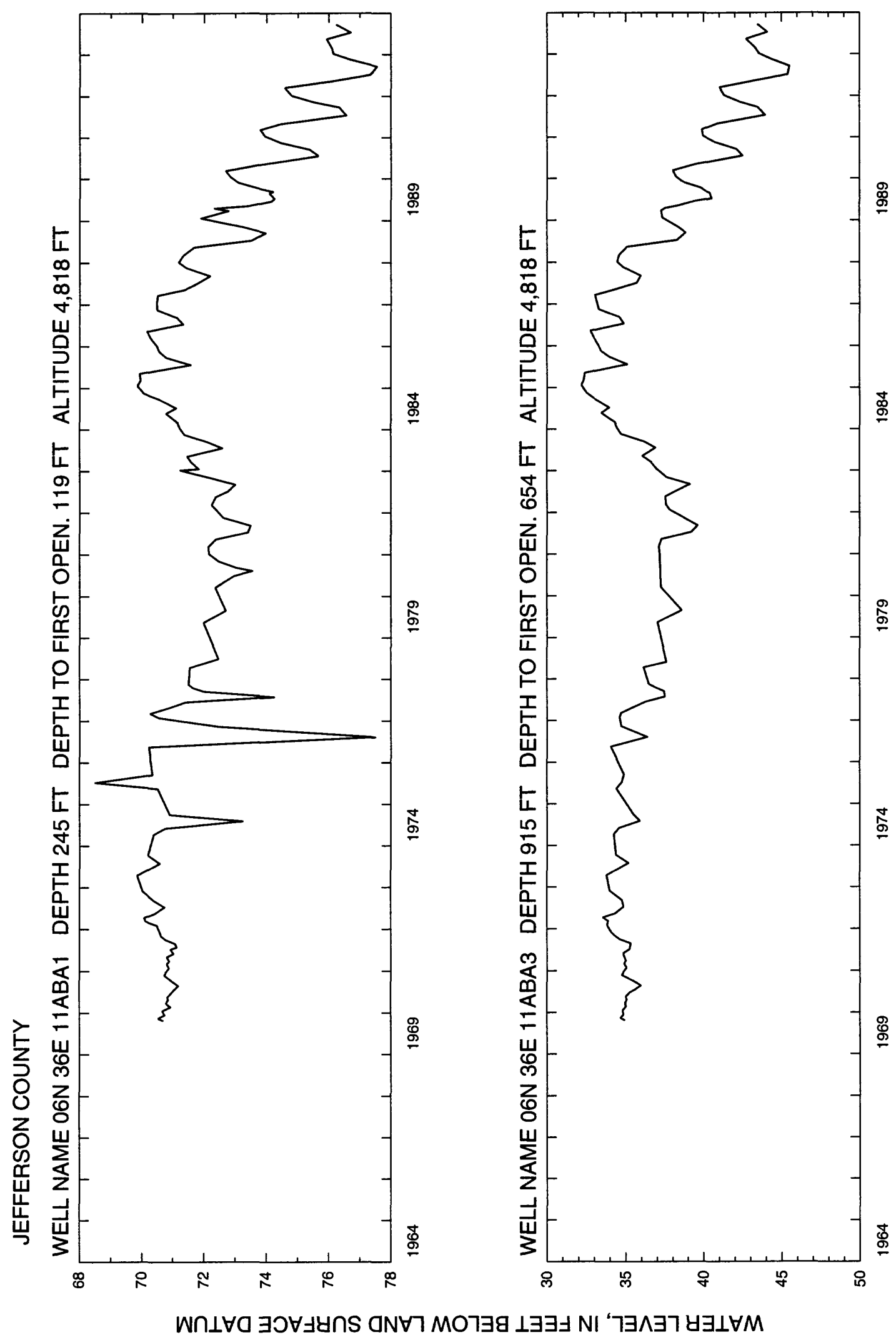




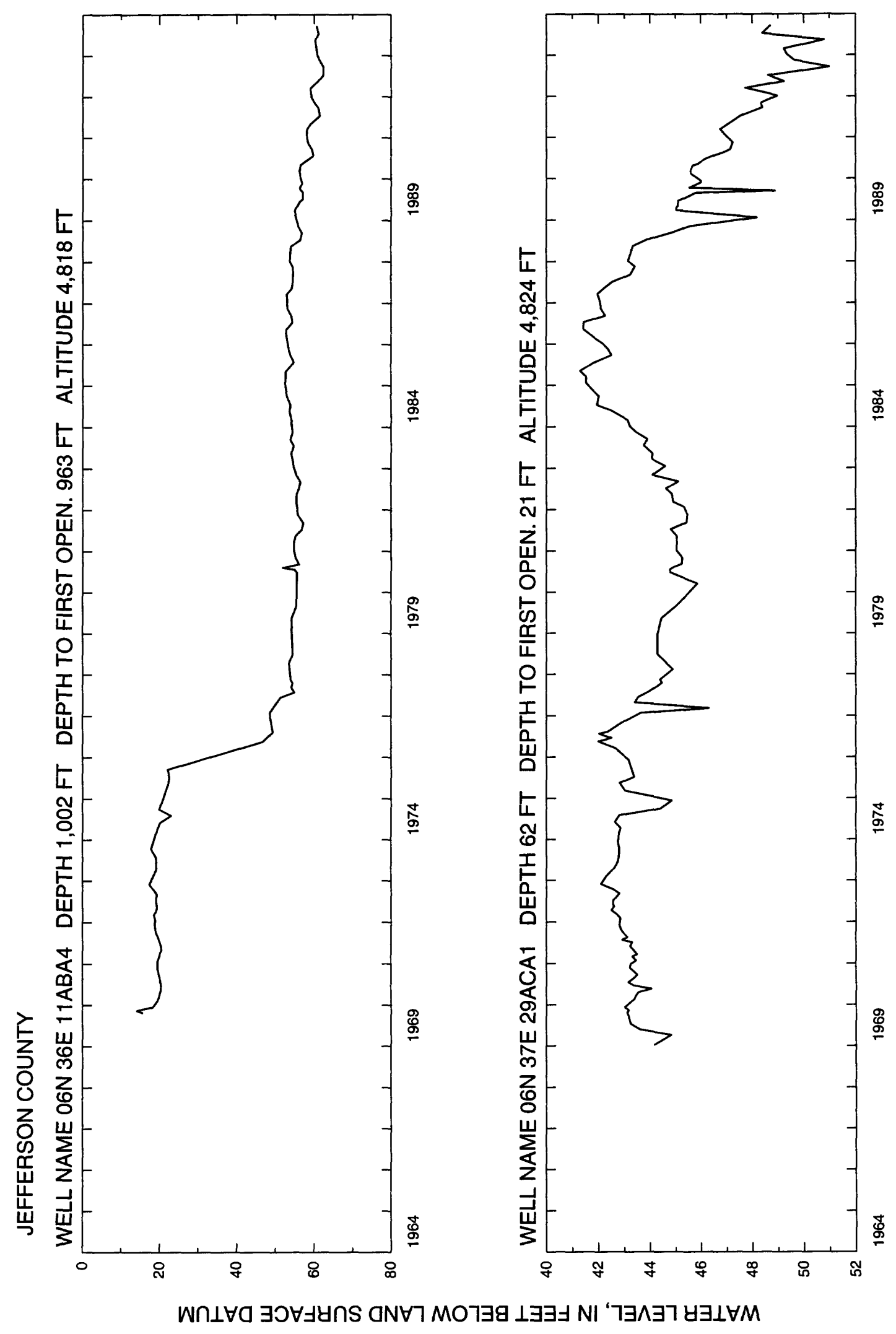




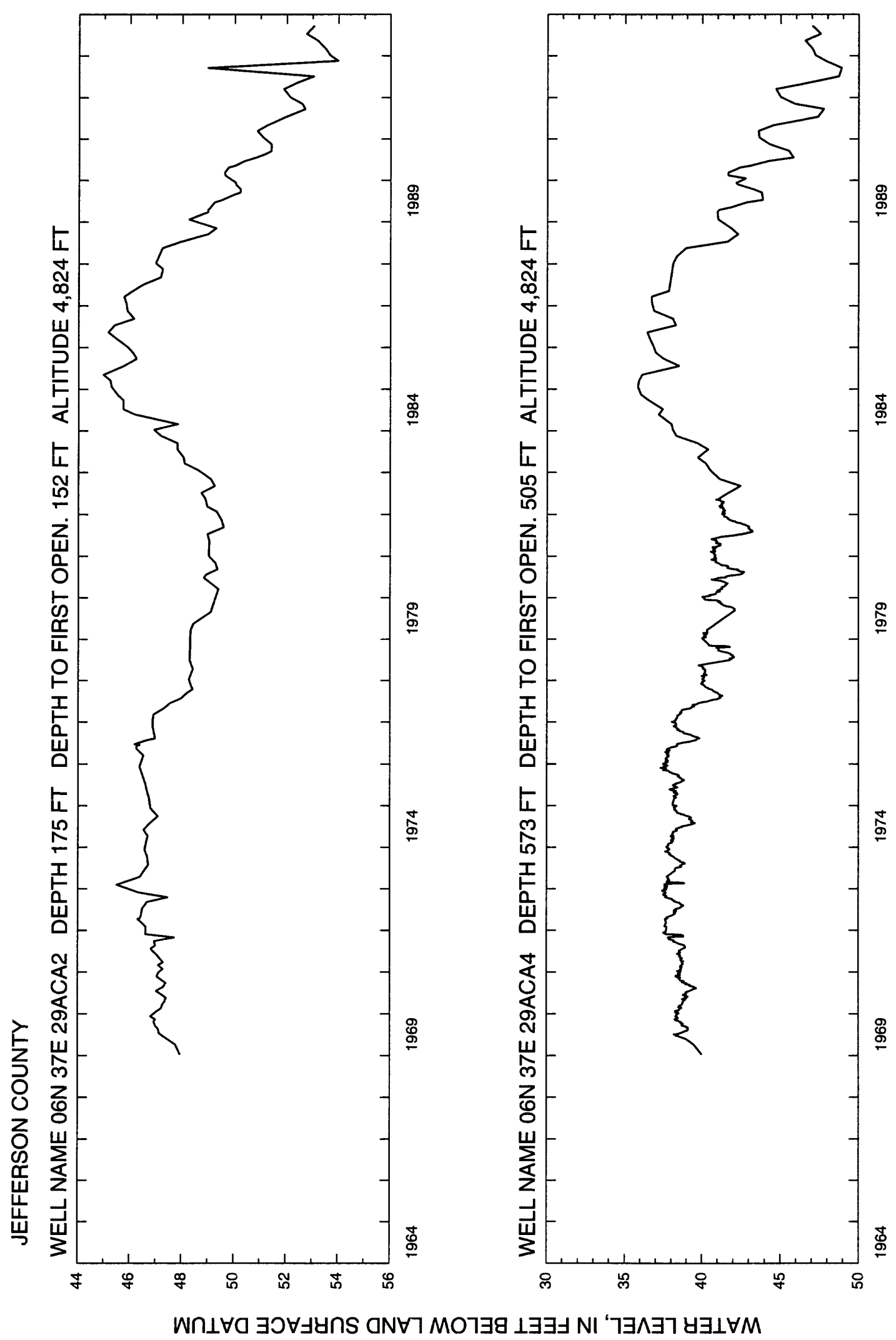




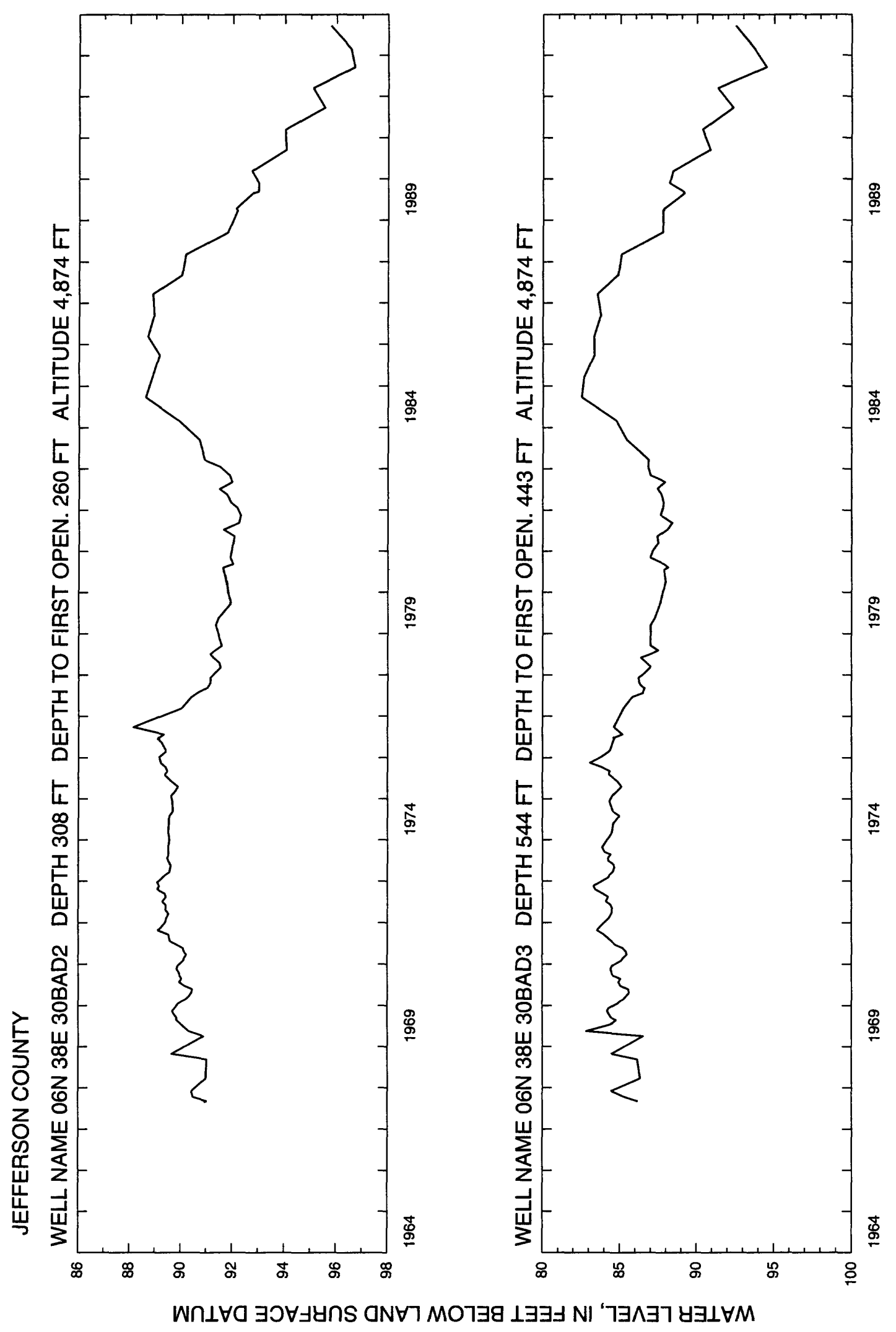




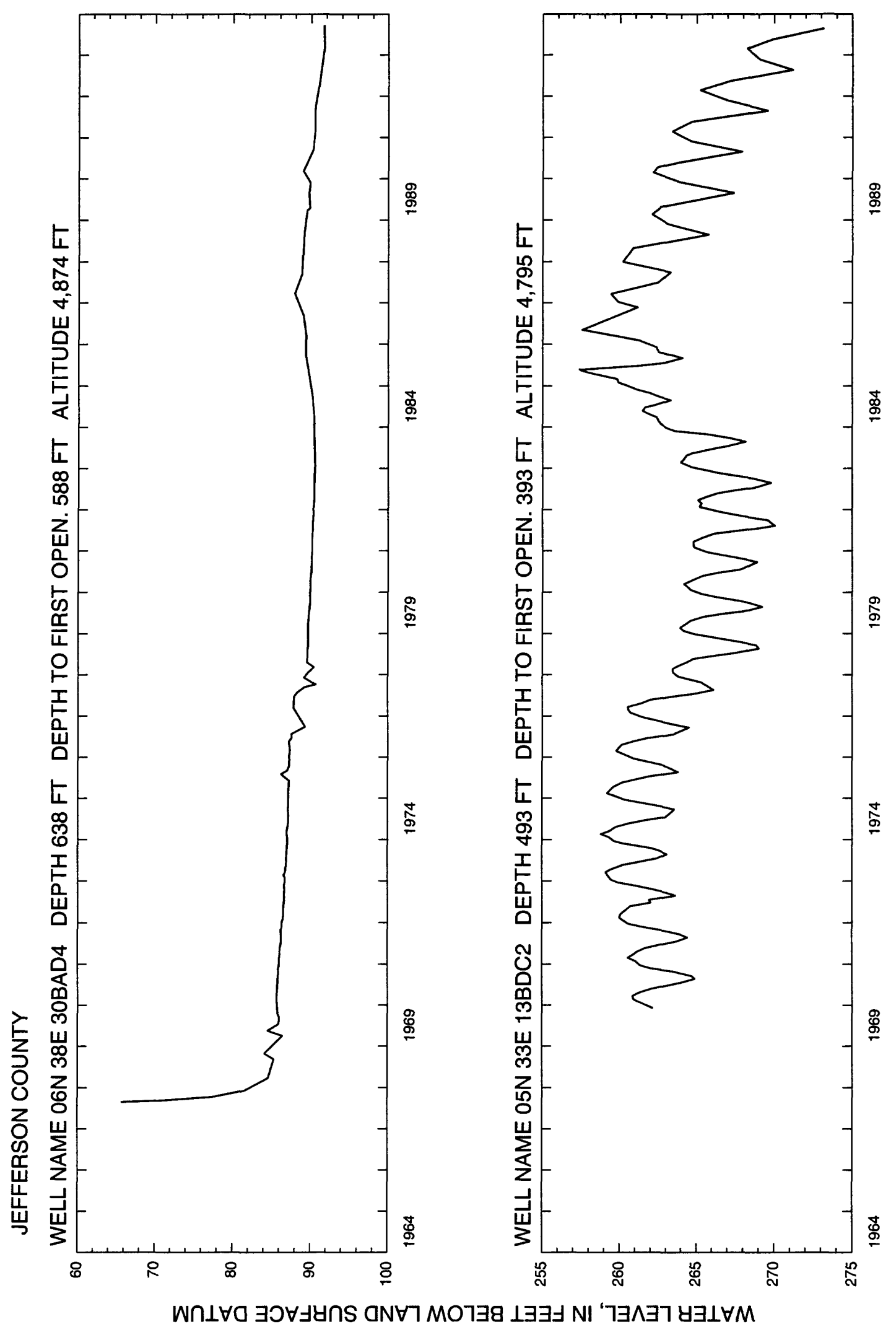




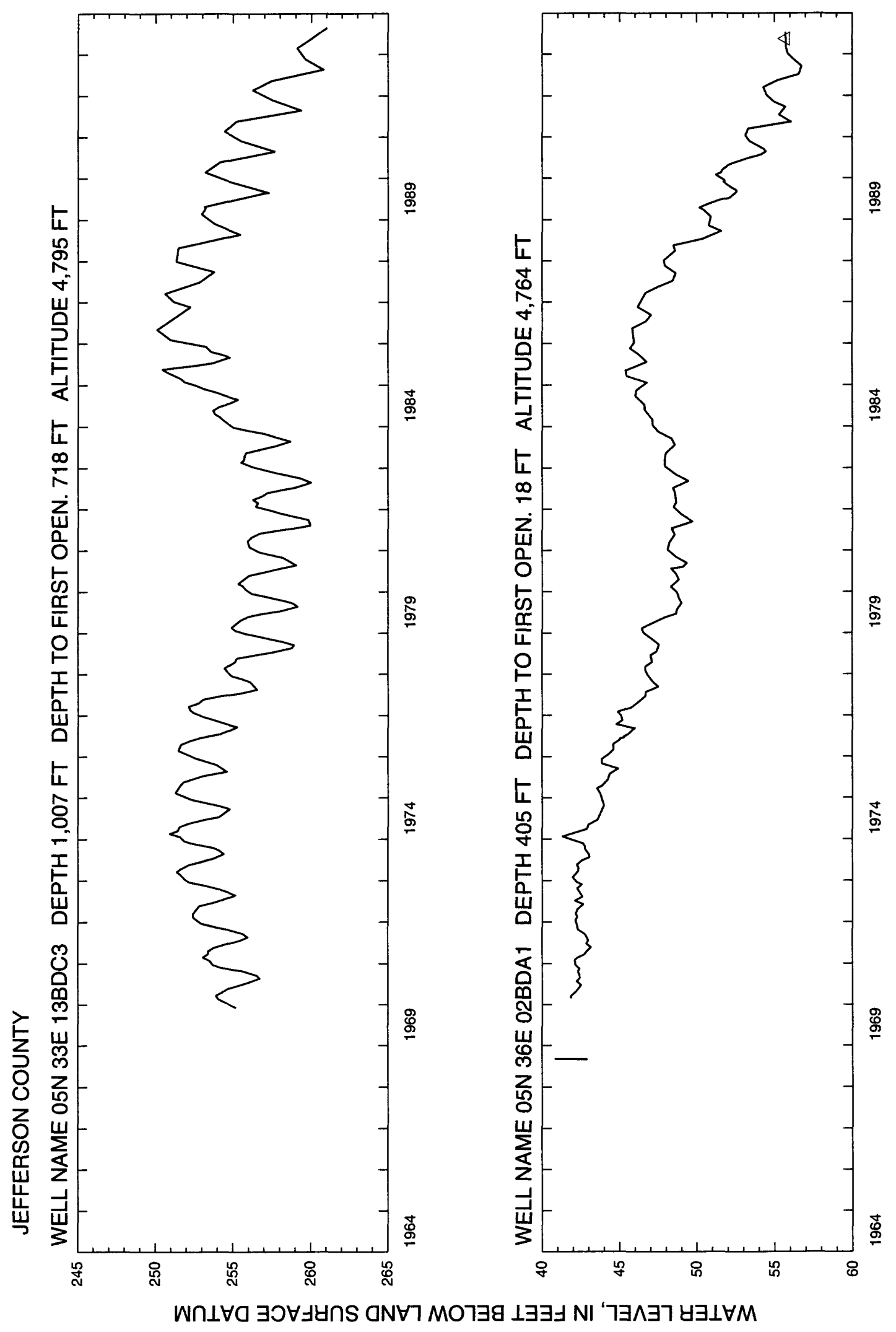




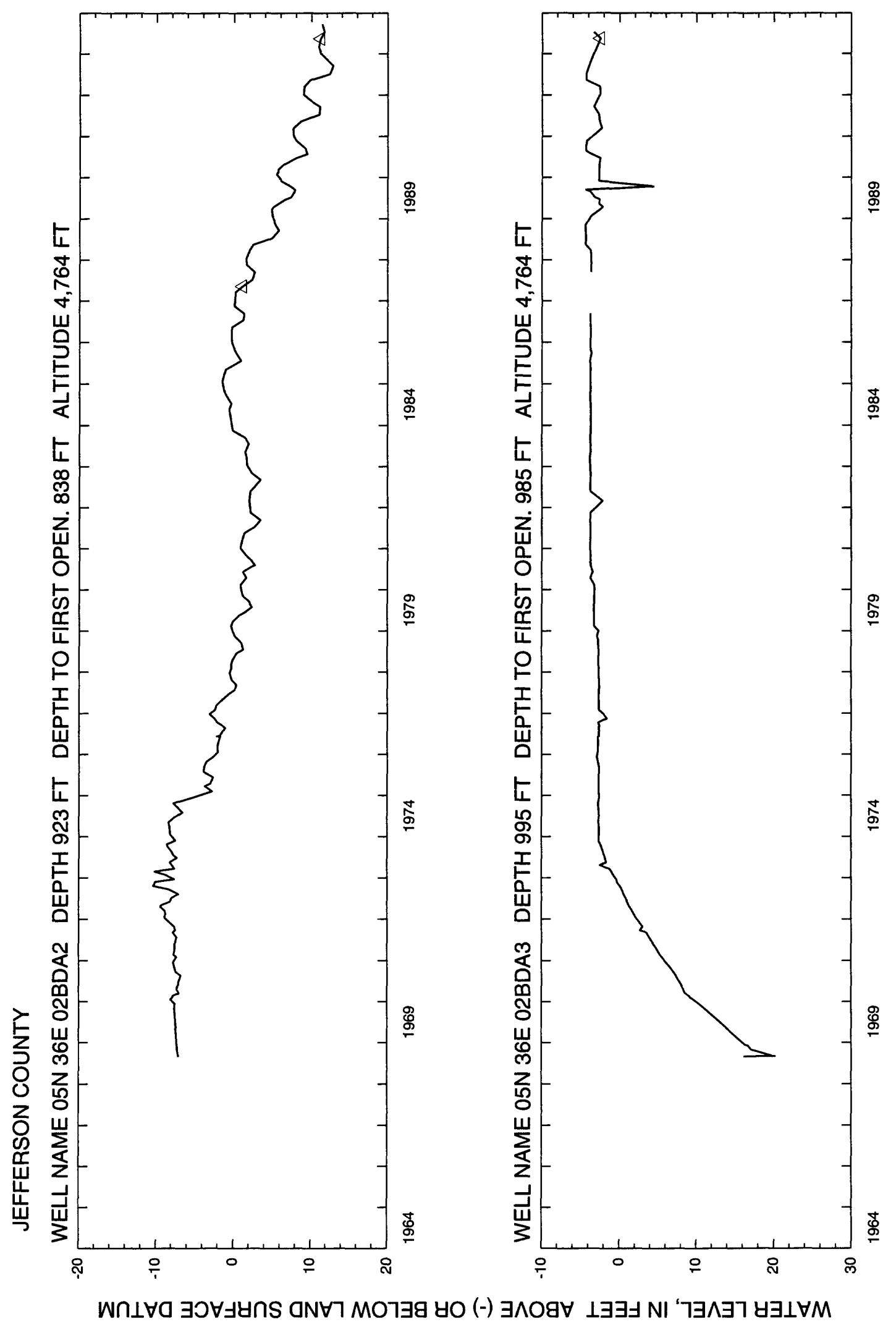




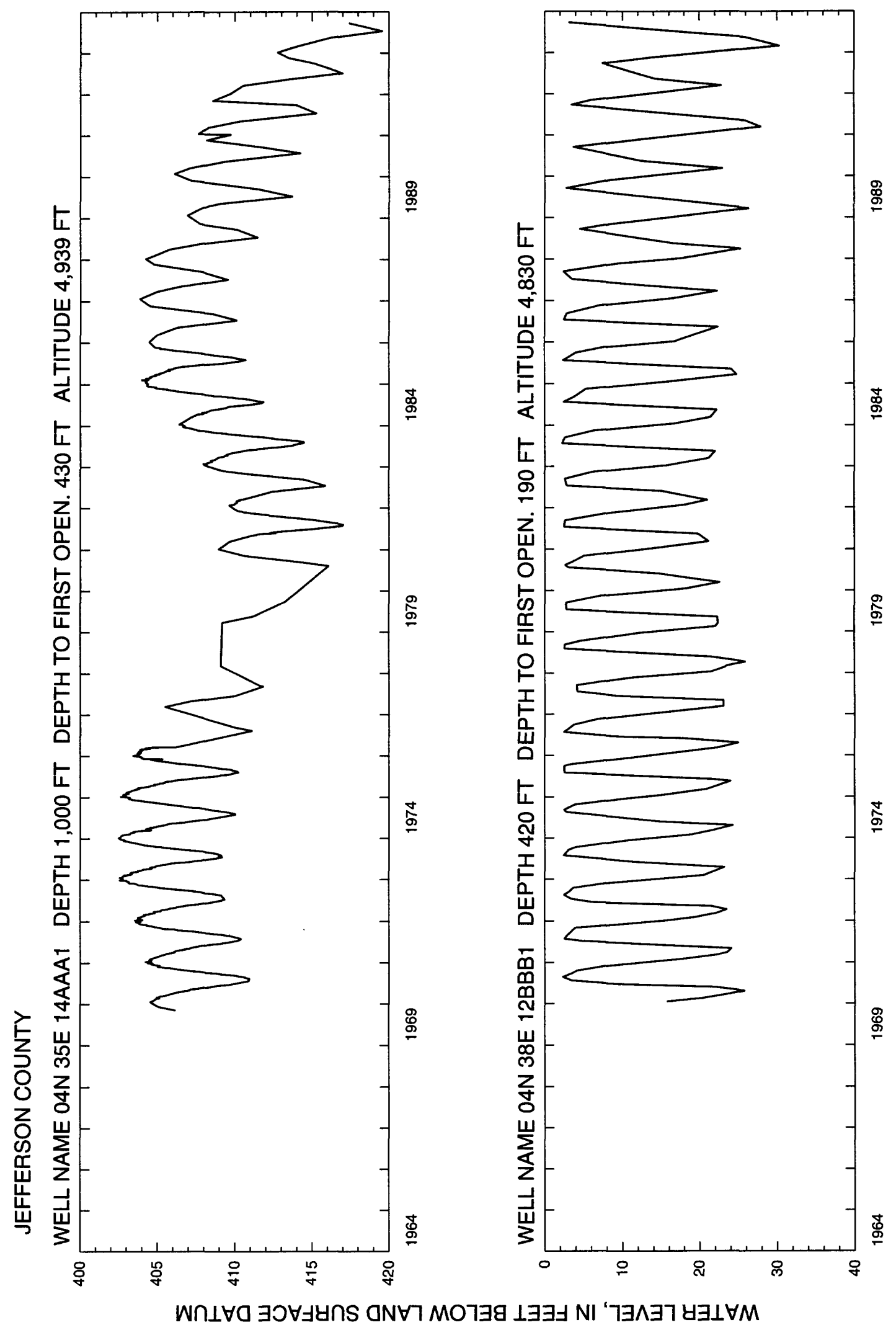




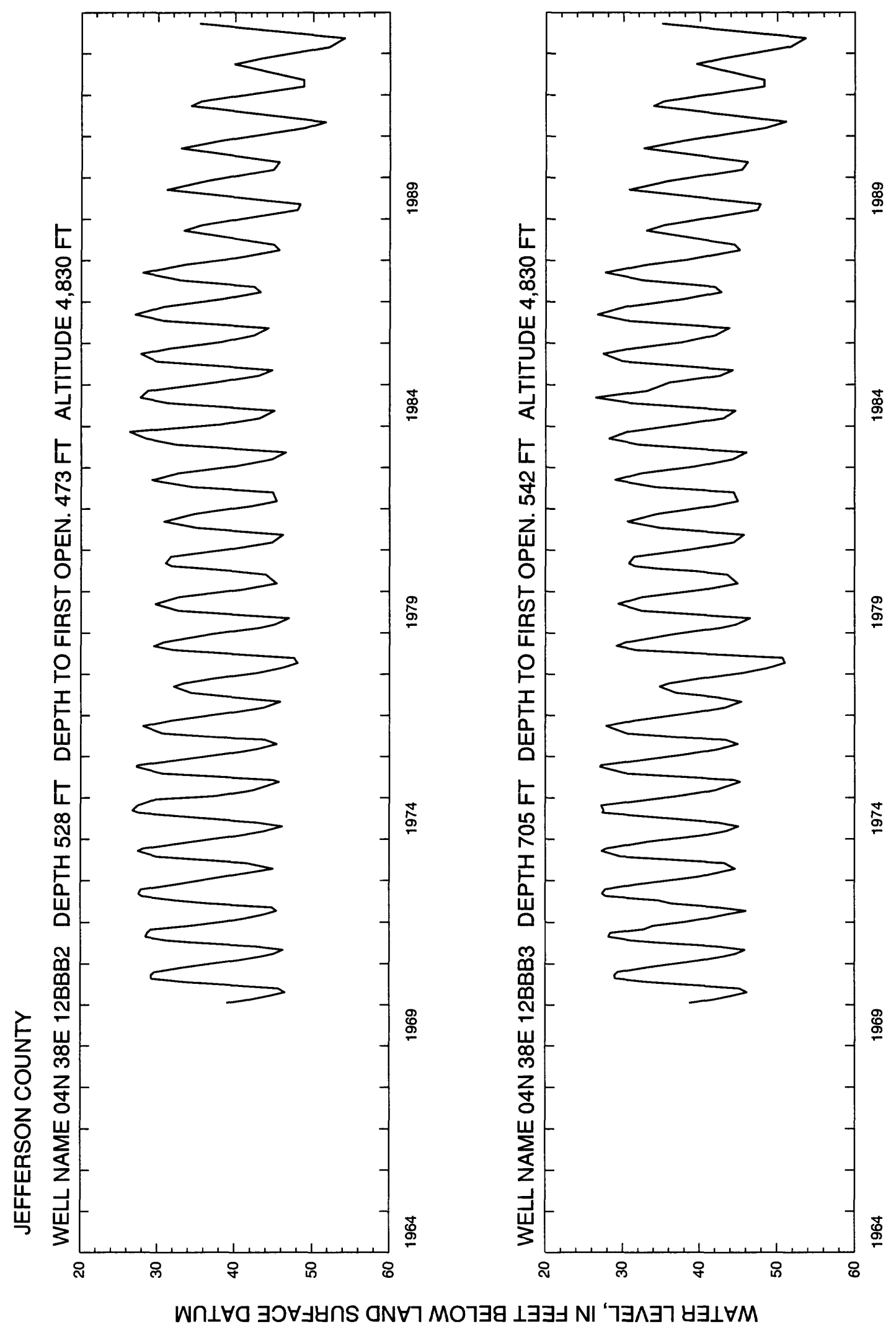




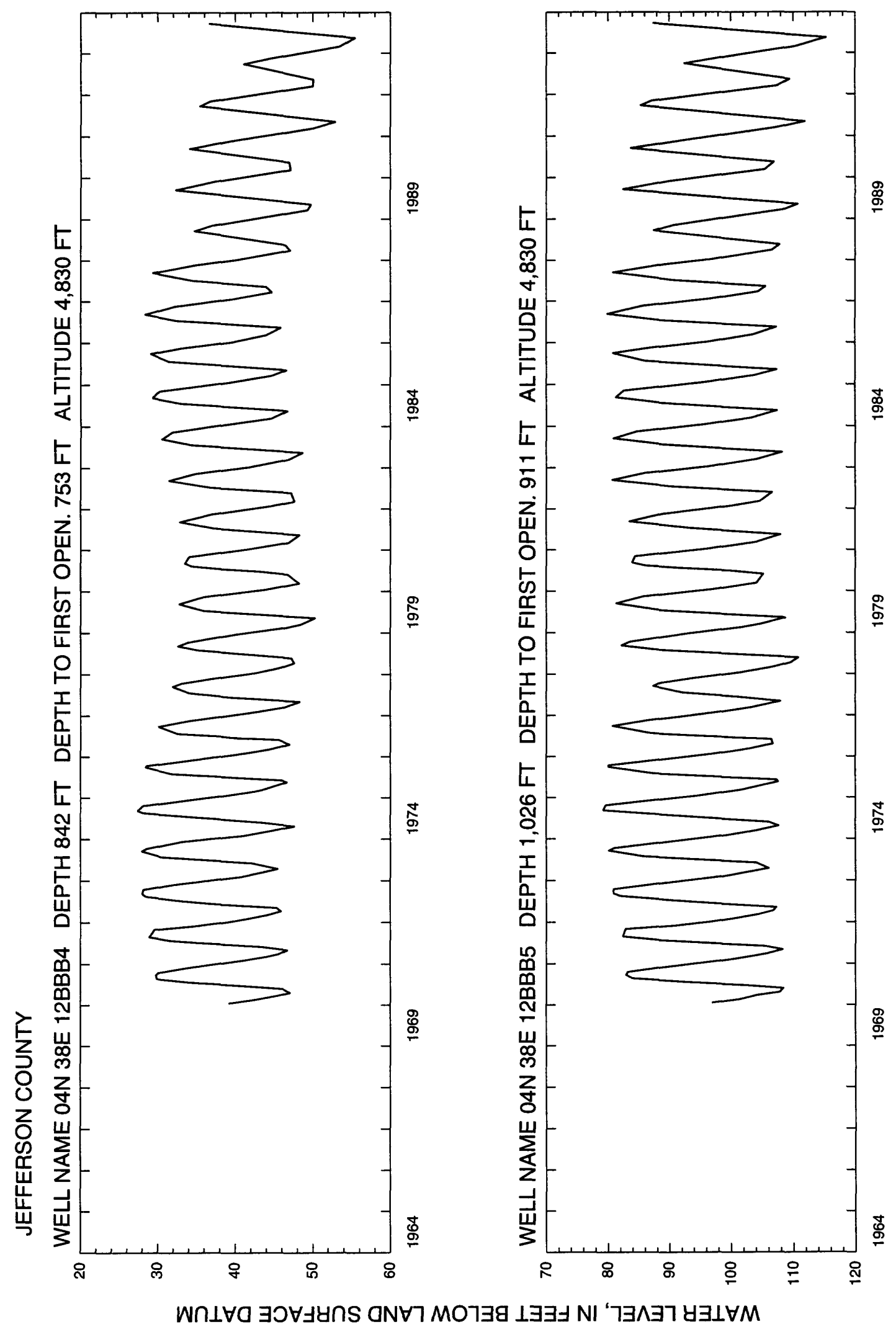




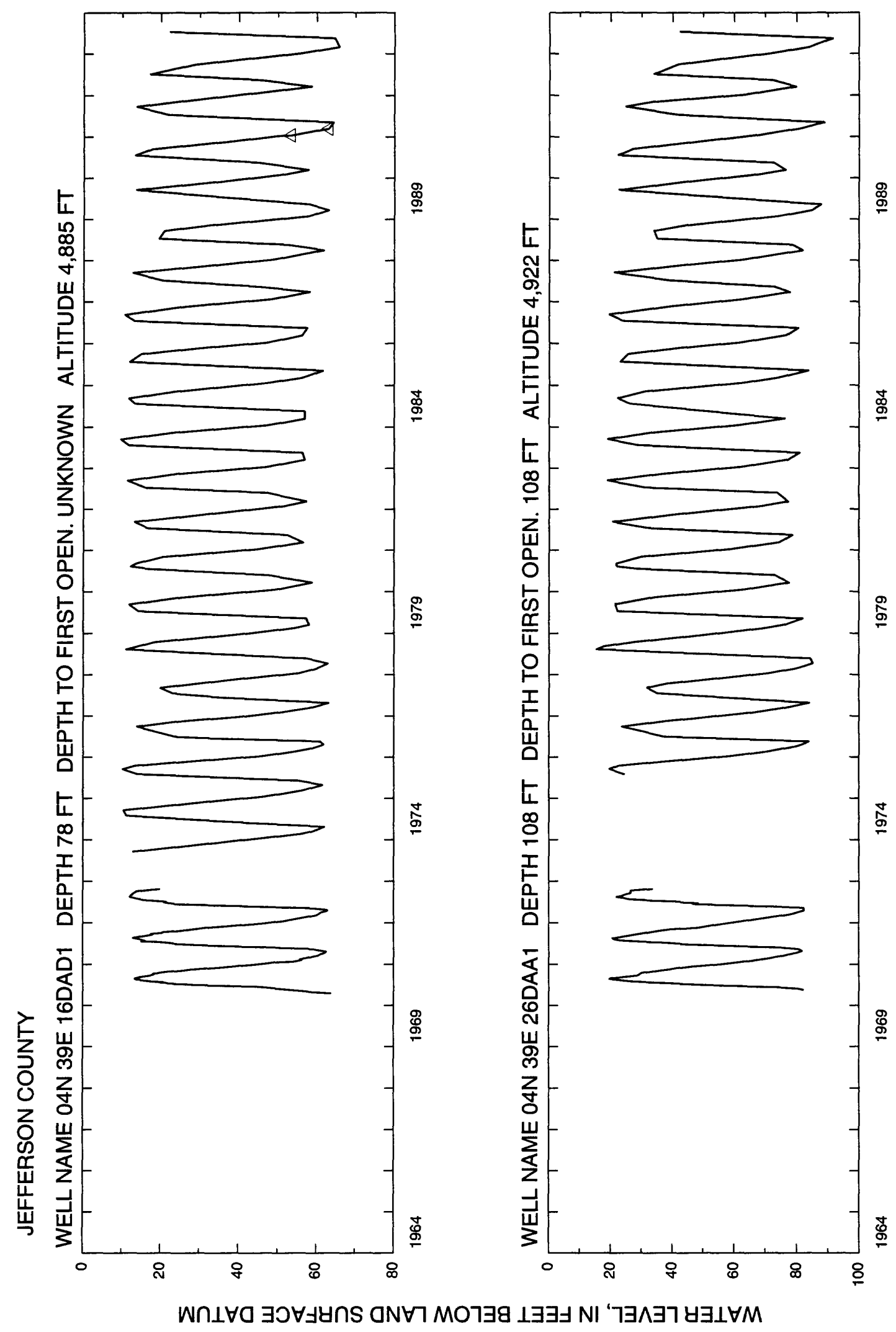

怘

品

옹

索

\%

芯 


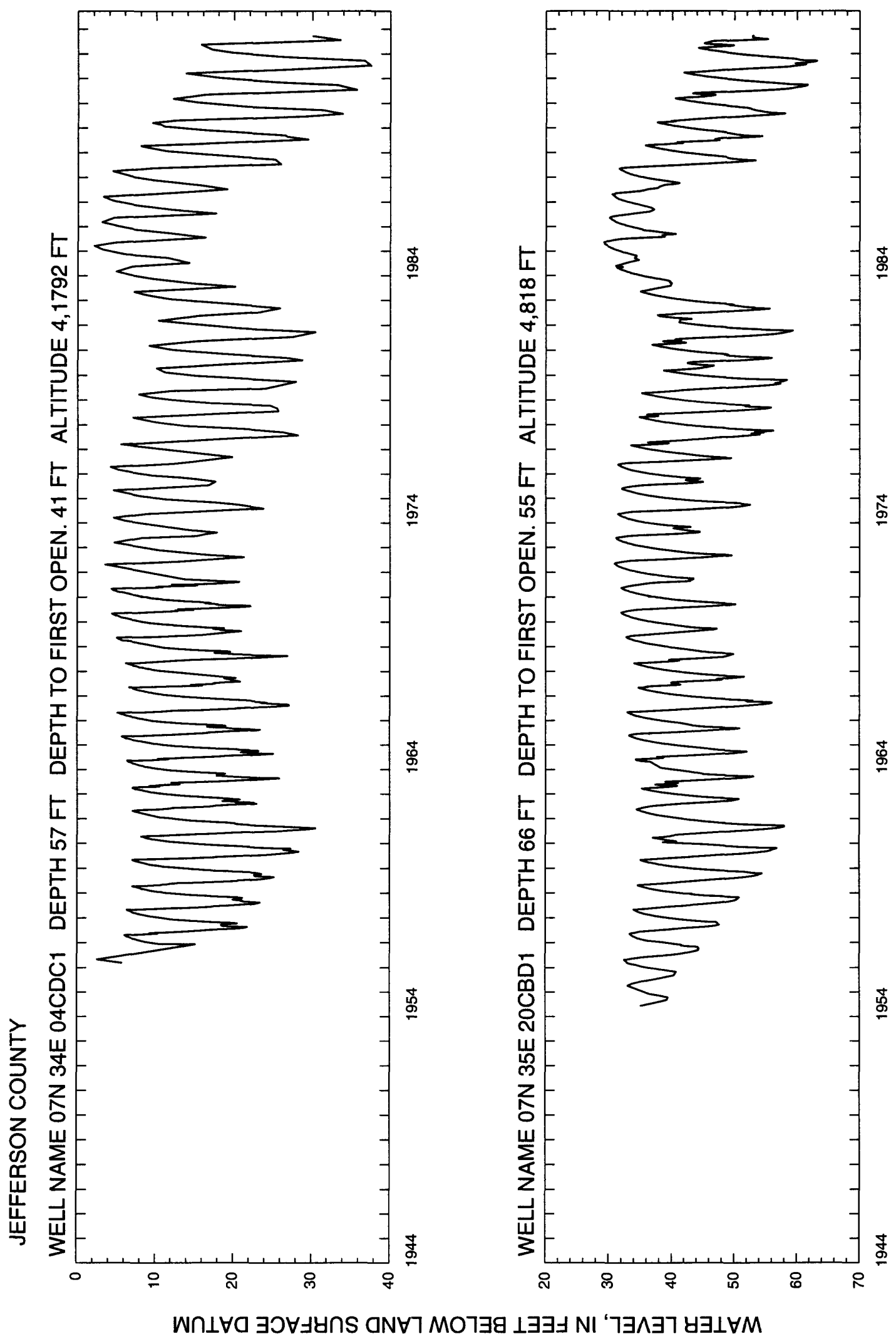

$\stackrel{ \pm}{\circ}$

$\stackrel{5}{5}$ 


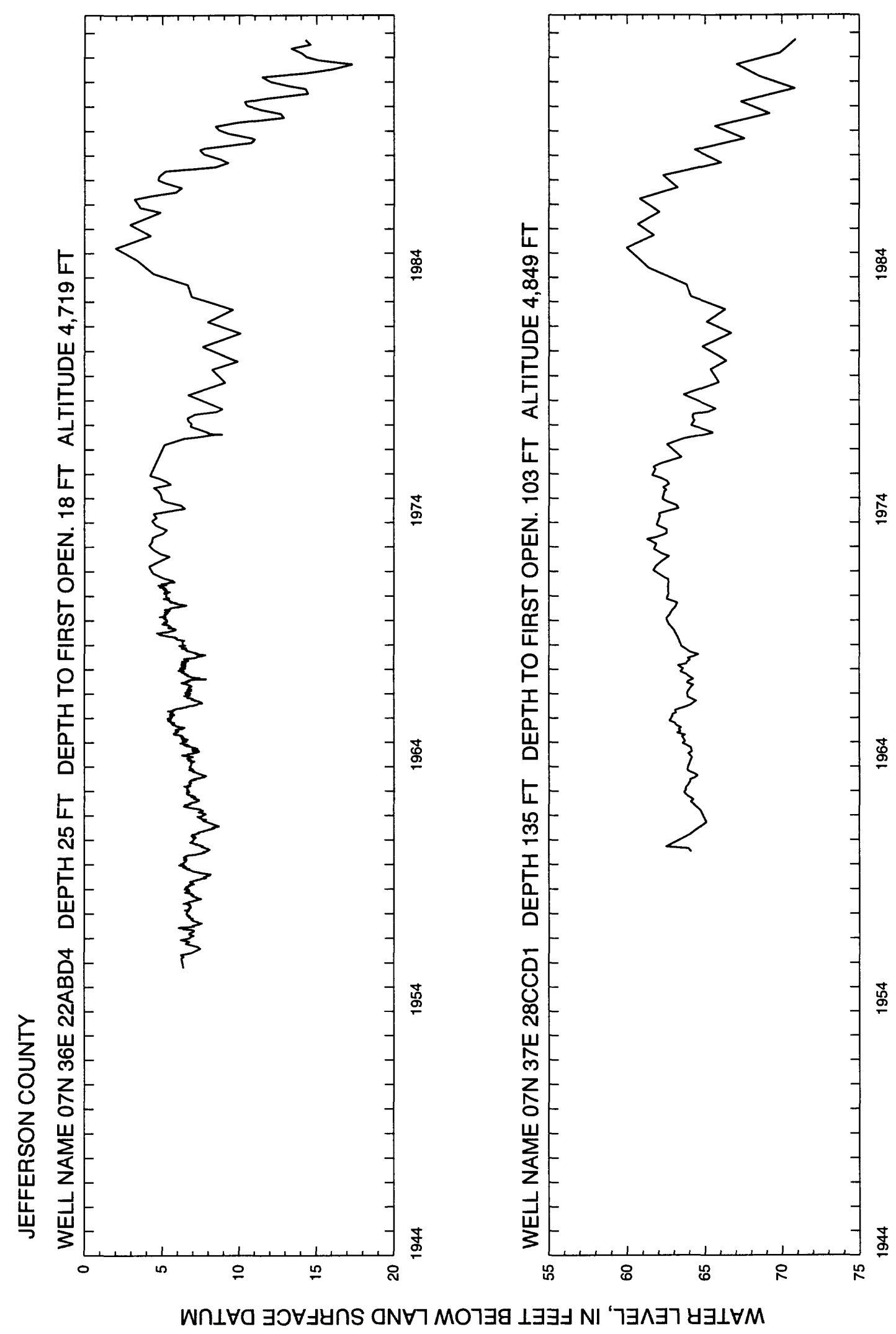




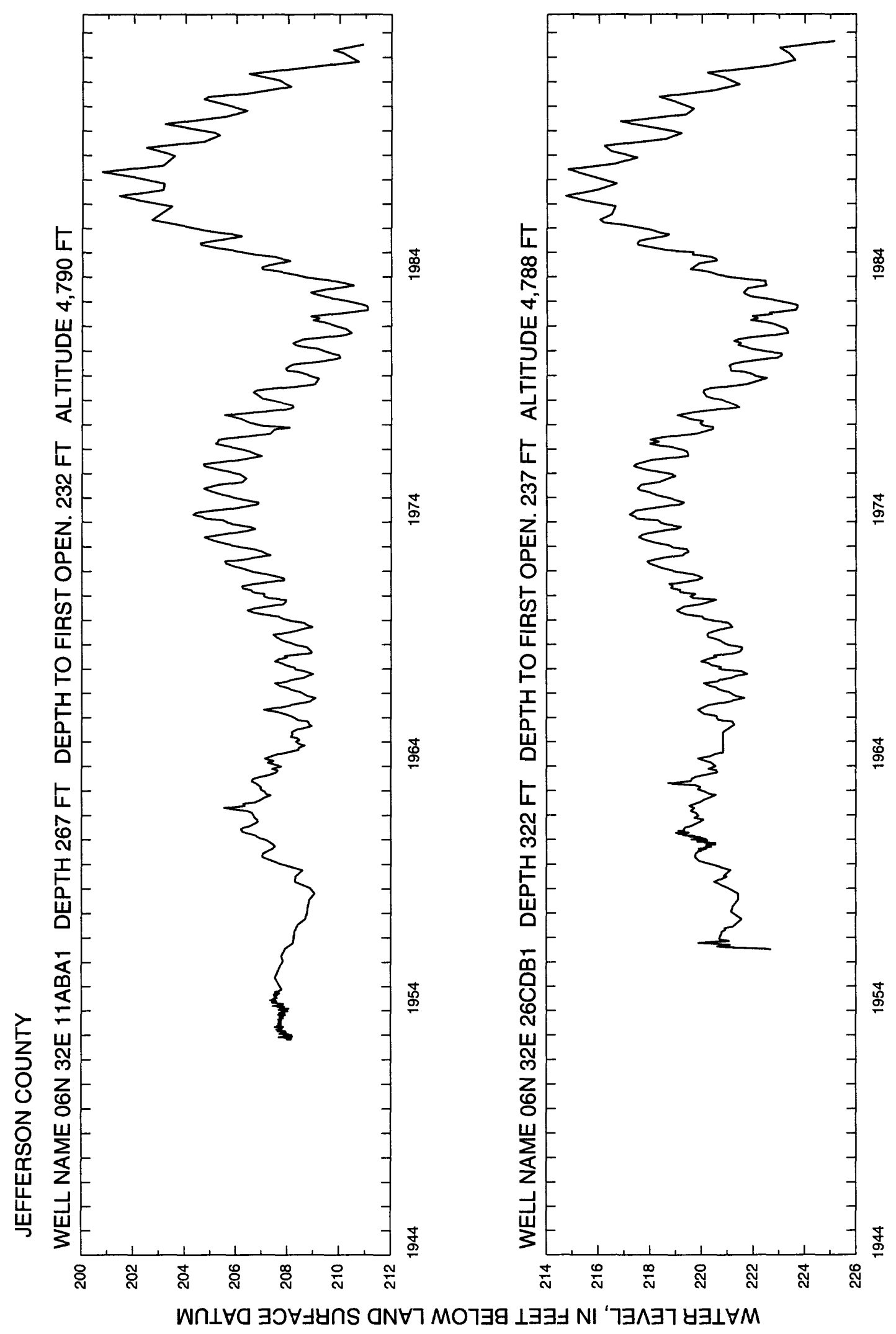




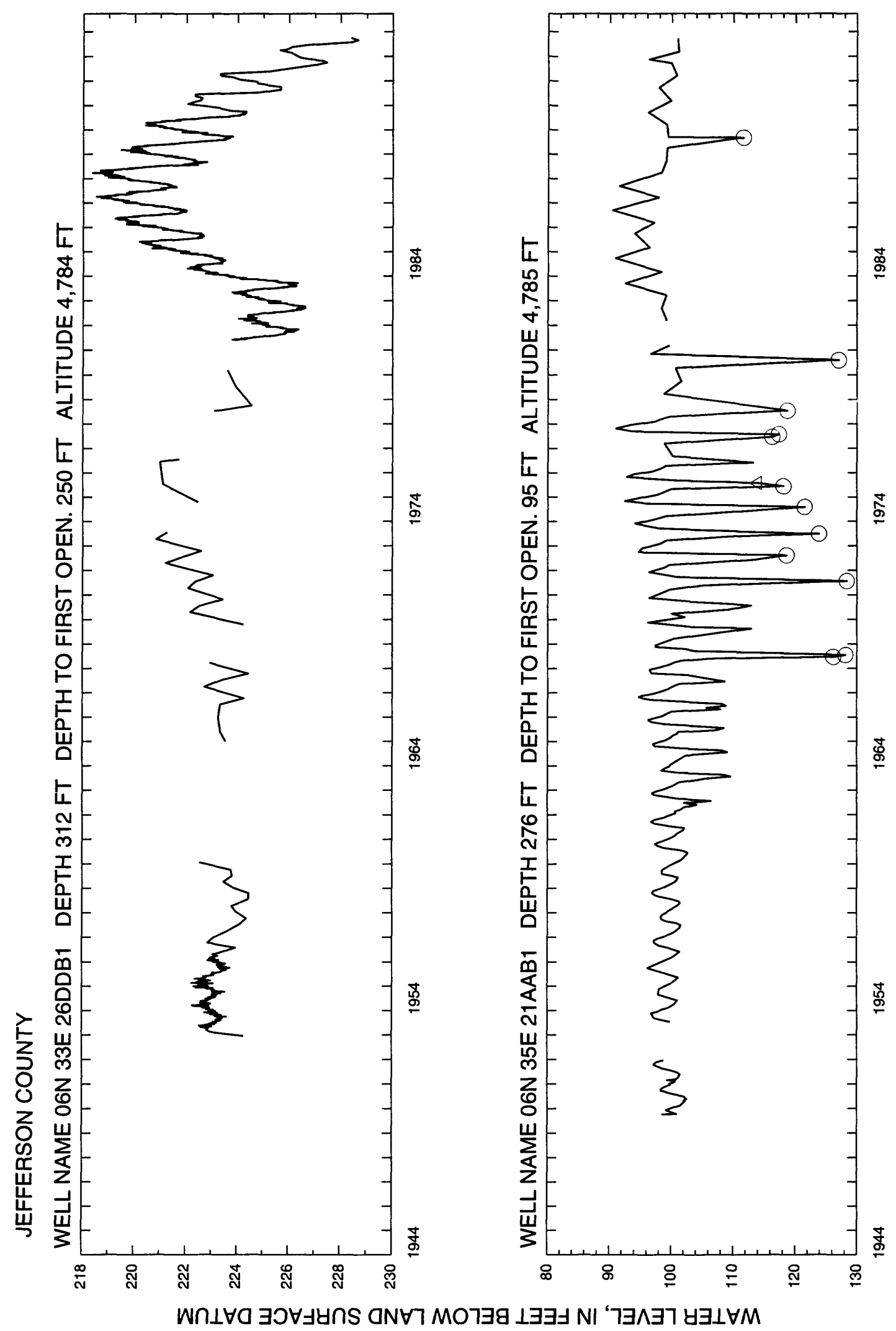




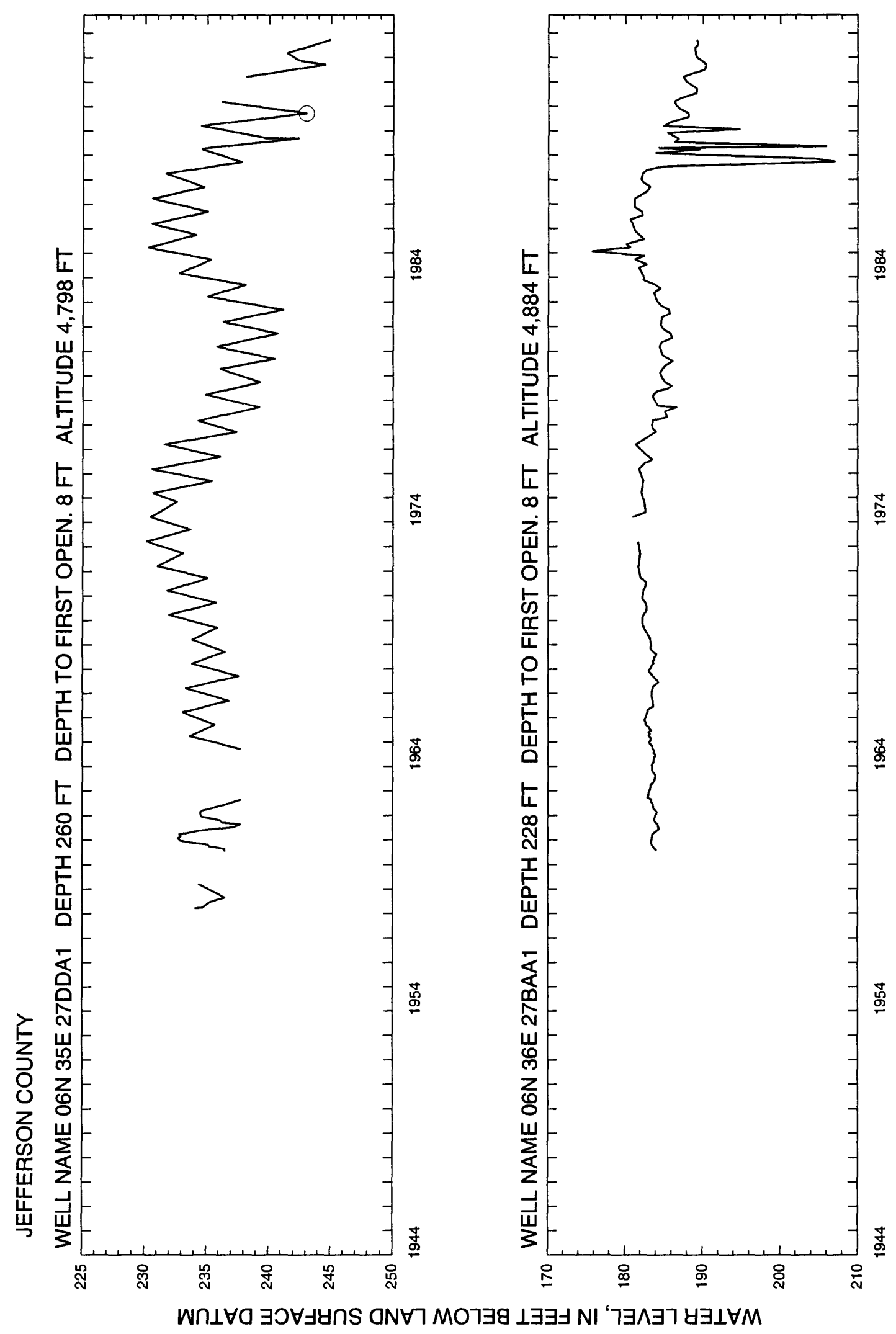




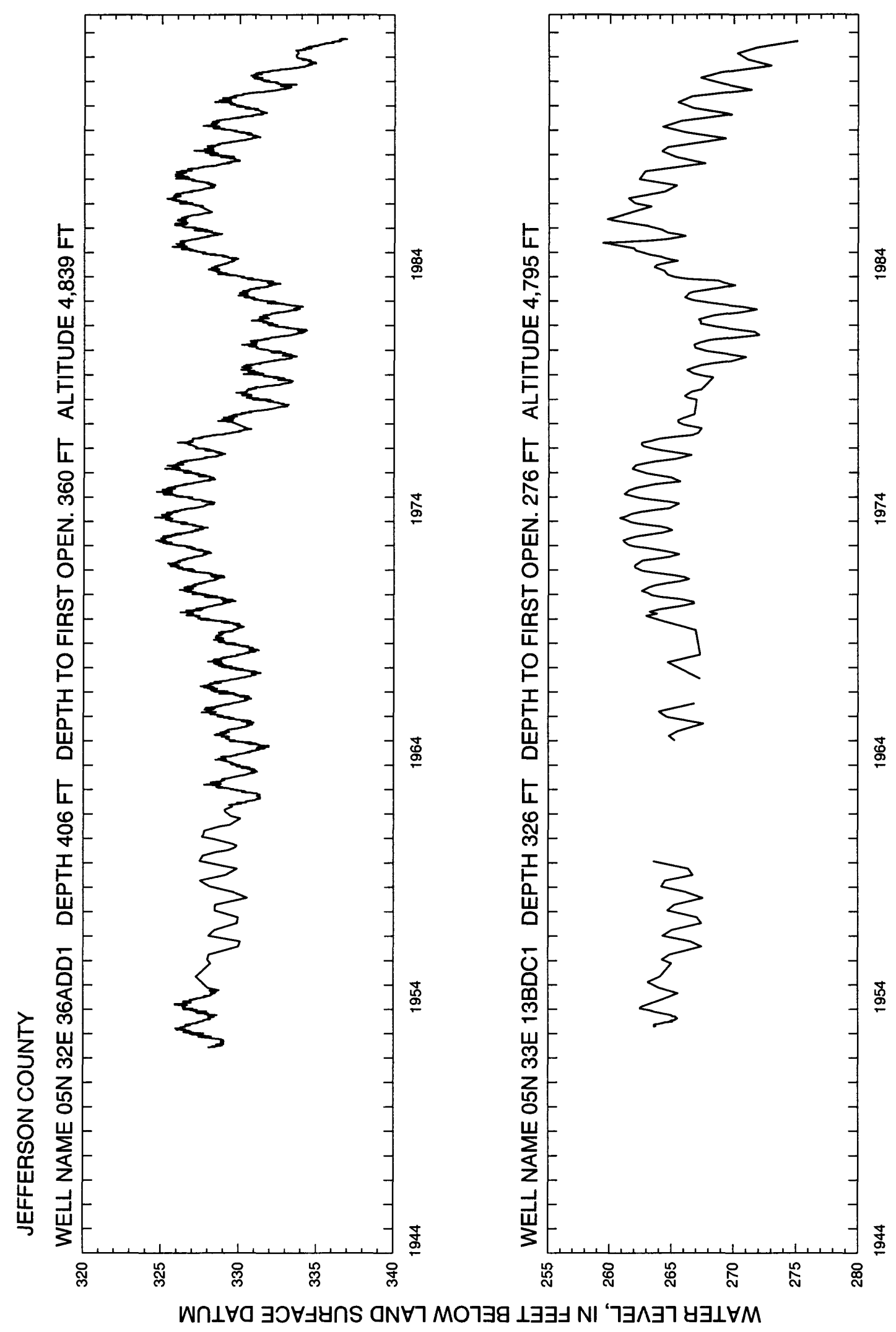




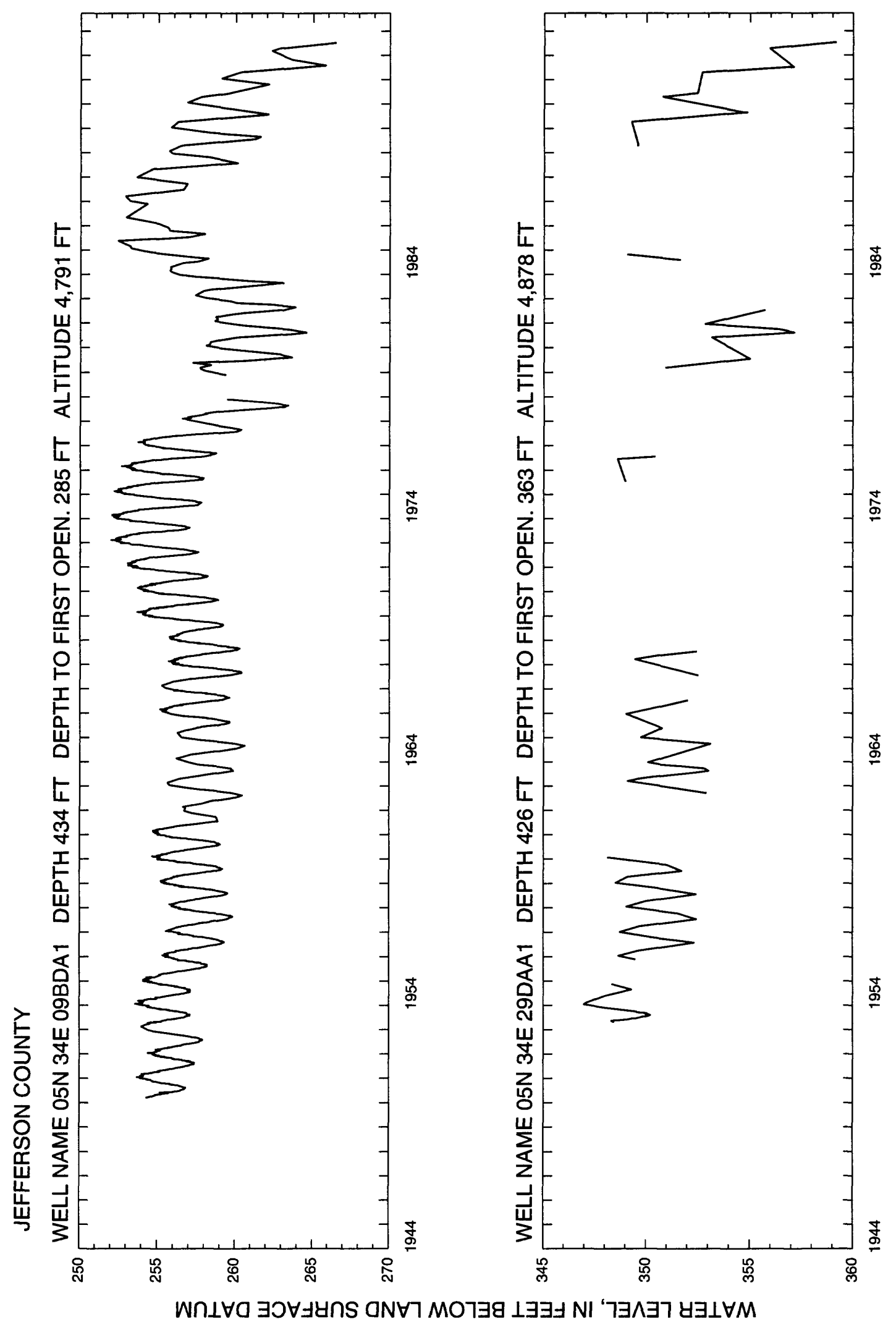




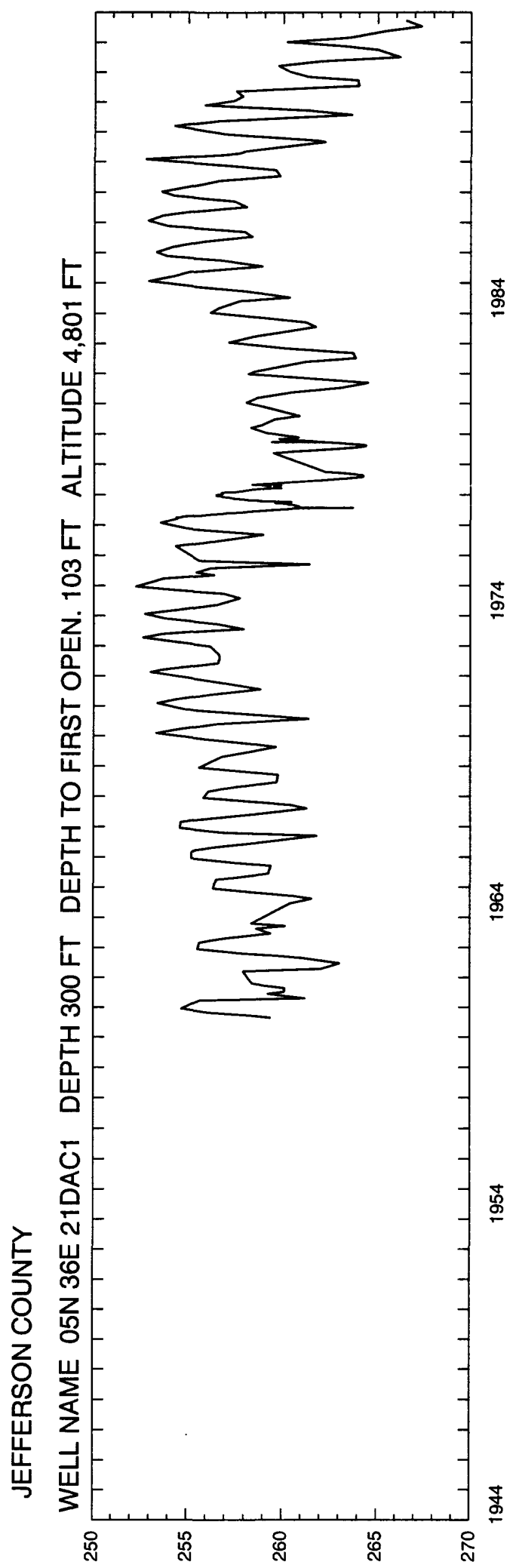

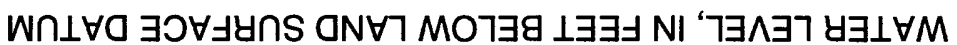


Jerome

267 (poge 269 follows) 


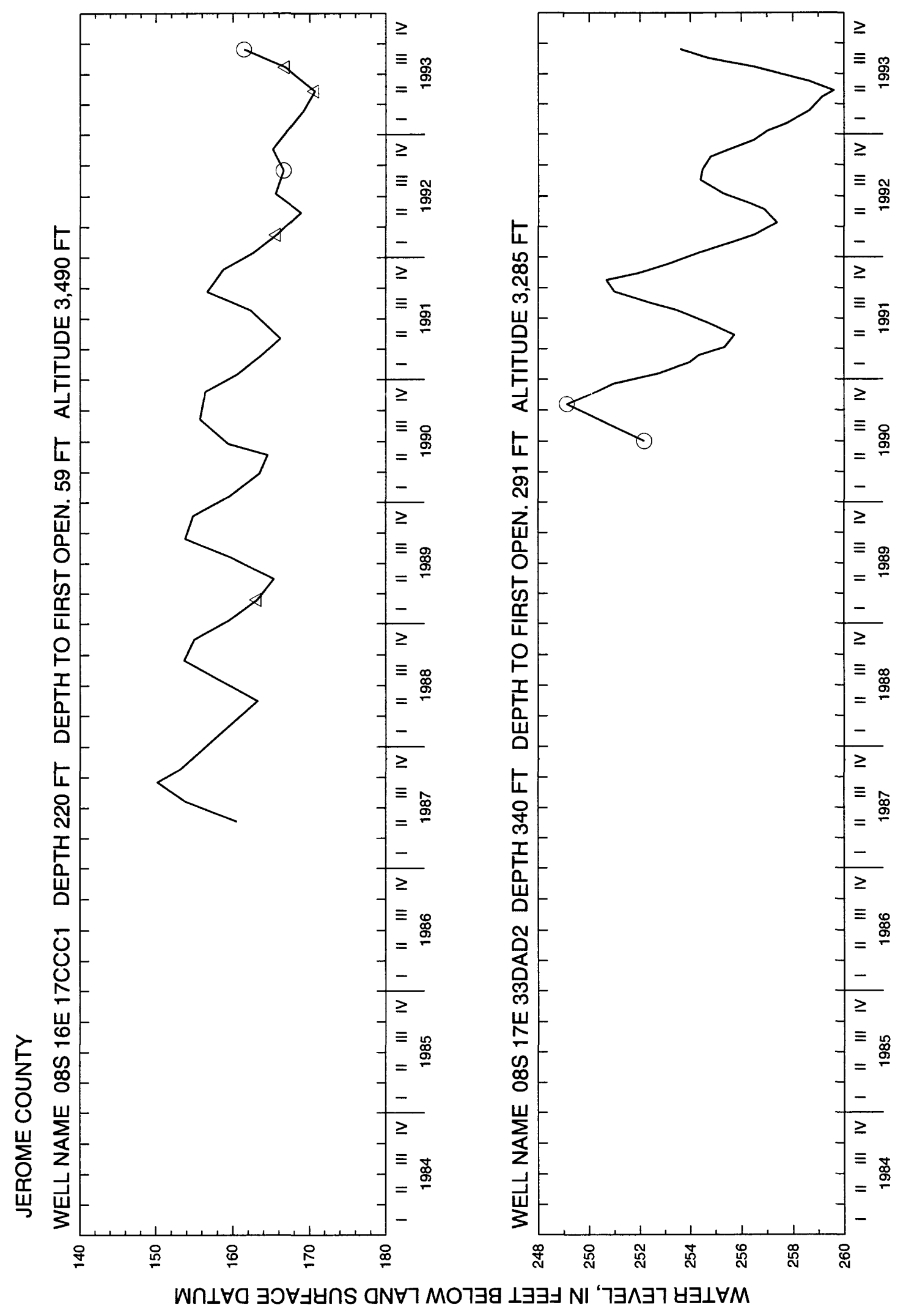




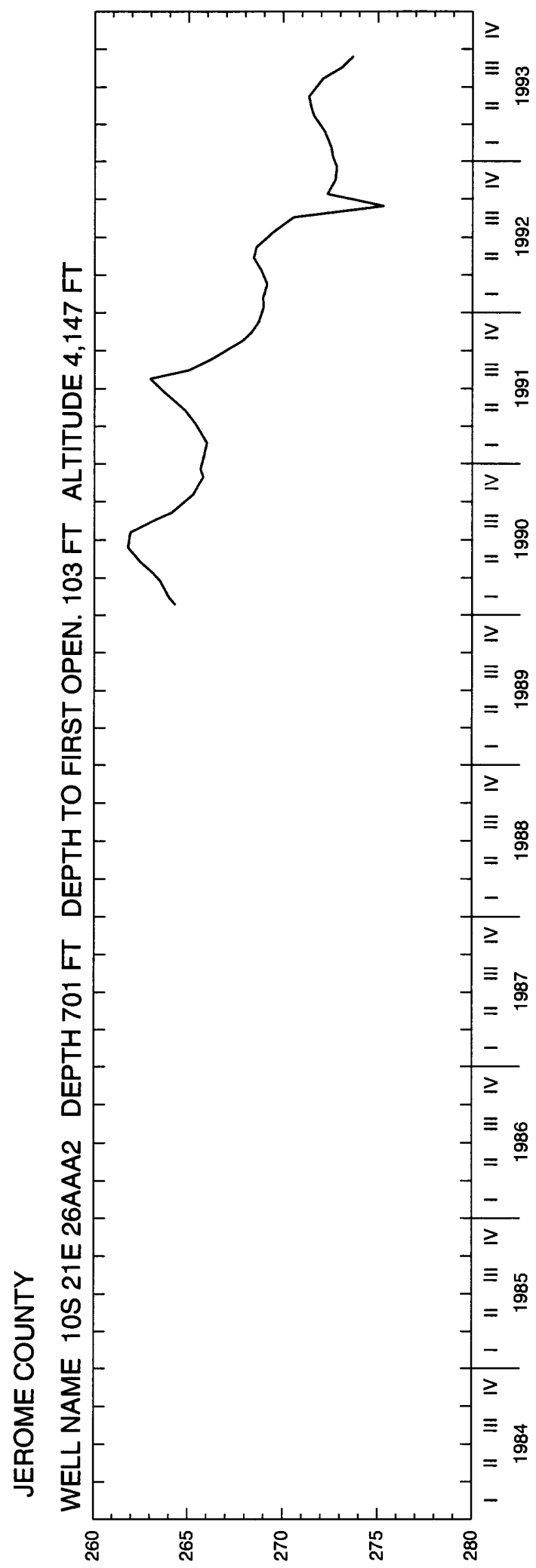

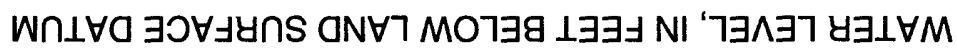




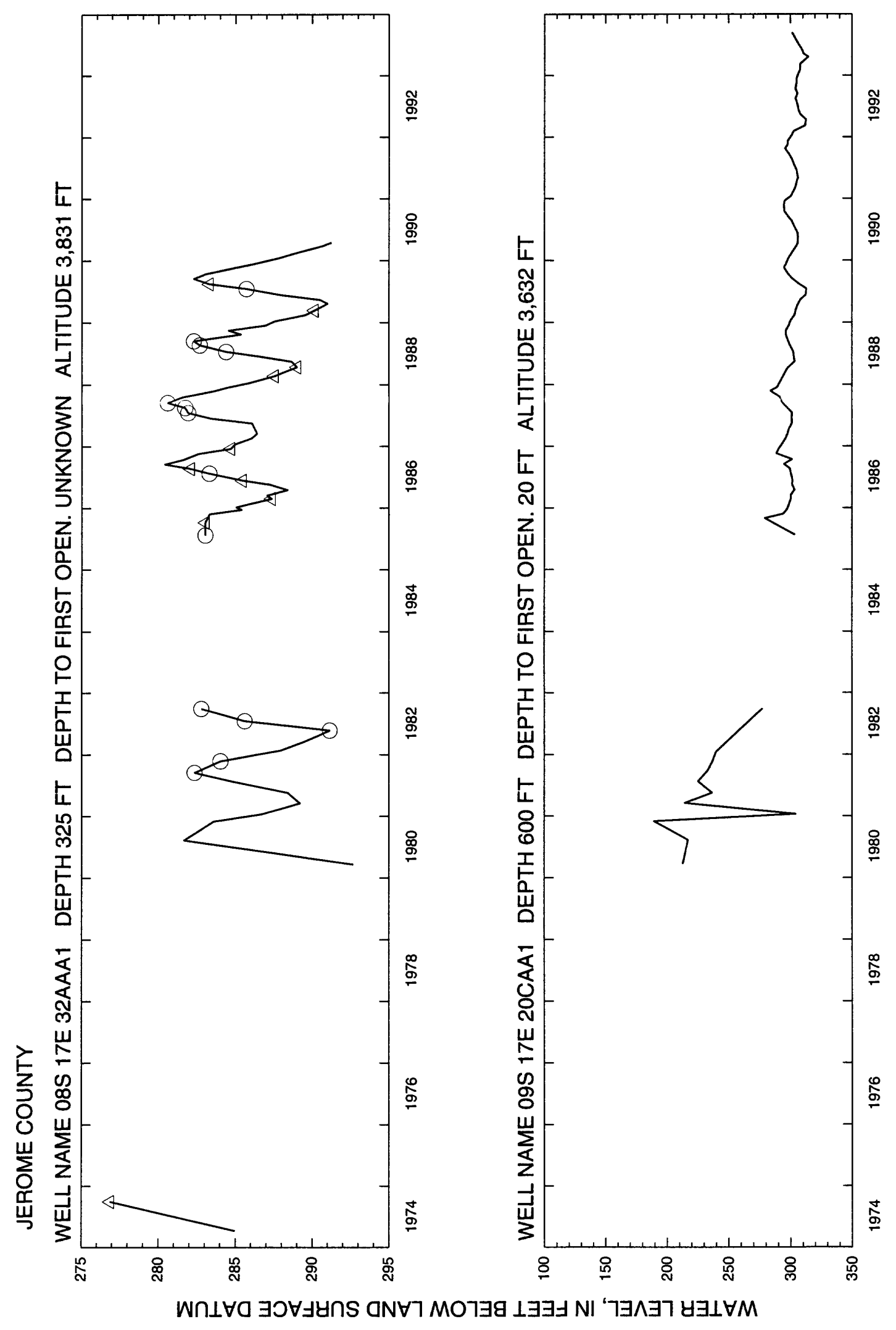




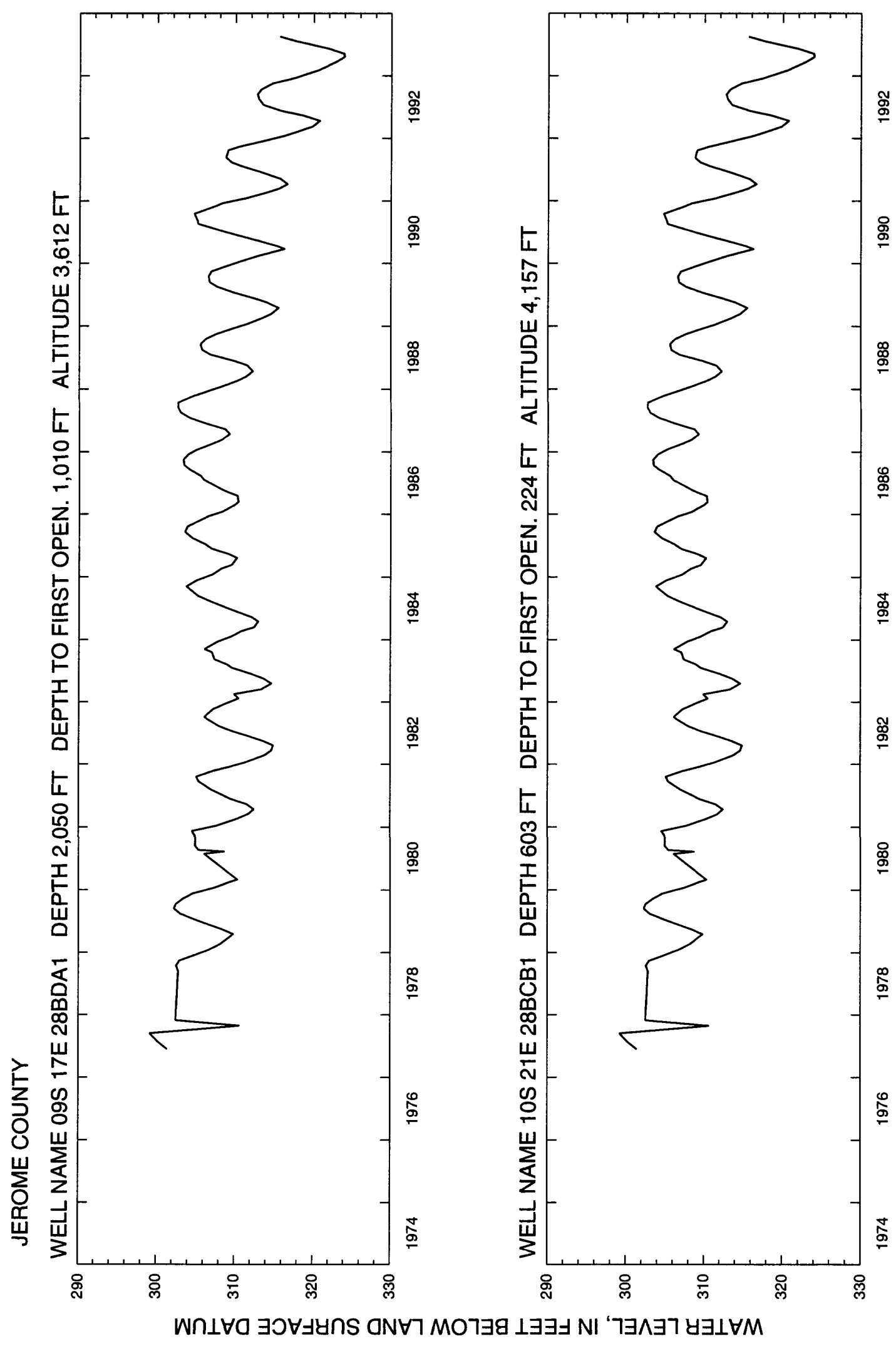




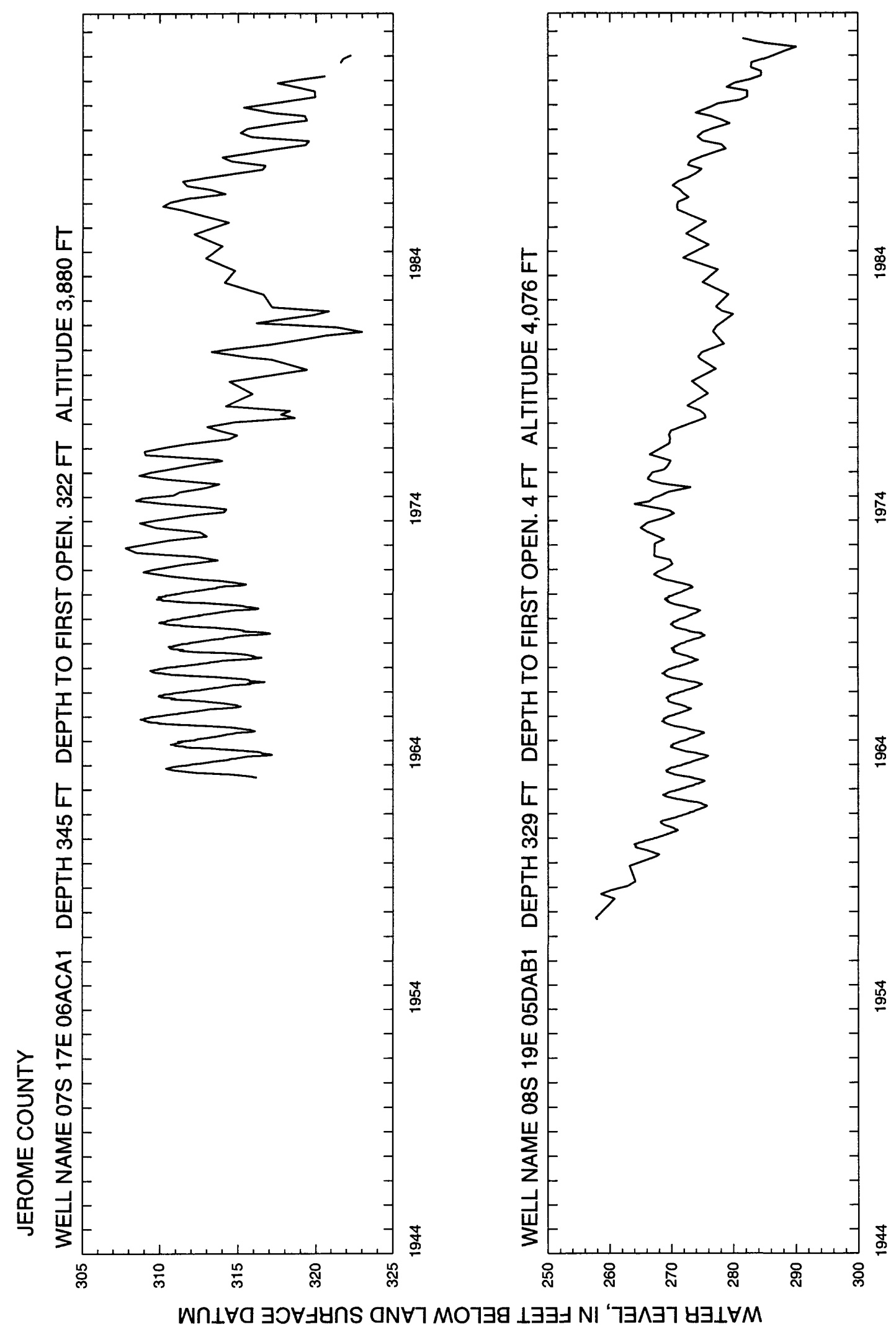




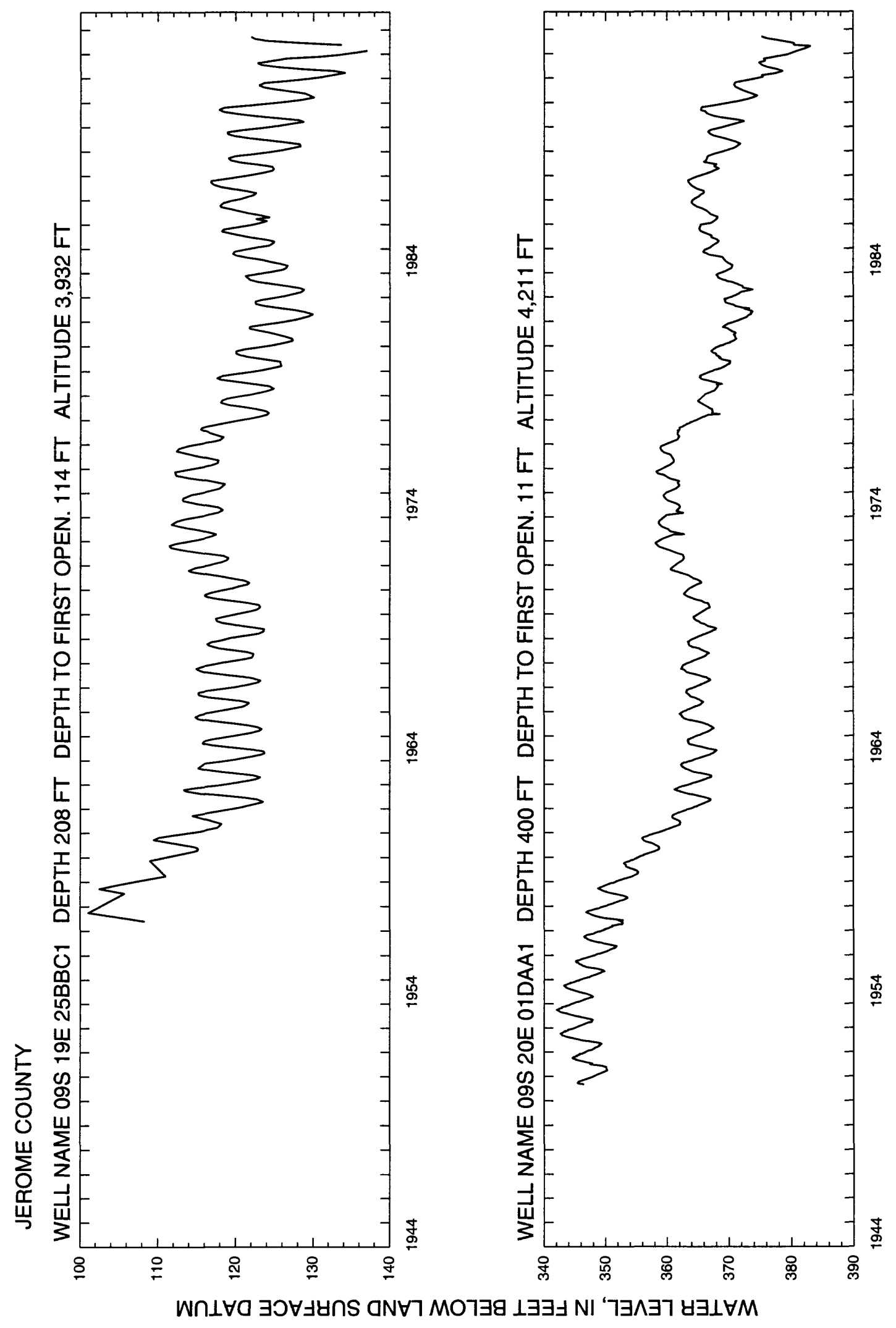




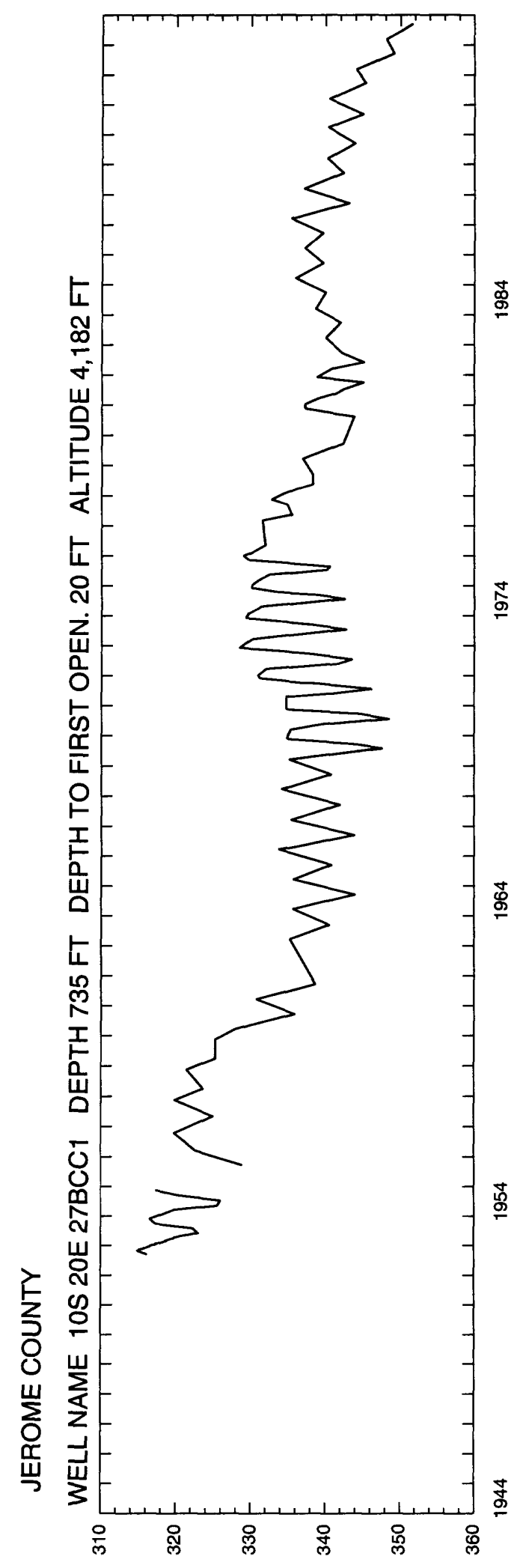

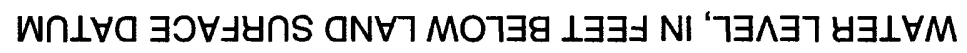


Kootenai 


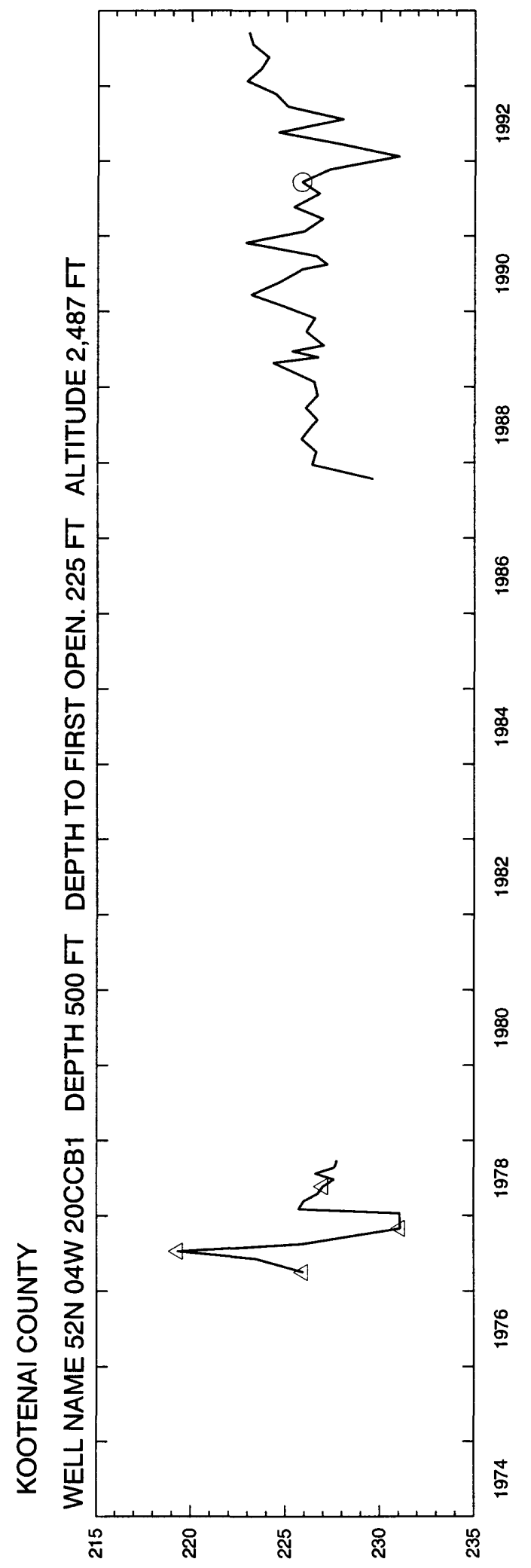

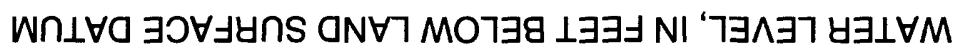




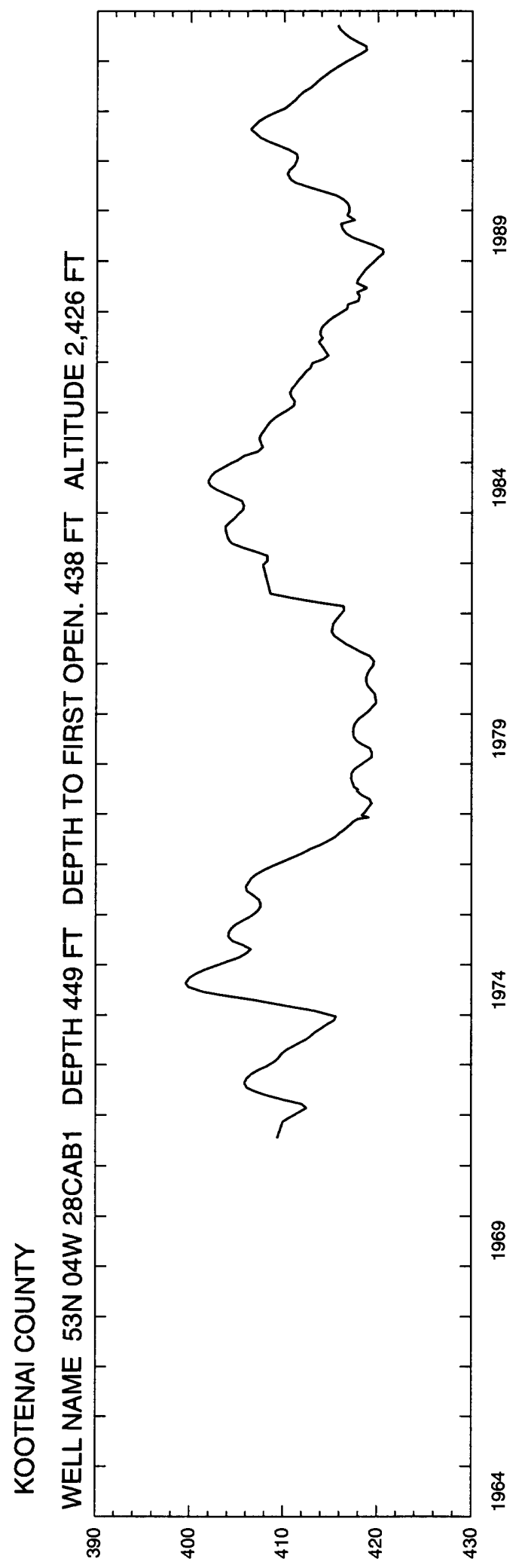

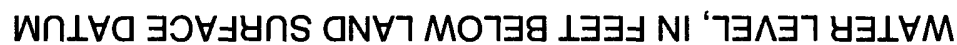




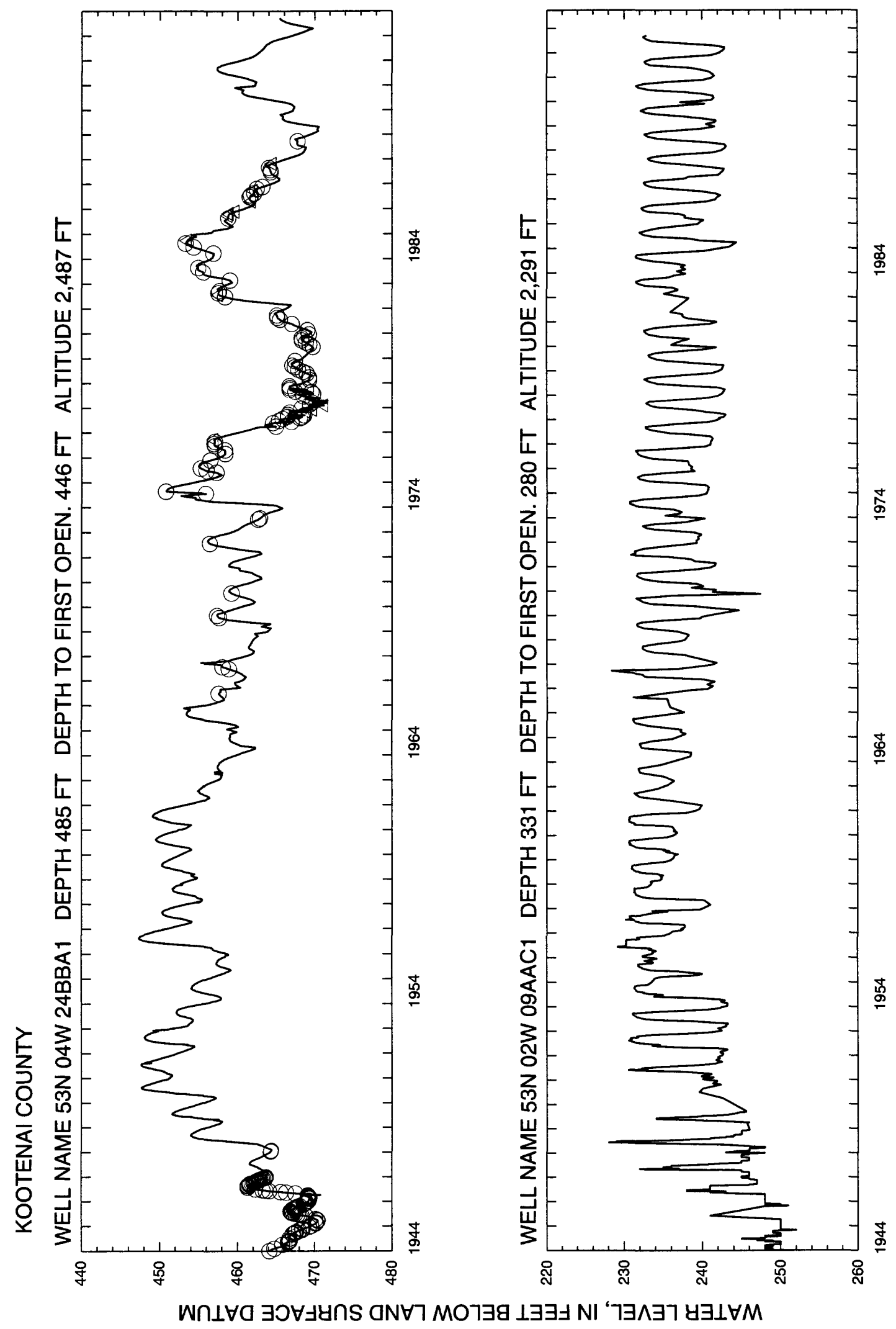




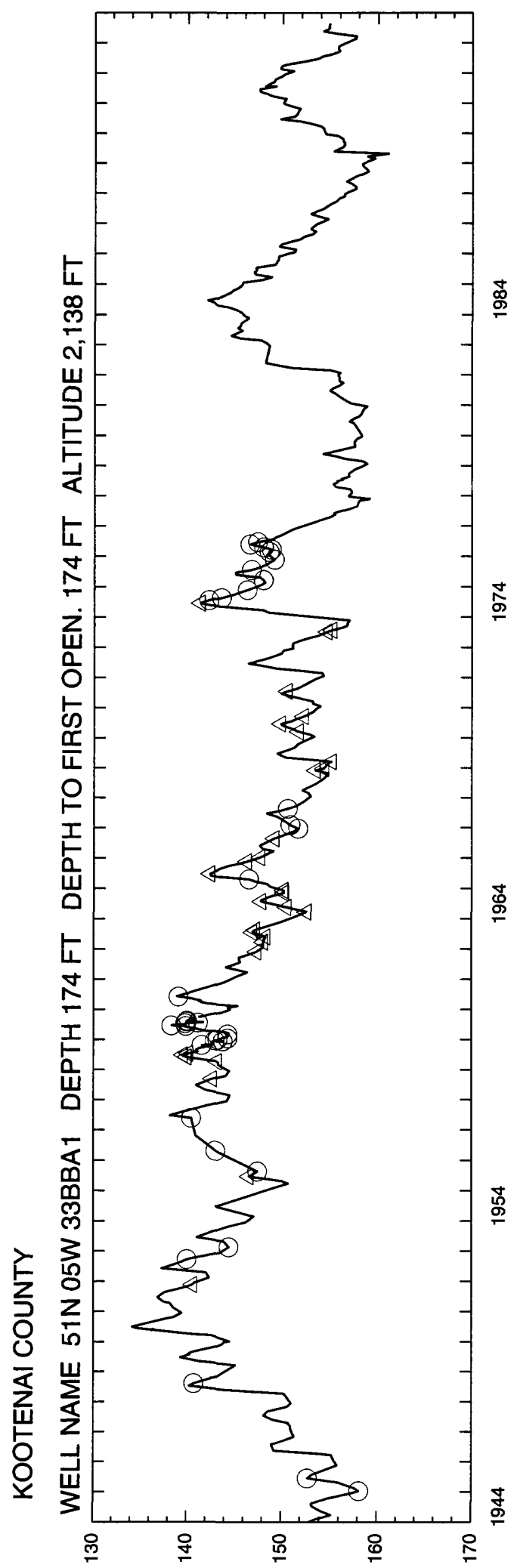

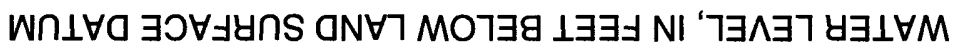




\section{Latah}




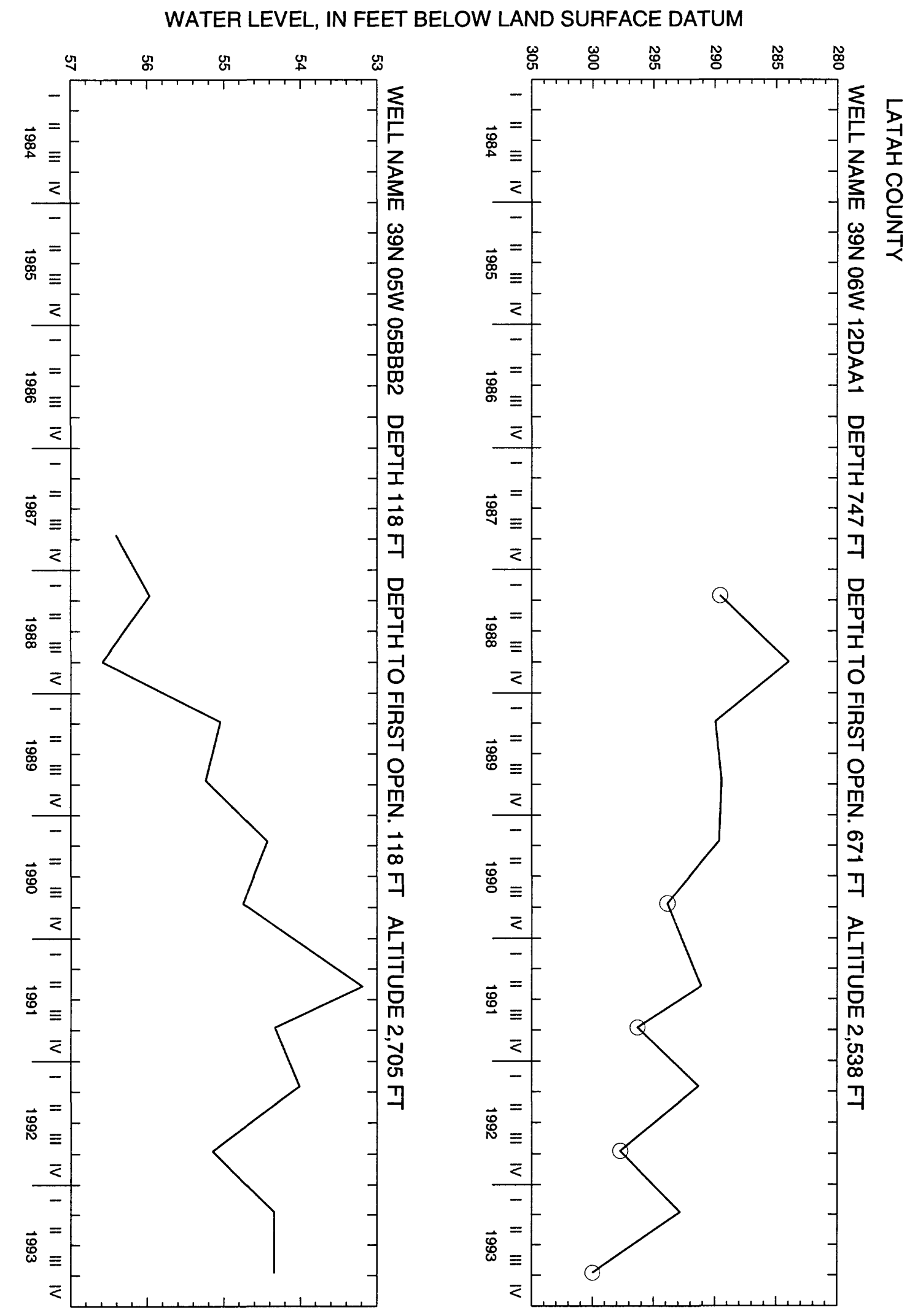




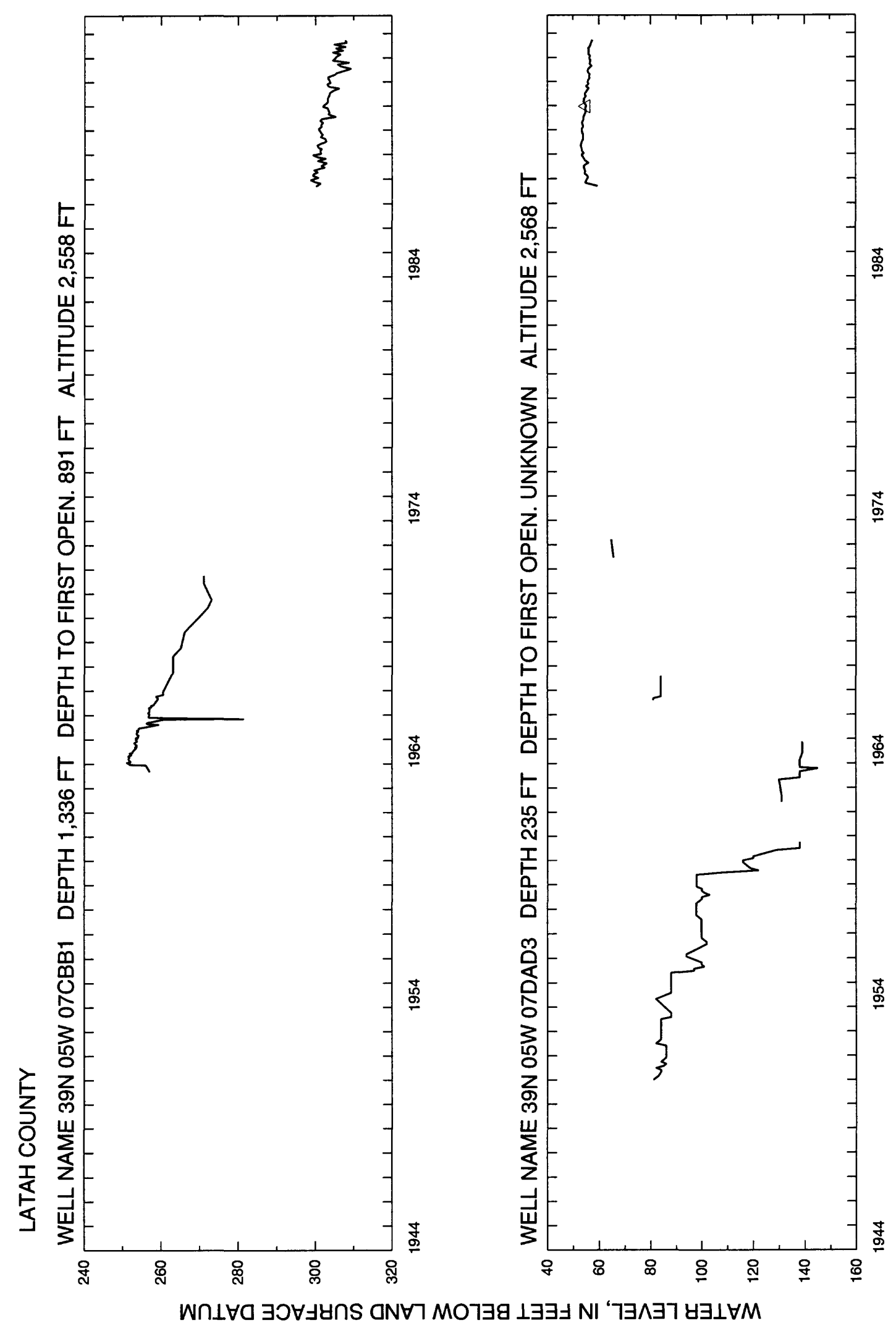




\section{Lemhi}




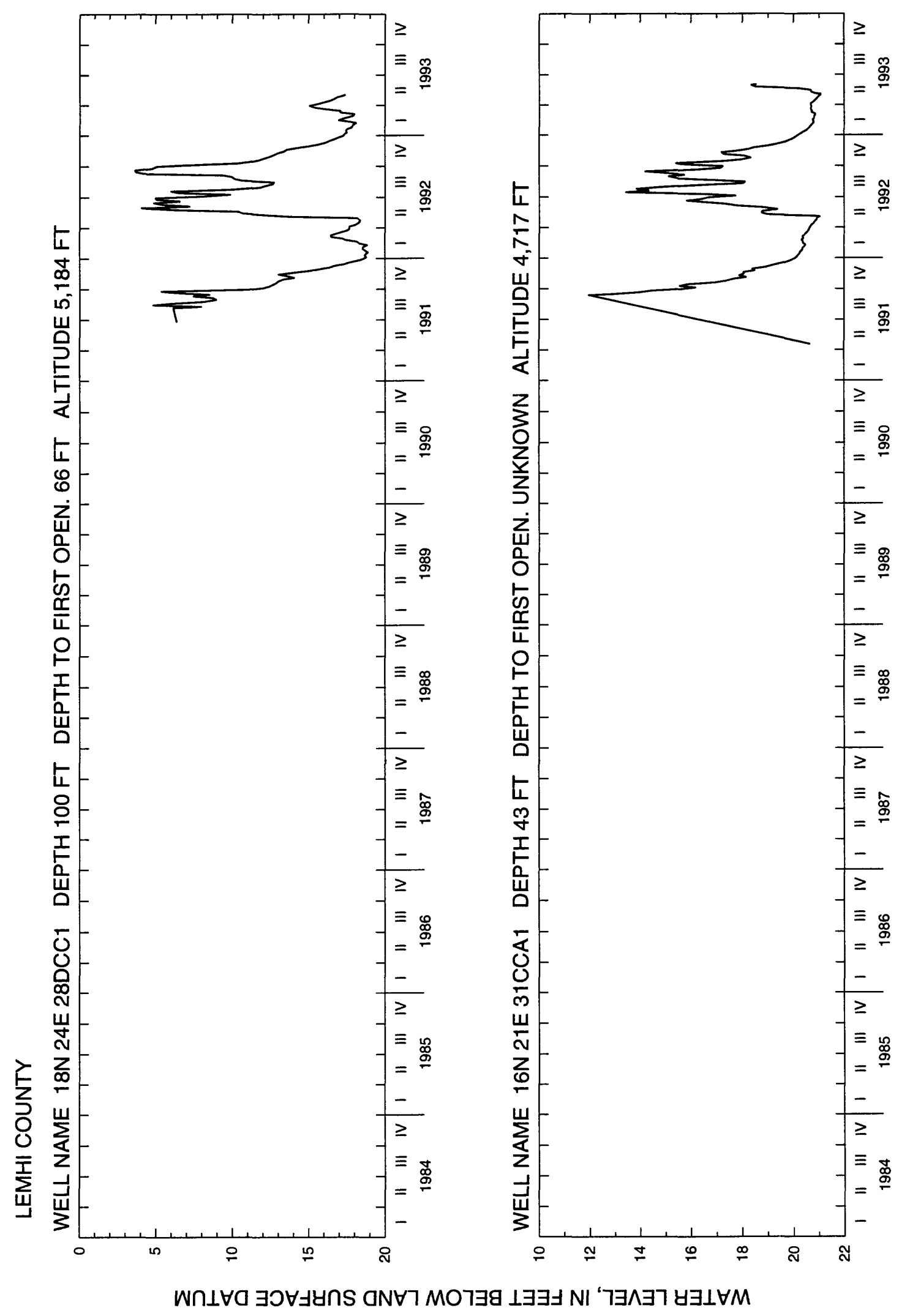




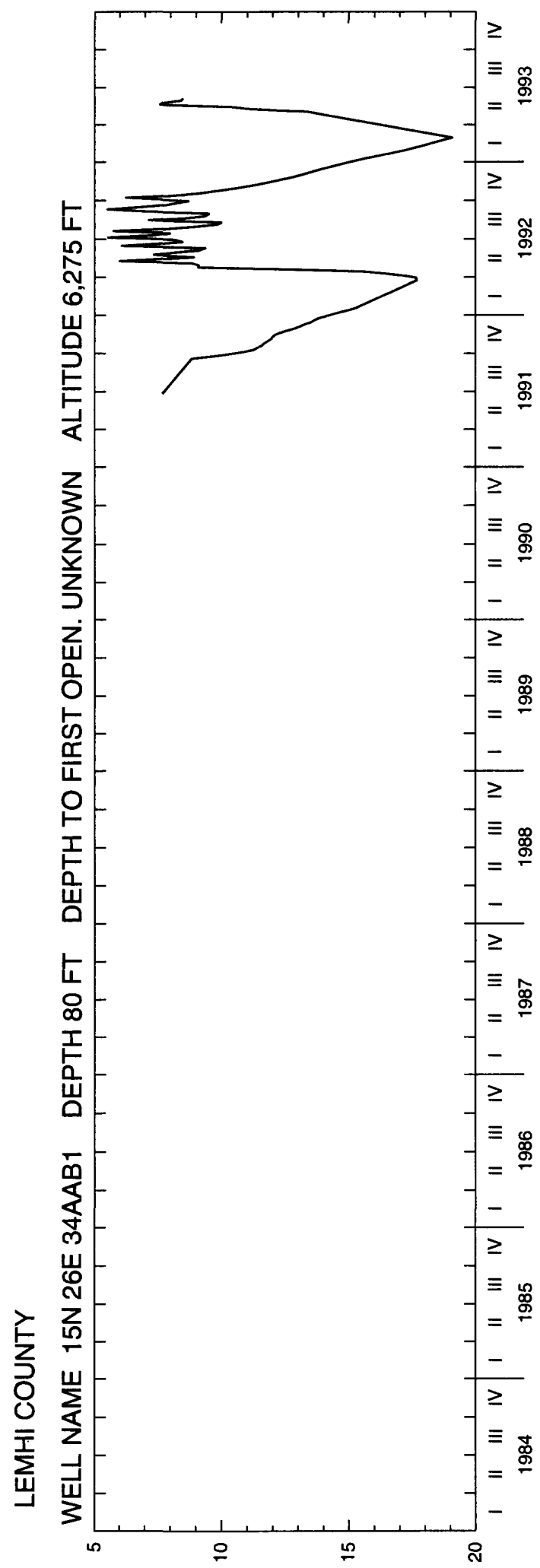

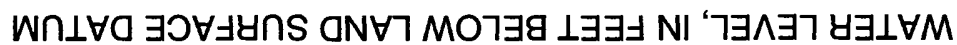




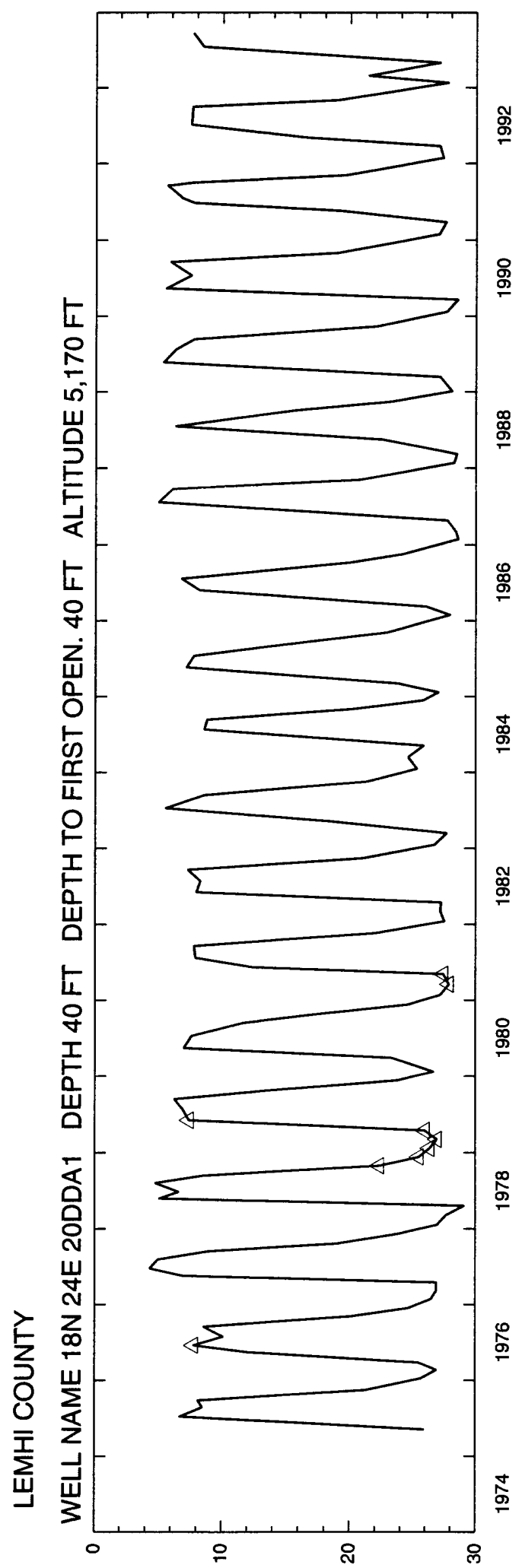

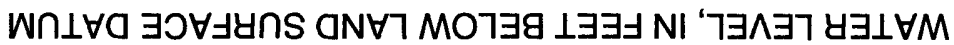




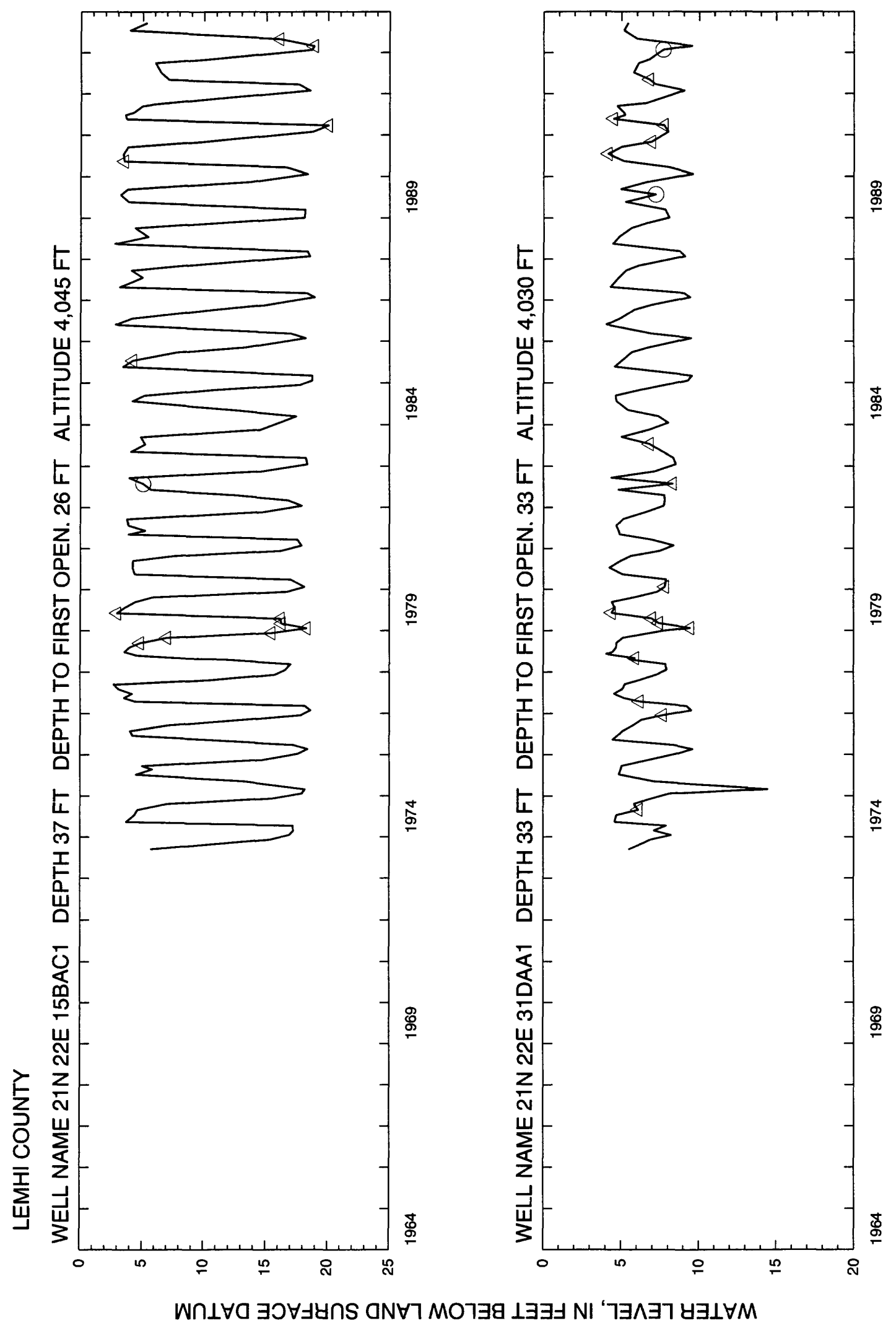




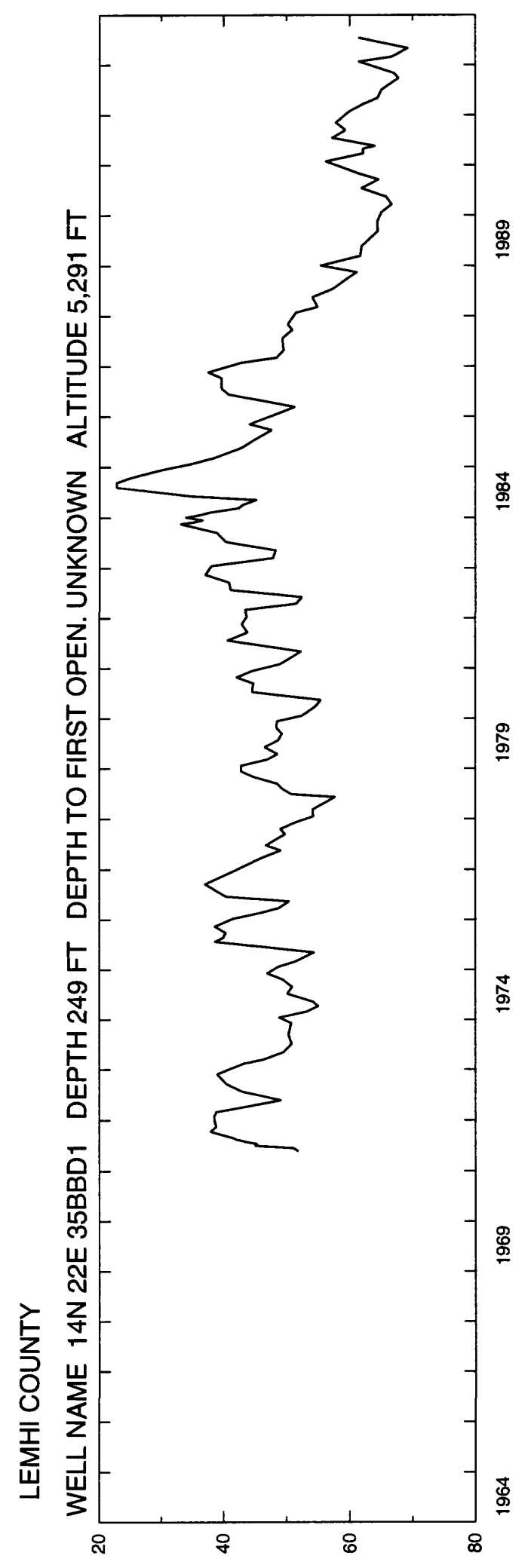

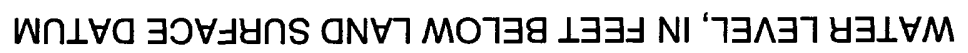




\section{Lewis}




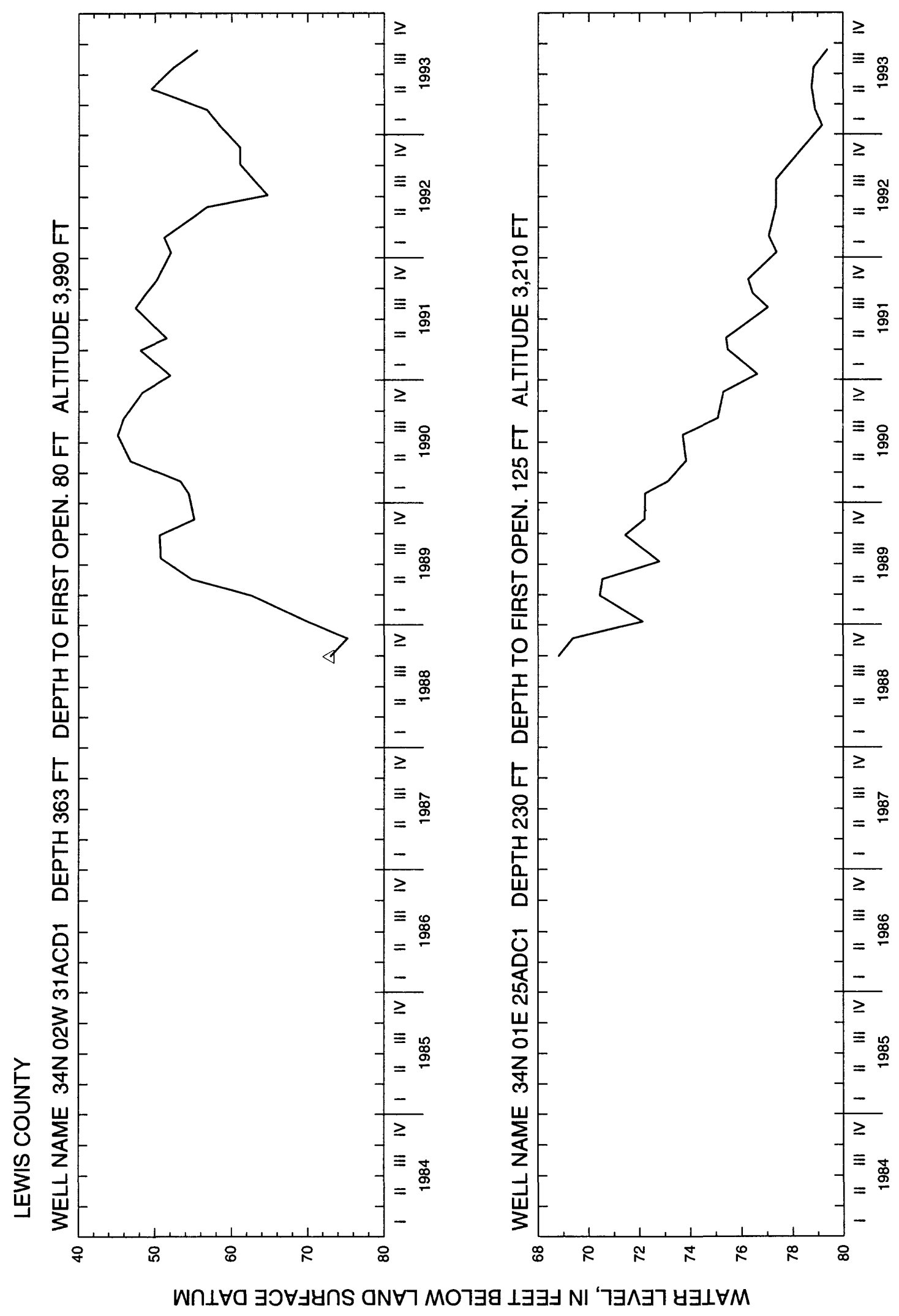

297 (page 299 follows) 
Lincoln

${ }_{290}$ (page 301 follows) 


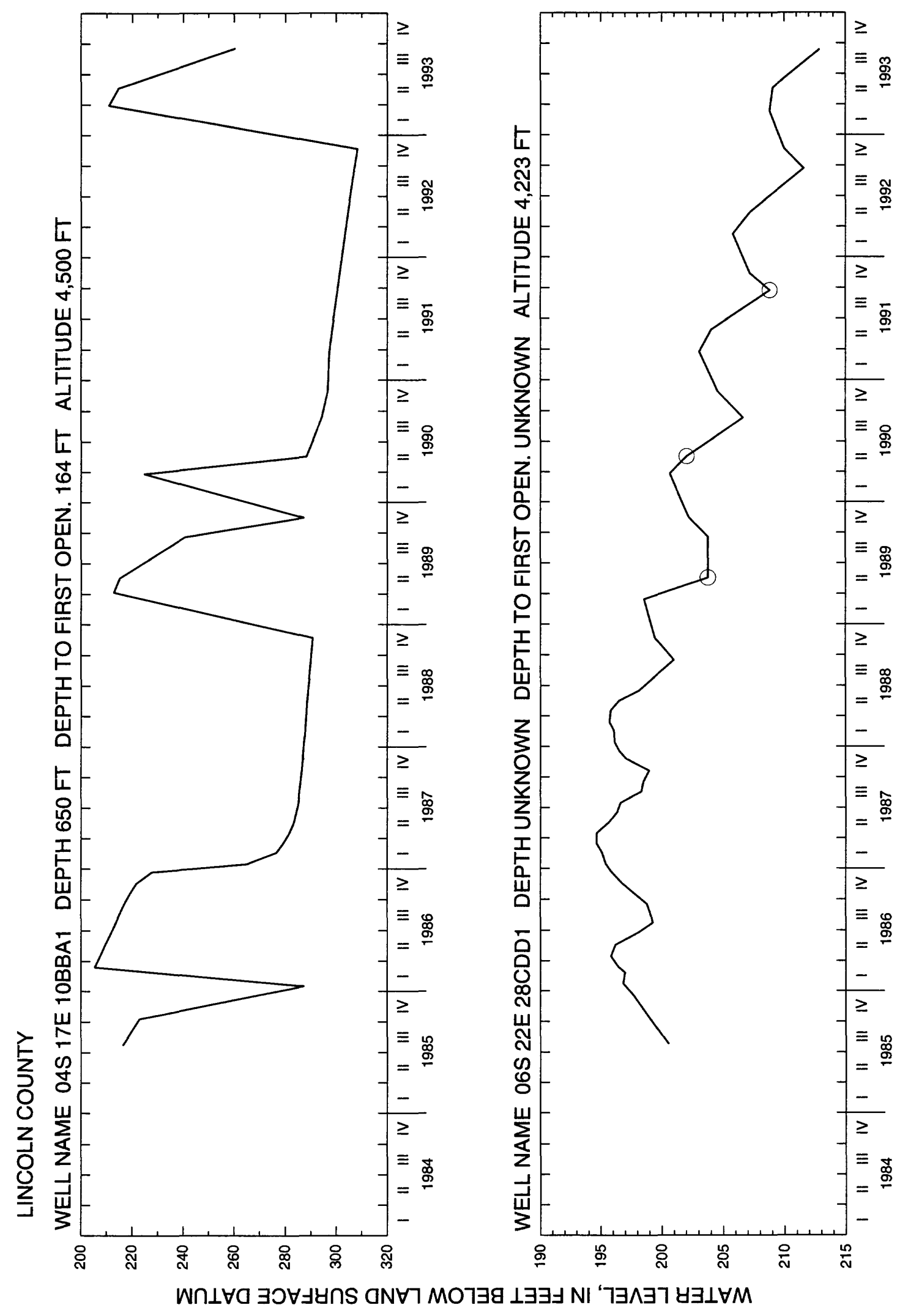




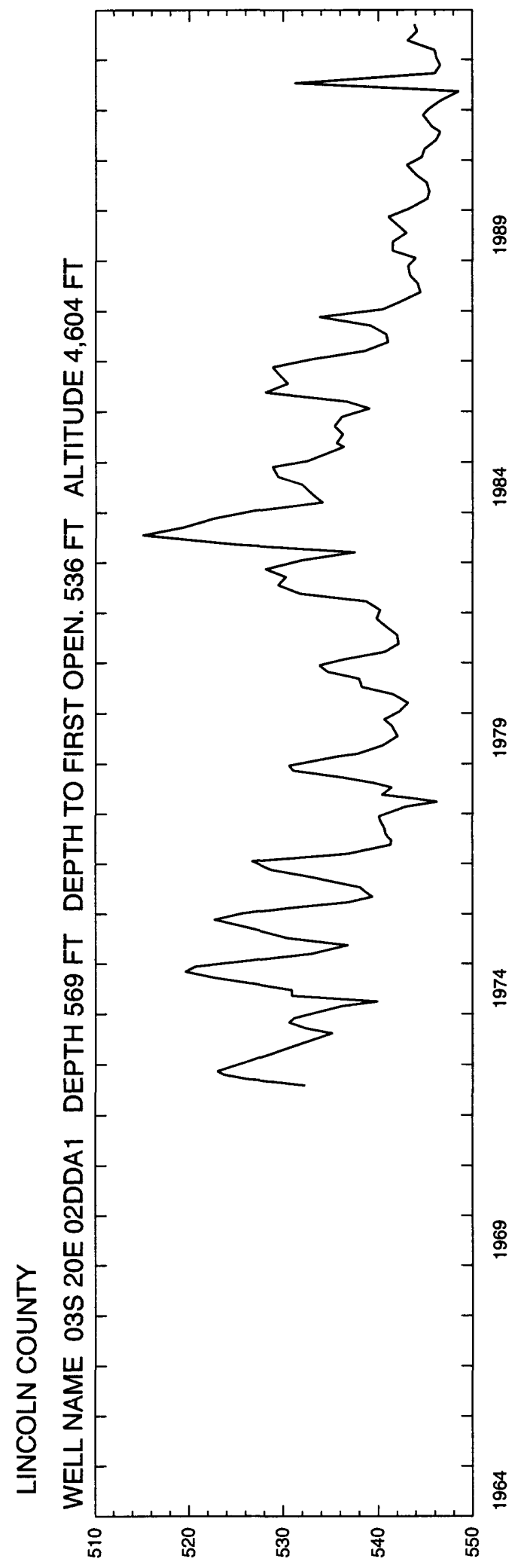

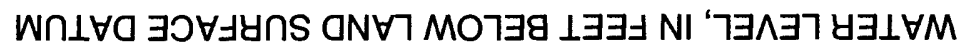




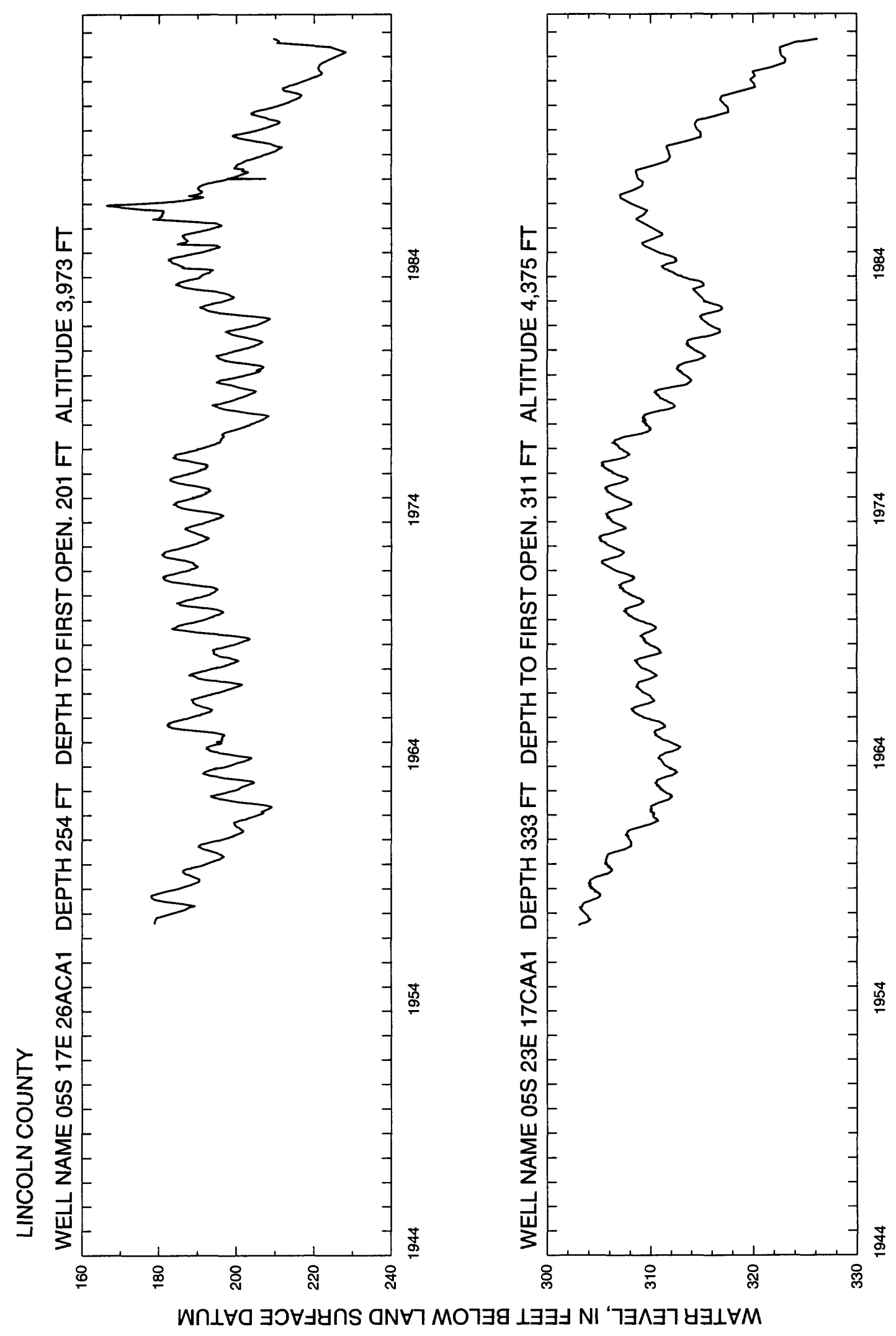




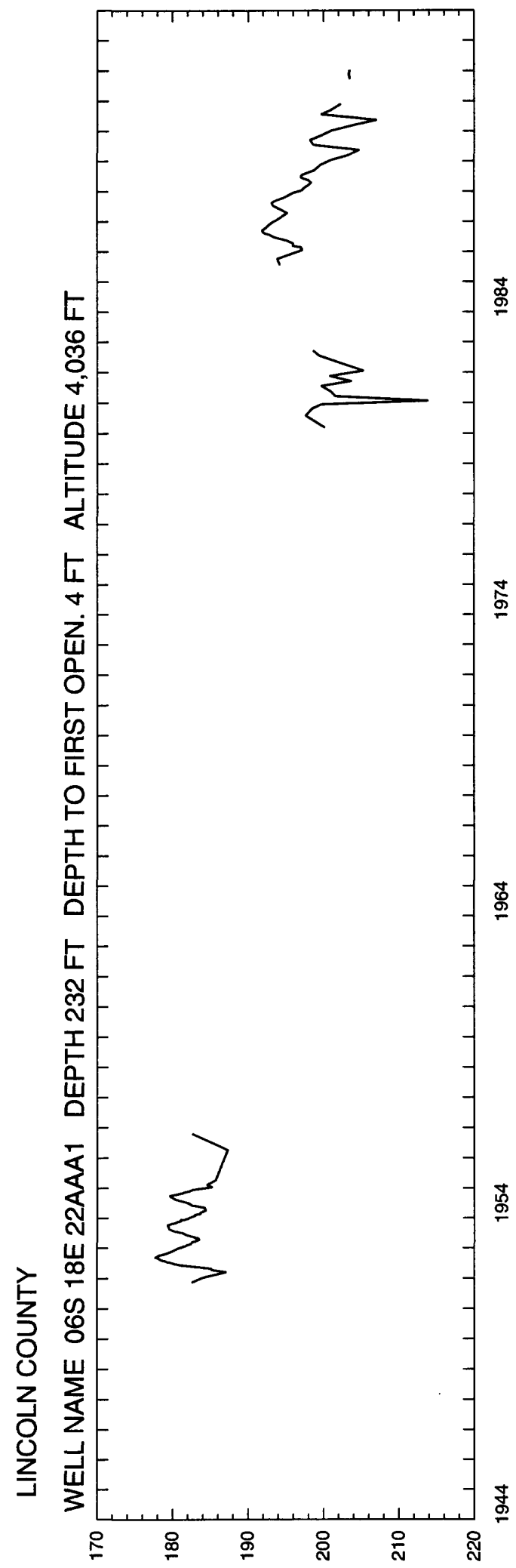

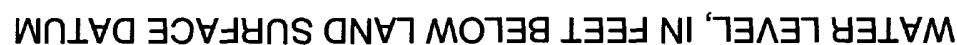


Madison 


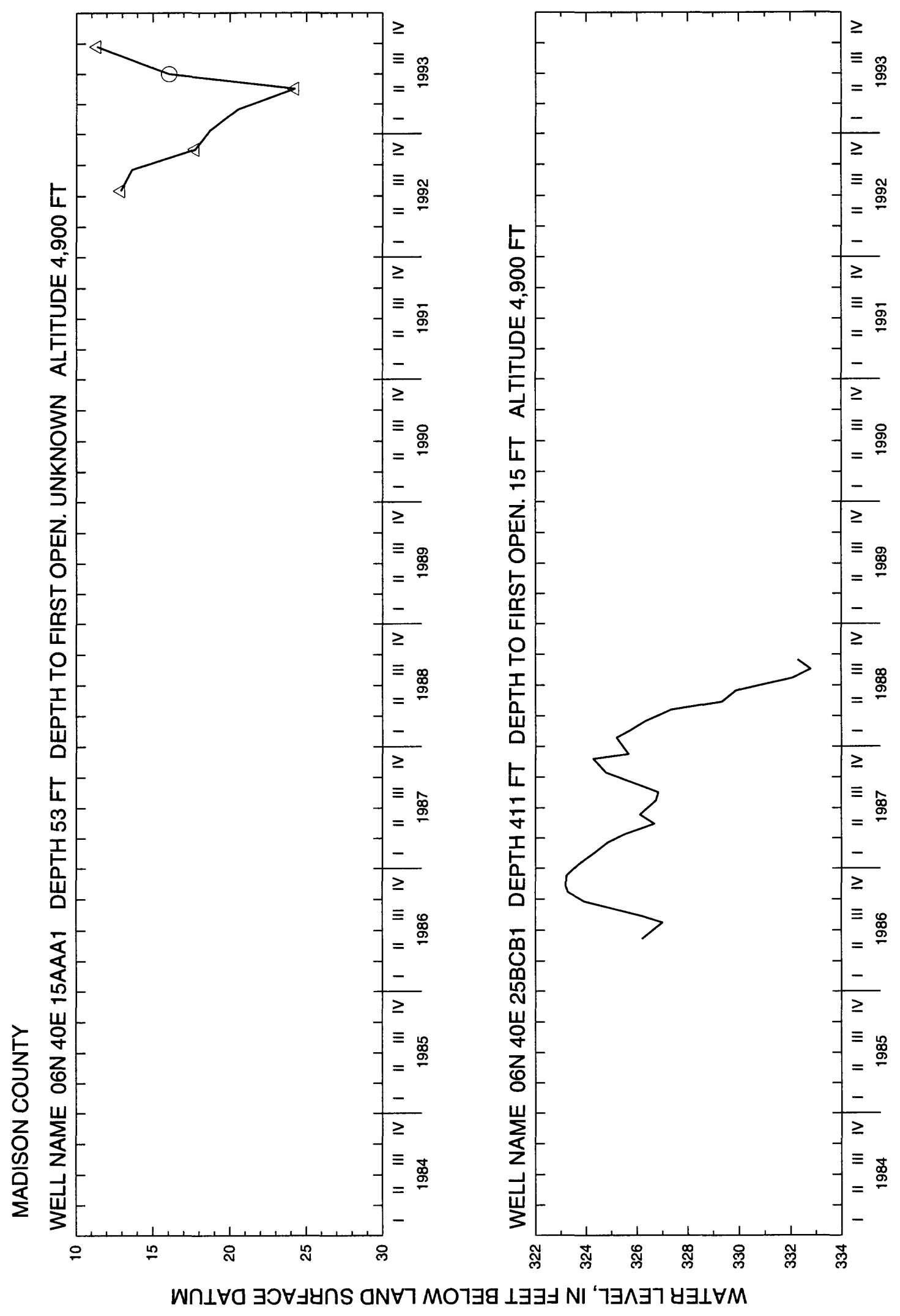




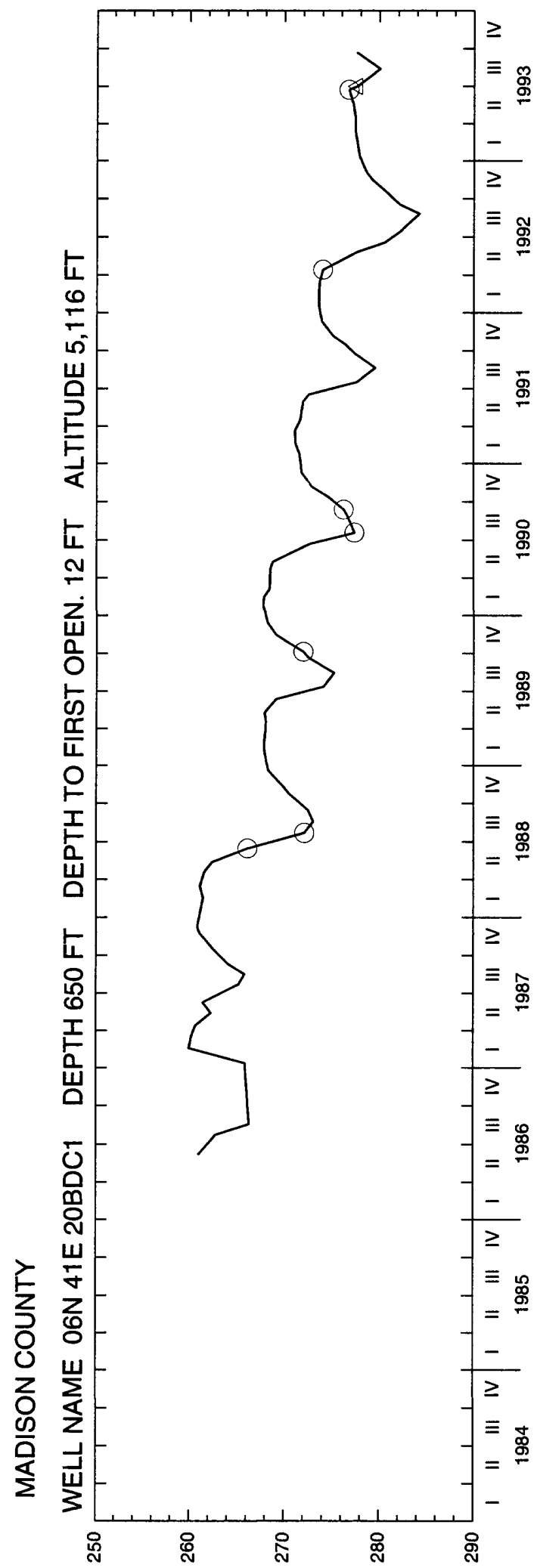

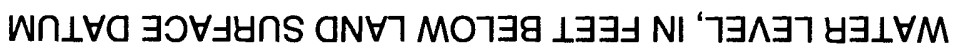




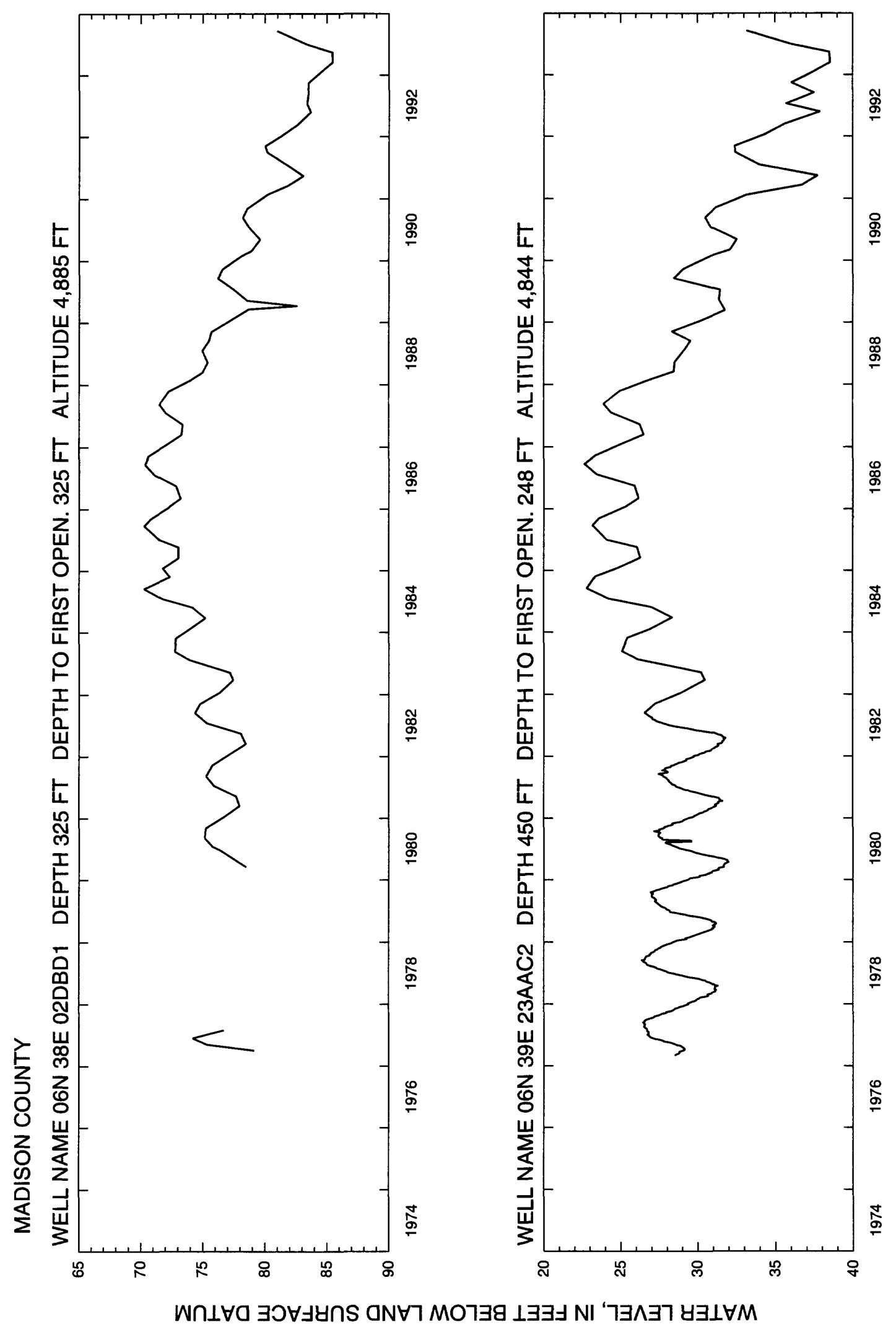




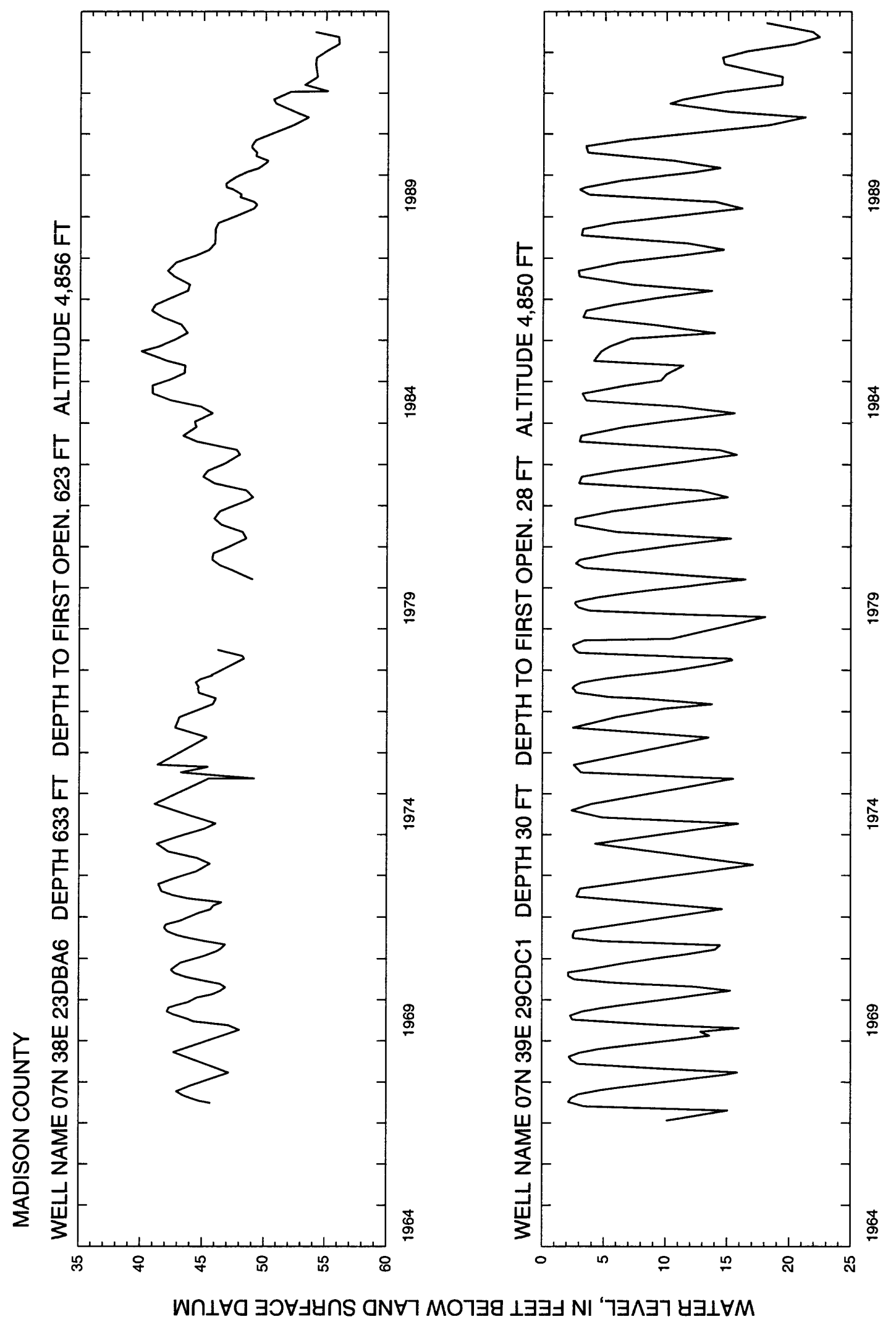




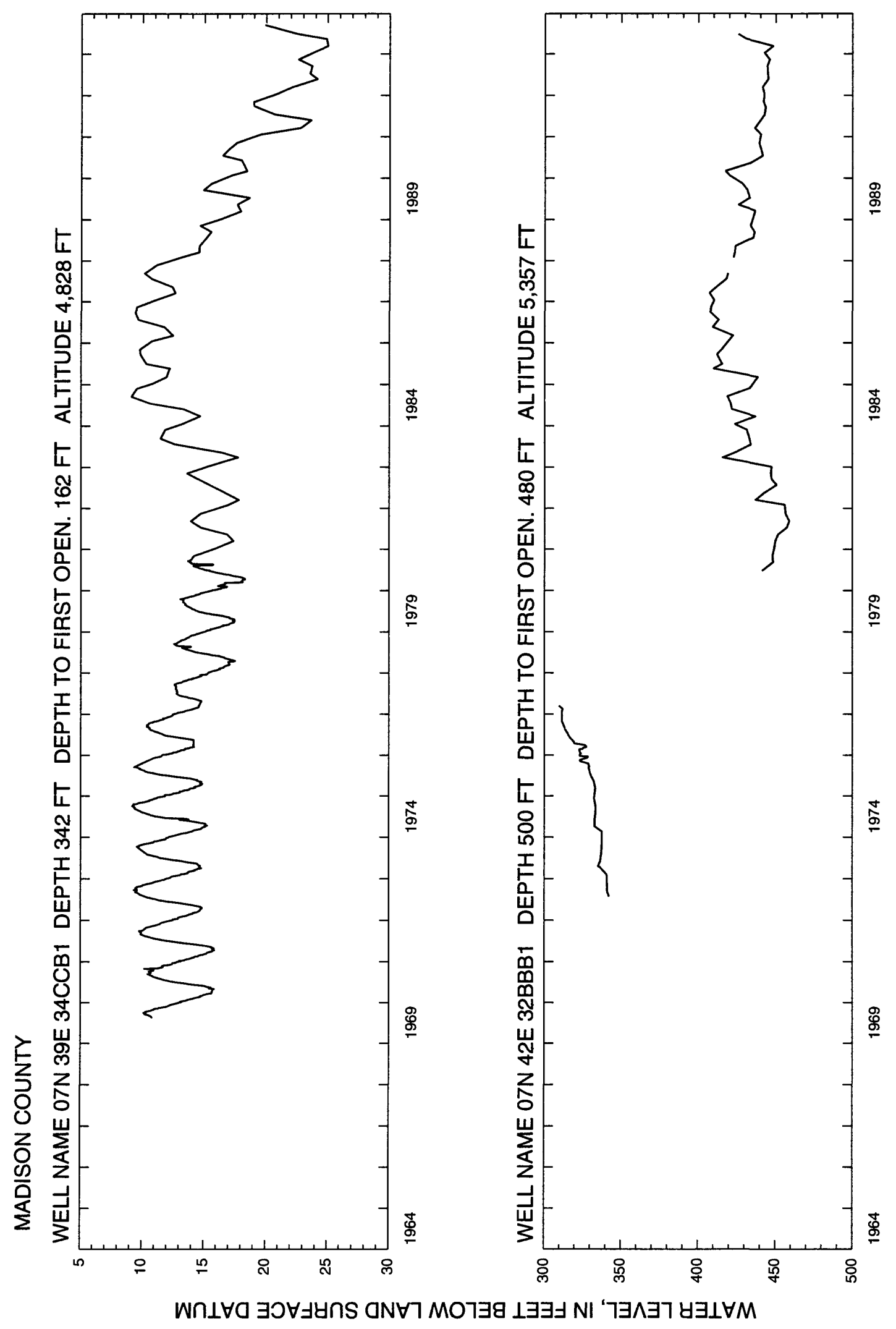




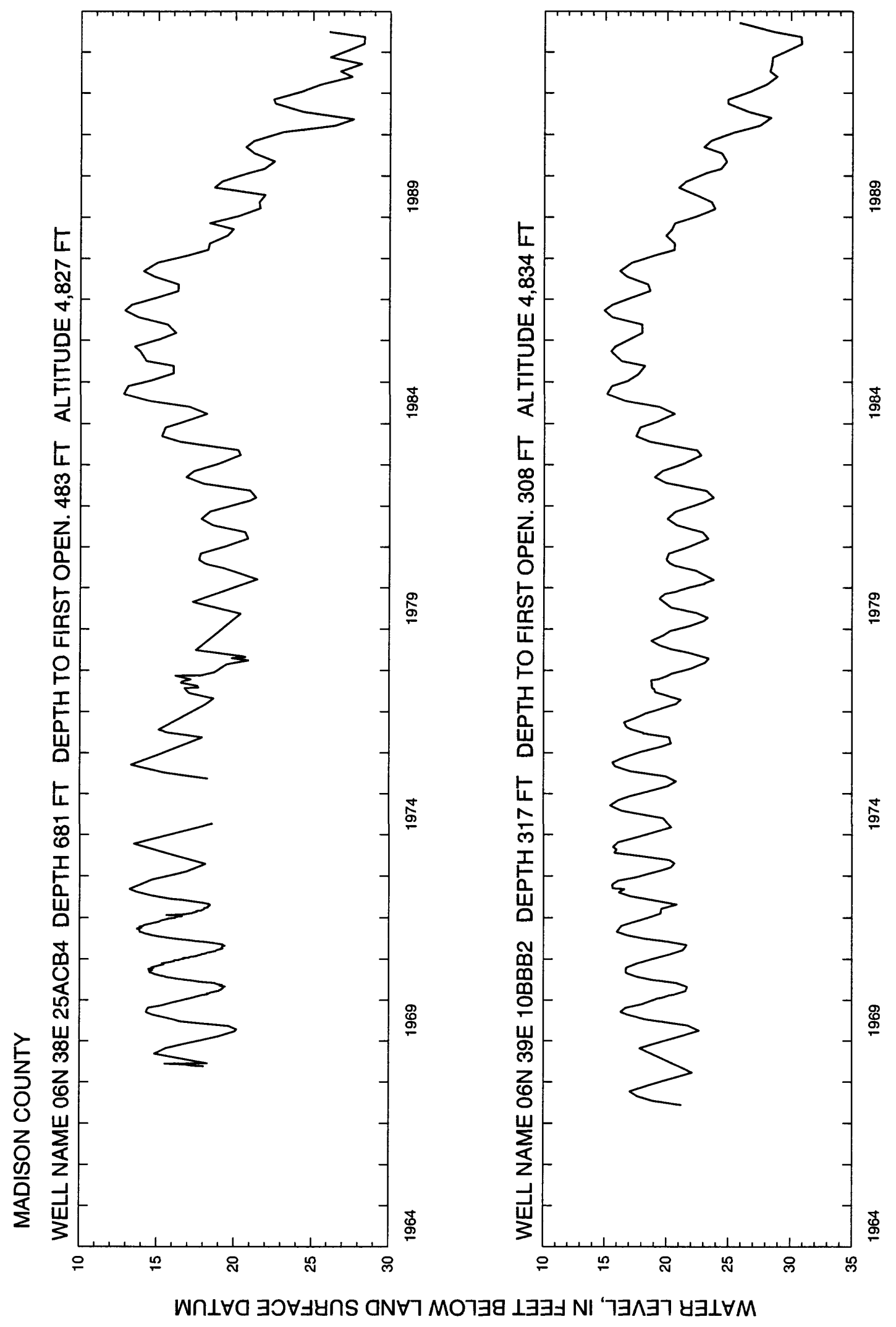




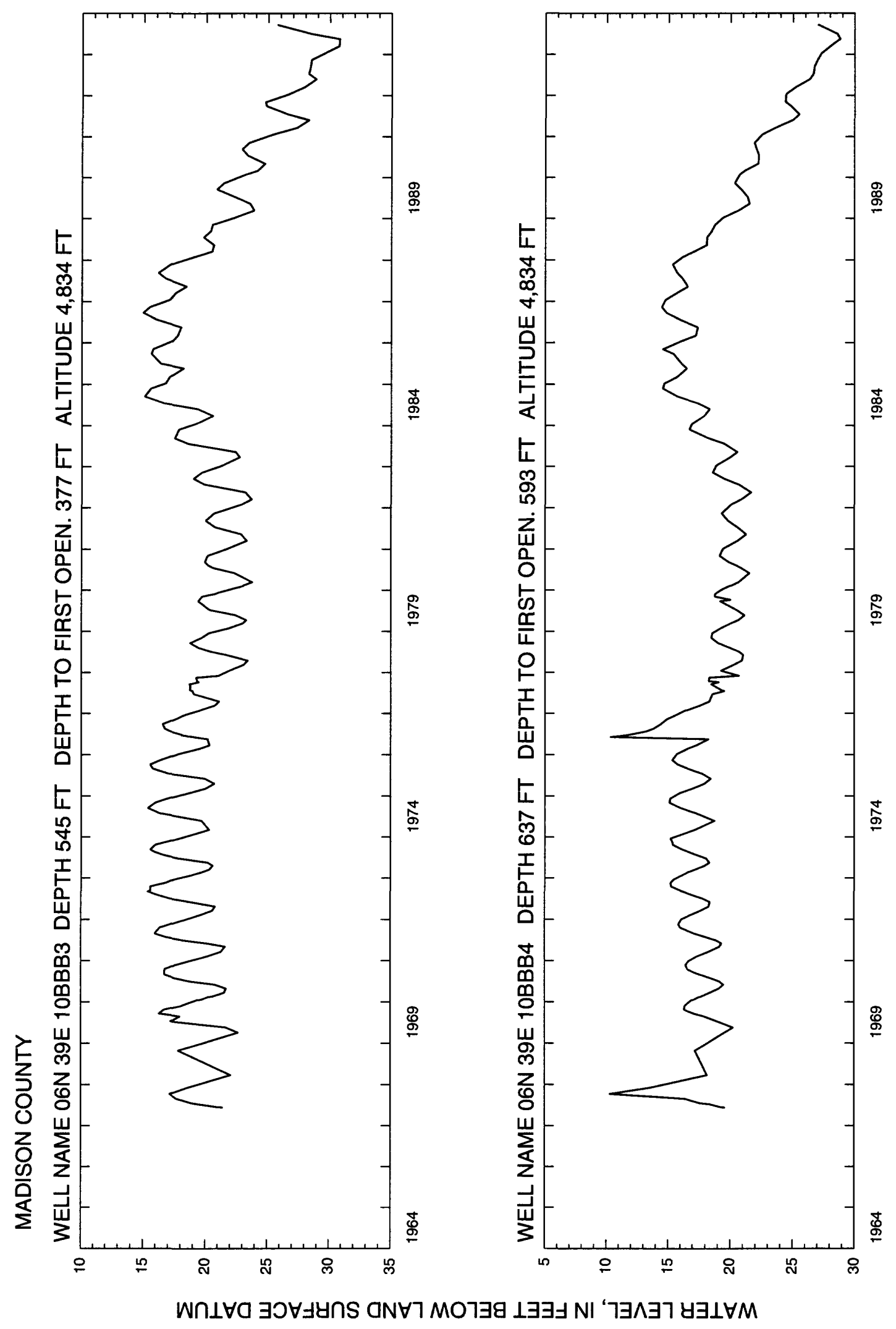




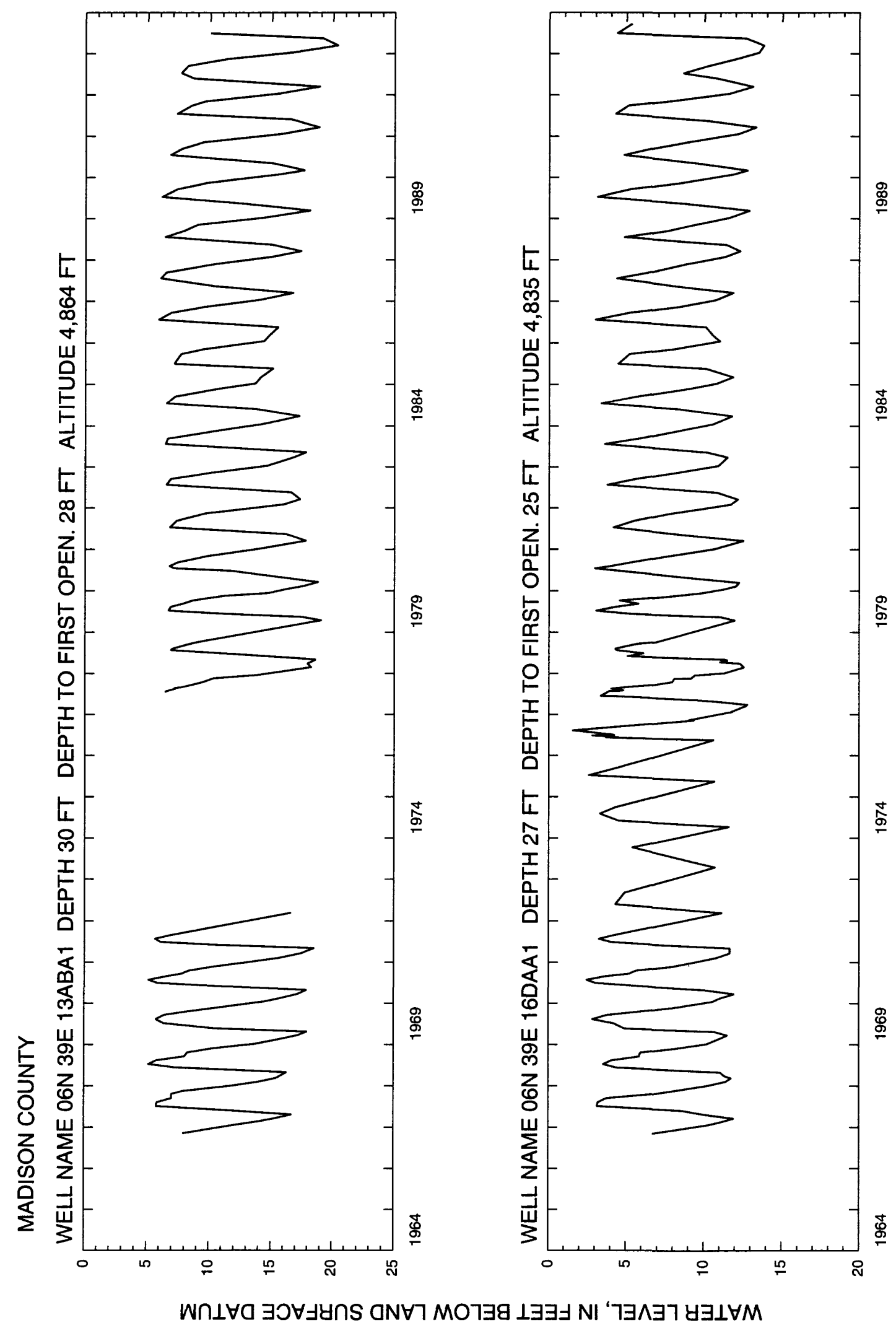

$\stackrel{\circ}{\circ}$

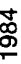

옹

$\stackrel{+}{\sigma}$

음

兽 


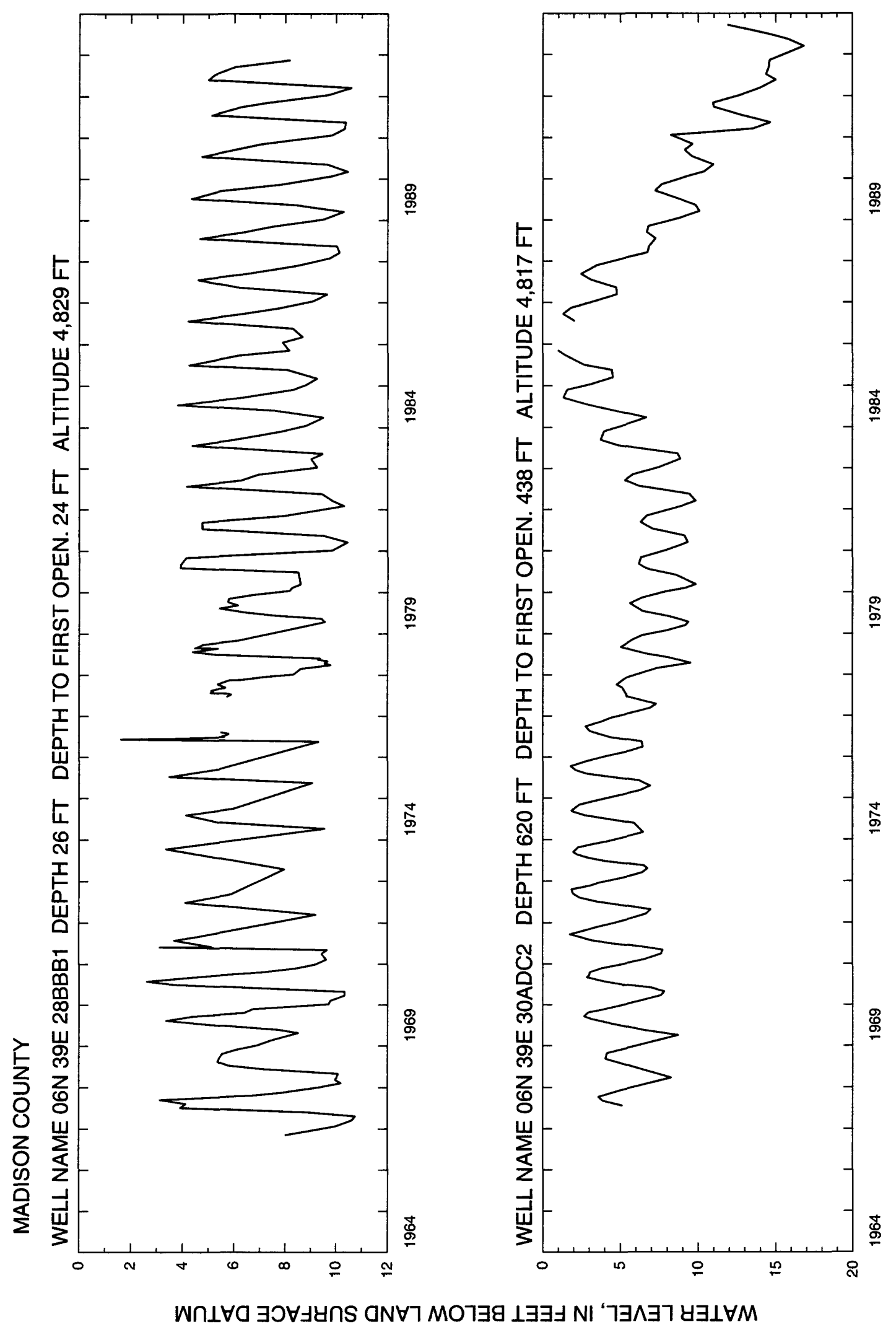




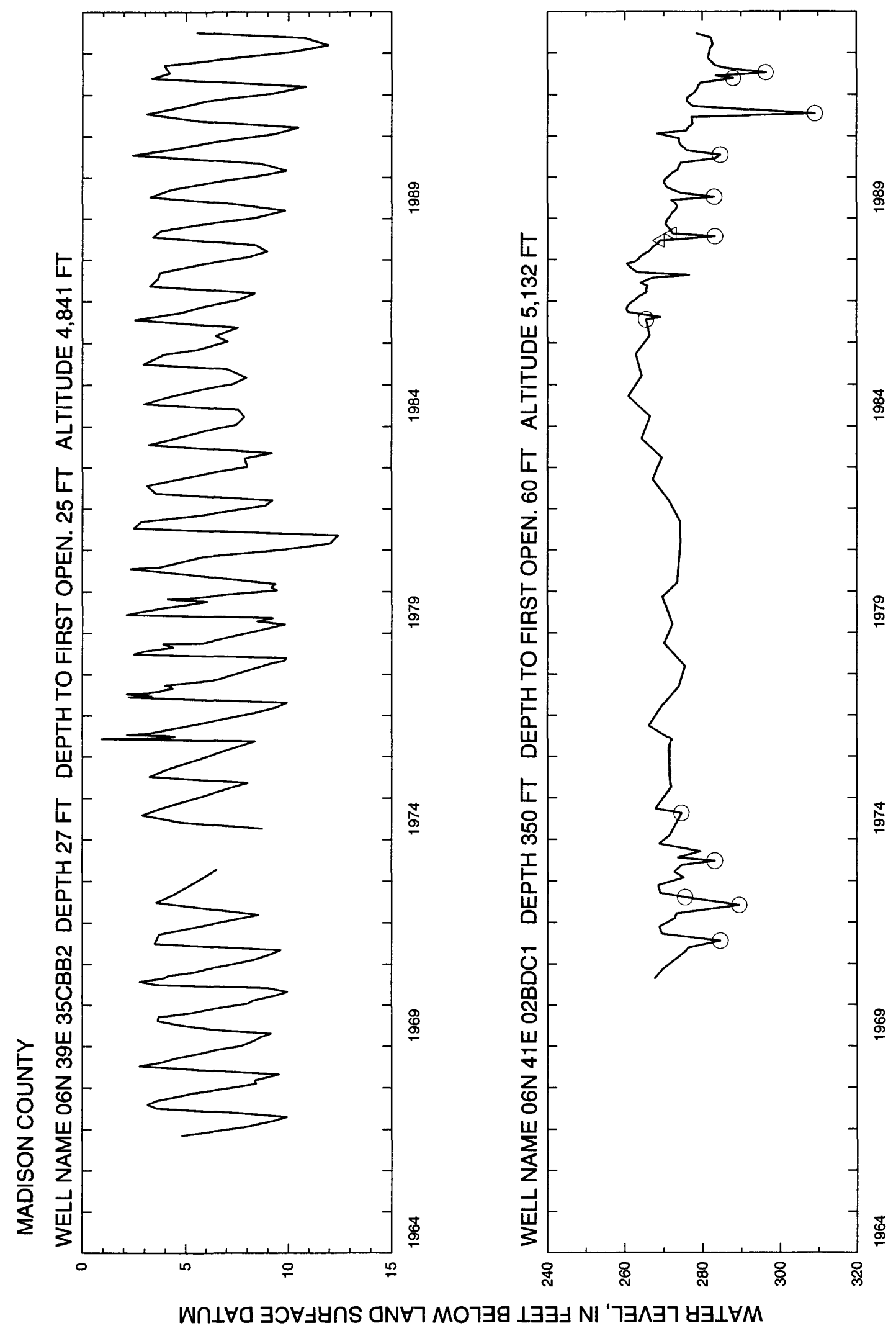




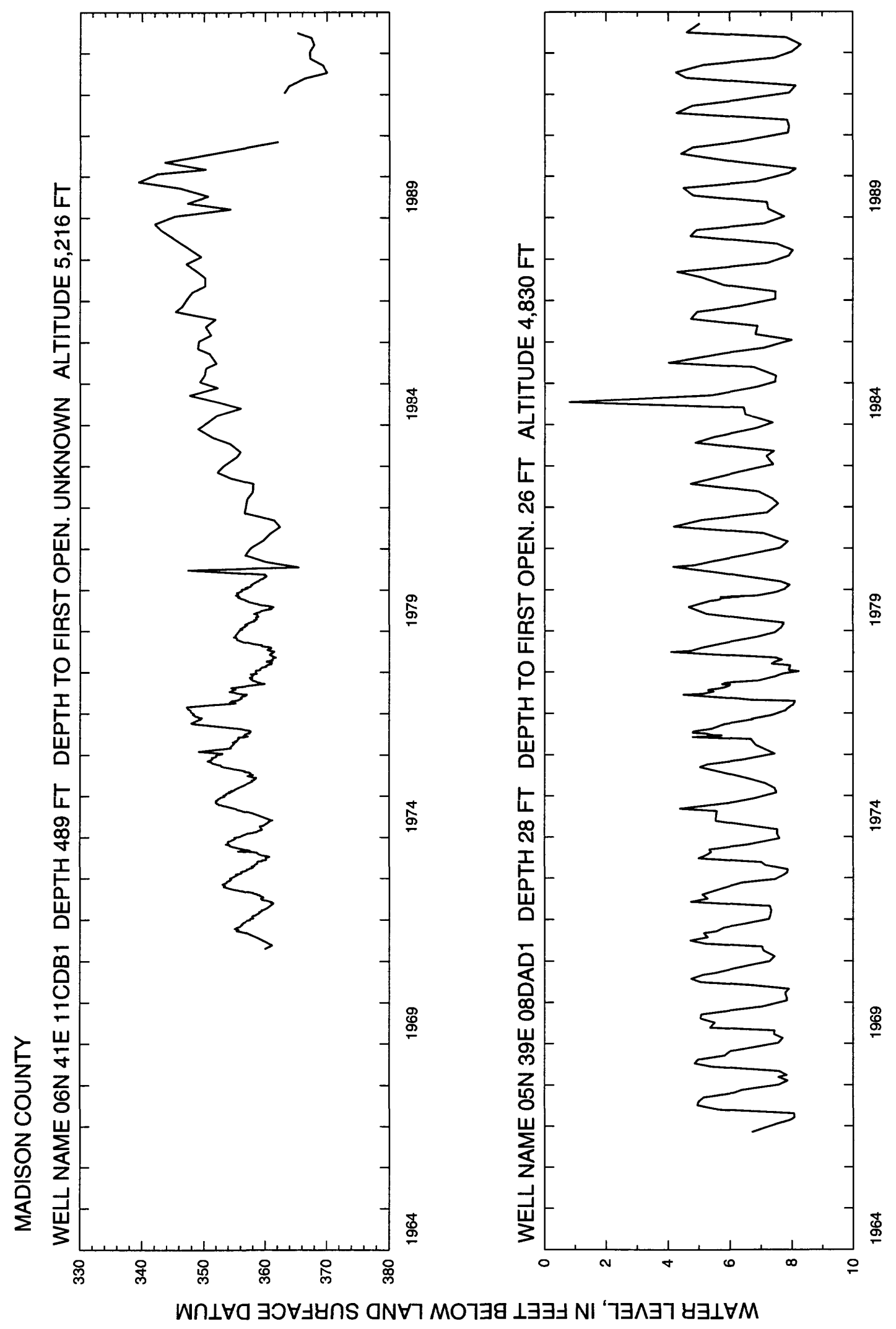




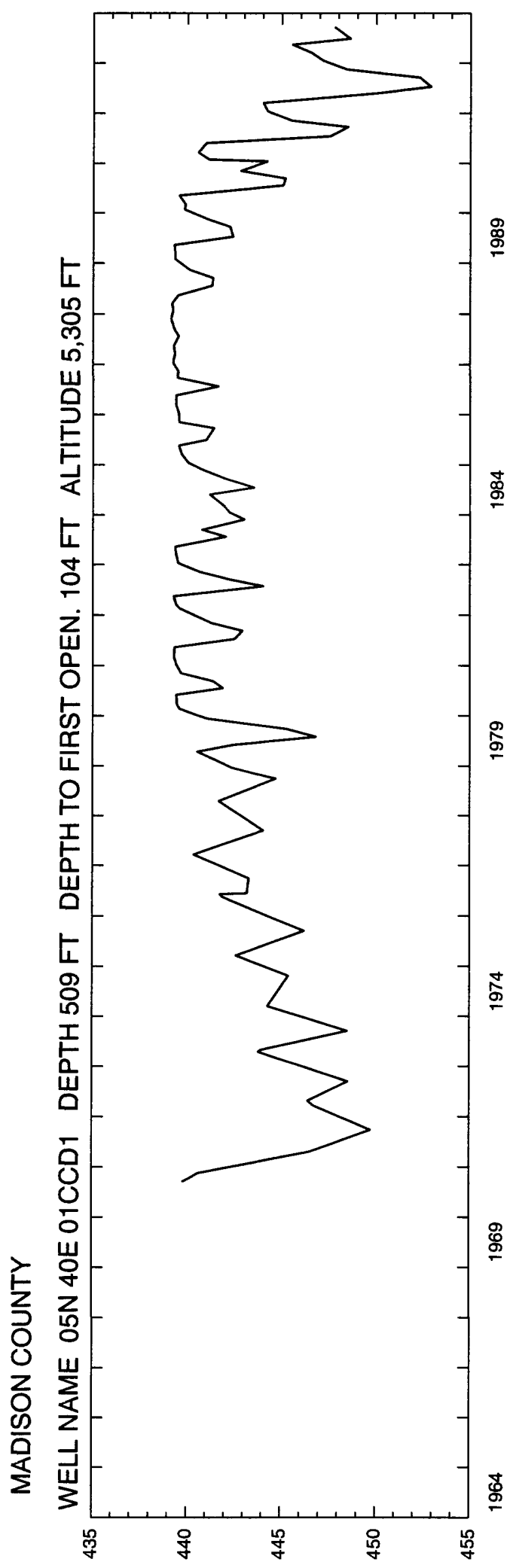

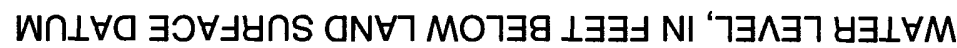




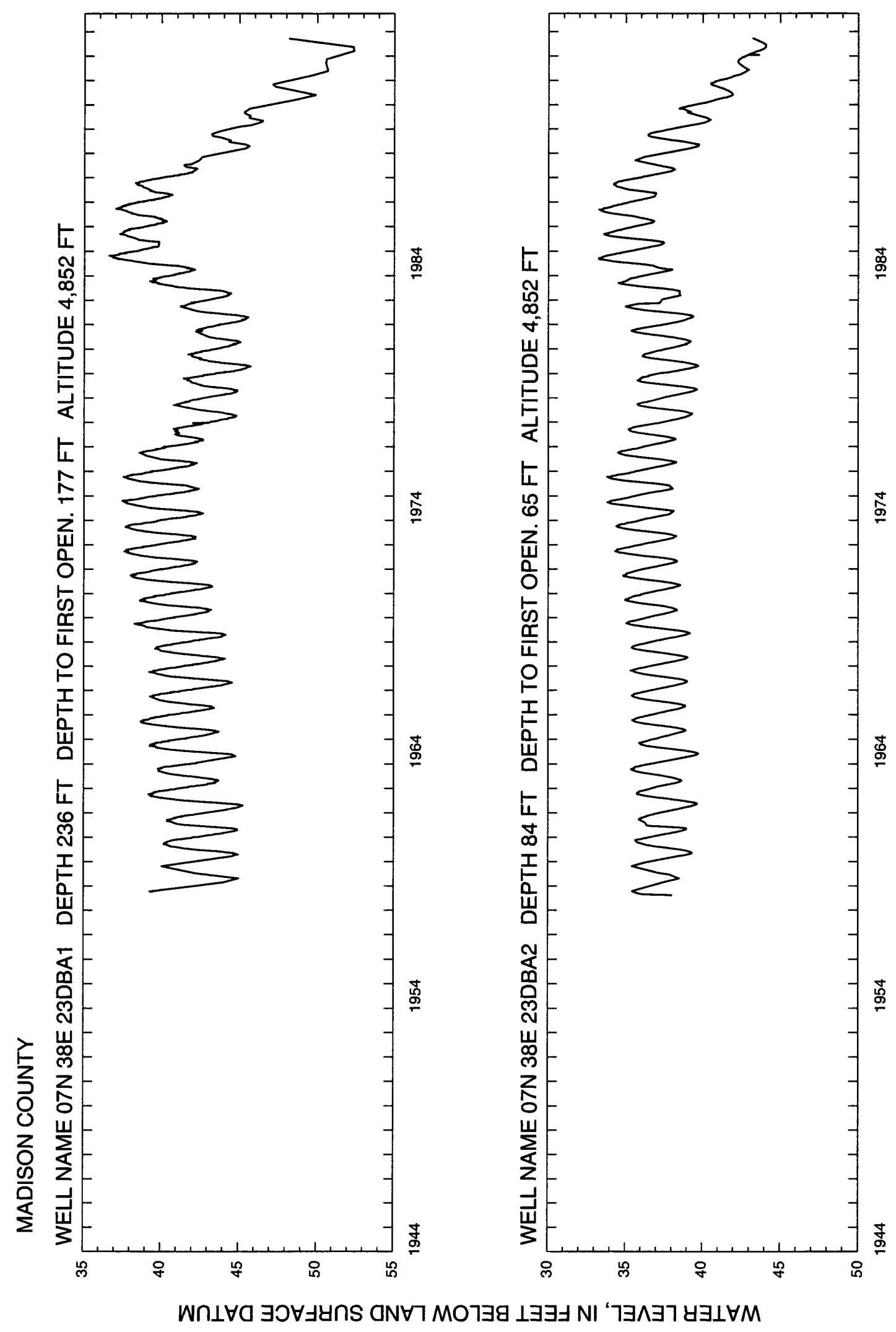




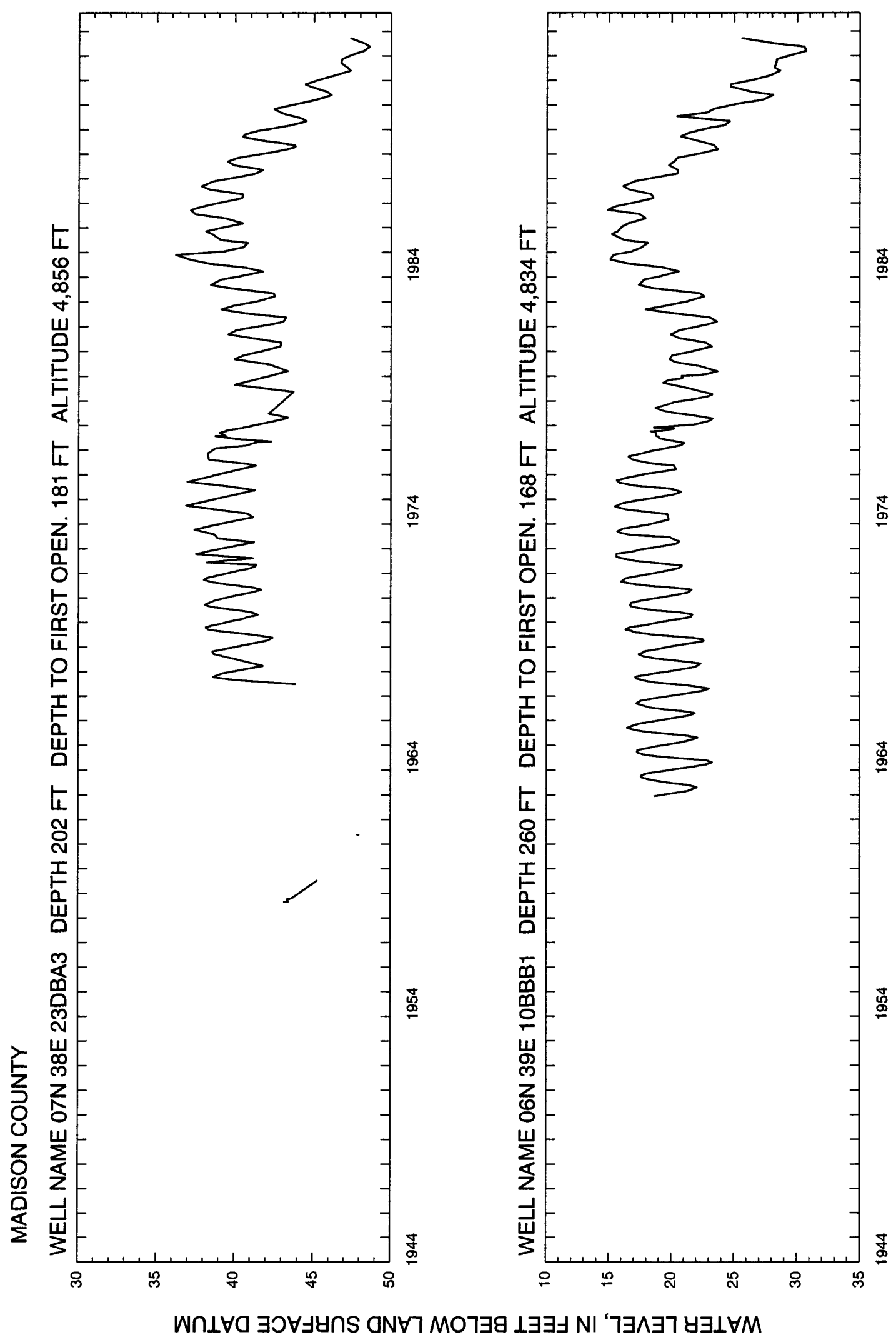




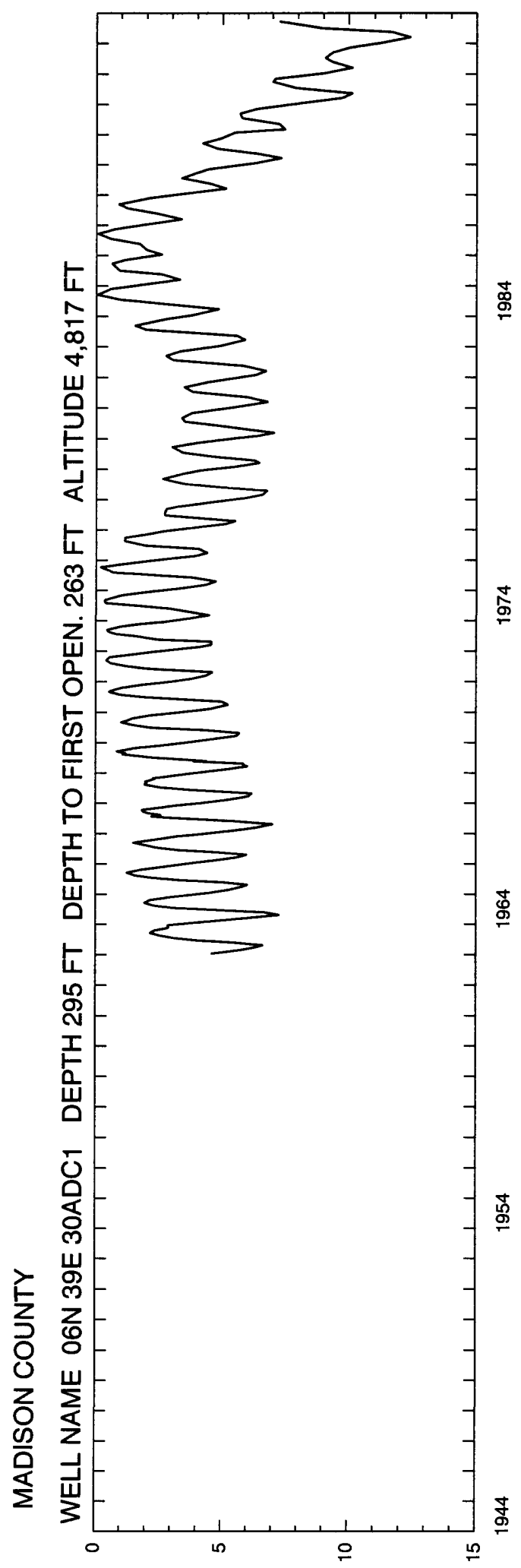

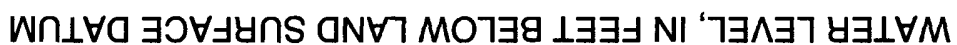


Minidoka

323 (page 325 folbus) 


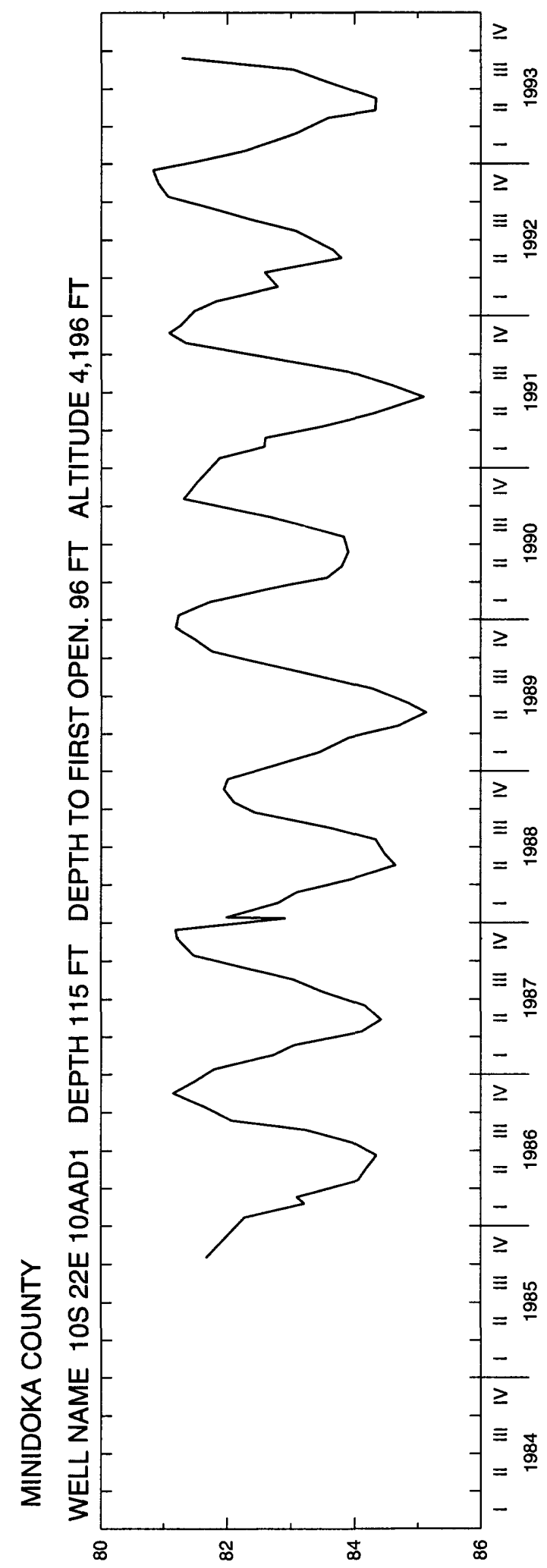

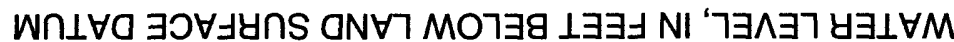




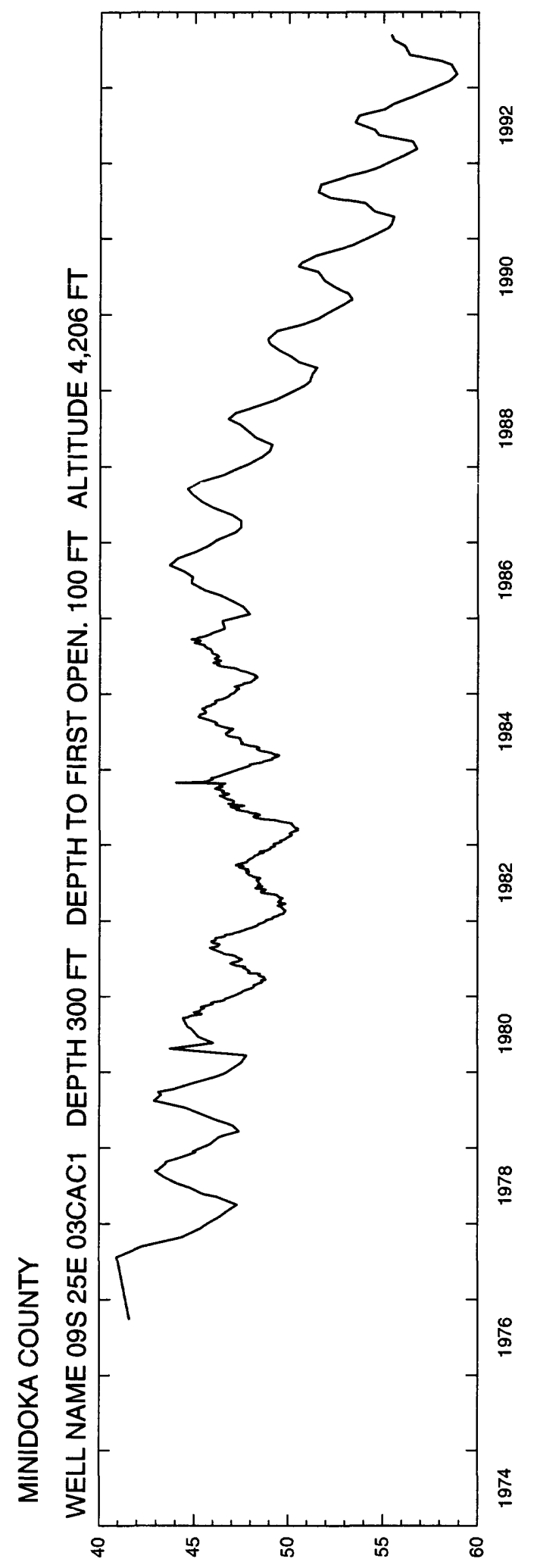

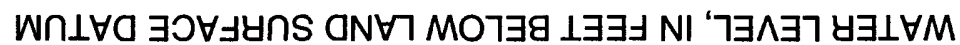




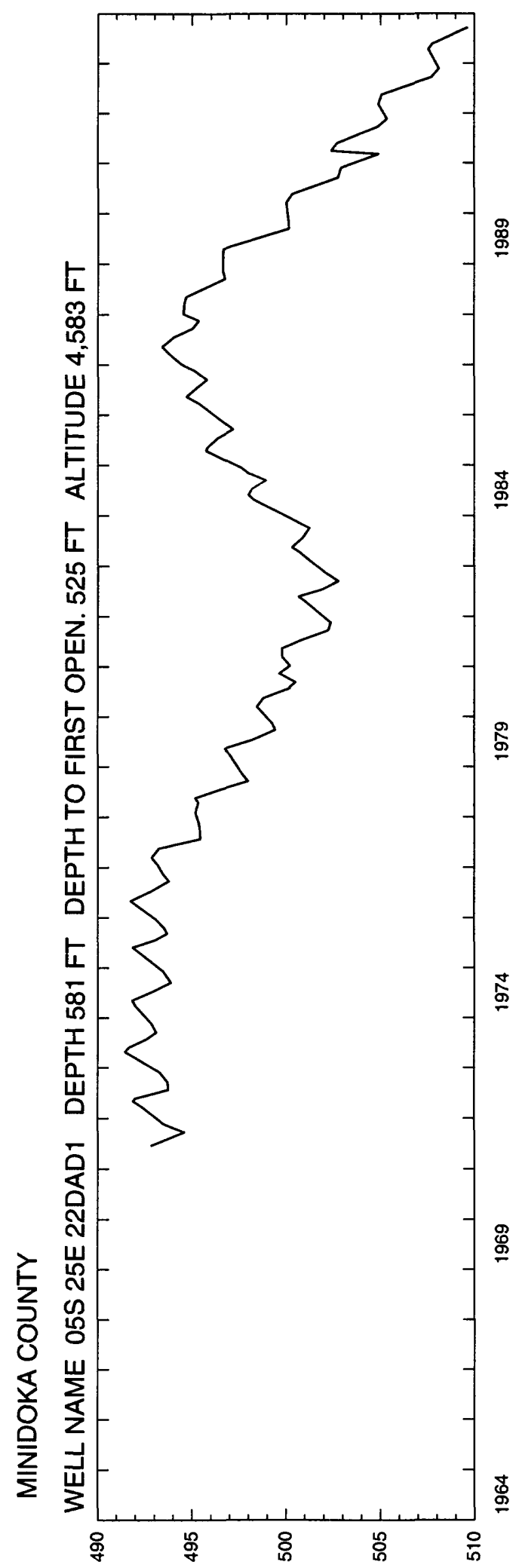

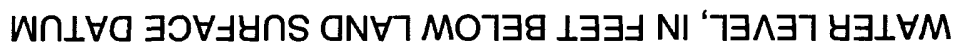




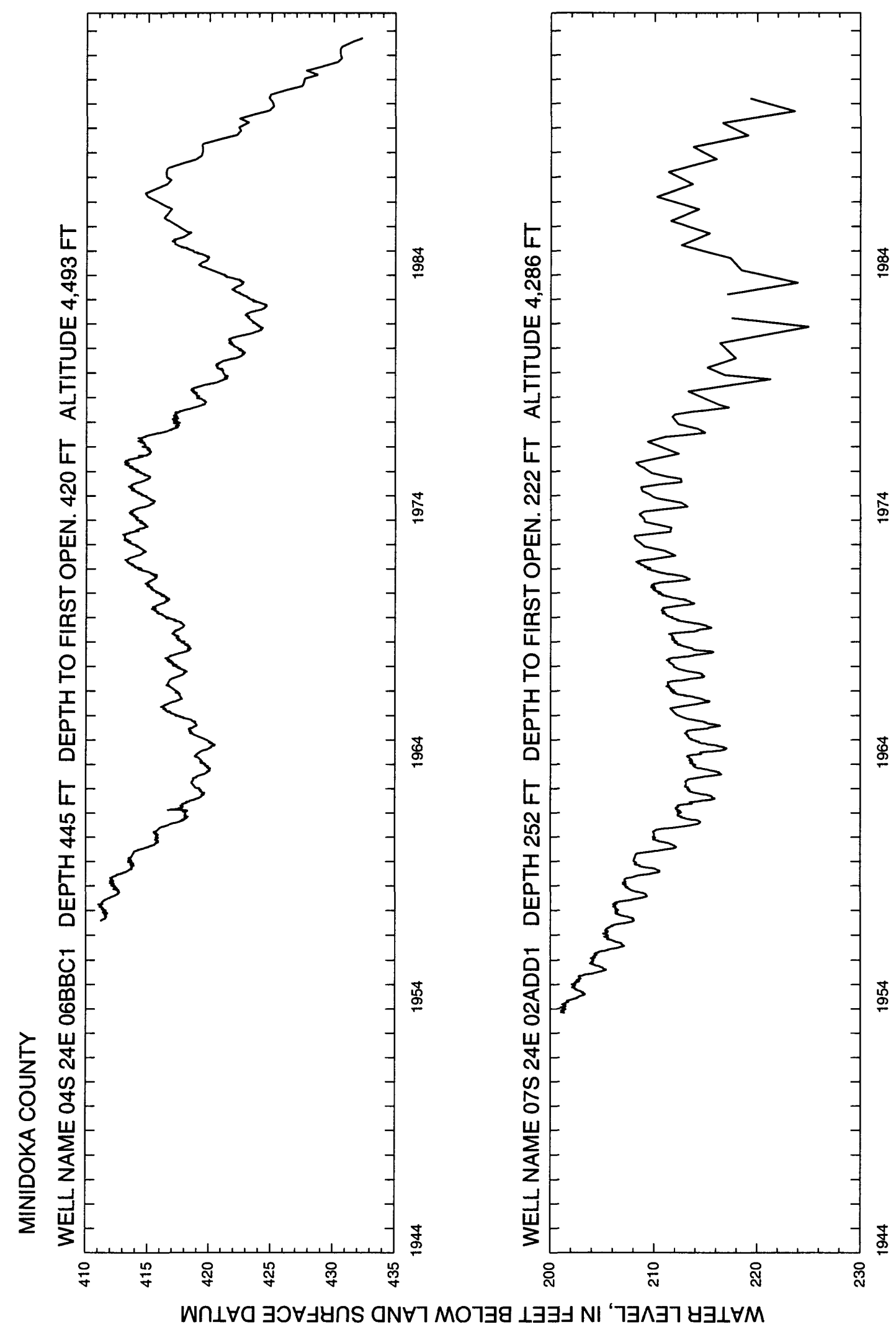




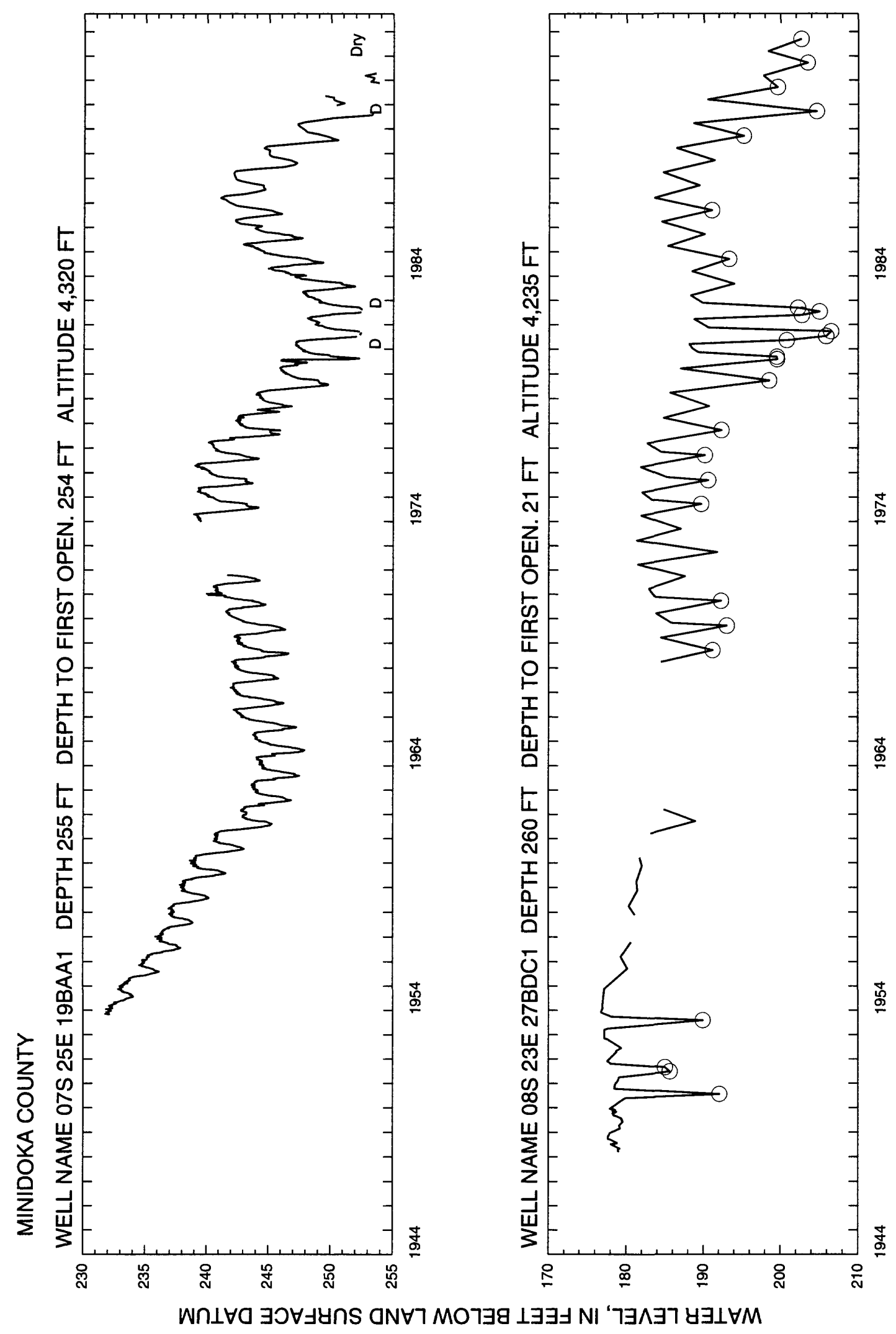




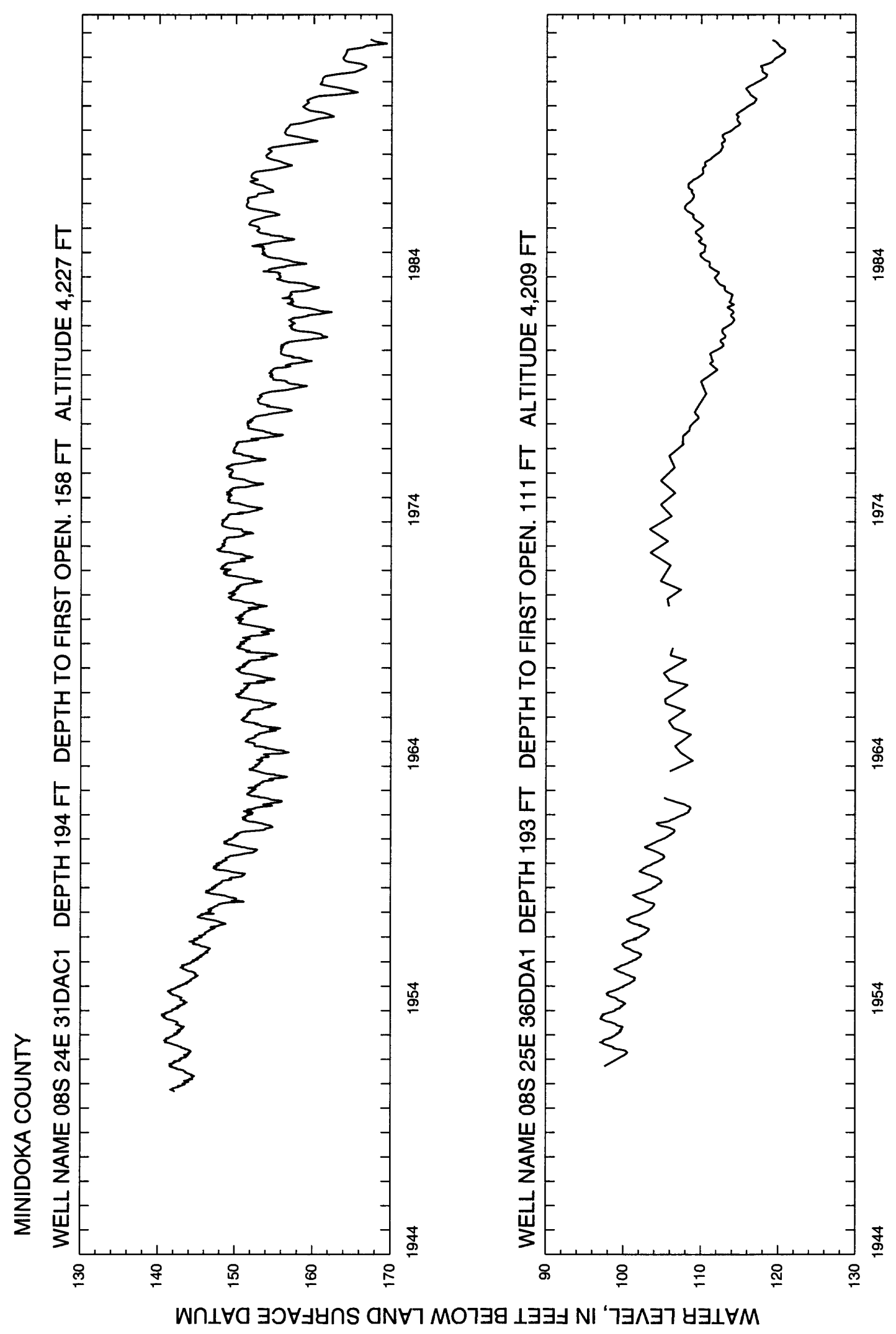




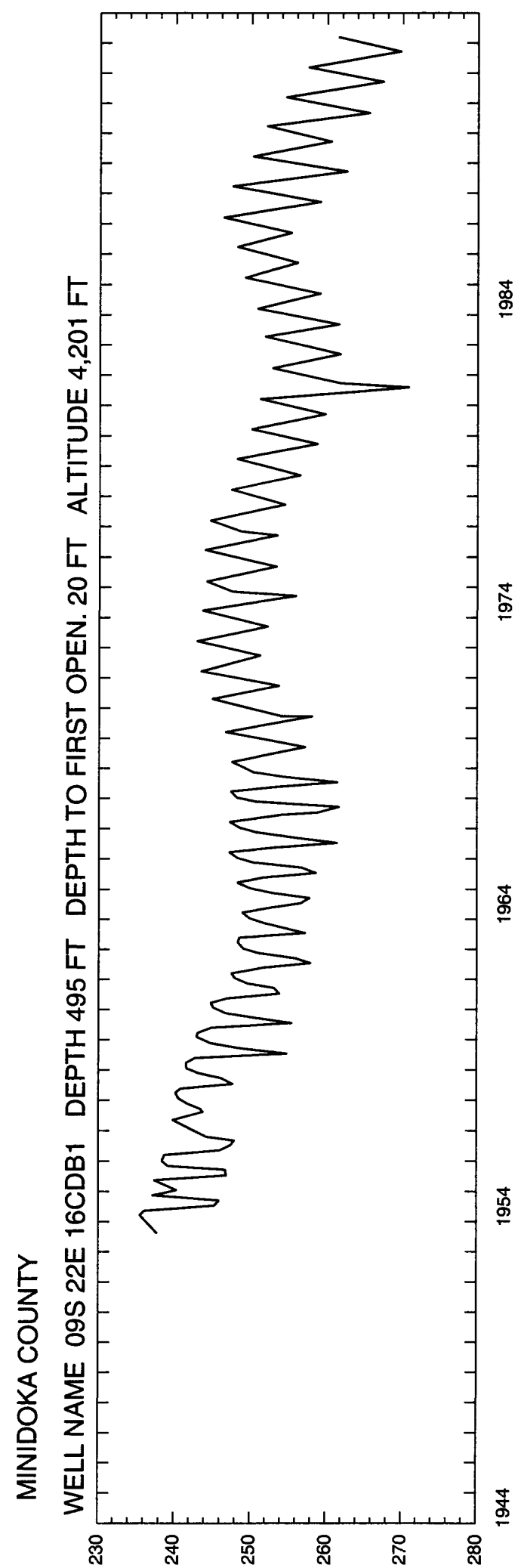

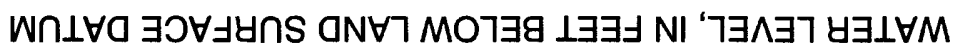

331 (page 333 follows) 
Nez Perce 


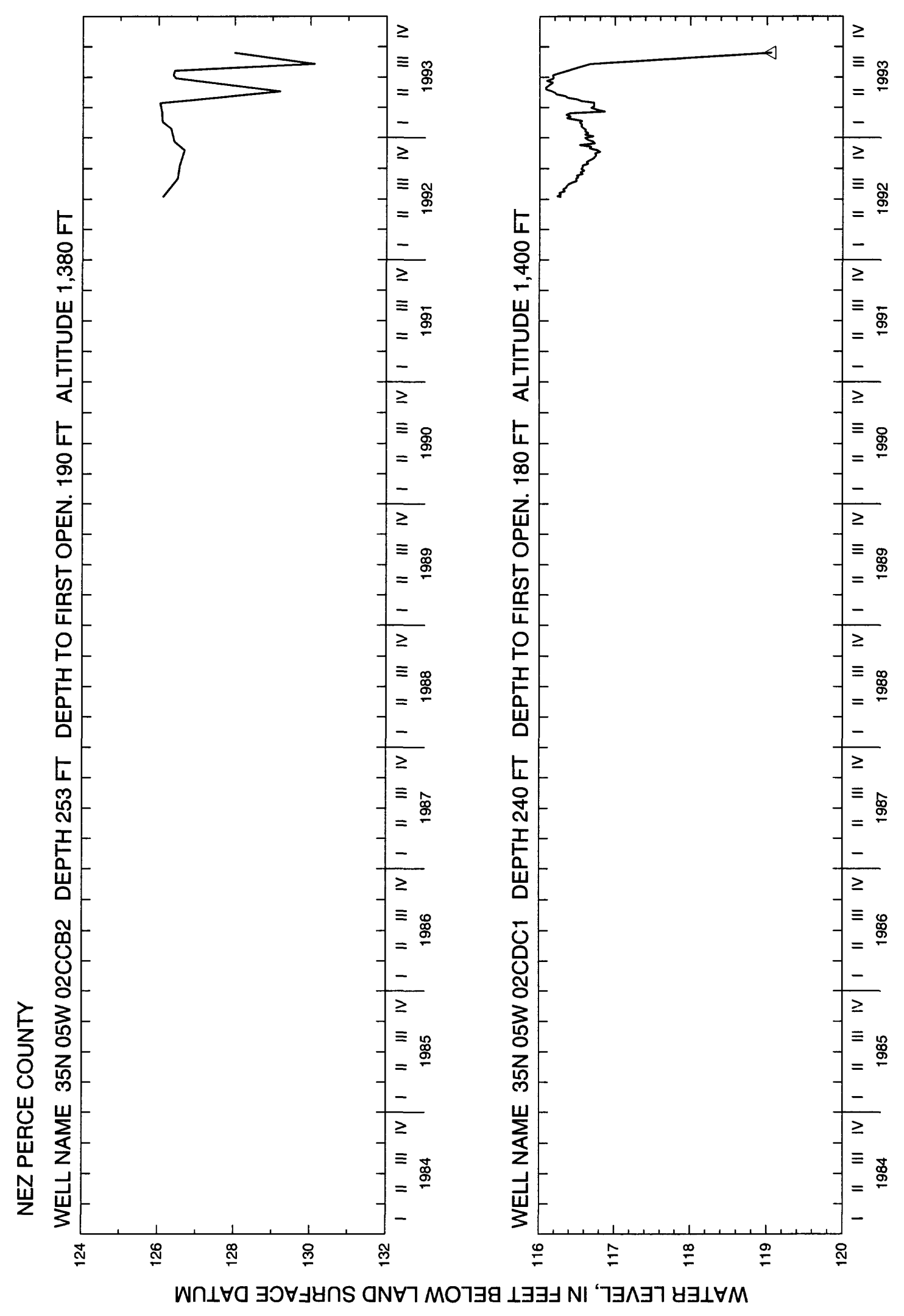




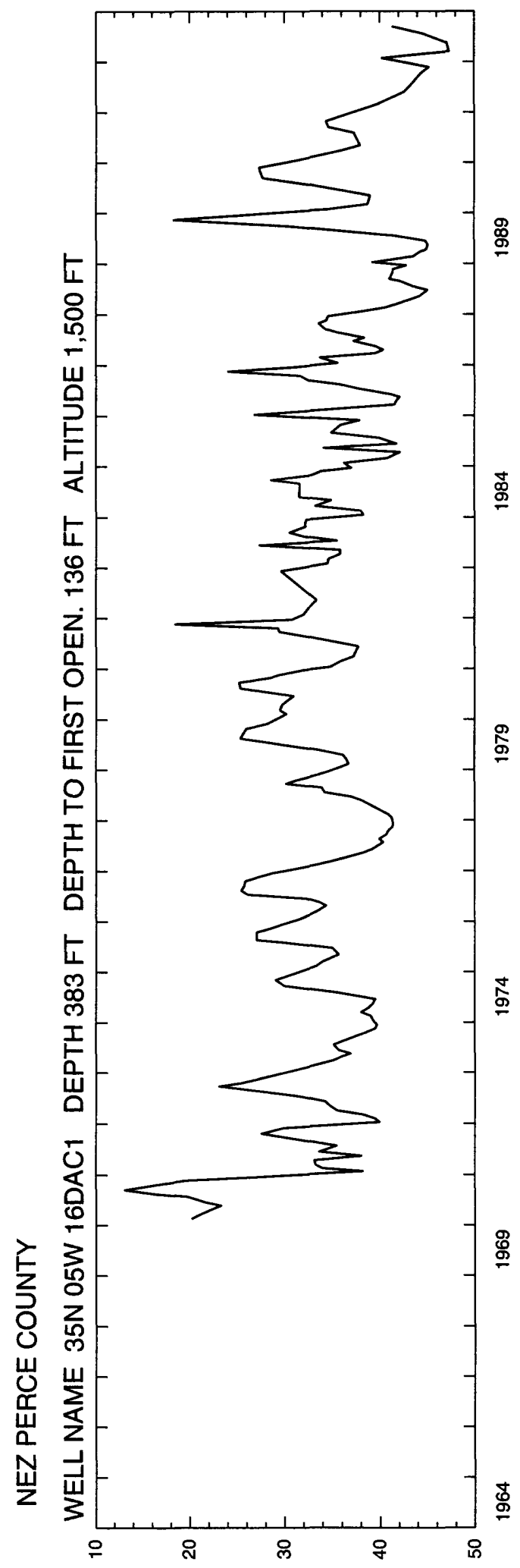

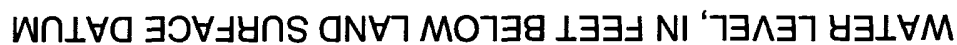


Oneida 


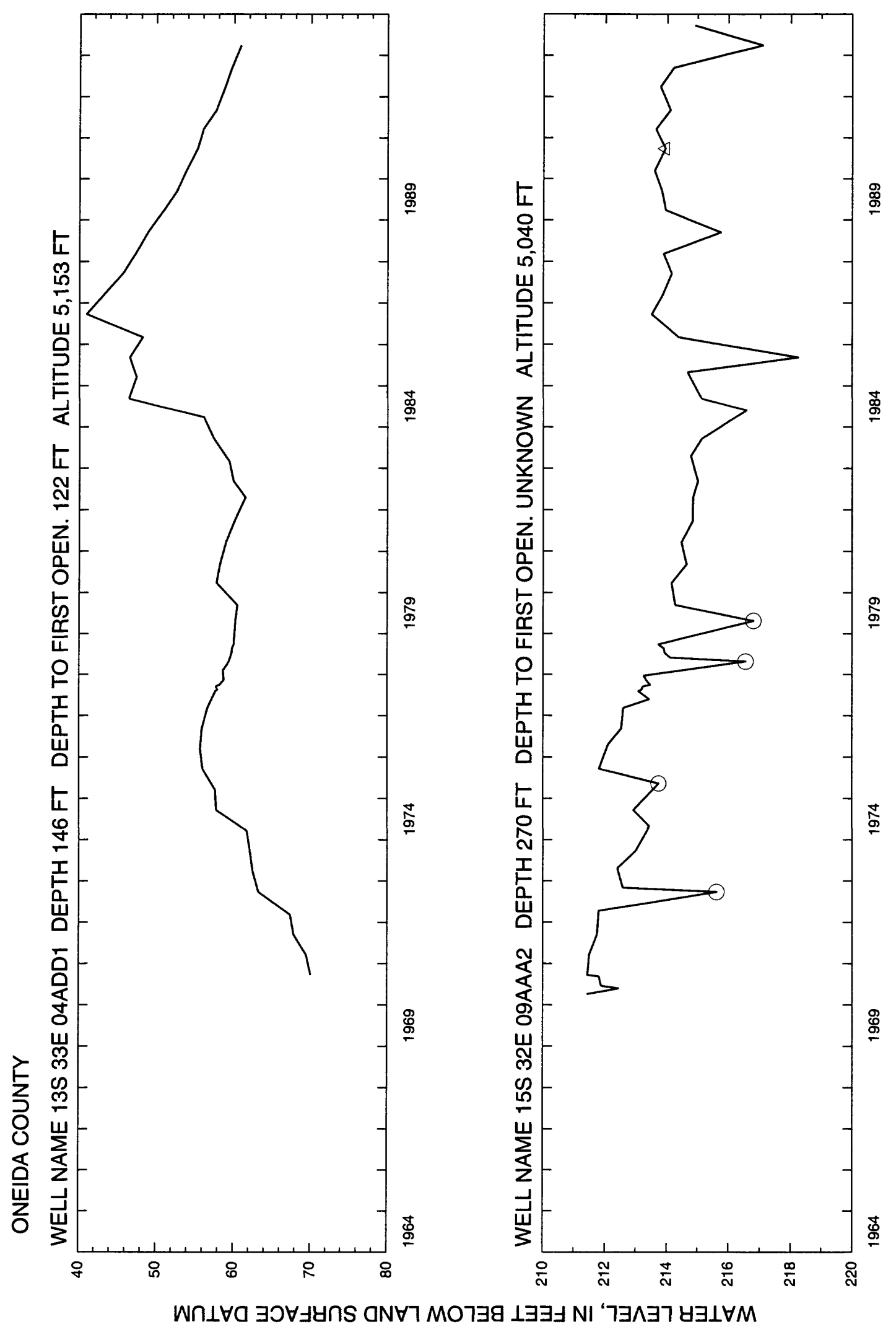




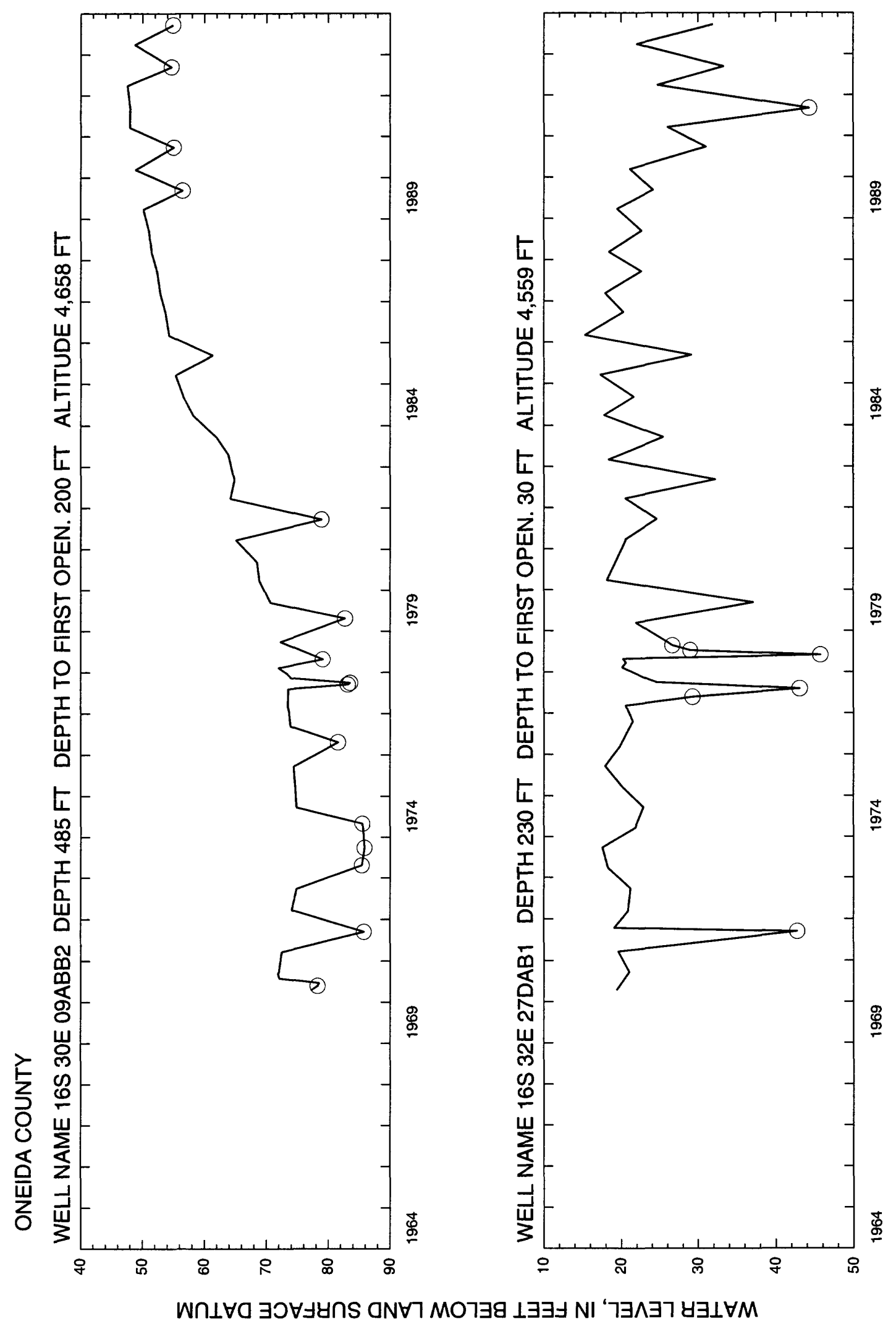




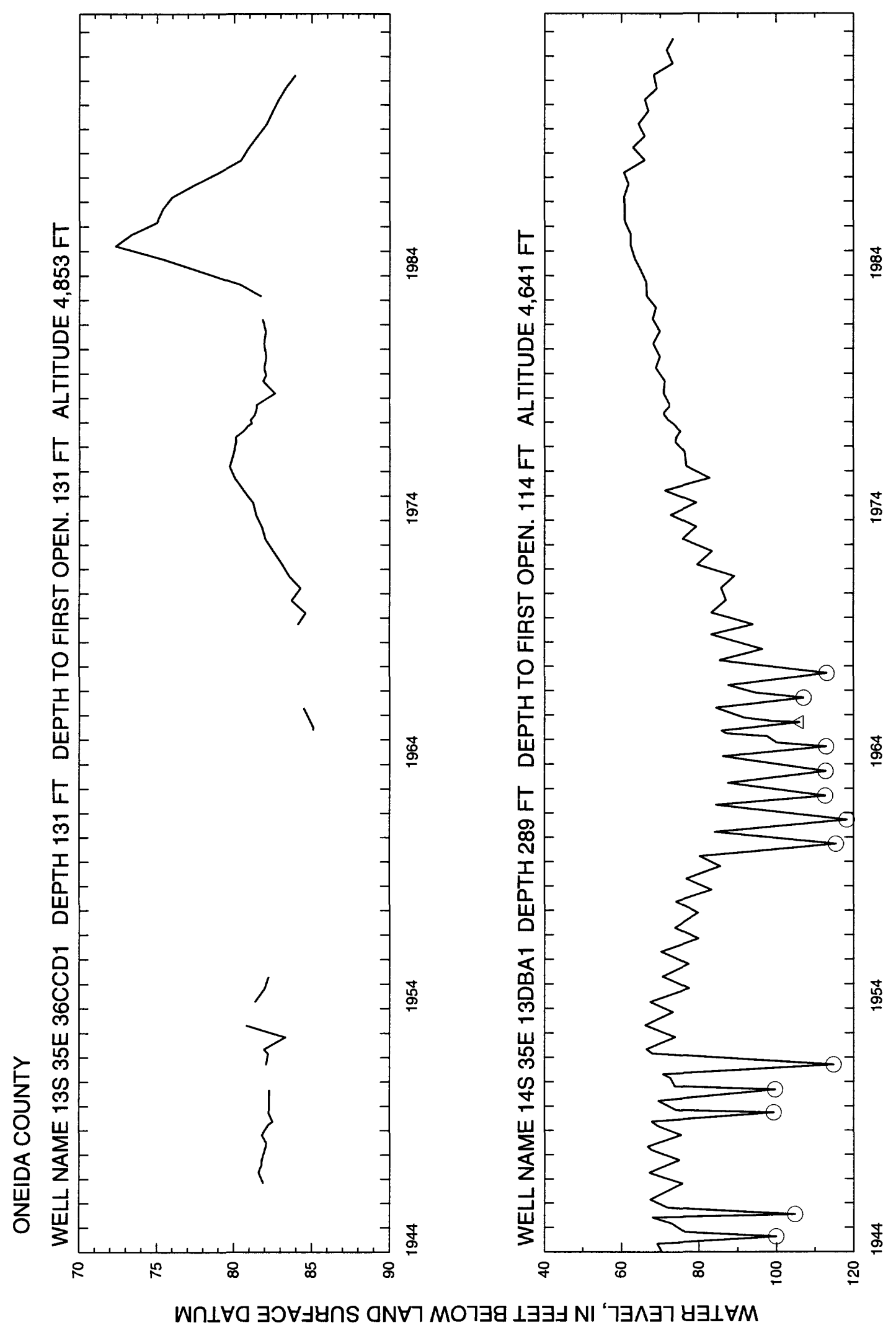




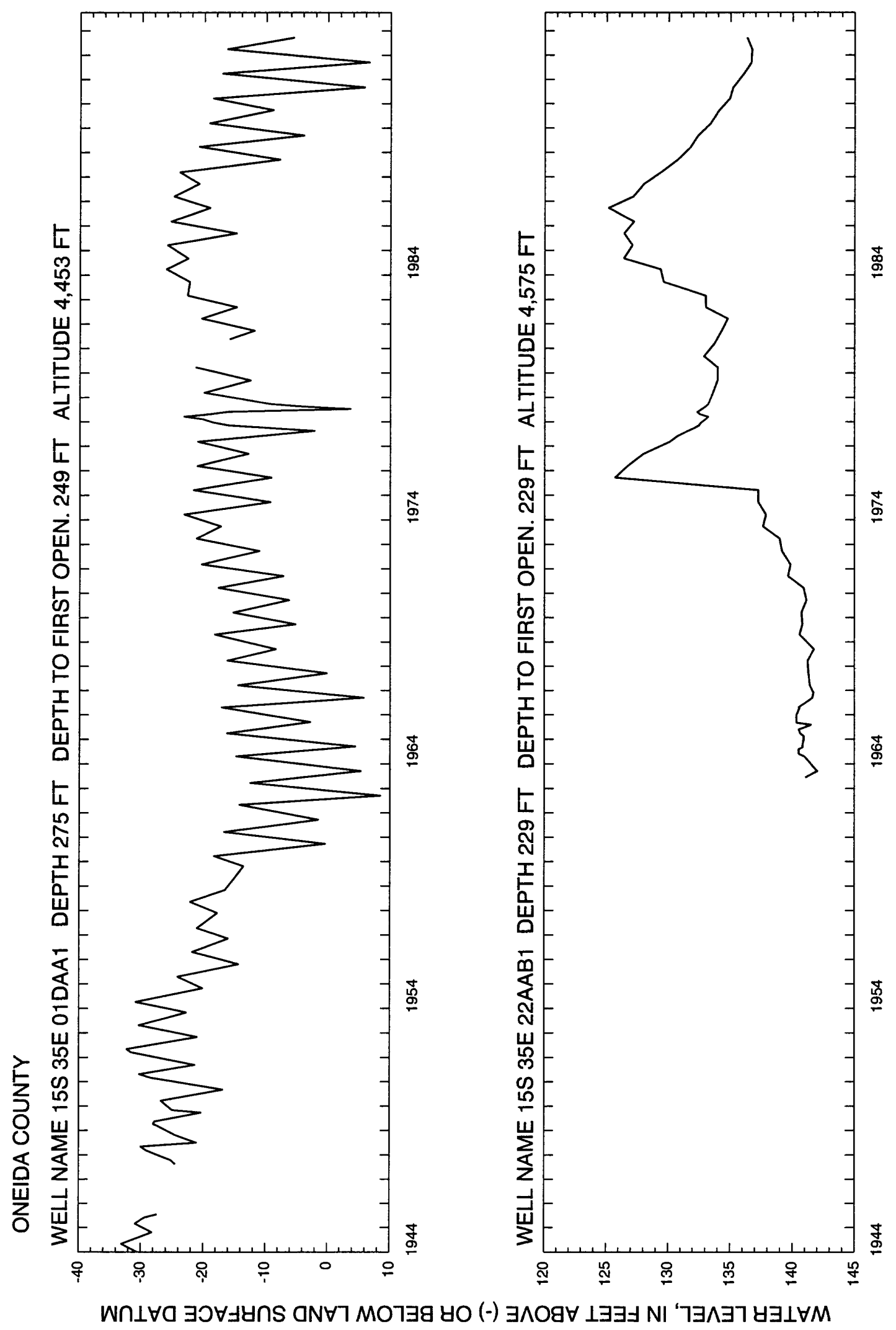




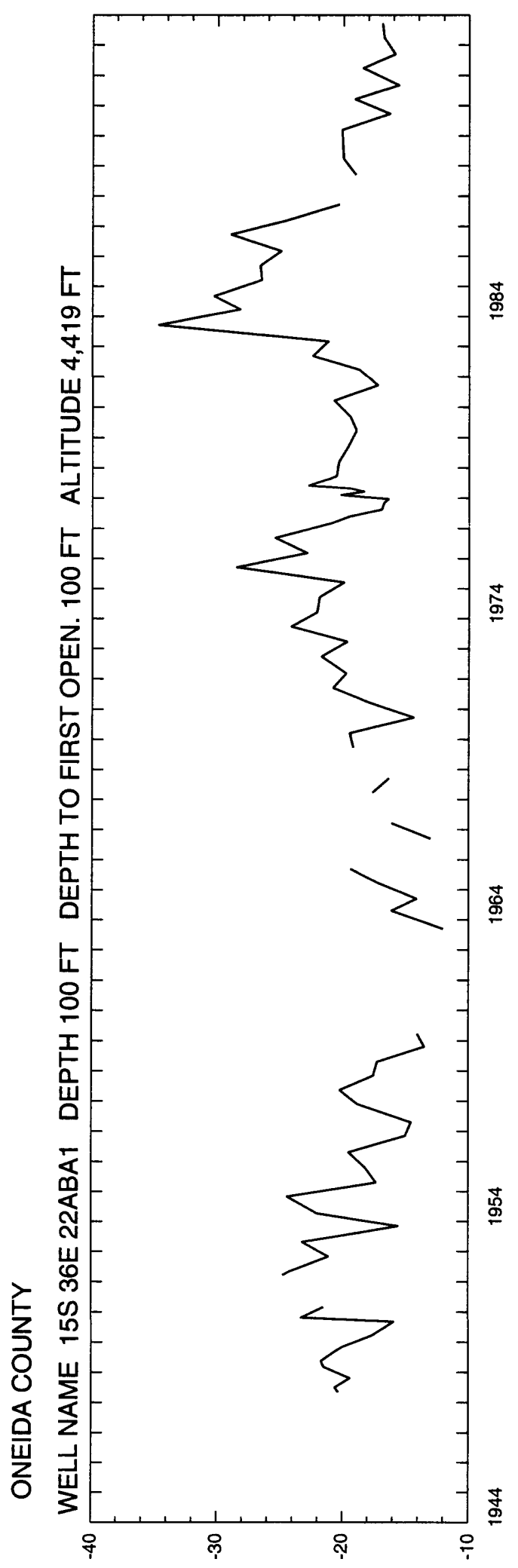

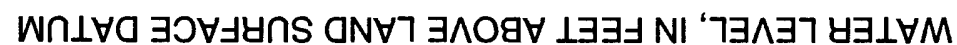

343 (pase 345 follows) 
Owyhee

345 (paye 347 Dollows) 


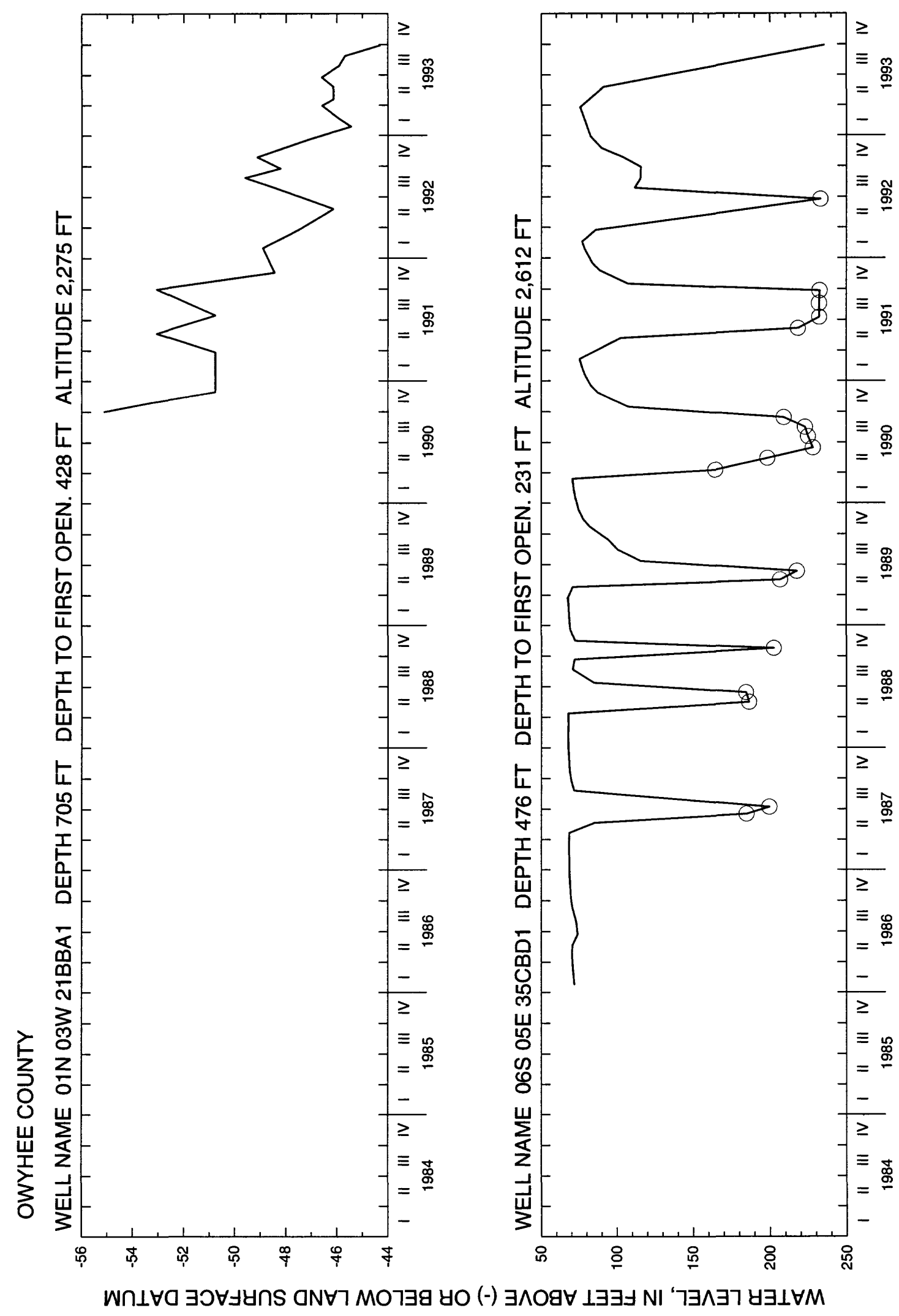




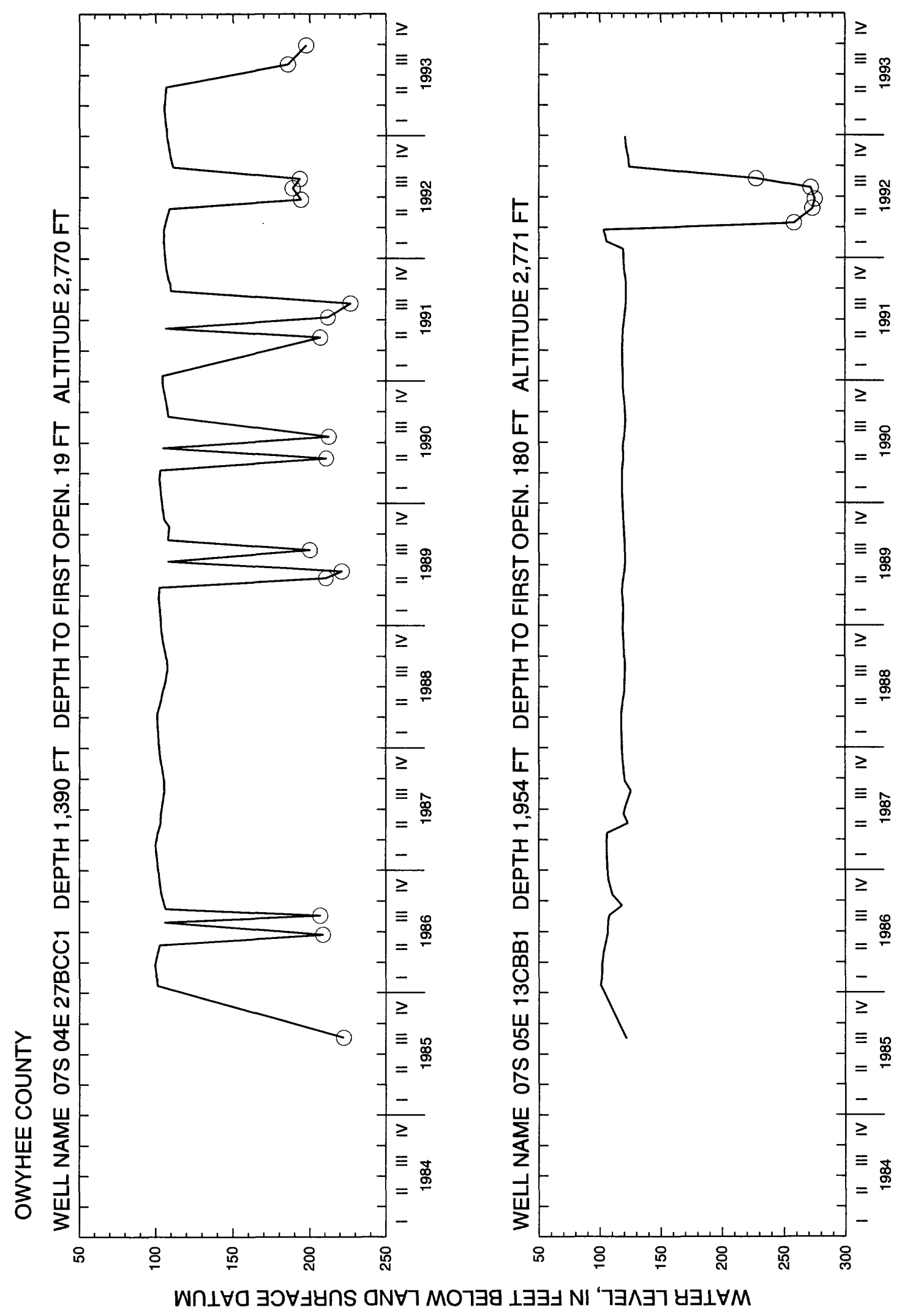




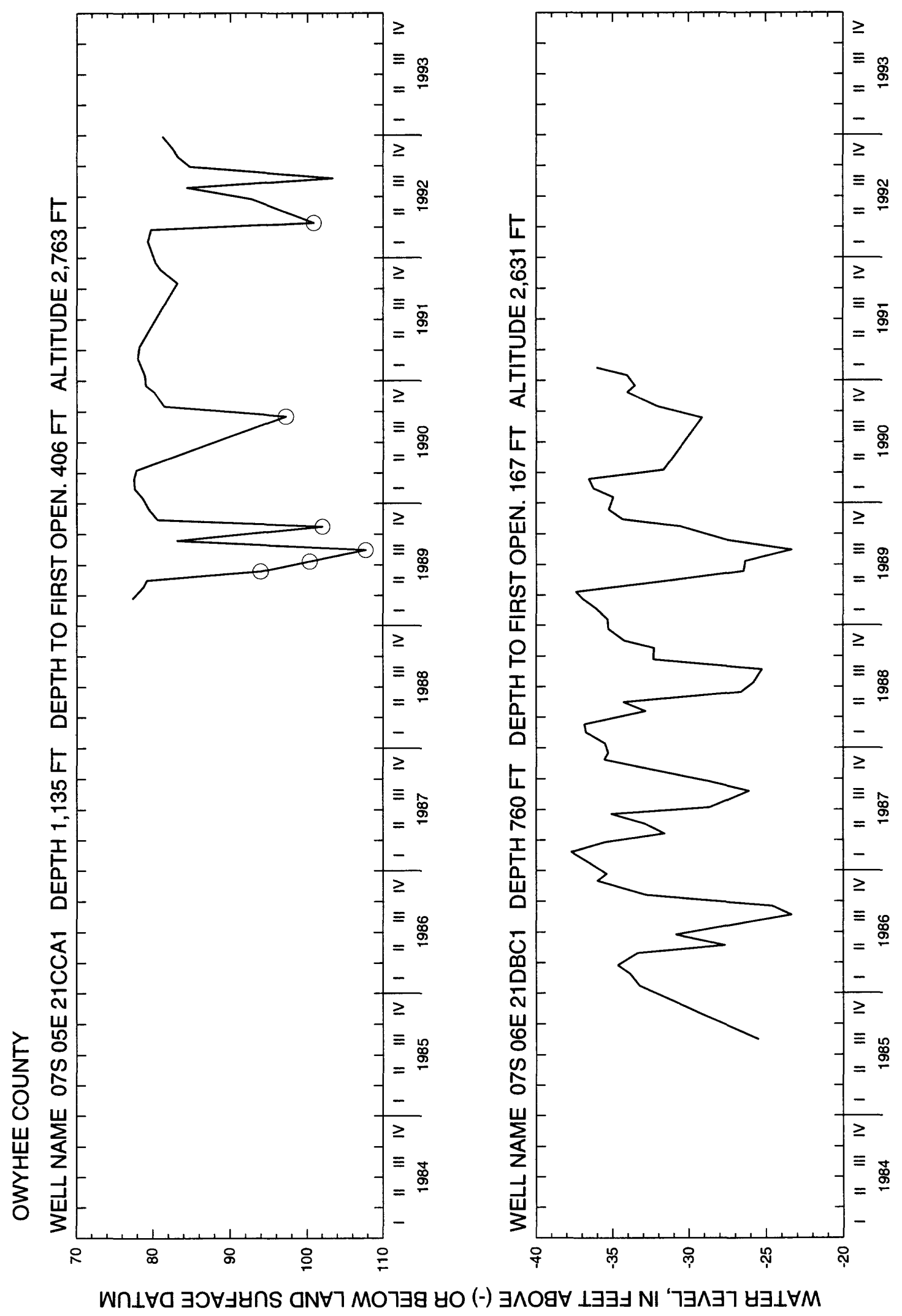




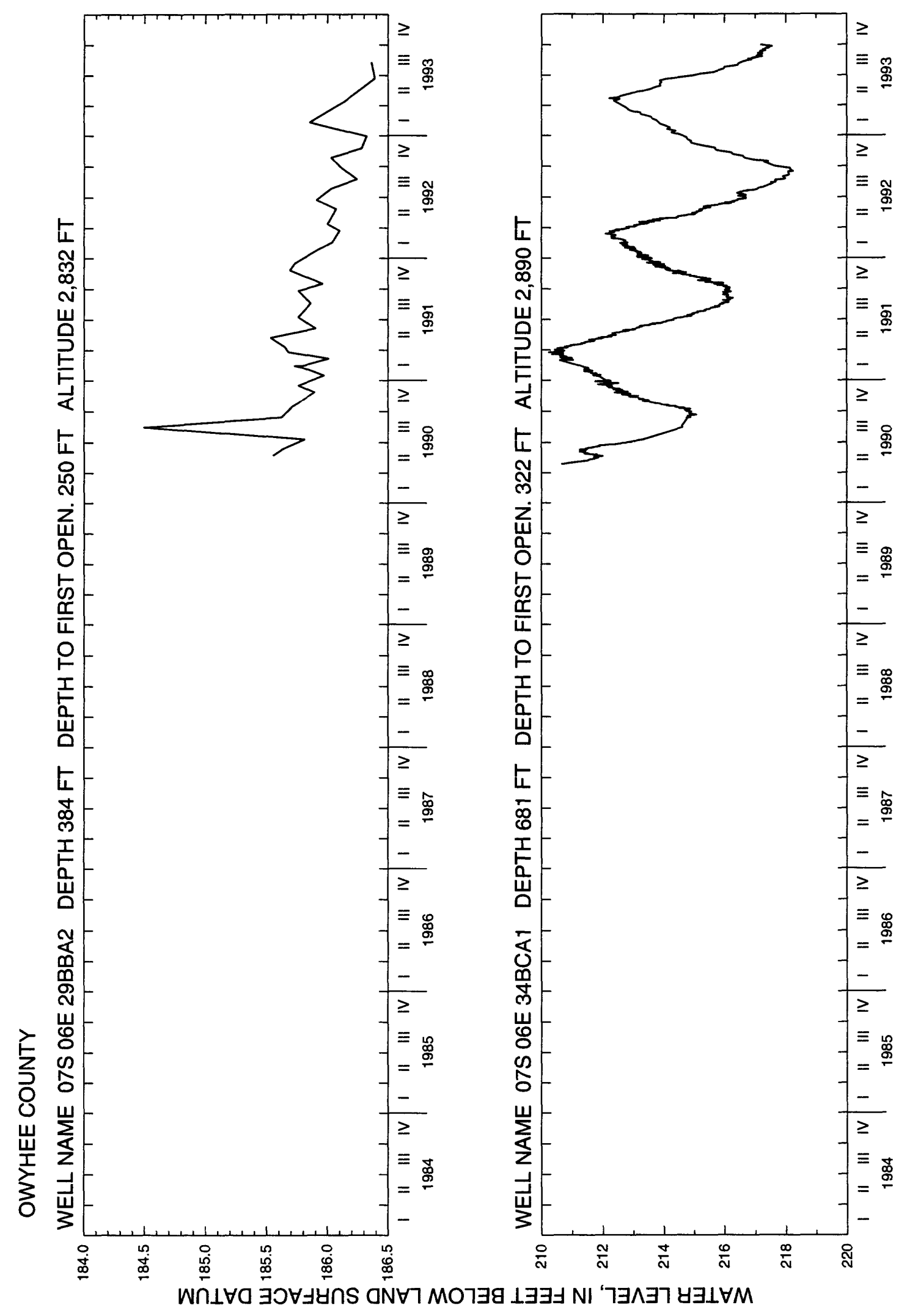




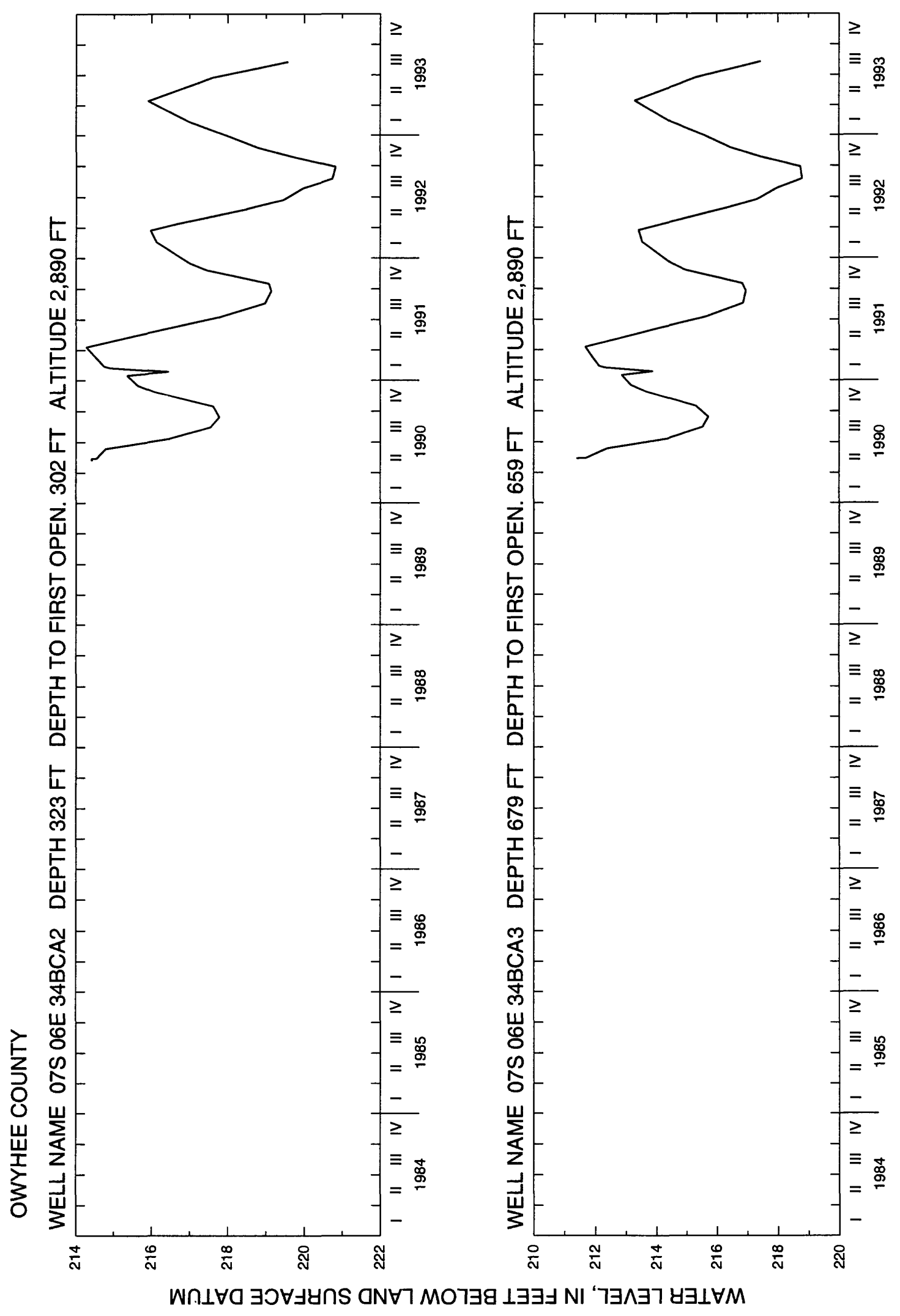




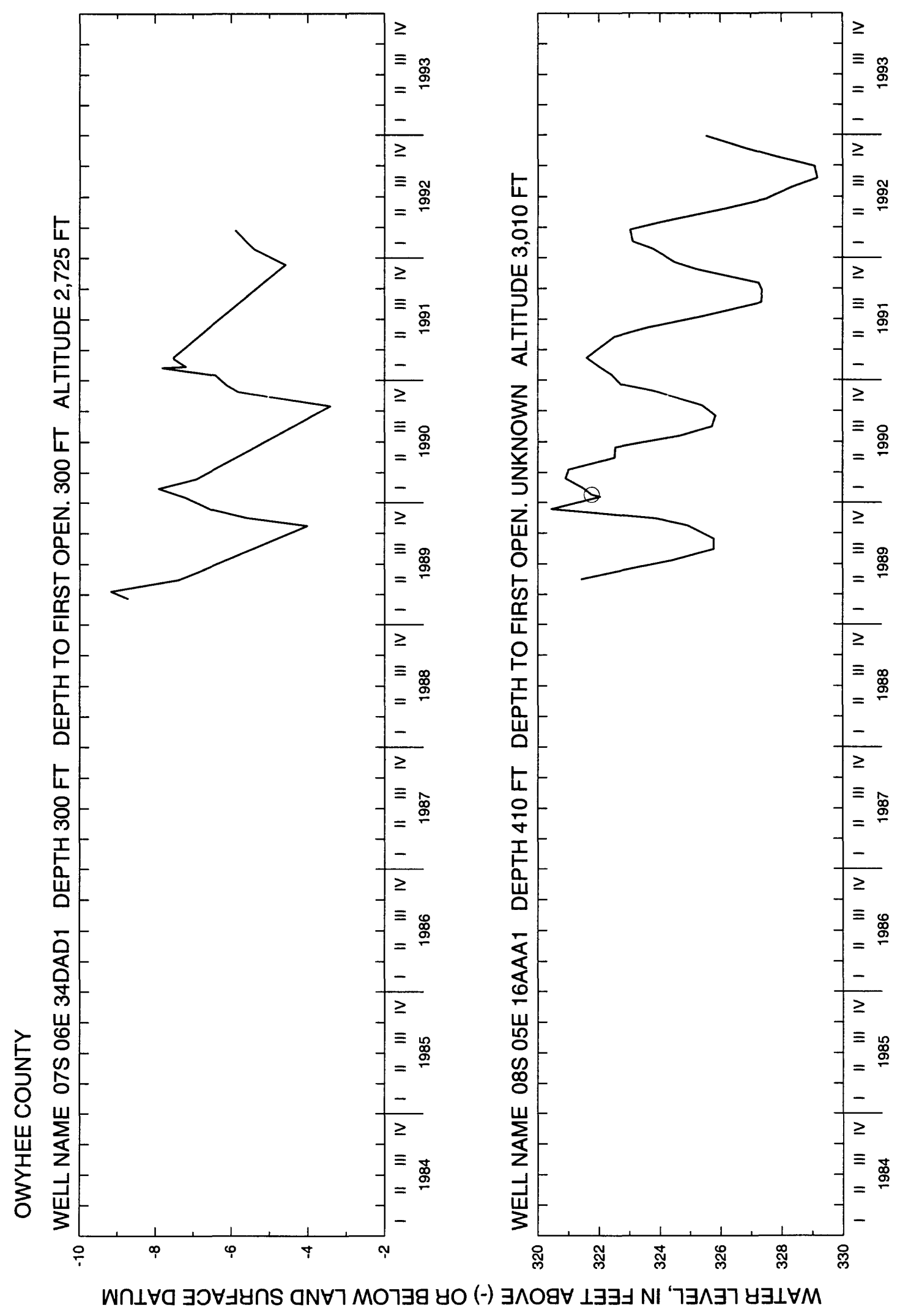




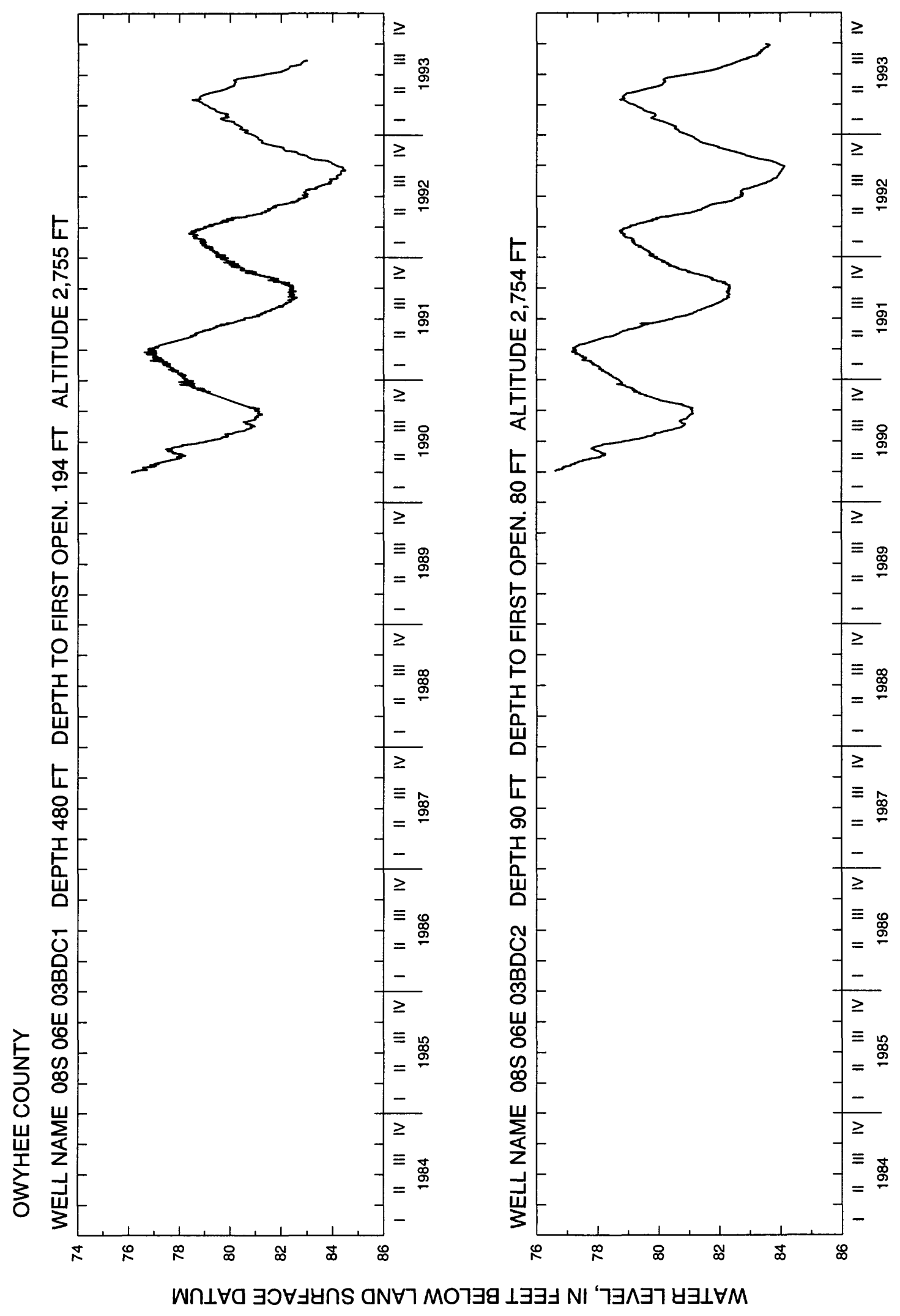




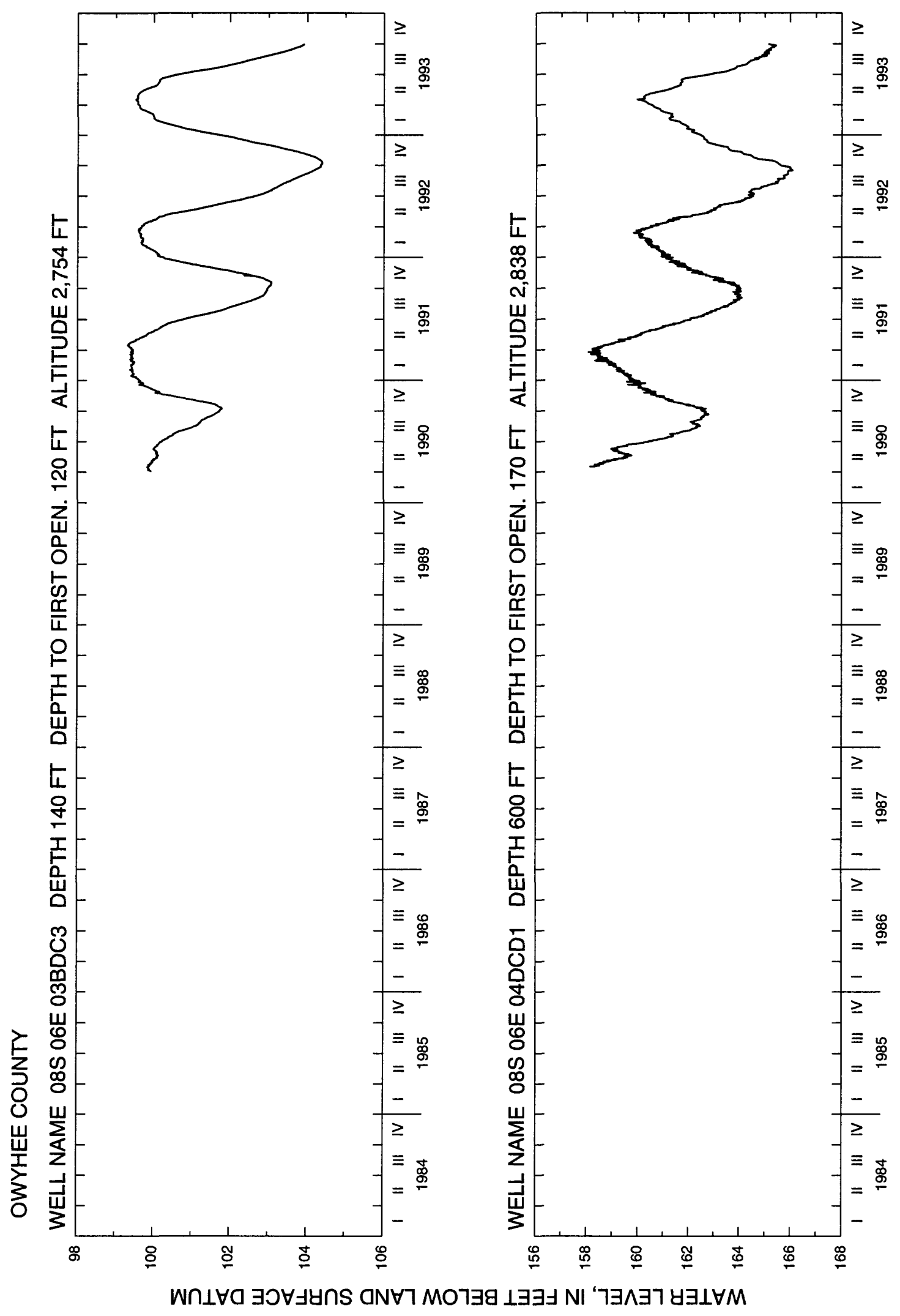




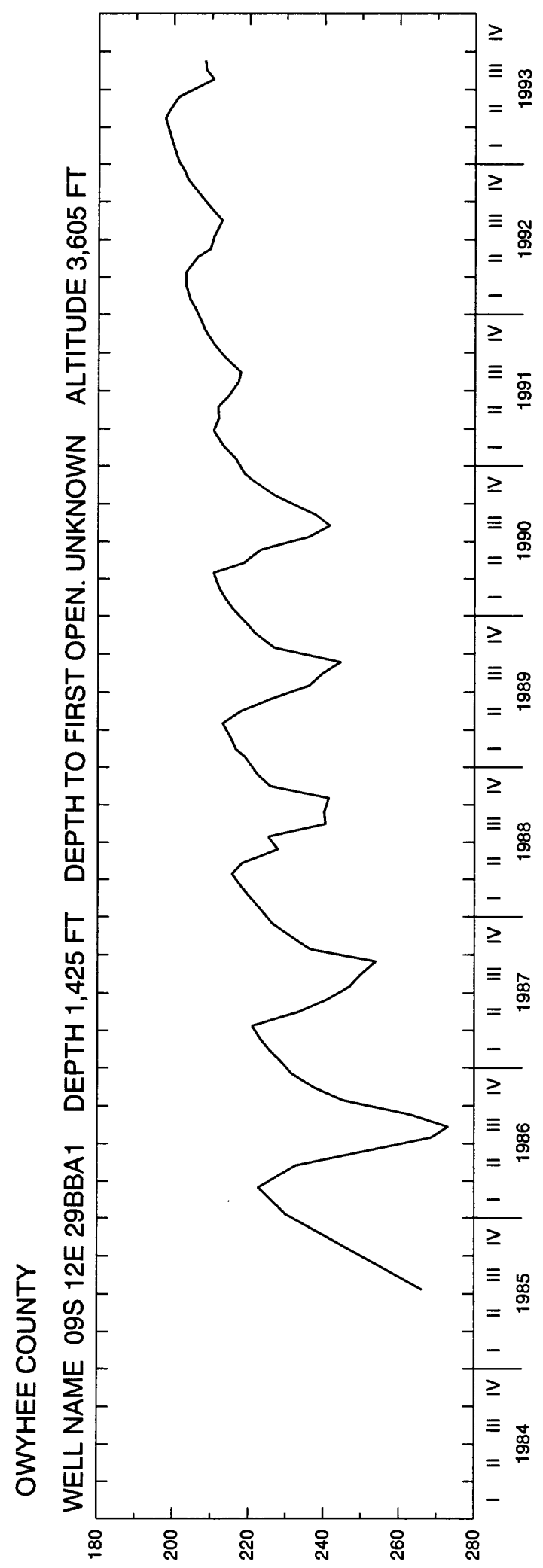

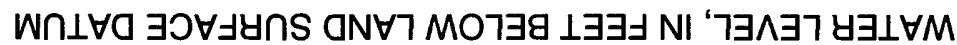




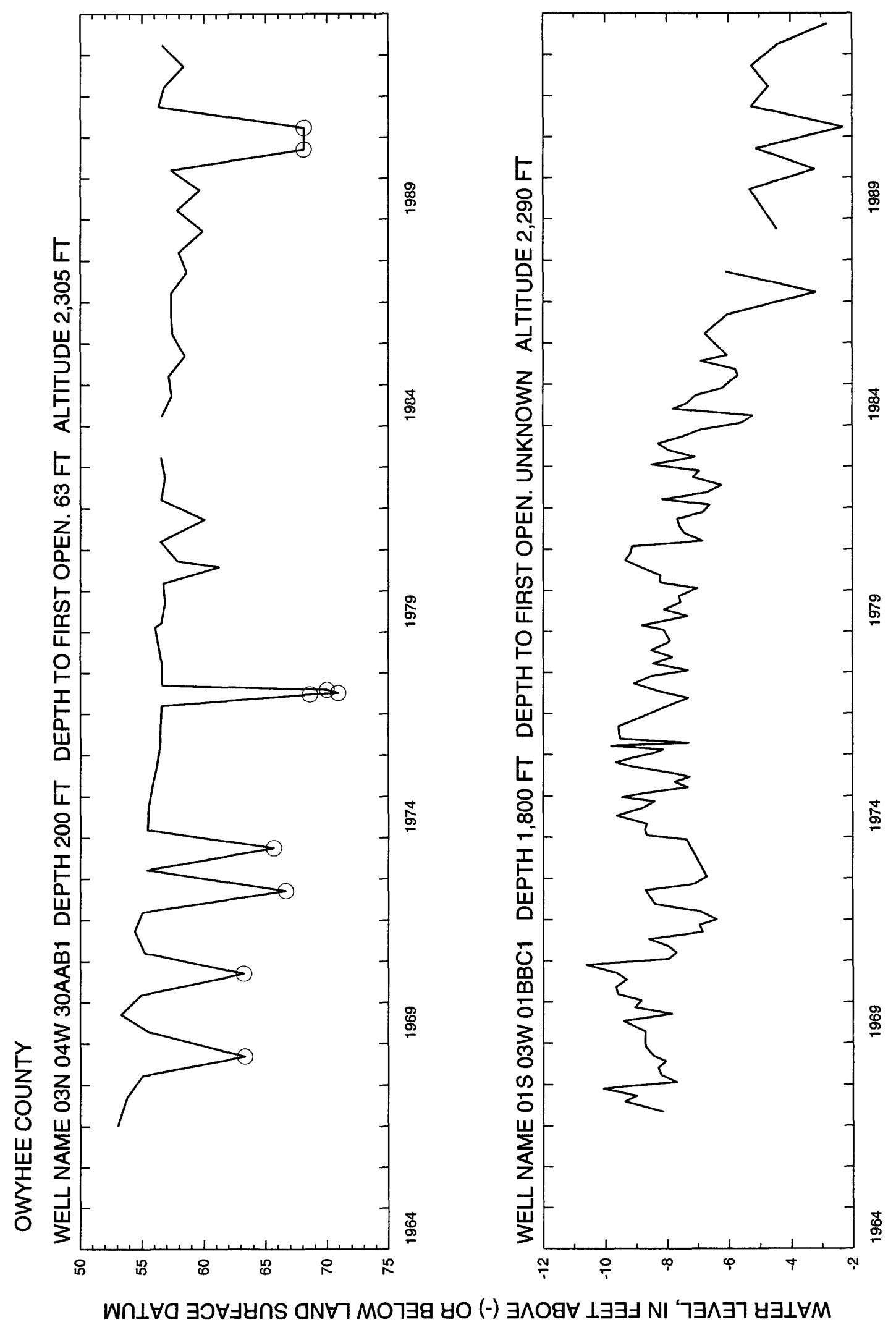




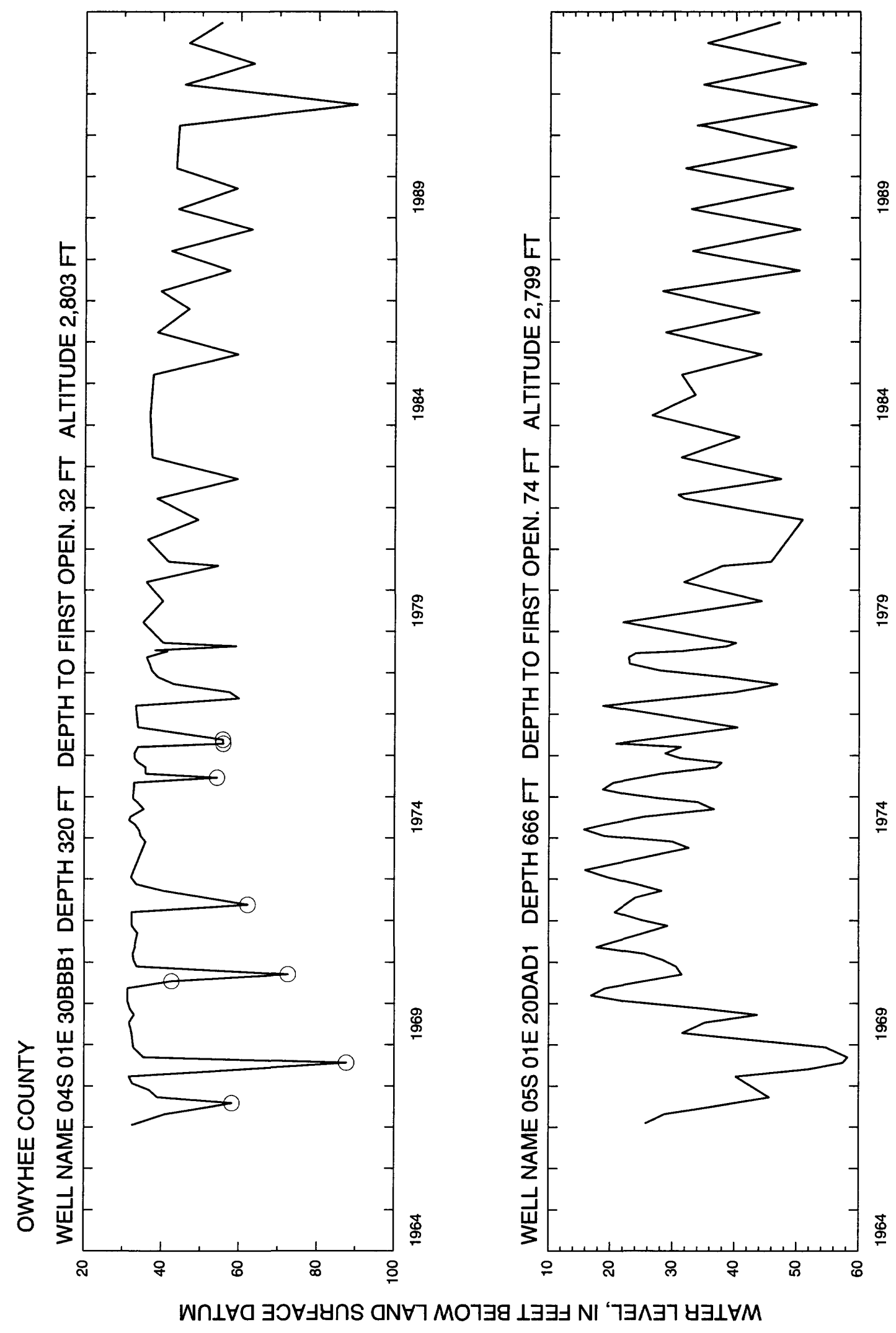

$\underset{8}{\stackrel{8}{\circ}}$

$\stackrel{\$}{\circ}$

옹

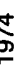

$\stackrel{8}{\circ}$

Ð 


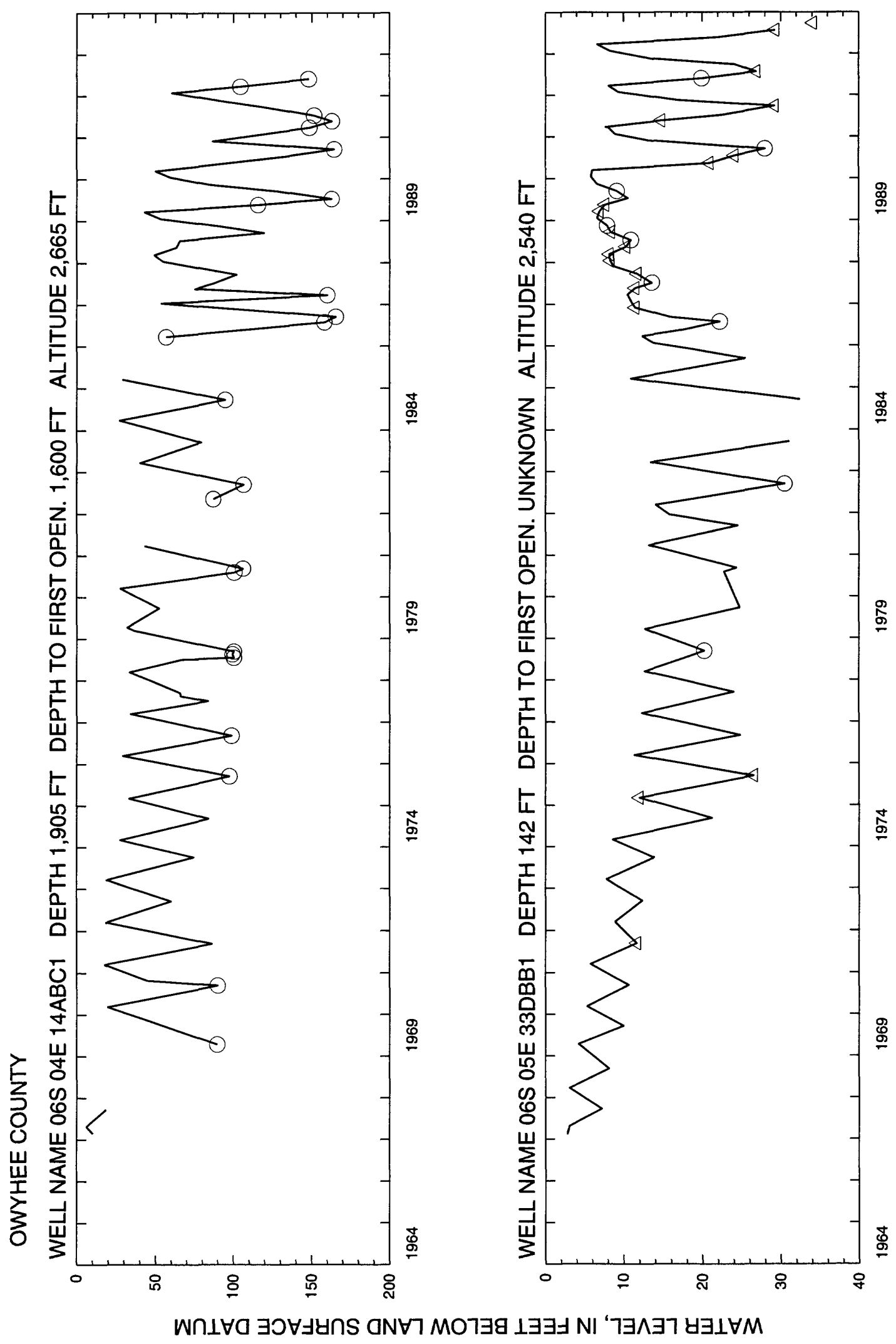




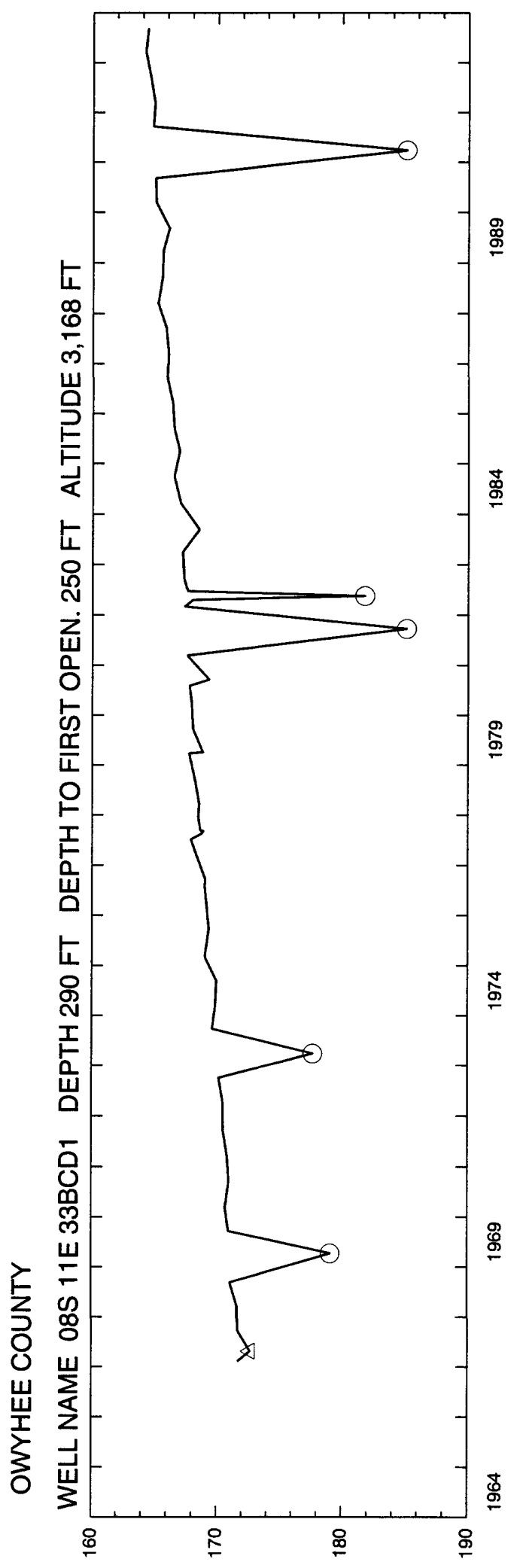

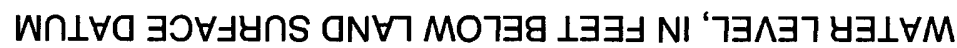




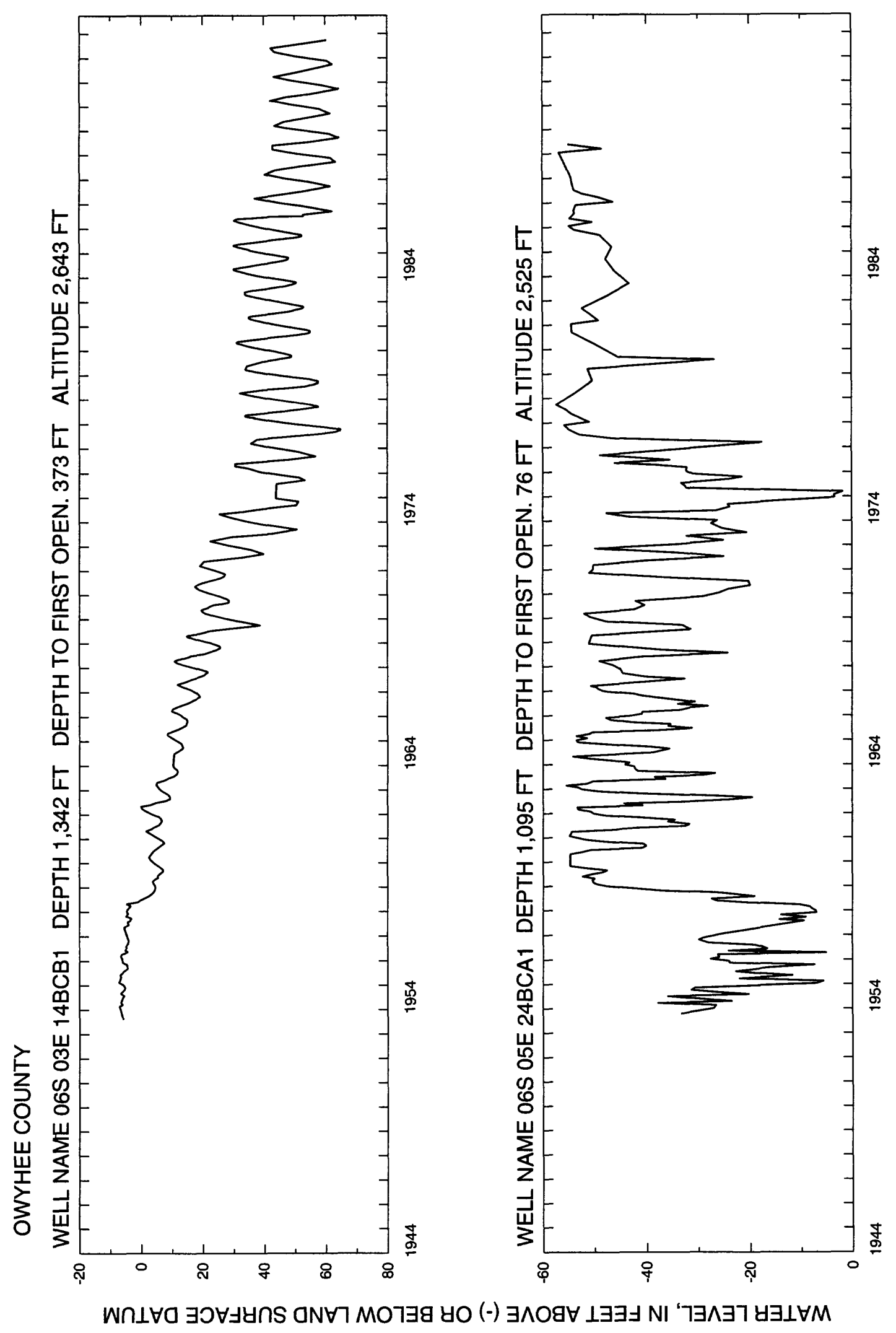




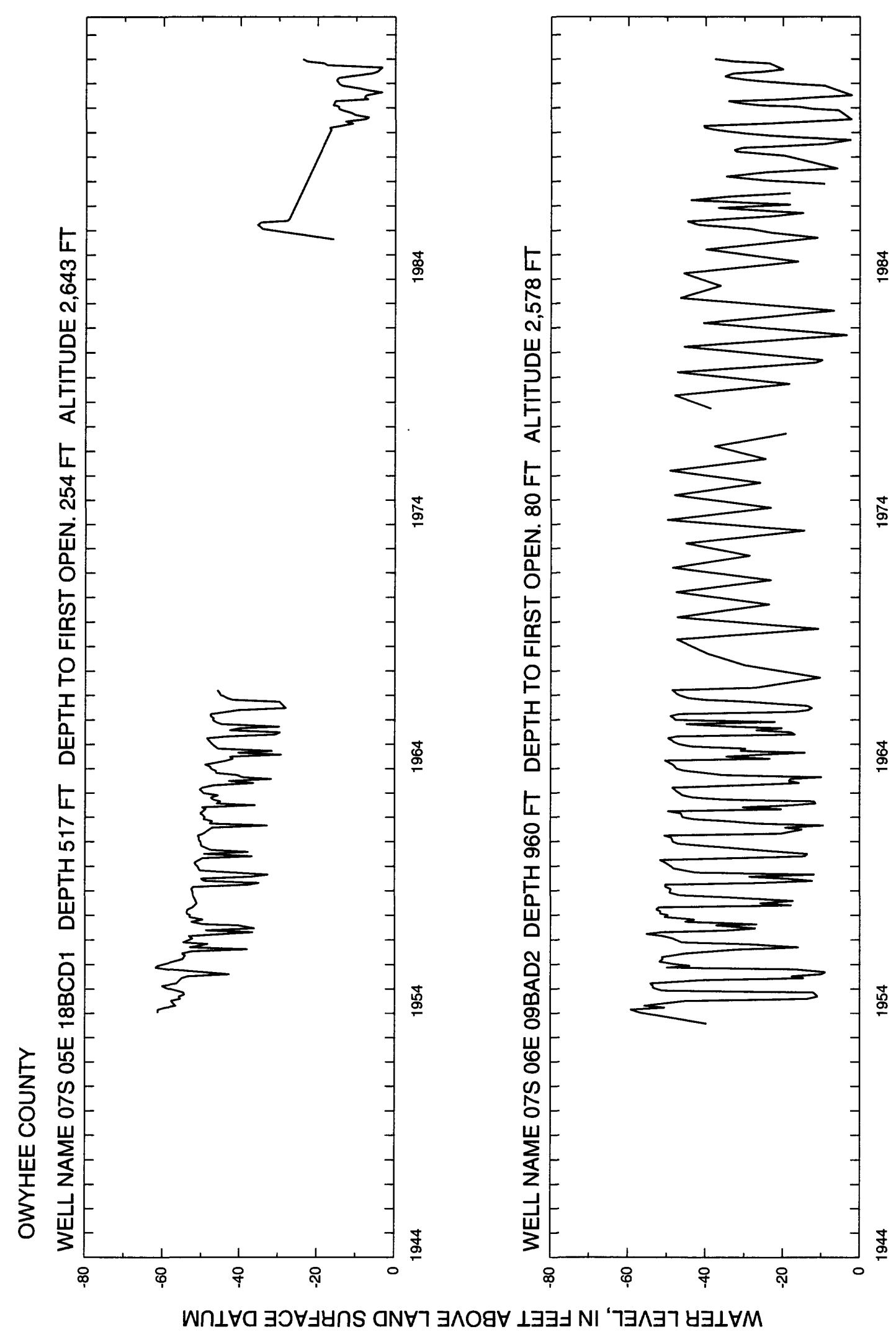




\section{Payette}

363 (oage 365 Aollows) 


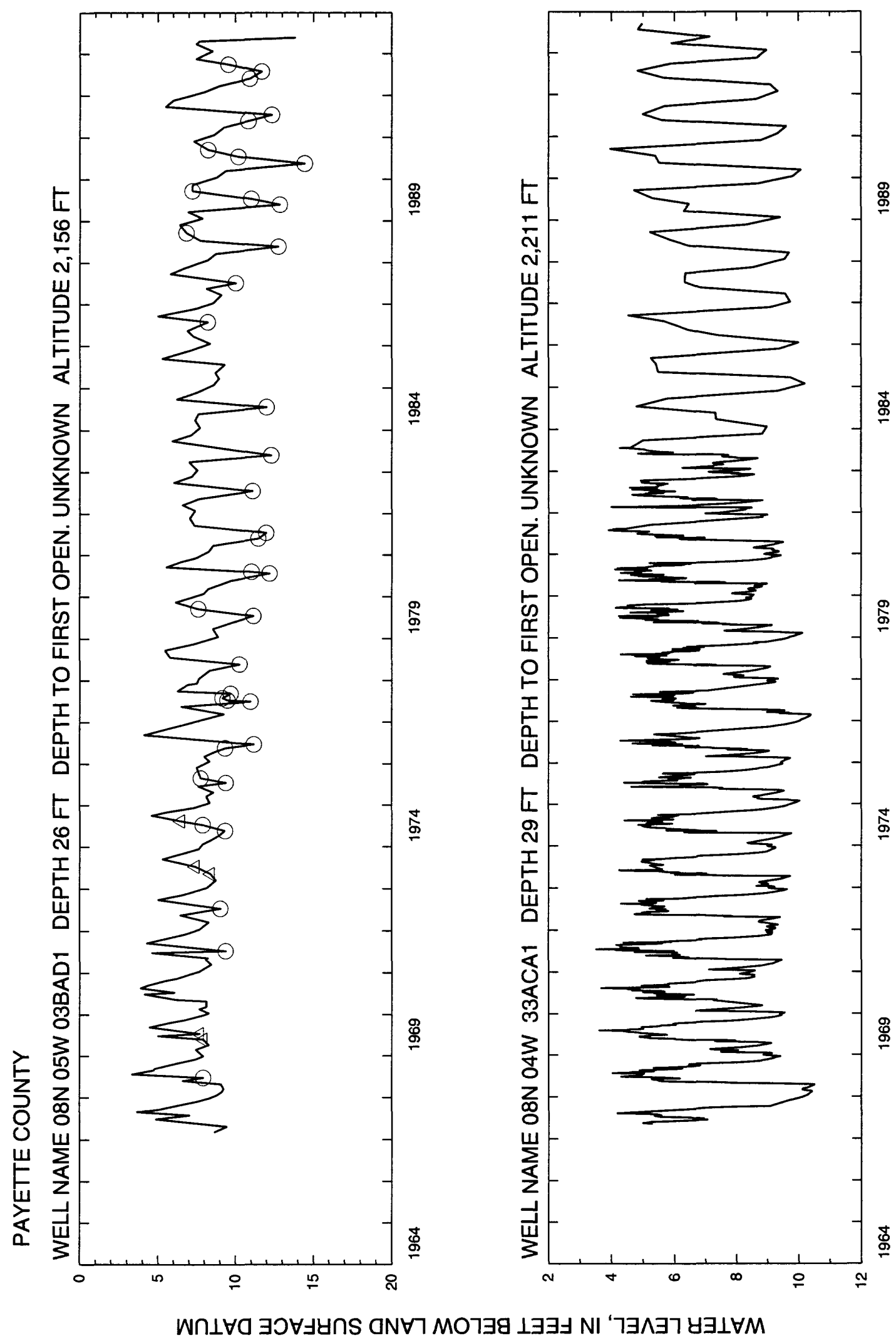

\begin{tabular}{l}
$\stackrel{8}{\circ}$ \\
$\stackrel{\square}{\circ}$ \\
\hline
\end{tabular}

呑

$\stackrel{+}{\stackrel{5}{\sigma}}$

$\stackrel{\circ}{\circ}$

$\stackrel{\$}{\$}$ 


\section{Power}


WATER LEVEL, IN FEET BELOW LAND SURFACE DATUM
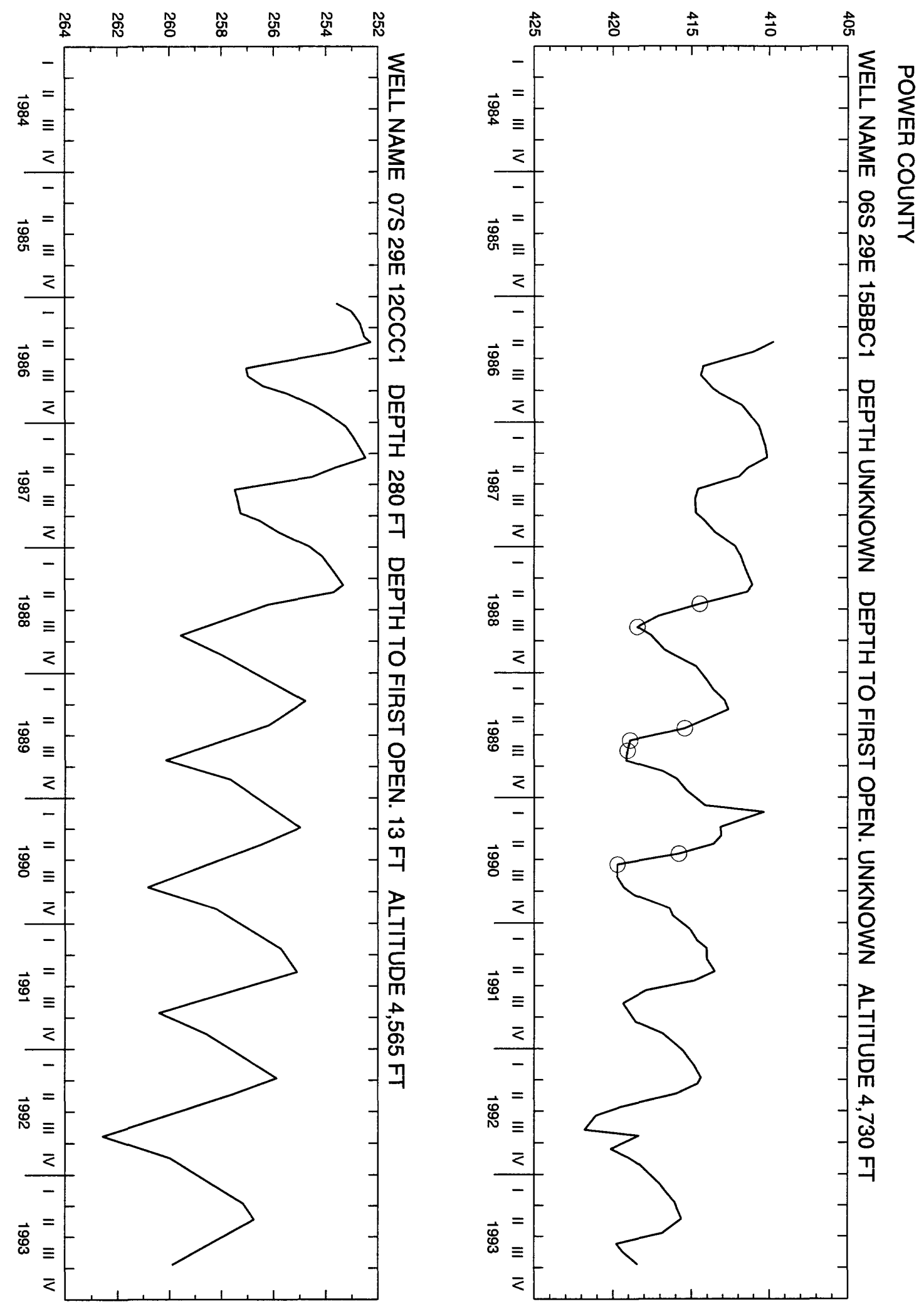


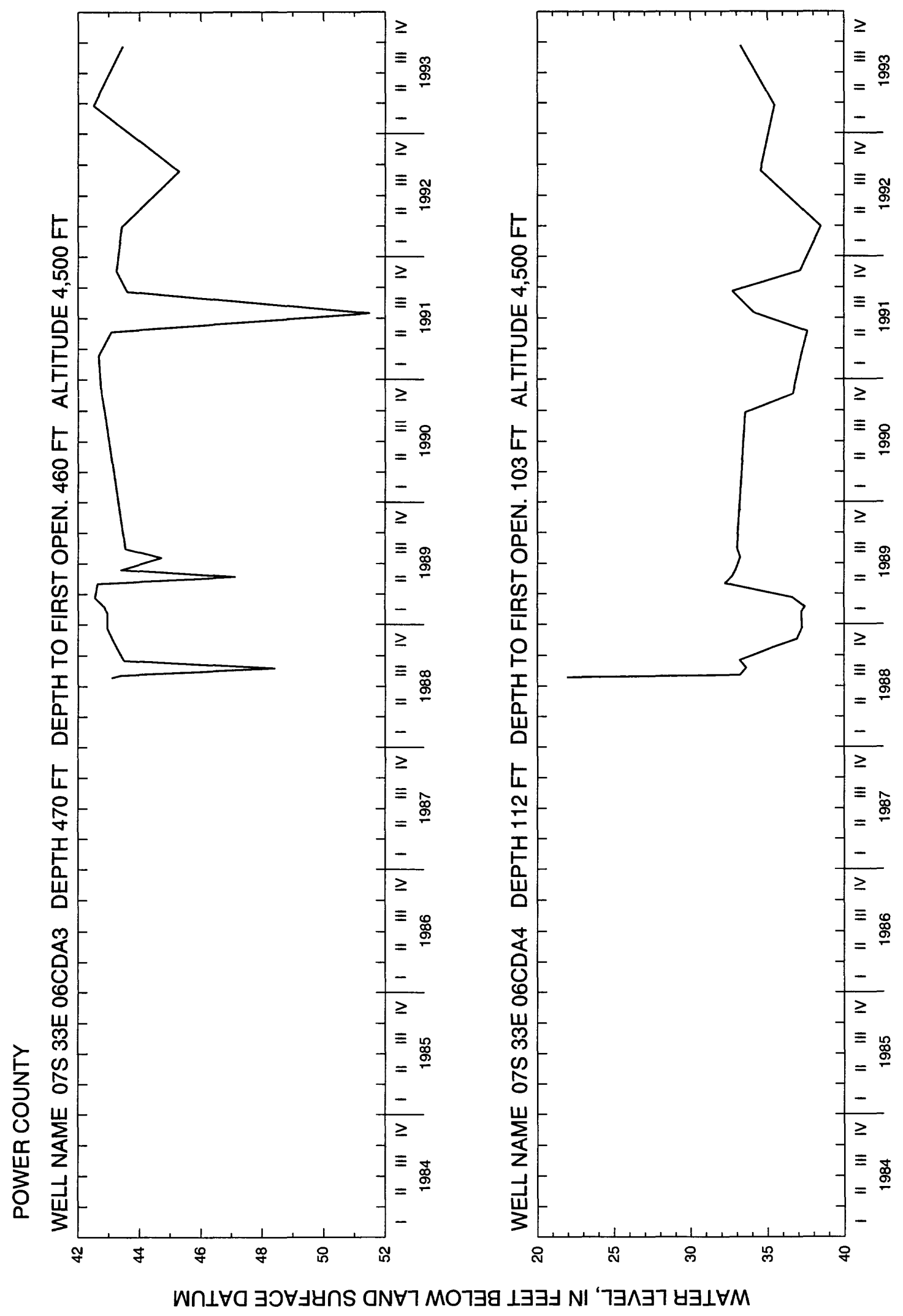




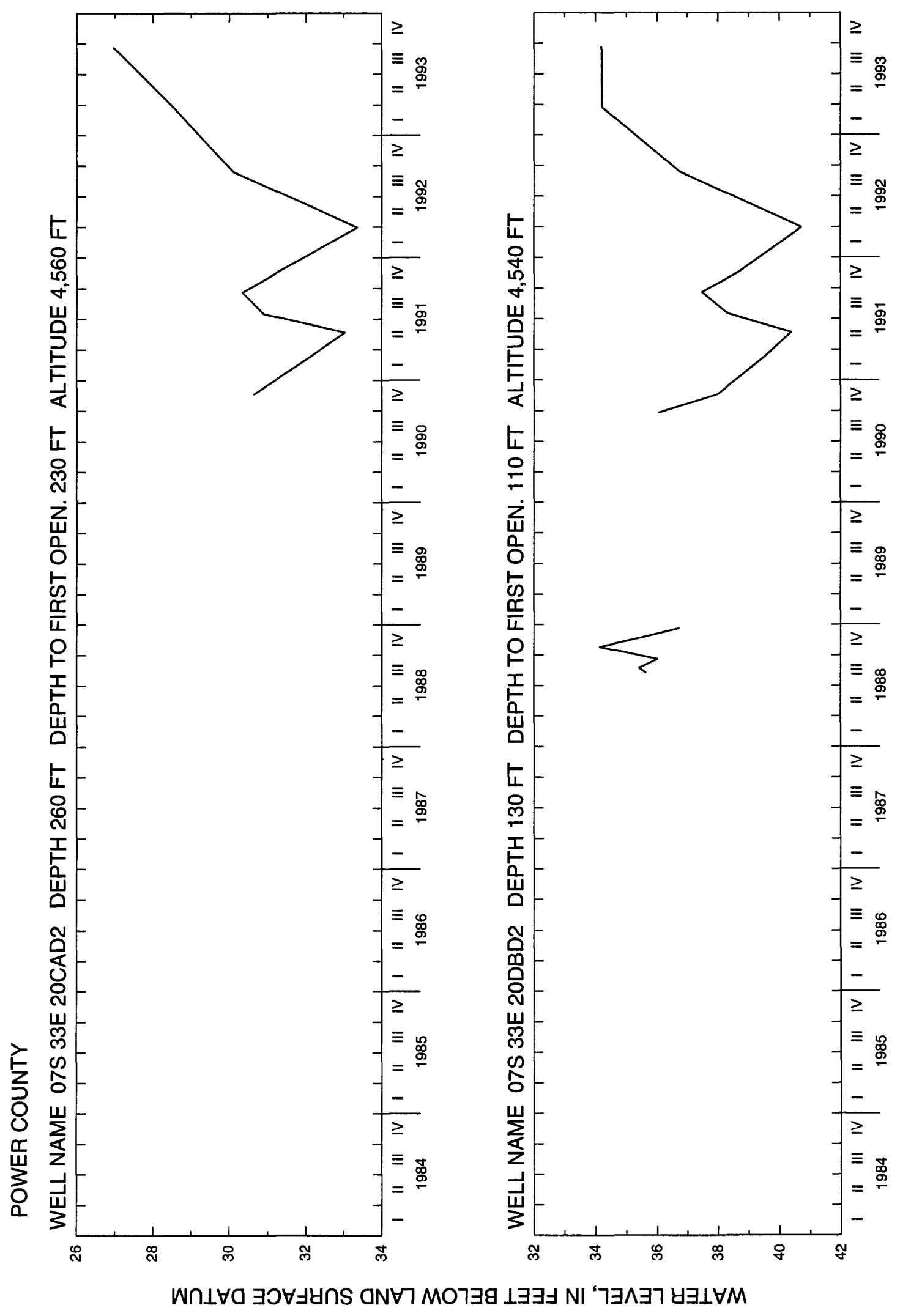




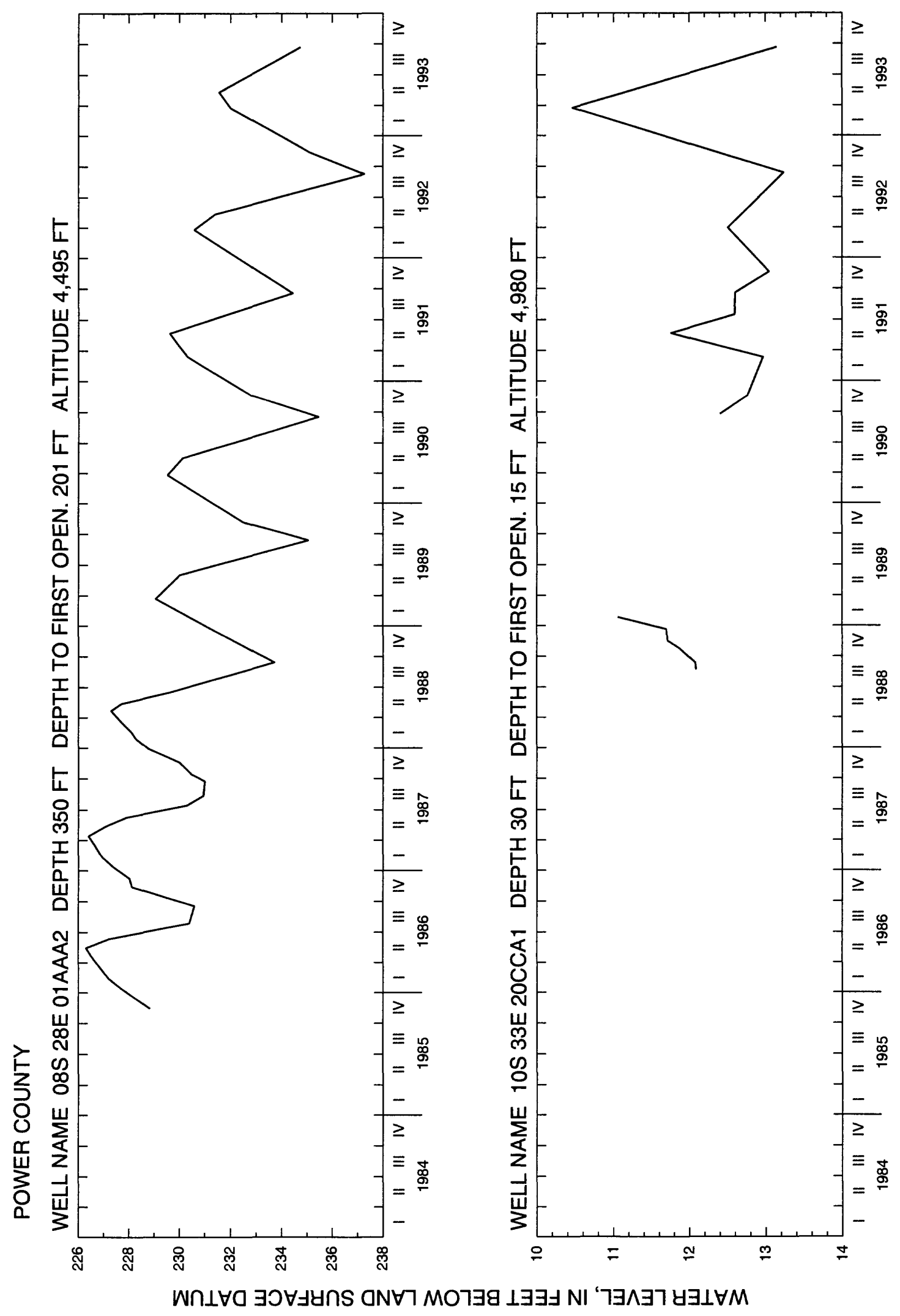




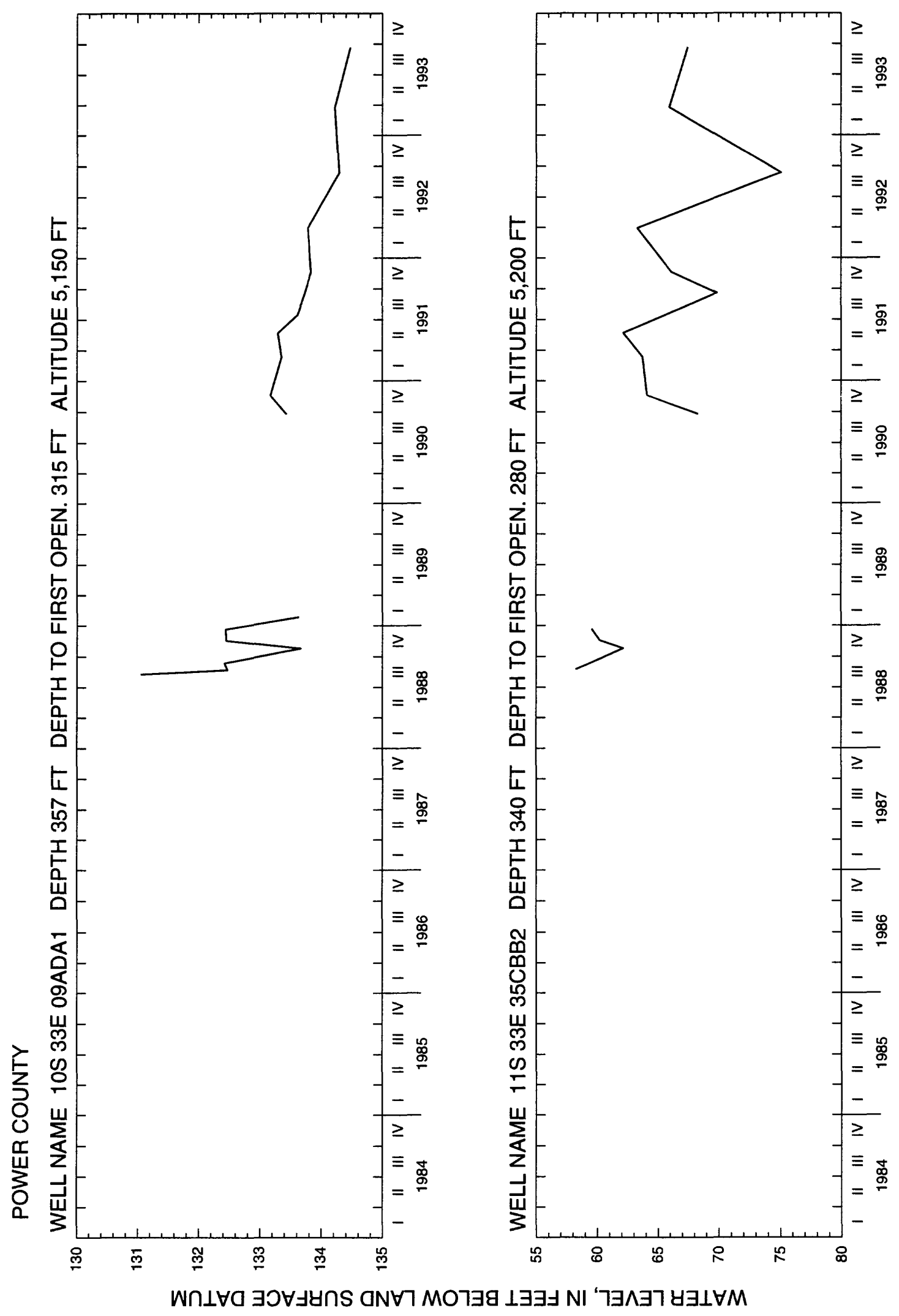




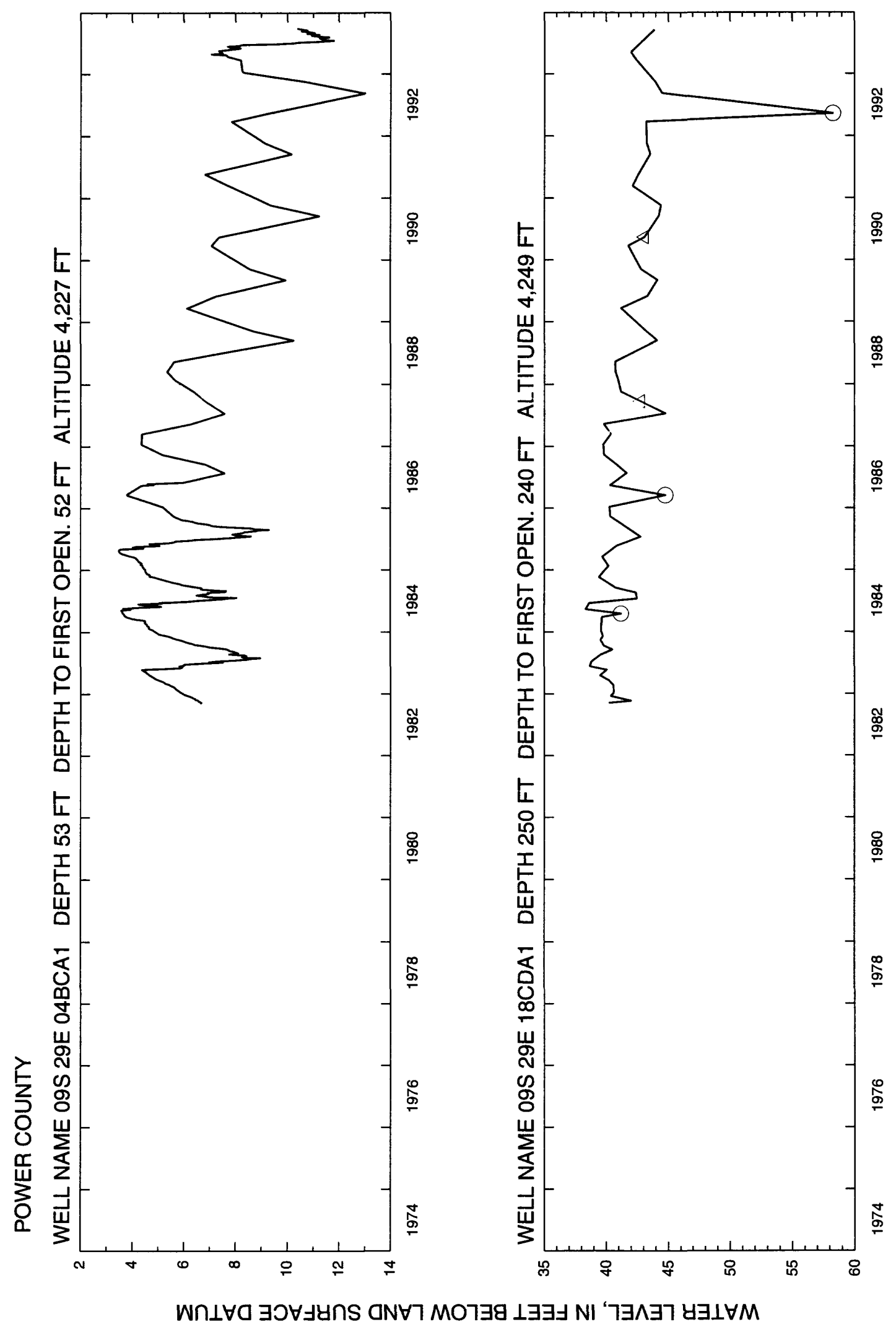




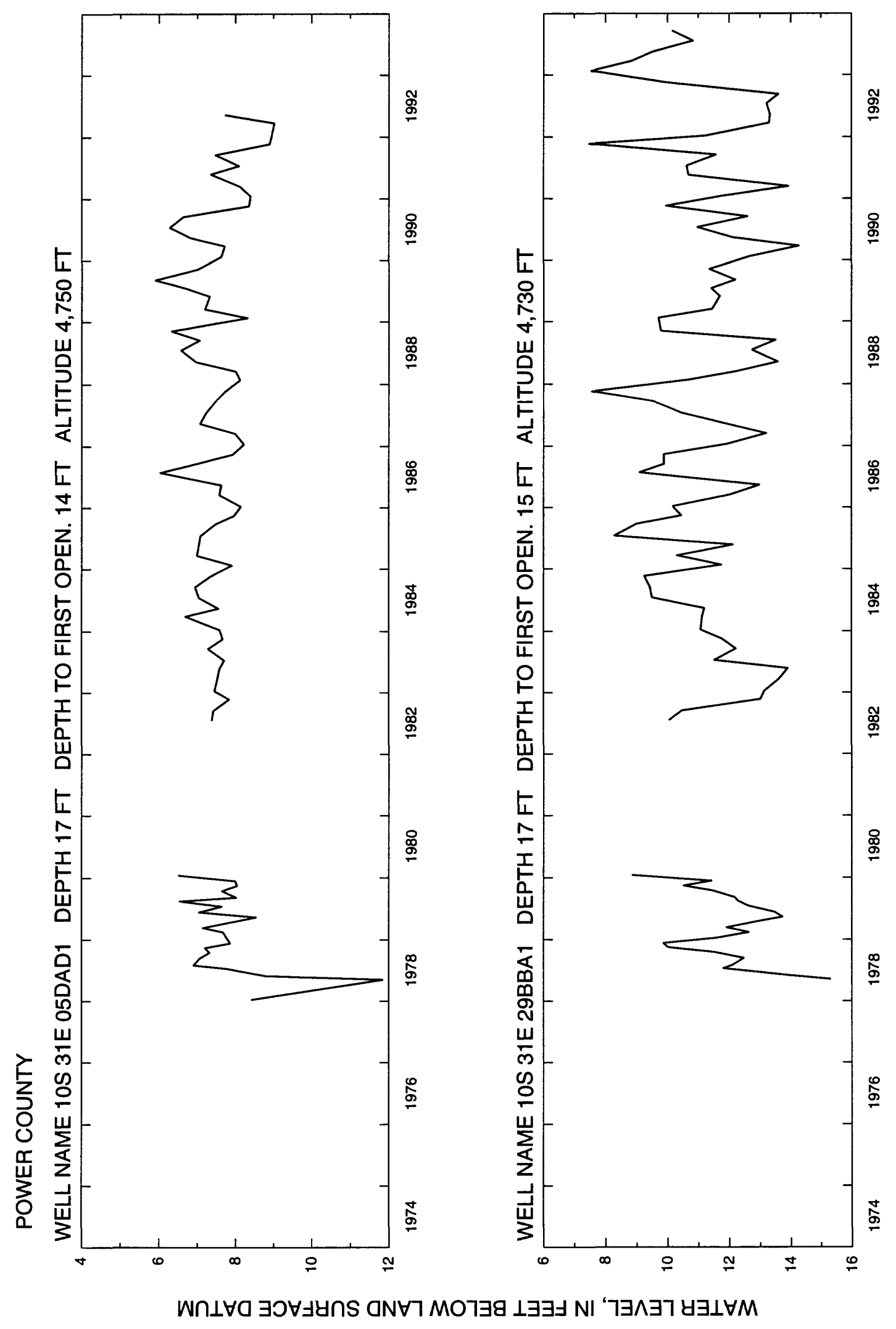




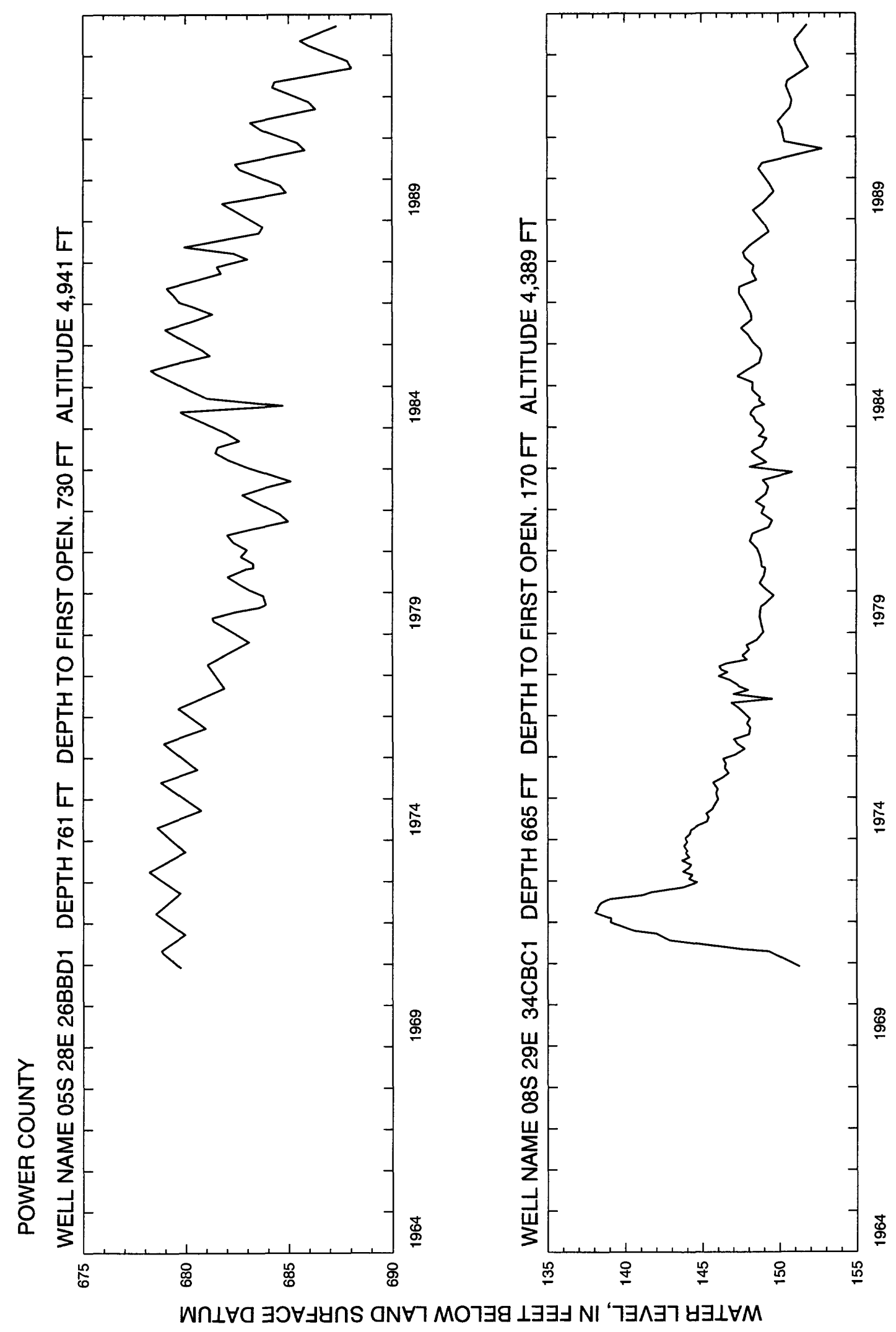




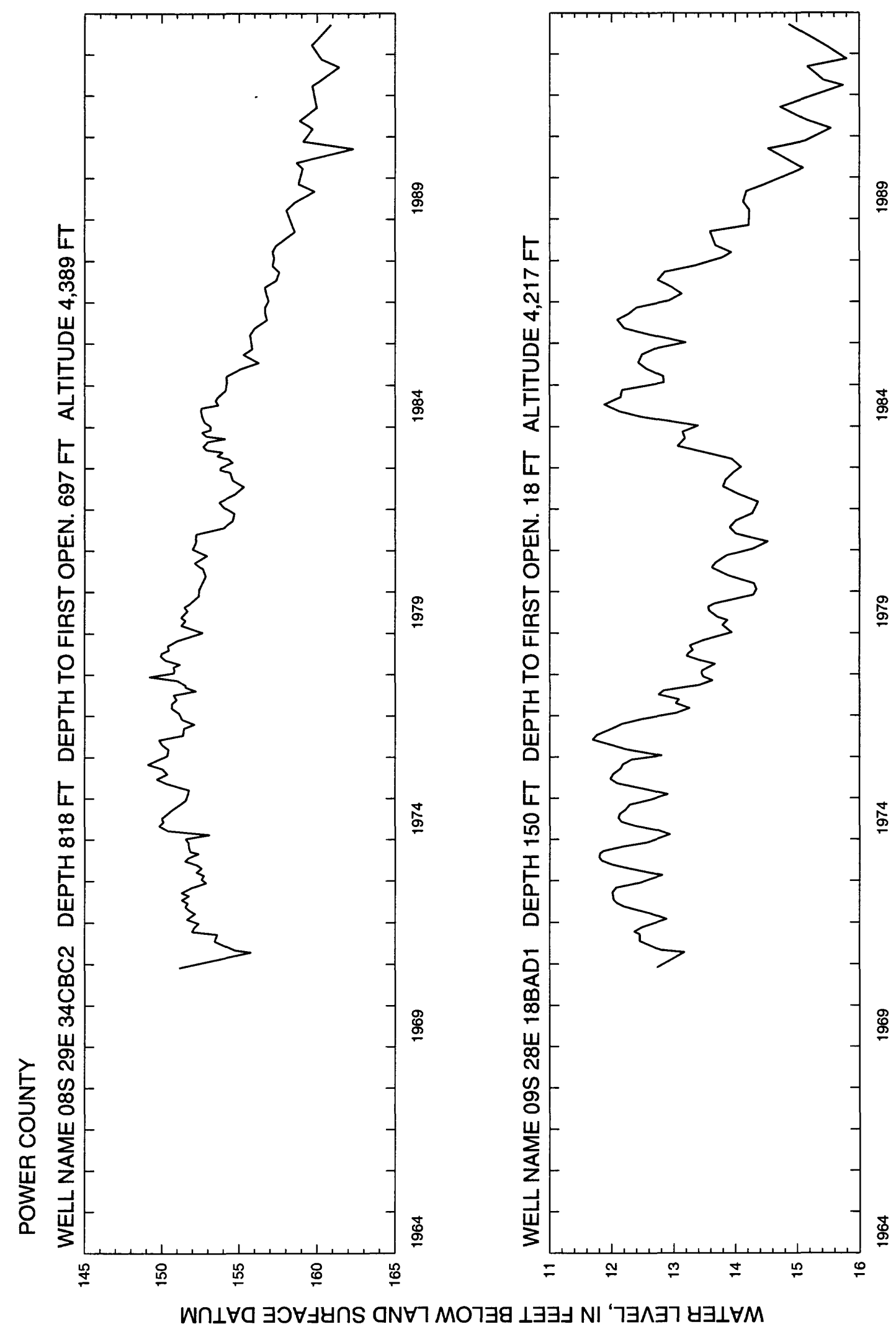




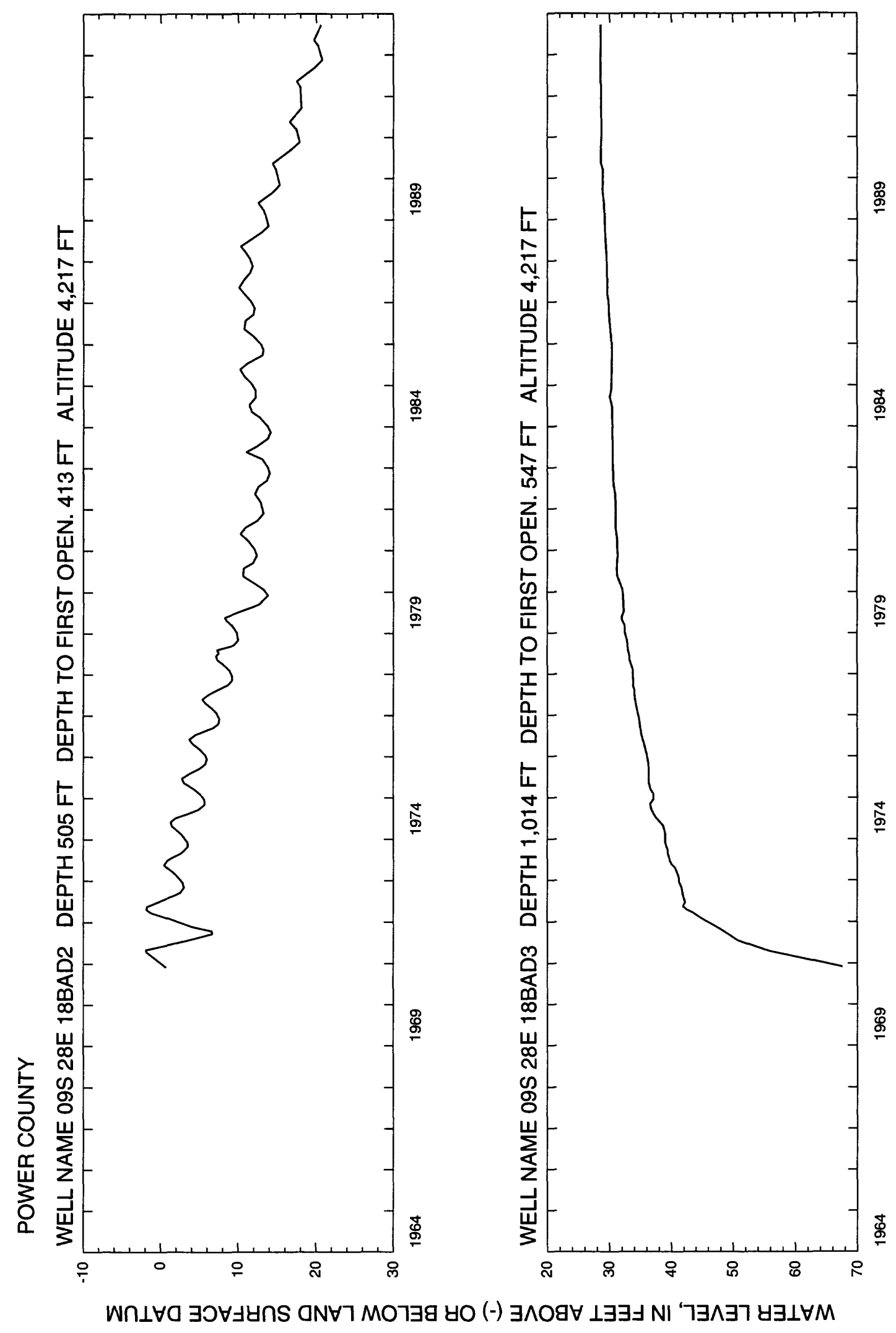




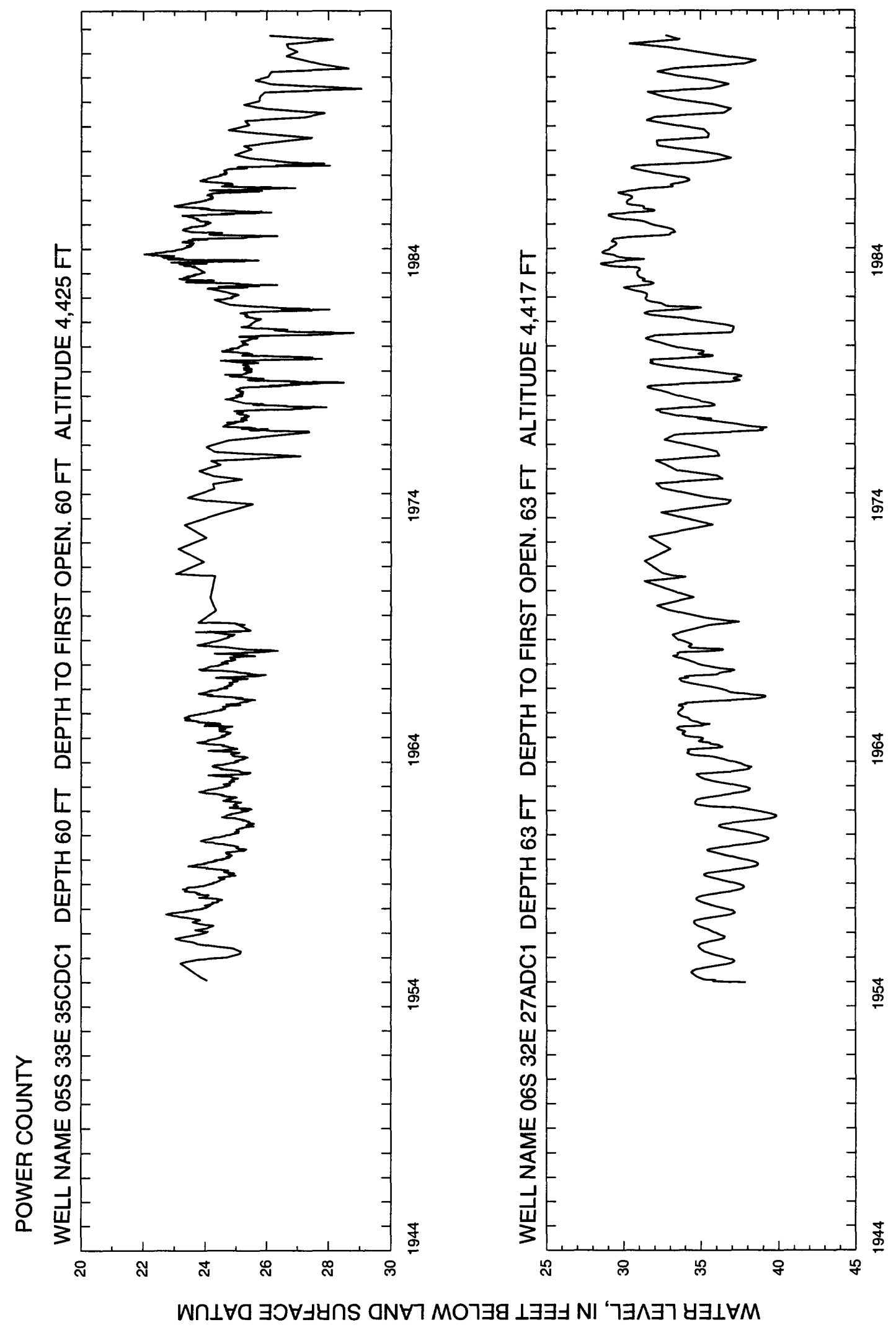




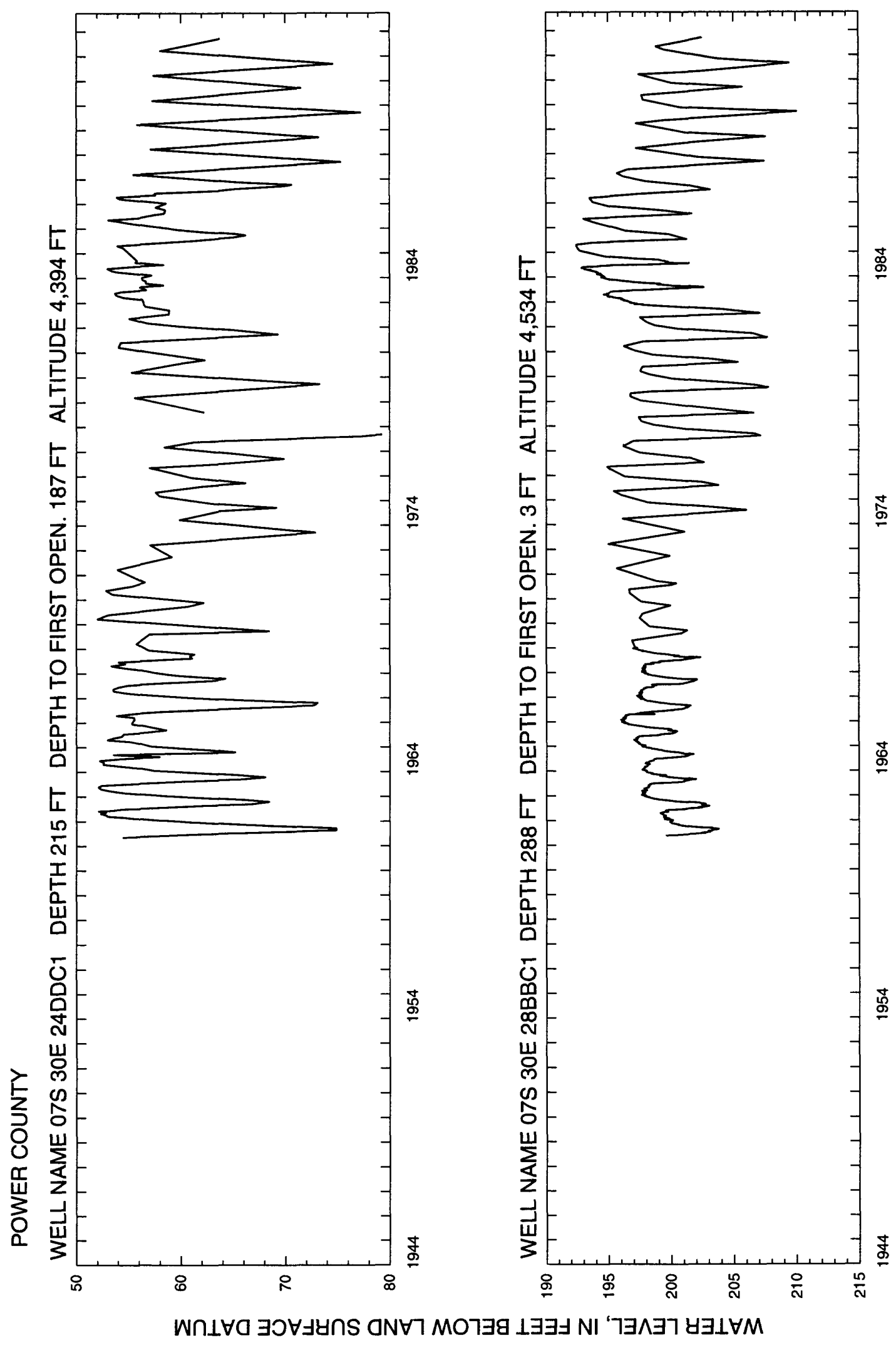




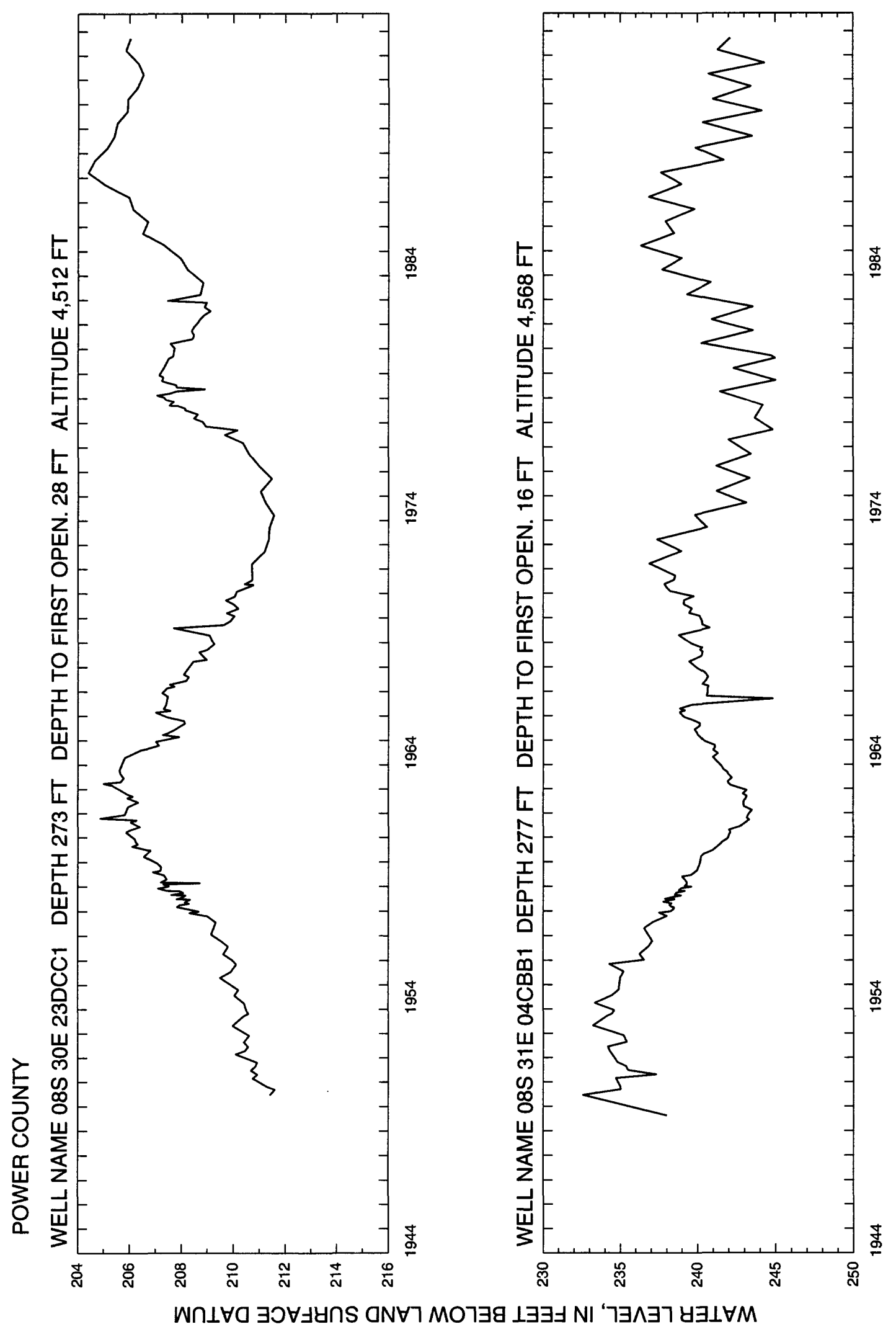

381 (paje 383 fillows) 
Teton

383 (oage 385 follows) 

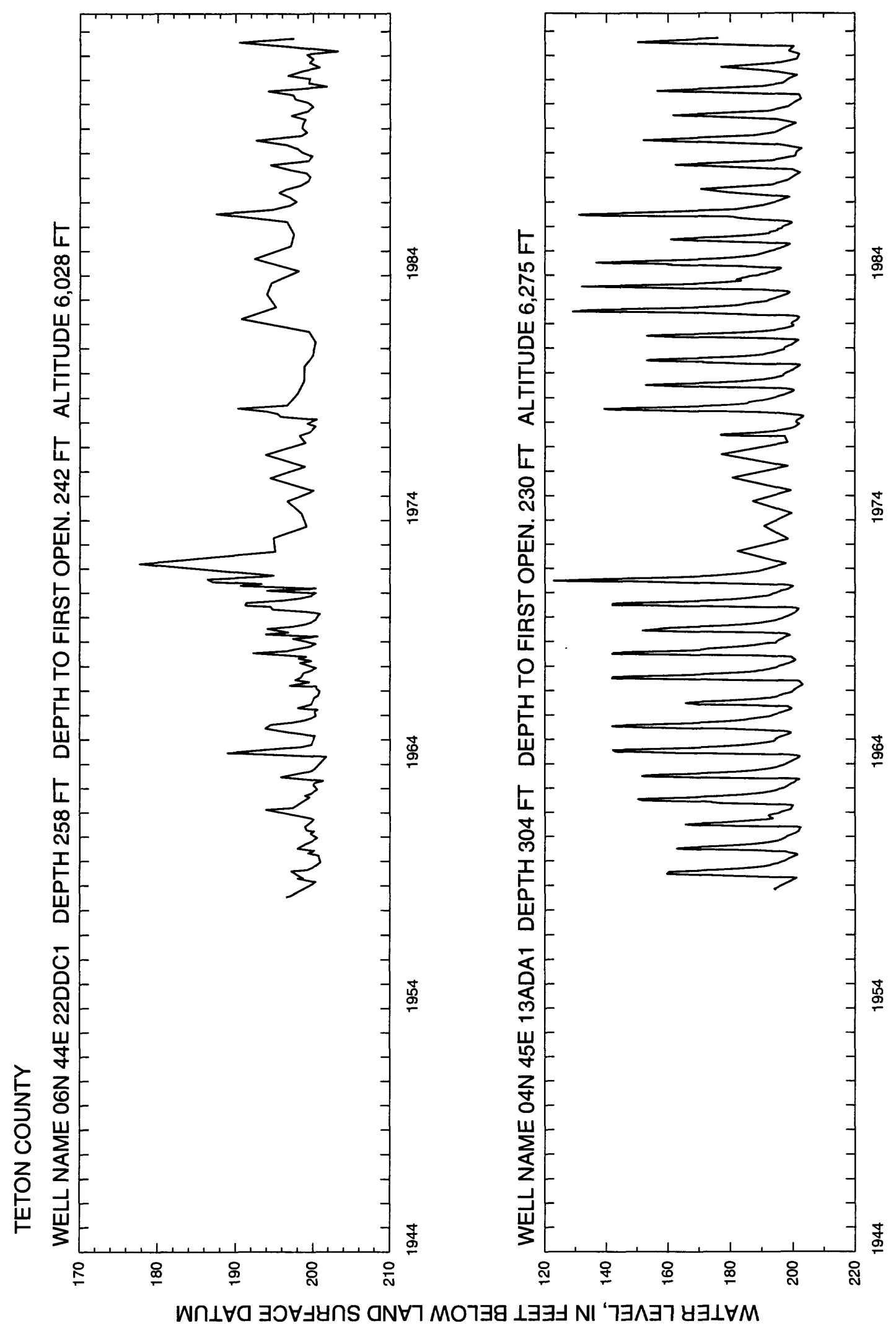

385 (paye 387 Lollows) 
Twin Falls

387 (paye 389 dollows) 


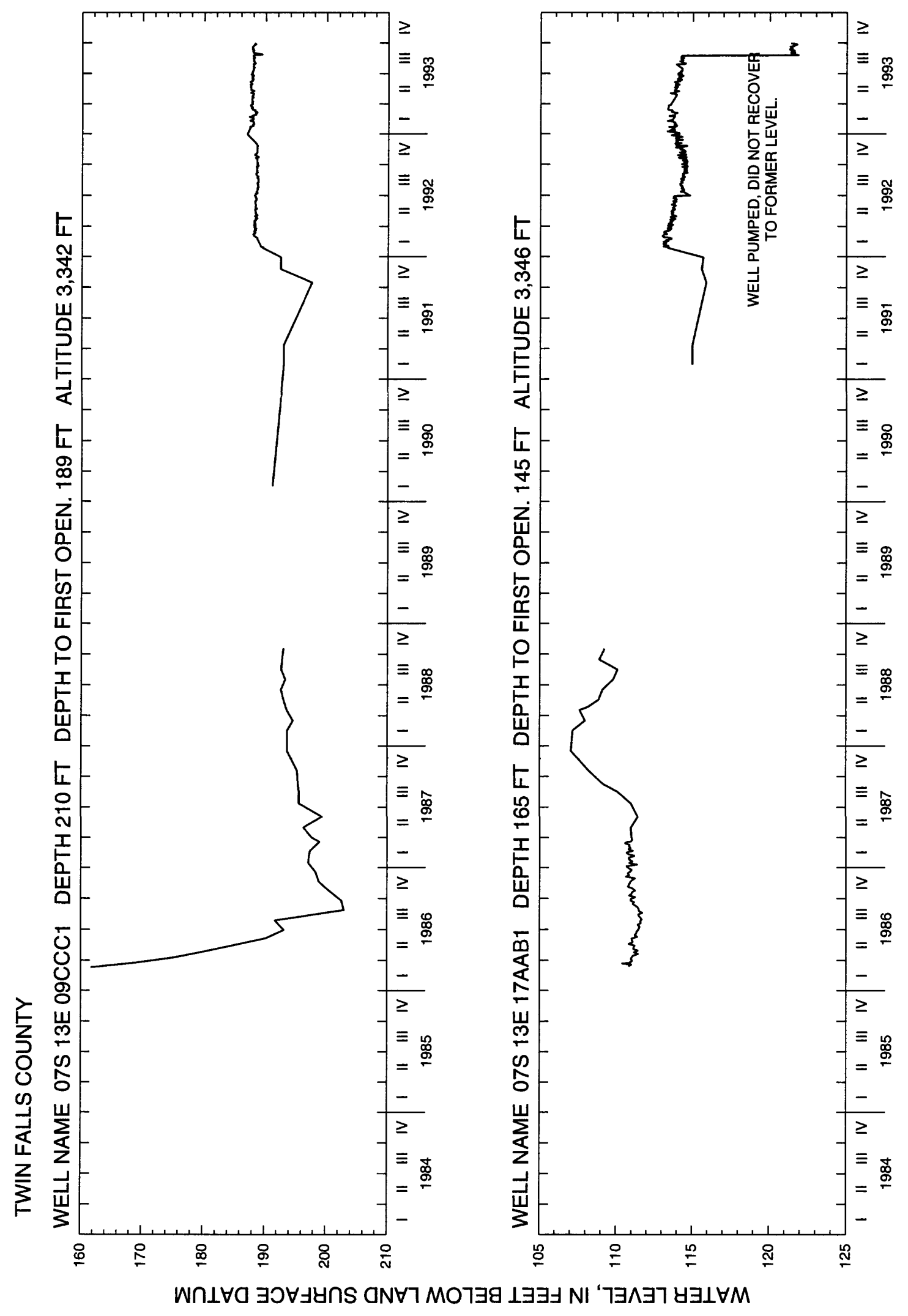




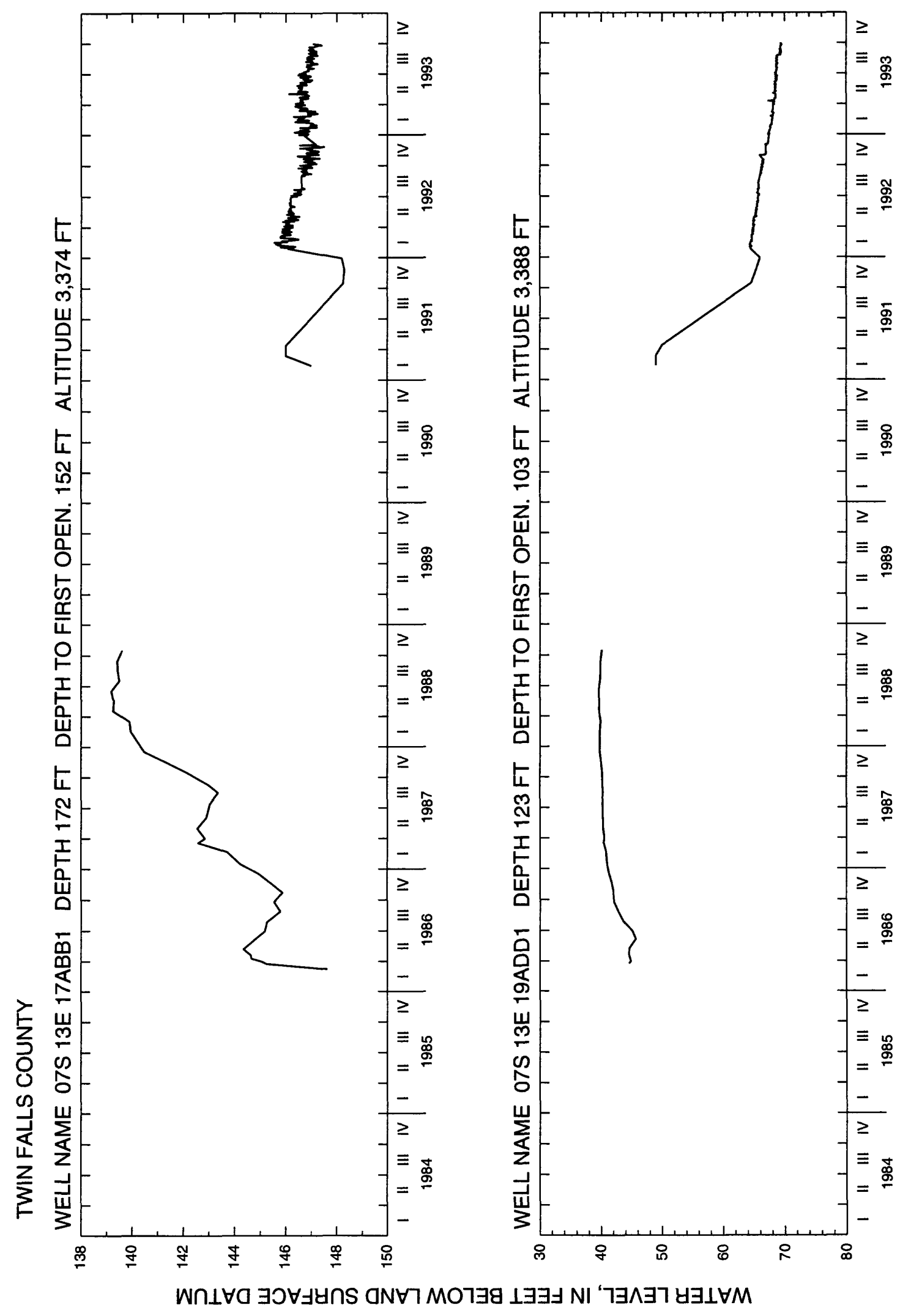




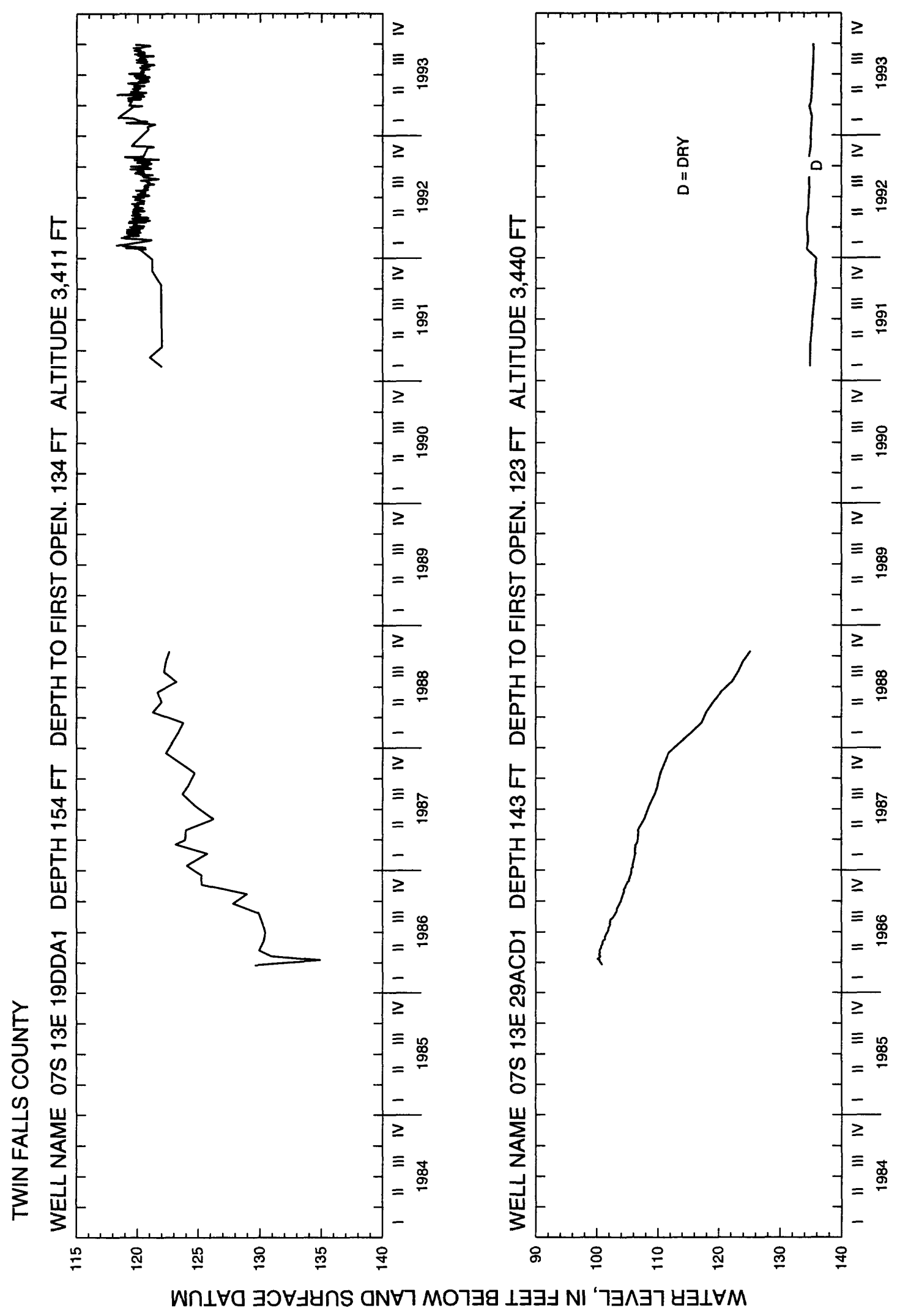




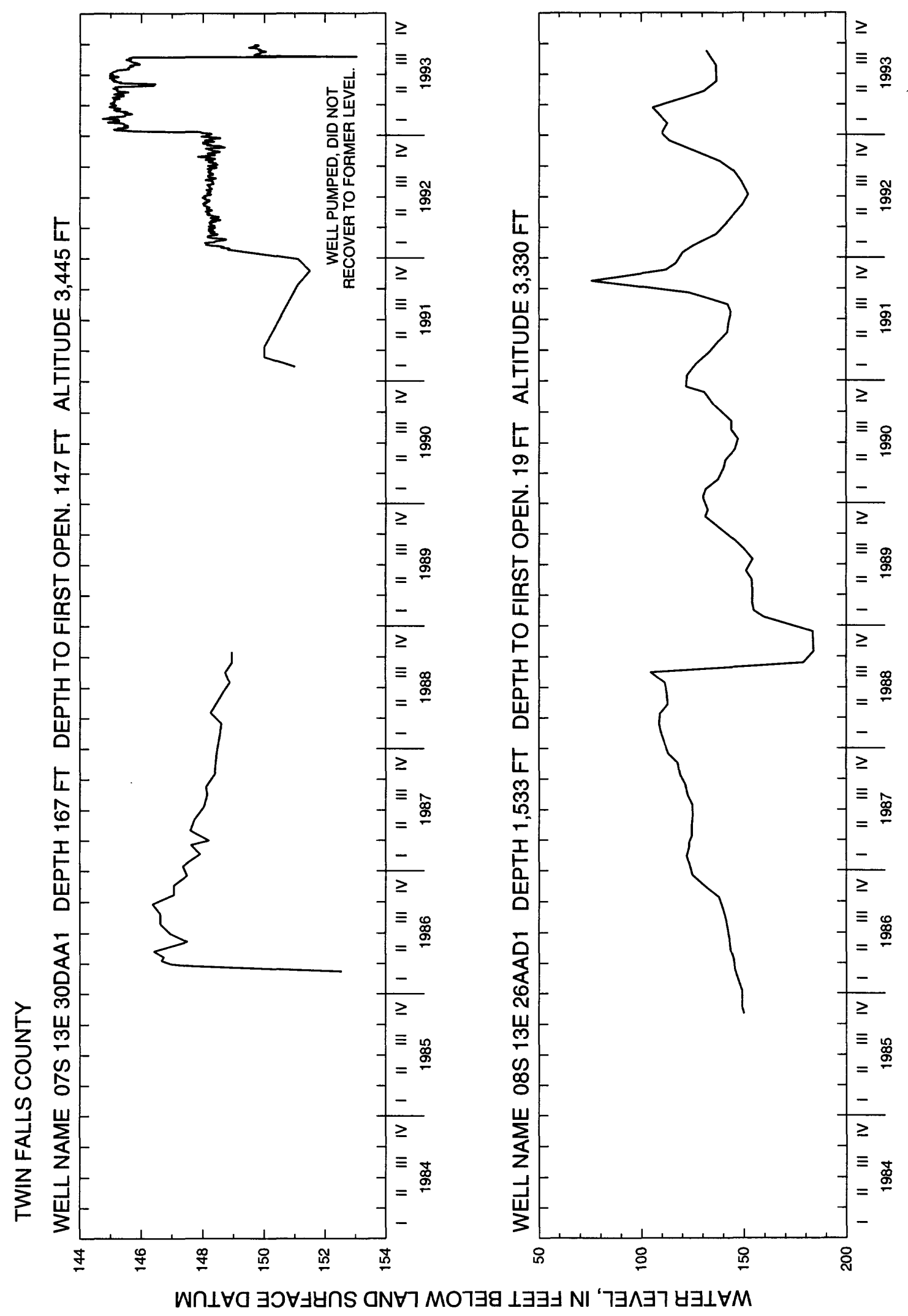




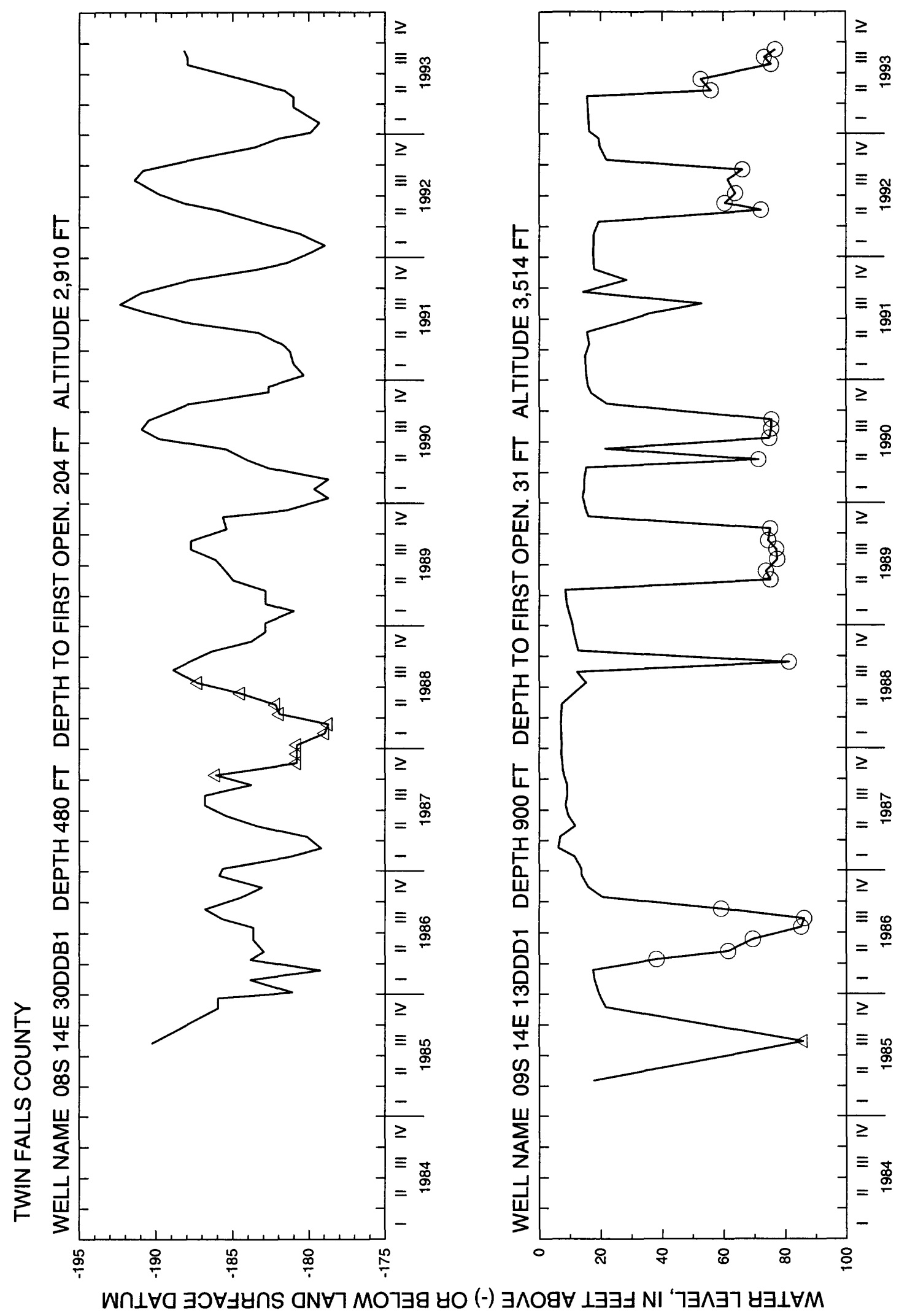




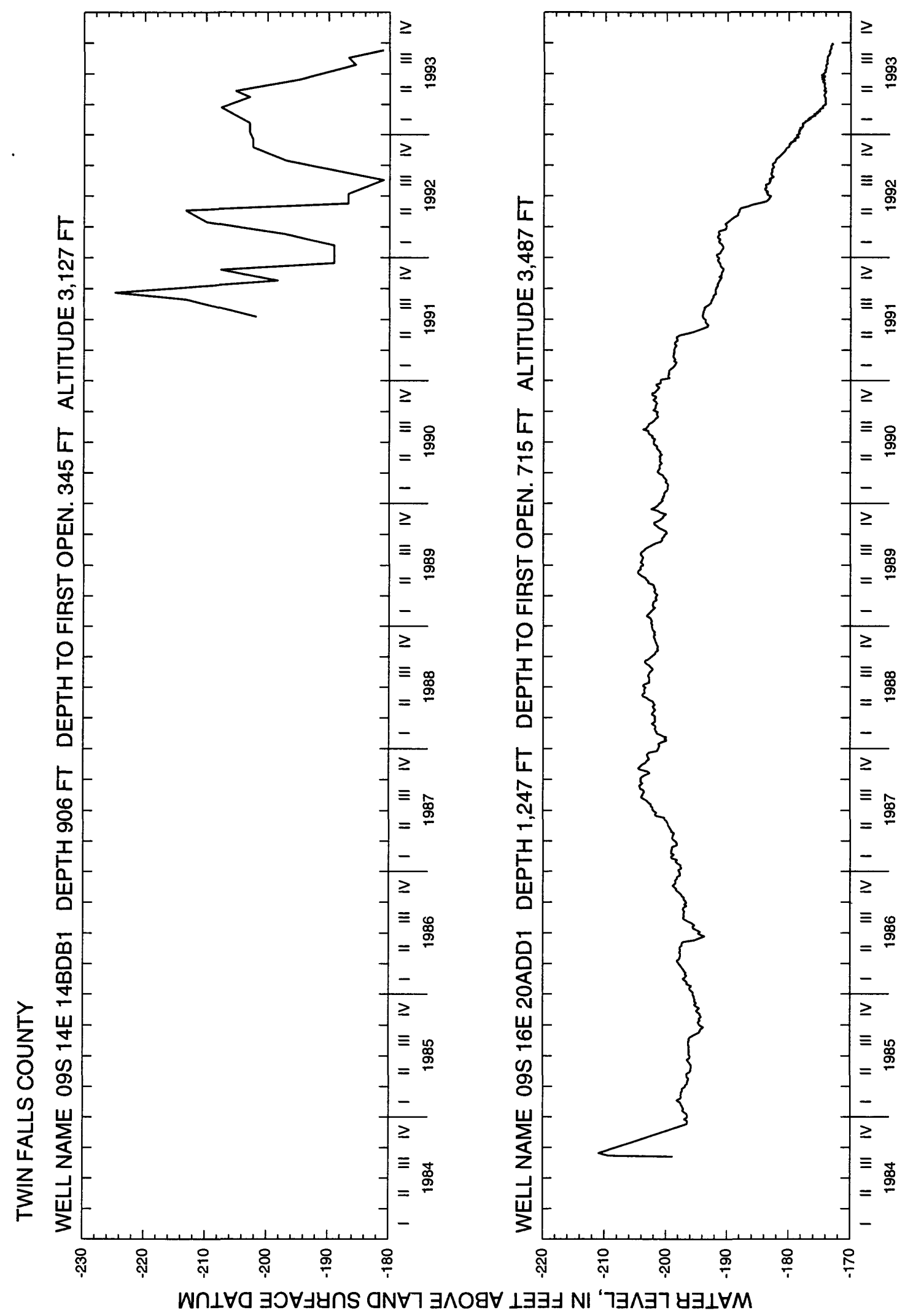




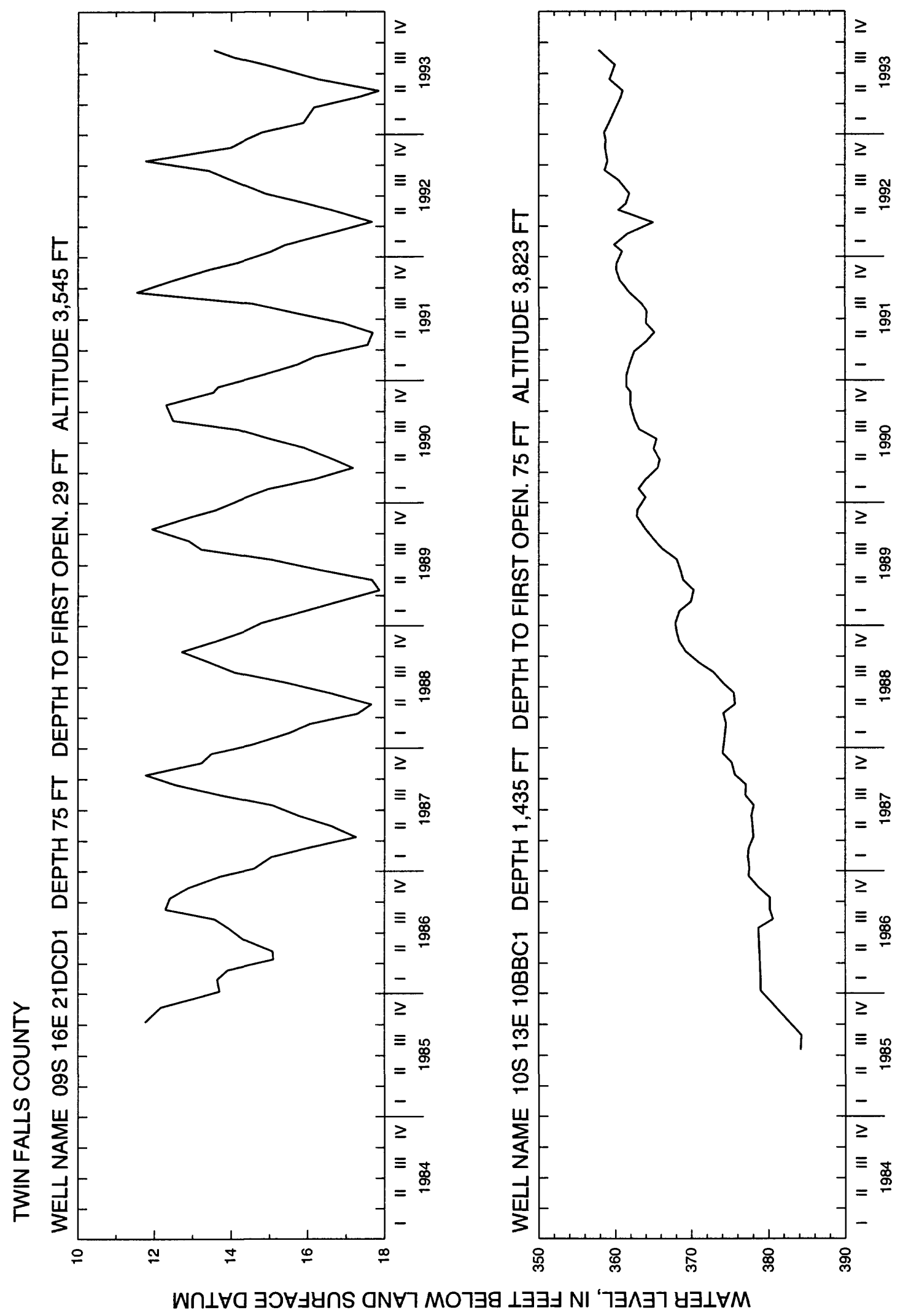




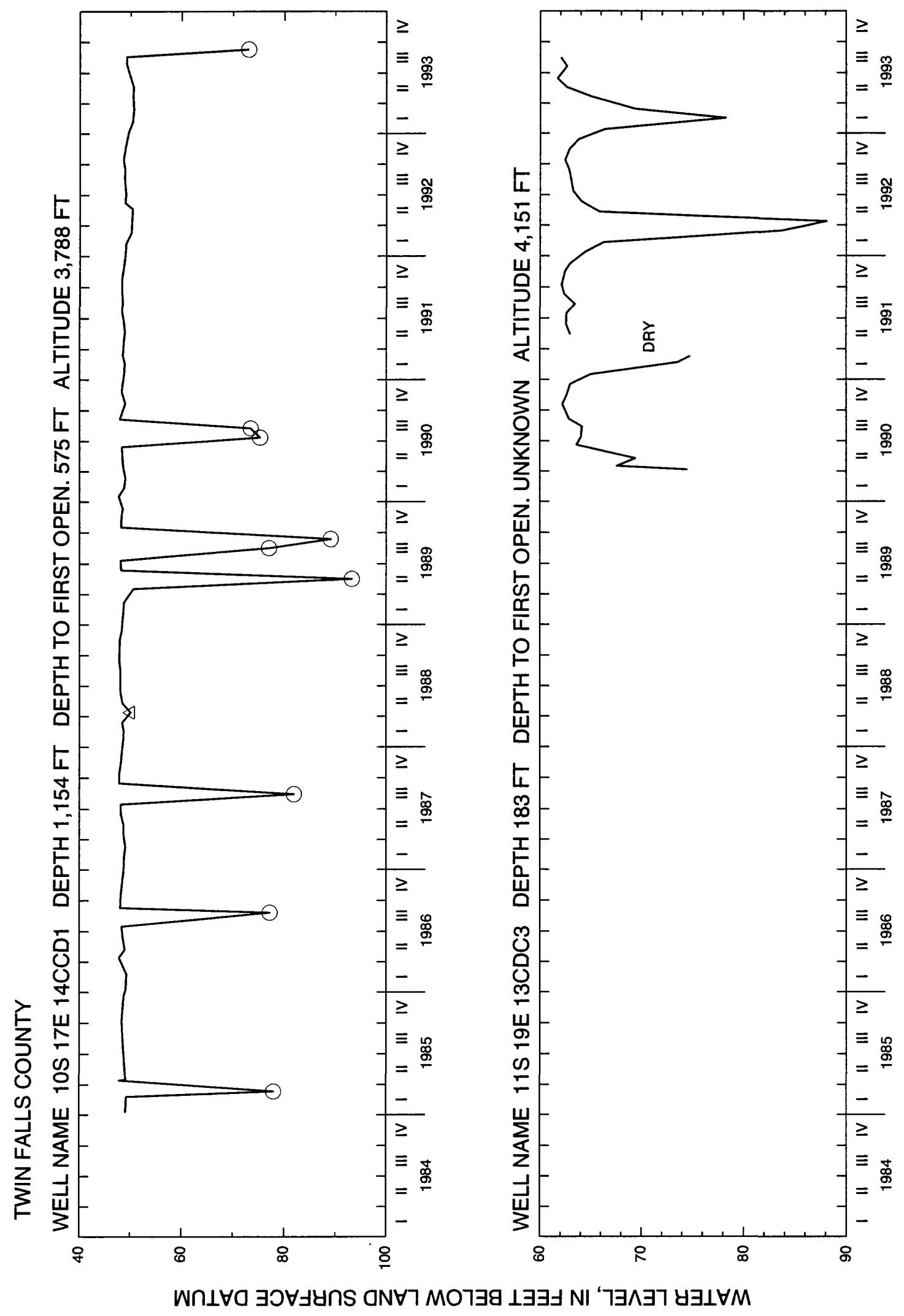




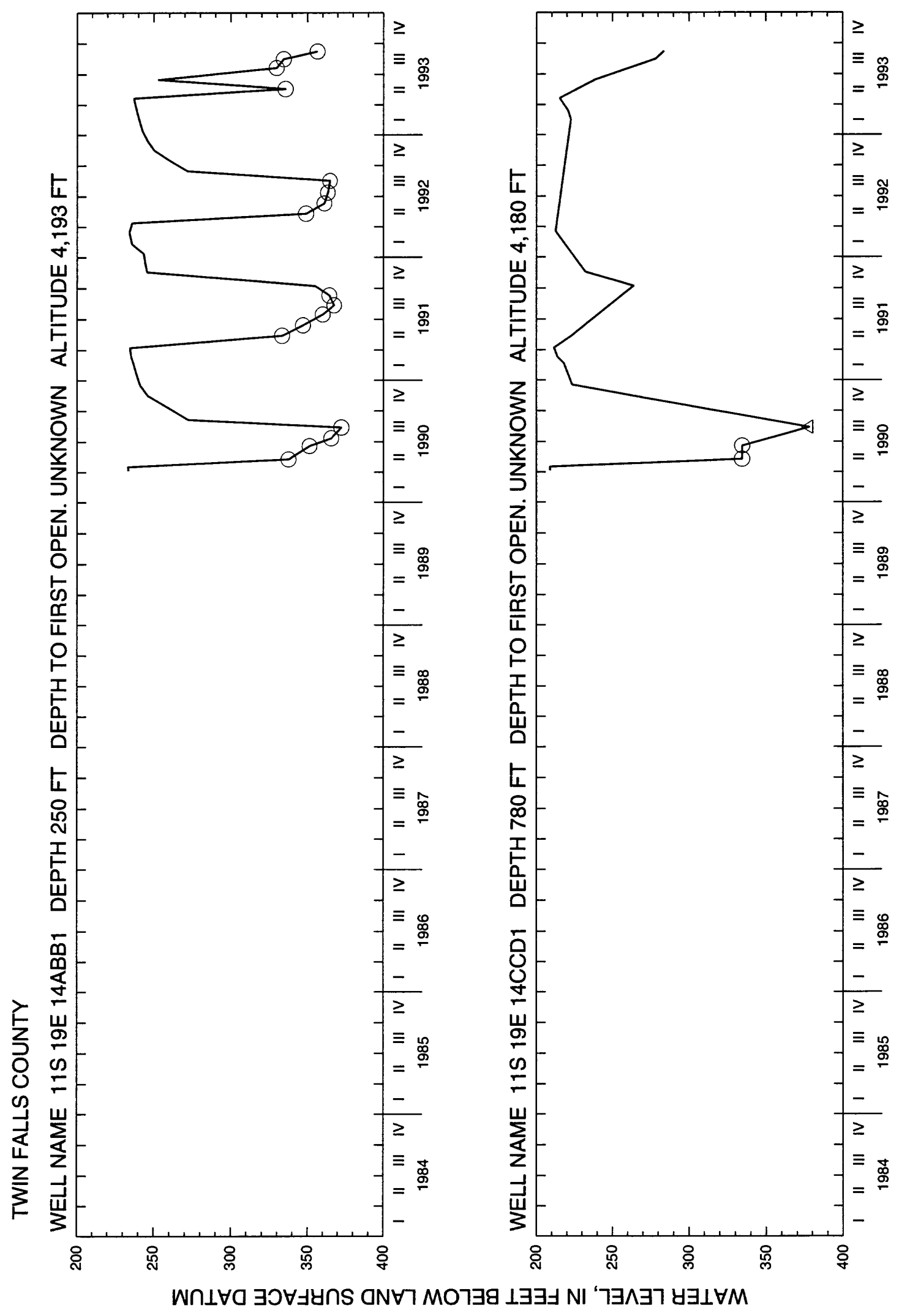




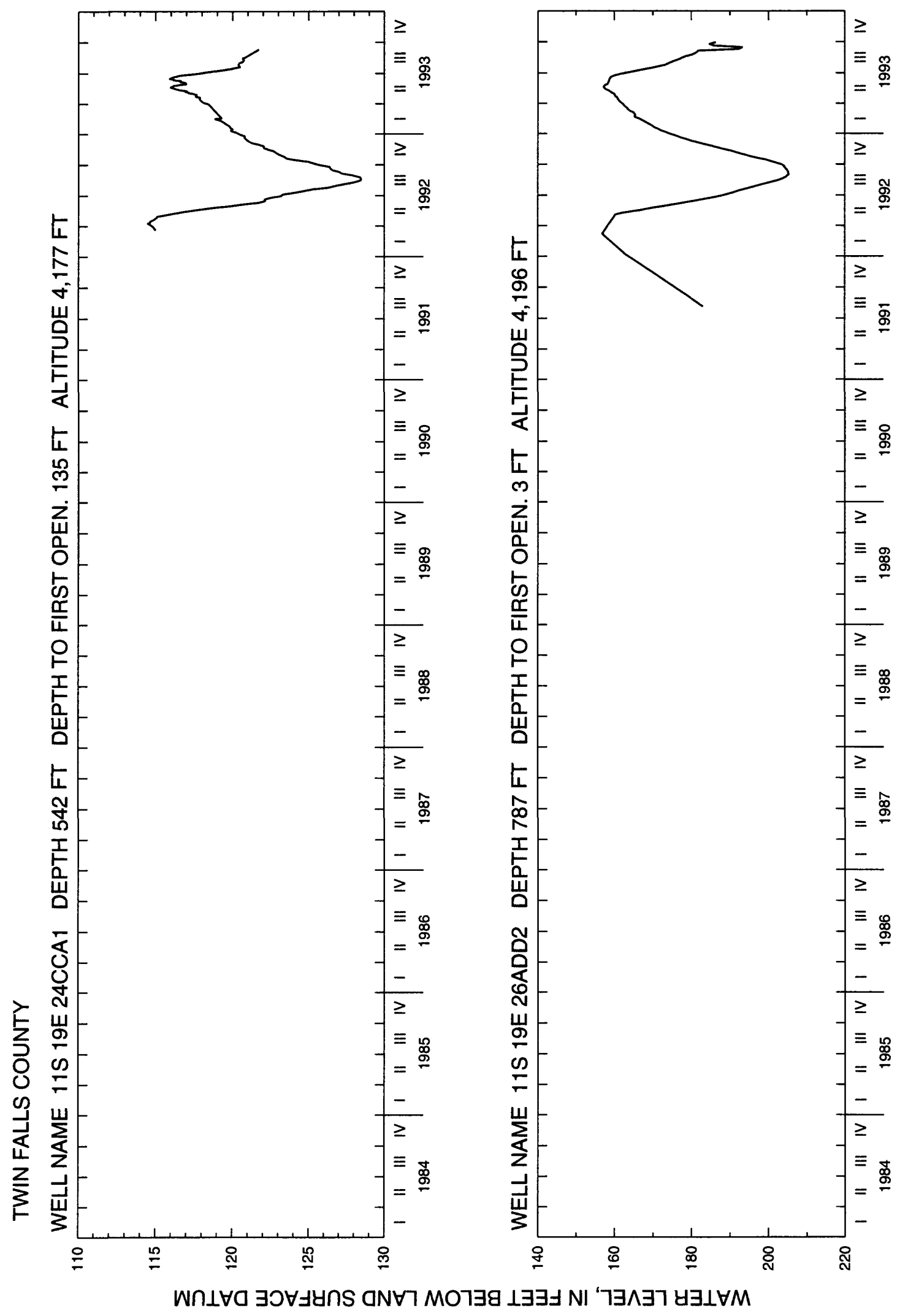




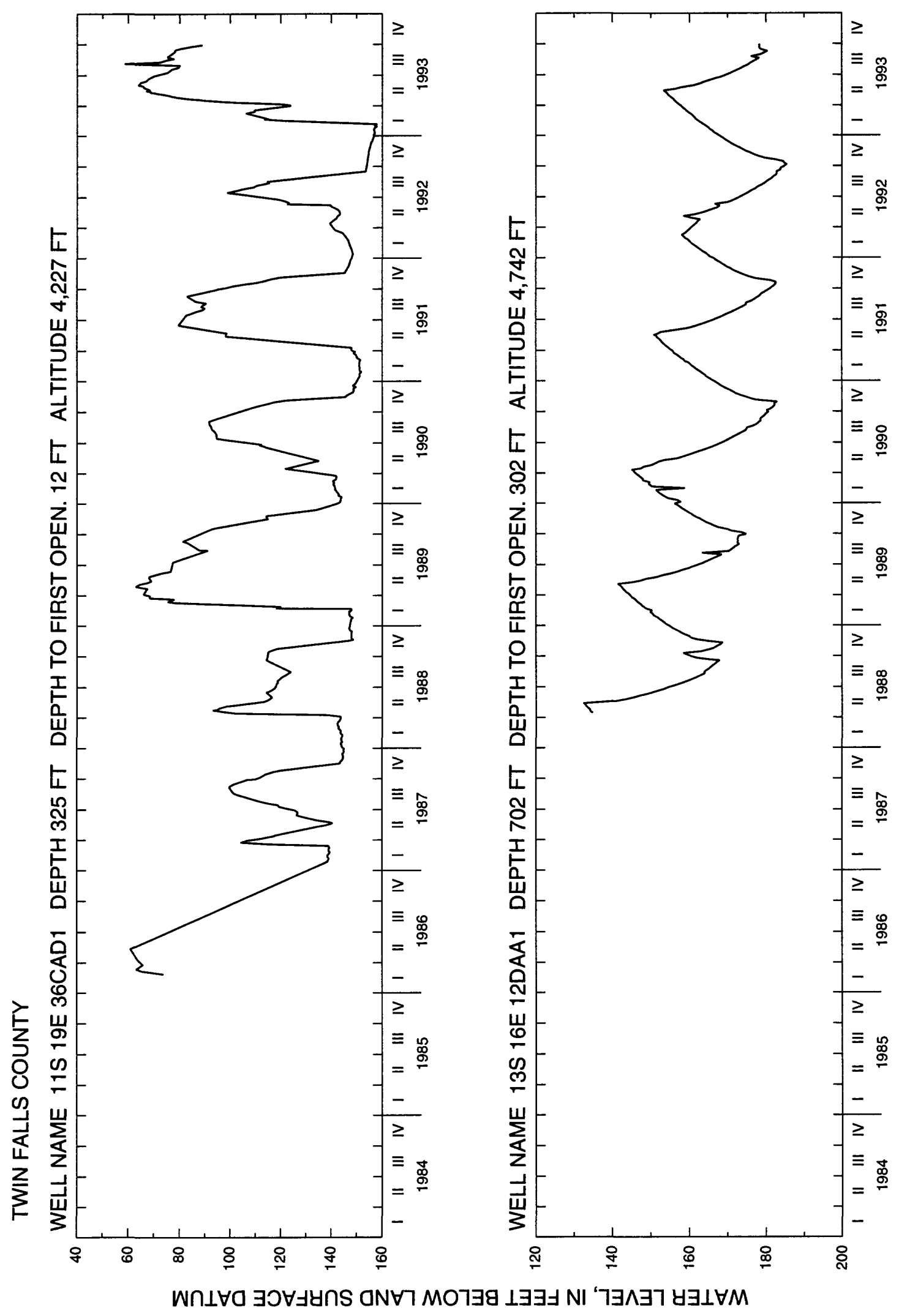




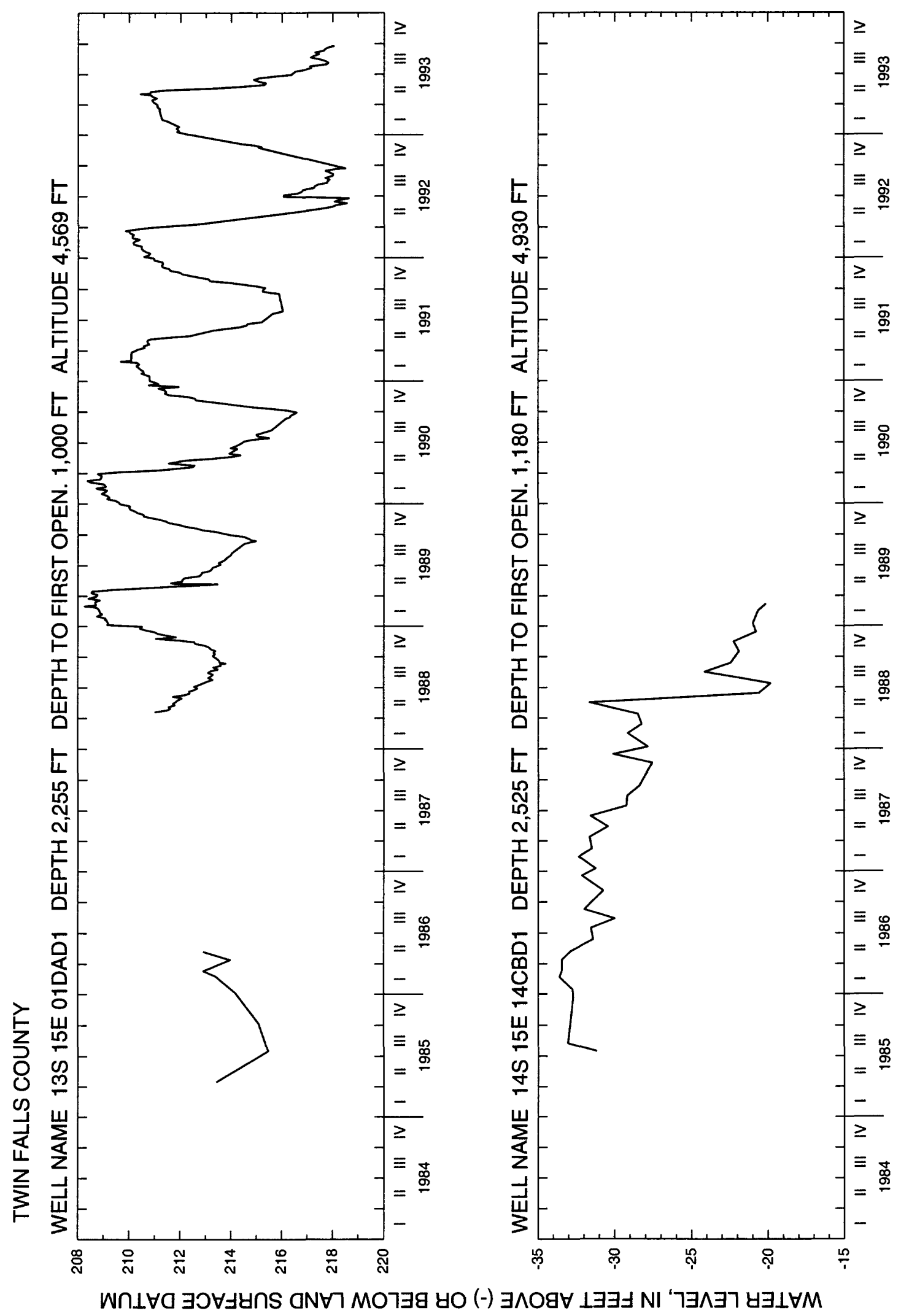




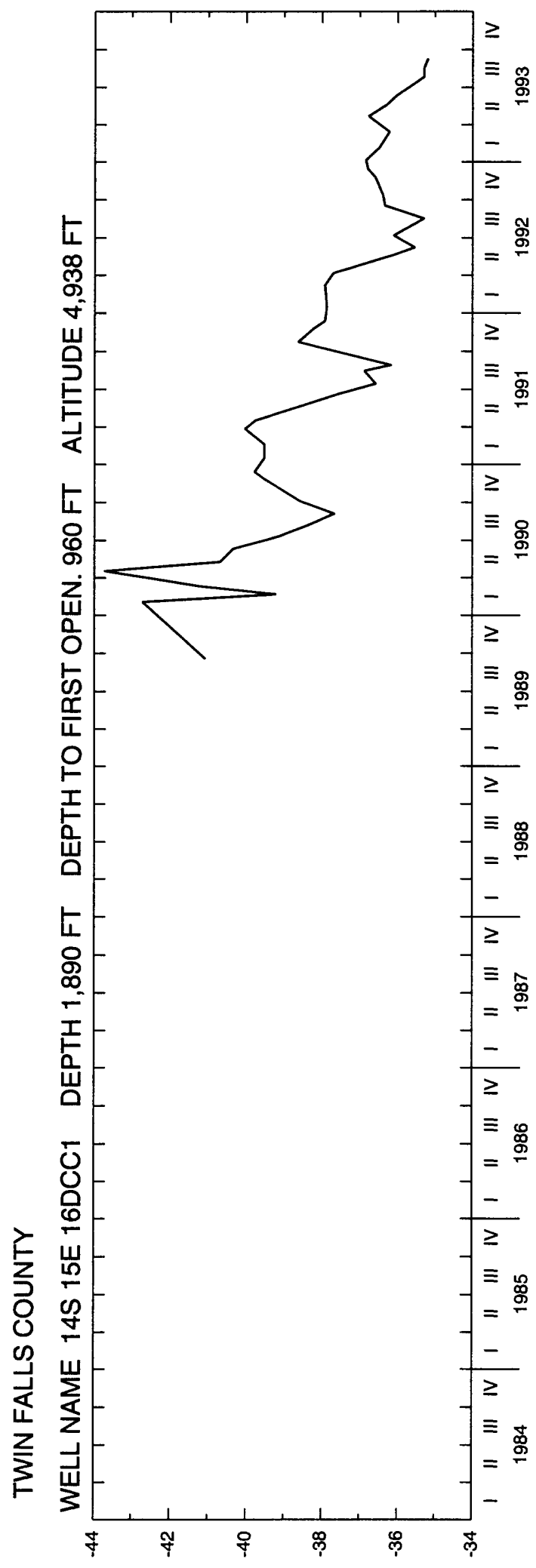

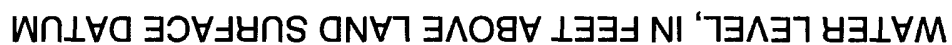




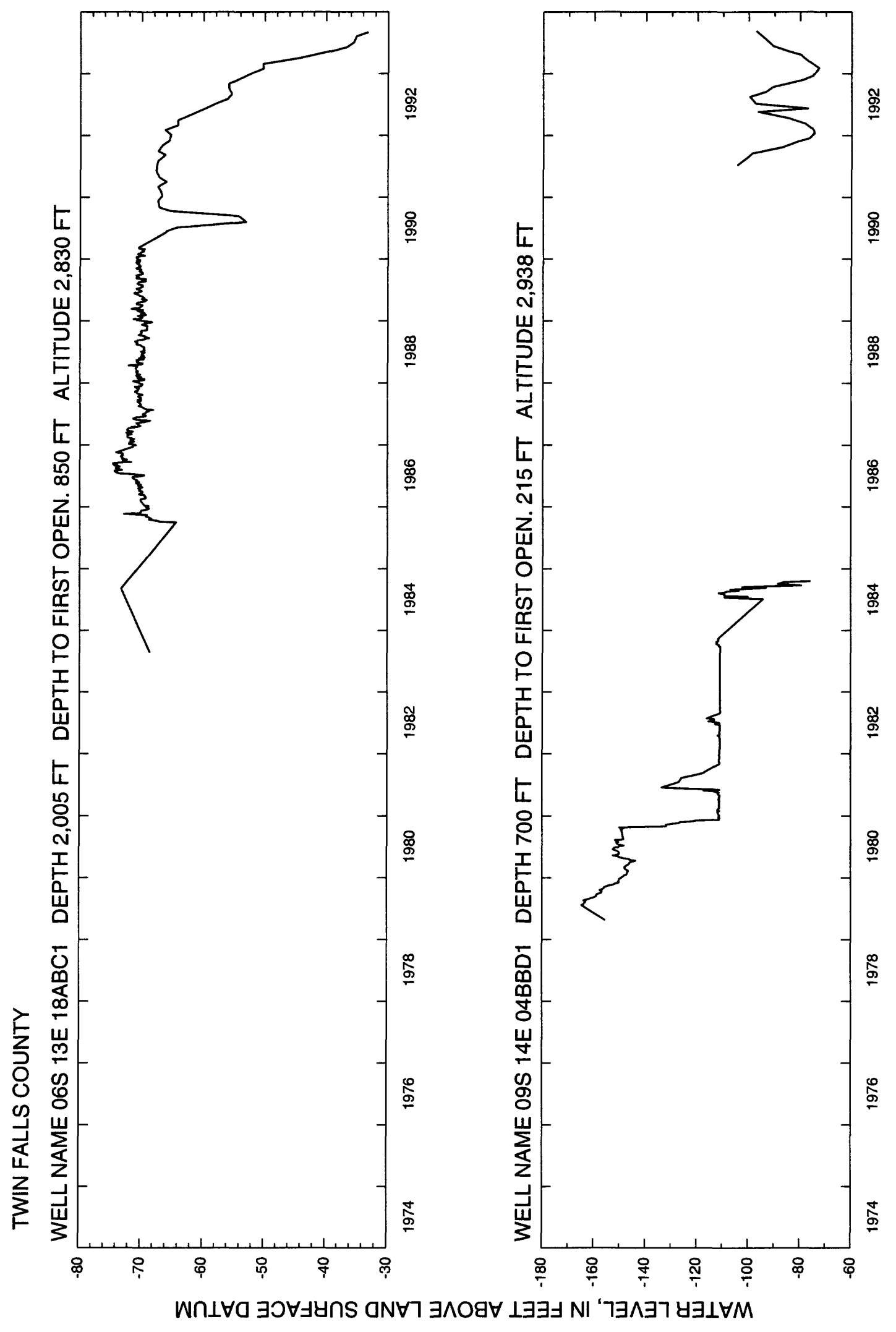




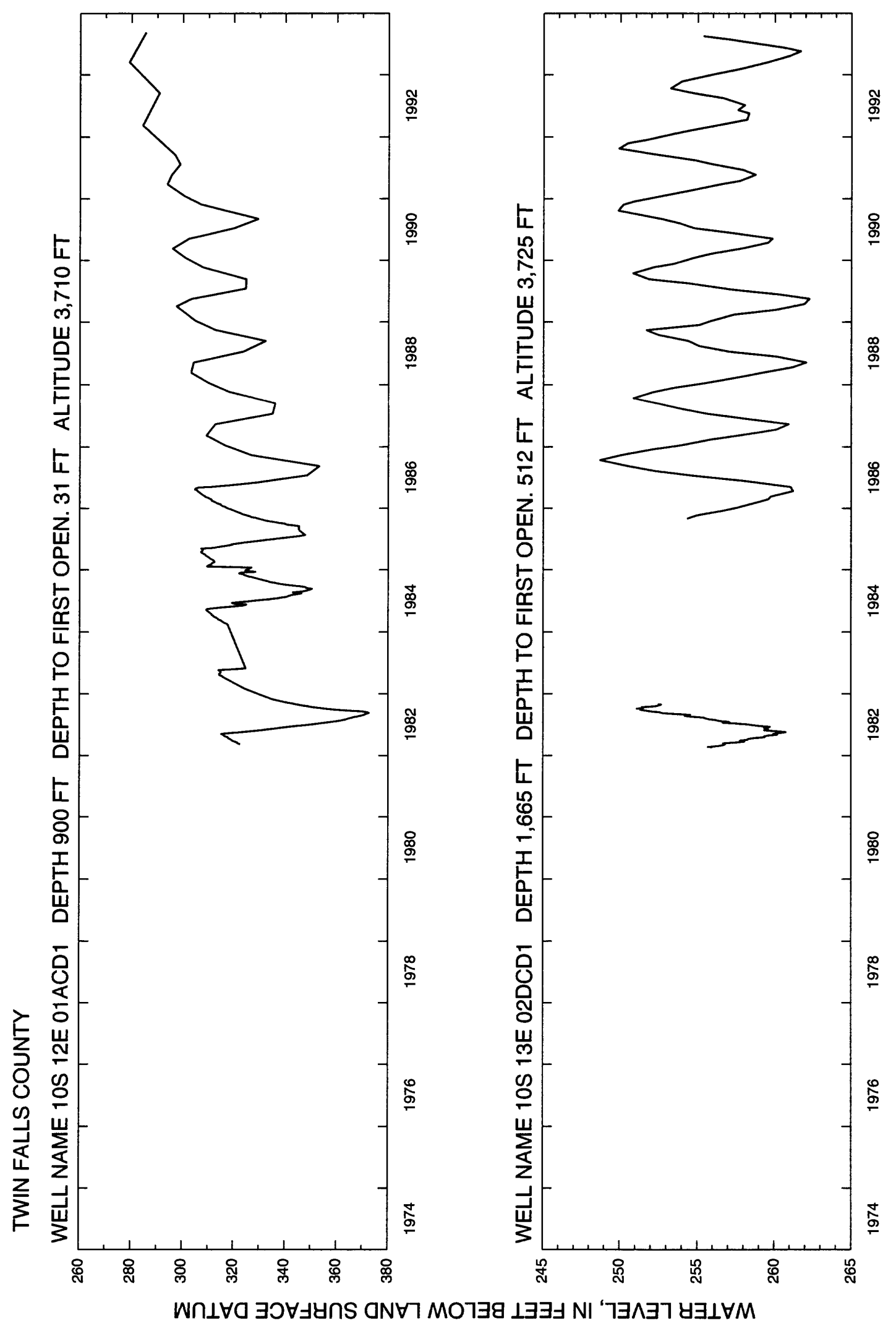




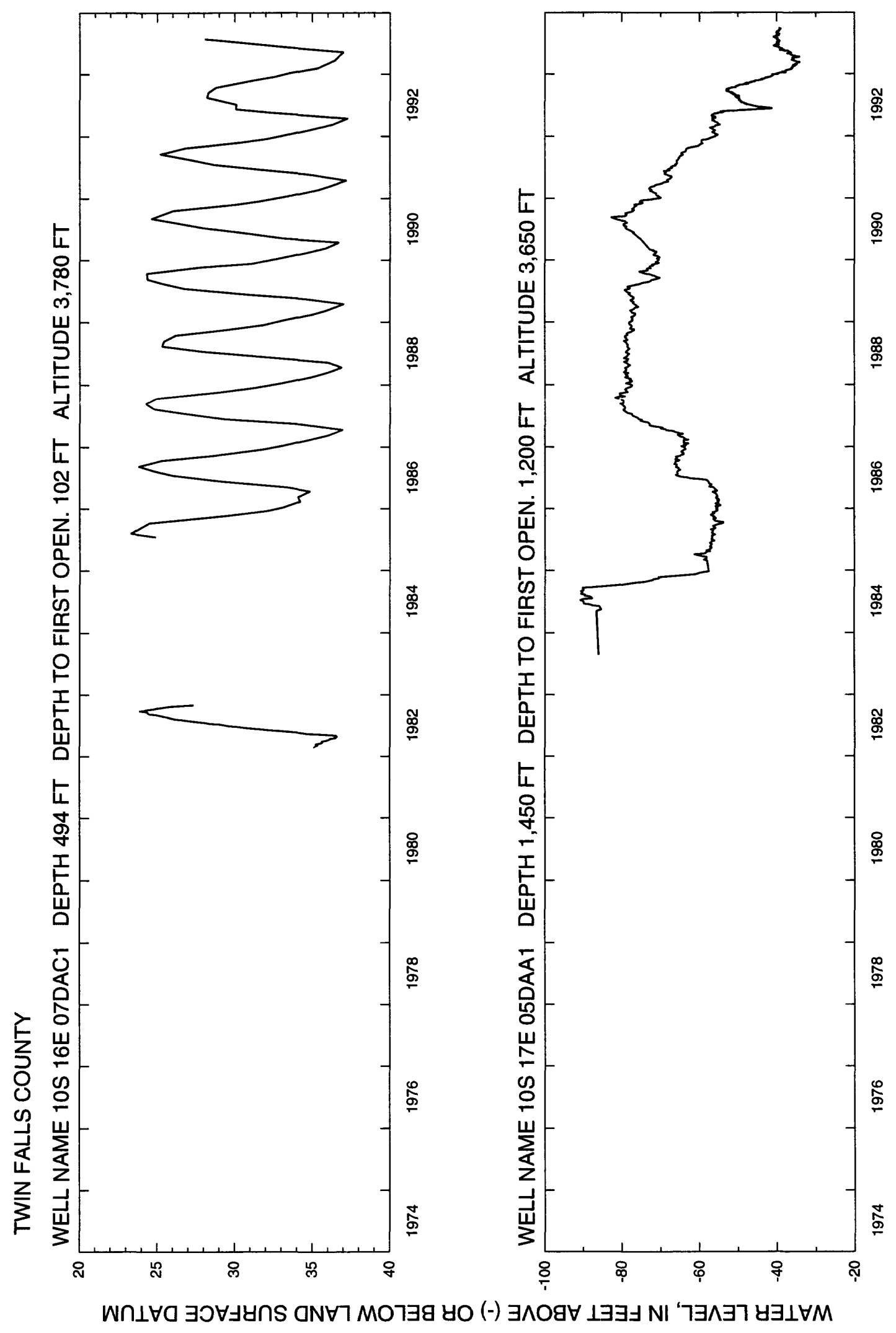




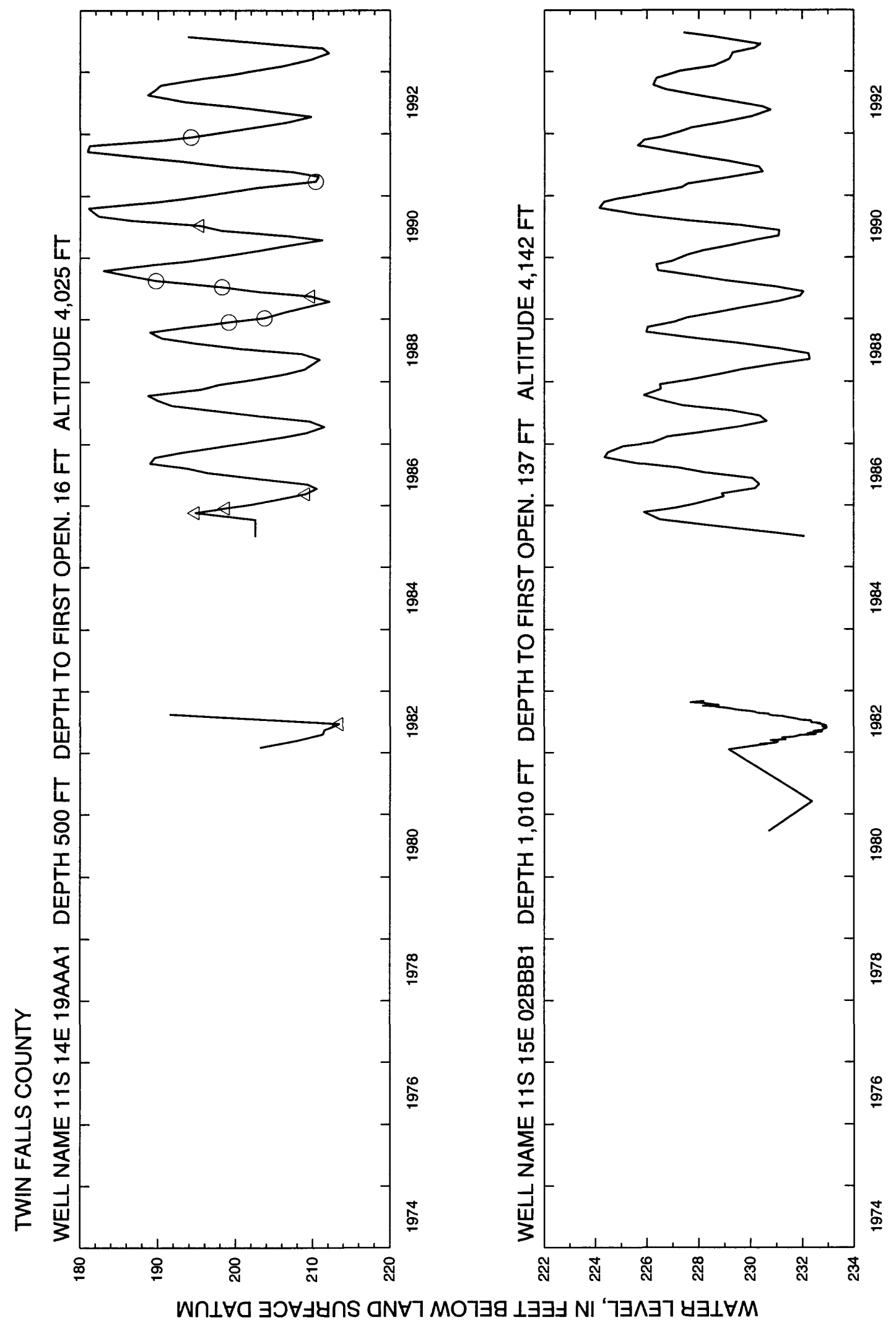




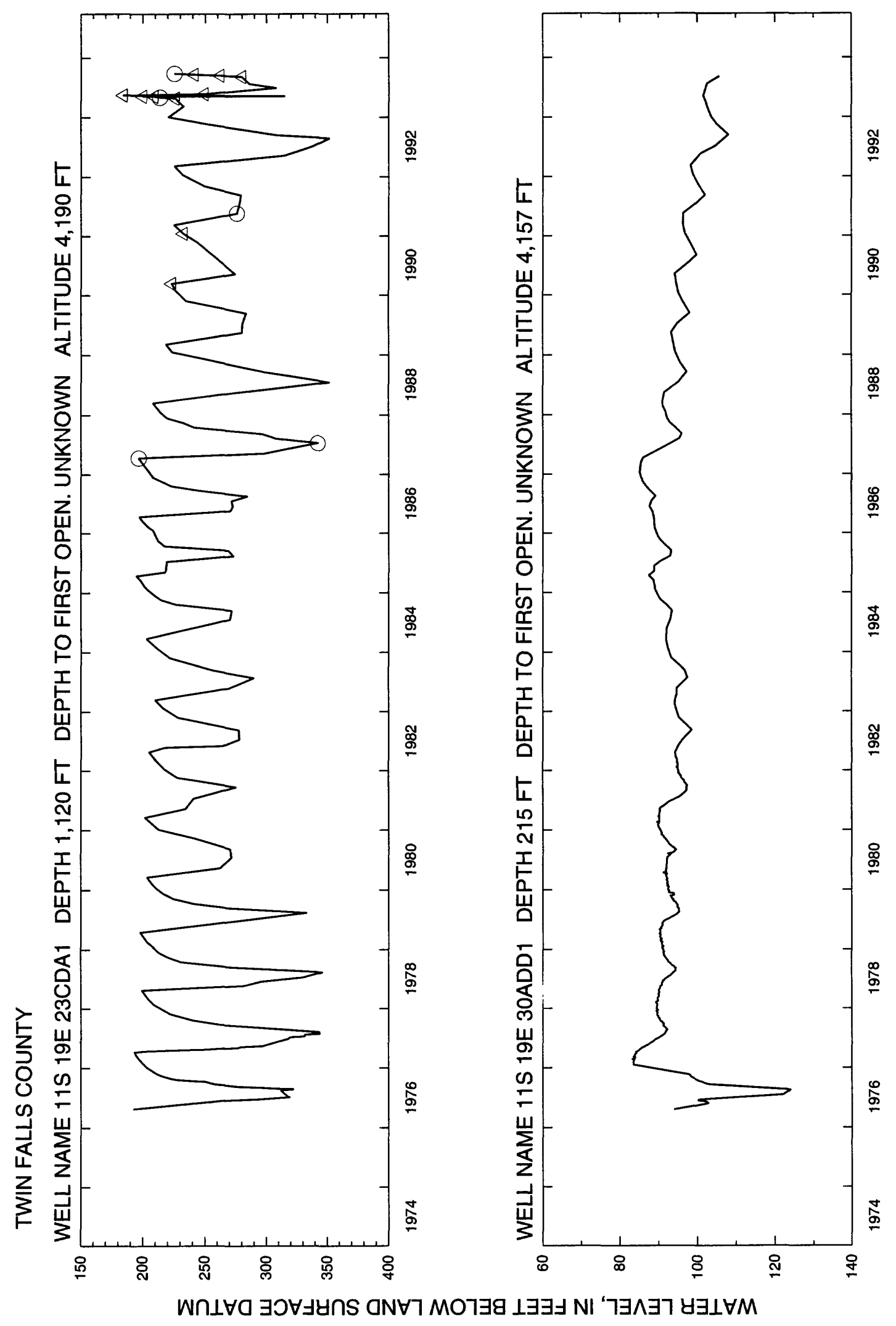




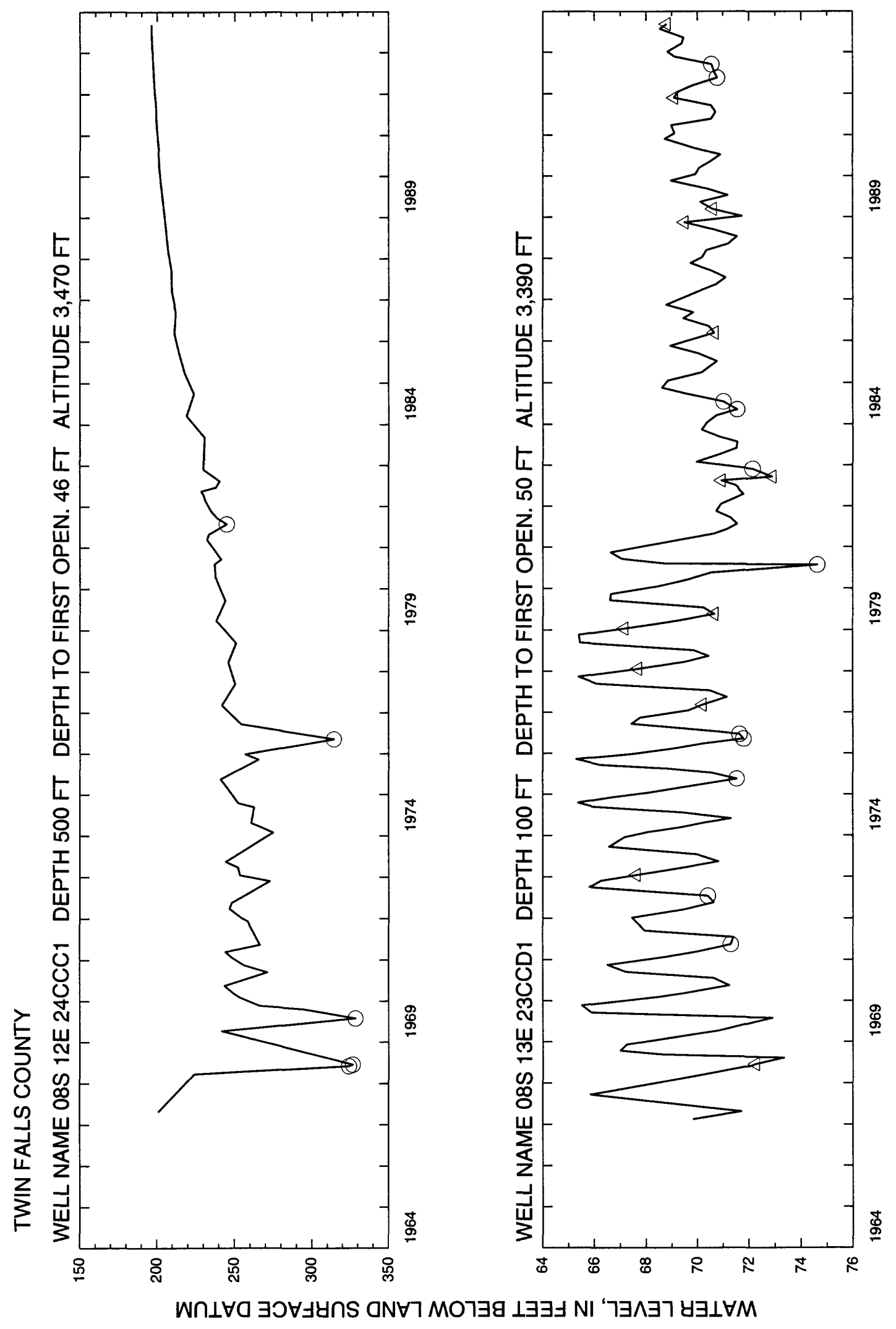




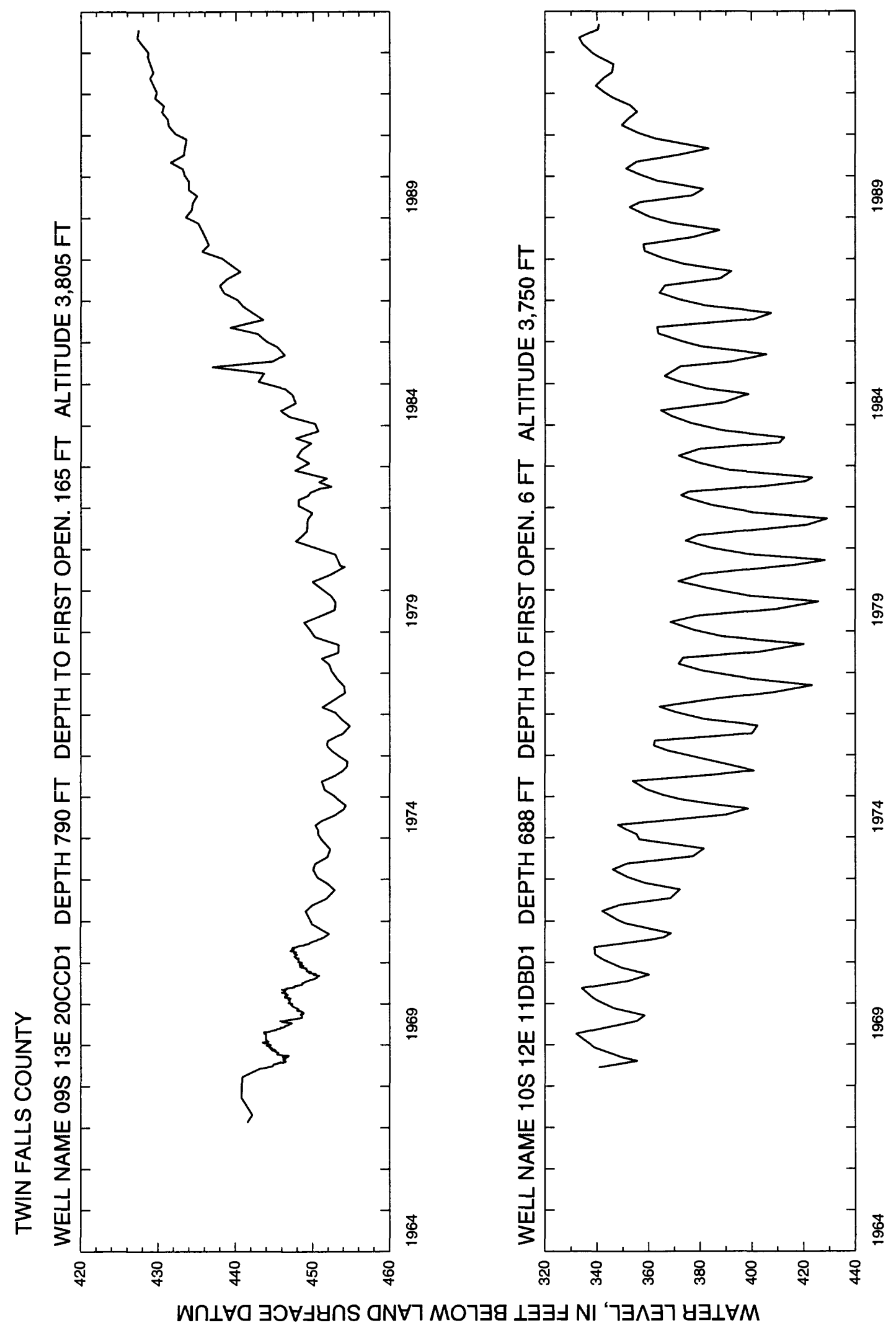




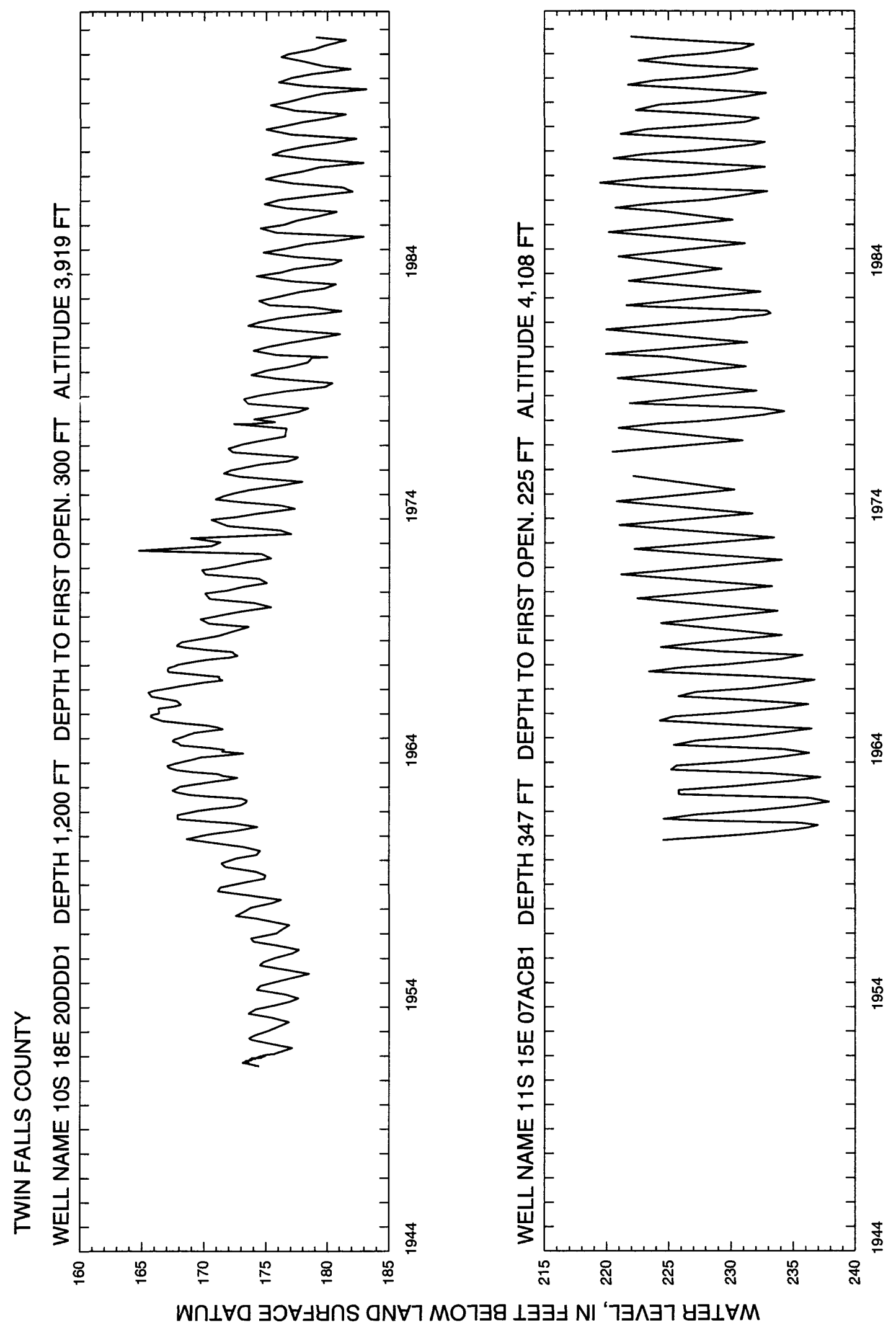




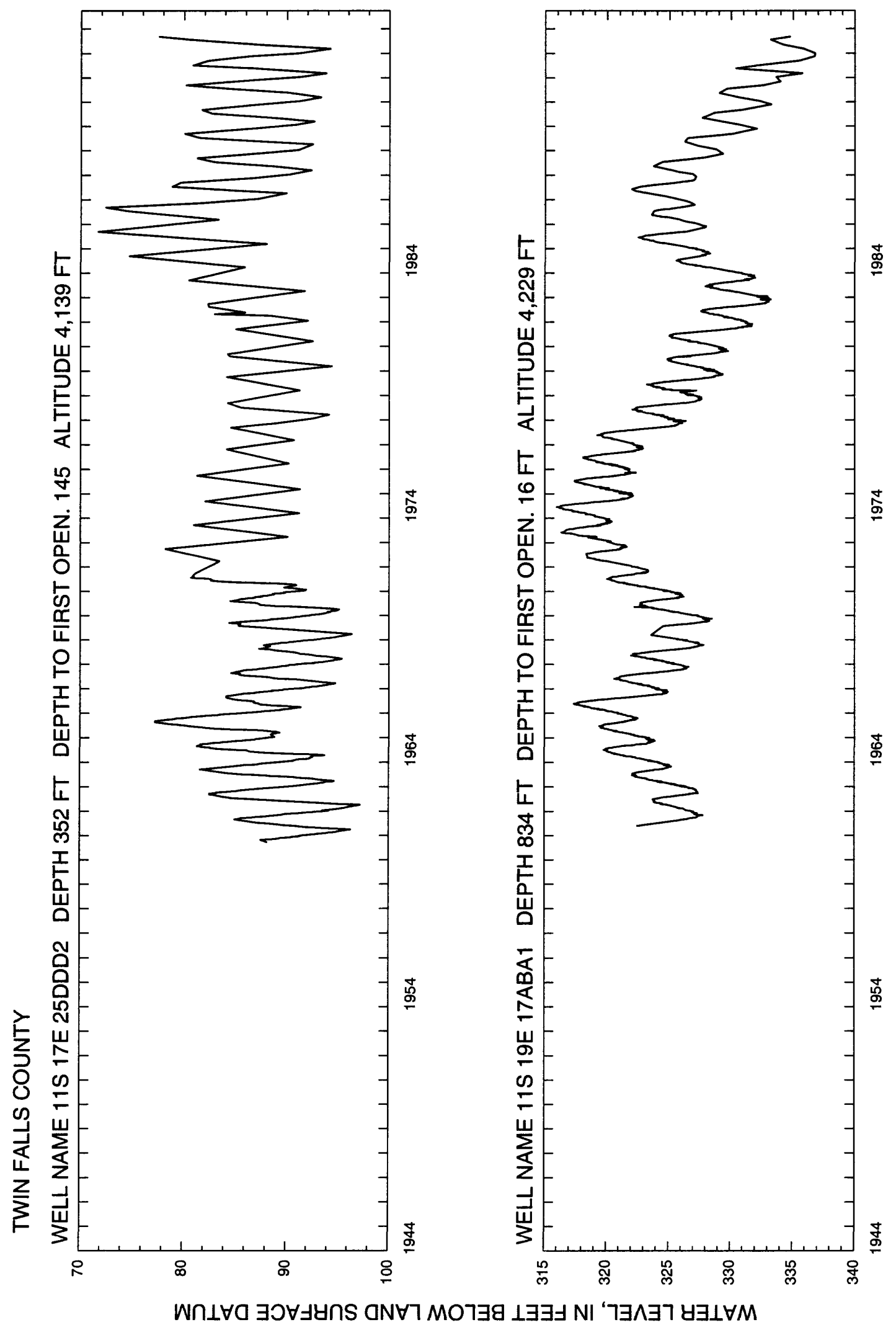




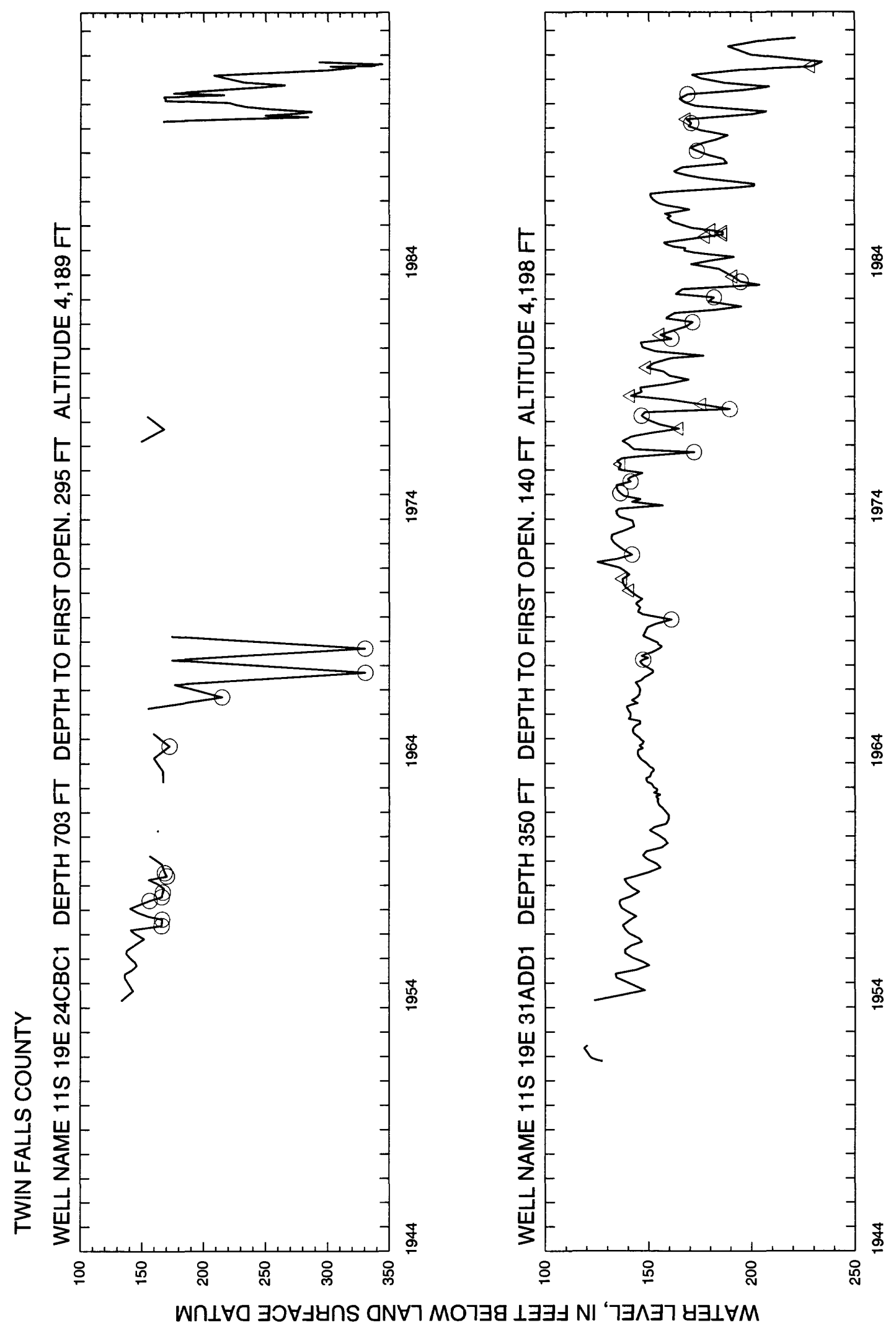




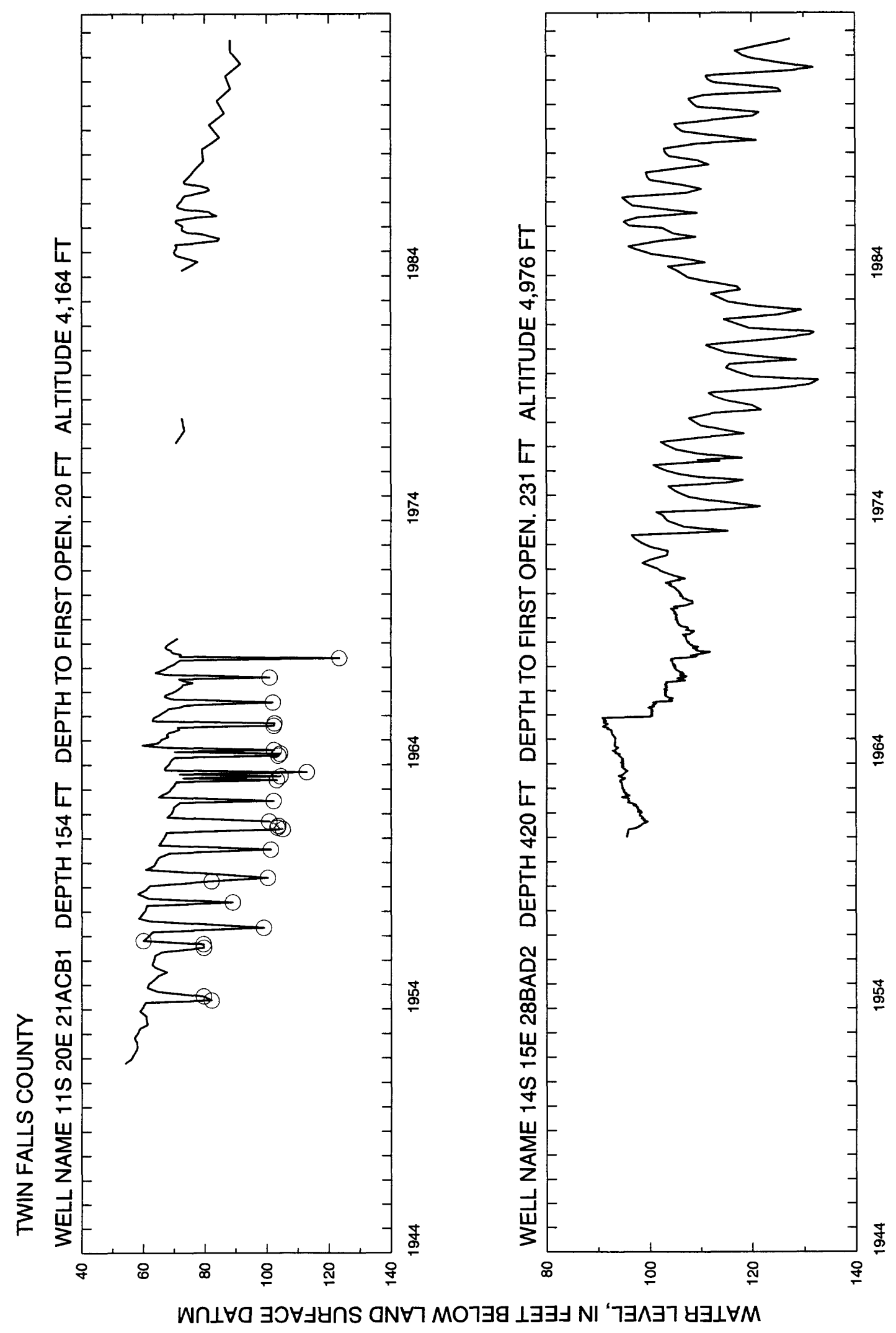


Valley

${ }^{413}$ (page 415 to llows) 


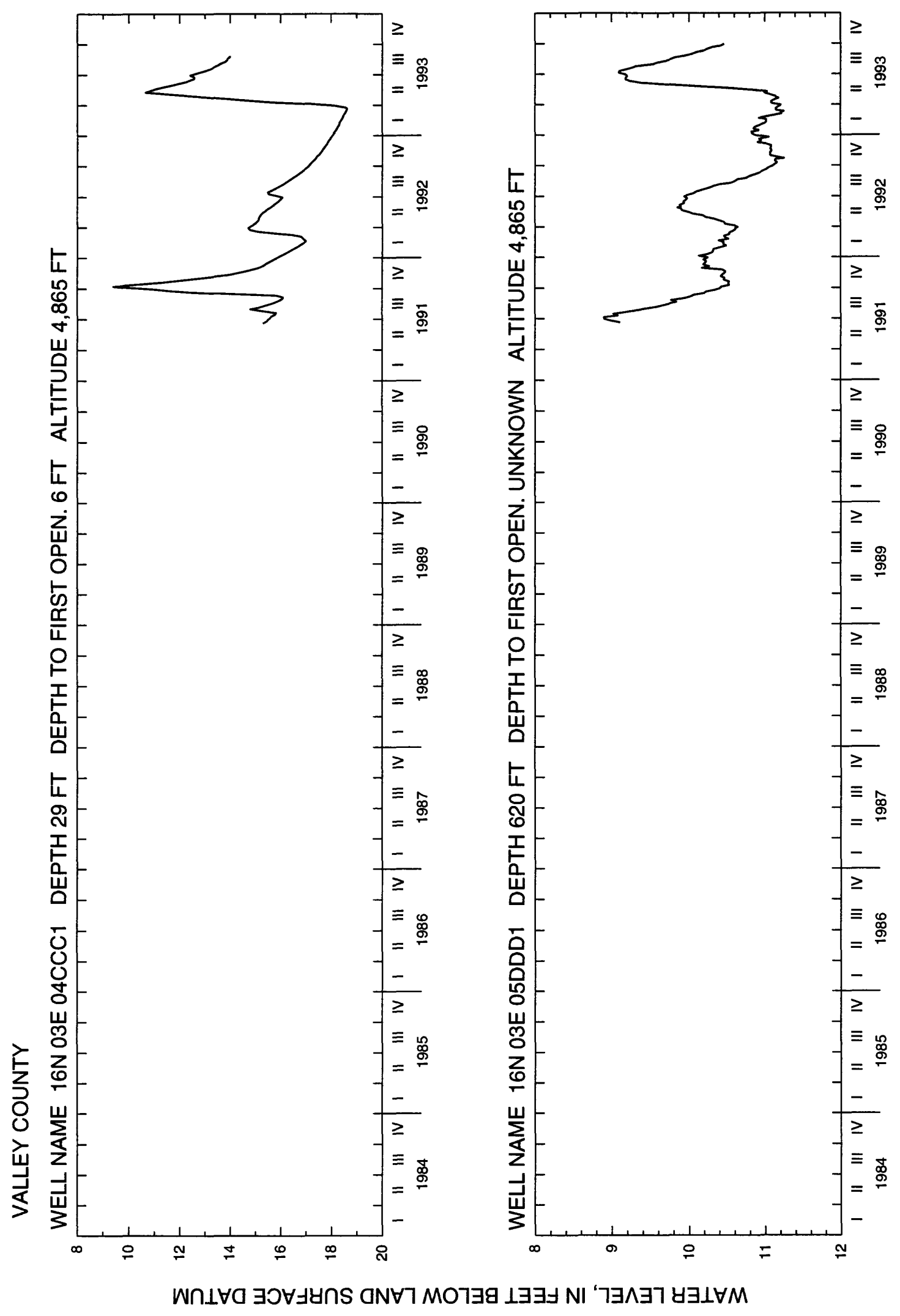




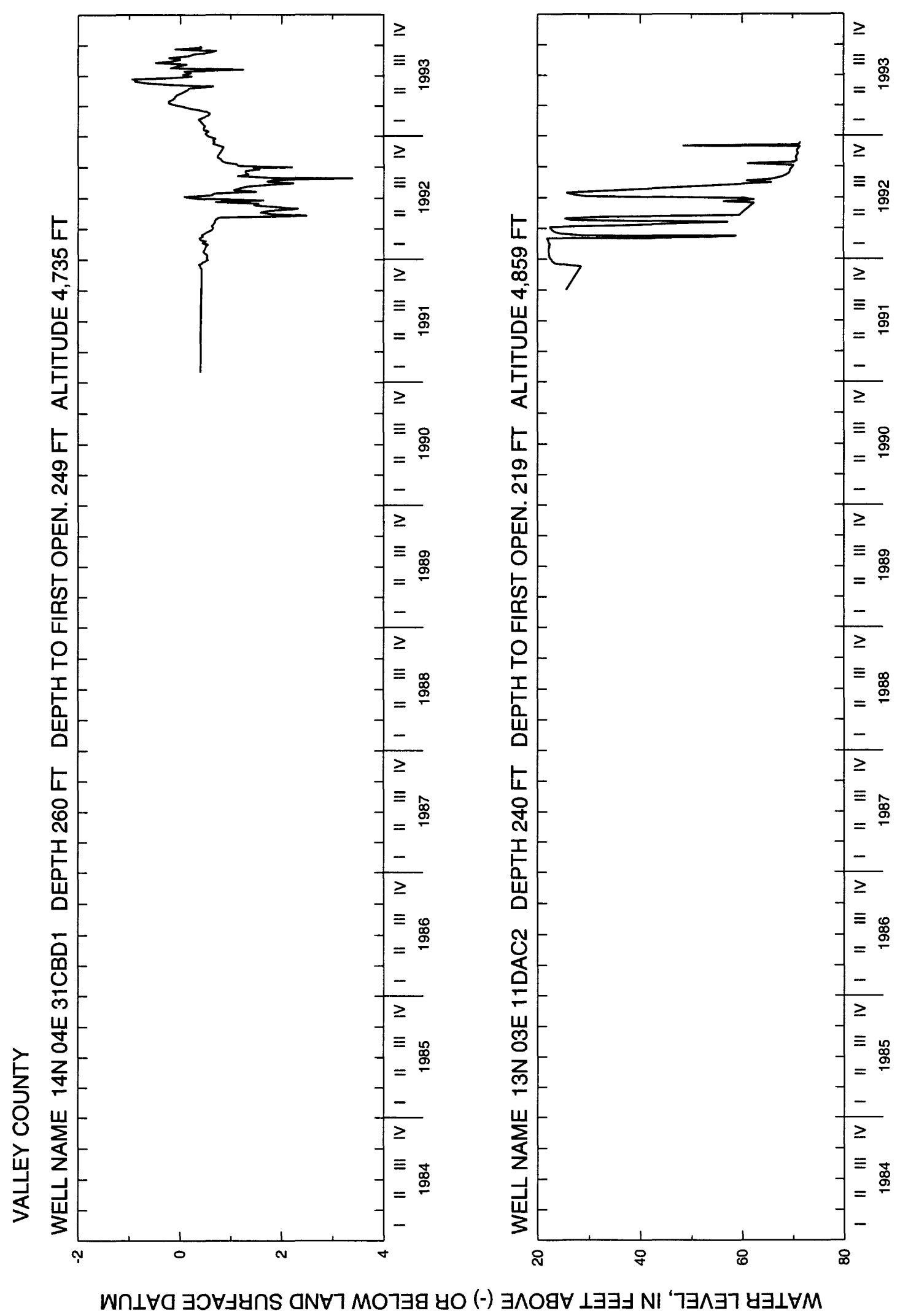




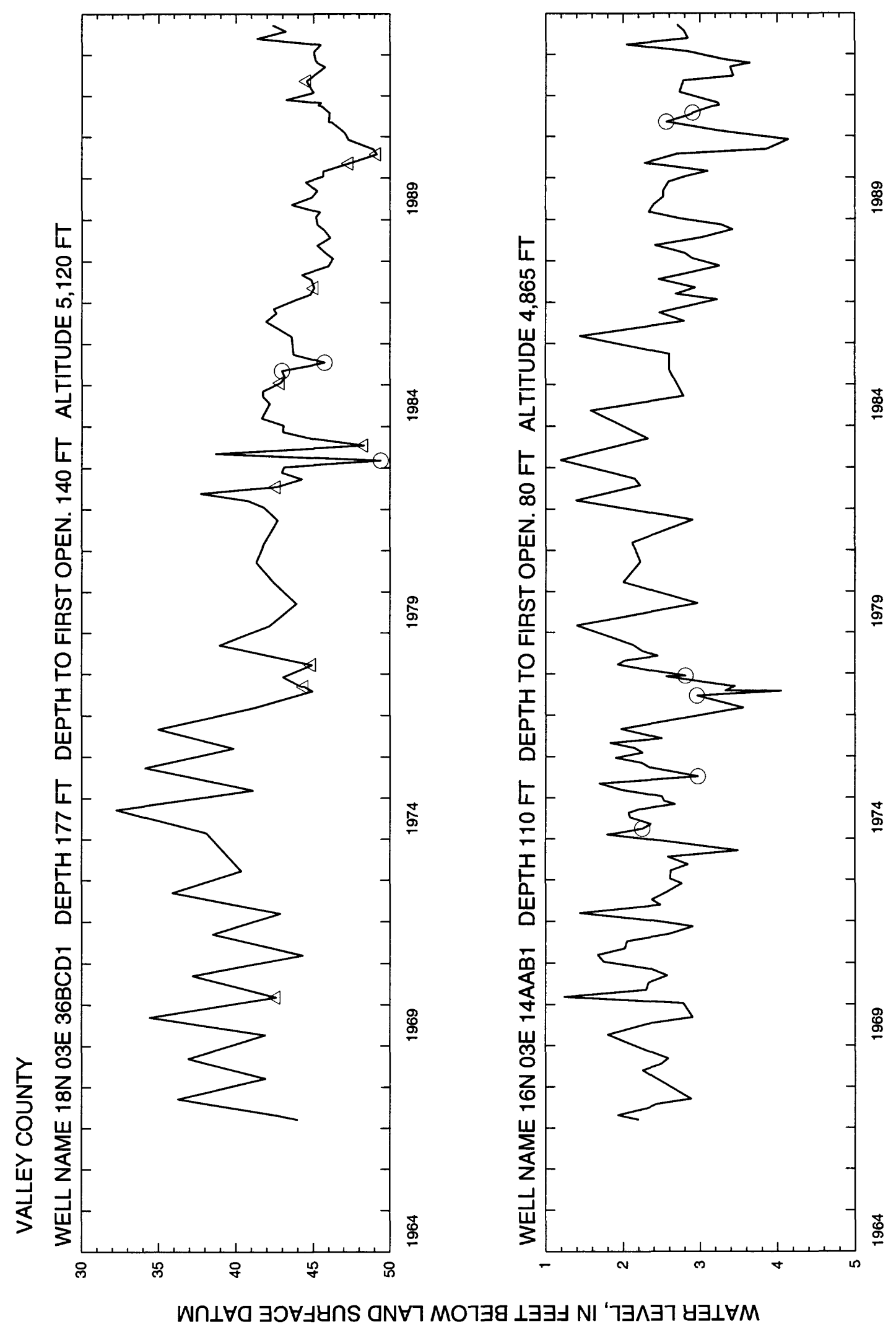




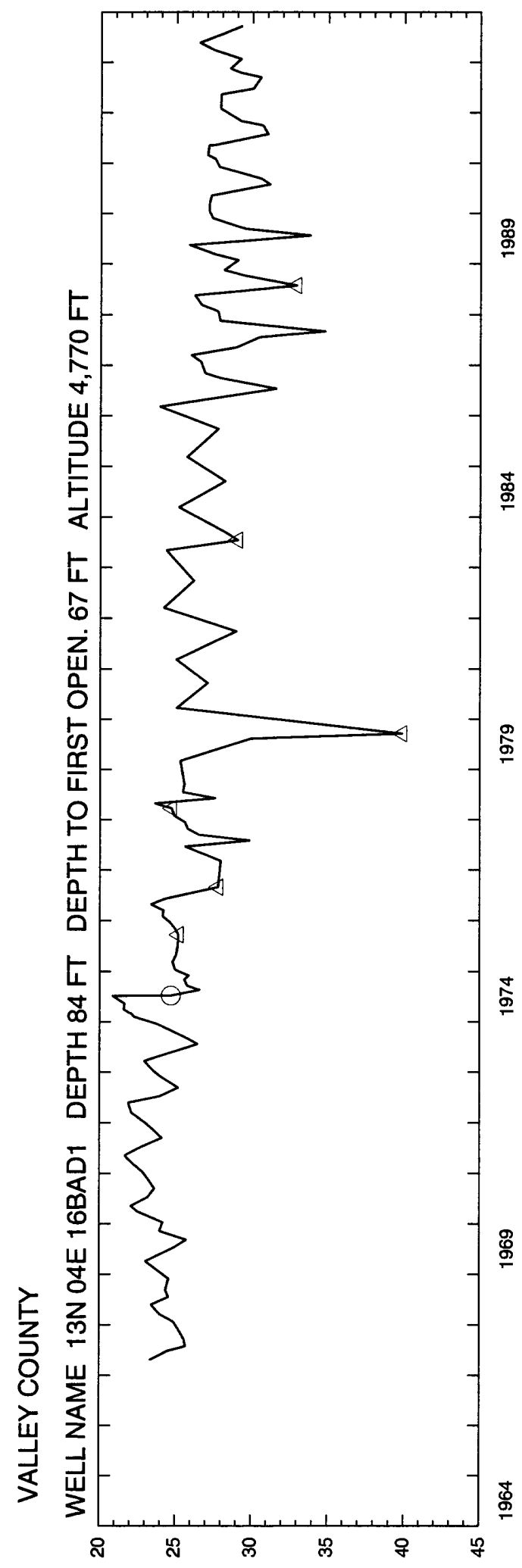

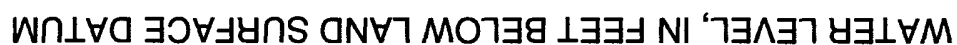




\section{Washington}




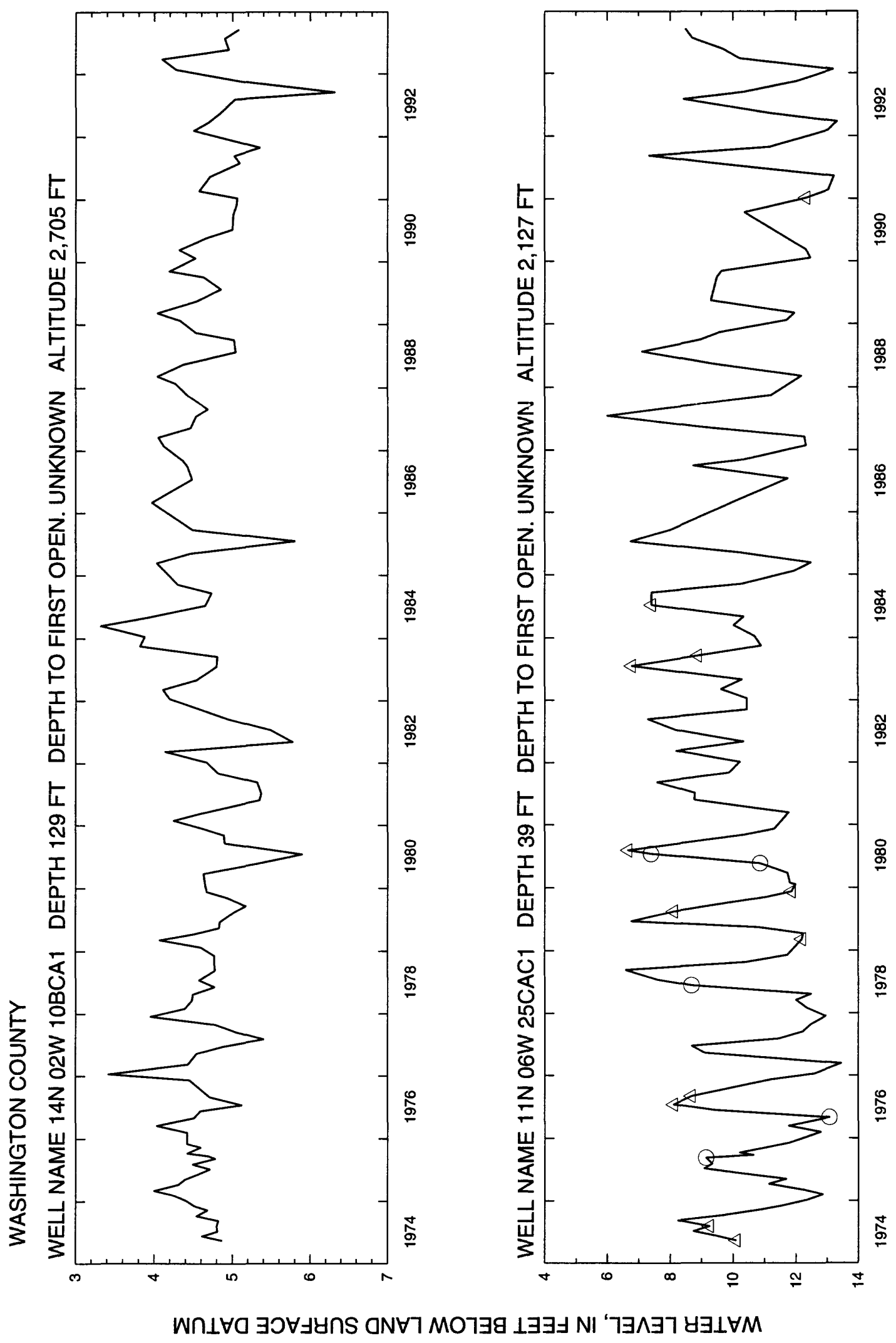




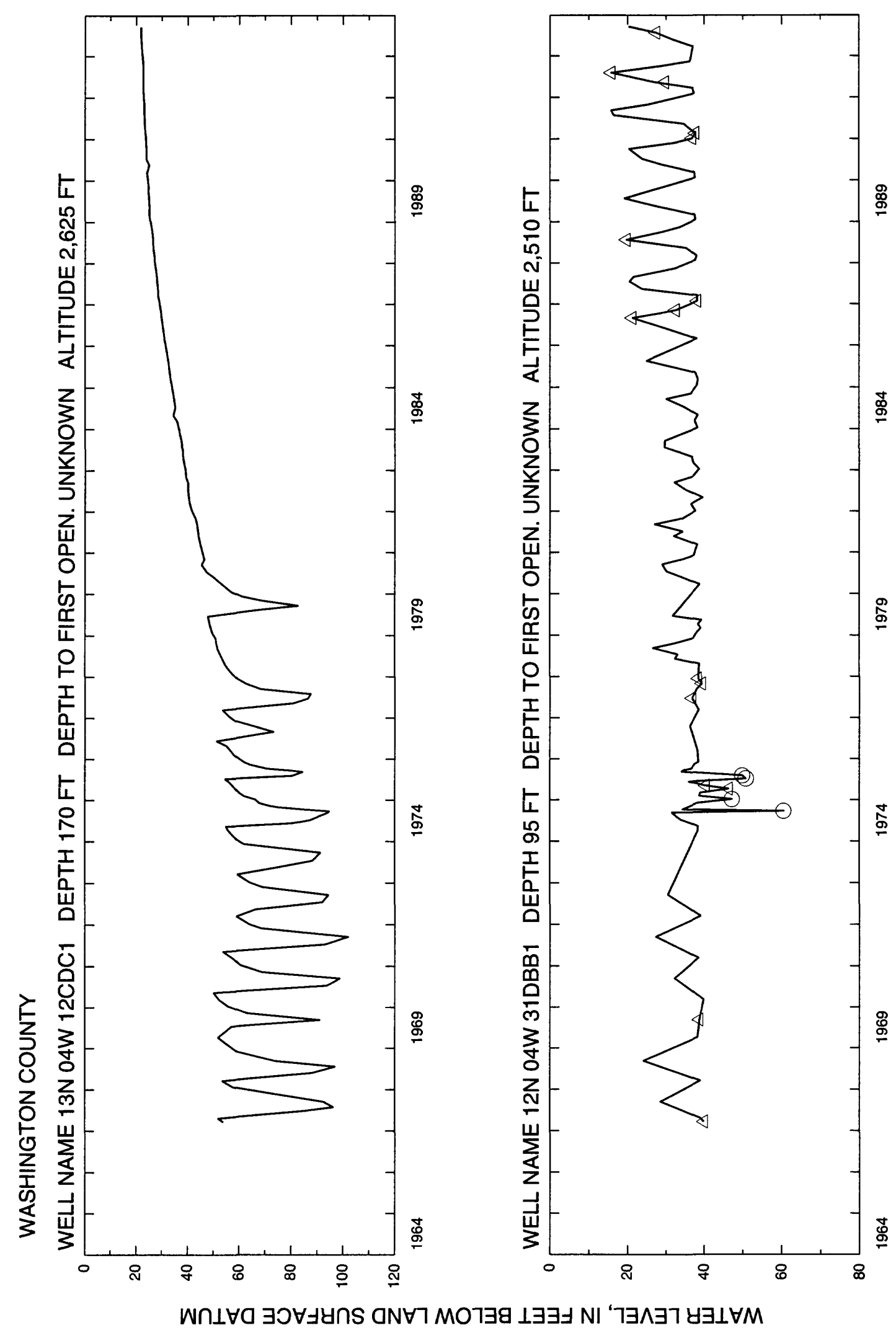

